\title{
Estudio comparativo de la producción y uso de artefactos líticos en el Macizo del Deseado (Santa Cruz, Argentina).
}

Lic. Virginia Lynch

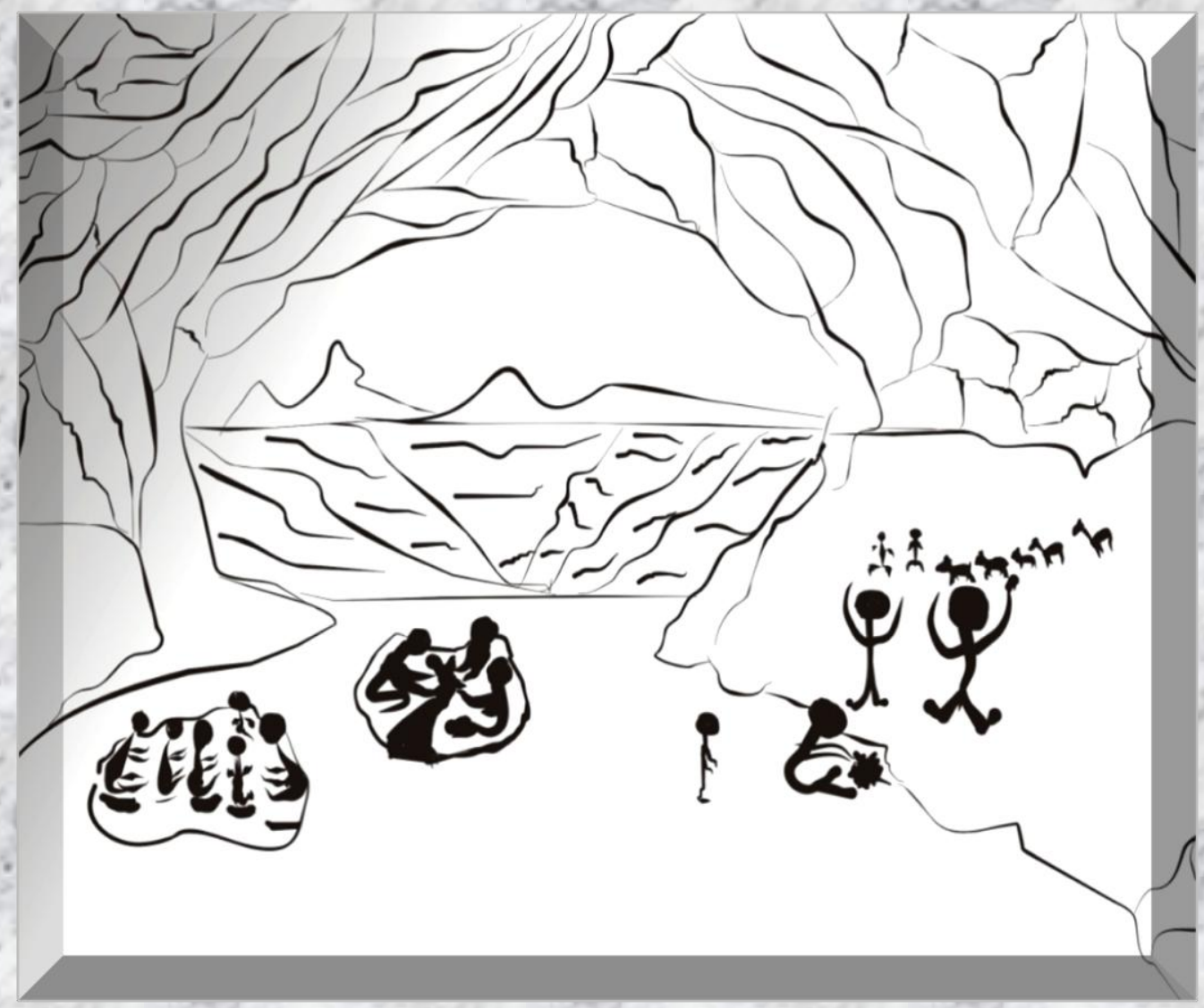

Directora: Laura Lucía Miotti.

Codirectora: Mónica Alejandra Berón.

Tesis para optar al Título de Doctor en Ciencias Naturales

Facultad de Ciencias Naturales y Museo (UNLP)

$$
2014
$$




\section{Estudio comparativo de la producción y uso de artefactos líticos en el Macizo del Deseado (Santa Cruz, Argentina).}

Lic. Virginia Lynch

Director: Dra. Laura L. Miotti

Co-director: Dra. Mónica A. Berón

Tesis para optar al Título de Doctor en Ciencias Naturales Facultad de Ciencias Naturales y Museo (UNLP) 2014 

“...Cuando creíamos que teníamos todas las respuestas, de pronto, cambiaron todas las preguntas...”(Mario Benedetti)

A mi familia, por su apoyo incondicional Y para Agostina, por los juegos postergados 



\section{Agradecimientos}

Varias han sido las personas que me han brindado su apoyo y afecto para que a lo largo de estos años haya podido realizar el manuscrito de esta tesis.

En primer lugar quisiera agradecer a mi directora Laura Miotti, quien me dio la posibilidad de realizar esta investigación con aportes sumamente valiosos para el desarrollo de mi formación científica. Su extenso conocimiento en el tema tratado y la transmisión de su experiencia a nivel personal, me brindaron mayor conocimiento y nuevos aprendizajes durante estos años.

Le estoy sumamente agradecida por haber puesto a mi disposición las colecciones arqueológicas que formaron parte de este trabajo de tesis doctoral, al igual que los equipos necesarios para realizar el análisis propuesto. Pero sobretodo le estoy agradecida por su apoyo, paciencia y comprensión en los momentos más difíciles que me ha tocado atravesar durante las distintas etapas de mi investigación.

También quiero agradecer a mi codirectora Mónica Berón, por su importante aporte en la lectura y corrección de este manuscrito, al igual que su continuo interés y apoyo en los avances de mi formación científica.

Le estoy sumamente agradecida a la Dra. Myrian Álvarez quien me formó en el análisis funcional de base microscópica, sin su ayuda y siempre buena disposición, este trabajo no habría podido ser llevado a cabo.

A mis compañeros y amigos del laboratorio (Bruno, Darío, Eloisa, Laurita, Lucía, Quique, Rocío, Franca y Natalia), sin su apoyo, comprensión y paciencia hubiera sido un camino más difícil.

En especial a Darío, Lucía y Marilén quienes brindaron importantes aportes, discusión y lectura al manuscrito de esta tesis; además de su apoyo incondicional y continuo afecto que hicieron más fácil de sobrellevar esta etapa.

A Marilén (Mary), por estar siempre ahí del otro lado, lejos y cerca a la vez, por su apoyo desde los primeros momentos de estudio de mi carrera y por seguir ahí aún después de tantos años.

Agradezco también el apoyo recibido por UNLP y CONICET a partir de las dos becas que me fueron otorgadas y que hicieron posible mi dedicación exclusiva a esta investigación doctoral. Igualmente agradezco a la Facultad de Ciencias Naturales y Museo por haberme brindado el espacio físico de trabajo durante estos años y a los 
subsidios PI-UNLP N550, PICT 1552 que financiaron los trabajos de campo y análisis realizados.

Agradezco especialmente a Chela, Carlos y Ramón, ya que sin su ayuda y su gran hospitalidad, los viajes largos y el frío hubieran sido más difíciles de sobrellevar. A las familias Koprowski y Ferreiro por permitirnos los accesos a sus propiedades y apoyar nuestras investigaciones.

Quiero agradecer a mis amigas, Gabi, Agus y Sabri por su compañía y afecto y por entender mis reiteradas ausencias durante el último año de escritura de esta tesis.

A mi familia, quienes supieron entender y apoyarme desde siempre en mis proyectos. A mi mamá por entender mis ausencias y brindarme siempre su cariño y apoyo. A mi hermana por compartir experiencias y por entender siempre mis preocupaciones. A mi papá, que pese a su ausencia, le debo todo el apoyo, la confianza y cariño que me tuvo siempre.

Por último, pero no menos importante, a Luciano y Agostina, mi proyecto de vida, sin su comprensión, apoyo constante, paciencia y sobretodo cariño no hubiera podido llegar a donde estoy. Gracias. 




\section{ÍNDICE GENERAL}

ÍNDICE DE FIGURAS......................................................................................XII

ÍNDICE DE TABLAS.....................................................................................

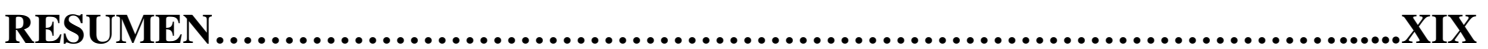

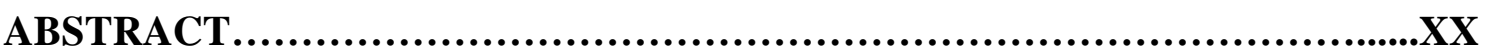

\section{CAPÍTULO I:}

Introducción ..........................................................................................................

I.1. Objetivos generales......................................................................................................5

I.2. Objetivos específicos...............................................................................................5

I.3. Hipótesis......................................................................................................................6

I.4. Organización de la tesis......................................................................................................7

\section{CAPÍTULO II:}

Antecedentes de investigación

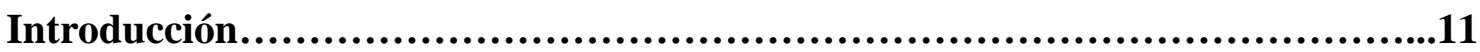

II.1. Análisis funcional de base microscópica y los aportes generados a nivel

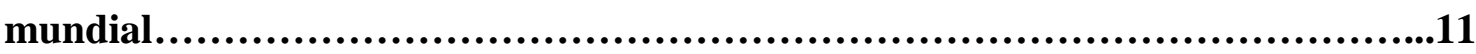

II.2. Primeras investigaciones y antecedentes metodológicos en el Macizo del

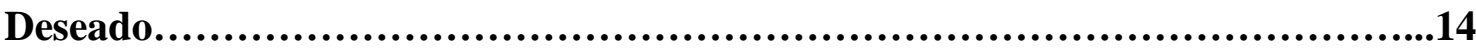

Sector de meseta:

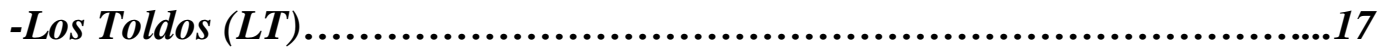

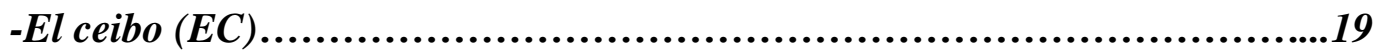

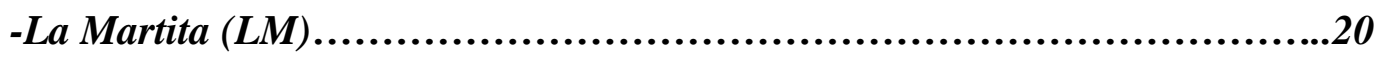

-Localidad Arqueológica La María..................................................22

- La María, sitio Casa del Minero 1 (CDM1)......................................22

- Cerro Tres Tetas 1 (C3T1).........................................................24

-La gruta: Cueva 1 de la laguna 2 ................................................26 
Sector del Río Pinturas:

-Cueva de las Manos (CDLM)

II.3. Antecedentes y metodologías aplicadas en los sitios bajo estudio..............28

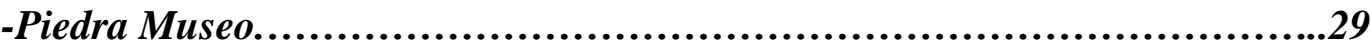

-Cueva Maripe...............................................................32

II.4. Importancia de la aplicación de estudios basados en microscopía óptica......33

\section{CAPÍTULO III:}

Área de estudio

Introducción.

III.1 Características geológicas y geomorfológicas generales del Macizo central de

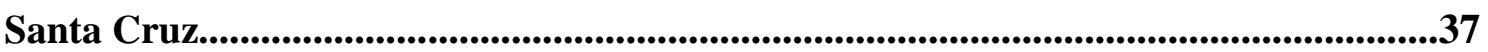

III.2. Unidades del paisaje......................................................39

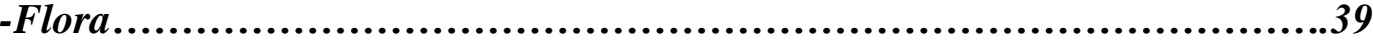

-Fauna ....................................................................... 40

-Unidades geológicas: potenciales fuentes de materias primas para la talla lítica..............................................................................42

III.3. Uso de los recursos disponibles........................................46

III.4.1. Paleoambiente y ocupaciones humanas iniciales..........................50

III.4.2. Holoceno Temprano y Medio..........................................52

III.4.3. Holoceno Tardío.........................................................54

\section{CAPITULO IV:}

Marco de referencia

Introducción..........................................................................59

IV.1. Organización de la tecnología lítica.....................................59

IV.1.1. Estrategias Tecnológicas...............................................61

IV.1.2. Estrategias del diseño.................................................63

IV.2. Organización del espacio................................................66

IV.3. Funcionalidad de los sitios...................................................68

IV.4. Marco de referencia metodológico..........................................69 
IV.4.1. Los estudios funcionales en la actualidad...............................73

IV.4.2. Alcances de su aplicación en el registro arqueológico.....................75

\section{CAPITULO V:}

Metodología y técnicas de análisis

Marco metodológico.................................................................81

4.1. Escala espacial............................................................81

V.2. Escala temporal..........................................................82

V.3 Conjuntos arqueológicos................................................82

V.4. Metodología experimental aplicada al análisis funcional....................83

V.5. Materias primas utilizadas en la serie experimental de referencia..............86

V.6. Serie experimental de uso...............................................90

V.7. Observación y registro de los rastros generados por el uso...................95

V.8. Alteraciones ocasionadas por procesos post-depositacionales..................98

V.9. Análisis estadísticos utilizados............................................101

\section{CAPÍTULO VI:}

Análisis del contexto de uso del instrumental lítico del sitio Cueva Maripe

VI.1. Características principales del sitio.....................................105

VI.2. Geoarqueología de la cueva............................................108

VI.3. Contexto arqueológico y cronología.....................................111

-Arte rupestre....................................................................112

-Zooarqueología.................................................................113

-Análisis del conjunto lítico.....................................................113

VI.4.1 Análisis de los conjuntos artefactuales.................................114

Cámara norte:

VI.4.1.1. Conjunto lítico de Capa 5..........................................115

VI.4.1.2. Artefactos no formatizados de Capa 5...............................121

VI.4.1. Resultados del análisis funcional de base microscópica...................123

VI.4.1.3. Integridad del conjunto e identificación de alteraciones tafonómicas.................................................................123

VI.4.1.4. Inferencia funcional de las modalidades de uso....................125 
VI.4.1.5. Materiales trabajados.........................................128

VI.4.1.6. Cinemática empleada............................................129

VI.4.1.7. Actividades desarrolladas............................................131

VI.4.2 Conjunto lítico de Capa 4: artefactos formatizados......................133

VI.4.2.1. Artefactos no formatizados (ANF) de Capa 4......................137

VI.4.2.2. Resultados del análisis funcional de base microscópica.............139

VI.4.2.3. Integridad del conjunto y alteraciones tafonómicas................139

VI.4.2.4. Inferencia funcional de las modalidades de uso.....................140

VI.4.2.5. Materiales trabajados.........................................142

VI.4.2.6. Cinemática empleada...............................................144

VI.4.2.7. Actividades desarrolladas.....................................145

VI.4.3. Conjunto lítico de Capa 3 y 2: Artefactos formatizados....................146

VI.4.3.1. Artefactos no formatizados (ANF) de Capa 3 y 2..................151

VI.4.3.2. Resultados del análisis funcional de base microscópica............153

VI.4.3.3.Integridad del conjunto e identificación de alteraciones tafonómicas............................................................153

VI.4.3.4.Inferencia funcional de las modalidades de uso......................153

VI.4.3.5. Materiales trabajados...........................................155

VI.4.3.6. Cinemática empleada...........................................156

VI.4.3.7. Actividades desarrolladas......................................157

VI.5. Cámara Sur:

VI.5.1. Conjunto lítico de la UA4: Artefactos formatizados.....................159

VI.5.1.1. Artefactos no formatizados (ANF) de UA4.......................161

VI.5.1.2. Resultados del análisis funcional de base microscópica.............162

VI.5.1.3.Integridad del conjunto e identificación de alteraciones tafonómicas.................................................................................................162

VI.5.1.2. Inferencia funcional de las modalidades de uso.....................164

VI.5.1.3. Materiales trabajados........................................165

VI.5.1.4. Cinemática empleada...........................................166

VI.5.1.5. Actividades desarrolladas.........................................167

VI.5.2. Conjunto lítico de la UA3: Artefactos formatizados......................168

VI.5.2.1. Artefactos no formatizados (ANF) de UA3.........................172

VI.5.2.2. Resultados del análisis funcional de base microscópica.............174 
VI.5.2.3.Integridad del conjunto e identificación de alteraciones tafonómicas...............................................................174

VI.5.2.4. Inferencia funcional de las modalidades de uso.....................177

VI.5.2.5. Materiales trabajados........................................178

VI.5.2.6. Cinemática empleada...........................................179

VI.5.2.7. Actividades desarrolladas.........................................181

VI.5.3. Conjunto lítico de la UA2: Artefactos formatizados......................182

VI.5.3.1. Artefactos no formatizados (ANF) de UA2 ........................186

VI.5.3.2. Resultados del análisis funcional de base microscópica.............187

VI.5.3.3. Integridad del conjunto e identificación de alteraciones tafonómicas...........................................................188

VI.5.3.4. Inferencia funcional de las modalidades de uso....................189

VI.5.3.5. Materiales trabajados.........................................190

VI.5.3.6. Cinemática empleada..........................................192

VI.5.3.7. Actividades desarrolladas......................................193

VI.6. Consideraciones generales...............................................194

VI.6.1.Componente 1................................................................194

VI.6.1.1. Integridad y alteraciones tafonómicas............................195

VI.6.1.2. Prácticas de consumo...............................................196

VI.6.1.3. Contexto de uso................................................198

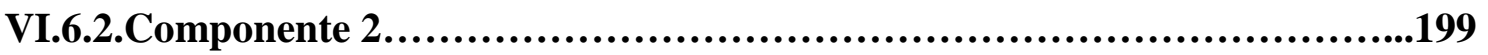

VI.6.2.1. Integridad y alteraciones tafonómicas...........................200

VI.6.2.2. Prácticas de consumo...........................................201

VI.6.2.3. Contexto de uso...................................................203

VI.6.3.Componente 3........................................................204

VI.6.3.1. Integridad y alteraciones tafonómicas............................204

VI.6.3.2. Prácticas de consumo.........................................205

VI.6.3.3. Contexto de uso..............................................206

\section{CAPÍTULO VII:}

Análisis funcional del instrumental lítico de la localidad arqueológica Piedra Museo

VII.1. Características principales del sitio....................................211

VII.2. Antecedentes de investigación........................................212 
-Geoarqueología................................................................212

-Dataciones obtenidas..............................................................214

-Arte rupestre......................................................................215

-Zooarqueología....................................................................215

-Análisis lítico...................................................................217

VII.3. Unidad estratigráfica 2 .................................................218

VII.3.1.Componente inferior: materiales de Capa 6.............................218

VII.3.1.1. Resultados del análisis funcional de base microscópica...........219

VII.3.1.2 Integridad del conjunto e identificación de alteraciones tafonómicas...................................................................219

VII.3.1.3 Materiales trabajados.........................................222

VII.3.1.4 Actividades desarrolladas.......................................223

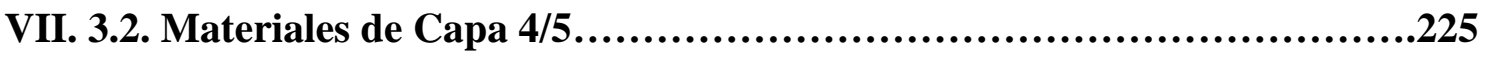

VII.3.1.1 Integridad del conjunto e identificación de alteraciones tafonómicas..........................................................226

VII.3.1.2 Inferencia funcional de las modalidades de uso...................227

VII.3.1.3 Materiales trabajados.........................................228

VII.3.1.5 Actividades desarrolladas.......................................229

VII. 3.3 Componente superior: materiales de capa 2 ...........................231

VII.3.3.1 Integridad del conjunto e identificación de alteraciones tafonómicas............................................................234

VII.3.3.2 Inferencia funcional de las modalidades de uso...................236

VII.3.3.3 Materiales trabajados..........................................237

VII.3.3.4 Cinemática empleada.............................................239

VII.3.3.5 Actividades desarrolladas.......................................239

VII.4. Unidad estratigráfica 1..............................................240

VII.4.1 Materiales de Capa 1................................................241

VII.4.1.1 Integridad del conjunto e identificación de alteraciones tafonómicas............................................................242

VII.4.1.2 Inferencia funcional de las modalidades de uso...................244

VII.4.1.3 Materiales trabajados.........................................244

VII.4.1.4 Cinemática empleada................................................245

VII.4.1.5 Actividades desarrolladas.......................................246

VII.5. Consideraciones generales...............................................247 
VII.5.1.Unidad estratigráfica 2:

VII. 5.1.1. Grado de intensidad y tipos de alteraciones.......................247

VII.5.1.2. Prácticas de uso.....................................................250

VII.5.1.3. Contexto de uso..............................................250

VII.5.2. Unidad Estratigráfica 1:............................................252

VII.5.2.1. Grado de intensidad y tipos de alteraciones........................252

VII.5.2.2.Prácticas de uso................................................253

VII.5.2.3.Contexto de uso...............................................253

\section{CAPÍTULO VIII:}

Discusión final y conclusiones

VIII. 1. Análisis de los mecanismos de formación de rastros de uso y alteraciones identificadas en los sitios .258

VIII.1.1. Mecanismo de formación de rastros de uso......................259

VIII.1.2. Integridad artefactual y alteraciones identificadas................261

VIII. 2. Prácticas de consumo y diseños elegidos en la manufactura de los artefactos empleados.......................................................264

VIII.2.1. Materiales trabajados y actividades desarrolladas................265

-Transición Pleistoceno/Holoceno y Holoceno temprano (Capa 5 de CN y UA4 de CS en Cueva Maripe y capa 6 y 4/5 de AEP1).....................265

-Holoceno medio (capa 4 de CN y UA2 de CS de Cueva Maripe y Capa 2 de

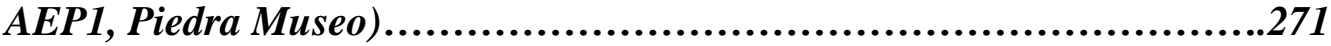

-Holoceno tardío (Capa 3 y 2 de CN y UA2 de CS de Cueva Maripe y Capa 1

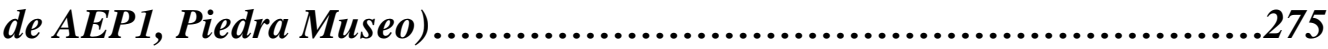

VIII.2.2. Opciones técnica seleccionadas durante los procesos productivos y los diseños elegidos.....................................................278

VIII.2.3. Variabilidad de los conjuntos observados y su relación con la funcionalidad de las ocupaciones arqueológicas..................................................290

Conclusiones....................................................................294

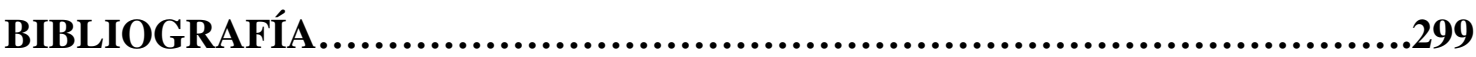

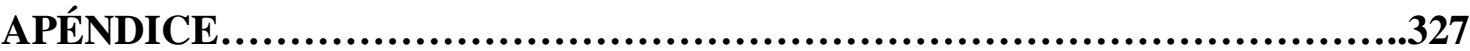




\section{ÍNDICE DE FIGURAS}

Figura 1: Sector de la meseta central de Santa Cruz bajo estudio .16

Figura 2: Visibilidad del sitio AEP1 respecto al paleolago y grabados dispuestos en un bloque de sitio AEG2.

Figura 3: Sitio arqueológico Cueva Maripe visto desde el cañadón La Primavera. Representaciones rupestres identificadas en la cámara sur (manos en positivo y negativo, Carden 2008) .33

Figura 4: El Cañadón La Primavera y la presencia de tropillas de guanaco frente al sitio Arqueológico Cueva Maripe

Figura 5: Afloramiento de ignimbritas de la formación Chön Aike, Cantera del Rojo (CDR), (Foto: Darío Hermo).

Figura 6: A) Coladas basálticas del cañadón La Primavera. B) Pedimento La Primavera 1 (LPP1) fuente secundaria de aprovisionamiento de materias primas .46

Figura 7: Raspador elaborado sobre roca silícea con residuos de coloración roja en la cara ventral....

Figura 8: Mapa geológico de la macro-área de estudio (tomado y modificado de Magnin 2010)

Figura 9: Observación de rastros de uso a partir de diferentes medios óptico (lupa trinocular aumentos de 10X a 63X-y microscopio metalográfico -aumentos de 100X a 500X-)

Figura 10: Modificaciones de las superficie de los artefactos ocasionadas por procesos postdepositacionales.

Figura 11: Panorámica y visibilidad del área. A) Vista del mallín de La Primavera. B) Sitio Cueva Maripe tomada desde la Cantera Rocky la más cercana al sitio 106

Figura 12: Plano del sitio Cueva Maripe, cuadrículas excavadas período 2003-2007. 108

Figura 13: Dibujo de la estratigrafía de $\mathrm{CN}$ y fechados obtenidos de las cuadrículas excavadas (modificado de Miotti et al., en prensa) 109 
Figura 14: Dibujo de los perfiles de CS y fechados asociados a cada capa identificada (modificado de Miotti et al., en prensa)

Figura 15: Dibujo en planta de la capa 5 de $\mathrm{CN}$, rasgos y agentes principales tafonómicos (modificado de Marchionni 2013)

Figura 16: Distribución espacial de AF en la capa 5, cuadrículas C5, D5 y D6. 116

Figura 17: Distribución de las materias primas por capa identificadas en $\mathrm{CN}$. .116

Figura 18: Variedades de materias primas identificadas en los artefactos formatizados de capa 5. .117

Figura 19: Materiales recuperados de la Capa 5 de $\mathrm{CN}$ de Cueva Maripe...................121

Figura 20: Distribución de densidades de ANF en Capa 5, cuadrículas C5, D5 y D6.........121

Figura 21: Histograma de materias primas identificadas en los ANF de capa 5.

Figura 22: Tipos de alteración reconocidas en los artefactos formatizados de la capa 5 de $\mathrm{CN}$

Figura 23: Fotos de alteraciones identificadas sobre los materiales recuperados en capa 5 de $\mathrm{CN}$.

Figura 24: Relación de filos potencialmente funcionales por pieza y rastros de uso identificados en la capa 5

Figura 25: Cantidad de filos potencialmente funcionales en capa 5. AF: artefactos formatizados y ANF: artefactos no formatizados.

Figura 26: Variedad de materias primas con rastros de utilización en capa 5 de Cueva Maripe.

Figura 27: Material identificado en la capa 5 de Cueva Maripe. . .128

Figura 28: Fotomicrografías de los materiales trabajados capa 5 de $\mathrm{CN}$ en Cueva Maripe....129

Figura 29: Correlación entre la cinemática empleada y el material trabajado en AF de la capa 5. 130

Figura 30: Relación entre la cinemática efectuada y la longitud de los filos empleados 131

Figura 31: Actividades inferidas a partir de las huellas de uso identificadas sobre los AF y ANF de capa 5 .

Figura 32: Dibujo en planta de capa 4 CN (modificado de Marchionni 2013).

Figura 33: Distribución de densidades artefactuales en capa 4 (AF) de las cuadrículas C5, D5, y D6 en CN. .134

Figura 34: Materiales recuperados de Capa 4 de Cueva Maripe...............................134

Figura 35: Variedad de materias primas en AF de capa 4 ................................ 135

Figura 36: Tamaños y módulos de longitud-anchura de AF en capa 4................... 137

Figura 37: Distribución de densidades artefactuales (ANF) de capa 4 en las cuadrículas C5, D5 y D6 de CN... 
Figura 38: Distribución de las variedades de materias primas utilizadas en ANF de capa 4 de

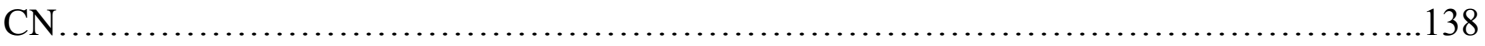

Figura 39: Distribución de tamaños en ANF de capa 4 de CN...........................138

Figura 40: Alteraciones identificadas en la capa 4 de $\mathrm{CN}$ de Cueva Maripe....................140

Figura 41: Relación de los filos observados y la presencia/ausencia de rastros de uso en AF de capa 4

Figura 42: Distribución de las distintas variedades de materias primas en AF y ANF con rastros de uso en capa 4 de $\mathrm{CN}$ .142

Figura 43: Materiales trabajados identificados en los artefactos líticos de capa 4 en CN......143

Figura 44: Materiales trabajados identificados en capa $4 \mathrm{CN}$ de Cueva Maripe 143

Figura 45: Expresa la diferencia significativa entre la longitud de los filos empleados en distintas cinemáticas sobre material duro

Figura 46: Relación entre diferentes cinemáticas empleadas en el trabajo sobre material duro y el ángulo de los filos utilizados 145

Figura 47: Actividades inferidas mediante el análisis funcional desarrollado en AF y ANF de capa 4 en $\mathrm{CN}$. 146

Figura 48: Dibujo en planta de capa 3 y 2 de CN (modificado de Marchionni 2013). 147

Figura 49: Distribución de densidad artefactual (AF) en las capas 3 y 2 de CN, cuadrículas C5, D5 y D6.

Figura 50: Distribución de las materias primas seleccionadas en la producción de AF de capa 3

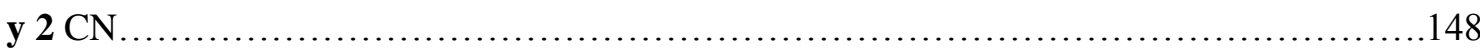

Figura 51: Materiales recuperados de la Capa 3 y 2 de Cueva Maripe........................149

Figura 52: Densidad artefactual (ANF) capas 3 y 2 de CN, cuadrículas C5, D5 y D6........ 151

Figura 53: Distribución de materias primas de ANF en capas 3 y 2 de CN................. 152

Figura 54: Frecuencia de ocurrencia de lascas/hojas entre las capas $(5,43$ y 2$)$ de CN (2: lascas y 3: hojas).

Figura 55: Relación de los filos observados y la presencia/ausencia de rastros de uso en AF de las capas 3 y 2 en CN. 154

Figura 56: Distribución de las materias primas con rastros de uso identificables en las capas 3

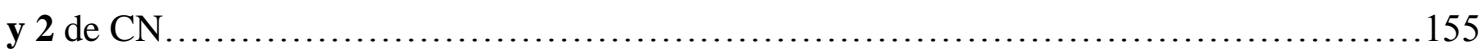

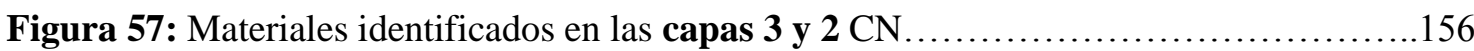

Figura 58: Diferencia estadísticamente significativa entre la cinemática empleada y el trabajo sobre material duro ( $\mathrm{AF}$ de capa 3 y 2 de $\mathrm{CN}$ ).

Figura 59: Inferencias de las actividades desarrolladas por los AF y ANF de capa 3 y 2 en $\mathrm{CN}$. 158

Figura 60: Distribución de la densidad de materiales líticos formatizados en sentido S-O en UA4 de CS, cuadrículas A12 y B12. 160

xviii 
Figura 61: Materiales recuperados de la UA4 de CS de Cueva Maripe. 161

Figura 62: Tipo de alteraciones identificadas en la UA4 de CS (AF y ANF) ................163

Figura 63: Integridad artefactual de la UA4 en CS.................................... 164

Figura 64: Relación de los filos observados y la presencia/ausencia de rastros de uso en AF de UA4 de CS. .165

Figura 65: Materiales trabajados identificados en la UA4 de CS...........................165

Figura 66: Materiales trabajados identificados en la UA4 CS ............................ 166

Figura 67: Actividades inferidas a partir del análisis efectuado en los artefactos recuperados de

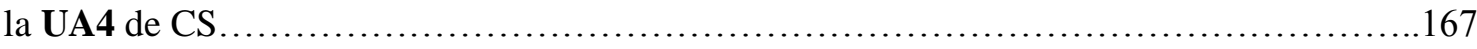

Figura 68: Distribución de AF en la UA3 de CS, sentido O-S (cuadrículas A12 y B12).......168

Figura 69: Materiales recuperados de la UA3 CS de Cueva Maripe.........................172

Figura 70: Distribución de ANF en la UA3 CS (cuadrículas A12 y B12), sentido O-S........172

Figura 71: Distribución de las materias primas seleccionadas en la producción de ANF en la

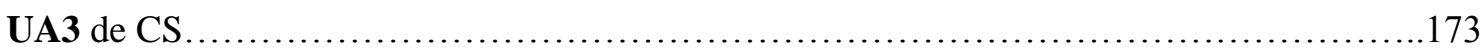

Figura 72: Alteraciones identificadas sobre los artefactos recuperados de la UA3 en CS......175

Figura 73: Diagrama de dispersión del tamaño de la muestra y riqueza (materias primas con rastros de utilización) en AF de la UA3 CS. .176

Figura 74: Gráfico de dispersión del tamaño de la muestra y riqueza en relación con las materias primas identificadas con rastros de uso en los ANF de UA3. .176

Figura 75: Relación de los filos observados y la presencia/ausencia de rastros de uso en AF de UA3 CS .177

Figura 76: Materiales trabajados identificados en la UA3 de CS...........................178

Figura 77: Materiales identificados en la UA3 de CS. 179

Figura 78: Diagrama de correlación entre la longitud de los filos utilizados sobre material duro y la cinemática empleada.

Figura 79: Diagrama de correlación entre la cinemática empleada y el ángulo de los filos utilizados.

Figura 80: Porcentajes de materiales trabajados identificados en el conjunto lítico de la UA3 de CS. 182

Figura 81: Distribución de los AF en UA2 de CS (cuadrículas A12 y B12) sentido O-S.....183

Figura 82: Materiales recuperados de la UA2 CS de Cueva Maripe...........................186

Figura 83: Distribución de ANF en la UA2 de CS (cuadrículas A12 y B2), sentido O-S.....186

Figura 84: Distribución de materias primas con rastros de uso identificables de los artefactos recuperados en la $\mathbf{U A 2}$ de CS

Figura 85: Tipos de alteraciones reconocidas sobre las piezas recuperadas de la UA2 de CS. 189 
Figura 86: Diagrama de distribución de materias primas con rastros de uso en relación al tamaño de la muestra y riqueza en los AF de UA2 de CS............................... 190

Figura 87: Materiales identificados en la UA2 de CS................................... 191

Figura 88: Materiales trabajados identificados en la UA2 CM..............................191

Figura 89: Diagrama de diferencias de media, ángulos de filos identificados en AF de UA2 en relación con la cinemática empleada y el trabajo sobre material duro.

Figura 90: Distribución de las actividades desarrolladas inferidas a través del análisis de los artefactos líticos de la UA2 de CS.

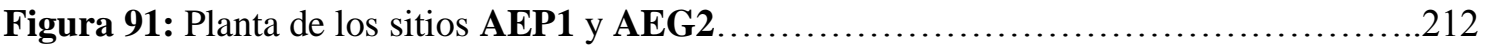

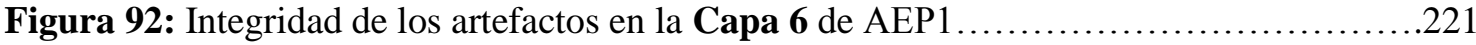

Figura 93: Artefactos recuperados de la Capa 6 de AEP1 ...............................222

Figura 94: Materiales identificados en la Capa 6 de la UE2 de AEP1 .........................223

Figura 95: Actividades desarrolladas e identificadas en los materiales recuperados de la Capa 6 de AEP1....

Figura 96: Artefactos recuperados de la Capa 4/5 de AEP1 .226

Figura 97: Integridad artefactual de los materiales recuperados en la Capa 4/5 de AEP1 ....227

Figura 98: Materiales identificados a partir del análisis efectuado en los material recuperados de la Capa 4/5. .228

Figura 99: Materiales identificados en la Capa 4/5 de la UE2 de AEP1 .229

Figura 100: Estado de los materiales recuperados de la Capa 2 de AEP1.... .232

Figura 101: Representación de materias primas utilizadas en los conjuntos observados de la Capa 2 de AEP1. .233

Figura 102: Materiales recuperados de la Capa 2 de AEP1 234

Figura 103: Resultado del análisis funcional realizado sobre los artefactos recuperados del componente superior de AEP1 (Capa 2).... .235

Figura 104: Alteraciones registradas en el componente superior de AEP1, Capa 2..........236 Figura 105: Alteraciones identificadas en las piezas recuperadas de Capa 2 de AEP1 (principalmente abrasión sedimentaria y lustre de suelo). .236

Figura 106: Relación entre los filos observados y los rastros de uso identificados en los AF del componente superior de AEP1 (Capa 2)

Figura 107: Materiales identificados en los artefactos recuperados del componente superior de AEP1 (Capa 2). .238

Figura 108: Materiales identificados en la Capa 2 de la UE2 de AEP1. .238

Figura 109: Detalle de las actividades realizadas en el componente superior de AEP1 (Capa 2).

Figura 110: Materiales recuperados de la capa 1 UE1 de AEP1 ..........................242

Figura 111: Tipos de alteraciones identificadas en la UE1 (Capa 1 de AEP1). 243 
Figura 112: Materiales identificados en la Capa 1 de la UE1 de AEP1

Figura 113: Actividades inferidas a partir del análisis funcional realizado en la UE1 (Capa 1 de AEP1). .246

Figura 114: Recursos utilizados en el componente 1 de Cueva Maripe (Capa 5 CN y UA4 CS) y componente inferior de AEP1, Piedra Museo (Capa 6 y 4/5)

Figura 115: Recursos identificados en el Componente 2 de Cueva Maripe y componente superior de AEP1 (Capa 2)

Figura 116: Recursos identificados en el Componente 3 de Cueva Maripe y capa 1 de AEP1, bloque temporal definido como Holoceno tardío

Figura 117: Trabajo sobre madera dura (estacionada) de manera transversal (raspado) 60' de trabajo

Figura 118: Pieza de sílice trabajada sobre cuero seco de manera transversal (raspado) 60' de trabajo

Figura 119: Trabajo sobre hueso fresco y formación del surco perimetral. Micropulido generado luego de 60' de trabajo realizado mediante acción transversal (raspado) .338

Figura 120: Micropulido de hueso observado bajo microscopio electrónico de barrido (modo ambiental 2000X) y curva de EDAX que evidencia picos de Ca, elemento constituyente 339

Figura 121: Lasca utilizada para corte de gramíneas (60' de trabajo). Micropulido bien diferenciado con estrías en forma de cometa que permiten observar el movimiento efectuado. .340

Figura 122: Vista del micropulido de gramíneas bajo microscopio electrónico de barrido (modo ambiental, 5000X) y curva de EDAX con alto contenido silíceo del material trabajado

Figura 123: Dibujos realizados por la Lic. Blanco Rocío y microfotografías de las distintas técnicas empleadas sobre soporte mineral durante la etapa experimental (VL).

Figura 124: Piezas experimentales elaboradas sobre basalto y trabajadas en distintos materiales 345

Figura 125: Trabajo sobre materiales duros a partir de lascas experimentales realizadas en basalto.

Figura 126: A) Mango etnográfico provenientes de la Prov. de Chubut. Colección Moreno, División Etnográfica del Museo de Ciencias Naturales de La Plata (Pieza No 1810). 348

Figura 127: Desarrollo de micropulido de madera en la cara dorsal (porción medial) de uno de los raspadores empleados (EU145), consecuencia de un dispositivo de enmangue .350

Figura 128: Experimento realizado en solución alcalina .354

Figura 129: Experimento realizado en solución ácida. 356 


\section{ÍNDICE DE TABLAS}

Tabla 1: Tipos de diseño artefactual definido a partir de las estrategias tecnológicas observadas.

Tabla 2: Detalle de los materiales trabajados y estado de cada material de acuerdo a los experimentos de uso realizados

Tabla 3: Variables consideradas para la observación de los rastros de uso generados a nivel experimental (tomado y modificado de Álvarez 2003). .98

Tabla 4: Fechados obtenidos hasta el momento de los distintos sector de Cueva Maripe (Miotti et al., en prensa)

Tabla 5: Grupos tipológicos identificados en la capa 5 de CN.............................118

Tabla 6: Grupos tipológicos identificados en la capa 4 de CN.................................

Tabla 7: Grupos tipológicos identificados en las capas 3 y 2 de CN........................148

Tabla 8: Fechados radiocarbónicos obtenidos de AEP1 ..................................214

Tabla 9: Artefactos formatizados recuperados de AEP1 ....................................219

Tabla 10: Medida centrales y de dispersión del grupo de raspadores, a partir del material trabajado, en los distintos bloques temporales identificados en Cueva Maripe.

Tabla 11: Características principales de artefactos con filos naturales del componente III (Holoceno temprano) de CM

Tabla 12: Descripción del trabajo realizado a partir de lascas elaboradas sobre basalto. RP: raspado, AS: aserrado y $\mathbf{C}$ : corte.

Tabla 13: Detalles de los experimentos realizados con raspadores enmangados

Tabla 14: Detalle de las piezas experimentales trabajadas en distintos materiales y utilizadas en soluciones químicas. 353 


\section{RESUMEN}

En esta tesis se plantea como objetivo general el estudio de la tecnología lítica y, principalmente, de las modalidades de utilización de los artefactos implementadas por los grupos cazadores-recolectores que habitaron la cuenca de los zanjones Rojo y Blanco de la Meseta Central de Santa Cruz.

Los objetivos propuestos fueron realizados a partir del análisis tecno-morfológico y funcional de base microscópica de los conjuntos artefactuales procedentes de los sitios Cueva Maripe y Alero El Puesto 1 (AEP1), de la localidad arqueológica Piedra Museo. Las ocupaciones identificadas en estos sitios abarcan distintos bloques temporales que van desde la transición Pleistoceno-Holoceno al Holoceno Tardío ( $c a .13 .000$ años $C^{14}$ AP hasta tiempos históricos).

La metodología aplicada, a partir de diferentes medios ópticos y mediante una intensa labor experimental, ha permitido determinar la recurrencia y variabilidad en usos y diseños de artefactos líticos durante los bloques temporales analizados en los distintos sectores de la cuenca. También permitió determinar las diferentes actividades que formaron parte de las prácticas cotidianas y rituales de los grupos que habitaron en el pasado.

Los instrumentos líticos, manufacturados sobre diferentes materias primas, fueron utilizados para procesar distintos materiales, en primer lugar hueso, cuero y madera, seguido por materias blandas animales y vegetales no leñosas, mediante diferentes opciones técnicas. Estas actividades se repartieron en forma heterogénea tanto a nivel intrasitio como intersitio.

Por otro lado, las diferencias establecidas a partir del estudio de las alteraciones postdepositacionales identificadas en los distintos conjuntos observados, permitieron discutir y profundizar el conocimiento acerca de los distintos procesos que intervinieron durante la formación del registro arqueológico, siendo el resultado de historias tafonómicas complejas. 
De esta forma los datos obtenidos han puesto de manifiesto las actividades efectuadas por las sociedades cazadoras-recolectoras mediante instrumentos líticos y la relación observada entre las variables de diseño y uso, permitiendo generar nuevos aportes a la discusión sobre la funcionalidad de los sitios y discutir la utilidad de conceptos teóricos en el estudio de la tecnología lítica. Por último, esta investigación permitió constatar aspectos económicos y simbólicos de las prácticas tecnológicas y formular la importancia que tuvo el contexto de uso de los instrumentos líticos en la organización social de los grupos que habitaron desde épocas tempranas este sector de la Meseta Central de Santa Cruz.

\begin{abstract}
This Thesis aims to study the lithic technology and mainly the use patterns of artefacts implemented by hunter-gatherer groups that inhabited the basin of the Rojo and Blanco ditches at the central plateau of Santa Cruz, from the Pleistocene-Holocene transition to the Late Holocene (form 13.000 years $\mathrm{C}^{14} \mathrm{BP}$ up to the present).

The main objective of this thesis was made basing on the techno-morphological and microwear analysis of lithic artefacts from Cueva Maripe and Alero El Puesto 1 (AEP1) sites, of Piedra Museo archaeological locality. The results allowed determining recurrence in the variability of uses and designs of lithic artefacts during the occupations analyzed in different sectors of the basin. This also allowed identifying the different activities that were part of the practices and daily rituals of the groups that lived in the past.

The stone tools, made of different raw materials, were used to process different materials, first bone, leather and wood, followed by soft materials from animals and plants, using different technical options. These activities are heterogeneously distributed both intrasite and intersite.

On the other hand, the study of different post-depositional alterations identified on the lithic artefacts, allowed to discuss and deepen the knowledge about the various processes involved in the formation of the archaeological record, result of complex taphonomic histories.
\end{abstract}


In this way the data obtained have shown the activities carried out by the huntergatherer societies from the study of the stone tools that allowed observing the relationship with the design variables and use, and to generate new contributions to the discussion of the study sites functionality. It also allowed discuss the usefulness of theoretical concepts in the lithic technology analysis. Finally, through this research it could be verified economic and symbolic features of technological practices and formulate the importance that the use context of stone tools has in the social organization of the groups that inhabited since early times in the central plateau of Santa Cruz. 
CAPÍTULO 1

Planteo de la problemática

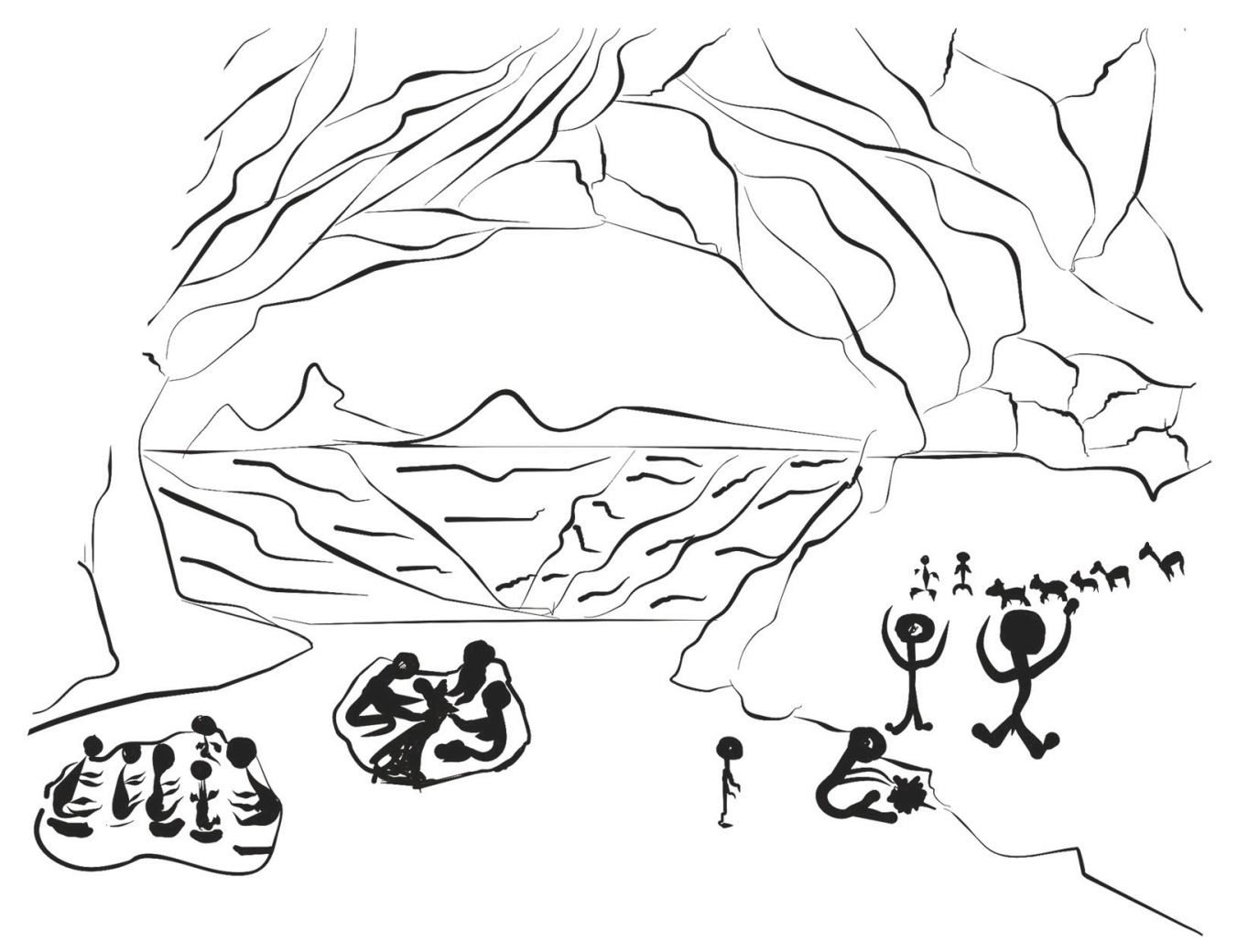





\section{INTRODUCCIÓN}

El interés de este trabajo ha sido analizar la tecnología lítica elaborada por grupos cazadoresrecolectores que habitaron desde épocas tempranas en la Meseta Central de Santa Cruz, Argentina. Esta temática será abordada a partir del estudio de la organización tecnológica con especial énfasis en la producción de artefactos líticos, el diseño elegido y el uso específico al cual fue destinado.

El eje central de investigación se encuentra focalizado en la tecnología lítica y la forma de la organización tecnológica en relación a la variabilidad artefactual y el modo en que esta variabilidad se expresa y relaciona a partir de aspectos funcionales, adaptativos y/o simbólicos. Para esto es necesario comprender el contexto de uso de los materiales líticos, que incluye conocer las actividades en los cuales los artefactos están inmersos, su frecuencia y ordenamiento espacio-temporal como el conocimiento adquirido durante el desarrollo de estas actividades (Álvarez 2003).

El análisis y la identificación del contexto de uso son de fundamental importancia para explicar la diversidad de los conjuntos líticos recuperados del contexto arqueológico, al igual que para comprender las estrategias tecnológicas empleadas y los factores que intervinieron en la manufactura y diseño de los artefactos.

Estos estudios intentan discutir otras cuestiones más generales como lo son las diversas estrategias económicas y sociales de movilidad de estos grupos, el uso del espacio y explotación de recursos disponibles en un medio que ha ido cambiando a lo largo del tiempo; cambio que se encuentra expresado en las unidades temporales identificadas en los casos de estudio.

El análisis se enmarca específicamente en el estudio tecno-morfológico y funcional de base microscópica de los materiales recuperados de dos localidades arqueológicas, sitio Piedra Museo y Cueva Maripe, ubicados en el macizo central de Santa Cruz, habiendo sido trabajados por otros investigadores desde hace varios años y dirigido por la Dra. Laura Miotti.

El estudio de materiales líticos es una línea de evidencia que permite comprender comportamientos, decisiones y selecciones de los grupos humanos que habitaron en el pasado. El aprovisionamiento de materias primas, elaboración de artefactos, uso y descarte de los mismos permiten reconocer a través del registro, comportamientos específicos, incorporando conocimientos acerca del uso del espacio y movilidad de estos grupos. 
La utilización de un instrumento, refleja una serie compleja de comportamientos económicos y sociales (Mansur-Franchomme 1987; Álvarez 2003; Leipus 2006) por lo que su abordaje es un requisito sumamente valioso para comprender la dinámica de las sociedades pasadas. El estudio del modo de empleo de un instrumento y del material sobre el cual trabajó, su relación con el diseño elegido, técnica de producción y materia prima empleada, permiten comprender las estrategias económicas y sociales utilizadas a lo largo del tiempo y la relación que estos grupos mantuvieron con un entorno cambiante y en algunos casos adverso.

Los conjuntos líticos estudiados de ambas localidades corresponden a tres grandes bloques temporales; Pleistoceno final/ Holoceno temprano, Medio y Tardío.

Con relación a la escala temporal es necesario aclarar que en los bloques establecidos se habrían producido cambio climáticos y ambientales que generaron importantes modificaciones en las poblaciones pasadas, incluyendo manifestaciones simbólicas (representaciones rupestres), innovaciones tecnológicas (instrumental especializado), redes de intercambio regional y extrarregional e incremento de la densidad poblacional que llevó a una mayor “complejización” en sociedades cazadoras-recolectoras (Borrero 1989-90; Berón y Politis 1997; Miotti et al.1999; Politis y Madrid 2001; Miotti 2003; Miotti y Salemme 2004). Estos cambios se vieron expresados en las decisiones y variabilidad tecnológica tanto en el uso de las materias primas (mayor diversidad de rocas utilizadas) como en las técnicas de manufactura empleadas en su producción.

El estudio de estos conjuntos se realizó primeramente a partir del análisis tecno-morfológico de piezas individuales y posteriormente el análisis funcional de base microscópica, siguiendo los lineamientos descriptivos propuestos por Mansur para la aplicación del mismo (1983, 1999).

Resulta necesario aquí remarcar que ninguno de los sitios mencionados en esta investigación han sido abordados de manera sistemática a partir de este marco metodológico de estudio, aún con las numerosas investigaciones desarrolladas para este sector de Patagonia, y muchísimas referidas exclusivamente al abordaje de la circulación y uso de materias primas (Cattáneo 2002 y Hermo 2008, entre otros). Hasta el momento existen dos tesis referidas a esta temática con materiales provenientes del sitio Los Toldos y El Ceibo (Mansur 1983a, Castro 1994). Por lo tanto, se considera de suma importancia las interpretaciones obtenidas a partir del mismo, permitiendo avanzar con los objetivos del proyecto general de investigación en el área. 


\section{I.1 Objetivos.}

\section{I.1.1. Objetivo General.}

El objetivo general de investigación ha sido analizar las estrategias tecnológicas, los procesos de producción y uso de artefactos líticos elaborados por las sociedades cazadorasrecolectoras de Patagonia Continental. La finalidad es determinar las tendencias espaciotemporales del diseño y la función de los materiales líticos durante el proceso de colonización y posterior consolidación territorial en la Meseta Central de Santa Cruz, Argentina.

\section{I.1.2 Objetivos Específicos.}

Analizar los mecanismos de formación y deformación de rastros de uso sobre las distintas materias primas líticas disponibles y explotadas en los sitios estudiados de la cuenca alta y baja de la Meseta Central de Santa Cruz.

- Aplicar el método del análisis funcional de base microscópica a los materiales líticos (filos y superficies) procedentes de los sitios Cueva Maripe y Piedra Museo, teniendo en cuenta sus características tecno-morfológicas y morfológico-funcionales.

Caracterizar a nivel macro y microscópico las alteraciones naturales y postdepositacionales registradas en los conjuntos recuperados, permitiendo obtener mayor información acerca de los procesos de formación del sitio y, de esta manera, evaluar su integridad.

Identificar a partir del análisis funcional de base microscópica de los artefactos líticos los posibles residuos presentes en los potenciales filos activos identificados.

Determinar posibles diferencias de usos en relación con las materias primas utilizadas en la manufactura de los artefactos a lo largo de los distintos bloques temporales identificados en las ocupaciones de los sitios. 
> Discutir la relación forma/función de los artefactos líticos que oriente la determinación de decisiones de los grupos humanos en la producción y utilización de los mismos.

Realizar un análisis comparativo de los materiales líticos extraídos del área de estudio. Esta comparación abarcará los bloques temporales que incluyen la transición Pleistoceno/Holoceno-Holoceno Temprano, Holoceno Medio y Tardío.

Testear las hipótesis planteadas acerca de la funcionalidad de los sitios en los distintos bloques temporales establecidos, a partir de los nuevos datos generados mediante el análisis funcional realizado.

\section{I.1.3. Hipótesis}

De acuerdo a los antecedentes generados para el área de estudio y en relación a los modelos de poblamiento propuestos (Borrero 1994-95; Borrero et al. 1998 y Miotti y Salemme 2004), las hipótesis planteadas en este trabajo de tesis han estado vinculadas a dos ejes principales: 1) el estudio del uso y diseño de la tecnología lítica en los bloques temporales que abarcan la transición Pleistoceno-Holoceno al Holoceno tardío, 2) la dinámica y movilidad de los grupos que habitaron la Meseta Central de Santa Cruz en los bloques temporales establecidos. De acuerdo a estos ejes las hipótesis planteadas han sido:

Hipótesis 1: Las condiciones ambientales que caracterizaron el Pleistoceno final hasta el Holoceno tardío, habrían influenciado las formas de organización social y explotación de los recursos disponibles en un medio ambiente cambiante y con condiciones críticas para el desplazamientos de los primero grupos que habitaron la Meseta Central, viéndose reflejado en la organización tecnológica.

Hipótesis 2: Durante la transición Pleistoceno-Holoceno, lapso para el que se infiere una intensidad de ocupación baja y menor conocimiento del ambiente, la distribución de los recursos habría jugado un rol importante en las decisiones tecnológicas, privilegiándose el uso de materias primas de muy buena calidad para la talla e instrumentos con diseños versátiles los cuales habrían tenido una mayor diversificación en los usos. 
Hipótesis 3: Durante el Holoceno medio y tardío, marcados por un incremento demográfico, mejor conocimiento del ambiente con recursos semejantes a los actuales y una mayor interacción social, se habrían generado ciertos cambios en la tecnología lítica, que se verían expresados en la producción de artefactos con diseños estandarizados. Esta estandarización estaría relacionada a la utilización de los artefactos en tareas específicas.

Hipótesis 4: La accesibilidad hacia los diferentes tipos de materias primas en el área habría sido un fuerte condicionante tanto para la elección de la técnica aplicada como para el tipo de diseño elegido en la elaboración de artefactos líticos.

\section{I.2. Organización de la tesis.}

La presente tesis se encuentra ordenada en ocho capítulos, donde se exponen los principales lineamientos teóricos-metodológicos en el estudio de la tecnología lítica de grupos que habitaron la Meseta Central de Santa Cruz desde finales del Pleistoceno al Holoceno tardío. Este estudio se realiza a nivel comparativo a partir de los bloques temporales establecidos en los sitios mencionados.

En el Capítulo II se presentan los principales antecedentes relacionados a los sitios con ocupaciones tempranas para el área y las características generales de los materiales recuperados del contexto arqueológico, junto con las metodologías de análisis aplicados hasta la actualidad. Estos antecedentes se refieren principalmente a sitios donde se aplicó la metodología de análisis funcional de base microscópica, para poder determinar la posible funcionalidad de los sitios y específicamente de los artefactos recuperados.

El Capítulo III expone las principales características del área de estudio y los recursos disponibles en el sector mencionado. Además se presentan datos etnohistóricos que avalan el uso de determinados recursos, a partir de la mirada de los primeros colonos que arribaron a las costas sur de nuestro actual territorio argentino. Las descripciones de estos relatos permiten, de manera indirecta, tener una mejor comprensión acerca de los modos de uso y de la variabilidad artefactual que presentaban los grupos cazadores-recolectores en épocas de conquista e indagar acerca de la conceptualización y uso del paisaje que estos grupos tenían de su ambiente.

El capítulo IV plantea los lineamientos teóricos que guían la investigación realizada. 
Se desarrolla una breve síntesis de los principales conceptos teóricos y criterios metodológicos que guiarán esta investigación. Los distintos tipos de diseños elegidos por los grupos que habitaron en el pasado y las características principales que presentan son puntos importantes a considerar a la hora de analizar le tecnología lítica de una sociedad particular. El Capítulo $\mathbf{V}$ hace mención a las distintas técnicas de análisis utilizadas para la determinación funcional de la tecnología lítica recuperada en los sitios bajo estudio. Esto abarca desde la realización de una serie experimental como referente en la observación de rastros de uso (a partir de lupa binocular, microscopio metalográfico y microscopio electrónico de barrido), hasta el análisis concreto de estos rastros sobre las piezas líticas arqueológicas. Además se plantean distintos análisis estadísticos para identificar posibles correlaciones entre variables del diseño de los filos y los usos identificados.

El Capítulo VI se exponen los principales resultados obtenidos del análisis funcional de base microscópica realizados en el sitio Cueva Maripe, a lo largo de las distintas ocupaciones identificadas. También se discuten los resultados obtenidos en relación a la hipótesis de uso diferencial de los distintos sectores identificados en la cueva (cámara sur y norte) realizando un análisis comparativo de las actividades inferidas a partir del estudio de microhuellas de uso.

El Capítulo VII se presenta las principales características del sitio, y los estudios realizados con anterioridad. También se describen los principales resultados obtenidos del análisis funcional realizado en base a los materiales recuperados de las distintas ocupaciones del sitio Piedra Museo.

El Capítulo VIII se desarrolla un análisis comparativo de los datos obtenidos en relación a los distintos bloques temporales identificados (transición Pleistoceno-Holoceno, Holoceno medio y Holoceno tardío) y se presentan las conclusiones principales de esta tesis. Para finalizar en el Apéndice se describen detalladamente los resultados y las principales características de los rastros de uso obtenidos a partir de una serie experimental de referencia, sobre diversas materias primas localizadas en el área bajo estudio. Asimismo, se hace referencia a los distintos procesos post-depositacionales, que pueden afectar de manera desigual el grado de preservación de los distintos tipos de micropulidos generados. 
CAPÍTULO 2

Antecedentes de investigación

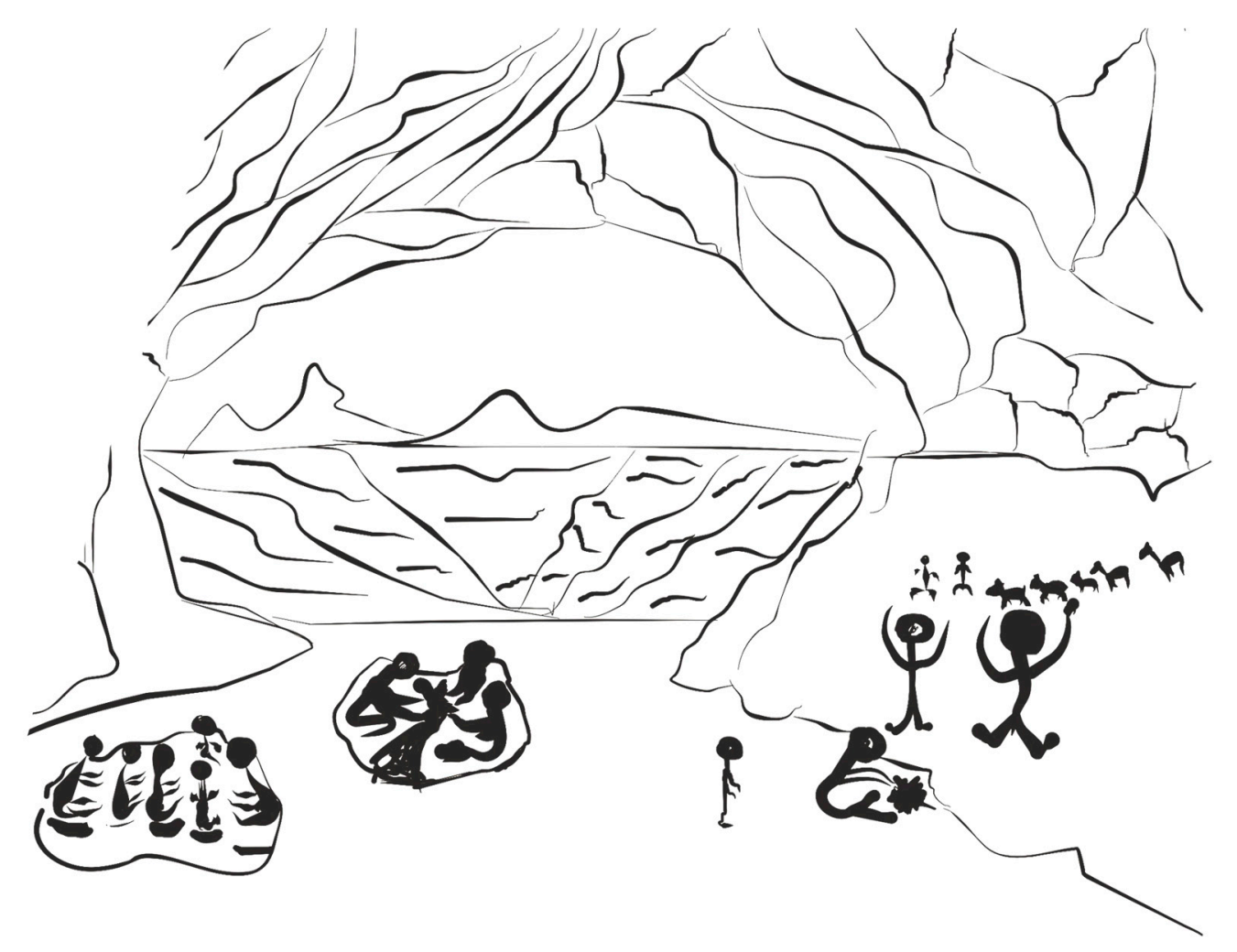





\section{INTRODUCCIÓN}

En este capítulo se presentan las distintas investigaciones realizadas en el área de estudio hasta momentos actuales, centrando un mayor interés en aquellos sitios donde fueron aplicadas metodologías específicas, incluyendo análisis funcionales de base microscópica, en los artefactos líticos registrados para diversos momentos de la ocupación cazadora-recolectora. La meseta central de Santa Cruz corresponde a un sector con numerosos sitios arqueológicos de ocupaciones tempranas y es por esta razón, que desde los inicios de la arqueología en Argentina hasta la actualidad, ha permitido responder algunos de los interrogantes relacionados al poblamiento americano, vías de acceso y disponibilidad de recursos que dieron paso a la consolidación territorial de grupos humanos en este sector de Patagonia.

Múltiples investigaciones arqueológicas focalizaron su interés en esta temática a partir de distintos marcos de referencia. Sin embargo, han surgido nuevas técnicas (SIG interespacial e intrasitio, microscopía de altos y bajos aumentos sobre artefactos líticos y óseos, liquenometría) permitiendo realizar estudios aún más detallados de la cultura material, de los paleoambientes y de las formas de uso de los distintos espacios. En este capítulo, se detallan los antecedentes metodológicos aplicados en la meseta central de Santa Cruz y plantea la relevancia de la incorporación de técnicas específicas, con el fin de generar un corpus de datos que permita una mejor comprensión del poblamiento inicial y su posterior desarrollo.

\section{II.1. Análisis funcional de base microscópica. Aportes generados a nivel mundial}

El estudio de los materiales líticos ha sido de fundamental importancia para la arqueología, permitiendo recuperar información acerca del modo de vida de una sociedad y la relación que esta ha generado con su entorno.

Desde el siglo XIX algunos investigadores como Lubbock (1872) y Evans (1872) trataron de dar una explicación funcional a los instrumentos líticos de sociedades pasadas, tomando como metodología la analogía etnográfica con instrumentos 
contemporáneos y dando inicio a las primeras explicaciones de carácter funcional de artefactos líticos.

Sin embargo, los estudios específicos relacionados con al uso de los materiales surgieron a partir de la obra "Prehistoric Technology" de Sergei Semenov (1964) y su traducción al inglés en la Universidad de Leningrado. Semenov consideraba que todas las materias primas al ser utilizadas sobre distintos tipos de materiales, conservaban rastros microscópicos de uso; que podían ser observados, analizados e identificados a partir del instrumental óptico adecuado. Determinó distintos tipos de rastros: estrías, microlascados y micropulidos, que podían ser identificados y analizados mediante el uso combinado de una lupa binocular y un microscopio de reflexión $(1964,1981)$.

...” Las huellas demostrativas de la utilización del útil en forma de brillo o pulido y las distintas intensidades de las mismas que se manifiestan como resultado de la fricción con la carne, piel, madera, hueso y cornamenta, no son solo características de herramientas de sílex, sino también para otros minerales del grupo de cuarzo (Semenov 1957) ... ".

Los postulados propuestos por este autor impulsaron a varios investigadores en la década del 70', a iniciar sus trabajos en el marco del análisis funcional, realizando experimentos sistemáticos y con distintas técnicas de observación microscópica (Tringham 1974; Keeley 1980; Anderson-Gerfaud 1981; Vaughan 1981; MansurFranchomme 1983; Plisson 1985, Plisson y Mauger 1988; Castro 1994,1996; Kardulias y Yerkes 1996; Álvarez 2003; Leipus 2006, entre otros).

A partir de esos estudios se generó una divergencia en cuanto a la metodología aplicada. Algunos autores, fundamentalmente en Estados Unidos, pusieron un gran énfasis en el análisis de microfracturas y microlascados, utilizando para esto la lupa binocular con bajos aumentos (Tringham 1974). Mientras que en Europa las investigaciones se desarrollaron mediante la utilización de microscopios metalográficos, focalizando en el estudio de estrías y micropulidos (Keeley 1974).

En la década del 80' ambas perspectivas fueron integradas y consideras como complementarias para un adecuado análisis funcional de los materiales líticos; dado que cada instrumento óptico permite observar distintos aspectos de los filos utilizados brindando información complementaria (Mansur-Fanchomme, 1983; Castro 1994; Álvarez 2003). 
Con el paso del tiempo, se ha ido incrementando la diversidad de los materiales a los que es posible aplicar esta metodología de análisis (óseo, metal, cerámica) junto con el desarrollo de nuevos medios ópticos (microscopio electrónico de barrido con posibilidad de un espectrómetro de Rayos-X dispersivo en energías - EDAX-) que provee información sobre la química de la muestra en forma cuantitativa y permite, por lo tanto, la identificación de residuos sobre las superficies de los artefactos utilizados.

En cuanto a la diversidad de materiales, es posible nombrar numerosos trabajos a nivel internacional sobre instrumental óseo (Newcomer 1974; Olsen 1979; Semenov 1964; Stordeur y Anderson-Gerfaud 1985; Johnson 1985; Peltier y Plisson 1989, D'Errico et al.1993; Villa y D’Errico 2001). Sin embargo, en nuestro país, se encuentra en estado inicial de desarrollo con buenas expectativas en su aplicación. Podemos mencionar los trabajos de Nami y Scheinsohn (1997) quienes incursionaron en estudios funcionales sobre descortezadores y retocadores arqueológicos de Tierra del Fuego, al igual que los desarrollados por Miotti y Cattáneo (2003) a partir de huellas de corte. Mientras que en Pampa, Johnson et al. (2000); Gutiérrez (2004), analizaron instrumental óseo del sitio la Olla 1, junto con los trabajos realizados por Buc (2005) aplicando esta metodología, a partir de una colección experimental de referencia, a materiales provenientes del Paraná inferior.

Asimismo, cabe mencionar la aplicación del análisis funcional microscópico a otros tipos de materiales como el metal y la cerámica, que hasta el momento no ha sido realizado en Argentina. En el primer caso corresponde nombrar las investigaciones realizadas por Sanahuja Yll (2006), donde a partir de estudios funcionales aplicados a artefactos elaborados en metal, plantea la diferenciación entre la definición de arma o herramienta prehistórica para los grupos que habitaron la Prov. de Almería en la Edad del Bronce (2250 a 1550 cal a. AC). Mientras que Clop García (2002) utiliza los medios ópticos para la identificación de huellas de uso y producción en elementos cerámicos del noreste de la península Ibérica.

En cuanto al uso de microscopía electrónica de barrido aplicado a material lítico en Argentina, aún se encuentra en un estadio inicial (Álvarez 2003; Mansur 1983, 1999). Esto se debe a los recaudos que deben considerarse al analizar cada pieza. Muchas de estas muestras provienen de excavaciones realizadas un siglo atrás, donde no era costumbre la toma de sedimento que rodea al artefacto a analizar. Esto genera dificultades a la hora de interpretar acerca de la procedencia de los residuos, ya que el contacto con otros materiales puede modificar el conteo de elementos, siendo ajenos al 
uso del mismo. Por otro lado, los costos y medios disponibles (microscopio de estas características en lugares cercanos para analizar la muestra) también generan complicaciones en su aplicación.

Pese a esto, los estudios relacionados a la utilización de materiales líticos en Argentina ha ido avanzando intensamente, debido al desarrollo de series experimentales numerosas que incluyen diversidad de materias primas, como así también multiplicidad de modos de empleo de las piezas (prensión manual o mediante distintos dispositivos de enmangue) (Mansur-Franchomme 1983; Castro 1994; Álvarez 2003, Álvarez et al. 2010; Leipus 2006; Mansur y Lasa 2005; Massigoge y Pal 2011; De Angelis 2012; Pal 2010, 2013, entre otros).

Si bien el análisis tecno-morfológico (Aschero 1975, 1983, Nelson 1991) continúa siendo el punto de partida para el estudio de la tecnología lítica, en la actualidad, han surgido nuevos marcos teóricos y de referencia, considerando como eje principal el estudio de los modos de producción y consumo de grupos humanos que habitaron en el pasado. La incorporación de esta metodología permitirá un mejor entendimiento acerca del contexto de uso del que forman parte los distintos objetos materiales, y en especial, los instrumentos líticos.

\section{II.2. Primeras investigaciones $y$ antecedentes metodológicos en el Macizo del Deseado.}

Las características principales y cronologías del poblamiento americano junto con los recursos disponibles y uso del paisaje desde la transición Pleistoceno e inicios del Holoceno, han sido temas de interés para numerosos investigadores (Schobinger 1969; Cardich et al. 1973; Gradin et al. 1979, Gradin 1980; Willey 1985; Lynch 1990; Dillehay et al. 1992; Borrero 1994-95, 1990; Nuñez Atencio et al. 1994; Meltzer 2003; Miotti 1990, 2003, 2006; Politis et al. 2004; Borrero y Miotti 2007, etc.). Los registros donde ha sido posible identificar elementos culturales asociados a megafauna extinta, son puntos claves para comprender el poblamiento inicial y sus potenciales vías de acceso a lo largo del continente. En Argentina, las primeras investigaciones arqueológicas centraron su interés en determinar estas primeras ocupaciones. Tal es el caso de los trabajos realizado por Ameghino y Moreno, en el siglo XIX, a partir de una perspectiva evolucionista y naturalista. 
Sin embargo, en Patagonia, más específicamente en la meseta central o Macizo del Deseado, los estudios iniciales acerca de esta temática fueron realizados a partir de las expediciones llevadas a cabo por Aparicio (1935) y Frenguelli (1933), quienes localizaron pinturas rupestres en el Cañadón de las Cuevas, actualmente localidad de Los Toldos y Aguada del Cuero. Posteriormente, bajo la dirección de Vignati y Rex González, realiza junto con Domingo García una nueva expedición donde se registraron y analizaron las pinturas que fueron reconocidas en las Cuevas de las Manos (Vignati y González 1949) y Cueva Charcamata en el Río Pinturas (Menghin 1952b) y en concheros de Bahía Solano con abundantes restos óseos y artefactos líticos asociados.

En la década del 40', llegaron a nuestro país Menghin y Bórmida, quienes influenciaron teórica y metodológicamente la arqueología de Pampa y Patagonia (Gradín 1980, Politis 1999) y tuvieron su renombre en la arqueología Argentina. Menghin caracterizó los estilos de arte rupestres de este sector (1952b y 1957), recurriendo a la asociación estratigráfica de los contextos arqueológicos, desde ese entonces en adelante, se realizarían estas asociaciones para dar contexto a las pinturas o representaciones rupestres (Gradín et al. 1976, Cardich 1977).

Este autor plantea entonces una secuencia cultural a partir de las excavaciones que realiza con anterioridad en el sitio Los Toldos, desde una perspectiva difusionista e influenciado por la escuela histórico-cultura de Viena, ideología fuertemente arraigada para ese entonces en los escritos de la época. Propone así, un cuadro cronológico de la "prehistoria" patagónica, donde las culturas más "avanzadas" eran expresividad de superioridad biológica. Sobre la base de las excavaciones realizadas en este sitio, propone que hacia los 9.000 años AC habría existido una cultura, que denominó Toldense, caracterizada por puntas triangulares pedunculadas sin aleta, con asociación a instrumentos óseos y relacionada con los niveles inferiores de las Cuevas de Magallanes estudiadas por Bird (1938). Asimismo, dispuso dos fases culturales denominadas Toldense I para Los Toldos y Toldense II para el área de Magallanes.

El aporte que brindó Menghin a la arqueología argentina, más allá de la corriente de pensamiento de la época, permitió en momentos posteriores, documentar las primeras ocupaciones del sitio Los Toldos. Su trabajo fue continuado por Cardich en 1973; mientras que Sanguinetti (1969) iniciaba sus estudios en el sitio Las Buitreras, en Río Gallegos, cuya secuencia estratigráfica habría brindado fechados superiores a 7.000 años AP. 
Hacia 1972 se inician las investigaciones en el área del Río Pinturas a cargo de Gradín, Aschero y Aguerre, realizando excavaciones en la Cueva de las Manos, Cueva Grande del Arroyo Feo y Cerro de los Indios (Gradín et al. 1976, 1979, Aguerre 1977).

A continuación se presenta los principales sitios con ocupaciones tempranas, las características más importantes de la cultura material y la metodología aplicada en su estudio, con especial énfasis en los sitios donde se aplicó análisis funcional de base microscópica.

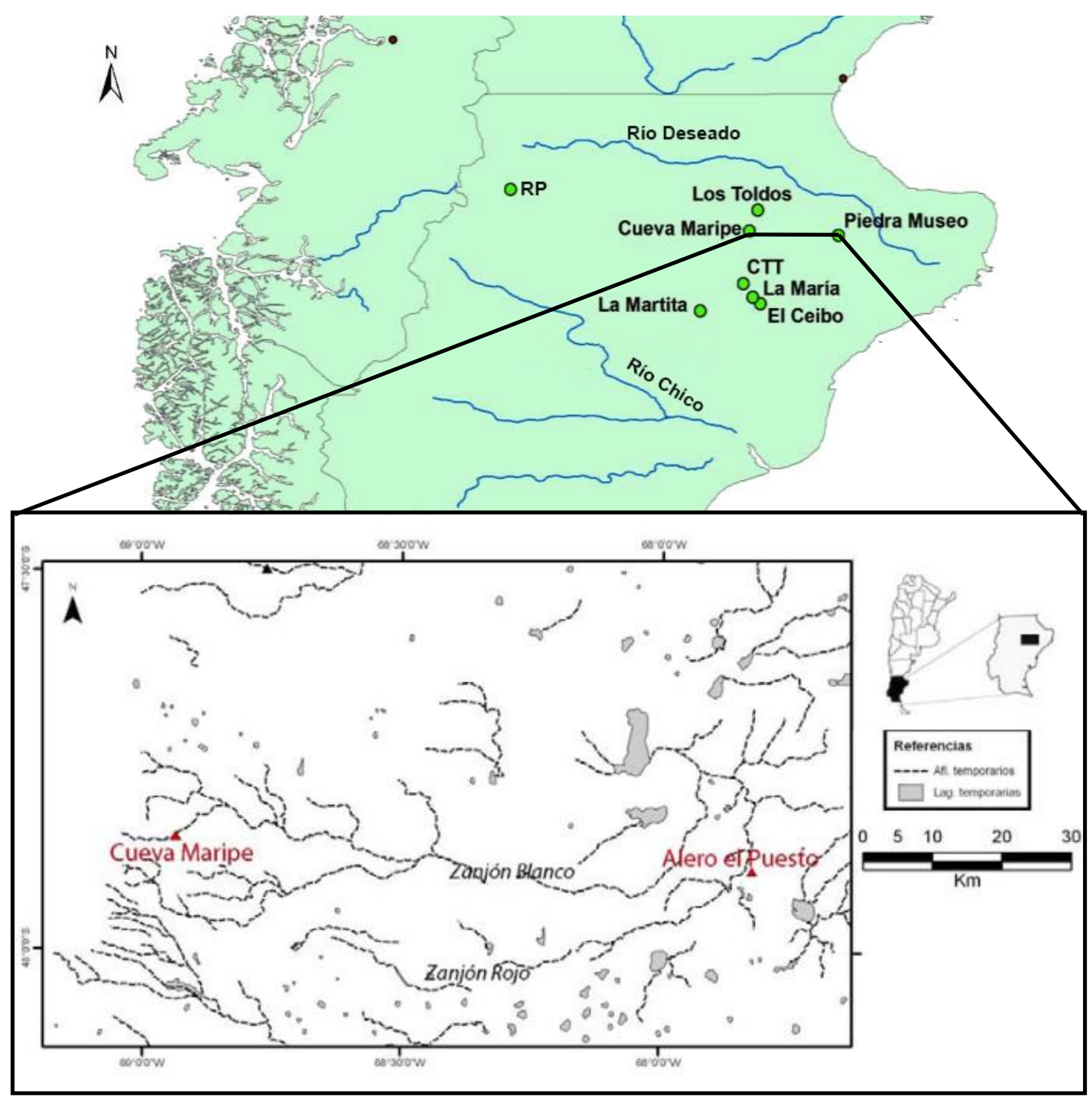

Figura 1: Sector de la meseta central de Santa Cruz bajo estudio. LT: Los Toldos, CM: Cueva Maripe; PM: Piedra Museo; EC: El Ceibo; LM: La martita; LM: Localidad Arqueológica La María; RP: Río pinturas, Cueva de las Manos. 


\section{Sector de meseta:}

\section{Los Toldos (LT)}

La primera ocupación humana temprana registrada en Patagonia fue documentada por Cardich en la cueva de la Estancia Los Toldos, ubicado en la planicie central de la Prov. De Santa Cruz.

Los primeros que visitaron este lugar hacia el año 1931 fueron Frenguelli y De Aparicio, quienes registraron abundantes sitios en el sector con manifestaciones rupestres. Sin embargo, fue dos décadas después que Menghin (1950) retomó y realizó excavaciones en uno de los catorce abrigos rocosos que se encontraban en el cañadón. Se observó diez estratos con ocupaciones humanas sucesivas que más adelante permitieron definir una secuencia cultural denominada Toldense, Casapedrense y Tehuelchense (desde la más antigua a la reciente).

Posteriormente Cardich, reinició los estudios en Los Toldos, definiendo una secuencia cultural de la Cueva 3, que se mantiene actualmente como referencia en numerosos investigaciones (Aguerre 1987, 2003 Paunero 2000).

De la estratigrafía de Los Toldos, se extrajo una única muestra de carbón proveniente de la base de la capa 11 de la Cueva 3, que arrojó fechados muy antiguos relacionado con ocupaciones humanas de $12.600 \pm 600$ años AP. Si bien su confiabilidad ha sido puesta en duda por su elevada antigüedad (Miotti y Salemme 2004), los materiales líticos recuperados fueron definidos como "Industria Nivel 11" (Cardich y Hadjuk 1973, Cardich 1977, Cardich y Flegenheimer 1978) y han sido considerados como "fósil guía" para comprender el poblamiento inicial de la Patagonia extrandina. Este Nivel 11, estaba caracterizado por instrumentos realizado sobre formas bases de tamaño grande a muy grande, con retoques marginales unifaciales, realizados por percusión directa o presión. Dentro del conjunto definido se incluían raspadores, cuchillos y raederas simples de forma irregular. Las puntas de proyectil que caracterizaban esta industria eran las denominadas "cola de pescado" correlacionadas con la capa 1 de Cueva Fell (Bird 1938, 1993). Los conjuntos líticos a su vez se encontraban en asociación con restos óseos pertenecientes a fauna extinta (camelidos -Lama guanicoe-, Lama gracilis y équido, Onohippidion-Parahipparion-).

El estudio de los materiales recolectados durante las excavaciones realizadas en los Toldos fue sistematizado por Cardich, teniendo en consideración variables tipológicas 
(tipo de puntas de proyectil), morfológicas (forma de artefacto, tamaño y espesor) y tecnológicas (formas bases, tipo, morfología y profundidad de los retoques y características principales del talón), al igual que las materias primas seleccionadas para su elaboración. Por otro lado, analizó igualmente otras evidencias de la ocupación humana en el sitio (análisis de pinturas rupestres, instrumentos elaborados sobre material óseo y conjuntos faunísticos - Cardich y Flegenheimer 1978- ).

La denominada industria Toldense, fue asociada a los niveles 9 y 10 y tuvo lugar a partir de los 8.750 años AP, seguido por el Casapedrense definido por las capas 6 y 7, con fechados de 7.260 \pm 350 años AP, especializados en la captura de guanacos, predominancia de hojas y sin puntas de proyectil. Los niveles superiores fueron enumerados como 1, 2, 3, siendo el nivel 1 los antecesores inmediatos de los Tehuelches.

La industria nivel 11 definida por Cardich con características particulares [evolución tecnológica de la unifacialidad a la bifacialidad, en asociación con fauna extinta y presencia de litos discoidales, (Menghin 1952b, Cardich et al. 1973, Bird 1993)] con fechados tempranos, permitió definir ciertos atributos que fueron corroborados a partir de la intensa labor generada por los arqueólogos que lo sucedieron.

En 1983 una pequeña muestra del nivel 11 de Los Toldos (15 instrumentos, 2 lascas retocadas y 4 sin retoques) sobre un total de 48 instrumentos, 4 núcleos, 171 lascas enteras y 250 desechos de talla, fue analizada bajo microscopía óptica para determinar su posible funcionalidad (Mansur-Franchomme 1983; Castro de Aguilar 1994).

Los resultados obtenidos a partir de este estudio permitieron identificar trabajo sobre cuero y en menor medida carne y madera. Todos los raspadores fueron utilizados para raspar cuero; mientras que en el caso de las raederas se evidenció actividades de movimiento transversal y longitudinal. En su mayoría los instrumentos fueron utilizados para las funciones que habían sido designados de acuerdo a su clasificación tipológica y mediante prensión manual. A diferencia de otros sitios que fueron sometidos al análisis funcional, Los Toldos (cueva 3) y el nivel 12 de El Ceibo (cueva 7), son los únicos que registran rastros de trabajo sobre material vegetal; mientras que en los demás sitios de la Meseta Central se registraron únicamente actividades de procesamiento derivados de productos animales (Mansur-Franchomme 1983, 1986; Castro de Aguilar 1994). 


\section{El ceibo $(E C)$}

Esta localidad se encuentra ubicada a los $48^{\circ} 31^{\prime} \mathrm{S}$ y $68^{\circ} 45^{\prime} \mathrm{W}$ unos $150 \mathrm{~km}$. al SE del sitio Los Toldos y presenta 9 abrigos rocosos con orientación hacia el norte. La mayoría de las investigaciones realizada en esa localidad, se refieren principalmente a la Cueva 7. En esta cueva, los conjuntos presentaron una baja frecuencia artefactual y dentro de los más antiguos, se puede mencionar los que provienen del nivel 12 que tendrían cierta asociación al nivel 11 de Los Toldos. La semejanza estaría dada por la morfología de los artefactos y su relación con la fauna extinta (Cardich 1979, Cardich et al 1981-82).

En la Cueva 7 pudo diferenciarse 13 capas naturales de la superficie hasta la roca de base, siendo la capa 12 la más profunda con 15 a $20 \mathrm{~cm}$. de espesor. Los conjuntos recuperados de esta capa, registraron restos de caballo prehistórico y camélido extinto (Lama gracilis) en conjunto con fauna actual (Cardich et al. 1982, Mansur-Franchomme 1983; Miotti 1998).

Los conjuntos óseos identificados se encuentran fragmentados y escasos, pudiéndose identificar diferentes especies: guanaco (Lama guanicoe) y caballo prehistórico (Onohippidium-Parahipparion-) extinto hace 10.000 años AP, junto con restos de camélidos como Lama (Vicugna) gracilis, en el mismo nivel (Cardich et al. 1987; Miotti 1998; Miotti y Salemme 1999).

En cuanto a las pinturas registradas en el reparo $\mathrm{N}^{\circ} 6$, se pudo definir cierta antigüedad a la tradición de motivos rupestres, el sector donde se encuentran estos es cercano a la Cueva 7, que habría registrado asociación con la Industria Toldense y el "Nivel 11". Los motivos identificados corresponden a negativos de manos, figuras de guanacos y escasas imágenes humanas. Sin embargo, la más antigua y mejor lograda corresponde a una imagen felínica de color rojo con pintas negras. Algunas ideas al respecto de esta figura, plantean que estaría representando un felino (Jaguarius onca mesembrina o Panthera Onca mesembrina) extinto hacia fines del Pleistoceno y que habría sido identificado en el sitio Cueva del Mylodón en Chile (Cabrera 1933, Borrero 198990,1990).

En cuanto a los materiales líticos analizados de las cuadrículas A, B y C del nivel 12 de la Cueva 7, se registró un total de 340 piezas de las cuales 92 corresponden a litos no modificados por el hombre (cantos rodados y trozos de rocas de la cueva); el resto incluyó 4 núcleos, 27 instrumentos, 85 lascas enteras y 132 fragmentos de talla (Cardich et al. 1981-82; Mansur-Franchomme 1983). 
Al igual que en el nivel 11 de Los Toldos, los instrumentos fueron en su totalidad trabajados unifacialmente, elaborados sobre lascas medianas a grandes, con filos regularizados mediante retoque marginal extendido a lo largo de más de un borde y, en algunos casos, llegan a cubrir todo el perímetro, logrando un uso intensivo de las formas bases, sensu Mansur- Franchomme (1983).

Los instrumentos recuperados son escasos, sin embargo, las características principales de estos (sobre lasca anchas con retoques unifaciales, marginales y escamosos) ha permitido plantear cierta semejanza con los del nivel 11 de Los Toldos (Cardich et al. 1987).

Estos materiales fueron sometidos por primera vez en Argentina (Mansur-Franchomme 1983), a un análisis minucioso de huellas de utilización de base microscópica. Con la traducción al inglés de los trabajos de Semenov (1964), en Europa y Keeley (1980) en EE.UU, la metodología de análisis funcional se encontraba, en estos países, en estado más avanzado de desarrollo, habiéndose aplicado a numerosos sitios (Semenov 1964, Tringham et al. 1974, Keeley 1980, Anderson-Gerfaud 1981, Voughan 1981, Plisson 1982). Los resultados obtenidos a partir de este análisis en El Ceibo, habrían permitido realizar las siguientes observaciones respecto a los materiales recuperados. En primer lugar, se identificó que la mayoría de los artefactos, habrían sido utilizados mediante prehensión manual sin ningún otro tipo de dispositivo de agarre. La mayoría de las piezas fueron trabajadas sobre pieles (frescas o secas). En algunos casos para cortar carne y un número reducido presentó rastros de trabajo sobre madera. Los artefactos que trabajaron carne no presentaron signos de contacto con material duro (hueso y/o tendones) lo que estaría indicando que la matanza y descuartizamiento de las presas se habría llevado a cabo en el exterior de la cueva y que los trozos de carne serían acarreados hacia el interior de la misma, donde se desarrollarían diversas actividades domésticas. Aunque los estudios zooarqueológicos realizados en este sitio por Miotti en 1989 (1998) sugieren, a partir de las unidades anatómicas, que sí se habrían desarrollado en el sitio actividades de procesamiento de presas (ver págs. 170). Estas dos hipótesis debieran ser testeadas nuevamente a partir de nuevos trabajos y materiales.

\section{La Martita (LM)}

Se encuentra a $\operatorname{los} 48^{\circ} 42^{\prime} \mathrm{S}$ y $69^{\circ} 15^{\prime} \mathrm{O}$ a $300 \mathrm{msnm}$. Esta localidad inicialmente estudiada por Aguerre (1982), cuenta con varios sitios a cielo abierto y cuatro cuevas 
contiguas. Su orientación se da hacia el este y abre hacia unos afloramientos, que de acuerdo a sus características, corresponderían al Grupo Bahía Laura, a metros del cauce del Río Seco (Aguerre 2003).

La cueva 4 de este conjunto se encuentra cercano a vertientes de agua dulce y en las excavaciones realizadas, período que abarca desde 1979-2003, pudieron identificarse 8 unidades estratigráficas, donde se han discriminado cuatro componentes culturales. Las capas sucesivas fueron identificadas desde lo superficial hasta la roca de base como: "actual" y "superior", asignadas hacia el Holoceno Tardío y en el segundo caso con un fechado de $1620 \pm 90$ años AP en la base de la capa 3 .

La parte superior de la capa 4 posee un fechado de $2190 \pm 115$ años AP y se encuentra asociado a un conjunto sin puntas de proyectil, ni evidencia de adelgazamiento bifacial, y presencia de pequeñas hojas y raspadores medianos; así como hojas que sirvieron como formas bases en la elaboración de instrumentos lo que podría estar correlacionado al nivel cultural Rio Pinturas III con tecnología de hojas (Aguerre 1987, 2003).

Los conjuntos publicados de la cueva 4 (capa 7) de este sitio, pueden incluirse como componente del denominado Toldense y presenta gran cantidad de artefactos fracturados, incluyendo puntas de proyectil, lo que ha permitido interpretar como un lugar de reemplazo y/o reavivamiento de piezas (Aguerre 2003).

Las materias primas utilizadas en la elaboración de estos artefactos, incluyen en su gran mayoría, guijarros de variados tamaño de sílices provenientes del cauce del Río Seco.

En cuanto a las técnicas aplicadas y morfología de las piezas, en su mayoría presentan retoques marginales o en menor proporción retoque o retalla marginal. También han podido recuperar piezas de talla bifacial definidos, en su mayoría, por la sección espesa y de aristas irregulares, utilizando igualmente el sílex como materia prima principal.

Por otro lado, han sido identificado piezas foliáceas, con mayor variedad en cuanto a la selección de materias primas (sílex, pórfidos y obsidiana), raederas (de retoque marginal), cuchillos retocados y puntas de proyectil de forma triangular sobre sílex y obsidiana.

Aguerre observa, a su vez, ciertas diferencias en el uso del espacio intraistio, lo que ha permitido plantear dos sectores: el interno, con presencia de lascas de adelgazamiento bifacial y tamaño pequeño de desechos y otro sector externo, con desechos más grandes y un incremento del uso de obsidiana con menor porcentaje de lascas externas. 
La presencia de obsidiana permitiría plantear la hipótesis de cierta selectividad en el uso de esta materia prima, ya que habría sido seleccionada en la producción de piezas con filos cortantes como bifaces (puntas de proyectil) y piezas foliáceas.

\section{Localidad Arqueológica La María}

La Localidad arqueológica La María se encuentra ubicada a $150 \mathrm{~km}$ de la ciudad de Puerto San Julián, Departamento de Magallanes, Santa Cruz. El sitio se localiza puntualmente a $\operatorname{los} 48^{\circ} 24^{\prime} 34^{\prime \prime}$ 'S y $68^{\circ} 51^{\prime} 23^{\prime \prime}$ O a 450 m.s.n.m.

Los estudios iniciales en esta localidad fueron dirigido por Cardich en 1982, realizando una prospección inicial y determinando dos sectores, en relación a los motivos de las pinturas rupestres y materiales superficiales: La María Bajo y La María La Quebrada (Cardich et al. 1982).

Dos años más tarde, se realizaron sondeos preliminares, analizando material de superficie e iniciando un relevamiento sistemático de las manifestaciones rupestres en ambos sectores (Franchomme 1991).

Sin embargo, es recién en 1996, cuando se comienza con un plan de excavación diseñado con objetivos específicos, como: identificar el inicio de las ocupaciones en esta localidad y establecer referentes estratigráficos culturales y naturales a partir de los sitios identificados (Miotti 1998; Paunero et al. 2005, 2007).

Hasta el momento, el análisis funcional de base microscópica fue realizado, en una muestra de 43 piezas de los conjuntos líticos del componente temprano del sitio Casa del Minero 1 (CDM1), (Cueto et al. 2012), arrojando como resultado un alto porcentaje de piezas con alteraciones postdepositacionales y en menor medida el trabajo sobre cuero y hueso en los artefactos con formatización.

Asimismo, se realizaron excavaciones a partir de sucesivas campañas en la Cueva La Mesada (sector La María Quebrada), con fechados tempranos del Holoceno Inferior 9.090 $\pm 40{ }^{14} \mathrm{C}$ AP- y Cueva de La Ventana (en el cañadón del mismo nombre) con una datación inicial de $7.970 \pm 40{ }^{14} \mathrm{C}$ AP.

\section{La María, sitio Casa del Minero 1 (CDM1)}

Se encuentra ubicado al sur del casco de la estancia, a unos $1360 \mathrm{mts}$. de La Laguna Grande, en el sector Cañadón de La Mina de La María, que a su vez contiene dos sitios 
más, Cueva Casa del Minero 2 y alero El Divisadero. Casa del Minero 1 es un sitio multicomponente que posee una ocupación continua que ha permitido diferenciar varias unidades estratigráficas: la unidad 1: correspondiente a materiales del siglo XX, la unidad 2: presenta evidencias de fogones y restos arqueológicos holocénicos tardíos, la unidad 3: contiene materiales arqueológico ubicado en tres componentes ocupacionales: 3 Superior (5190 \pm 80 años 14C AP), 3 Medio y 3 Inferior (10250 \pm 110 años 14C AP), y la unidad 4: con abundante contenido cultural y evidencia de estructuras de fogones, con fechados de $10.999 \pm 55$ años ${ }^{14} \mathrm{C}$ AP y $10.967 \pm 55$ años ${ }^{14} \mathrm{C}$ AP (Paunero et al. 2004).

En esta tesis se profundizarán los estudios realizados en la Unidad 4, debido a que los materiales de esta unidad fueron sometidos al análisis funcional de base microscópica (Cueto et al. 2012).

La unidad mencionada presenta una mayor densidad de artefactos y productos de talla que los correspondientes a la unidad $3 \mathrm{C}$ que posee un volumen superior de sedimento excavado. La unidad inferior presenta un total de 1445 piezas y para su análisis fueron divididas en cuatro grupos: núcleos, artefactos formatizados, productos de talla y litos no modificados. La muestra estudiada a partir de microscopía óptica fue de 43 piezas, entre las cuales 11 corresponden a artefactos formatizados y 33 a productos de talla.

Los artefactos no formatizados presentan un tamaño chico a mediano y estan elaborados sobre materias primas de procedencia local: sílex, xilópalo y calcedonia, en su mayoría roca de grano fino o criptocristalino.

El análisis arrojó como resultado que en relación a los artefactos formatizados se identificó el material trabajado únicamente sobre 3 piezas (dos identificadas como raspado sobre cuero y una utilizada a partir de acciones longitudinales sobre hueso Cueto et al. 2012- ).

En cuanto a los productos de talla, fueron observadas 33 piezas con 61 filos naturales. En ninguno de los casos pudieron registrarse rastros de utilización, ni evidencia de pátinas o lustres de origen natural (sedimentos o fluidos), mientras que 13 de las piezas presentaron evidencia de lustre térmico, agrietamientos y cambio de coloración, sin que esto impida la observación de rastros de uso (Cueto y Frank 2008).

Los análisis realizados hasta el momento sobre los materiales líticos de este sitio, han permitido determinar que en su interior, se habrían llevado a cabo distintas etapas de formatización de materias primas como sílex marrón-rojizo, calcedonia y xilópalo, ya que se han recuperado tanto artefactos en estado final de formatización como también 
productos de talla de este proceso. La ausencia de núcleos estaría indicando que las rocas serían ingresadas al sitio como preformas o formas bases, para luego realizar la formatización final, mediante percutores duros y blandos. Estas piezas habrían sido utilizadas en distintas funciones (trabajo sobre cuero y hueso) (Paunero et al. 2004, Cueto et al. 2012).

\section{Cerro Tres Tetas 1 (C3T1)}

Esta localidad arqueológica se encuentra ubicada en la Ea. San Rafael, a 48 8' 58' S y $68^{\circ} 56^{\prime}$ W, entre 450 y 480 msnm, Departamento Deseado, Santa Cruz (Paunero 1994, 1996, 2002, Paunero y Castro 2001). A 35 km. en dirección norte de las localidad La María y el Ceibo (Cardich 1987) y a 75 km. en dirección suroeste de Piedra Museo (Miotti 1995, Miotti et al. 1999).

Las excavaciones sistemáticas se iniciaron entre los años 1994-1995 en la Cueva 1, que se ubica a alrededor de $9 \mathrm{~m}$ sobre el nivel del cauce temporario, abriendo hacia el oeste y con una profundidad de $11 \mathrm{~m}$ y una dimensión de boca de alrededor $21 \mathrm{~m}$. En las 9 cuadrículas excavadas, la secuencia estratigráfica fue discriminada en 11 unidades, considerándose un sitio multicomponente.

Esta cueva presenta manifestaciones rupestres en la totalidad de sus paredes que evidenciaría la presencia de grupos humanos colonizadores desde épocas tempranas. Estas ocupaciones estarían igualmente representada por un contexto de fogones con cronología radiocarbónica, asociados a un conjunto lítico con características tecnológicas y funcionales diagnósticas, en una clara estratigrafía. Esta tecnología destaca la presencia de láminas, bifaces y técnicas especiales para su elaboración (tratamiento térmico) e indica el uso de diversas materias primas de origen local (variedades de sílices), como alóctonas (obsidiana) con fuente de origen determinada en Pampa del Asador, a $200 \mathrm{~km}$ de distancia (Stern 2004).

Como ha sido mencionado anteriormente, hacia el interior de la Cueva 1 de C3T se localizaron cuatro fogones pertenecientes al componente inferior (unidad 5), tres de ellos en la base y el restante, ubicado inmediatamente debajo de un nivel de rocas medianas de derrumbe y superpuesto a otro fogón. Los artefactos líticos al igual que los restos óseos recuperados de esta unidad (en asociación con estos fogones) no se localizaron dentro, sino rodeando estas estructuras o en sectores próximos de la matriz sedimentaria. El análisis funcional y de distribución espacial de los artefactos indicó, la 
existencia de áreas de corte y de raspado, como actividades de procesamiento secundario de productos animales o derivados, principalmente cuero y en menor medida hueso (Paunero y Castro 2001).

Para este análisis se seleccionaron 57 piezas sobre un total de 523 que incluyeron: raspadores (7), raspadores/raederas (1), raederas (4), cuchillos (3), lascas retocadas (6), chopper (1), percutor (1), núcleos (2), láminas (2) y lascas (30) como productos de talla. Esta muestra fue vista en tres niveles de análisis de acuerdo a lo propuesto por Castro (1994,1996): a ojo desnudo (analiza el universo que conforma una pieza y la ubicación relativa de sus partes potenciales), a lupa binocular (permite establecer los daños presentes sobre los filos, marcando tendencias en relación a la dureza del material trabajado) y el último nivel corresponde al microscopio metalográfico (que permite observar detenidamente el material trabajado, estado (fresco o seco) y el movimiento efectuado) (Paunero y Castro 2001).

De acuerdo a los resultados obtenidos, las sustancias identificadas en esta muestra habrían sido mayoritariamente trabajo sobre cuero, hueso y en menor medida indeterminado, que probablemente haya sido actividades de trabajo sobre carne. No se observaron rastros de trabajo sobre madera o gramíneas. Mientras que en cuanto a los productos de talla, de 32 artefactos sólo 1 presentó rastros de utilización (Paunero y Castro 2001).

A partir de estos resultados funcionales y de distribución espacial intrasitio, se pudo advertir la existencia de áreas de distribución de actividades (Paunero y Castro 2001; Paunero et al. 2007). Por lo tanto, para el componente inferior pleistocénico del sitio Cerro Tres Tetas, los instrumentos habrían sido elaborados, retocados/reactivado y utilizados en su interior, evidenciado a partir de una gran cantidad de esquirlas de reactivación; lo que indicaría la elaboración de diseños específicos para las distintas actividades desarrolladas.

Las estructuras de fogones, la diversidad en los diseños y usos de los materiales líticos, ausencia de restos óseos quemados y evidencia de áreas de actividad múltiples y específicas, estarían indicando que este sitio habría sido parte de un campamento más amplio que incluye zonas aledañas, donde se llevaron a cabo diversas actividades residenciales (Paunero et al. 2007; Paunero 2009). 


\section{La gruta: Cueva 1 de la laguna 2}

Este sitio se encuentra localizado en las estribaciones meridionales del Macizo del Deseado, principalmente hacia el sector sur del Macizo. Los fechados más próximos al área de La gruta corresponden al Holoceno temprano, Cueva 4 de la Martita y el sitio El Verano (Aguerre 2003; Durán et al. 2003). En la Cueva 4 de La Martita los depósitos más antiguos ( $c a .8050$ y 7940años AP) muestran la presencia de artefactos de grandes dimensiones, existiendo similitudes estilísticas con los recuperados de la cueva El Verano, fechado en ca. 8900 y 7500 años AP (Durán et al. 2003).

Sin embargo, el sitio La Gruta, se encuentra localizado en un área cercana a los fechados más tempranos registrados para Patagonia (Cardich et al. 1973; Paunero 2000; Miotti y Salemme 2004; Paunero et al. 2007). La Cueva 1 está ubicada en un área cercana a la laguna 2 y se trata de un abrigo de dimensiones reducidas y con buena visibilidad de la laguna cercana, que funciona como atractor de guanacos (Lama guanicoe) u otros animales en búsqueda de agua. El sondeo inicial de este abrigo arrojó un fechado de ca. 10.656 años AP (Franco y Cattáneo 2009). Los materiales líticos recuperados de este primer sondeo estuvieron representados principalmente por productos de talla a excepción de una única hoja. Estos materiales estuvieron confeccionados principalmente sobre materias primas de grano fino, rocas silíceas, calcedonia, obsidiana negra y gris y madera silicificada.

Los estudios realizados hasta el momento incluyeron análisis de las pinturas rupestres registradas con anterioridad por Gradin y Aguerre (1983), identificando distintos motivos en una localidad homónima, ubicada al sur de una laguna próxima al casco de la misma. Por otro lado, se hicieron estudios de aprovisionamiento y manufactura de artefactos líticos (Franco et al. 2010 y 2012).

Los resultados obtenidos hasta el momento muestran que los grupos cazadoresrecolectores habrían utilizado la cueva 1 de la laguna 2 durante el Pleistoceno finalHoloceno temprano. La posición de la cueva con buena visibilidad hacia la laguna con probable presencia de animales, junto con las características de los materiales líticos recuperados (lascas de tamaño pequeños, lascas de reactivación y de adelgazamiento final de artefactos bifaciales), sugiere que podría haber sido un sitio de funciones logísticas para el lapso comprendido entre el ca.10.845 y 10.480 años AP. Por otro lado, la ausencia de fauna en el registro estaría indicando que las actividades de procesamiento fueron realizadas en otros sectores del espacio (Franco et al. 2010). 


\section{Sector del Río Pinturas:}

\section{Cueva de las Manos (CDLM)}

Es un yacimiento ubicado a los $49^{\circ} 09^{\prime} \mathrm{S} / 70^{\circ} 45^{\prime} \mathrm{O}$, en la margen derecha del curso superior del Rio Pinturas, constituido por cuevas, aleros y paredones con abundantes representaciones rupestres.

Fueron definidos tres niveles culturales I, II, III mediante el estudio de los restos materiales recuperados (Gradin et al. 1976, Aguerre 1977). El nivel III se encuentra vinculado a abundantes restos de guanaco concentrados en determinados sectores, lo que habría permitido plantear la hipótesis de un basural hacia el interior del sitio (Mengoni Goñalons y Silveira 1976). Las representaciones rupestres identificadas en el yacimiento permitieron definir una secuencia estilísticas (Grupo A, B y C), siendo "el grupo A" las series inferiores con escenas de caza, con guanacos y figuras humanas, pintadas en ocre y que estarían relacionadas con un fragmento de roca desprendidas del techo de la cueva y un instrumento pintado igualmente con ocre, asociado a fechado en ca. 9.300 años AP (Gradin et al. 1976).

Los restos óseos de las ocupaciones identificadas como Toldense (capa 6) corresponden en su mayoría a restos de Lama guanicoe con rastros de descarne y trozamiento (Mengoni Goñalons y Silveira 1976). Esto habría permitido plantear que los grupos que habitaron este sitio tendrían una tecnología con puntas de proyectil apedunculadas junto con bolas de piedra como armas arrojadizas, que les permitió un aprovechamiento primordial del guanaco complementado con animales de menor consumo.

Cattáneo y Aguerre, retoman los materiales provenientes de este sitio en el 2009, aplicando una metodología novedosa de análisis funcional de base microscópica, mediante un microscopio de barrido laser confocal (MBLC) y un software denominado PHILOS, que permite a partir de un registro de imágenes de materiales trabajados con anterioridad determinar el uso de distintos artefactos líticos. En este estudio, los autores proponen como muestra el grupo tipológico de raspadores provenientes de las capas 4c, 5 y 6, de las campañas realizadas con anterioridad por Gradin, Aschero y Aguerre (Gradin et al. 1976 y Aguerre 1977) que cuentan con fechados desde 1610 años AP a 9300 años AP. Estos autores, proponían para cada una de estas capas, la aparición de distintas recurrencias de subgrupos de raspadores. Sin embargo, este análisis se llevó a cabo teniendo en consideración variables relacionadas al uso, mantenimiento, reciclaje y 
descarte de los instrumentos; que al no realizarse mediante estudios de microscopía para atribuciones funcionales, varios interrogantes habrían quedado sin respuestas (Gradín et al 1976, Aguerre 1977).

Es así que, años más tarde, los materiales son retomados por Cattáneo y Aguerre analizando 41 de estos instrumentos y llegando a identificar el trabajo sobre distintos materiales. De los resultados obtenidos, se pudo comprobar que la capa 4 presentaba raspadores que habían sido utilizados sobre un único material, relacionados en actividades de raspado sobre material leñoso y no leñoso. Por otro lado, las huellas identificadas como raspado de cuero o hueso fueron escasos y se establecieron en raspadores con filos cortos, livianos y sin posibilidad de manipulación mediante dispositivos de enmangue. Asimismo, los raspadores espesos con usos identificables de vegetal y cuero, fueron definidos como los más pesados y grandes correspondientes al conjunto de la capa 6, ausentes en las demás capas. Igualmente pudo determinarse ciertos patrones en relación al uso/diseño, en donde se comprobó que la combinación del trabajo sobre madera y hueso, las formas y tamaños de los artefactos eran muy variables. Sin embargo; para el caso de raspadores que trabajaron madera y cuero, las formas estaban más estandarizadas, con filos rectos, largos y piezas más pesadas dentro del conjunto. También, cabe mencionar, que se identificó una disminución respecto al tamaño en las distintas capas a través del tiempo (capa 6 tamaños más grandes) y que podría estar relacionado a un sistema de sostén determinado. Como conclusión, los autores proponen que para la capa 6 , se observaría una mayor variabilidad tipológica y funcional; aunque mencionan la necesidad de ampliar la muestra correspondiente a la capa 4c. Mientras que para la capa 5 se identifica el trabajo sobre vegetales únicamente. Esto permitiría plantear que, a través del tiempo, habría una disminución en la variedad de los grupos tipológicos en momentos iniciales de ocupación, con usos específicos. Y que la estandarización de los instrumentos, en momentos posteriores, estaría acompañado de una multifuncionalidad para cada clase de artefacto (Cattáneo y Aguerre 2009).

\section{II.3. Antecedentes y metodologías aplicadas en los sitios bajo estudio}

Como ha sido mencionado en el apartado anterior numerosas cuevas y aleros rocosos fueron seleccionados por las poblaciones humanas para el desarrollo de diversas actividades desde épocas tempranas. En la meseta central de Santa Cruz han sido 
registrados varios ejemplos de estas manifestaciones de ocupación. Sin embargo, en esta tesis han sido tomados como eje principal dos sitios: Piedra Museo y Cueva Maripe, que serán tratados con mayor detalle en este apartado y de los cuales proceden los materiales líticos analizados por la autora de esta tesis.

En principio, cabe mencionar, que ambos sitios corresponden a cuevas y aleros rocosos, trampas sedimentarias que presentan buenas condiciones de preservación de elementos arqueológicos, a diferencia de sitios a cielo abierto. Estas cavidades permiten muy buenas posibilidades para marcar límites temporales y espaciales, a partir de unidades estratigráficas que permiten obtener dataciones radiocarbónicas confiables.

Las condiciones de preservación de materiales en estos lugares hace propicio la aplicación de metodologías específicas para su análisis, como es el caso de microscopía óptica para determinar rastros de utilización en artefactos líticos (Semenov 1964; Keeley 1977, 1980; Anderson-Gerfaud 1981; Vaughan 1981; Mansur-Franchomme 1983, 1986,1999).

A continuación se detallan las características principales de los sitios mencionados y las distintas metodologías aplicadas hasta el momento en los materiales recuperados.

\section{Piedra Museo}

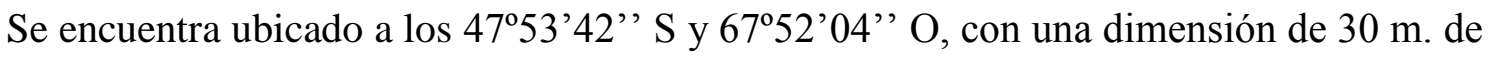
boca y una profundidad máxima hacia el fondo de la cueva de $5 \mathrm{~m}$., que se abre hacia un conglomerado tobáceo relicto de una ingresión marina Prejurásica de la Fm. El Museo (Panza 2001).

Los trabajos sistemáticos en esta localidad fueron iniciados hacia fines de 1980, sin embargo, los primeros relevamientos en la zona fueron realizados por De Aparicio y Frenguelli en 1933 (Investigadores del Museo de Ciencias Naturales de La Plata y del Museo Etnográfico de Buenos Aires para ese entonces), prospección que se llevó a cabo con el fin de obtener hidrocarburos y un conocimiento más detallado de las culturas que se encontraban en este sector.

A partir de estas primeras expediciones, fueron registradas varias pinturas rupestres y características generales de numerosos sitios del área.

Desde estos primeros relevamientos, pasaron casi 30 años hasta que la Dra. Miotti inició sus labores en el sitio, a partir de la localización de los mismos e inicio de las primeras 
excavaciones sistemáticas y trabajos de prospección en la cuenca relictual de los zanjones Blanco y Rojo (Miotti 1992, 1996, Miotti et al. 1999, 2003).

En principio, el abrigo rocoso de Piedra Museo, fue sectorizado en dos áreas: Alero el Puesto 1 (AEP1), lugar de menor reparo y Alero El Galpón 2 (AEG2), con mayor reparo, presencia de arte rupestre, petroglifos y una continuidad de uso que se extiende hasta tiempos actuales como puesto en el siglo XX.

Varias de las hipótesis planteadas en relación las ocupaciones identificadas en este sitio habrían considerado a Piedra Museo como un lugar estratégico, debido a que se abre hacia un lago pleistocénico en el cauce del zanjón Elornia y por lo tanto, habría sido un atractor de manadas de animales, por su disponibilidad de agua, como también de recursos alimenticios, para grupos humanos. Por otro lado, dispone de muy buena visibilidad, ya que desde este punto es posible observar en su totalidad la comarca (el Cerro Madre e Hija, Los Pirámides, El Cuadro y el Fortín como otros ítems del paisaje) (Miotti et al. 1999, 2003, 2008).

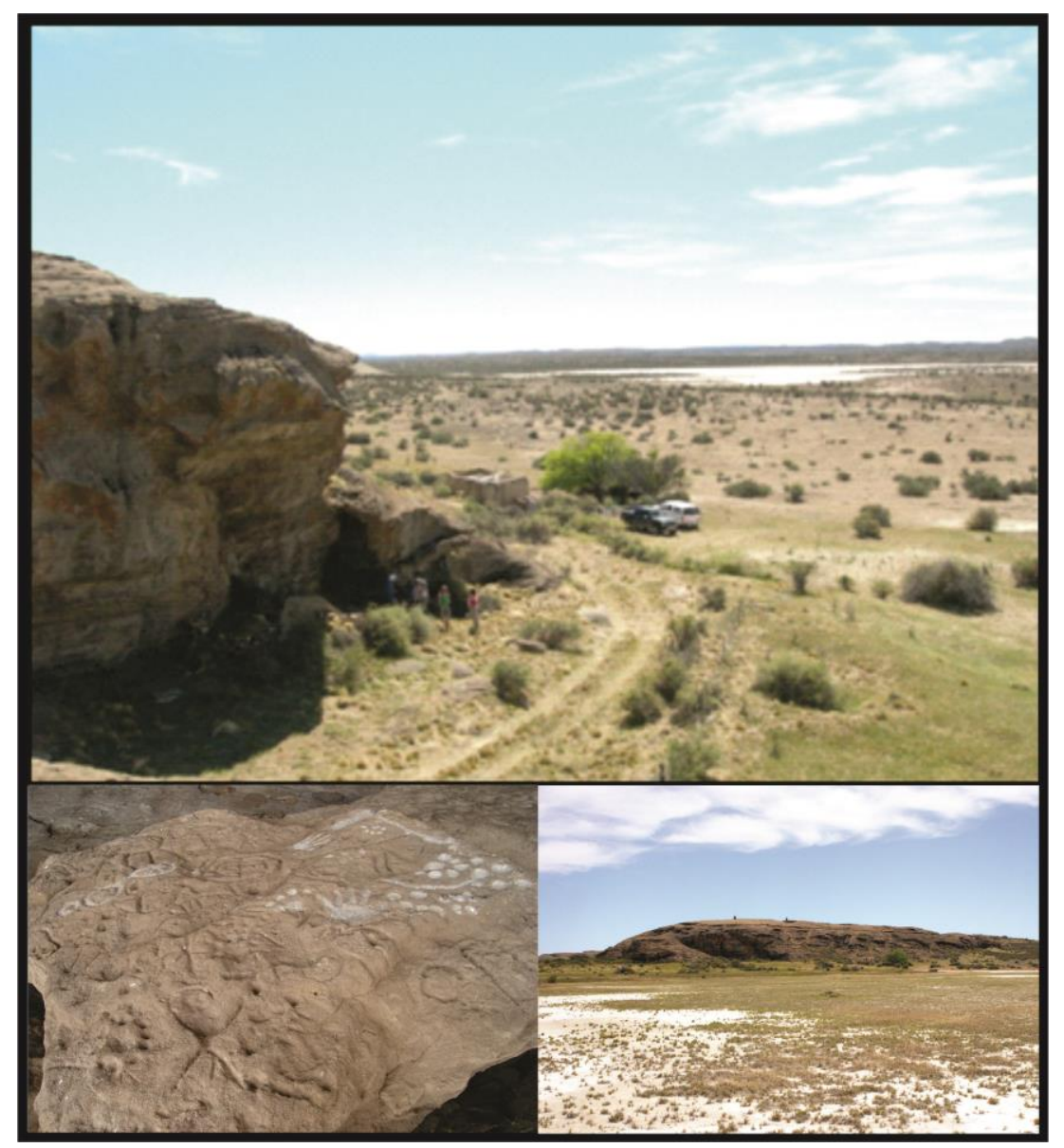

Figura 2: Visibilidad del sitio AEP1 respecto al paleolago (imagen tomada por la Dra. Fernández, campaña realizada 2008) y grabados dispuestos en un bloque de sitio AEG2. 
En el sitio AEP1 fueron reconocidas 6 unidades estratigráficas; siendo la más antigua la UE6 donde fueron identificados los materiales correspondientes a las primeras ocupaciones humanas. Esta unidad contenía fechados de $12.890 \pm 90$ A.P. (15.595 \pm 380 años cal A.P.) y $10.925 \pm 65$ años $C^{14}$ A.P. (12.872 \pm 93 años cal A.P.) mientras que otra más tardía (UE 4/5) presentó fechados de $10.400 \pm 80$ A.P. (12.320 \pm 196 años cal A.P.) y $9.230 \pm 105$ A.P. (10.424 \pm 125 años cal A.P.) (Miotti et al. 1999).

Los estudios zooarqueológicos realizados en los conjuntos asociados a estas primeras ocupaciones registró presencia de fauna extinta en la UE6: Hippidion saldiasi (fechado en $10.925 \pm 65$ años C ${ }^{14}$ A.P.), Lama (vicugna) gracilis, Rheidae, Mylodon sp. $(12.890 \pm 90$ años $C^{14}$ A.P.), en conjunto con especímenes de Lama guanicoe (guanaco), Canis sp., aves de tamaño mediano y Rodentia (Miotti 1996; Miotti et al. 1999, 2003, Marchionni 2012). Mientras que en la UE4/5, si bien hay restos de megafauna, su presencia disminuye en comparación con la anterior unidad y se observa un incremento en los porcentajes de guanaco (Lama guanicoe) y ñandú (Rhea americana).

En cuanto al estado de preservación de los materiales, se pudo comprar que en la unidad 6, la presencia de óxido de manganeso sobre varias de las superficies óseas estaría indicando ambientes depositacionales húmedos y/o ácueos. Mientras que, para la unidad 4/5 estas modificaciones no estarían evidenciadas, y en cambio se observa depositación de concreciones carbonáticas sobre las superficies óseas (Miotti et al. 2000; Miotti y Marchionni 2012; Marchionni 2013).

El análisis de material lítico permitió identificar, al igual que en el caso anterior una marcada diferencia entre las U6 y U4/5. En la primera de estas unidades la materia prima utilizada en la elaboración de los artefactos es de muy buena calidad para la talla (calcedonia y sílex de muy buena calidad). Mientras que en relación a los diseños no presentan una gran inversión, ya que en su mayoría corresponde a lascas con filos naturales a excepción de una punta de proyectil "cola de pescado".

En cuanto a los materiales de la UE 4/5 se observa una mayor inversión en los diseños (cepillos, raspadores, cuchillos) y un incremento en la variedad de materia primas utilizadas (Miotti 1995; Miotti y Cattáneo 1997; Miotti et al. 1999, 2000 y Cattáneo 2002). Mientras que en el componente superior (UE2) con ocupaciones datadas en el Holoceno Medio

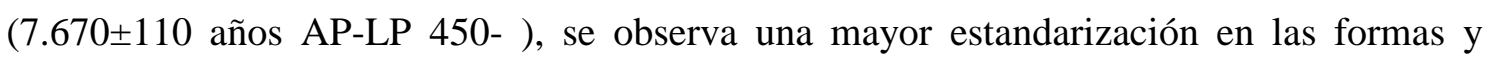
variedad de las materias primas seleccionadas (Cattáneo 2002). 


\section{Cueva Maripe}

Se encuentra ubicada en el curso medio del mallín La Primavera, el cual recorre $10 \mathrm{~km}$ en sentido SW-NE por un valle desde su naciente en la meseta Los Ventisqueros, hasta su desembocadura el Zanjón Blanco. Sus coordenadas geográficas son: 47 51'05' sur y $68^{\circ} 56^{\prime}$ 03' oeste, a $562 \mathrm{msnm}$ sobre la base de un afloramiento de tobas e ignimbritas de la formación Chön Aike. (Miotti et al. 2005, 2007, 2013).

Este sitio multicomponente corresponde a una cueva que posee una abertura de $24 \mathrm{~m} \mathrm{y}$ $26 \mathrm{~m}$ de profundidad a partir de la línea de goteo con un declive natural de $12,5 \%$. Se encuentra constituida por dos cámaras principales separadas por un tabique rocoso. La cámara más grande se ubica en el sector norte de la cueva (de ahora en más $\mathrm{CN}$ ) y se subdivide en el fondo en dos cámaras de menor tamaño. La cámara que se localiza en el sector sur (CS), es más pequeña y presenta una conexión con su aledaña hacia el fondo de la cueva permitiendo la comunicación entre ambas.

Las excavaciones realizadas a lo largo del período 2003-2006 a cargo de la Dr. Laura Miotti, incluyen $38 \mathrm{~m}^{2}$ excavados (nueve cuadrículas), alcanzando una profundidad máxima hasta la roca de caja de $2 \mathrm{~m}$.

A lo largo de las excavaciones han podido ser identificados diferentes niveles arqueológicos, distinguiéndose tres resoluciones temporales: Holoceno temprano, medio y tardío con fechas radiocarbónicas que abarcan desde los ca. $9518 \pm 64$ hasta ca. 1078 \pm 40 AP (Miotti et al. 2011, 2013).

En ambas cámaras fueron identificadas estructuras de combustión pudiéndose recuperar restos vegetales que han tenido buena conservación en el registro.

El depósito estratigráfico de Maripe se encuentra constituido superficialmente, por una espesa capa de excremento vacuno y ovino que alcanza una potencia máxima de $70 \mathrm{~cm}$ hacia la CN. Estos sedimentos evidencian la utilización de esta cueva como refugio de animales domésticos y silvestres hasta la actualidad (Miotti et al. 2007, 2011). 


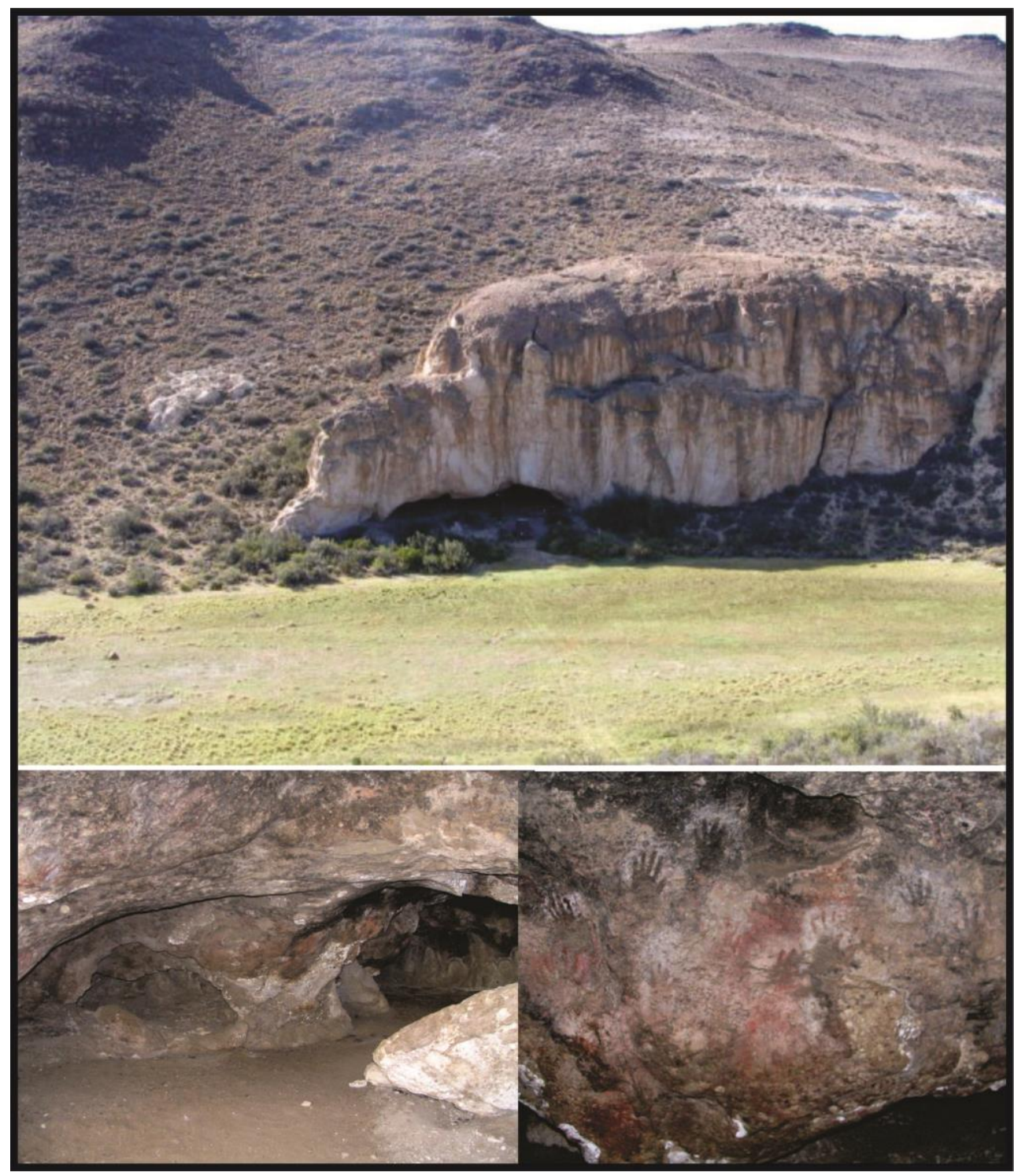

Figura 3: Sitio arqueológico Cueva Maripe visto desde el cañadón La Primavera. Representaciones rupestres identificadas en la cámara sur (manos en positivo y negativo, Carden 2008).

\section{II.4. Importancia de la aplicación de estudios basados en microscopía óptica}

Esta línea de investigación tiene un buen desarrollo en Argentina, si bien en los últimos años los trabajos han ido incrementándose, resta mucho por investigar en relación a los alcances y limitaciones de los estudios microscópico orientados a la determinación del uso en distintos tipos de artefactos (variedad de materiales, óseo, metal, cerámica) o técnicas de manufactura empleadas (piqueteo o pulidos).

Esta tesis tiene por objetivo determinar el modo de uso de los artefactos líticos correspondiente a los sitios Cueva Maripe y Piedra Museo, ya que son de gran relevancia para comprender el poblamiento inicial de la meseta central de Santa Cruz. 
En el caso de Piedra Museo, si bien se realizó un primer intento de determinación funcional sobre los artefactos líticos para indagar acerca de los potenciales usos, la metodología aplicada y el marco de referencia difieren del aquí presentado y es por esta razón que se considera necesaria una revisión y ampliación de la muestra analizada de los distintos bloques temporales identificados en Piedra Museo desde el Pleistoceno Final.

Para el caso de Cueva Maripe, esta tesis sería un primer intento de aplicar esta metodología en materiales correspondientes a ocupaciones desde el Holoceno Temprano hasta el Holoceno Tardío.

El análisis morfo-tecnológico de los artefactos no es suficiente para vincular aspectos tecnológicos con el uso que se habría destinado a los mismos. Es así que, el estudio de rastros generados por uso, jugaría un rol central a la hora de reconstruir las estrategias de producción (conjunto de decisiones y elecciones vinculadas con la obtención de materias primas y estrategias de uso) y por lo tanto, en la determinación de la utilización de un instrumento de trabajo en distintos procesos productivos.

El análisis funcional de microscopía óptica es una vía metodológica que permite recuperar información acerca del empleo y organización de tecnología lítica aplicada a la optimización de los recursos en distintos tipos de sociedades. Esta metodología de estudio es la única forma de inferir los usos para los cuales fueron confeccionados y destinados los artefactos (Mansur-Franchomme 1983; Álvarez 2003; Leipus 2006). Permite comprender e interpretar el modo de vida de éstas sociedades prehistóricas, a partir una concepción que las vincula directamente con el medio ambiente en que se desarrollan.

La accesibilidad a los medios ópticos adecuados para llevar a cabo el análisis permitió profundizar en esta temática, identificar la función de los sitios en cada bloque temporal y discriminar áreas de actividades específicas que permitirían sostener la hipótesis de uso diferencial del espacio intrasitio como parte de un campamento más amplio de grupos cazadores recolectores.

Por lo tanto, el análisis funcional en conjunto con el estudio tecno-morfológico son vías metodológicas que facilitan la solución a preguntas acerca de los recursos utilizados por los primeros pobladores y sus posibles rutas de movilidad al sur de nuestro actual territorio. 


\section{CAPÍTULO 3}

\section{Área de estudio}

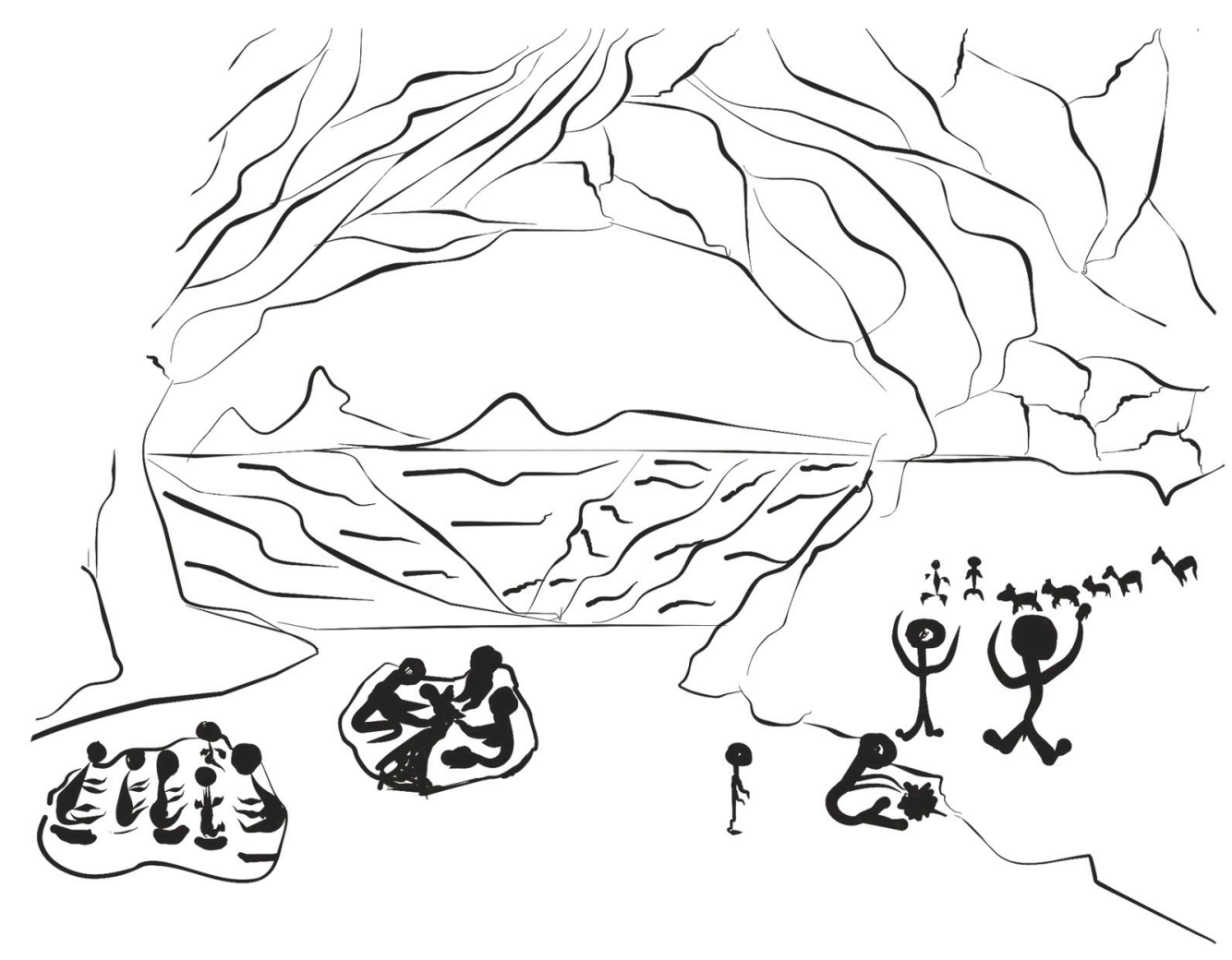





\section{INTRODUCCIÓN}

En este capítulo se describen las principales características ambientales del sector investigado, junto con sus límites espacio-temporales; con el fin de enmarcar el estudio de la tecnología lítica desde su obtención y producción hasta su utilización y descarte. La caracterización de los recursos disponibles y potenciales en un área son el punto de partida para la comprensión del proceso de consumo de una sociedad determinada. El estudio y la identificación de los recursos que estuvieron disponibles a lo largo de las distintas ocupaciones de la meseta central de Santa Cruz, permiten registrar la interacción establecida con los grupos cazadores-recolectores del pasado y su medio circundante.

\section{III.1 Características geológicas y geomorfológicas generales del Macizo central de Santa Cruz}

La siguiente tesis se enmarca dentro de un área ubicada en la Prov. de Santa Cruz con una extensión de $140 \mathrm{~km}$ de Oeste a Este y $80 \mathrm{~km}$ en sentido Norte-Sur. Está delimitada por los paralelos/meridianos $47^{\circ} 30^{\prime} 53^{\prime \prime}$ y $48^{\circ} 06^{\prime} 43^{\prime \prime} \mathrm{S}$ y $67^{\circ} 36^{\prime} 59^{\prime \prime}$ y $69^{\circ}$ $10^{\prime} 02^{\prime \prime}$ O, sector que corresponde a la denominada Patagonia Extra-Andina.

La provincia de Santa Cruz está formada por dos estructuras geológicas; hacia el oeste se extiende la cordillera de los Andes y hacia el este la meseta. Esta meseta, ubicada en el centro de la provincia, se encuentra delimitada en el sector por los ríos Deseado, hacia el norte, Chico, al oeste por el río Mayo y al este se extiende hasta el sector de costa, confluyendo hacia el Océano Atlántico (De Giusto et al. 1980 y Ricciardi y Rolleri 1980).

La denominación de "macizo" o "nesocratón" dada a este sector fue formulado por Feruglio en 1949 (en De Giusto et al. 1980) debido al comportamiento pasivo, rígido y con gran estabilidad tectónica del área. Sin embargo, otros autores (Sruoga et al. 2008), consideran que este concepto debe abandonarse por el de "comarca" o "región del Deseado", debido a que en la actualidad el sector mencionado se encuentra atravesando procesos de subducción. 
Según Panza (2001), la evolución y estructura de la región corresponde al producto de ciclos diastróficos de diversas intensidades, que se habrían producido a lo largo del Fanerozoico y estarían relacionados con la orogenia andina junto con la dorsal mesoAtlántica.

De acuerdo a este mismo autor, pueden registrarse en la meseta dos tipos de paisajes: el mesetiforme (sector occidental y central) y el de relieve irregular (sector este) con picos aislados y cerros alternados con zonas bajas.

El paisaje actual ha sido consecuencia de numerosos eventos tanto de origen fluvial y volcánico junto con procesos erosivos eólicos (De Giusto et al. 1980; Panza 2001). Las unidades geológicas de esta región tienen su origen debido a procesos volcánicos, expresado a partir de la presencia, abundante y de amplia distribución, de rocas cuyas características litológicas han sido y son apropiadas para la manufactura de artefactos tallados y pulidos; que habrían facilitado la supervivencia de grupos humanos desde épocas tempranas (Miotti 1998; Miotti et al. 2007, Cattáneo 2002, Hermo 2008, Magnin 2010, Hermo y Lynch en prensa).

Dentro de estas rocas, se puede mencionar aquellas que componen el grupo Bahía Laura (de edad jurásica) y cuya formación corresponde a un episodio piroclástico-lávico que habría cubierto gran parte del área investigada. Esta unidad está integrada por las formaciones Chön Aike y La Matilde (Lesta y Ferello 1972).

La primera de estas formaciones, se compone de una secuencia espesa de ignimbritas de composición riolítica a riodacítica, las cuales conforman mantos compactos y espesos que forman grandes paredones y crestas abruptas. Mientras que la segunda (asignada al Mesojurásico superior) está formada por tobas y tufitas, con delgados mantos ignimbríticos intercalados (Panza 2001). Esta formación posee además inclusiones de restos fósiles, troncos, tallos y estróbilos de araucarias, que se encuentran altamente representadas en el sector correspondiente al Monumento Nacional Bosques Petrificados (MNBP) y cerros bajos que rodean el sitios arqueológico Piedra Museo (Panza 2001). Es importante aclarar, que estos restos fósiles, habrían sido utilizados como materia prima para la confección de artefactos tallados por las sociedades cazadoras-recolectoras que habrían habitado la meseta.

De la formación Chön Aike, han sido registradas cuevas y oquedades debido a la presencia de grandes paredones y crestas muy abruptas. Tal es caso del sitio Cueva Maripe; mientras que el alero de Piedra Museo (AEP1) corresponde a una arenisca coquinoide de la Formación el Museo, donde se abre la cueva grande (De Aparicio 
1933-35, Miotti 2000 y Zárate et al. 2000). Otros aleros y cuevas en relación con esta formación fueron documentados para Aguada del Cuero, Tito del Valle, Cañadón de Los Toldos (Cardich et al.1973; Blasi et al. 1997; Miotti y Cattáneo 1997; Cattáneo 2002; Hermo y Miotti 2003).

De acuerdo a estos registros se puede observar que el paisaje geomorfológico del área es claramente volcánico, con altitudes que varían entre los 1.000 y $200 \mathrm{msnm}$, salvando las zonas de "bajos" que alcanzan, como en PM sólo 140 msnm, o el Gran bajo San Julián. Mantos basálticos y paredones abruptos caracterizan la cuenca alta de los zanjones Blanco y Rojo, donde se ubica una de las localidades arqueológicas (Cueva Maripe) que constituye el objeto de estudio de la presente investigación (Miotti y Hermo 2000). Por otro lado, en la cuenca baja de estos zanjones, se localiza la otra localidad estudiada, Piedra Museo, con el sitio excavado AEP1, cuyo paisaje se encuentra conformado por zonas bajas con lomadas y cerros aislados dominantes.

El sistema fluvial presente en el área, responde al curso particular de cada uno de los ríos principales del sector estudiado (Deseado y Chico) y corresponde a un sistema endorreico múltiple conformado por cursos efímeros de régimen intermitente, que transportan agua durante la estación lluviosa- invierno y comienzos de primavera(Panza 1982, Miotti y Hermo 2000).

El zanjón Blanco y el Rojo (o Elornia) constituyen las cuencas hidrográficas endorreicas de mayor relevancia en este estudio. El primero de estos zanjones tiene un sentido Oeste-Este, en su parte central, mientras que el curso inferior corre con dirección hacia el norte, con desagüe en la laguna La Porfiada. El segundo zanjón recorre toda la comarca en sentido Suroeste-Noreste desembocando en la laguna grande del MNBP (Monumento Natural Bosques Petrificados, $30 \mathrm{msnm}$.). La presencia de colectores secundarios está dada por los zanjones Cañadón Largo y Del Piche (Panza 2001, Magnin 2010).

\section{III.2. Unidades del paisaje:}

\section{-Flora}

El área estudiada corresponde al territorio fitogeográfico denominado Provincia Patagónica que a su vez se encuentra dentro del Dominio Andino-Patagónico (Cabrera 1971) y debido a las características ambientales de esta región las formaciones vegetales 
son en su mayoría xerófilas y están compuestas por arbustos bajos y achaparrados, en forma de placas adheridas al suelo y abundantes plantas espinosas. En los sectores más húmedos y protegidos de los fuertes vientos patagónicos (valles profundos hacia el oeste y cañadones) predomina la estepa graminosa (Cabrera 1976). Dentro de las especies características de la zona se puede mencionar la presencia de estepa como la Chuqiraga avellanedae (quilembai), Naussauvia glomerulosa (colapiche), Junellia tridens (mata negra) y Stipa speciosa (coirón amargo).

La mata negra corresponde a uno de los arbustos que se puede encontrar en el sector de estepa aunque puede extenderse hacia otros sectores como lo son las terrazas, mesetas y fondo de cañadones o valles fluviales cerca de mallines. Los cañadones también presentan arbustales de mata amarilla (Anartrophyllum rigidum), molle (Schinus polygamus) y calafate (Berberis heterophylla) (Cabrera 1971).

En la parte sur del distrito el quilembai es sustituido por la mata negra; mientras en el sector de cañadones aparecen arbustos como la mata guanaco (Anartrhophylum rigidum), calafate (Barberis sp.) y la mata mora (Senecio filaginoides).

En mesetas sedimentarias y basálticas altas subsiste el coirón blanco (Festuca pallescens) uno de los mejores forrajes junto con el coirón poa (Poa dusenii) (Oliva et al. 2004).

\section{-Fauna}

Los animales que ocupan este sector se encuentran adaptados a la excesiva aridez que caracteriza el ambiente de estudio. Los de mayor tamaño y herbívoros conforman una amplia lista que ha constituido parte de la dieta alimenticia de las poblaciones locales durante largo tiempo. Dentro de esta pueden ser mencionados: el guanaco (Lama guanicoe), la mara (Dolichotis patagonum), el chinchillón anaranjado (Lagidium Wolffsohni) y el chinchillón de la siena (Lagidium Viscacia). Dentro de los carnívoros de gran tamaño, han sido identificados el puma (Puma concolor) y de tamaño pequeño el zorro colorado (Pseudolopex culpaeus), gato del pajonal (Lynchailurus pajeros), gato montés (Puma geophagy) y zorro gris (Pseudolopex griseus).

Mientras que los mamíferos de menor tamaño están representados por la comadreja patagónica (Lestodelphis halli), zorrino patagónico (Canepatus humboldtii) y el piche (Zaedyus pichiy) y de dieta omnívora el tuco-tuco (Ctenomys magellanicus) y el cuis (Microcavia autralis). 
Las especies de aves comunes que ocupan actualmente esta área corresponden al: ñandú petiso (Pterocnemia pennata), el águila mora (Geronoaetus melanoleucus), la bandurria austral (theristicus melanosis), jote (Cathartes aura y Coragyps atratus), el ñacurutú (Bubo magellanicus); cauquén (Chloephaga picta) y el carancho (Caracara plancus). Otras aves menores de este ambiente son la martineta o copetona (Eudromia elegans), el chimango (Milvago chimango), la lechuza de campanario (Tyto alba), la agachona patagónica (Attagis malouinus) y la perdiz chica o inambú pálido (Nothura darwinii) (Narosky y Yzurieta 2010).

Sin embargo, la fauna que se encuentra actualmente en este sector de meseta, difiere de aquellos identificados milenios atrás y muchos de los cuales se encuentran extintos. Tal es el caso del caballo americano (Hippidion saldiasi), extinto hacia el ca. 9000 años AP y cuyos restos fueron recuperados en numerosos sitios de esta región, Cueva 3 de Los Toldos y El Ceibo (Cardich 1987) junto con uno de los sitios bajo estudio, Piedra Museo - AEP1- (Miotti 1995, 1998; Miotti y Salemme 1999; Miotti et al. 2003). Otro tipo de fauna extinta fue Lama vicugna gracilis y Hemiauchenia perodoxa, cuyos restos fueron registrados en el sitio Casa del Minero 1 -Paunero et al. 2007. Igualmente los cérvidos como el huemul (Hippocamelus bisulcus) que pudieron haber habitado la región hasta la llegada de los europeos (Miotti 1998) y el ñandú común (Rhea americana), actualmente ubicada en la región pampeana y en otros sectores de Sudamérica, al igual que el felino desaparecido en la Patagonia después de la transición Pleistoceno holoceno (Pantera onca), que ha sido representado en las pinturas rupestres del sitio arqueológico El Ceibo (Cardich 1987). 


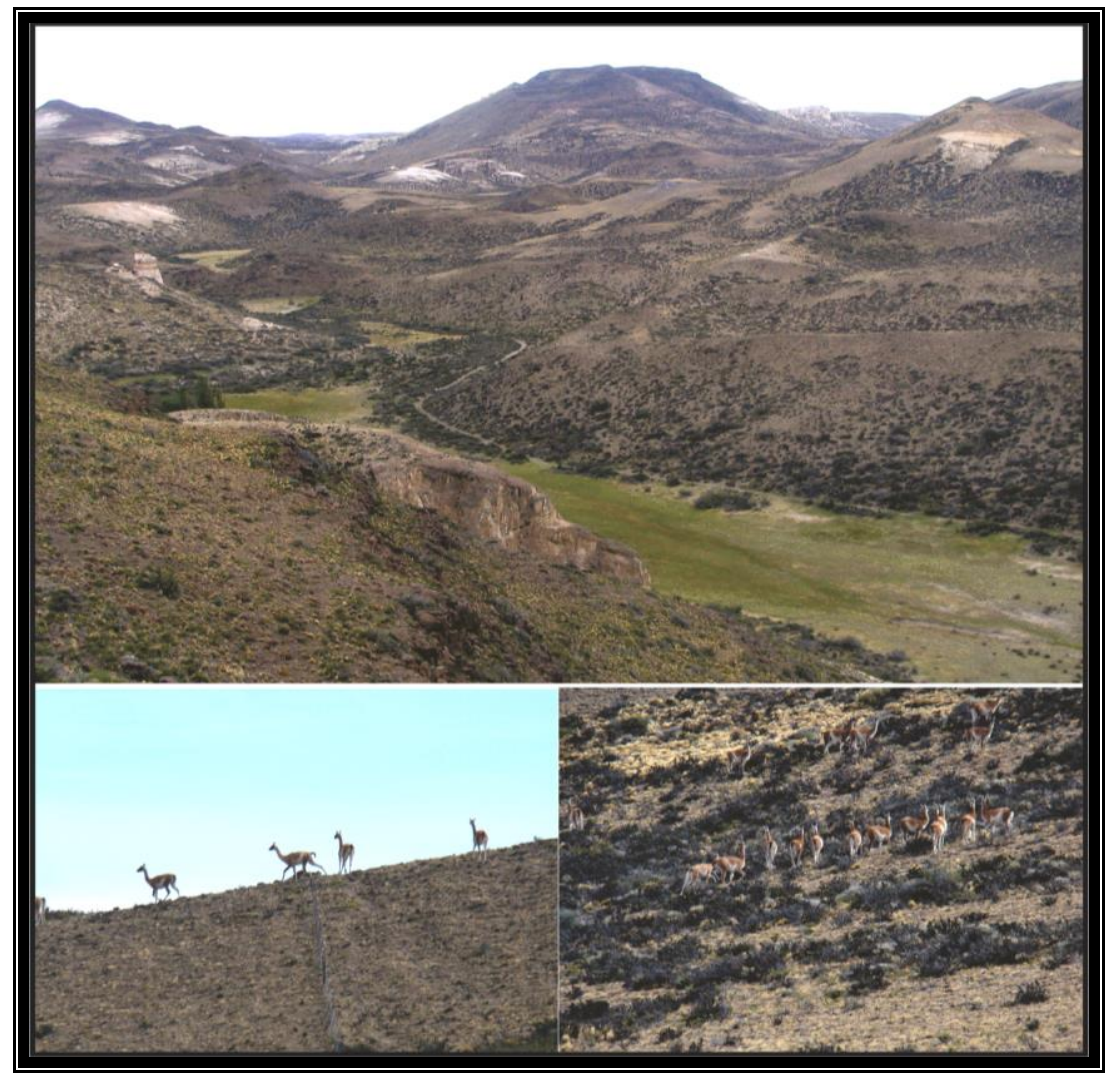

Figura 4: El Cañadón La Primavera y la presencia de tropillas de guanaco frente al sitio Arqueológico Cueva Maripe (fotos de la autora).

\section{-Unidades geológicas: potenciales fuentes de materias primas para la talla lítica}

La superficie bajo estudio presenta un paisaje con alta disponibilidad de materias primas de buena calidad para la talla. La mayoría de las rocas disponibles presentan características físico-químicas (fractura concoide, marcada criptocristalinidad, alta dureza, tamaño adecuado y alto contenido silíceo) propicias de haber sido utilizadas desde las primeras ocupaciones en los sitios analizados (Cattáneo 20002, 2006 y Hermo 2008, 2009).

\section{Fuentes primarias}

Tal como plantea Panza (2001), la geología del área y las relaciones estructurales de cada unidad que se encuentran en ella son relativamente simples. Los afloramientos rocosos más antiguos corresponden a tobas y pelitas de la Fm. Roca Blanca, del Liásico Superior, localizada al suroeste de Piedra Museo. Posteriormente en relación de 
discordancia erosiva esta unidad se encuentra cubierta por basalto, andesitas y aglomerados volcánicos de la Fm. Bajo Pobre (Dogger inferior).

A continuación de estos, se encuentra un complejo piroclástico-lávico de suma importancia en relación con los sitios bajo estudio, representado por el Grupo Bahía Laura. En este punto cabe hacer una descripción más detalla de las rocas que lo componen, ya que este grupo presenta rocas propicias para ser utilizadas en la talla de artefactos líticos.

El Grupo Bahía Laura (Dogger superior- Malm inferior) se encuentra constituido por las formaciones Chön Aike (ignimbritas riolíticas) y La Matilde (tobas, tufitas y bosques petrificados de araucarias al sur de Piedra Museo, donde ha sido localizado un sitio cantera taller, 17 de Enero, en la Ea. El Sargento).

La primera de estas formaciones, está constituida por ignimbritas de composición riolítica asociadas a aglomerados volcánicos gruesos. Las facies lávicas son minoritarias y se encuentran igualmente rocas hipabisales ${ }^{1}$ (pórfiros riolíticos, Panza 2001). La cantera del Rojo (Ea. La Lotita, en el basalto Las Mercedes, Hermo 2008); la cantera Platense (en la Localidad Las Mercedes, afloramiento primario, Magnin 2010) y el sitio Taller D9 de superficie (crestón de ignimbrita donde se hallaron numerosos artefactos de sílice rojo, Magnin 2010), son algunos de los afloramientos que han podido registrarse en relación con la formación Chön Aike. Asimismo, se identificaron otras vetas de menor tamaño en los campos, rellenando fisuras o cavidades en rocas volcánicas de esta formación. Siendo potenciales recursos los rodados que constituyen los clastos de los conglomerados volcánicos de Chön Aike y nódulos que se forman en grietas y oquedades de esta misma formación (Miotti 1998, Cattáneo 2002, Hermo 2008).

Por otro lado, en las Eas. La Escondida y La Magdalena, Panza (2001), describe la presencia en esta unidad de afloramientos de obsidiana negra a gris-negruzca, pero que debido a sus características litológicas (alta fragmentación interna) probablemente no haya sido utilizada para la talla (Magnin 2010).

La obsidiana además de poseer características óptimas para la talla (Civalero 1999), ha sido utilizada por los grupos que habitaron la meseta en distintos momentos de ocupación, lo que ha permitido plantear su carácter simbólico (Miotti 2008, Hermo y Miotti 2011). Sin embargo, hasta el momento, no ha podido ser identificado un origen

\footnotetext{
${ }^{1}$ Formadas a profundidades intermedias debido al desplazamiento parcial del magma.
} 
local de esta materia prima, habiendo sido registrada su procedencia en el sector denominado Pampa del Asador, ubicada alrededor de unos $170 \mathrm{~km}$ de los sitios estudiados (Stern 1999, 2004; Bayón y Flegenheimer 2004; Hermo 2009; Hermo y Miotti 2011; Magnin 2010).

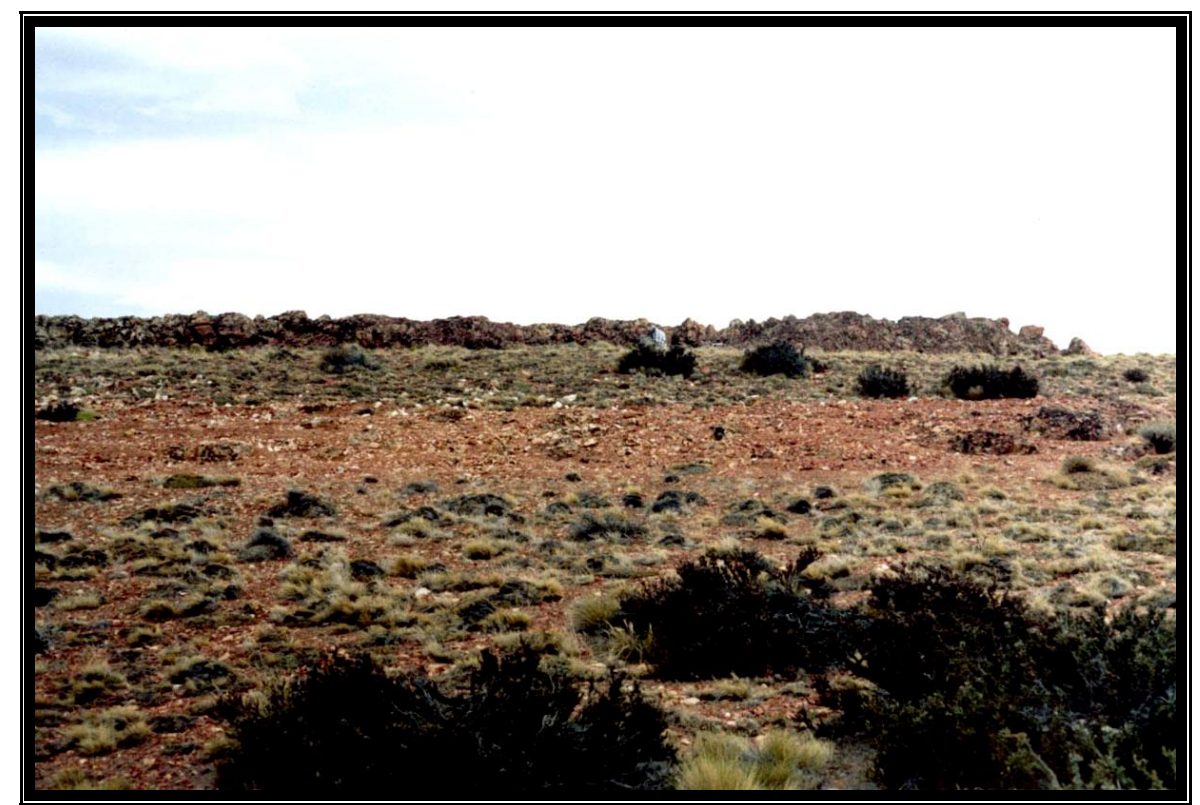

Figura 5: Afloramiento de ignimbritas de la formación Chön Aike, Cantera del Rojo (CDR), (Foto: Darío Hermo).

En cuanto a la Fm. La Matilde, se encuentra constituida principalmente por tobas, tufitas e ignimbritas altamente silicificadas y es portadora de troncos petrificados de araucariáceas (ópalos y calcedonias) (Panza 2001), que en ciertos sectores, pueden presentar excelente calidad para la talla, permitiendo obtener artefactos delgados y de filos largos (Miotti y Cattáneo 1997, Cattáneo 2000; 2002, Hermo 2005).

Las rocas identificadas en esta formación pueden estar dispuestas de manera aislada, concentradas o dispersas (Cattáneo 2005, Di Lello et al. 2005), por lo que las materias primas puede considerarse como heterogéneamente distribuidas en estas formaciones.

Existe a su vez, otras formaciones igualmente importantes en cuanto a la composición litológica, tal es el caso de la Fm. Bajo Grande. Esta formación, se encuentra separada del Grupo Bahía Laura por una relación de marcada discordancia angular y está constituida por conjuntos de sedimentitas y piroclastitas continentales de variados colores (Panza 2001). En la localidad arqueológica La Primavera esta formación se encuentra asociada a la Cantera Del Verde (CDV) (Miotti com. pers. 2003), formada 
por tobas, tufitas, areniscas, conglomerados y restos fósiles (troncos petrificados, improntas de ramas y tallos).

Por otro lado, es importante mencionar otro tipo de formación denominada Fm. Baqueró, el miembro inferior de esta formación está constituido por areniscas gruesas a conglomerados, limolitas y arcillitas, mientras que el superior presenta cineritas blancas y gris blanquecinas, con tobas más resistentes de tonalidades castaño-amarillento. Los conglomeraos de esta formación se encuentran en los paleocauces del Zanjón Blanco e igualmente en el sector de la Ea. La Dorita, Bajo Grande, Las Mercedes, Aguada del Cuero y MNBP, presentando troncos petrificados con mal estado de preservación que en muchos caso permiten observar simplemente la impronta. En Cueva Moreno, de Aguada del Cuero, (Miotti 2000; Hermo 2008; Carden 2009) estos troncos petrificados constituyen el techo de la cueva y si bien poseen una amplia distribución las características de este tipo de xilópalo (con planos internos de fractura) no permiten su utilización como materia prima para la talla de artefactos. Sin embargo esto no ocurre en la cantera Rocky (Hermo 2008), donde es posible obtener ignimbritas riolíticas de buena calidad y variados colores (marrón oscuro).

\section{Fuentes secundarias}

Numerosas fuentes secundarias (conos aluviales y planicies de pedimentos) constituyen sectores de depositación de distintas materias primas por derrumbes y deslizamientos. Estos depósitos contienen nódulos de variada procedencia y litología, que han sido meteorizados y trasladados por acciones fluviales y de gravedad. En el caso del cañadón La Primavera se puede encontrar la cantera LP-P1 (Pedimento nivel I), donde se registraron clastos de diversas unidades geológicas totalmente erosionados o en vías de erosión (Hermo 2008). Este sector fue muestreado durante los trabajos de campo realizados en el 2010 con el fin de obtener materias primas de diversas características litológicas para la elaboración de la serie experimental de referencia (para más detalle ver capítulo IV).

La localidad Piedra Museo presenta acumulaciones de clastos psefíticos de materias primas de calidades excelentes concentradas en los cordones litorales de un paleolago al sur del sitio donde fueron practicadas las excavaciones principales de la localidad PM, AEP1. Este tipo de depósitos fueron fundamentales fuentes de aprovisionamiento lítico para esta localidad (Cattáneo 2002). 


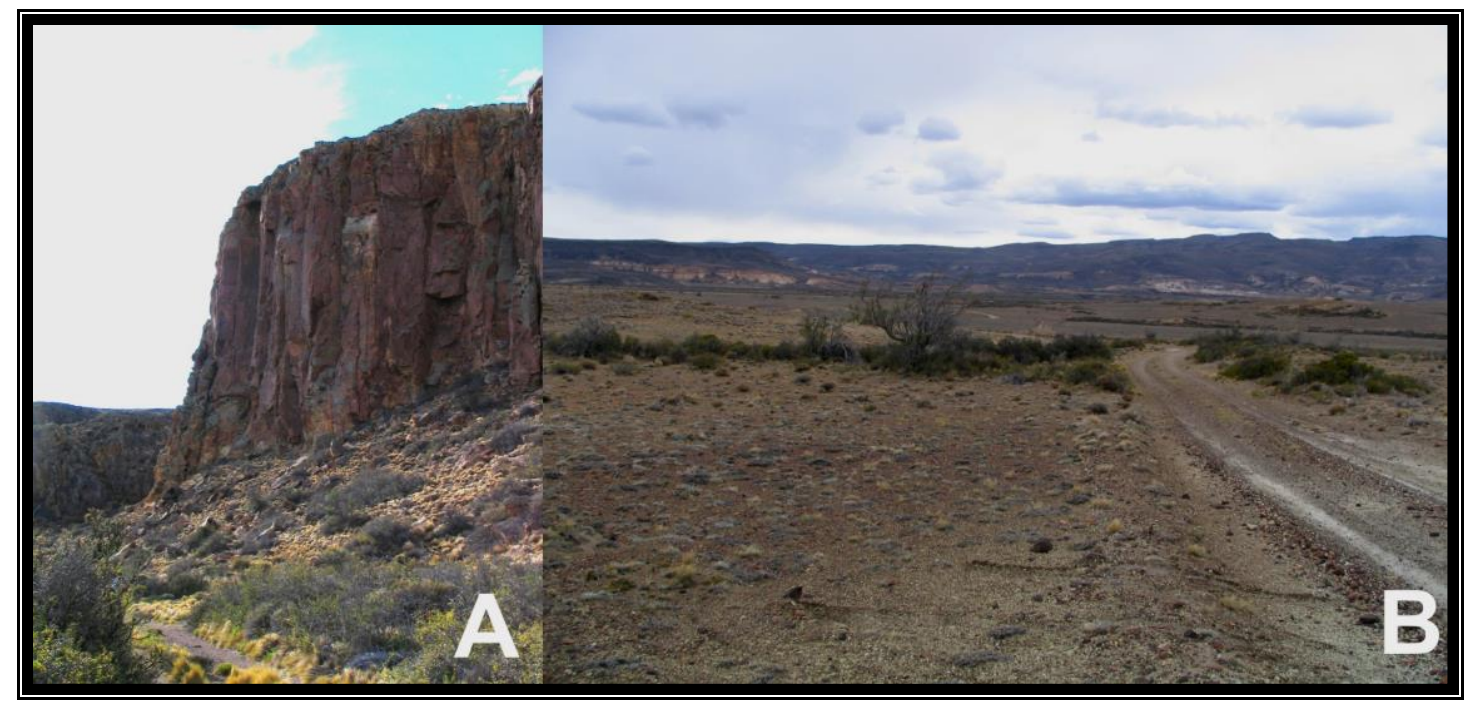

Figura 6: A) Coladas basálticas del cañadón La Primavera. B) Pedimento La Primavera 1 (LP-P1) fuente secundaria de aprovisionamiento de materias primas.

\section{III.3. Uso de los recursos disponibles}

El uso de distintas especies de animales y recursos vegetales, mencionados en el apartado anterior, fueron seleccionados para su uso por los grupos que colonizaron la meseta central desde finales del Pleistoceno (Cabrera 1971, Gradín y Aguerre 1992, Crivelli Montero et al. 1992, Magnin 2006c). Las diversas actividades desarrolladas cotidianamente por estas sociedades iban desde el aprovisionamiento de recursos alimenticios, hasta las materias primas para la elaboración de distintas herramientas ya sea para la caza, confección de viviendas y vestimenta.

En cuanto a los recursos vegetales asociados a la alimentación, se puede mencionar el uso de diversas plantas en la elaboración de infusiones, tal es el caso del té pampa (Satureja darwinii), la tuna (Maihuenia patagónica) y plantas con bayas comestibles como el calafate (Barberis buxifolia), las cuales se comen directamente y además de ellas se producen dulces, jarabes y vinos junto con la madera utilizada como medicina (Magnin 2010), y también como colorantes (Musters [1869-1870] 1964; 1991).

Entre otras plantas medicinales se puede mencionar: paramela (Adesmia boronioides), cuyas hojas ayudan como desinflamatorio, mamuel choique (Adesmia Volckmanni Phippi) también utilizada como forraje durante el invierno, alfilerillo (Erodium cicutarium) planta forrajera que ayuda en las hemorragias de partos e igualmente como diurético y malva rubio o yerba de sapo (Marrubium vulgare) con diversas propiedades 
que la hacen propicia para usos variados ya sea como infusión, en medicinas y como repelente efectivo.

La utilización de plantas con alta toxicidad, tanto para el hombre como para los animales, ha sido registrada desde épocas post-hispánicas. Dentro de estas se puede mencionar la pichaga (Trifolium sp.) y el coirón huecú (Festuca argentina).

Otras utilidades han sido la tintura para la lana (plantas como el calafate, mata verdeLepidophyllum cupressiforme-, mata mora y duraznillo).

El mamuel choike, el calafate y el molle (Schinus marchandii), son actualmente utilizados como leña en poblaciones locales aunque ya había sido mencionado este uso por el etnólogo austríaco, Gusinde (1982-1989). Asimismo, en el sector de Magallanes donde escaseaban los árboles para la manufactura de arcos, estos eran obtenidos mediante trueque por medio de sus vecinos meridionales (Martinic 1995).

La elaboración de toldos y parapetos, incluía la madera de molle debido a que los mismos llegan a medir hasta $3 \mathrm{mts}$. de altura, junto con el duraznillo (Colliguaja integerrima) y el yoayín (Lycium chilense) con 2 mts. y sin espinas (Musters [1987] 1997, Pérez de Micou et al. 1992 y Nacuzzi y Pérez de Micou 1983).

El uso del molle como leña fue igualmente documentado en uno de los sitios bajo estudio (Piedra Museo - AEP1- (Miotti et al. 2003) y en el sitio Cerro Tres Tetas hacia el ca. 11.000 A.P. (Paunero 2003a). Mientras que el uso del coirón fueguino (Festuca gracillima) fue documentado para el acondicionamiento de las superficies de ocupación, dispuestos en "camadas" en distintos estratos o unidades (Cueva Maripe, cámara norte y en los pisos de ocupación "Patagoniense" de la Cueva 3 de Los Toldos (Miotti 1998 y Osterrieth 2000; Osterrieth et al. 2002) y a partir de crónicas (Cooper 1946; Claraz 1988; Goñi 2010) donde se menciona a través del uso de plantas para la preparación de superficies de ocupación.

En cuanto a los recursos faunísticos, la región Patagónica, posee una amplia variedad de recursos pero que, con anterioridad a la llegada de los primeros colonizadores, esta variedad estaba incrementada por animales que se extinguen hacia el Holoceno temprano. Entre ellos se puede mencionar el caballo americano (Hippidion saldiasi), registrado en sitios como Cueva del Mylodon al límite de la frontera Argentina-chilena, [(Roth 1899) en Alberdi et al. 2001, Mengoni Goñalons y Silveira 1976, Sanguinetti y Borrero 1977, Martin 2008; Borrero y Martin 2012] y Cueva Pali Aike cercano al Estrecho de Magallanes (Bird 1938 y Arnold y Libby 1951, Alberdi et al. 1987). Mientras que en la meseta central de Santa Cruz, los sitios Los Toldos-Cueva 3-, El 
Ceibo (Cardich y Miotti 1983, Cardich 1987) y Piedra Museo- AEP1- (Miotti 1998; Miotti et al. 2003) presentan resto de estos équidos.

Además del caballo americano extinto, también han sido reconocidos otros animales como: Lama (vicugna) gracilis (igualmente localizados en los sitios Los Toldos, El Ceibo y Piedra Museo (Miotti y Salemme 1999, 2005; Miotti y Marchionni 2012; Miotti et al. 2013) junto con el sitios Casa del Minero 1 (Paunero et al. 2007), Hemiauquenia perodoxa (sitio Casa del Minero 1, Paunero et al. 2007); cérvidos como el huemul (Hippocamelus sp.) que pudieron haber habitado la región incluso hasta la llegada de los europeos (Miotti 1998; Norma Díaz et al. 2007); el ñandú común (Rhea americana) actualmente en la región pampeana y otros sectores de Sudamerica y por último, un solo felino (Panthera onca mesembrina) siendo su presencia plasmada en las pinturas rupestres del Ceibo (Cardich 1987) y materiales zooarqueológicos (Miotti 1998; Miotti et al. 2007, 2010), cuevas de Ultima esperanza (Borrero et al. 2005).

-Colorantes naturales: pigmentos minerales y vegetales.

El uso de pigmentos hematíticos u "ocres" y yeso para la elaboración de pinturas rupestres ha sido ampliamente documentado en el sector estudiado.

Los relatos de viajero y cronistas nos informan acerca del uso de pigmentos sobre cueros y pinturas corporales que eran empleados en distintos momentos, ya sea en el duelo, en la guerra o en ceremonias (Musters [1869/1870] 1979; Gomez Otero 1996b; Aguerre 2000; Fiore 2004; Fiore et al. 2008).

En la Localidad arqueológica de Los Toldos, ubicado en las cabeceras del zanjón del Pescado, durante las excavaciones realizadas en la Cueva 2, se recuperaron restos de pigmentos rojos y rocas con pintura del mismo color en los niveles culturales definidos como "Toldense" (Menghin 1950). Por otro lado, durante los trabajos realizados por Cardich en la Cueva 3 de este mismo sitio, fueron igualmente recuperados restos de pigmentos rojos y rocas con pintura asociados a las capa 9 cuyo techo fue datado en $8750 \pm 480$ años A.P. (Cardich et al. 1973). Para los niveles más profundos (11 a y 11 b) de la excavación de la cueva 3, Cardich obtuvo un fechado radiocarbónico de $12.600 \pm$ 650 años A.P. (FRA 98). En esta matriz se encontraron restos de pigmentos de color amarillo, que supuso pudieron haber sido utilizados para la preparación de pinturas rupestres (Cardich et al. 1973). Sin embargo, las pinturas amarillas solo están presentes en la Cueva 2 y no son las primeras en el orden de las superposiciones. 
Otro sitio con restos de pigmentos y que conforma el objeto de estudio de esta tesis; corresponde a Piedra Museo- AEP1- (Miotti 1996, Miotti et al. 1999, Cattáneo 2002). Durante las excavaciones, se recuperaron restos de pigmentos en todos los niveles de ocupación; sin embargo, la unidad 6 [componente inferior datado en $12.890+90$ (AA 20125) y 10.925 + 65 años A.P. (OXA 8528), Miotti et al. 1999] posee mayor variedad de colores (blanco, amarillo y rojo) y en asociación a un fragmento de roca de arenisca coquinoide con restos de pintura roja en la cuadrícula L (Carden 2008, Miotti et al. 2011).

En el sitio Cueva Maripe, fueron recuperadas ocho muestras de pigmentos rojos en estratigrafía. Uno de estas analizada por difractometría de rayos X, comprobando la presencia del pigmento hematita (Miotti y Carden 2007). Este mineral pudo usarse en la fabricación de las pinturas rupestres, al igual que otros usos posibles, para pintar cueros, el cuerpo y artefactos de madera (Miotti y Carden 2007; Miotti et al. 2011).

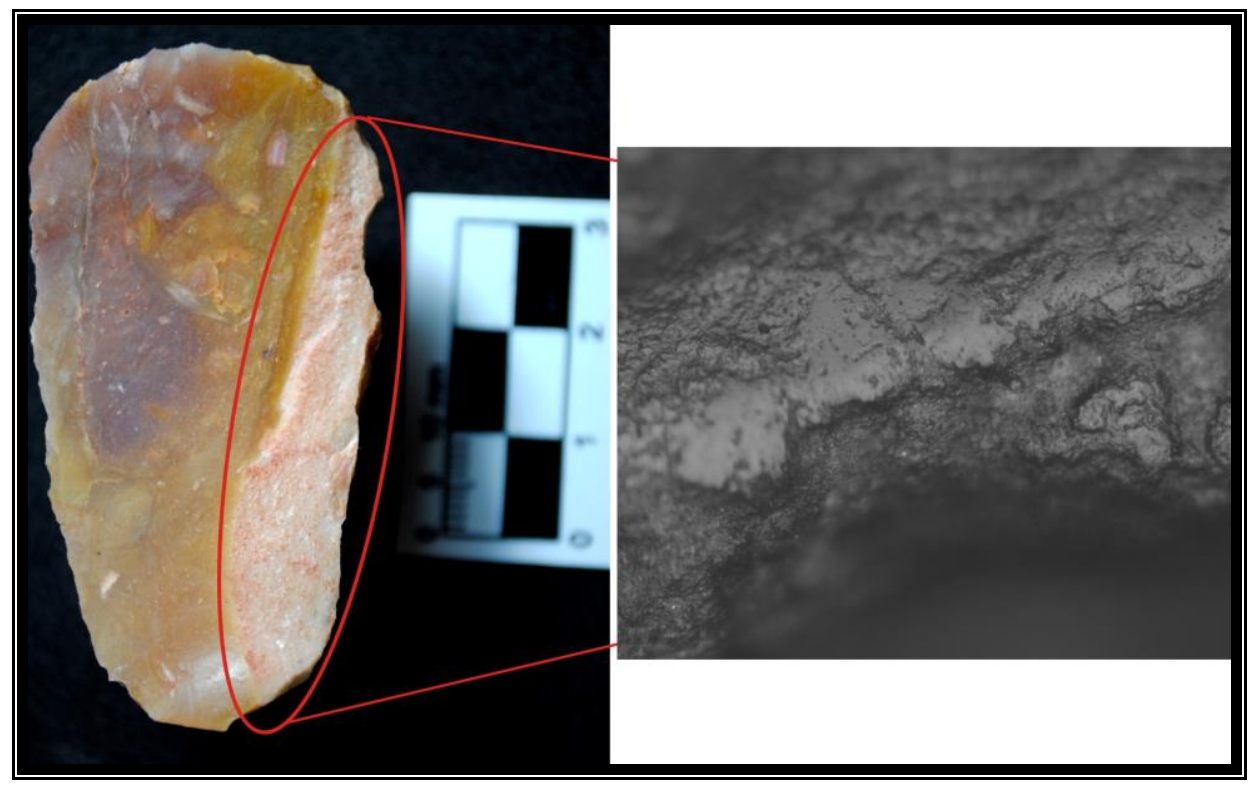

Figura 7: Raspador de filo fronto-lateral con residuos de coloración roja en la cara ventral, recuperado en Cueva Maripe. Filo lateral donde se observa formación de micropulido brillante y espeso posiblemente de material duro con abundantes esquirlamientos y estrías que permiten observar un movimiento de acción transversal (aumento 200X).

La Localidad La Primavera presenta numerosos afloramientos de ocre en distintos sectores. De acuerdo a la hoja geológica, las formaciones Bajo Pobre, Baqueró, Laguna Palacios y Salamanca presentan “óxido de hierro" (Panza 2001). Durante los trabajos de campo realizados en el 2003 y 2011, han podido ser recuperados muestras de “ocre" en puntos de contacto entre coladas basálticas y otras rocas subyacentes como tobas. Estos 
son útiles para ser molidos y usados en pinturas sobre diversos soportes como así también en tratamientos de cuero y decoración de los mismos.

Otros contextos arqueológicos donde ha sido mencionado la presencia de pigmentos es el sector del río Pinturas, en las nacientes del Deseado, a $145 \mathrm{~km}$ en dirección noroeste del área de estudio, sitios Cueva de las Manos y Cerro Casa de Piedra 5, donde se analizó la composición mineralógica de pinturas procedentes de la roca soporte, así como otros elementos recuperados en las capas arqueológicas. Este trabajo permitió determinar que las pinturas de distintos colores (entre rojizos y ocres) contenían hematina, maghemita, natrojarosita e illita, el "negro" probablemente es carbón molido u óxido de manganeso. Mientras que otros pigmentos minerales fueron mezclados con yeso puro o cristalino y un fijador cuya naturaleza perecedera no permitió su preservación (Iñíguez y Gradín 1977, Gradín et al. 1987).

\section{III.4. Paleoambiente y ocupaciones humanas iniciales}

La transición Pleistoceno-Holoceno ha sido un momento de elevada inestabilidad que complejizó la llegada y expansión de los diversos grupos cazadores-recolectores que habitaron la amplia región patagónica. Los momentos iniciales de colonización estuvieron acompañados por una gran inestabilidad climática lo que probablemente haya generado que los primeros asentamientos no hayan sido homogéneos y se encuentre relacionado a la disponibilidad de los recursos en el área. Sin embargo, estas características no imposibilitaron ocupaciones semipermanentes, viéndose reflejado en los números sitios con fechados radiocarbónicos tempranos que se extienden entre el 13.000 y 10.500 años $C^{14}$ A.P. (Borrero 1994-95; 1998; Miotti 2003; Miotti y Salemme 2004; Paunero et al.2007; Salemme y Miotti 2008; Ariztegui et al. 2010; Franco et al. 2010).

El Macizo del Deseado corresponde entonces a un área que presenta numerosos sitios con ocupaciones tempranas. Los primeros grupos humanos habrían necesitado tiempo suficiente para reconocer y adaptarse a su nuevo ambiente y a sus características físicas (disponibilidad de agua y de materias primas) (Kelly 2003; Meltzer 2003; Rockman y Steele 2003).

De acuerdo a lo propuesto por Salemme y Miotti (2008), la colonización humana para este período, estaría caracterizada por momentos de continuidad como así también discontinuidad, con movimientos poblacionales rápidos seguido por momentos de 
estasis. Se sugiere que las causas de esta movilidad estarían asociado a factores ambientales y las decisiones tomadas por los grupos de acuerdo a las opciones disponibles para ellos.

Los estudios paleoambientales indican que para ese entonces habrían existido dos cambios climáticos cuyas repercusiones podrían haberse reflejado para Sudamérica en estos movimientos poblacionales: Antartic Cold Reversal (ACR): evento frío reverso antártico registrado en la cuenca del lago Huelmo/Mascardi (Ariztegui et al. 1997) y Younger Dryas (YD): evento de frío reverso, junto con intervalos climáticos de menor rango como el Byrd Ice Core hacia los 10.9 ka. BP. Esto eventos habrían terminado hacia los $10.200 \mathrm{C}^{14}$ AP. (11.800 ca. AP.)

De acuerdo a esto y siguiendo el modelo de poblamiento propuesto para el área de estudio (Borrero 1989-90; Miotti y Salemme 2004), el proceso de exploración, definido como etapa inicial de expansión humana hacia áreas inhabitadas, estaría condicionado por estos cambios climáticos de avances y retrocesos glaciarios. El período final del Tardiglaciar, hacia los 13.000-15.800 ca. A.P. y 8800 ca. AP. (Miotti y Salemme 1999), habría estado caracterizado por condiciones ambientales de bajas temperaturas. La gran cantidad de agua retenida en los glaciares habría provocado el descenso del nivel del mar y por consiguiente la línea de costa habría estado ubicada a unos $200 \mathrm{~km}$ más al este de la línea actual (Ponce et al. 2011b). Estas condiciones ambientales se verían reflejadas para el Macizo del Deseado en la secuencia polínica de Los Toldos. La presencia de estepa de Ephedra estarían sugiriendo condiciones climáticas áridas en donde la precipitación es menor a los 200 mm entre los 12.600 (14.900 años cal A.P.) y 11.000 años $C^{14}$ A.P. (12.900 años cal A.P.) (Páez et al. 1999). En el alero de Piedra Museo se habría desarrollado estepa de arbustos de Asteraceae subf. Asteroideae y vegetación halofítica (Borromei 2003). Mientras que en Los Toldos, hacia los 11.000 años $C^{14}$ A.P., la estepa de arbustos Ephedra habría sido reemplazada por estepa de gramíneas (hierbas) en ambiente de semidesierto situado sobre un plateau a unos $700 \mathrm{~m}$ s.n.m. Hacia los 10.000 años $C^{14}$ A.P. (11.500 años cal A.P.) la estepa graminosa habría sido reemplazada por una estepa arbustiva dominada por Asteraceae (Páez et al. 1999). De acuerdo a estos resultados entre los 11.000 y 10.000 años $C^{14}$ A.P., hubo un incremento en la humedad efectiva relacionada con aumento en las precipitaciones y condiciones más frías.

Teniendo en cuenta estas características, se ha propuesto que los asentamientos tempranos pudieron haberse dirigido hacia las zonas de cañadones con cuevas y abrigos rocosos 
(Miotti y Salemme 2004). La alta movilidad que caracterizaba estos primeros primeros grupos humanos, podría haber estado basada en redes de comunicación (Miotti 1995; Miotti y Salemme 2004; Miotti et al. 2011; Flegenheimer et al. 2013), con el fin de obtener información sobre lugares con potenciales recursos (agua, materias primas líticas, fauna, abrigo, reparo, etc.).

En el nivel más antiguo de AEP-1 (Localidad Piedra Museo), posee fechados que van desde los 12.890 a $11.000 \mathrm{C}^{14}$ años A.P., lo cual permite inferir que las primeras ocupaciones corresponden, a ese momento. Por otro lado, cabe mencionar los fechados obtenidos sobre restos óseos de fauna extinta (caballo americano- Hippidion saldiasi-), con edades estimadas en 11.000 años $\mathrm{C}^{14}$ A.P., siendo este animal característico de condiciones ambientales de pastizal abierto. Otras especies asociadas a estos fechados corresponde a un camélido extinto (Lama gracilis) y ñandú grande (Rhea americana), ambas especies pasteadoras y que indicarían igualmente condiciones menos áridas en la escala microregional (Miotti 2011). Los estudios polínicos realizados por Borromei (2003), indican dos cambios de acuerdo a las condiciones ambientales, uno cerca de los $11.000 \mathrm{C}^{14}$ años A.P. (12.900 años cal A.P.), debido a un incremento en la humedad efectiva y condiciones frías; y el otro, hacia los $9500 \mathrm{C}^{14}$ años A.P. (10.800 años cal A.P.), explicado como incremento en la temperatura y precipitación variando en los rangos actuales. Asimismo en sitios cercanos a Piedra Museo, también han sido encontrado restos de fauna extinta (Hemiauchenia paradoxa) en el sitio Casa del Minero 1, unidad 4 con fechados de $10.967 \pm 55$ años $C^{14}$ A.P. y $10.999 \pm 55$ años $C^{14}$ A.P. ejemplares típicos de estepa graminosa (Paunero et al. 2005), como igualmente de Lama gracilis, en los sitios de El Ceibo, Los Toldos-cueva 3- (Cardich et al. 1987), La Martita (Aguerre 1987) y Cerro Tres Tetas (Paunero 2000e). En el componente inferior de Piedra Museo (capa 6), se registró también Mylodon sp. junto a estas especies (Marchionni y Vázquez 2012).

\section{III.4.1. Holoceno Temprano y Medio}

La retracción de los glaciares se habría dado hacia los $10.000 \mathrm{C}^{14}$ A.P. (Coronato et al. 1999) y durante este proceso las condiciones ambientales habrían estado caracterizadas por paisajes intercalados por bosques y estepa con escasa presencia de elementos arbóreos (Markgraf, 1993; Borrero y Franco 2000; Cassiodoro et al. 2013). 
De acuerdo con Heusser (1989a, b) la comunidad forestal comienza a desarrollarse como grupos aislados en la estepa arbustiva. Estas condiciones transitorias pueden haber durado hasta mediados del Holoceno, cuando asumió esencialmente el bosque (Heusser y Rabassa, 1995).

En el Lago Cardiel, después de 9.500 años $C^{14}$ A.P. los estudios diatomológicos han demostrado que la humedad efectiva para el área se habría extendido hasta los $7.700 \mathrm{C}^{14}$ A.P. (Markraf et al. 2003; Gilli et al. 2005).

Por otro lado, se ha inferido para este período, un mejoramiento climático que se ve reflejado en la estepa herbácea en áreas de Patagonia (Cardich y Miotti 1983; Miotti 1998, 1996; Miotti et al. 1999; Miotti y Salemme 1999, 2003; Paunero 2003; Borromei 2003).

Hacia inicio del Holoceno Medio (desde los 7.500 años $C^{14}$ A.P.-8.000 años $c a$. A.P.hasta los 3.500 años $C^{14}$ A.P.-3.700 ca. A.P.-) se produjo la consolidación territorial por parte de los grupos cazadores-recolectores; acompañado por un proceso crítico de aridización de los ambientes que se extendió hacia todo el Holoceno (7.000-6.000 años $\mathrm{C}^{14}$ A.P.) (Coronato et al. 1999; Miotti y Salemme 2004).

La disminución de la continentalidad, producida por el ascenso del nivel del mar consecuencia del deshielo, coincidiría con ambientes de estepa herbácea (Miotti 2011). Esto habría traído como consecuencia la desaparición de numerosos sitios arqueológicos tempranos, que habrían quedado bajo el agua y que podrían ser reflejo de la etapa de consolidación territorial siguiendo el modelo de poblamiento propuesto para el área (Borrero 1989; Miotti 2003, 2011; Miotti y Salemme 2004) y con la idea de un proceso centrípeto (Miotti 2004; Miotti y Magnin 2012).

Por otro lado cabe mencionar la acción volcánica, ya que durante el Holoceno, al menos 12 erupciones fueron registradas hacia el 6700 AP y hacia el 3600 años AP, las cuales arrojaron abundantes materiales piroclásticos (Naranjo y Stern 1998). Las cenizas arrastradas habrían caído a mas de $100 \mathrm{~km}$ del volcán formando depósitos con espesores de menos de $10 \mathrm{~cm}$. (López 1994). Su marca fue registrada en numerosos sitios de Patagonia (Miotti 1998; Paunero 2000a, 2003; Durán et al. 2004; Miotti y Salemme 2004). Tal es caso del sitio Piedra Museo- AEP1- donde se observó un hiatus entre las unidades estratigráficas que podría estar indicando estas actividades sísmicas y/o volcánicas, haciendo inhabitable el alero debido a posibles desprendimientos masivos del techo y pudiéndose explicar como el abandono, reorganización y redistribución de los grupos humanos en otras áreas y retorno nuevamente al lugar cuando el espacio del mismo estuvo disponible. 
Los contextos arqueológicos estudiados en relación a estos momentos estarían evidenciando esta mayor movilidad e interacción de grupos que habitaron la meseta central. Los restos malacológicos recuperados de contextos mesetarios avalarían estas hipótesis (Salemme y Miotti 2008), mientras que los conjuntos arqueofaunísticos evidencian una especialización en el uso de los recursos con una dieta basada exclusivamente en la caza del guanaco (Lama guanicoe) y complementada con ñandú (Pterocnemia pennata) (Miotti 1998; Miotti y Marchionni 2011; Miotti et al. 2009; Marchionni et al. 2011).

Por otro lado, el análisis de los conjuntos líticos, evidencian un incremento en la producción de elementos (raspadores, sobadores, punzones) relacionados a la fabricación de toldos y parapetos. Esto permitiría sostener la hipótesis planteada en relación al incremento de la movilidad e interacción que caracterizó a los grupos que habitaron la Patagonia durante este período.

Asimismo, las condiciones climáticas dominantes podrían haber favorecido el desarrollo de ambientes capaces de sustentar una mayor cantidad de población. Los fechados radiocarbónicos realizados en numerosos sitios son más abundantes hacia el Holoceno Medio, lo que sustentaría el proceso de consolidación territorial que habría marcado este momento (Orquera 1984-85; Borrero 1994-95, 2001; Miotti y Salemme 1999; Borrero y Franco 2001; Miotti 2003 y b; Politis 1999; Paunero 2009; Salemme y Miotti 2008).

\section{III.4.2. Holoceno Tardío}

Este período incluye los últimos 3.500 años $C^{14}$ A.P. y corresponde al inicio de la configuración ambiental actual de la región Patagónica; con ocupaciones estables para algunos sectores (Miotti y Salemme 2008). Los estudios realizados en las cuevas La Martita y Alero Cárdenas presentan un cambio hacia la conformación florística actual durante el Holoceno Tardío (Mancini 1998).

Los análisis de las fluctuaciones de los niveles del Lago Cardiel permitieron estimar cambios en la humedad a lo largo del Holoceno (Stine y Stine 1990) y una progresiva desecación ambiental que habría comenzado hacia los 2.500/2.000 años A.P. (González 1992), intensificado hacia los 900 años A.P. con el desarrollo de la denominada Anomalía Climática Medieval (1.150-600 años calendáricos A.P. - Stine 1994- ). Estas condiciones implicarían cambios en la distribución de los recursos críticos de Patagonia, como el agua, por lo que necesariamente se habrían generado cambios en la movilidad de los grupos cazadores-recolectores. Así, durante los periodos de menor humedad se 
privilegiarían para el asentamiento los espacios con una alta disponibilidad de agua, recursos faunísticos, leña, y reparos, como las cuencas bajas. Este proceso de reducción de la movilidad residencial, ausente en momentos previos, habría llevado a la formación de núcleos de poblaciones en determinados sectores ambientales, a partir de los cuales se desarrollarían movimientos logísticos y estacionales hacia otros sectores -cuencas lacustres altas o mesetas- para la obtención de recursos específicos, como materias primas y presas (Goñi y Barrientos 2004; Goñi 2010).

En la meseta central los estudios palinológicos y sedimentológicos de la localidad Los Toldos, sugerirían igualmente condiciones climáticas más áridas a semiáridas para este período (Cardich 1977); hipótesis sustentada con los conjuntos faunísticos analizados de la Cueva 3 (Miotti 1998/98).

Por otro lado, la alta frecuencia de cronologías posteriores a los 2.000 años A.P. hasta momentos históricos en cuencas lacustres bajas, evidenciaría la acentuada ocupación para este bloque temporal (Goñi 2010). Este reacomodamiento territorial estuvo relacionado con el incremento de las poblaciones para ese entonces, junto con los cambios ambientales, que ocasionaron modificaciones en características organizativas de las sociedades cazadoras recolectoras (Borrero 1998; Bellelli et al. 2008; Goñi et al. 2000; Belardi y Borrero 1999; Belardi et al. 2010).

En otros sectores como el Lago Argentino, fue registrado un marcado descenso de la intensidad de las ocupaciones, posiblemente vinculado con la denominada Pequeña Edad de Hielo (Borrero y Franco 2000; Cassiodoro et al. 2013).

Los cambios identificados en las representaciones rupestres, incremento en la frecuencia de aparición de los motivos de "pisadas" hacia otros territorios, corresponderían a marcadores culturales como parte de la identidad grupal. Esto habría surgido debido a la presión demográfica y a la competencia intergrupal que caracterizó este período. Los territorios corresponderían a espacios abiertos a otros grupos humanos, pero habrían sido marcados mediante representaciones rupestres, lo que habría permitido una apropiación simbólica del espacio (Belardi y Goñi 2006; Carden et al. 2009).

El período de contacto hispano-indígena (siglo XVI) estaría, caracterizado por la etapa de saturación del espacio, siguiendo el modelo de poblamiento propuesto (Borrero 1994-95; Miotti y Salemme 2004). Este período estaría caracterizado por una reducción en la movilidad residencial de los grupos e incremento de las partidas logísticas para la obtención de diferentes recursos (Miotti 1998; Goñi 2010). La incorporación del caballo como elemento primordial en la vida de estos grupos (caza, movilidad, cueros y 
elementos de intercambio), generó cambios sustanciales. Siguiendo las fuentes etnohistóricas Antonio de Viedma [1783] 1972, señala que la población local de San Julián realizaría traslados hacia el norte, sur y oeste para intercambiar sus mantas de cuero o quillangos, plumas de ñandú, entre otras cosas, por caballos y artículos manufacturados por otras comunidades u obtenidos por las mismas de los europeos (Buscaglia 2011).

Siguiendo lo propuesto por Miotti y Salemme (2004) la etapa "final" de estos grupos cazadores-recolectores, se habría dado por múltiples factores ambientales, junto al impacto generado por el choque entre diversas culturas; mientras que para otros (Goñi 2010; Goñi et al. 2000), factores ambientales como una mayor aridización del paisaje, habrían generado retracción de estas sociedades a lugares de concentración de recursos en momentos anteriores a la llegada de los europeos. 
CAPÍTULO 4

Marco de referencia

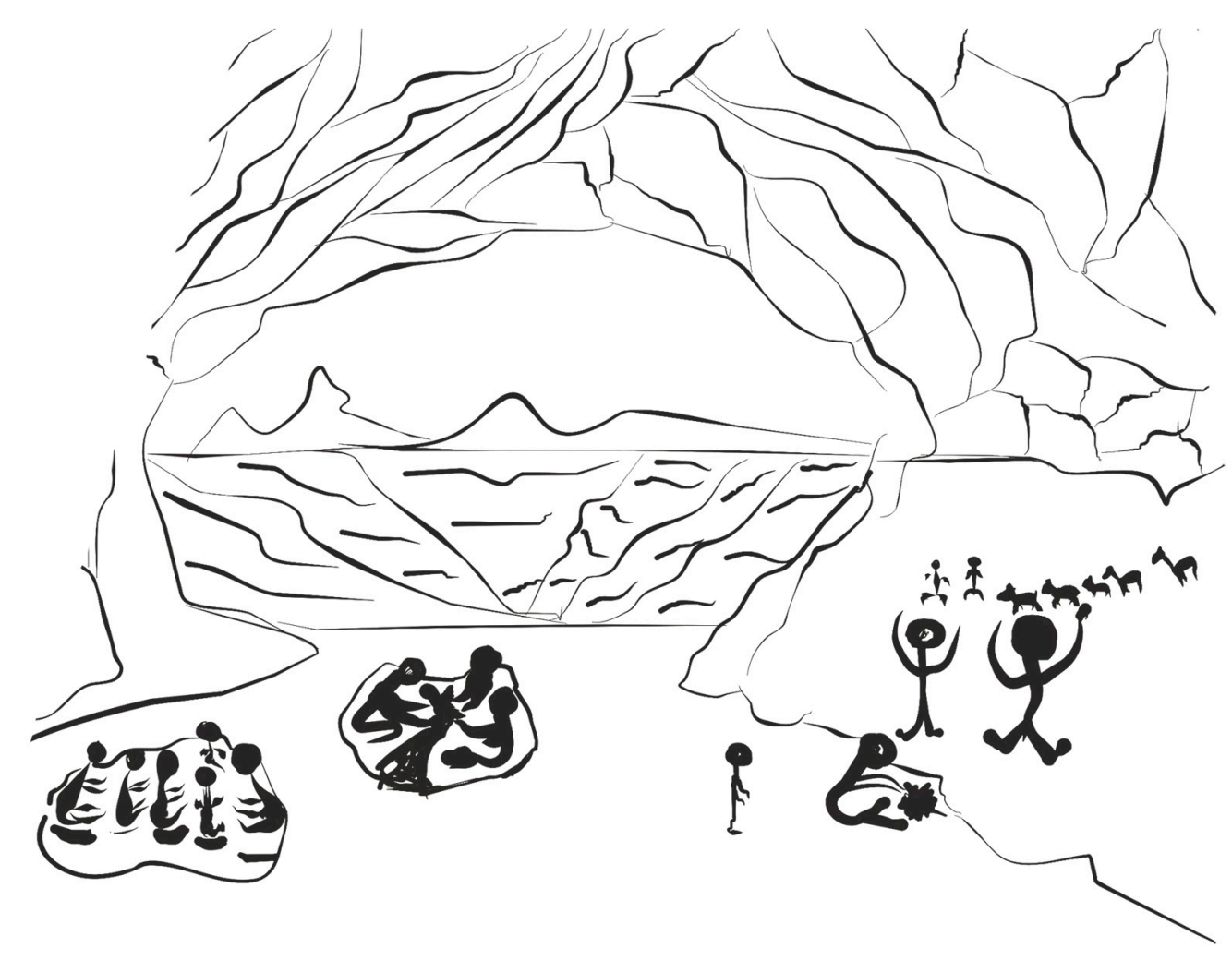





\section{INTRODUCCIÓN}

El estudio de la organización tecnológica de grupos cazadores-recolectores que habitaron el Macizo Central de Santa Cruz, desde el Pleistoceno final hasta el Holoceno Tardío, permite abordar otras cuestiones relacionadas con el rango de movilidad y distribución en relación a un ambiente determinado. Los distintos diseños expresados en la tecnología lítica, han sido una vía de acceso para comprender estas cuestiones de índole más general. El estudio del uso de los artefactos líticos en relación con el diseño de una determinada tecnología, permite indagar acerca de la funcionalidad de los sitios y del espacio en un bloque temporal determinado.

Desde los inicios de la arqueología en nuestro país y especialmente en el sector patagónico, el estudio de grupos humanos que habitaron esta región, ha sido llevado a cabo desde distintos enfoques y marcos de referencia. Sin embargo, en las últimas décadas y aún en el presente, los lineamientos teóricos han delimitado el estudio de la tecnología lítica a propuestas de índole procesual influenciada por conceptos ecológicos evolutivos. No obstante, otras líneas de investigación han permitido introducir nuevas propuestas para comprender los modos de vida de sociedades cazadoras-recolectores; ampliando el espectro hacia nuevos interrogantes y metodologías (Estévez y Vila 1996; Mansur 1999; Briz 2004; Briz y Vietri 2011).

\section{IV.1. Organización de la tecnología lítica.}

A partir de la década del 80 'el análisis de la tecnología lítica desarrollada por las sociedades del pasado experimentó cambios teóricos- metodológicos que impactaron en las capacidades interpretativas de la arqueología como disciplina. Hasta ese entonces los estudios tipológicos, eran considerados como un subsistema aislado en relación con el desarrollo social (Pfaffenberger 1988, 1992), ideas que fueron paulatinamente abandonadas en pro de una mayor interacción entre ambos.

Esto produjo un cambio en la interpretación de la tecnología desde distintas perspectivas teóricas y como generadora de cambios indispensables para comprender las estrategias llevadas a cabo por las sociedades del pasado, que a la vez, constituía un 
marcador de las relaciones sociales. De esta manera, la tecnología fue concebida como un fenómeno complejo compuesto por múltiples dimensiones interrelacionadas entre sí, como la economía, la política y la ideología (Nelson 1991; Pfaffenberger 1992; Dobres y Hoffman 1994; entre muchos otros).

En este sentido, la manufactura, uso y descarte de los instrumentos posee una connotación social que se relaciona con el quehacer cotidiano y con las relaciones sociales que de allí se generan; siendo por lo tanto, fundamental para comprender y analizar los cambios, innovaciones y transformaciones que ocurren en distintos aspectos de la organización social (Álvarez 2003; Briz et al. 2013).

La arqueología trabaja con objetos tangibles, que en cierta medida hacen interpretable las relaciones sociales entre los seres humanos y entre estos y la naturaleza (Jones y Boivin 2010). La cultura material es un buen indicador de esta relación y del estado de la misma; y en este sentido, los objetos arqueológicos, no son meros productos pasivos, sino posibles determinantes que habilitan gestos, pensamientos y acciones y que marcan el rumbo de nuevas manos y pensamientos, como punto de partida del conocimiento que colabora activamente a construir (Gosden y Marshall 1999; Jones 2002; Lull 2005). Los artefactos como productos materiales de comportamientos de una sociedad determinada, se relacionan estrechamente con las estrategias de organización empleadas por la misma. En este sentido, los artefactos líticos pueden ser entendidos como entidades morfológicamente dinámicas a través de su vida de uso, y el continuo cambio morfológico de estos, se encuentra en estrecha asociación con las necesidades de los individuos que los usan. Es así que, las interpretaciones generadas a través de los mismos, podrán ser más productivas si se considera el contexto y la situación para la que fue hecho, usado, modificado y descartado un determinado artefacto (Andrefsky 2009).

La tecnología lítica es parte de una organización tecnológica y se refiere a la forma en que los artesanos y quienes usan los artefactos, organizan sus vidas y actividades en relación con estas. La forma en que los artefactos son diseñados, producidos, reciclados y descartados, se encuentra en estrecha relación con las prácticas de uso de una sociedad determinada, que a su vez, está íntimamente relacionada con el medio y las estrategias de explotación aplicadas a los recursos disponibles en ese medio (Torrence 1983; Koldehoff 1987; Nelson 1991; Carr 1994; Andrefsky 2006).

Siguiendo a Nelson, se entiende como organización tecnológica “...the selection and integration of strategies for making, using, transporting, and discarding tools, and the 
materials needed for their manufacture and maintenance..." (Nelson 1991: 57). Dichas estrategias constituyen etapas cruciales para entender la organización y complejización de la tecnología, conformando de este modo la base para establecer la dinámica del comportamiento tecnológico.

Sin embargo, esto es algo más complejo, no solamente en relación a la producción de los artefactos líticos, sino también, en cuanto al uso del espacio que conlleva a la formulación de distintos modelos de estrategias aplicadas por sociedades del pasado. Los análisis funcionales de artefactos y los estudios vinculados con las reconstrucciones paleoambientales han ayudado en esta cuestión, permitiendo esclarecer algunas de las numerosas preguntas respecto al comportamiento de los grupos humanos en el pasado (Mansur 1999, Mansur y Lasa 2005, Álvarez 2004; Álvarez y Briz 2006, Leipus 2006, Miotti et al 2011, Cassiodoro et al. 2013, Flegenheimer et al. 2013; Weitzel y Gonzalez 2012, entre otros autores).

\section{IV.1.1. Estrategias Tecnológicas}

El trabajo de Binford $(1969,1973,1979,1980)$ abrió paso al estudio de la tecnología desde una perspectiva organizativa que fue definido y discutido por diversos autores (Andrefsky 1994,1998; Bamforth 1986; Bousman 1993; Kelly 1988; Koldehoff 1987; Nelson 1991; Carr 1994a, 1994 b; Odell 1996; Torrence 1989). De acuerdo con Binford, la organización tecnológica puede ser entendida "in terms of strategies that are responsive to concrete situational variables" (Binford 1979:255). En términos generales, los instrumentos responden a las estrategias implementadas y son considerados como un medio para resolver problemas: "Tools are not ends in themselves but are used by people as part of a larger strategy for coping with their social and physical environment" (Torrence 1989). Estos problemas pueden referirse a cuestiones de escasez, accesibilidad o predictibilidad de recursos. Sumado a otras cuestiones de índole simbólica y social como el prestigio (Hayden 2009) o las restricciones de acceso a un recurso determinado (tabúes).

Las estrategias mencionadas por Binford (1979) se refieren a dos tipos; la conservada y expeditiva y Nelson (1991) agrega una más, la oportunista. Los conceptos de conservado y expeditivo caracterizan a las dos estrategias tecnológicas más utilizadas para explicar el producto material que resulta de la implementación de las mismas. En cuanto a las dos primeras se refieren a las estrategias de mantenimiento de los artefactos 
líticos incluyendo manufactura elaborada, transporte, reconformación, ocultamiento y almacenamiento. La primera estrategia se diferencia de la expeditiva, a partir de la disponibilidad de materia prima para confección y uso en el mismo lugar, en momentos donde las condiciones lo requieran. En este caso se invierte mayor tiempo en la manufactura de los artefactos favoreciendo el momento de aprovisionamiento (Binford 1973, 1976, 1979). Bamforth (1986) a su vez caracteriza los artefactos en relación al tipo de estrategia establecida por los grupos. Siguiendo a este autor, los conjuntos que representan una estrategia de tipo conservada, serían conjuntos tecnológicamente refinados, diferentes morfológicamente y con artefactos individuales empleados para varios propósitos. Mientras que los relacionados a una estrategia de tipo expeditiva, corresponderían a utensilios manufacturados, usados y descartados según las necesidades del momento; conjuntos líticos tecnológicamente más sencillos y morfológicamente menos pautados o estandarizados (Binford 1979). Mientras que las estrategias oportunísticas contrastarían, con la expeditividad, ya que en este último caso, se trata de un comportamiento no planeado que responde a condiciones inmediatas (Nelson 1991).

Siguiendo las reflexiones de Nelson (1991), los criterios establecidos por Bamforth (1986) se refieren más al tipo de diseño establecido que a una estrategia tecnológica. La diversidad de actividades aplica a un diseño versátil, mientras que el reciclado a un diseño flexible (sensu Nelson 1991). Por lo tanto, estos diseños constituyen respuestas a diferentes condicionamientos o estrategias para utilizar el ambiente y no son criterios que posibiliten la definición de conservación (Nelson 1991).

En los últimos años, en nuestro país se reavivó la discusión sobre la operatividad de aplicar estos conceptos (organización tecnológica, conservación y expeditividad) en relación al registro arqueológico (Bayón et al. 1995, 2001; Escola 2004). El comportamiento relacionado con la selección de las estrategias implementadas es atribuido a diversas variables y se basa en la evaluación de los costos involucrados en el uso eficiente del tiempo, energía y recursos, como por ejemplo, disponibilidad de materia prima, localización de fuentes de aprovisionamiento, manufactura, transporte y movilidad, variando el énfasis puesto en cada variable (Bamforth 1986; Binford 1979; Kelly 1992, 1999; Torrence 1989). Sin embargo, no es conveniente ni productivo realizar una separación terminante entre las estrategias y menos aún, considerar a todo el contexto de un sitio bajo un solo tipo de estrategia. Estas deben considerarse opciones 
de planificación para un medio físico y social determinado, evidenciando la complejidad del registro arqueológico.

\section{IV.1.2. Estrategias del diseño}

A partir de la definición de estas estrategias tecnológicas, otro aspecto igualmente importante corresponde al diseño establecido de los artefactos que conforman la tecnología lítica. El diseño se refiere a variables conceptuales de utilidad que condicionan las formas de los instrumentos y la composición de los equipos (Nelson 1991). La identificación de las distintas variables de diseño en los conjuntos artefactuales líticos, permite una mejor interpretación de las estrategias tecnológicas implementadas por las poblaciones pasadas.

El modelo propuesto por Nelson, toma en cuenta cinco variables para hablar de diseño: confiabilidad, mantenibilidad, transportabilidad, flexibilidad y versatilidad (Nelson 1991).

Mientras que, para Bleed (1986), el diseño es una variable que puede ser cambiada de acuerdo a su eficacia o utilidad y tiene en cuenta los diseños alternativos para optimizar la disponibilidad de cualquier sistema técnico: confiables "reliability" y mantenibles "maintainability", los cuales tienen diferentes aplicaciones óptimas y características físicas. En el primer caso los instrumentos son confeccionados para el momento de necesidad, mientras que en el segundo pueden ser hechos fácilmente para cumplir con la función ante una eventual fractura o en el caso de que no sean apropiados para realizar las tareas manualmente.

Un diseño confiable puede presentar como caracter el sobrediseño (Bleed 1986), esto se refiere a que determinadas partes del artefacto contarán con refuerzos para facilitar la incorporación de enmangues. Tal es el caso de la morfología del pedúnculo que se observa en puntas de proyectil o en palas y/o azadas. Este caracter le otorga confiabilidad justamente a partir de estos sectores sobrediseñados o fortalecidos; no solamente en el caso de la presencia de enmangues, sino también, como refuerzo extra ante posibles roturas generadas por la fuerza producida durante su utilización.

Otra característica de la confiabilidad de un artefacto, corresponde a que estos, son elaborados por especialistas quienes poseen los conocimientos adecuados para lograr el producto final aplicando las técnicas necesarias de manufactura (Bleed 1986). 
Por otro lado, un diseño mantenible, se trata de aquel que puede ser hecho o modificado para multipropósitos (Bleed 1986). En este sentido, corresponde al diseño flexible en los términos de Nelson (1991), quien también lo distingue a partir de instrumentos que mantienen una forma generalizada, es decir, que no cambian la forma para satisfacer una variedad de necesidades, en este último caso los denomina diseños versátiles. La mantenibilidad, para Nelson, se obtiene en el costo de tiempo invertido en la manufactura y uso.

Este mismo autor plantea que la falta de disponibilidad de rocas influye directamente sobre el diseño de núcleos y utensilios y condiciona secundariamente el mantenimiento y el reciclamiento de los artefactos. En contra posición, Bamforth (1986) formula que es el principal factor que influye en la organización tecnológica y, por ende, los artefactos serán mantenidos y/o reciclados sólo cuando la provisión de materia prima escasee.

No se puede dejar de reconocer la importancia del trabajo de Bleed, sin embargo, las categorías de diseños confiables y mantenibles estuvieron fuertemente ligadas al modelo forager-collector, lo que generó un esquema simplista e insuficiente para explicar el amplio rango de variabilidad que presenta el registro arqueológico (Escola 2004). Es por esta razón, que fue discutido por varios autores (Bousman 1993; Carr 1994; Myers 1989; Torrence 1989) quienes consideraron que ambos diseños pueden ser alternativas viables en un mismo registro y por ende, dejar de ser vistas como categorías opuestas. En otro ámbito de discusión, se pone el acento en las dificultades relacionadas a la operatividad de las variables propias que definen el diseño y a los criterios establecidos (Hayden 1979; Hayden et al. 1996). Se considera que son conceptos sumamente abstractos y por esta razón, susceptibles a cierta subjetividad a la hora de aplicarlos en el registro arqueológico. Frente a este problema, el manejo de conceptos más generales o abarcativos pueden ser una buena solución a este dilema.

El concepto de instrumentos formales e informales en relación con las estrategias conservadas y expeditivas, formuladas por Andrefsky (1994) pueden ser un ejemplo de estas categorías. En este sentido, los instrumentos informales se vinculan con una tecnología expeditiva/oportunista y los define como artefactos simples, con poca inversión de energía y tiempo en cuanto al trabajo de aprovisionamiento y producción, sin un patrón formal en su diseño. Estos se encuentran manufacturados, utilizados y descartados en un corto período de tiempo (lascas no retocadas y algunos fragmentos bipolares). Por otro lado, los instrumentos formales, presentan una mayor inversión de trabajo en su manufactura, tales como los instrumentos retocados sobre lascas, bifaces y 
núcleos preparados (Andrefsky 1994). Sin embargo, algunas críticas a estos diseños se refieren a la inexistencia de gran esfuerzo en la manufactura de estos, junto con habilidades promedio para su elaboración; por lo que la expeditividad debería entenderse a partir de estudios tecnológicos más profundos.

Por otro lado, Escola (2004), intenta explicar en qué medida las estrategias expeditivas influencian el diseño de los artefactos y plantea la demanda funcional como un elemento condicional del diseño, el cual define como "utilitario". Este tipo de diseño toma en cuenta la utilización y/o formatización de biseles, ángulos de filos y morfología de los bordes, que permiten hacer frente a las distintas necesidades con poca inversión de trabajo en la manufactura. Incluiría manufacturas de filos simples capaces de ajustarse a un espectro funcional más amplio y bordes orientados a funciones específicas (Escola 2004).

Las actividades de manufactura, uso y descarte tendrían lugar en el contexto de uso, siendo poco frecuentes las tareas de mantenimiento y reparación, haciendo referencia a los conceptos de uso y demanda funcional (Escola 2004). Sin embargo, los trabajos referidos a estos puntos de interés, no se basaron en análisis funcionales de base microscópica para dar un mayor sustento a estas afirmaciones. Teniendo en cuenta, que un artefacto lítico se convierte en instrumento cuando va unido a una técnica en un contexto social determinado, generando una transformación en la materia sobre la cual actúa (Ingold 1997). En este sentido, el análisis de la organización tecnológica debe abordarse, como las técnicas que intervienen en la obtención, producción y consumo de recursos en donde los instrumentos participan como instrumentos de trabajo (Álvarez 2003; Briz et al. 2013).

\begin{tabular}{|c|c|}
\hline Estrategias de diseño & Características principales \\
\hline Bleed (1986) & $\begin{array}{l}\text { Confiables: } \\
>\text { Actúan cuando es necesario. } \\
>\text { Presentan elementos sustitutos seguros } \\
\text { (sobrediseño, construcción robusta, partes } \\
\text { reforzadas). } \\
>\text { Con reemplazos de emergencia sencillos y } \\
\text { estandarizados. } \\
\text { Mantenibles: } \\
>\text { Livianos y transportables, para ser } \\
\text { rápidamente modificadas o reparadas. } \\
>\text { Diseños modulares con recambio fácil de los } \\
\text { componentes dañados. }\end{array}$ \\
\hline
\end{tabular}




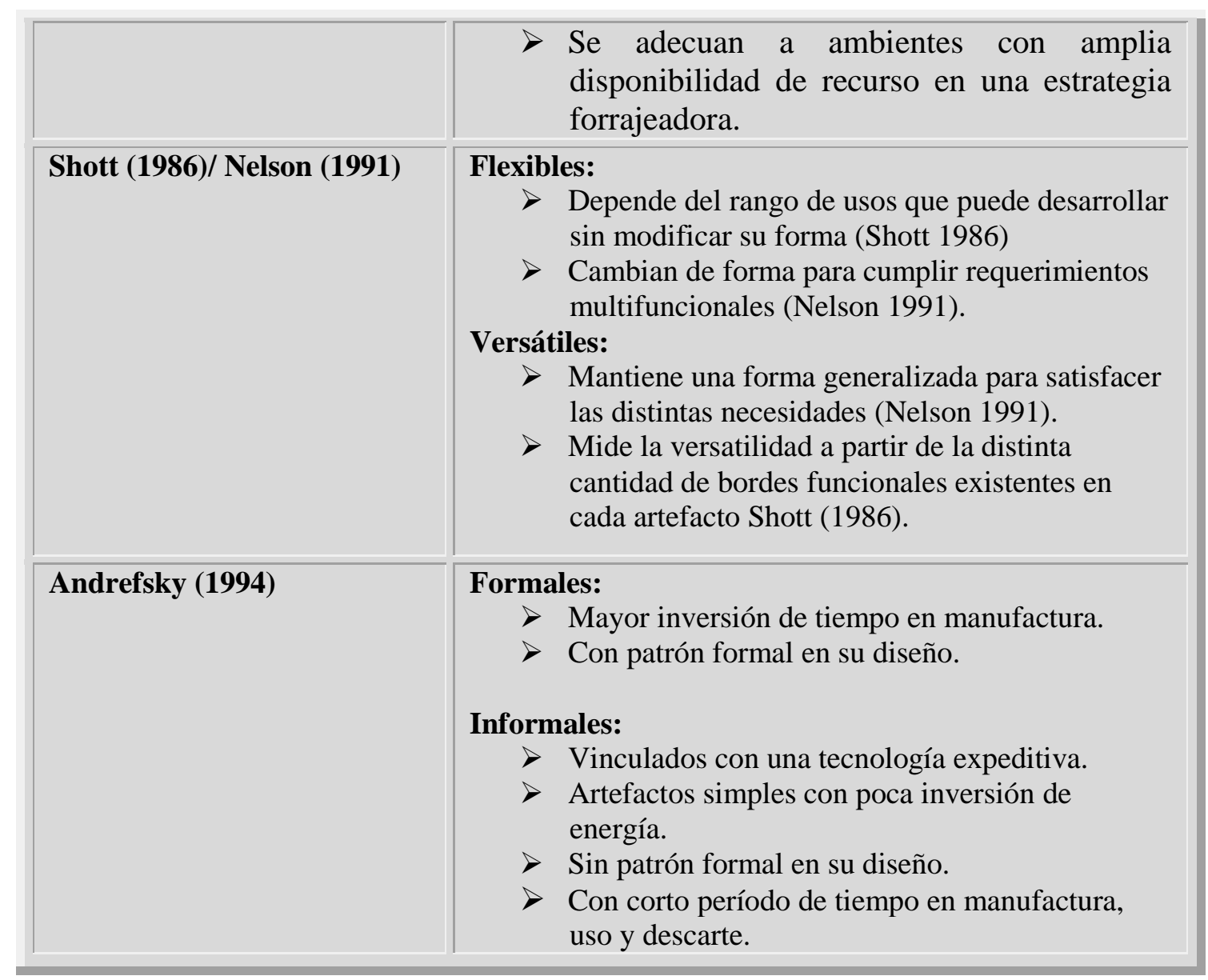

Tabla 1: Tipos de diseño artefactual definido a partir de las estrategias tecnológicas observadas.

\section{IV.2. Organización del espacio}

La distribución espacial del registro arqueológico es el producto de una continua modificación del paisaje; en función de la práctica social a lo largo del tiempo y el espacio (Torrence 1986; Criado Boado 1993 y Parcero Oubiña et al. 1998).

Las comunidades humanas transforman los espacios físicos llenos de contenidos mediante actividades diarias, creencias y sistemas de valores; transformando un sector del ambiente en paisaje humanizado (Binford 1982; Deetz 1990; Criado Boado 1993; Saunders y Hobbs 1994; Ingold 2005; Magnin 2012; entre otros). Así, las acciones humanas, se encuentran expresadas a partir de un determinado ordenamiento de los restos materiales y la utilización diferencial del espacio podrá ser observado en el registro a partir de su distribución, continuidades o discontinuidades. La formación de sitios incluye no solamente los remanentes materiales y/o simbólicos de las acciones humanas, sino también la multiplicidad de procesos naturales que afectan y modifican el 
registro (Schiffer 1987; Burroni et al. 2002). En este sentido, el registro arqueológico es considerado como un continuo y su estructura entendida a partir de la variación en la densidad artefactual (Foley 1981).

Un sitio puede ser definido como una significación de la expresión material de acciones generadas en el pasado por grupos humanos, de límites observables y definibles. Estas unidades empíricas que define el arqueólogo en el desarrollo de su disciplina, pueden indicar un sólo evento ocupacional o bien numerosas ocupaciones y se encuentran enmarcadas en un espacio limitado por el propio accionar humano.

Los sitios como cuevas, aleros o abrigos rocosos son lugares propicios y de buena conservación para el material arqueológico; ocupados por los grupos humanos como un elemento más dentro del paisaje (Paunero 2003). Ahora bien, ¿Cómo se entiende el paisaje? y ¿Cuáles son sus límites? En este sentido, el paisaje no es meramente el mundo que vemos sino una construcción, composición de ese mundo (Cosgrove 1985). Con respecto a una unidad cultural específica, representa "... una manera en la que se ha expresado, a ellos mismos y a su mundo, mediante relaciones con la naturaleza, y mediante el cual ha subrayado su propio papel social, y el de otros, con respecto a la naturaleza externa..." (Cosgrove 1985). Este paisaje, como constructo de las poblaciones humanas y medio en el que estas mismas poblaciones sobreviven y se sustentan, implica la existencia de un patrón, en un contexto interior al lugar como así también entre lugares (Binford 1982; Deetz 1990; Hubert 1994).

Las pautas observables en los restos materiales, al igual que en espacios vacíos, vienen dadas de las interacciones entre el dominio de lo culturalmente organizado, la distribución de los recursos y el espacio vital no culturalmente organizado (Binford 1983).

Los paisajes son principios organizados fundamentales para la forma y estructura de la actividad de los pueblos: como constructos materiales que transmiten información y como documentos históricos (Hugill and Foote 1995). Son construcciones dinámicas en el sentido que cada comunidad y cada generación impone su propio mapa cognitivo de un mundo, antropogénico e interconectado, de morfología, planificación y significado coherente (Parcero Oubiña et al. 1998).

Definido el paisaje como un proceso cultural, podemos decir entonces que el mismo se conforma como objeto de estudio arqueológico, al igual que los restos materiales dejados por la actividad humana en el pasado. Es el estudio del paisaje el que adquiere significación a través de una nueva forma de concebir un conocimiento profundo de 
todos los aspectos de una sociedad que cambia a lo largo del tiempo, proceso que se ve reflejado en el territorio que ocupa y la forma en que lo explota o usa.

\section{IV.3. Funcionalidad de los sitios}

El acercamiento desde la organización de la tecnología es una de las vías que permite evaluar y explicar la variabilidad tecnológica y su vinculación con otros aspectos de la organización de los grupos humanos, entre ellas la subsistencia, la movilidad y las estrategias sociales.

La función de un sitio puede ser definida a partir de la identificación de las actividades llevadas a cabo en este y su relación con el paisaje y los recursos disponibles en él. Las decisiones tomadas en relación a la disposición de estos recursos y a las actividades desarrolladas por los grupos humanos, son variables determinantes en la adopción de un patrón de asentamiento y dependerán en primera instancia, del funcionamiento de una sociedad determinada. Esta disposición en el espacio, referente a las características intrínsecas de una sociedad y a los recursos disponibles, permite una estructuración del espacio a escala macro o microregional.

En este sentido, sería esperable para bases residenciales, un conjunto de actividades diversas con patrones espaciales heterogéneos y complejos, donde sectores del sitio estarían destinados a actividades específicas, mientras que para campamentos de corto lapso ocupacional se esperaría un rango de actividad menor, con una sola ocupación corta o múltiple superpuesta. Por otra parte, los sitios de uso limitados, representarían una sola actividad con ocupaciones muy cortas (Bamforth 1992). Por lo tanto, la funcionalidad de un sitio puede ser determinada teniendo en consideración dos puntos de partida; como un todo y de allí, en relación con el paisaje circundante. La variabilidad macroscópica de un artefacto lítico permite determinar la funcionalidad de un sitio, sin necesidad de la observación individual de un artefacto o de cada filo en particular. Sin embargo, el uso al que fue destinado ese artefacto, solo puede ser abordado a partir del estudio de cada artefacto en particular y cada filo individual, esto puede ser llevado a cabo a partir del análisis funcional microscópico, concretizando la relación entre los grupos que habitaron en el pasado y ese espacio construido a través de la adquisición y uso de los recursos disponibles en el mismo (Álvarez 2003). 


\section{IV.4. Marco de referencia metodológico}

La naturaleza "dinámica" de los instrumentos y artefactos líticos fue por mucho tiempo reconocida y trasladada directamente a partir de la analogía etnográfica, siendo innecesario el avance del estudio de este aspecto en la arqueología. La fijación de tipos a partir de rasgos morfológicos, determinó categorías idealistas acerca de la supuesta funcionalidad de los artefactos (Dunnell 1992; Adams et al. 1998).

La problemática fundamental de la construcción de estos "tipos", es la carga subjetiva de los mismos, ya que no son el reflejo real de la cultura de un grupo determinado, sino modelos construidos por el arqueólogo de acuerdo a su imagen de cultura y a su historia particular (Lumbreras 1981). En este sentido, el registro se produce y/o traduce en base a una concepción estática e incapaz de reconocer la naturaleza dinámica del registro arqueológico, debido a la necesidad de una coherencia respecto a su carga teóricametodológica (Argelés et al. 1995; Bate 1998; Estévez y Vila 2000).

Con la aparición de los métodos de datación independientes, el análisis de los artefactos tallados fue restringido, hasta ese entonces a un mero acto clasificatorio, siendo posteriormente cuestionado y dejado de lado abriendo paso a una concepción dinámica de la cultura material (Briz 2007; Vila y Estévez 2000).

La necesidad de los arqueólogos por incorporar una concepción dinámica de los artefactos líticos tallados, permitió el desarrollo de trabajos acerca de la identificación funcional de dichos instrumentos. De la mano de obras como la de Semenov (1964) Tecnología Prehistórica, traducida al inglés en 1981, generó un campo de investigación que permitió contrastar las interpretaciones morfo-funcionales que hasta ese entonces incluían la mayoría de las interpretaciones de las sociedades prehistóricas. El poco cuestionamiento de las categorías básicas que se habían formulado para el análisis lítico hasta ese entonces, produjo que los resultados obtenidos a partir del análisis funcional debieran incorporarse a las clasificaciones preexistentes, observándose que un gran número de artefactos no retocados habían sido utilizados como instrumentos (Juel Jensen 1988; Vila 1986; Álvarez 2003; Briz 2002, 2004). La tipología tradicional en base a criterios morfológicos había identificado determinados instrumentos que bajo los criterios de forma-función quedaban sin sentido, por lo que fue necesario replantear el concepto de instrumento y rastros de talla, debido a la presencia de varios artefactos que carentes de retoques habían sido utilizados. 
Es a partir de este tipo de análisis, que varios autores se han atrevido a pensar en recuperar la dinámica de las sociedades pasadas, materializada en el registro arqueológico, pero teniendo siempre presente métodos lógicos y objetivos concretos formulados teóricamente.

Todo elemento constituyente de la materialidad arqueológica, es en última instancia, la materialización de relaciones sociales de producción y consumo, que son base inicial para la construcción de toda relación social ulterior (Briz 2007).

Siguiendo los conceptos de este autor, la arqueología tiene por objetivo explicar las formas de organización socio-económica que se desarrollaron en el pasado, con sus específicas condiciones históricas, así como el proceso histórico del que ellas son causa y consecuencia (Barceló 1981; Argelés et al. 1995; Clemente et al. 1996; Briz 2004; Lull 2005). Es así que todo instrumento de producción, corresponde a un producto final del proceso de producción y también a un valor de uso que se incorpora, al ser empleado (consumido), como instrumento de producción, en un nuevo proceso productivo (Briz 2002; Clemente et al. 1996).

¿Pero, cómo es posible a partir del registro arqueológico recuperar las formas de organización socio-económicas que se desarrollaron en el pasado, en un momento histórico particular? Para esto es necesario implementar metodologías que incluyan como objeto de estudio la dinámica social que se encuentra materializada en el registro arqueológico.

El análisis de base microscópica, ha abierto una puerta hacia el dinamismo de las sociedades del pasado. De acuerdo a Semenov, la forma y la función de un instrumento son la materialización concreta de producción y consumo, la morfología es el producto final del proceso de producción, mientras que la función, es la materialidad resultante en el instrumento empleado (Semenov, 1981). Los rastros de uso dejados en el instrumento, nos dan un indicio del objeto trabajado (materia trabajada), como así también del trabajo efectuado (movimiento, cinemática y energía), generado mediante el instrumento de producción, es en este sentido entonces, que corresponden a la materialidad del trabajo (Semenov 1981 en Briz 2002).

El contexto de uso de un instrumento no debe ser dejado de lado, la cinemática (movimiento desarrollado durante el trabajo), la naturaleza y el estado del material trabajado, el orden espacio-temporal (actividades cotidianas o especiales) y el conocimiento o habilidades de una sociedad, deberán ser tenidas en cuenta para un 
análisis detallado de la sociedades humanas del pasado (Álvarez, 2003, Briz et al. 2013).

Esta metodología, de la mano de la analogía etnográfica indirecta y acompañada de la arqueología experimental, provee elementos ricos y provechosos para generar hipótesis sobre la cinemática del trabajo y las modalidades de procesamiento de los recursos: las huellas dejadas en lo instrumentos, esquirlamientos, estrías y micropulidos, permiten entender el comportamiento humano (dinamismo) del pasado.

Los esquirlamientos se identifican con fracturas microscópicas de los filos y se tiene en cuenta su continuidad, terminación y morfología. Este rastro permite determinar la dureza del material trabajado y en alguna medida el movimiento del trabajo efectuado. Las estrías corresponden a rasgos lineales que se producen como consecuencia del material trabajado, dan información acerca de la cinemática efectuada durante el trabajo. Mientras que los micropulidos, visibles a partir de un microscopio metalográfico, son porciones de la superficie de la roca que reflejan la luz incidente de un modo diferente al resto, generados por el calor, la fricción y la humedad del trabajo realizado, sumado al material que se desprende, transformándose en un gel de Sílice (Semenov 1964; Keeley 1978, 1980; Anderson-Gerfaud 1980, 1981; Voughan 1981, 1985; Mansur-Franchomme 1981, 1983, 1986, 1990).

El fundamento del análisis funcional de base microscópica, se basa en que durante el uso de un instrumento se producen alteraciones de diversos tipos en la zona activa que está en contacto con el material trabajado; el análisis bajo el microscopio de dichas alteraciones brinda información sobre la cinemática del uso y el material en el cual se trabajó. Para que los postulados sean válidos es necesario reconocer qué tipo de huellas o rastros son dejados para cada uno de los materiales trabajados y de cada tipo de trabajo realizado, por lo que es de fundamental importancia un extenso programa experimental para realizar este registro.

Estos experimentos deben ser un conjunto organizado, sistemático y coherente, en donde se controlan las variables que intervienen durante el uso y las huellas que ello genera. El reconocimiento del uso en un artefacto se basa en la analogía de los rastros que presenta con lo observado en una pieza experimental (González Urquijo e Ibáñez Estévez 1994; 2003).

Por mucho tiempo, se realizaron numerosos trabajos y experimentaciones sistemáticas siguiendo esta línea de investigación (análisis funcional), pero varios de ellos se diferenciaban en cuanto a las técnicas de observación microscópica, lo que trajo como 
consecuencia dos líneas metodológicas distintas debido al equipo utilizado y por lo tanto también a los rastros de uso que se estaban observando (Castro de Aguilar 1994; Castro 1996a, 1996b).

En Estados Unidos se desarrolló la denominada escuela de bajos aumentos, que utilizaba como método de observación la lupa binocular, generando un fuerte desarrollo del trabajo experimental y el estudio de las fracturas de los filos utilizados (esquirlamientos) (Tringham et al. 1974). Por el otro lado, en Europa se había desarrollado una línea diferente que utilizaba como método de observación, el microscopio de luz incidente, por lo que su objeto de estudio se centró en la observación de micropulidos y estrías, acercándose un poco más hacia los postulados de Semenov. (Anderson-Gerfaud 1981; Keeley 1974; Plisson 1985, 1987; Mansur 1999)

A mediados de la década del 70', en el marco del análisis microscópico, estas dos orientaciones se denominaron "Low power approach" y "High power approach". En el primero los rastros de uso registrados fueron las microfracturas y los microlascados, denominados como "edge damage" y se consideraron los atributos como la morfología, distribución, delineación de sus terminaciones y las dimensiones. Esta perspectiva de análisis ha sido criticada por varias razones, dentro de las cuales podemos nombrar la gran variabilidad que presentan los atributos de los microlascados y microfracturas empleados como criterios diagnósticos (Mansur-Franchomme 1983; Vaughan 1981) y por la imposibilidad de diferenciar aquellos microlascados producto del uso de un artefacto con los producidos por factores naturales y tecnológicos (Anderson-Gerfaud 1981; Keeley 1980; Mansur-Franchomme 1981,1983).

El análisis de altos aumentos, adoptado por Keeley, se centra en el estudio de las estrías microscópicas y en los micropulidos, pero teniendo en cuenta los microlascados. Dentro de este marco uno de los aportes más importantes fue la explicación detallada de los procesos de formación de los micropulidos, en relación a la materia trabajada y la cinemática del trabajo, confeccionando para ello un estricto plan de trabajo experimental donde las variables controladas permitieron identificar 6 tipos de micropulidos (madera, piel, asta, carne, hueso y plantas no leñosas) (Keeley 1974, 1977,1980).

Desde la década del 80, estas dos perspectivas se comenzaron a utilizar de manera conjunta, puesto que sus diferencias, no se debían a un marco teórico distinto, sino a una diferencia de aumento en los instrumentos utilizados para la observación. No debiera existir ningún tipo de oposición entre la utilización de bajos o de altos 
aumentos, puesto que se trata de técnicas analíticas complementarias, destinadas a caracterizar diferentes tipos de rastros que deben su desarrollo a procesos diferente pero que la falta de su integración llevaría un incorrecta interpretación global de los datos (Mansur-Franchomme 1983; Castro 1994; Mansur 1999).

\section{IV.4.1. Los estudios funcionales en la actualidad}

El avance en los estudios de análisis funcional, ha permitido igualmente determinar residuos adheridos a las superficies de los filos utilizados. Estos pueden presentarse de dos maneras distintas, una adherida al filo y otro incluido dentro de la capa del micropulido (Briuer 1976; Shafer y Holloway 1979; Anderson 1980; Juel Hensen 1988; Mansur 1992, 1999; Castro 1994).

El análisis de estos residuos puede realizarse mediante el uso del microscopio electrónico de barrido (SEM), siendo numerosos los estudios focalizados en la morfología de estos residuos (Briner 1997: Shaper y Holloway 1979; Anderson, 1980), sin embargo son pocos los referidos al análisis químico, a excepción del análisis de sangre (Loy and Nelson 1986; Loy 1993; Hyland et al. 1990).

El método químico para la detección de residuos sobre la superficie de un instrumento, permite determinar la presencia de elementos cuya masa atómica sea mayor a 12 , realizando un análisis químico cualitativo de los elementos presentes en una muestra.

Rots y Williamson (2004) plantean algunas diferencias entre el análisis funcional de microrrastros y el estudio de residuos presentes en la superficie de los instrumentos trabajados, el análisis de residuos por sí solo no permite identificar el filo trabajado, puesto que los residuos en general están localizados en zonas alejadas del filo, lo que impide dicha identificación. Este problema podría ser solventado a partir de datos provenientes del análisis funcional, detectando esquirlamientos, micropulidos, y filos redondeados. En segundo lugar, la presencia de residuos por contacto accidental (por ej.: residuos de plantas), no asociado al verdadero uso del artefacto, puede provocar confusiones a la hora de analizar los datos, este inconveniente no se ha visto en los rastros de uso, puesto que estos están concentrados claramente en una zona particular del instrumento.

El tercer problema que plantean Rots y Williamson, en relación al tratamiento de residuos, se refiere a la conservación de los mismos, en especial los residuos orgánicos, por lo que la ausencia de residuos no siempre implica la falta de uso de un instrumento, 
ya que éste pudo haber sido removido luego de su uso. Por último, la presencia de residuos ha sido interpretada como la última etapa de uso de un instrumento, el problema se plantea con aquellos instrumentos que hayan sido utilizados sobre más de un material, instrumentos de uso múltiples han sido identificados a partir del análisis de residuos. Cada residuo tiene distinto patrón de distribución sobre la superficie del artefacto, las estrías en la superficie de un residuo persistente como la resina, puede indicar un segundo evento de uso.

Los residuos adheridos a la superficie pueden ser una nueva solución para recuperar información acerca del uso de los instrumentos y de las condiciones ambientales en las que estuvieron envueltos. Si es de origen inorgánico (mineral) más que orgánico, tiende a persistir por mayor tiempo en un medio ambiente cambiante, por lo que muchas veces este ambiente favorece la preservación del instrumento lítico y como consecuencia el residuo adherido al mismo (Jahren et al.1997)

Ambos métodos, el análisis de micropulidos a partir de un microscopio metalográfico y el análisis mencionado con anterioridad a partir del microscopio electrónico de barrido, son complementarios del análisis funcional de los conjuntos líticos arqueológicos, permitiendo descubrir con el tiempo, el medio ambiente y las estrategias de vida de una sociedad pasada, a partir del estudio de los artefactos manufacturados por la misma.

Si bien ambos métodos han servido para una mejor interpretación de los hechos prehistóricos, el análisis de microrrastros ha sido criticado por hacer uso de la analogía, puesto que sus interpretaciones se basan en ejemplos experimentales. Al igual que el método anterior, el análisis de residuos también incluye la analogía en sus interpretaciones debido a que se basa en análisis de similitudes morfológicas entre los residuos conocidos y los observados, por lo que ambos métodos enfrentan el mismo tipo de problema (Rots y Williamson, 2004).

Otra de las críticas que se le ha hecho al análisis de microrrastros es el tiempo que consume observar una pieza bajo el microscopio metalográfico, ya que cada pieza debe ser observada en su totalidad, puesto que pueden ser identificables huellas de enmangue, entre otras y esto lleva alrededor de una hora, pero la información obtenida en el análisis es tan rica que compensa dicha inversión de tiempo. 


\section{IV.4.2. Alcances de su aplicación en el registro arqueológico}

Los rastros de uso constituyen la evidencia material del proceso de producción y consumo, es en estos rastros que encontramos tanto el indicio del objeto de trabajo como el trabajo mismo, generado mediante el instrumento de producción (Briz 2004).

$\mathrm{El}$ análisis funcional permite generar información fundamental para determinar el uso específico de un sitio y procurar información sobre áreas en donde se desarrollaron actividades especializadas, la caracterización de los modos de uso de un artefacto permite arribar al verdadero concepto de "artefacto", como instrumento que interviene en la modificación y adquisición de las materias primas (Mansur- Franchomme 1983, Leipus 2006).

El análisis microscópico de los rastros de uso de un instrumento permite ver no solo las actividades que se desarrollaron dentro de un determinado sitio, sino también el modo en que se empleó cada instrumento, puesto que es posible determinar la presencia de mangos y la posible reactivación de un artefacto, permitiéndonos hacer inferencias acerca de una parte del dinamismo inmerso en el registro arqueológico.

También es posible plantear relaciones entre la diversidad artefactual de un conjunto arqueológico dado el verdadero uso de cada instrumento, aportando datos que permitan discutir la organización tecnológica de grupos prehispánicos.

Las evidencias del proceso de producción del artefacto (retoque, bulbo, etc.), como del proceso de consumo (instrumento), son las improntas materiales del trabajo, socialmente articulado (tecnología) que se desarrollan dialécticamente (Briz 2004).

Al igual que este último autor, concuerdo que la mejor forma de abordar el análisis de los conjuntos líticos es a partir de una integración de estudios (morfológicos y funcionales), apoyados por el desarrollo de la estadística para permitirnos desarrollar una mejor interpretación de los hechos. Desde lo morfológico, a partir de la obtención de datos que sistematicen nuestro conjunto lítico, mientras que desde lo funcional, datos que nos den información acerca del trabajo desarrollado por cada instrumento, permitiendo manifestar el dinamismo de las sociedades pasadas a través del registro arqueológico. Por lo tanto los tres enfoques de estudio de conjuntos líticos (tecnológico, morfológico y funcional), no deben ser considerados excluyentes entre sí, por el contrario, deben ser considerados complementarios para un correcto análisis de las sociedades cazadoras recolectoras del pasado. 
La tecnología puede ser entendida como el conjunto de conocimientos y actividades puestos en práctica en la realización material de los procesos de producción de bienes y de reproducción social. Ella implica explotación de recursos naturales y establecimiento de relaciones sociales para la producción y uso de los bienes que genera; puede ser la verdadera mediadora de la interrelación entre las sociedades y el medio ambiente (Mansur et al.2005). La tecnología comprende acciones físicas, realizadas por actores sociales, quienes están condicionados por un contexto social y natural determinado (Álvarez, 2003).

El estudio de las formas de producción y uso de los artefactos arqueológicos, debiera focalizar la comprensión global del funcionamiento de un sistema social (Mansur et al. 2005). El funcionamiento de una sociedad requiere de la explotación de recursos naturales, seleccionados, procesados y transformados para la confección de bienes, es decir para todo aquello incluido en la tecnología (Mansur et al. 2004), por lo que el estudio de los materiales líticos permite inferir técnicas de manufactura y uso que implican decisiones y selecciones dentro del marco del conocimiento social y hasta en determinadas ocasiones también en el campo de lo individual (Álvarez 2003).

Todo instrumento lítico recuperado de un contexto arqueológico, forma parte de una cadena que va desde la idea o concepción de un instrumento hasta su pérdida o descarte. A lo largo de esta cadena se van evidenciando gestos técnicos para la confección, transporte y modificación de la materia prima y posteriormente, para el uso del instrumento confeccionado a partir de dicha materia prima (enmangamiento, reactivación, reformatización, etc.), reflejando un sistema complejo de comportamientos económicos y sociales (Mansur-Franchomme 1987a).

Los procesos de producción y uso de los instrumentos líticos están condicionados no solamente por factores ambientales, sino también por selecciones y decisiones sociales, las cuales pueden determinarse en el registro arqueológico a partir del uso diferencial de materias primas líticas, técnicas de manufacturas y uso, reactivación, reutilización, modos de descarte, etc. (Álvarez, 2003; Álvarez et al. 2010). Estas decisiones y selecciones sociales, actualmente pueden evidenciarse en el registro arqueológico a partir del desarrollo del análisis funcional, de estudios tecnológicos que incluyan materias primas y técnicas de confección y del uso de conceptos tales como cadena operativa y secuencia de reducción, que si bien no constituyen más que herramientas metodológicas abren la puerta a otros aspectos de la vida de las sociedades cazadoras- 
recolectoras (movilidad, acceso y explotación de distintos recursos, sistema de asentamientos) que en muchos casos han sido dejados de lado. 

CAPÍTULO 5

\section{Metodología y técnicas de análisis}

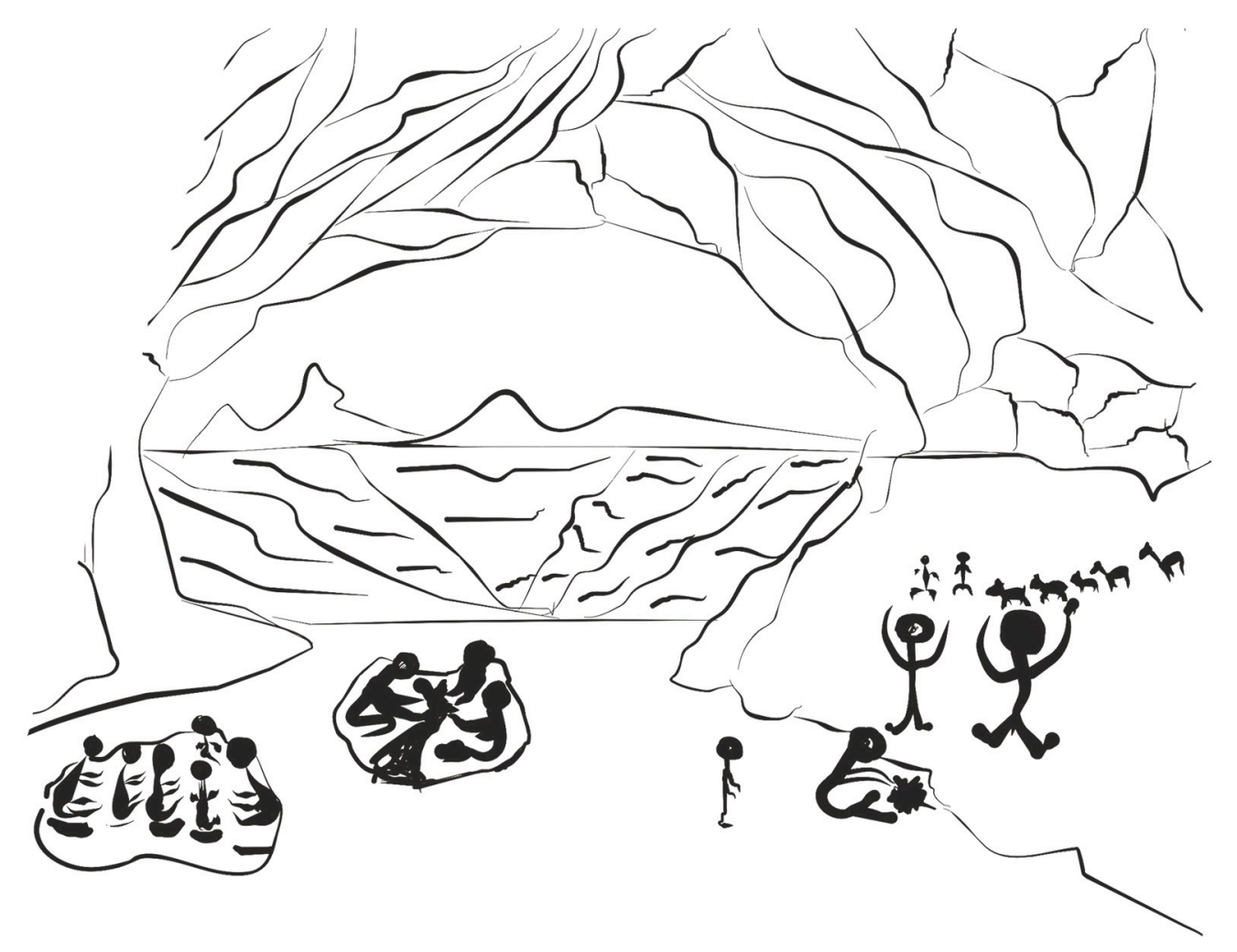





\section{MARCO METODOLÓGICO}

En este capítulo se presentan las estrategias metodológicas que guían la presente investigación al igual que las escalas espaciales y temporales utilizadas. La metodología de análisis funcional permite abordar la problemática del contexto de uso de los materiales líticos recuperados de diferentes sitios arqueológicos e inferir los usos específicos a los cuales fueron destinados, al igual que los modos de empleo utilizados por las sociedades en el pasado (Semenov 1964; Keeley 1980; Anderson-Gerfaud 1981; Mansur-Franchomme 1983; Castro 1994; Álvarez 2003; Leipus 2006). Esta metodología de análisis incluye diferentes etapas en su aplicación, las cuales pueden ser: 1) el reconocimiento de las características principales de los conjuntos líticos a analizar (materias primas utilizadas y tipos de artefactos), 2) confección de una serie experimental teniendo en consideración las características definidas con anterioridad, para indagar acerca de los principales factores que intervienen en la formación y deformación de los rastros de uso, a partir de atributos observables mediante diferentes medios ópticos y 3) observación y reconocimiento de los rastros generados por el trabajo realizado sobre diferentes materiales y estados (fresco, seco, estacionado, no estacionado) (Ver Apéndice), para posteriormente aplicar estos conocimientos a las colecciones arqueológicas.

\section{V.1. Escala espacial}

La escala de análisis en la que se trabajó incluyó como macro-área de estudio la meseta esteparia conocida como Nesocratón del Deseado, Macizo del Deseado o Altiplanicie Central, que se ubica entre los ríos Deseado y Chico, en la Provincia de Santa Cruz.

Mientras que como meso-escala en el sentido de Delcourt y Delcourt (1988) fue seleccionada la cuenca del Zanjón Rojo y Blanco en el sector noreste del Macizo central del Deseado como unidad espacial. Esta cuenca residual tiene una extensión aproximada de 140 kilómetros en sentido oeste-este y 80 kilómetros norte-sur y se localiza entre los

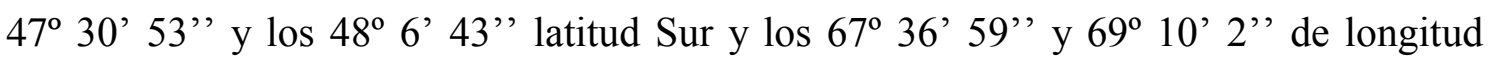
Oeste. 
De esta cuenca provienen los conjuntos líticos analizados procedentes de los sitios AEP-1 de la Localidad arqueológica Piedra Museo, en la cuenca baja del Zanjón Rojo y el sitio Cueva Maripe de la Localidad La Primavera ubicado en las cabeceras del Zanjón Blanco (Capítulo II, figura 1).

El paisaje analizado fue caracterizado mediante información obtenida a partir de la hoja geológica (Panza 2001), las cartas topográficas y datos obtenidos en campo acerca de recursos móviles o escasos como fuentes de agua.

\section{V.2. Escala temporal}

Los conjuntos líticos se agruparon para su análisis en cuatro rangos temporales: Transición Pleistoceno-Holoceno (ca.13.000-8500 años AP), Holoceno temprano ( $c a$. 8500 a 7500 años AP), Holoceno medio (ca. 7500-3000 años AP) y Holoceno tardío (desde ca. 3000 años AP hasta la actualidad). Para esto se tuvo en consideración indicadores cronológicos relativos y absolutos, estratigráficos, geomorfológicos y arqueológicos (Cattáneo 2002; Miotti y Cattáneo 1997; Miotti y Salemme 2004; Miotti et al. 1999; Miotti et al. 2007; Hermo 2008; Miotti y Marchionni 2011, Marchionni 2013; Mosquera 2012). Esto permitió comparar la estructura de los conjuntos líticos en cada momento establecido, analizando variaciones y las posibles causas de estas a lo largo del tiempo.

\section{V.3. Conjuntos arqueológicos.}

El análisis de los conjuntos líticos arqueológicos fue llevado a cabo a partir de su clasificación en grupos: instrumentos ${ }^{1}$, $\operatorname{artefactos}_{\text {formatizados }}^{2}$ y no formatizados ${ }^{3}$; a partir del estudio de variables tecno-morfológicas y morfológico-funcionales. La descripción de los conjuntos se efectuó mediante ciertos atributos utilizados en la clasificación morfológica sistematizada por Aschero $(1975,1983)$ y complementados con otras propuestas de uso actual (Andresfky 1998, Nelson 1991, Aschero y Hocsman 2004). En esta tesis si bien se toma el concepto de tipos como un método de

\footnotetext{
${ }^{1}$ Son litos utilizados para una o varias tareas concretas, manuales o ideológicas. Pueden estar formatizados o no, pero su principal característica es que debe evidenciar su uso.

${ }^{2}$ Litos modificados luego de su extracción inicial para un uso probable.

${ }^{3}$ Artefactos líticos de origen antrópico que han sido generados por el proceso de reducción de núcleos y/o manufactura o mantenimiento de instrumentos, mediante técnicas de presión o percusión. Se seleccionaron artefactos de tamaño mayor a 4 y con un filo potencialmente utilizable de $30 \mathrm{~mm}$.
} 
organización y estudio de los conjuntos líticos, estos son considerados como una construcción por parte del investigador con el fin de ordenar, mediante una recurrencia de rasgos, los artefactos. Es en este sentido, que los rasgos de mayor importancia considerados para comprender el contexto de uso de los conjuntos líticos bajo estudio, estuvieron focalizados en las características principales de los filos (forma primaria ${ }^{4}$ y secundaria $^{5}$, sección longitudinal, tipo de retoque, variables métricas de las piezas y de los filos primarios y secundarios, con especial atención a la longitud, espesor y ángulo del filo medidos en milímetros). Igualmente se tuvo en cuenta las materias primas utilizadas, sobre todo en el análisis de formación de los rastros de uso identificados, siguiendo los criterios establecido de trabajos anteriores realizados para Patagonia en particular (Mansur-Franchomme 1983, 1986, 1999; Castro de Aguilar 1994; Castro y Moreno 1994).

\section{V.4. Metodología experimental aplicada al análisis funcional.}

Como ya ha sido mencionado en el apartado anterior, el análisis funcional de base microscópica consiste en una vía de aproximación a la tecnología de una época determinada (Semenov 1981). Siendo la tecnología definida como el conjunto de conocimientos y procedimientos materiales que, mediante diferentes operaciones, lleva a la realización de un determinado producto. El desarrollo de esta metodología abarca dos instancias importantes para su aplicación; una de ellas implica el análisis propiamente dicho de artefactos líticos recuperados del registro arqueológico, mientras que la otra, incluye la realización de experimentos mecánicos de simulación de uso, controlando diversas variables durante su aplicación (Mansur-Franchomme 1983, 1986; Castro 1994; Álvarez 2003; Leipus 2006).

De acuerdo con esto, la realización de un protocolo experimental implica un punto de partida fundamental a la hora de implementar esta metodología en sitios arqueológicos.

Los experimentos deben formar un conjunto organizado y sistemático en los cuales deben controlarse las variables que intervienen durante el uso de un instrumento y, más tarde, los rastros que se generan:

\footnotetext{
${ }^{4}$ Conformación del borde (Aschero 1975, 1983)

${ }^{5}$ Forma del filo en relación con la figura geométrica o lineal simple que inscribe su contorno (Aschero 1975).
} 
"...Todo experimento es limitado, no demuestra ni refuta plenamente la estructura teórica que trata de comprobar. Sin embargo, sirve de medio para la demostración de la hipótesis y también de instrumento para su desarrollo ulterior. El experimento, por ello, no sólo contiene lo que se comprueba directamente, sino también lo nuevo, lo que no ha sido previsto por el experimentador yes así que amplía su representación teórica..."(Kopnin 1969: 137, en Nami 1998).

Por lo tanto, el análisis funcional plantea la necesidad de formular dos clases de experimentos para su aplicación: los replicativos o de simulación y los analíticos o mecánicos (Anderson-Gerfaud 1981; Castro 1994; 1996; González Urquijo e Ibáñez Estévez 1994; Gutiérrez Saez 1990; Mansur-Franchomme 1983a; Plisson 1985; Vaughan 1981).

En el primer caso, se llevan a cabo diversos trabajos que podrían haber sido realizado en el pasado (por ejemplo raspado de cuero, corte de madera para la preparación de astiles, o de huesos para la confección de instrumentos), se reproducen experimentalmente y posteriormente se observan los resultados. Estos rastros sirven de muestra comparativa en relación con el material recuperado del registro arqueológico, permitiendo plantear asociaciones de trabajos específicos realizados en condiciones artificiales y, por lo tanto, identificar el material trabajado en el pasado.

Por el contrario, los experimentos analíticos, tienen por objetivo el estudio de cada una de las variables que componen los experimentos anteriores, y consecuentemente, el propósito principal no es el conocimiento acerca de las acciones realizadas en el pasado, sino controlar las variables que intervienen en el desarrollo de los experimentos (Mansur-Franchomme 1983, Castro de Aguilar 1994, Álvarez 2003 y Leipus 2006).

Si bien este tipo de experimentación forma parte esencial en la aplicación del análisis funcional en contextos arqueológicos, sus limitantes han sido señalados en numerosas ocasiones y se encuentran relacionadas con los referentes etnográficos y su aplicación en el registro (Kamminga 1982; Unger-Hamilton 1988; Mansur-Franchomme1983, 1986; Unrath et al. 1986).

Por otro lado, los experimentos replicativos desarrollados en el programa experimental, no permiten reconocer más acciones que las allí desarrolladas, ya que los rastros generados se encuentran asociados a un trabajo concreto. Es por esta razón, que la serie debe ser ampliamente representativa del material a analizar, tanto en relación a las 
materias primas como a las acciones desarrolladas, para un buen análisis posterior a nivel arqueológico (GonzálezUrquijoelbáñezEstévez1994; Mansur 1999; Álvarez 2003).El reconocimiento del uso de un artefacto lítico arqueológico, se basa en la asociación analógica entre los rastros que presenta y los que han sido observados por el investigador, sin embargo, es en este punto donde puede llegar a entrar en conflicto el modelo planteado con anterioridad. ¿Qué ocurre cuando las huellas no coinciden con aquellas registradas experimentalmente? Podría suceder, por ejemplo, que un artefacto usado en actividades de adelgazamiento de cueros en el pasado, no presente las mismas características que los empleados en la serie experimental de referencia. Si bien en ambos casos es posible identificar que se trabajó el mismo material, los innumerables procesos que afectaron ese instrumento luego de su depositación a lo largo del tiempo, producen que estos rastros difieran entre sí. Por lo tanto y en primer lugar, hay que fijar qué aspectos y hasta qué punto pueden diferir los rastros sin afectar la interpretación. En segundo lugar, es necesario establecer niveles de interpretación parciales y, por último, como elaborar una hipótesis alternativa cuando los rastros de utilización son diferentes de los conocidos por la experimentación, dado que no se ha controlado la influencia de cada variable (Álvarez 2003; Leipus 2006).

El sistema analítico ofrece una respuesta más adecuada a esta problemática. Ante un conjunto de rastros desconocido, el investigador en análisis funcional puede establecer hipótesis sobre el trabajo que las originó a partir del conocimiento que tiene sobre el comportamiento de cada variable de uso. En consecuencia, la experimentación analítica permite crear una herramienta de interpretación funcional más sistemática y flexible. El número de variables que determinan las características de los rastros de uso es muy amplio, por lo cual el sistema de deducción es complejo. Este se debe realizar en diferentes fases, desde las deducciones más simples a las más complejas. En este proceso los rastros observados en algunas piezas experimentales permiten desarrollar la inferencia hasta el nivel del conocimiento más profundo y detallado, mientras que otros casos la deducción debe quedar en un nivel más general. Este tipo de análisis, sistemático a la vez que flexible, sólo se puede practicar partiendo de una definición detallada de las variables que intervienen en el trabajo y de los tipos de rastros que generan en las diferentes materias primas registradas en los contextos arqueológicos de estudio (Mansur-Franchomme 1983, 1990; Castro de Aguilar 1994; Álvarez 2003; Leipus 2006). 


\section{V.5.Materias primas utilizadas en la serie experimental de referencia.}

El desarrollo de las huellas dejadas por el uso de un instrumento varía en cuanto a disposición y tiempo de desarrollo dependiendo del tipo de materia prima utilizada. La mayoría de las investigaciones referidas al análisis funcional han sido realizadas sobre materias primas silíceas y es por esta razón que existe una detallada caracterización de los rastros de uso generados sobre este tipo de materia prima (Keeley y Newcomer 1977; Keeley 1980; Anderson Gerfaud 1981; Mansur-Franchomme 1983; Moss 1983; Plisson y Mauger 1988; Levi Sala 1993, 1996). Sin embargo, en los últimos tiempos, la aplicación del análisis funcional en numerosos sitios ha ido incrementando la variedad de materias primas posibles para su aplicación (Lewenstein 1981; Knutsson 1986,1990; Oayama 1995; Mansur 1999; Álvarez 2003; Yerkes et al. 2003; Leipus 2006; Pal 2009,2010b), y si bien, los principios generales de formación de rastros de uso pueden ser empleados en distintas clases de rocas, es necesario llevar a cabo experimentos minuciosos y sistemáticos con el fin de hacer un buen registro tanto de los rastros de uso, como así también tecnológicos y de deformación, para su posterior aplicación a nivel arqueológico.

La importancia que tienen estos estudios, reside en que proveen de valiosa información respecto a los modos de uso y estado del material trabajado, permitiendo indagar acerca de la funcionalidad de los sitios y de las estrategias de explotación de recursos. Para esto, el punto de partida consiste en establecer las materias primas disponibles en el área de estudio y comprender las características estructurales y composicionales que estas presentan.

Los sitios analizados en esta tesis, como ya ha sido mencionado con anterioridad, se encuentran localizados en la provincia geológica del Macizo del Deseado (De Giusto et al.1980), sector caracterizado por una intensa actividad volcánica con escasa cubierta sedimentaria cuaternaria. Por lo tanto, las formaciones rocosas identificadas para la zona corresponden a un origen volcánico con alto contenido silíceo.

La geología del área es relativamente simple para el sector donde se emplaza el sitio arqueológico Piedra Museo (Panza y Genini 1998). El complejo piroclástico - lávico del Grupo Bahía Laura, es considerado como el más relevante para nuestro estudio, integrado por las Formaciones Chön Aike (ignimbritas riolíticas) y La Matilde (tobas, tufitas). Esta última es la portadora de los fósiles de araucarias que encontramos al norte de la Localidad Piedra Museo, en el MNBP (Miotti y Cattáneo 1997; Miotti et al. 1999; Cattáneo 2002, 2005; Cattáneo et al. 2004). 
Por otro lado, para el área circundante al sitio Cueva Maripe, las rocas de mayor relevancia en este estudio, son aquellas que pertenecen a las formaciones Bajo Pobre, La Matilde y Chön Aike, cuyas rocas conforman más del 50\% de la totalidad aflorante (Panza 2001; Moreira 2005).

Su caracterización geológica corresponde principalmente a la formación Chön Aike, y secundaria de Bajo Grande y Baqueró, formaciones ricas en rocas con alto valor silíceo y una baja representación de otras unidades geológicas, que no poseen relevancia en relación al aprovisionamiento de rocas útiles para la talla. Sin embargo, los depósitos que cubren niveles de pedimentos y depósitos de conos aluviales, actúan como concentradores de fragmentos rocosos provenientes de la degradación de formaciones cercanas. Estos niveles, presentan evidencia arqueológica de su aprovechamiento como fuentes de recursos líticos. Cattáneo (2002, 2005), Hermo $(2008,2009)$ y Magnin (2010), los proponen como "áreas de concentración de recursos" líticos de diversas litologías y cualidades para la talla, destacando a los niveles de pedimento como aquellos de mayor concentración.

Las materias primas usadas para la elaboración de los artefactos procedentes del sitio AEP-1, fueron determinadas a partir de muestras de mano y estudios geológicos (Miotti y Cattáneo 1997, Cattáneo 2002, 2004, 2005). Como resultado se identificaron las siguientes variedades de rocas:

> Ignimbrita y toba silicificada: roca de grano fino, de textura porfírica, con abundantes fenocristales de cuarzo, feldespato y biotita. Su coloración es variada (castaño-rojiza) y se encuentran asociadas a la Formación Chön Aike y La Matilde del Grupo Bahía Laura (Panza 1982; Panza y Genini 1998).

> Basalto: corresponde a una roca con textura porfídica de grano fino a mediano de coloración negro a negro-verdoso. Se encuentra asociado a la Formación Bajo Pobre (Panza 2001).

$>$ Xilópalo: Es una roca caracterizada por un elevado grado de silificación, lo que permite muchas veces que presente una fractura concoide. Su coloración corresponde a bandas irregulares de tonalidades castañas. La presencia de xilópalo en el área se encuentra asociada a la Formación la Matilde y Baqueró (De Giusto et al. 1980 y Panza 1982). En la primera de estas unidades mencionadas es donde han sido registrados grandes troncos silicificados de 
araucariáceas. Esta formación se extiende hacia el área del bosque petrificado y la Localidad Piedra Museo en un radio de 50 Km (Miotti y Cattáneo 1997).

$>$ Calcedonia: roca microcristalina sin inclusiones de coloración blanco translúcida con tinciones castañas translucidas.

> Ópalo: se caracterizan por ser homogéneos, de gran dureza y resistencia.

$>$ Obsidiana: roca que se encuentra en bajas proporciones en los conjuntos arqueológicos del área en comparación con otras materias primas utilizadas. Ha sido fuente de estudios más profundos con el fin de establecer su fuente de abastecimiento primaria (Stern 1999; Belardi et al.2006). Stern $(1999,2000)$ realizó análisis de desechos de obsidiana determinando su semejanza con muestras provenientes de Pampa del Asador a 170 km de distancia en línea recta.

Con respecto a Cueva Maripe la clasificación propuesta por Hermo (2008)en base a cortes ha permitido plantear los siguientes grupos:

$>$ Ignimbritassilicificadas Grupo 1 (ISG1):ignimbritas silicificadas registradas en Cantera del Rojo (CDR) y en el Pedimento 1 de La Primavera (LP-P1), a 12 km y $5 \mathrm{~km}$ de Cueva Maripe, respectivamente.

> Ignimbritassilicificadas Grupo 2 (ISG2): otras variedades de ignimbritas silicificadas, registradas en la cantera Rocky (200 m de Cueva Maripe). Las tonalidades son castañas oscuras a rojizas y no se registró presencia de inclusiones observables a ojo desnudo.

> Rocas silíceas Grupo 1 (RSG1): roca de coloración negra, en su mayor parte microcristalina, con tinciones blanquecinas a castañas.

> Rocas silíceas Grupo 2 (RSG2): rocas riolíticas, de tonalidades mayoritariamente castañas, que no muestran características ignimbríticas y que presentan bandeados y/o tinciones zonales, que las diferencian de ISG1.

> Rocas silíceas Grupo 3 (RSG3): rocas silíceas sin inclusiones, de tonalidades exclusivamente castañas, pudiendo o no presentar bandeados y tinciones zonales (manchas).

$>$ Otras rocas silíceas (RSGx): incluye aquellas variedades rocosas silíceas que no se corresponden con los grupos anteriores.

> Calcedonias Grupo 1 (CG1): calcedonias blancas translúcidas, con tinciones negras y/o castañas asimismo translúcidas, sin inclusiones y microcristalinas. 
Otras calcedonias (CGx): Se incluyen todas las calcedonias que no responden a la definición de CG1.

> Ópalos Grupo 1 (PG1): variedad de ópalo microcristalino, principalmente negro, aunque con zonaciones castañas.

Otros ópalos (PGx): Se incluyen todas las variedades de ópalo no consideradas enPG1.

>bsidiana (OB): roca utilizada en bajas proporciones a nivel arqueológico, de coloración negra y cuya procedencia hasta el momento se encuentra relacionadaa Pampa del Asador, a 120 km de distancia en línea recta (Stern 1999; 2000; 2004; Belardi et al. 2006).

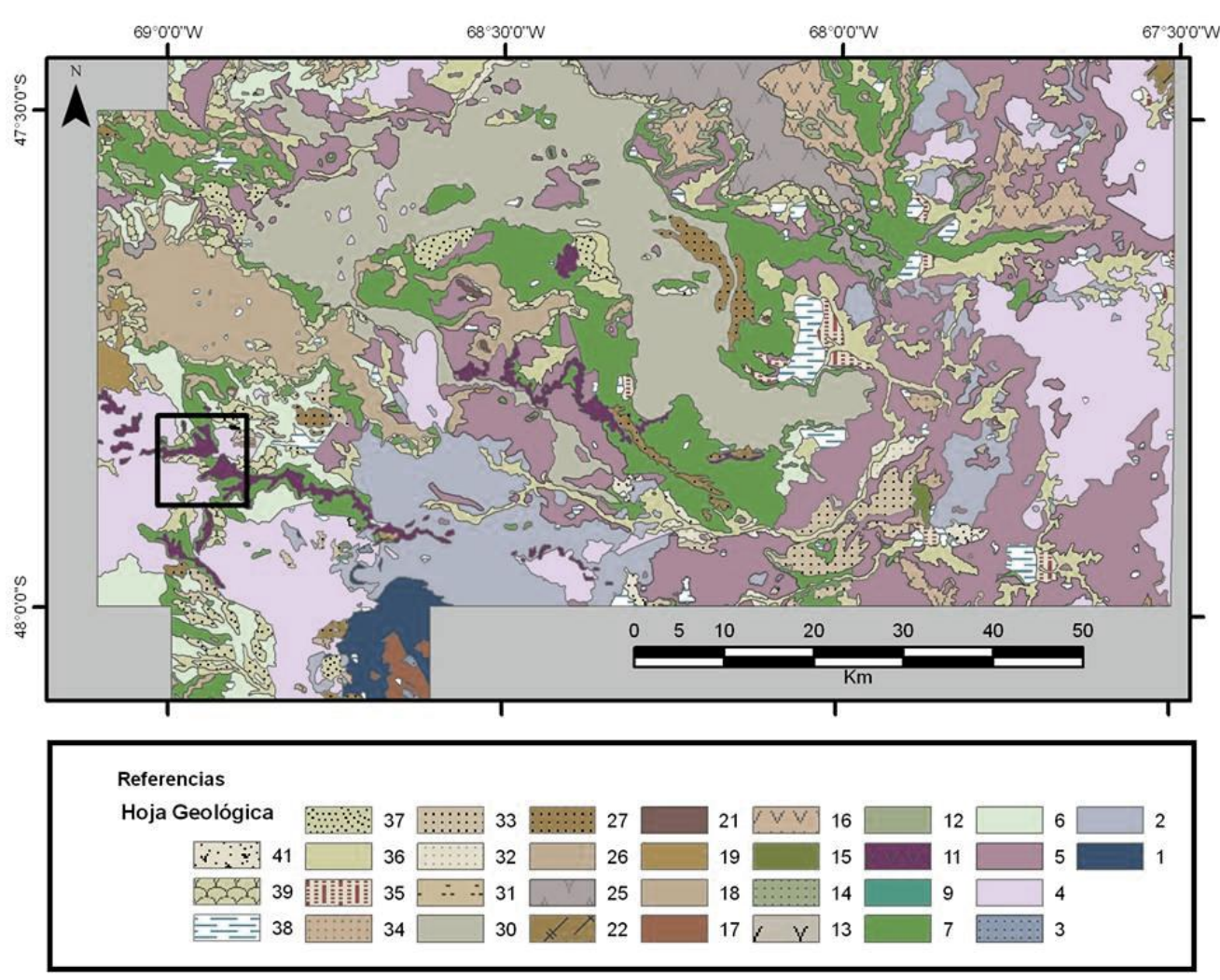

Figura 8: Mapa geológico de la macro-área de estudio (tomado y modificado de Magnin 2010). 4 (Formación geológica Chön Aike, localidad arqueológica La Primavera), 4 (Formación geológica Chön Aike, localidad arqueológica Los Toldos), 5 (Formación La Matilde, localidad Los Toldos) y 15 (Formación El Museo, localidad Piedra Museo).

A partir de esta descripción, se puede observar que las materias primas usadas corresponden en su mayoría a rocas criptocristalinas con diferencias composicionales en relación al tamaño de los cristales de cuarzo y a su composición mineralógica (Hermo 2008). Estas características pueden intervenir en la formación de los rastros de uso de 
acuerdo al modelo propuesto por Mansur-Franchomme (1986, 1990; Mansur 1999); mientras que también se observa la presencia de basalto, roca heterogénea, con pasta o matriz microcristalina con cristales incluidos, representado en muy bajas proporciones en los conjuntos estudiados. Es por esta razón, que se consideró de fundamental importancia un extenso desarrollo experimental a partir de este tipo de rocas sobre distintos materiales, estados y tiempo de utilización. A continuación serán detalladas algunas de las variables consideradas en la serie experimental de referencia y las características principales de los rastros de uso a observar (ver Apéndice).

\section{V.6. Serie experimental de uso}

El contexto de uso de los materiales líticos constituye uno de los ejes fundamentales para el abordaje de la organización tecnológica de las sociedades en el pasado. El análisis funcional de base microscópica permite establecerá partir de la identificación de rastros generados mediante la utilización de un instrumento (Mansur-Franchomme 1986-1990):

$>$ sobre qué material trabajó el artefacto y estado

qué movimiento realizó durante su empleo

$>$ la duración del trabajo efectuado

El estudio en conjunto de macro y microrrastros constituye un requisito indispensable dentro de los enfoques actuales del análisis funcional.

La aplicación de esta metodología a los conjuntos líticos procedentes de distintos contextos arqueológicos se ha ido incrementando en los últimos años. Esto ha permitido una mejor comprensión respecto a las relaciones entre los instrumentos utilizados, la funcionalidad de los sitios, patrón de asentamientos, desarrollo de estrategias productivas y los sistemas sociales del pasado (Keeley 1980; Kamminga 1982; Moss y Newcomer1982; Mansur-Franchomme 1983; Symens 1986; Castro de Aguilar 1994; Álvarez 2003; Rots y Williamson 2004; Leipus 2006; Leipus y Mansur 2007; De Angelis 2013; Pal 2009; 2013). 


\section{Variables consideradas}

La serie experimental realizada incluyó un total de 163 artefactos líticos, de los cuales 15 corresponden a artefactos formatizados (raspadores de filo frontal) utilizados mediante dispositivos de enmangue. En la serie experimental se utilizaron las siguientes variables:

\section{-Materia Prima}

La muestra a estudiar incluye gran parte de la diversidad de materias primas disponibles y utilizadas para la talla en el área. La realización de la serie experimental incluyó, por lo tanto, dos grandes grupos de rocas: homogéneas (o criptocristalinas), de grano fino y heterogéneas o de grano mediano a grueso (Mansur 1992, 1999).

La experimentación con estos diversos tipos de materias primas fue realizada a partir del conocimiento de las características físico/químicas, tanto de las rocas utilizadas como del material trabajado, realizando un registro de todas las variables vinculadas con el proceso de uso.

Se consideró el modelo de formación de rastros para materias primas homogéneas y heterogéneas basada en la variabilidad estructural, composicional y de diversas reacciones al ser expuestas a experimentos de utilización, alteración o tecnológicos, propuesto por Mansur (1986/1999).

Asimismo, se consignaron distintas variables para la identificación de estas huellas de uso, incluyendo entre ellas tanto a los macrorrastros como así también microrrastros. Entre los macrorrastros se incluye la presencia de esquirlamientos o modificaciones de los filos que se producen como consecuencia de fracturas que alteran su sección longitudinal o delineación. Los mismos son identificados a partir de negativos de lascados que se extienden a lo largo del filo sobre una o ambas caras de la pieza, de distintas formas y terminaciones (Keeley 1980). Los microrrastros son alteraciones de la superficie del filo por modificaciones de la estructura cristalina de la roca (Semenov 1964, Keeley 1980, Mansur-Franchomme 1983, 1999). Dentro de este grupo se pueden identificar tres tipos ${ }^{6}:$ 1) micropulidos2) estrías microscópicas 3) redondeamiento o alisado de filos.(Ver Apéndice)

\footnotetext{
${ }^{6}$ Más adelante se detallan las características principales de cada uno y las causas de su formación.
} 


\section{-Morfología de la zona activa}

Las posibilidades que un útil ofrece de transformar una materia dependen de la forma del filo (Álvarez 2003) y en relación a esto se pueden mencionar cuatro variantes:

Puntual: cuando las aristas activas de un artefacto confluyen en un punto.

Bisel de Buril: cuando la zona activa es un bisel de tipo buril, sea natural o creado por retoque.

Lineal: cuando la zona activa es un filo.

Masiva: cuando la zona activa es una superficie.

\section{-Filo utilizado}

En los casos en que las zonas activas son filos, se registraron las siguientes variables:

Situación: Siguiendo la segmentación morfológica de Brèzillion (1983)la situación del filo en la pieza pueden ser: frontal, lateral, convergente (simétrico o asimétrico), axial, normal y perimetral.

Delineación: rectilíneo, cóncavo o convexo (Aschero 1983-1975).

Longitud: medida en centímetros con un calibre electrónico.

Angulo de bisel: medida tomada en grados agrupadas en seis categorías: rasantes $\left(0^{\circ}\right.$ $\left.30^{\circ}\right)$, muy oblicuos $\left(30^{\circ}-50^{\circ}\right)$, oblicuos $\left(50^{\circ}-80^{\circ}\right)$, abruptos $\left(80^{\circ}-100^{\circ}\right)$, obtusos $\left(100^{\circ}-\right.$ $\left.120^{\circ}\right)$ y muy obtusos $\left(120^{\circ}-180^{\circ}\right)$.

\section{-Material trabajado}

Los distintos tipos de materias primas utilizadas en la producción de artefactos líticos a nivel arqueológico pueden variaren relación a su estructura cristalina y al patrón de fractura (en general, concoide). Por lo que es necesario realizar, una serie de experimentos con cada una de ellas para determinar sus diferencias en relación a los materiales trabajados, los que a su vez, varían en cuanto a la dureza, al estado (fresco o seco) y composición general. 


\begin{tabular}{|c|c|c|c|}
\hline $\begin{array}{l}\text { Origen del } \\
\text { recurso }\end{array}$ & $\begin{array}{l}\text { Tipo de } \\
\text { Recurso }\end{array}$ & Especie trabajada & Estado \\
\hline \multirow{4}{*}{ Recurso animal } & Cuero & $\begin{array}{l}\text {-Bos Taurus } \\
\text {-CapraHircus } \\
\text {-Ovis Aries }\end{array}$ & $\begin{array}{l}\text {-Seco } \\
\text {-Fresco } \\
\text {-Remojado-húmedo }\end{array}$ \\
\hline & Piel & -Ovis Aries & -Fesco \\
\hline & Hueso & -Bos Taurus & $\begin{array}{l}\text {-Seco } \\
\text {-Fresco } \\
\text {-Remojado-húmedo }\end{array}$ \\
\hline & Carne & -Bos Taurus & -Fresco \\
\hline \multirow{2}{*}{ Recurso Vegetal } & Madera & $\begin{array}{l}\text {-Schinusmarchandii } \\
\text {-Condaliamicrophylla }\end{array}$ & $\begin{array}{l}\text {-Estacionada } \\
\text {-No estacionada }\end{array}$ \\
\hline & $\begin{array}{l}\text { Plantas no } \\
\text { leñosas }\end{array}$ & Gramíneas & -Fresco \\
\hline Recurso Mineral & $\begin{array}{l}\text { Material } \\
\text { mineral }\end{array}$ & Toba coquinoidea & \\
\hline
\end{tabular}

Tabla 2: Detalle de los materiales trabajados y estado de cada material de acuerdo a los experimentos de uso realizados.

\section{-Tiempo de utilización}

La secuencia experimental se dividió en bloques temporales de 5',15',30',45' y 60'. Concluido cada bloque, se observó el estado del filo activo. En caso de detectar embotamiento, la primera serie de piezas trabajadas, se dejó sin reactivar, mientras que la siguiente se reactivó.

\section{-Actividad desarrollada durante el tiempo de utilización}

Se realizaron dos clases de acciones, siguiendo las propuestas de Keeley (1980); Mansur-Franchomme (1983, 1986, 1990 y 1999) y Álvarez (2003):

-Acciones Longitudinales: en las que el filo se desplaza en forma paralela al material trabajado entrando en contacto ambas caras del filo.

-Acciones transversales: el filo se desplaza en forma perpendicular al material trabajado y en general, entra en contacto una sola cara del filo.

De acuerdo a esto las actividades fueron divididas en:

\section{Acciones longitudinales.}


-Cortar: consiste en insertar el filo de manera oblicua o perpendicular en el material trabajado, ejerciendo un movimiento unidireccional o bidireccional. En general se aplica al trabajo con sustancias blandas.

-Aserrar: consiste en insertar de manera perpendicular al material trabajado, desplazando el artefacto de manera bidireccional. Se aplica generalmente a sustancias resistentes.

\section{Acciones transversales.}

-Alisar: consiste en frotar una superficie con un artefacto que se desplaza en forma bidireccional y con un ángulo de trabajo agudo.

-Raspar: consiste en la abrasión de una superficie con un artefacto que se desplaza en un ángulo superior a $45^{\circ}$, a menudo próximo a $90^{\circ}$.

-Descortezar: incluye la reducción de una superficie con un movimiento bidireccional del artefacto y con un ángulo de trabajo agudo.

En todas estas actividades la fuerza es ejercida de manera prolongada y requiere movimientos de desplazamiento en el espacio.

De acuerdo a estas actividades los movimientos efectuados fueron clasificados en:

TR: transversal o perpendicular.

LO: Longitudinal o paralelo.

LT: Longitudinal y transversal.

RO: Rotación.

IM: Impacto o penetración.

ND: No determinable.

\section{-Ángulo de trabajo}

Es el ángulo que forma la bisectriz del ángulo del filo al entrar en contacto con la materia trabajada. Se dividen en:

Agudos: $0^{\circ}$ a $35^{\circ}$.

Intermedios: $35^{\circ}$ a $70^{\circ}$.

Rectos: $70^{\circ}$ a $90^{\circ}$.

Sobrepasados: más de $90^{\circ}$

\section{-El contacto}


Las caras de contacto son aquellas que forman el borde activo con respecto al material a trabajar. En ángulos de trabajo que superan los $90^{\circ}$ suelen intervenir ambas caras (dorsal y ventral) por lo que el desarrollo de huellas de uso, en este caso particular, suele darse en las mismas.

\section{V.7. Observación y registro de los rastros generados por el uso.}

La observación de los rastros de uso generados se llevó a cabo mediante un microscopio metalográfico Nikon Epiphoto 200 bajo el campo de iluminación claro con aumentos de 50X a 500X (microrrastros), mientras que los macrorrastros fueron observados bajo una lupa trinocular, Nikon modelo SMZ800 con aumentos de 10 a 63X (Figura 8).La determinación de residuos, fue realizada a partir de un microscopio electrónico de barrido modelo Quanta 200, con modos de observación en alto y bajo vacío y modo ambiental. Este microscopio cuenta además con un espectrómetro de Rayos-X dispersivo en energías (EDAX, SDD Apolo 40), que permitió determinar la composición química de la muestra de manera semicuantitativa.

El uso de distintos medios ópticos se debe a que cada uno de estos permite la observación de distintos tipos de rastros, debido a las posibilidades ópticas y propiedades técnicas de cada uno (disposición de luz, campo de observación, distancia de trabajo y aumento) (Ver Apéndice, nomenclatura y planillas de observación de rastros de uso).

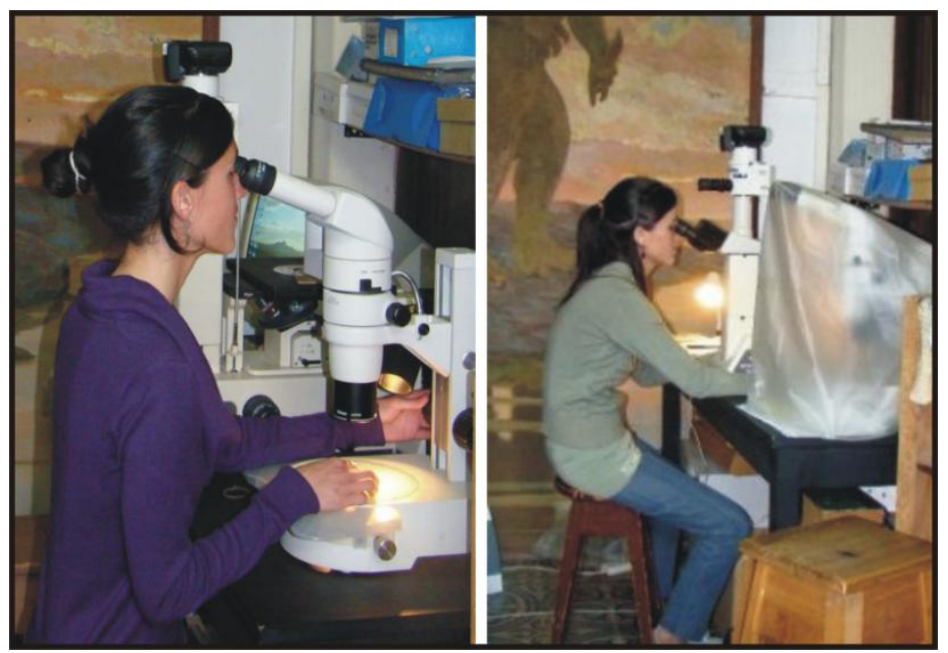

Figura 9: Observación de rastros de uso a partir de diferentes medios óptico (lupa trinocular -aumentos de 10X a 63X-y microscopio metalográfico -aumentos de 100X a 500X-). 
A partir del microscopio metalográfico, es posible establecer los distintos tipos de micropulidos, definidos como sectores de la superficie del filo trabajado que refleja la luz incidente de manera diferente a los sectores no trabajados (Keeley 1977, 1980). Este rastro permite identificar el material utilizado y ha sido considerado como criterio diagnóstico frente a la ausencia de otros tipos de rastros. La formación de los micropulidos fue ampliamente estudiado, ya que no sólo permitía generar información acerca del material trabajado, sino también, de su estado y tiempo de utilización (Mansur-Franchomme 1983, 1986, 1990; Castro 1994; Álvarez 2003; Leipus y Mansur 2007). Existen varias hipótesis acerca de su formación, entre las cuales se puede mencionar la generada por Witthoft (1967), quien consideraba que su origen se debía a una pérdida del material de la superficie al entrar en contacto con el material trabajado (“micropulido por abrasión") y que estos eran consecuencia de la fusión de la sílice vegetal durante el trabajo de plantas. Sin embargo, esta teoría incluía solamente un tipo de micropulido. Las observaciones realizadas por Mansur (1986-1990) respecto a los residuos observados dentro de los micropulidos y sus diferencias en relación a los distintos materiales trabajados, ocasionaron el abandono de estas ideas. Actualmente, la hipótesis más aceptada en cuanto a la formación de los micropulidos, es la generada por Anderson-Gerfaud (1981) quien consideró que estaba relacionado con la disolución de la capa superficial de la sílice en zonas localizadas del filo. Este se transforma en un gel, que luego se solidifica en sílice amorfo y que en determinadas ocasiones incorpora fragmentos del material trabajado. El grado de desarrollo de los micropulidos varía principalmente en relación al tiempo de utilización, materia prima seleccionada en la producción (propiedades físico-mecánicas de las rocas que dependen de los minerales que la componen) y a las características microtopográficas de la superficie del filo trabajado. En los sectores altos el desarrollo va a ser mayor que en sectores negativos o bajos (Mansur-Franchomme 1983; Castro 1994; Álvarez 2003; Leipus y Mansur 2007; Pal 2009). De acuerdo a esto, Mansur (1999) ha desarrollado un modelo de formación de rastros de uso para materias primas homogéneas y heterogéneas, teniendo en consideración la textura y estructura de los distintos materiales (cuarzo hialino, obsidiana, ignimbritas, riolitas y cuarcitas), para determinar los diferentes estadios de los rastros de uso en cada una de esas materias primas. 


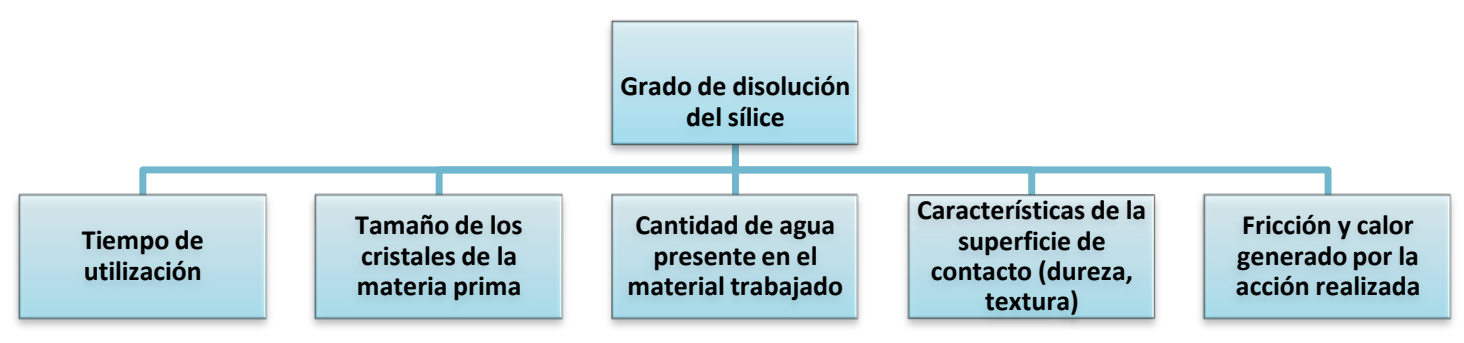

Figura 10: Variables que intervienen en la formación de los micropulidos (tomado y modificado de Mansur 1981).

Otro tipo de microrrastro son las estrías, surcos lineales que se pueden desarrollar en una o ambas caras del filo (Semenov 1964, Mansur-Franchomme 1983; 1990). Las estrías incluyen numerosos tipos, algunos de los cuales, deben su origen a factores naturales (Mansur 1981; Leipus y Mansur 2007).Según Keeley estas son referentes del trabajo intencional, siempre y cuando estén acompañadas de micropulido, permitiendo identificar la direccionalidad del movimiento (Keeley y Newcomer1977).

Las causas del origen de este tipo de rastro, se creyó, en principio, que se debía a pequeños "granos de arena "que eran introducido accidentalmente durante el trabajo (sensu Semenov 1964, "scratchingagents"), sin embargo, la falta de observaciones sistemáticas y estudios experimentales dejó estas propuestas en simple teoría. Posteriormente, fue Mansur-Franchomme(1981; 1983) quien definió el origen concreto de estas huellas, a partir de una serie experimental que fue observada bajo microscopia electrónica de barrido. De acuerdo a esta autora, las formaciones de estrías se deben a dos tipos de agentes abrasivos: el primero corresponde a partículas de polvo o granos de arena que son introducido al realizar el trabajo entre el filo utilizado y el material trabajado, lo que provoca la abrasión. En segundo lugar, intervienen los microlascados que se desprenden del filo utilizado como consecuencia de la fricción y el trabajo propiamente dicho (a mayor dureza del material trabajado mayor cantidad de desprendimientos de microlascas).

Actualmente, la identificación de residuos sobre los filos utilizados ha ido cobrando mayor interés en el campo de la traceología. Los nuevos medios ópticos permiten identificar de manera cuantitativa los componentes orgánicos e inorgánicos sin destruir o modificar (cobertura de oro) las piezas. Esto permite identificar distintos tipos de residuos, que en casos excepcionales de preservación, pueden estar adheridos sobre los filos o incluidos en la sílice superficial (macro y microresiduos), (Mansur 1999; Álvarez 2003; Zurro 2010; Zurro et al. 2006). 


\begin{tabular}{|c|c|}
\hline Tipo de rastro & Variables registradas \\
\hline Micropulidos & 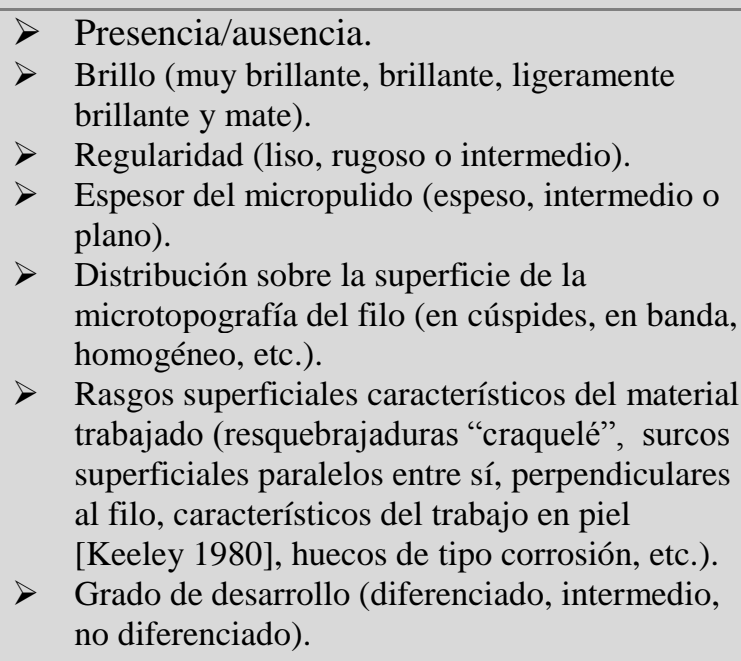 \\
\hline Esquirlamientos & $\begin{array}{l}>\text { Presencia/ausencia. } \\
\text { Continuidad (continua, discontinua o } \\
\text { aislada). } \\
>\quad \text { Morfología (semicircular, trapezoidal, en } \\
\text { melladuras). } \\
>\quad \text { Terminación (simple, escalonada, en } \\
\text { charnela). } \\
\text { Dimensión (micro o macroscópicos o } \\
\text { ambas). }\end{array}$ \\
\hline Estrías & $\begin{array}{l}>\text { Tipo de estría (de fondo rugoso, lisas, etc.). } \\
>\text { Orientación (paralela o perpendicular, } \\
\text { longitudinal al filo). } \\
>\quad \text { Longitud (corta, intermedia o larga). }\end{array}$ \\
\hline Redondeamiento & $>$ Presencia /ausencia. \\
\hline
\end{tabular}

Tabla 3: Variables consideradas para la observación de los rastros de uso generados a nivel experimental (modificado de Álvarez 2003).

\section{V.8. Alteraciones ocasionadas por procesos post-depositacionales}

Desde el proceso de producción, uso y descarte de un artefacto hasta el momento de recuperación por parte de los arqueólogos, la superficie de los artefactos estuvieron expuestas a numerosos daños y transformaciones, consecuencia directa de factores ambientales como culturales.

Estas modificaciones pueden ser vistas, de acuerdo a su grado de desarrollo, tanto a ojo desnudo (pulido, brillo, cambio de color de las piezas), como así también microscópicamente (con altos y bajos aumentos). 
Algunos investigadores han tenido en consideración esta temática como foco de estudio, para determinar patrones en las alteraciones naturales que afecten de manera desigual a los rastros generados por el uso de un instrumento (Rottländer 1975; Vaughan 1981; Mansur-Franchomme 1983, 1986; Plisson y Mauger 1988; Levi Sala 1993; Kaminska et al.1993, entre otros).

Anderson-Gerfaud (1981) y Keeley (1981) definieron tres tipos de alteraciones: A) daño del filo, B) superficies brillantes y C) presencia de patinas blancas. El primero se refiere a un marcado esquirlamiento del filo dificultando la observación de microrrastros, debido a que, el filo trabajado también se encuentra igualmente afectado. La observación de superficies brillantes en una pieza determinada, se relaciona directamente a ataques químicos y mecánicos naturales, tales como la solifluxión, percolación del agua y acción eólica (Röttlander 1975; Stapert 1976;Keeley 1981; Mansur-Franchomme 1983, 1999; Levi Sala1986a y b, 1996; Burroniet al. 2002). Mientras que la presencia de patinas tiene un origen diverso y puede presentarse con diferentes grados de desarrollo (áreas localizadas del filo o sobre toda la superficie de un artefacto).

Otro aporte importante a esta temática de estudio, fueron las investigaciones desarrolladas por Plisson y Mauger en 1988, quienes centraron su interés en observar el modo en que afectaban los procesos naturales a los rastros generados por el uso de un instrumento. En principio, consideraron que estas alteraciones no eran lo suficientemente intensas como para enmascarar los micropulidos originados por uso, sin embargo, posteriormente, enfatizaron en las complicaciones que causan tanto en estrías como en micropulidos, ocasionando la eventual desaparición de los rastros (Burroni et al. 2002).

En este sentido, podemos mencionar que existen distintos niveles de modificaciones de acuerdo a la intensidad en que actúan los diferentes procesos luego de la depositación de un artefacto; por lo tanto, las modificaciones pueden ser: leves (apenas un lustre sobre las superficie pero que aún permite observar los rastros tecnológicos y aristas frescas), moderadas (puede observarse modificaciones en sectores de una o ambas caras del instrumento en forma de playas de abrasión. Los rastros tecnológicos comienzas a verse afectados a partir de un leve aplanamiento y/o redondeamiento de las aristas. Pese a esto los rastros de uso pueden ser observados, que en el caso de los micropulidos dependerá de su grado de desarrollo) e intensas (desarrollo de playas de abrasión sobre ambas 
caras del instrumentos con gran intensidad. En estos casos la observación de los rastros de uso es sumamente dificultosa) (Figura 9).

En nuestro país, el estudio minucioso y sistemático acerca de estos procesos, fue llevado a cabo por varios investigadores a partir de la observación del material lítico arqueológico (caso de Los Toldos y El Ceibo- Mansur-Franchomme 1983,1986, 1999-; Casa del Minero 1 -Paunero y Castro 2001-; Túnel I -Álvarez 2003-; Arroyo Seco 2Leipus 2006- y el sitio Laguna La Barrancosa 1 -Pal 2008- ). Sin embargo, las causas que originan estos procesos, muchas veces como consecuencia de modificaciones químicas en contextos arqueológicos, fueron escasamente abordadas mediante análogos experimentales (Mansur-Franchomme 1983, 1987; Álvarez 2003; Leipus 2006).

En este sentido, el estudio de la determinación de agentes que pudieron haber intervenido en la formación del depósito y sus efectos sobre la superficie de los artefactos, puede ser observado mediante distintos atributos (pátinas, lustres, abrasión) brindando una mejor información acerca de las actividades que pudieran haber sido desarrolladas en el pasado (Ver Apéndice).

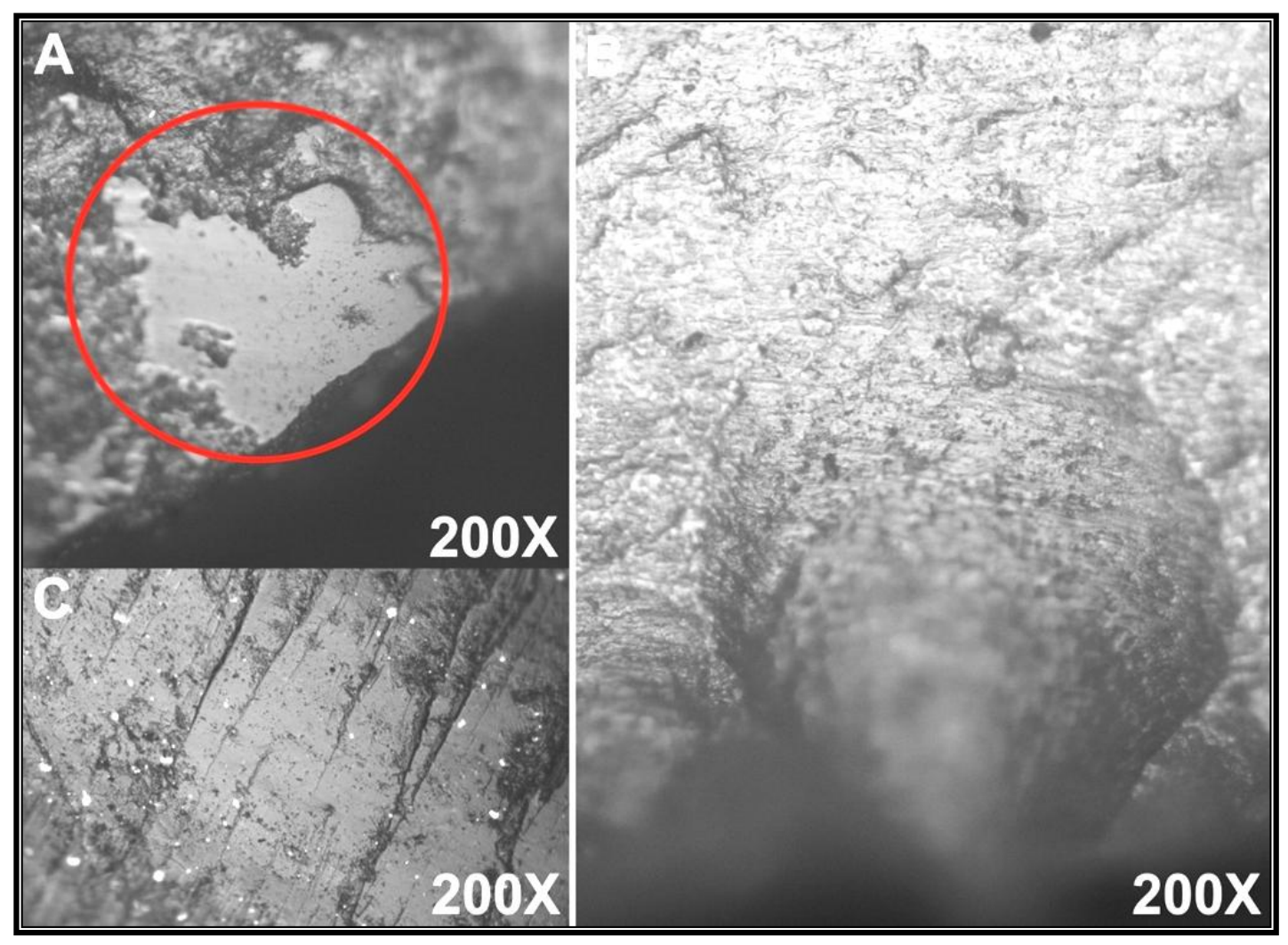

Figura 10: Modificaciones de las superficie de los artefactos ocasionadas por procesos post-depositacionales. A) puntos brillantes "bright spots"; B) esquirlamientos y pulido de sedimento y C) estrías tecnológicas modificadas por pulido de sedimento. 


\section{V.9. Análisis estadísticos utilizados}

Para testear las diferencias establecidas en los diseños utilizados en la producción de los conjuntos líticos analizados, se realizaron diferentes test estadísticos no paramétricos para variables cuantitativas. Dentro de estos se consideró la aplicación de: Chi-cuadrado (pruebas para una muestra); U de Mann-Whitney (prueba para dos muestras independientes) y $\mathrm{H}$ de Kruskal-Wallis (prueba para varias muestras independientes).

La primera de estas permite indagar si la determinación empírica de una variable categórica se ajusta o no a una determinada distribución teórica; o sea corresponde a un estadístico para comparar las frecuencias observadas o empíricas con las esperadas o teóricas de cada categoría analizada (Barceló 2007).

La prueba U de Mann-Whitney es una prueba no paramétrica de diferencia de medias para tamaño de muestras pequeñas $(\mathrm{n} \leq 30)$. Esta prueba está diseñada para analizar datos con una variable independiente categórica y una variable dependiente cuantitativa al menos ordinal, en donde interesa comparar dos grupos o muestras (Siegel y Castellan 1988; Barceló 2007).

La prueba $\mathrm{H}$ de Kruskal-Wallis consiste en una prueba no paramétrica con una variable categórica y una variable dependiente cuantitativa, al menos ordinal donde interese comparar muestras. La prueba mencionada anteriormente consiste en analizar más de dos muestras independientes (Kruskal-Wallis 1952). 



\section{CAPÍTULO 6}

\section{Sitio}

Cueva Maripe

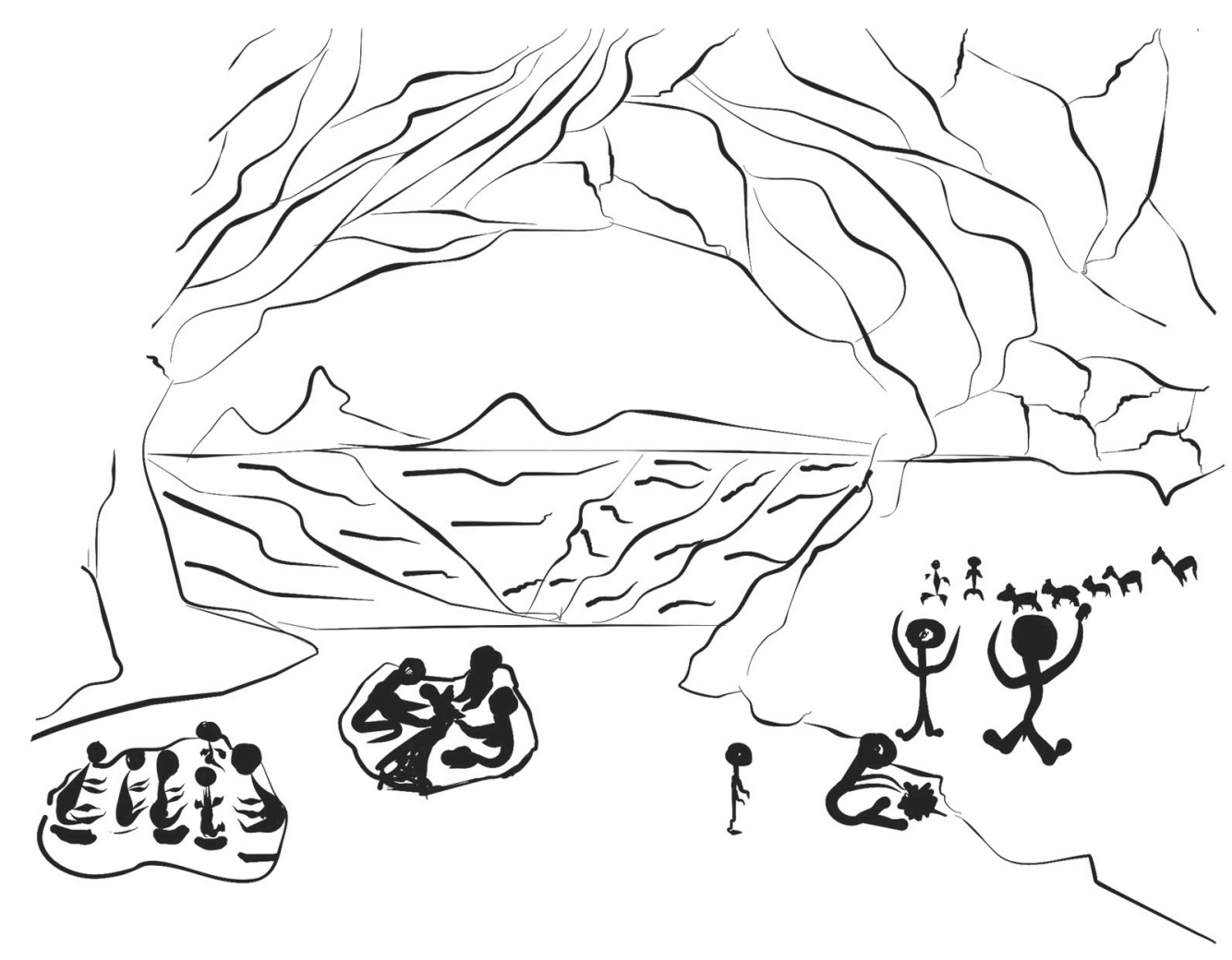





\section{ANÁLISIS DEL CONTEXTO DE USO DEL INSTRUMENTAL LÍTICO DE CUEVA MARIPE}

En este capítulo se presentan las características principales del sitio Cueva Maripe, en base a una síntesis de las investigaciones realizadas hasta el presente. Lo cual constituye el marco arqueológico y ambiental en el que se encuentra el contexto lítico analizado. En este sentido, el objetivo principal en este capítulo es presentar los resultados alcanzados del análisis realizado mediante la metodología funcional de base microscópica, considerando el diseño de los conjuntos recuperados de cámara norte (CN) y sur (CS) en los distintos bloques temporales identificados en el sitio. Debido a la complejidad y diferencias estratigráficas registradas en ambas cámaras (Miotti et al. 2007; 2013 e.p.), los resultados serán expuestos de manera independiente, aunque el análisis generado será discutido considerando los resultados obtenidos para cada bloque temporal, siguiendo los criterios dados en los trabajos arriba citados.

\section{VI.1. Características principales del sitio}

La Localidad arqueológica La Primavera es un cañadón tributario del Zanjón blanco en el sector norte del Macizo del Deseado, donde se emplaza el sitio arqueológico Cueva Maripe (Miotti et al. 2007). Las excavaciones en este sitio comenzaron en el año 2003, con una continua labor que generó abundante información arqueológica y paleoambiental (Fernández 2013; Fernández y Salemme 2012; Miotti y Marchionni 2009; 2013 e.p.; Miotti et al. 2008) acerca de los grupos cazadores-recolectores que habitaron este sector de la meseta central. Las investigaciones llevadas a cabo en el sitio y sus alrededores han permitido identificar numerosas fuentes de recursos minerales y bióticos, disponibilidad de agua permanente (mallín que recorre unos $10 \mathrm{~km}$ en sentido SO-NE) lo que sirve como atractor de animales (Miotti 2010).

Las materias primas líticas son de muy buena calidad para la talla y los minerales pigmentarios para la elaboración de pinturas se encuentran asimismo disponibles en esta localidad (Carden 2009; Hermo 2008a y b; Magnin 2010; Miotti 2008; 2010; Miotti et al. 2007; Miotti et al. 2011; 2013 e.p.). 


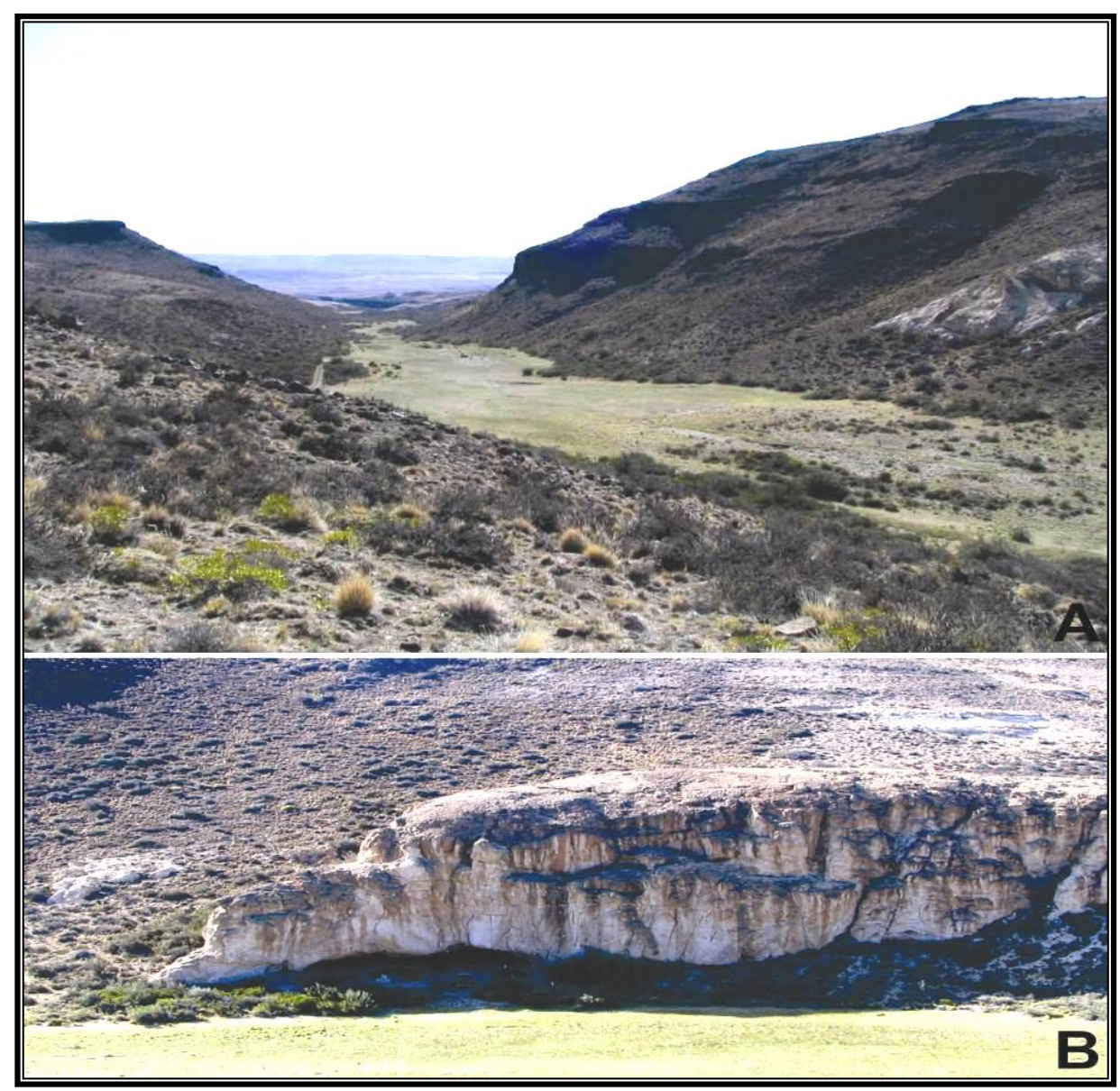

Figura 11: Panorámica y visibilidad del área. A) Vista del mallín de La Primavera. B) Sitio Cueva Maripe tomada desde la Cantera Rocky la más cercana al sitio (Foto tomada de la campaña 2010, LV).

Cueva Maripe se localiza específicamente a los $47^{\circ} 51^{\prime} 05^{\prime}$ ' S y $68^{\circ} 56^{\prime} 03^{\prime}$ ' O y corresponde a una cueva externa de unos $24 \mathrm{~m}$. de boca y $26 \mathrm{~m}$. de profundidad desde la línea de goteo con un declive natural de la superficie actual de 12, $5 \%$ hacia la entrada (Miotti et al. 2007). En su interior se encuentra dividida por un tabique rocoso que separa la cueva en dos grandes sectores, cámara norte $(\mathrm{CN})$ y sur $(\mathrm{CS})$, siendo la $\mathrm{CN}$ el área de mayor tamaño. La secuencia cultural de Cueva Maripe indica una alta redundancia ocupacional evidenciada a partir de la gran cantidad de restos materiales recuperados (instrumentos líticos y óseos, arte mobiliar y pigmentos, al igual que restos óseos y vegetales). Cabe aclarar también, que debido a sus características específicas, protección y reparo de los fuertes vientos del sur y del oeste, esta cueva habría sido utilizada hasta 1950 por la familia a la cual debe su nombre, los vestigios de su presencia se encuentra evidenciados en la CS, a partir de una pirca que delimitaba el sector doméstico (área de fogones y cocina) donde fueron hallados materiales de vidrio y metal (Miotti et al. 2007). 
Las características particulares de cada cámara que compone la cueva hace que difieran entre sí, y debido a esto el análisis de los materiales recuperados en estratigrafía han sido llevados a cabo teniendo en consideración estas diferencias. Las características microambientales de cada cámara ha permitido plantear en trabajos anteriores la hipótesis de uso diferencial en los distintos momentos de ocupación identificados (Hermo 2008; Marchionni 2013; Miotti y Marchionni 2009; Miotti et al. 2007; Lynch 2011, 2013). Actualmente y debido a estas características particulares han sido realizados análisis a partir de distintas líneas de investigación (tafonómicos, zooarqueológicos, geoarqueológicos, de estructura del espacio y análisis macroscópico lítico), aplicando SIG intrasitio con el fin de ajustar la resolución temporal y generar un conocimiento más acabado acerca de las ocupaciones humanas (Miotti et al. 2013 e.p.). Con anterioridad a estos estudios, se observó que la estratigrafía de $\mathrm{CN}$ presentaba una mayor potencia sedimentaria que la sur, lo que habría permitido discriminar concentraciones de materiales asignándolos a dos conjuntos (superior e inferior). Mientras que en CS, la secuencia se encuentra más comprimida sin poder observarse esta diferenciación clara en la distribución de los materiales, considerándolos como una sola unidad de análisis (Miotti et al. 2007).

Los recientes estudios han permitido profundizar en esta temática generando una clara diferenciación en seis capas, tres de las cuales presentan abundantes restos materiales (Miotti et al. 2013 e.p.). 


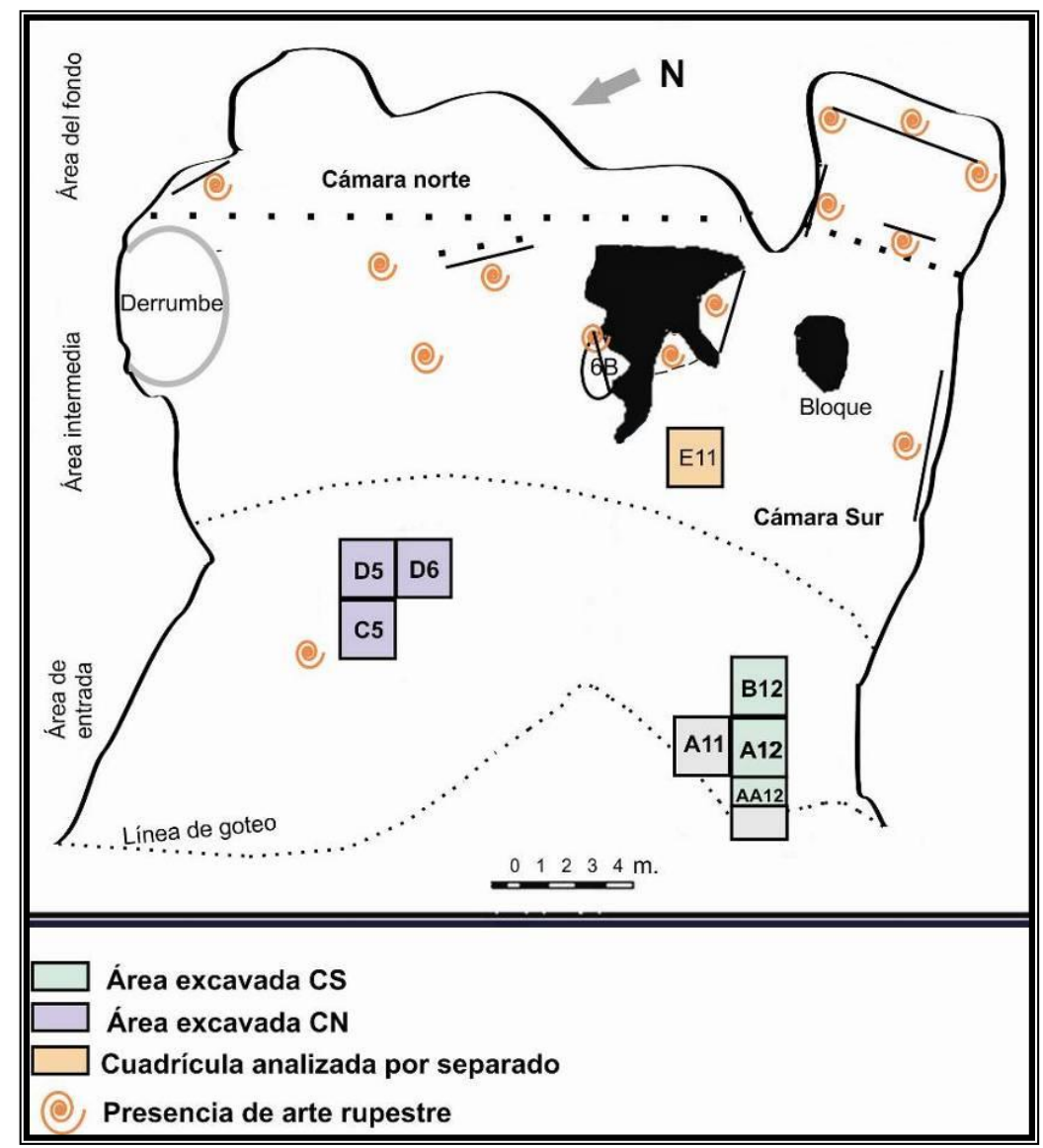

Figura 12: Plano del sitio Cueva Maripe, cuadrículas excavadas período 2003-2007. ${ }^{1}$

\section{VI.2. Geoarqueología de la cueva}

Las excavaciones arqueológicas de Cueva Maripe fueron realizadas en los dos sectores mencionados con anterioridad y hasta el presente han sido excavadas 9 cuadrículas de $2 \mathrm{~m} \times 2 \mathrm{~m}$ y una de $2 \mathrm{~m} \times 1 \mathrm{~m}$ (la muestra analizada proviene de 8 de estas cuadrículas), cubriendo una totalidad de $34 \mathrm{~m}^{2}$ y siguiendo niveles artificiales de $10 \mathrm{~cm}$. con control de las capas naturales. Se procedió de esta manera debido a los límites transicionales de estas capas.

Las características particulares a nivel estratigráfico de cada cámara permiten registrar diferencias en relación a rasgos geológicos y estratigráficos particulares. Estas diferencias incluyen la tasa de depositación del sedimento que varía entre ambas cámaras (1cm cada 103 años en CN mientras que en CS $1 \mathrm{~cm}$ cada 250 años), lo que impide su correlación (Miotti et al. 2007). Sin embargo, la capa superficial de guano

\footnotetext{
${ }^{1}$ Cabe aclarar que las cuadrículas E11 y A11 no fueron consideradas en esta tesis. La E11 no posee hasta el momento ningún fechado radiocarbónico y los materiales procedentes de la A11 todavía no han sido analizados. Estos objetivos se presentan como parte de la agenda a futuro expuesto en el Capítulo VIII de este manuscrito.
} 
recubre de manera homogénea ambos sectores, con aporte de la roca de caja (tobas de la Formación Chön Aike, Panza 2001). Por debajo se extiende la capa 2, que corresponde a un evento de quemazón de la cueva en momentos históricos. Estas dos unidades apoyan sobre las demás capas, tres de las cuales presentan contenido arqueológico prehispánico (3, 4 y 5). Hacia el final de la secuencia se encuentra la capa 6 (de $0.40 \mathrm{~m}$ ) estéril en materiales arqueológicos y que corresponde a la disgregación de la roca de caja, que en la $\mathrm{CN}$ se encuentra relativamente más baja que en la CS debido a la diferencia en la tasa de depositación $(0,001 \mathrm{~cm} / a$ ño en $\mathrm{CN}$ y $0,004 \mathrm{~cm} /$ año en CS) (Miotti et al. 2011).

La caracterización composicional macroscópica de cada una de las capas fue realizada en el campo por el Dr. Rabassa (Rabassa et al. 2007) y en laboratorio microscópicamente por el Lic. Mosquera (Mosquera 2012). Los análisis realizados han permitido determinar tres segmentos de acuerdo a los rasgos composicionales de cada capa. En la CN, el segmento inferior corresponde a la capa 6, arqueológicamente estéril, de textura arenosa con ausencia de estructura interna distinguiéndose del resto de la secuencia. El segmento medio corresponde a las capa 3, 4 y 5 de la secuencia estratigráfica. Con textura que varía entre grava-areno-fangosa y areno-fango-gravosa con un incremento del porcentaje de grava debido al derrumbe del techo de la cueva. Asimismo, se identificó un alto contenido de carbón y estructuras de combustión principalmente en la capa 4.

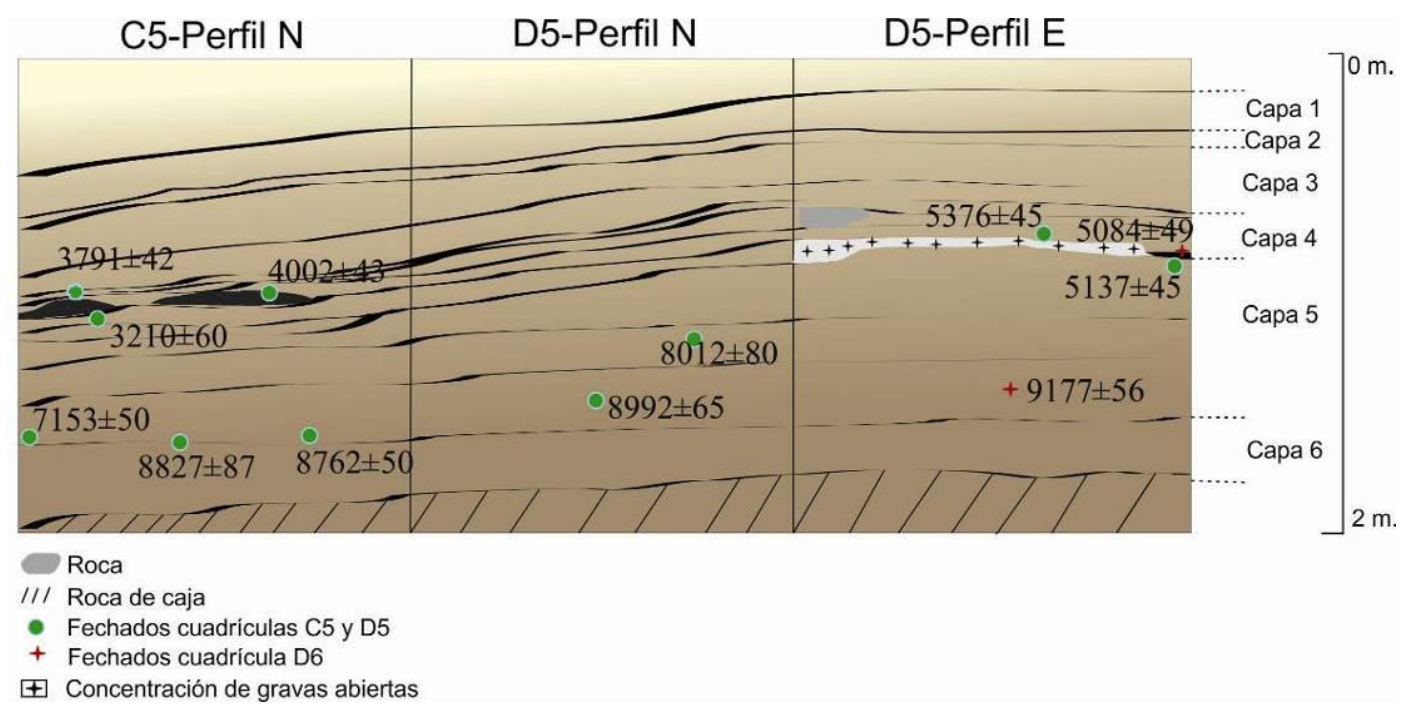

Figura 13: Dibujo de la estratigrafía de CN y fechados obtenidos de las cuadrículas excavadas (modificado de Miotti et al., en prensa) 
La CS presenta una mayor complejidad en su estratigrafía, ya que la secuencia se halla más comprimida que en el sector norte. Las excavaciones se realizaron de la misma manera, a partir de niveles artificiales de $10 \mathrm{~cm}$ cada uno debido a que la baja tasa sedimentaria comprimió el depósito dando una imbricación de los fogones y de los materiales. Al igual que en $\mathrm{CN}$, fueron distinguidos tres componente a partir de la caracterización microscópica de cada capa identificada del perfil sur de las cuadrículas A12 y B12. Sin embargo, a diferencia de la CN se observó una filtración intermitente de agua mediante escurrimiento a través de la roca de caja. El componente inferior (capas 5 y 6) de 0,25 m de potencia, presenta una textura areno-fango-gravosa, sin estructuración y compuesta principalmente por roca de caja con bajo aporte de clastos. La capa 6, al igual que en la $\mathrm{CN}$, es arqueológicamente estéril, posee una escasa potencia apareciendo en algunos sectores de la cámara. Los clastos de la roca de caja de CS se encuentran más redondeados debido a la presencia de mayor humedad lo que a su vez habría influido en una mayor compactación de este sector y a la formación de un "pantano" principalmente en la capa 3 (Mosquera 2012).

El segmento medio (capa 3 y 4) presenta una textura areno-fango-gravosa y fangogravoso, con estructuración de ámbito palustre y abundante presencia de carbones en la base de la capa 3 (Rabassa et al. 2007). Mientras que el segmento superior se encuentra constituido igualmente que en la cámara norte por estiércol de ganado (Miotti et al. 2007; 2011).

B12 Perfil S

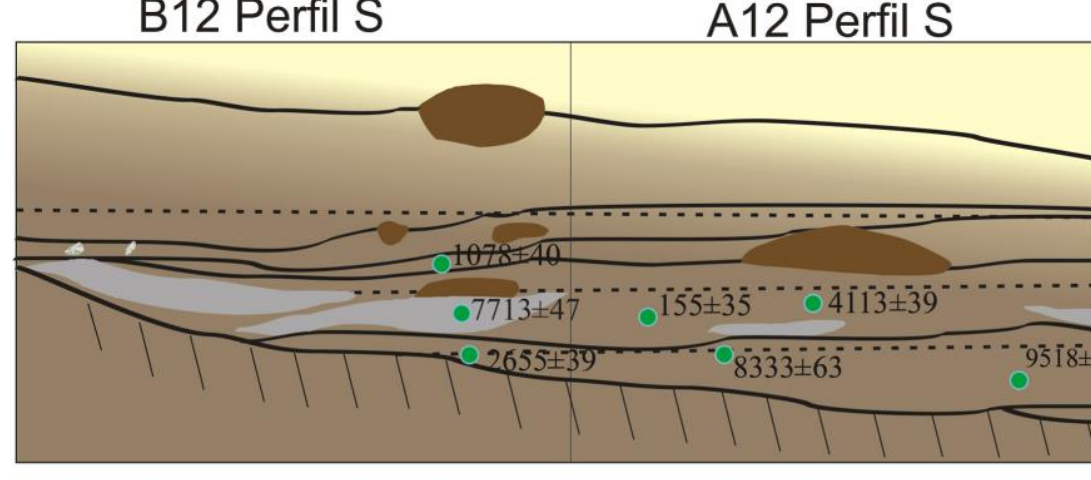

Rocas

III Roca de caja

UA Unidad analítica

\section{A12 Perfil S}

Figura 14: Dibujo de los perfiles de CS y fechados asociados a cada capa identificada (modificado de Miotti et al., en prensa). 


\section{VI.3. Contexto arqueológico y cronología}

Los materiales recuperados de Cueva Maripe proceden de ambos sectores mencionados con anterioridad e incluye artefactos líticos y óseos en conjunto con arte rupestre. Estos materiales se encuentra asociados a fechados que abarcan los bloques temporales ubicados desde la transición Pleistoceno-Holoceno hasta el Holoceno tardío.

Los fechados obtenidos hasta el momento en $\mathrm{CN}$, de cada una de las capas identificadas, corresponden a un total de 14 dataciones (Miotti et al. 2011) y 8 para CS, sin superposición entre ambas cámara. En estos fechados se incluyen 2 que pertenecen al panel 6B cuyos materiales aún se encuentran en proceso de análisis. A continuación se presentan estos fechados y su procedencia a nivel estratigráfico.

\begin{tabular}{|c|c|c|c|c|c|c|c|}
\hline$n$ & Capa & Cuadrícula & Sector & Código & ${ }^{14} \mathrm{C}$ años $A P$ & Cal. AP & Material \\
\hline \multicolumn{8}{|c|}{ Cámara Norte } \\
\hline 1 & 5 & D6 & SW & AA951 & $9177 \pm 56$ & $10496-10234$ & Carbón \\
\hline 2 & 5 & D5 & NW & AA65179 & $8992 \pm 65^{*}$ & $10249-9912$ & Carbón \\
\hline 3 & 5 & C5 & NW & AA95127 & $8827 \pm 87$ & $10181-6909$ & Hueso \\
\hline 4 & 5 & D5 & SE & AA95126 & $8012 \pm 80$ & $9091-8608$ & Hueso \\
\hline 5 & 5 & C5 & SE & AA65178 & $8762 \pm 50 *$ & $10115-9556$ & Carbón \\
\hline 6 & 5 & $\mathrm{C} 5$ & $\begin{array}{c}\text { NW } \\
\text { SE perfil }\end{array}$ & AA99069 & $7153 \pm 50$ & $8152-7858$ & Carbón \\
\hline 7 & 4 & D5 & E & AA99071 & $5376 \pm 45$ & $6284-6004$ & Carbón \\
\hline 8 & 4 & D5 & SE & AA99070 & $5137 \pm 45$ & $5990-5749$ & Carbón \\
\hline 9 & 4 & D6 & SE & AA65173 & $5084 \pm 49 *$ & $5928-5716$ & Carbón \\
\hline 10 & 4 & $\mathrm{C} 5$ & $\mathrm{NE}$ & AA99067 & $4002 \pm 43$ & $4782-4300$ & Carbón \\
\hline 11 & 4 & C5 & NW & AA99068 & $3791 \pm 42$ & 4383-3992 & Carbón \\
\hline 12 & 4 & $\mathrm{C} 5$ & $\mathrm{NE}$ & LP-1497 & $3210 \pm 60^{*}$ & $3579-3272$ & Carbón \\
\hline 13 & & P6B & SE & AA95123 & $3535 \pm 62$ & $3980-3642$ & Hueso \\
\hline 14 & & P6B & SW & AA95124 & $1907 \pm 48$ & 1949-1719 & Hueso \\
\hline \multicolumn{8}{|c|}{ Cámara Sur } \\
\hline 1 & 4 & A12 & SW & AA65175 & $9518 \pm 64 *$ & $11102-10594$ & Carbón \\
\hline 2 & 4 & A 12 & SE & AA65174 & $8333 \pm 63^{*}$ & $9479-9136$ & Carbón \\
\hline 3 & 3 & B12 & SW & AA65177 & $7703 \pm 47 *$ & $8584-8411$ & Carbón \\
\hline 4 & 3 & A 12 & SE & AA65181 & $4113 \pm 39 *$ & $4821-4522$ & Carbón \\
\hline 5 & 2 & B12 & SW & AA65176 & $1078 \pm 40^{*}$ & $1061-928$ & Carbón \\
\hline 6 & 3 & A12 & SE & AA95121 & $155 \pm 35$ & $285-(-2)$ & Carbón \\
\hline 7 & 4 & B12 & SW & AA95122 & $2655 \pm 39$ & $2849-2736$ & Carbón \\
\hline 8 & 2 & A 11 & NW & AA95118 & $1403 \pm 46$ & $1394-1264$ & Hueso \\
\hline
\end{tabular}

Tabla 4: Fechados obtenidos hasta el momento de los distintos sectores de Cueva Maripe (Miotti et al. en prensa). *Fechados publicados en Miotti et al. 2007: 558.

En un trabajo reciente (Miotti et al. en prensa) se exponen los resultados obtenidos a partir de la aplicación de técnicas de SIG intrasitio mediante un modelo digital (software GRASS 6.4), para ajustar la resolución temporal y estratigráfica de Cueva Maripe. Este modelo permitió dividir la secuencia, al menos para $\mathrm{CN}$, lo que facilitó el 
estudio del conjunto arqueológico con una mayor resolución (Miotti et al. 2007 y Hermo 2008).

Así, se generaron modelos tridimensionales (modelos de elevación digital - MED) representativos de las diferentes capas observadas en la estratigrafía de la cueva, a partir de las cuales se testeó la asignación de capa a cada uno de los registros tridimensionados, extendiendo el análisis de los materiales en relación a su contexto estratigráfico (Ceraso 2011, Informe de Beca UNLP; Miotti et al. 2011).

Debido a esto y siguiendo los criterios ya establecidos con anterioridad para el estudio de los conjuntos faunísticos recuperados de CS (Marchionni 2013), en esta tesis se consideran los niveles artificiales utilizados durante las excavaciones para la asignación de unidades analíticas, agrupadas igualmente en tres bloques temporales, según los fechados readiocarbónicos obtenidos para esta secuencia.

\section{Arte rupestre}

Cueva Maripe presenta una gran cantidad de pictogramas en varios sectores de la cueva. En su mayoría corresponde a negativos de manos, con una mayor diversidad y cantidad de motivos en la cámara sur (Carden 2009, Motti et al. 2009). El grado de preservación de las pinturas es heterogéneo y de integridad baja sobretodo en el sector norte, debido a una mayor exposición solar como también a los fuertes vientos patagónicos. Aún así han podido ser distinguidos 14 sectores con arte rupestre localizados en las distintas áreas de la cueva en relación con la profundidad hacia el interior y la incidencia de la luz que reciben (Carden 2009). Presenta una gran cantidad de motivos pintados (225), que en su mayoría corresponde a negativos de manos (91\%), con menores proporciones de líneas (7\%), círculos y motivos zoomorfos (1\% respectivamente). La disposición de estos motivos se localizan principalmente en el sector medio y del fondo de la cueva, probablemente esto se deba a la menor preservación de las pinturas como consecuencia de la exposición solar de manera directa. A su vez, la superposición de motivos sugiere la posibilidad de diferentes momentos de producción. Sin embargo, esta situación en conjunto con los distintos niveles de ocupación registrados en la cueva dificulta una mejor contextualización temporal.

Aun así, la mayor parte de los pigmentos recuperados han sido asignados al Holoceno medio y tardío, principalmente de coloración roja y algunos pocos amarillos. Mientras que los que aparecen en CS han sido asociados al Holoceno temprano (Carden 2009). 
La muestra de pigmentos fue analizada por el Centro de Investigación Geológica de la Universidad Nacional de La Plata por DRX y los resultados son tratados de manera específica en la investigación de tesis doctoral realizada por la Lic. Rocío Blanco.

\section{Zooarqueología}

Los análisis de los conjuntos faunísticos realizados hasta el momento incluyeron los materiales asignados tridimensionalmente (Miotti y Marchinni 2009) como también la secuencia estratigráfica completa (Marchionni 2013).

Los resultados obtenidos indican que el guanaco (Lama guanicoe) habría sido la especie mayormente representada en ambos sectores de la cueva. Los perfiles de meteorización muestran tendencias más marcadas de estadios más bajos en CN que en CS, mientras que las tendencias de fragmentación ocurren a la inversa siendo mayor en la CS, al igual que la frecuencia de especímenes con signos de alteración térmica (Marchionni 2013).

Estos resultados permitieron concluir que los guanacos habrían sido introducidos al sitio como resultado de cacerías en la zona, habiéndose realizado actividades de procesamiento secundario y consumo con uso heterogéneo del espacio interior de Cueva Maripe, lo que estaría indicando que el sitio habría funcionado como una base residencial donde el mayor procesamiento habría sido realizado en CS (Marchionni et al. 2012).

\section{Análisis del conjunto lítico}

Los análisis realizados con anterioridad a esta tesis incluyen estudios macroscópicos de los conjuntos recuperado en estratigrafía (Hermo 2008). A su vez, estos materiales se encontraban asignados a partir de esta primera aproximación de grano grueso en donde $\mathrm{CN}$ presentaba dos componentes, mientras que CS, era considerado como una sola unidad de análisis, con un menor grado de resolución para poder discriminar distintos bloques temporales. En cuanto a los estudios realizados hasta el momento, a partir del análisis de estos conjuntos líticos, muestran que el mayor número de artefactos se encuentra en la CS; mientras que la representación de artefactos formales es similar en ambos sectores (Hermo 2008). Sin embargo, las ocupaciones identificadas igualmente permitieron determinar diferencias en cuanto a las concentraciones. La mayor cantidad de artefactos corresponden al Holoceno medio en ambos sectores de la cueva, con una 
amplia y clara predominancia de raspadores de filo frontal corto. Por otro lado, la presencia de núcleos (principalmente de materias primas silíceas de procedencia local), evidenciarían las etapas iniciales de reducción que serían continuadas y/utilizadas en CS. Este proceso de talla, también registra la presencia de armas ya que en CS han podido ser recuperadas puntas de proyectil, algunas de las cuales, fueron elaboradas sobre materias primas no locales o alóctonas. Mientras que en $\mathrm{CN}$ fueron hallados tres fragmentos de boleadoras (Hermo 2008). De esta manera Hermo (2008) propone que la CS habría funcionado como espacio habitacional mientras que la norte conformaría un espacio alternativo destinado a actividades especiales.

\section{VI.4.1 Análisis de los conjuntos artefactuales}

En $\mathrm{CN}$ los materiales líticos analizados proceden de las cuadrículas que han sido excavadas hasta la roca de caja y corresponde a C5, D5 y D6, con una superficie de 12 $\mathrm{m}^{2}$. El análisis incluyó el total de artefactos formatizados (AF) recuperados en estratigrafía y artefactos no formatizados (ANF) de tamaño mayor a 4 (sensu Aschero 1975,1983) y con filo potencialmente utilizable (de sección longitudinal rectilínea y mayores a $30 \mathrm{~mm}$ ). Los materiales líticos habían sido analizados macroscópicamente considerando las capas naturales y los niveles artificiales durante la excavación e incluyendo únicamente el bloque temporal correspondiente al Holoceno medio (Hermo 2008). En esta tesis la aplicación de SIG intrasitio ha permitido ajustar el grado de resolución asignándole capas a los materiales mediante modelos tridimensionales. Es por esta razón, que se han tenido en cuenta algunas variables tecno-morfológicas (Aschero 1975, 1983) para realizar el estudio funcional y de diseño de los materiales correspondientes a las distintas ocupaciones identificadas en el sitio. Los artefactos recuperados se encuentran distribuidos en 4 de las 6 capas detalladas a partir de estos estudios, siendo la capa 4 la que presenta una mayor concentración de elementos.

En CS se analizó, al igual que en el sector norte, el total de AF y se tuvo en consideración las mismas características para la muestra de los ANF. Estos materiales proceden de las cuadrículas A12, B12, distribuidos al igual que en cámara norte, en 6 capas de las cuales 3 presentaron materiales. 


\section{Cámara norte $(\mathrm{CN})$ :}

El estudio de los conjuntos líticos recuperados fue realizado a partir de cada una de estas capas, teniendo en consideración los fechados obtenidos a partir de la secuencia de ocupaciones.

Los conjuntos analizados totalizan 104 artefactos formatizados (AF) de los cuales fueron observados (filos y superficie) mediante microscopía óptica un total de 198 filos. Mientras que los artefactos no formatizados (ANF) constituyen el mayor porcentaje de la muestra con un total de 235 piezas y 257 filos observados.

El análisis de distribución de los materiales líticos permitió observar que la cuadrícula D6 presentaba una mayor concentración de AF con un 47\% (N=18) en especial hacia el sector SE de esta cuadrícula, seguido en menores proporciones por la cuadrícula C5 $(\mathrm{N}=15,40 \%)$ y D5 $(\mathrm{N}=5,13 \%)$. Mientras que la distribución de los ANF presenta igualmente una mayor concentración de materiales en la D6 con un $(\mathrm{N}=55,48 \%$ (principalmente hacia el sector SW, seguido por las cuadrículas C5 (N=39, 34\%) y D5 $(\mathrm{N}=21,18 \%)$.

\section{VI.4.1.1. Conjunto lítico de Capa 5}

Esta capa es la más antigua con registro de materiales arqueológicos y posee un fechado del techo de ca. 9177 a 7153 años AP, lo que permitiría relacionarlo al Holoceno temprano o a la transición Pleistoceno/Holoceno (ver Borrero et al. 1998; Miotti 1998; Miotti y Salemme 1999).

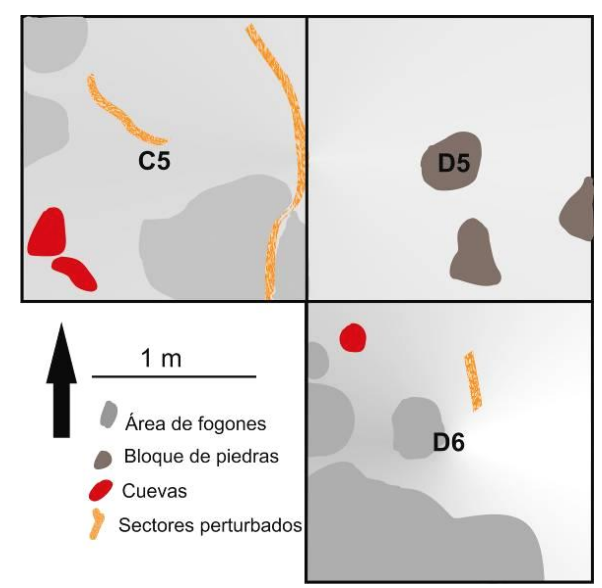

Figura 15: Dibujo en planta de la capa 5 de CM, rasgos y agentes principales tafonómicos (modificado de Marchionni 2013). 
De esta capa se recuperó un $28 \%(\mathrm{~N}=38)$ del total de artefactos formatizados con 8 grupos tipológicos identificados, sin embargo, el mayormente representado en la totalidad de la muestra a lo largo de toda la secuencia, corresponde al grupo de raspadores.
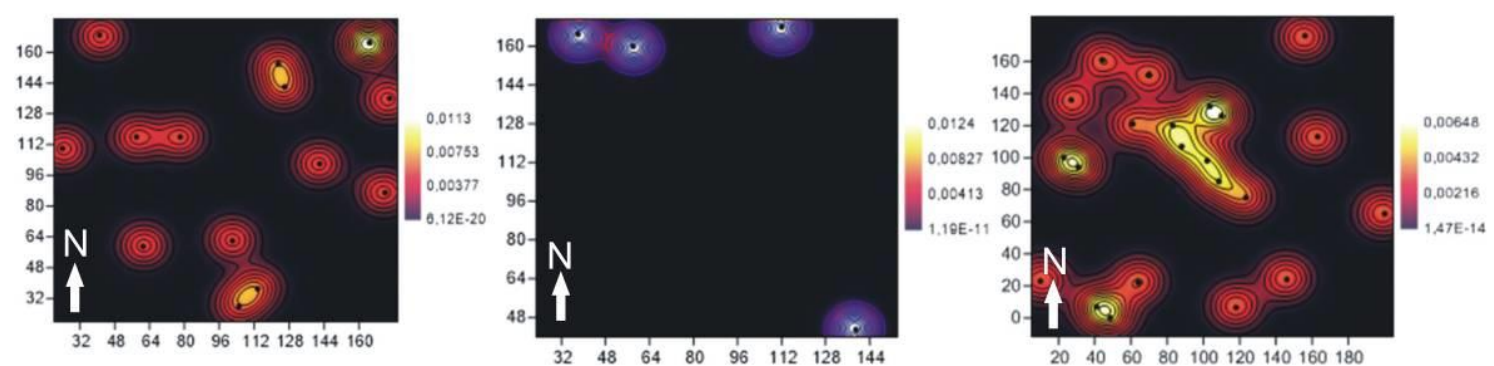

Figura 16: Distribución espacial de AF en la capa 5, cuadrículas C5, D5 y D6.

Los artefactos formatizados se encuentran elaborados en su mayoría sobre materias primas locales, con amplia representación de rocas con alto contenido silíceo, principalmente de la variedad ISG1 (34\% del total de la muestra) (Figura 17).

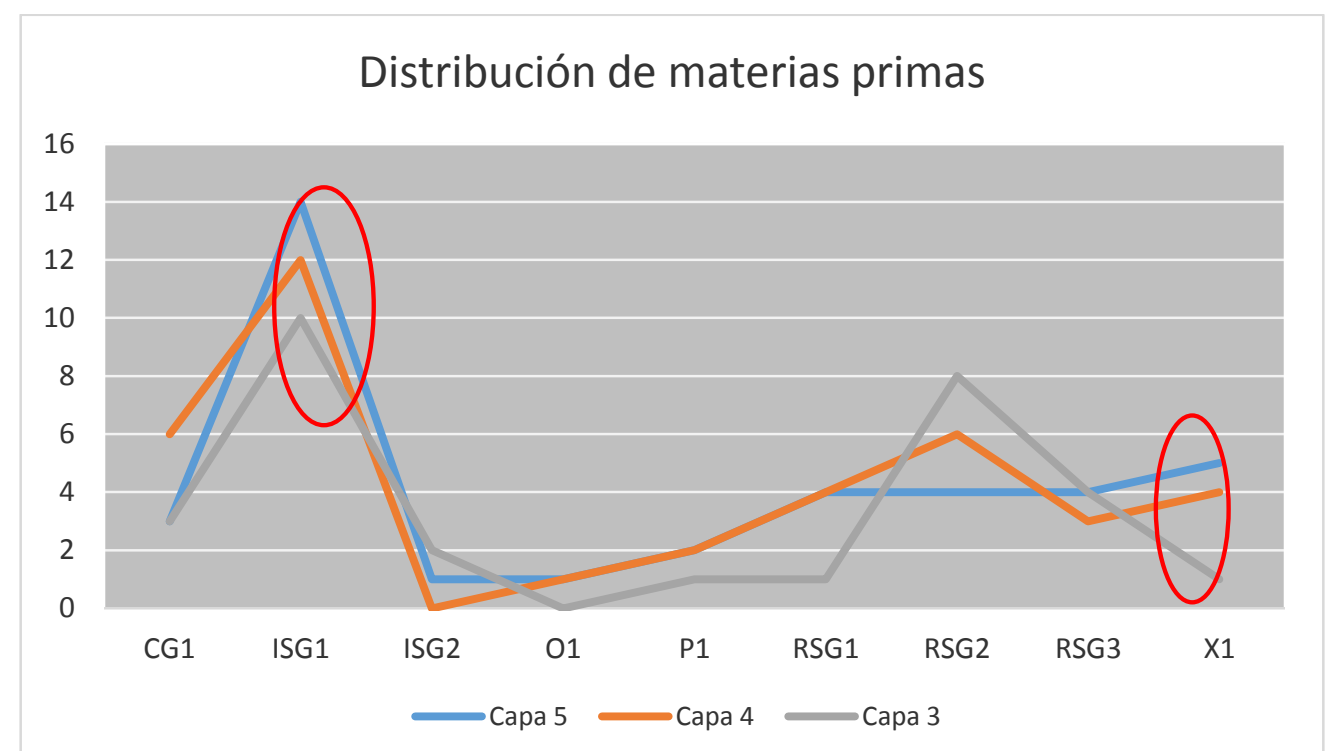

Figura 17: Distribución de las materias primas por capa identificadas en CN. CG1: calcedonia grupo 1; ISG1: ignimbrita silicificada grupo 1; ISG2: ignimbrita silicificada grupo 2; O1: obsidiana; PG1: ópalo grupo 1; RSG1: roca silícea grupo1; RSG2: roca silícea grupo 2; RSG3: roca silícea grupo 3 y X1: xilópalo grupo 1.

Sin embargo, en la capa 5 se han notado ciertas diferencias en cuanto a la selección de materias primas para la elaboración de artefactos formatizados. Se observa una mayor utilización de xilópalo (13\%) que en el resto de la secuencia de cámara norte, donde este tipo de materia primas se haya en menores proporciones (Capa $410 \%$ y capa 3 3\%). La 
única materia prima alóctona identificada para la confección de AF corresponde a la obsidiana (de coloración negro), cuya procedencia se encuentra relacionada al sector denominado Pampa del Asador, a unos $120 \mathrm{~km}$ al oeste de distancia de esta cueva (Magnin 2010). Sin embargo, el uso de xilópalo junto con obsidiana correspondería a rocas de trayectorias mayores a $50 \mathrm{~km}$ (Hermo 2008, 2009, Figura 18).

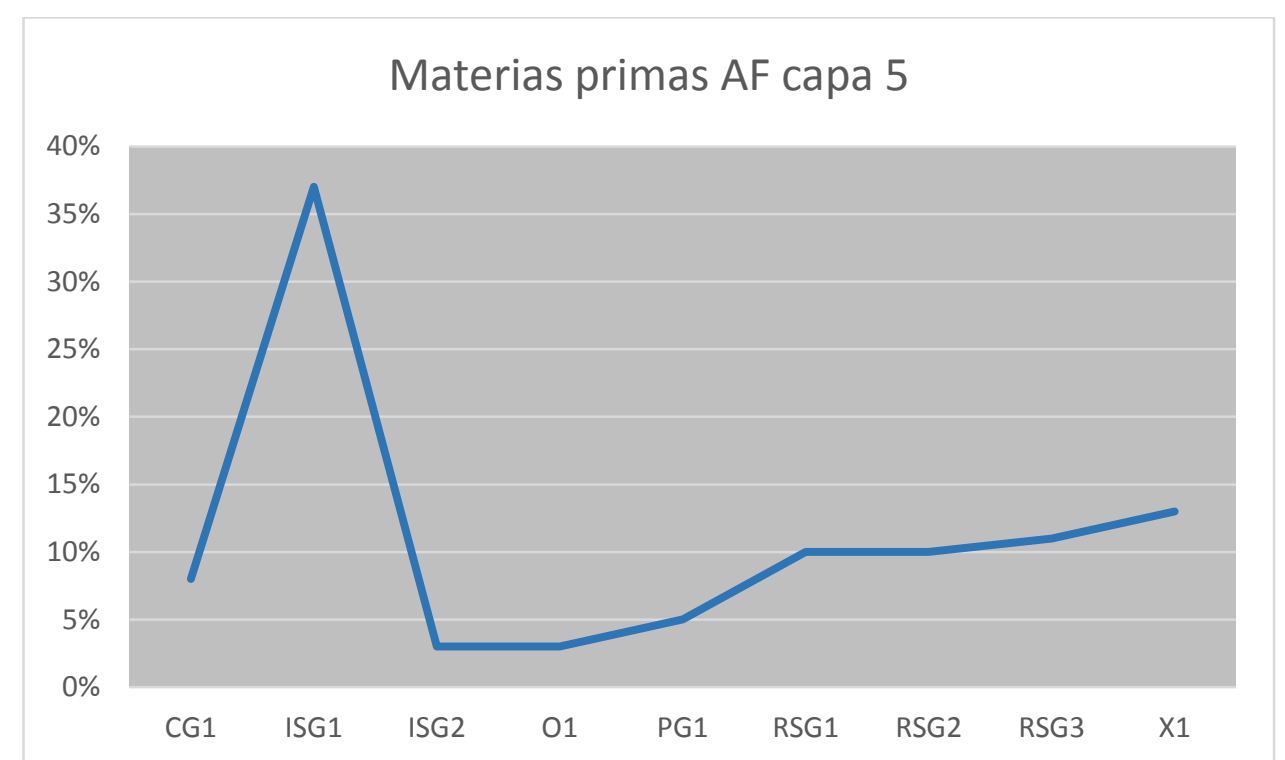

Figura 18: Variedades de materias primas identificadas en los artefactos formatizados de capa 5. CG1: calcedonia grupo 1; ISG1: ignimbrita silicificada grupo 1; ISG2: ignimbrita silicificada grupo 2; O1: obsidiana; PG1: ópalo grupo 1; RSG1: roca silícea grupo1; RSG2: roca silícea grupo 2; RSG3: roca silícea grupo 3 y X1: xilópalo grupo 1.

En cuanto al estado de las piezas el mayor porcentaje corresponde a las piezas fracturadas sin talón (50\%) seguido por piezas enteras $(35 \%)$ y fracturadas con talón $(15 \%)$.

La selección de formas bases para la confección de los artefactos formatizados incluye tanto lascas como hojas y en algunos casos no han podido ser determinadas por el estado de la pieza. Sin embargo, la selección de estas formas varía en las distintas ocupaciones identificadas en el sitio. En la capa 5 el mayor porcentaje corresponde a lascas $(50 \%)$ y en menor medida a hojas como formas bases.

A continuación se presentan los grupos tipológicos identificados en la capa 5, detallándose las características principales de sus elementos, con el fin de indagar en el diseño elegido a lo largos de las ocupaciones del sitio (Tabla 5). 


\begin{tabular}{|c|cccccccccccc|}
\hline AF & BF & CP & CU & FND & MUR & PBS & PP & RD & RP & UF & FNRC \\
\hline $\begin{array}{c}\text { Capa5 } \\
\text { Piezas N=38 }\end{array}$ & 5 & 1 & 1 & - & 1 & & 1 & 1 & 6 & 20 & 2 & - \\
\hline $\begin{array}{c}\text { Total filos } \\
(\mathbf{N = 6 1 )}\end{array}$ & 5 & 1 & 1 & 9 & 1 & 1 & 1 & 11 & 24 & 2 & 5 & \\
\hline
\end{tabular}

Tabla 5: Grupos tipológicos identificados en la capa 5 de CN. BF: Pieza bifacial; CP: cepillo; CU: cuchillo; FND: filo no diferenciado; MUR: muesca retocada; PP: punta de proyectil; RD: raedera; RP: raspador; UF: unifaz; FNRC: filos naturales con rastros complementarios.

\section{-Piezas Bifaciales y Unifaciales (BF/UF)}

El grupo de piezas bifaciales y unifaciales consta de pocos especímenes, sin embargo la totalidad de estos grupos se encuentra en la capa 5 . Se registraron 5 bifaces y 2 piezas trabajadas unifacialmente. Las materias primas seleccionadas para su confección corresponden al igual que en la mayorías de los artefactos formatizados a rocas de origen local, criptocristalinas y con alto contenido silíceo, de muy buena calidad para la talla. Dentro de las variedades identificadas se pudo determinar las siguientes materias primas: ISG1 (43\%) y en menor medida PG1 (15\%), ISG2 (14\%), X1 (14\%) y RSG1 (14\%). En cuanto a las variables métricas, las piezas presentaron en su mayoría tamaños grandes (83\%) a mediano-grandes (17\%), con módulo de longitud-anchura principalmente corto muy ancho $(50 \%)$.

\section{-Cepillos (CP)}

Este grupo tipológico se encuentra constituido por un único elemento en el sector norte dentro de la cueva y elaborado sobre una roca silicificada del grupo 2 (RSG2) de coloración marrón. Este cepillo presenta un tamaño muy grande y módulo de longitudanchura mediano-normal. En cuanto al filo potencialmente utilizable se pudo observar la presencia de un solo filo con una longitud de $86,5 \mathrm{~mm}$ y ángulo del filo rectilíneo de $87^{\circ}$.

\section{-Filos No diferenciados (FND)}

Este grupo constituye el $11 \%$ del total de la muestra de artefactos formatizados en capa 5 presentando un total de 3 piezas con 4 filos potencialmente utilizables. La materia 
prima para su confección fue la ISG1 de coloración roja. El tamaño de la muestra en todos los casos fue grande, mientras que el módulo mediano alargado estuvo más representado (67\%). En relación a los filos potencialmente utilizables se determinó una longitud promedio de $41 \mathrm{~mm}$ y un ángulo promedio de $54^{\circ}$.

\section{-Muesca retocada}

El grupo se encuentra representado por un solo elemento en la capa 5. Esta pieza corresponde a la única pieza confeccionada sobre obsidiana negra para los momentos iniciales de ocupación. Cabe aclarar, que si bien en el resto de la secuencia se ha registrado un mayor porcentaje de elementos sobre este tipo de materia prima, este artefacto reviste atención, ya que hasta el momento no ha podido ser encontrado la fuente primaria de procedencia en sectores cercanos.

En cuanto a las características principales se puede mencionar que presenta un tamaño mediano pequeño y módulo de longitud-anchura corto ancho.

\section{-Punta de Proyectil (PP)}

Corresponde a una punta de proyectil apedunculada elaborada sobre una variedad de roca silícea grupo 1 (RSG1) de coloración negro, tamaño mediano pequeño y módulo de longitud-anchura mediano normal.

\section{-Grupo de raspadores (RP)}

Como ha sido mencionado este grupo tipológico se encuentra ampliamente representado a lo largo de la secuencia de ocupación de Cueva Maripe, con un 33\% del total de la muestra de artefactos formatizados. Sin embargo, las características particulares de estos han permitido determinar ciertas diferencias tanto en el diseño elegido para su elaboración como en el uso concreto de los mismos. La totalidad de elementos adscriptos a este grupo en $\mathrm{CN}$ corresponde a 54 piezas con 116 filos. En su mayoría se encuentran elaborados sobre una gran variedad de materias primas silíceas criptocristalinas, principalmente de la variedad ISG1 (43\%). Sin embargo, la capa 5 presenta 18 raspadores, confeccionados sobre otro tipo de materias primas como 
xilópalo $(\mathrm{X} 1,23 \%)$, calcedonia (CG1, 12\%), roca silicificada (RSG2, 12\%) y menores proporciones de otras variedades de calcedonias y ópalos (6\%).

En cuanto a las variables métricas se ha podido determinar que el mayor porcentaje en la capa 5 lo ocupan los raspadores con tamaño mediano grandes (41\%), seguido en menores proporciones por aquellos de tamaños mediano pequeño $(35 \%)$ y en menor medida grandes (4\%). En cuanto al módulo de longitud-anchura se registró que el mayor porcentaje lo ocupan los rapadores medianos normales (47\%). En cuanto a las características de los filos principales, se observó un ángulo promedio de $30^{\circ}$ y una longitud de $70 \mathrm{~mm}$. Sin embargo, del total de la muestra un $78 \%$ presentaron filos complementarios, entre los cuales se identificaron filos secundarios de raspadores (18 $\%)$, muescas retocadas $(6 \%)$, RBO $(5 \%)$, raederas $(3 \%)$, cuñas $(2 \%)$, filos no diferenciados $(11 \%)$ y filos naturales con rastros complementarios $(52 \%)$.

\section{-Grupo de Raederas (RD)}

Este grupo posee un menor porcentaje dentro de la muestra de artefactos formatizados (8\%), y en algunos casos se presentan como filos complementarios al grupo de raspadores. Sin embargo, en este apartado se menciona las características principales de estas piezas con el fin de observar los rasgos principales que permitan relacionarlas con usos específicos. Es así que este grupo consta de 7 piezas con 10 filos analizados. Al igual que en el caso anterior fueron elaboradas en su mayoría sobre sobre rocas criptocristalinas de tres tipos de variedades; el mayor porcentaje corresponde al xilópalo (57\%), seguido en menores proporciones por los grupos de RSG2 (15\%), ISG1 (14\%), RSG3 (14\%). En cuanto a los tamaños identificados el mayor porcentaje corresponde a piezas muy grandes (57\%), mientras que el módulo de longitud anchura más representada es el mediano normal (43\%). Del total de la muestra (29\%) solamente dos piezas presentaron filos complementario no diferenciados. 


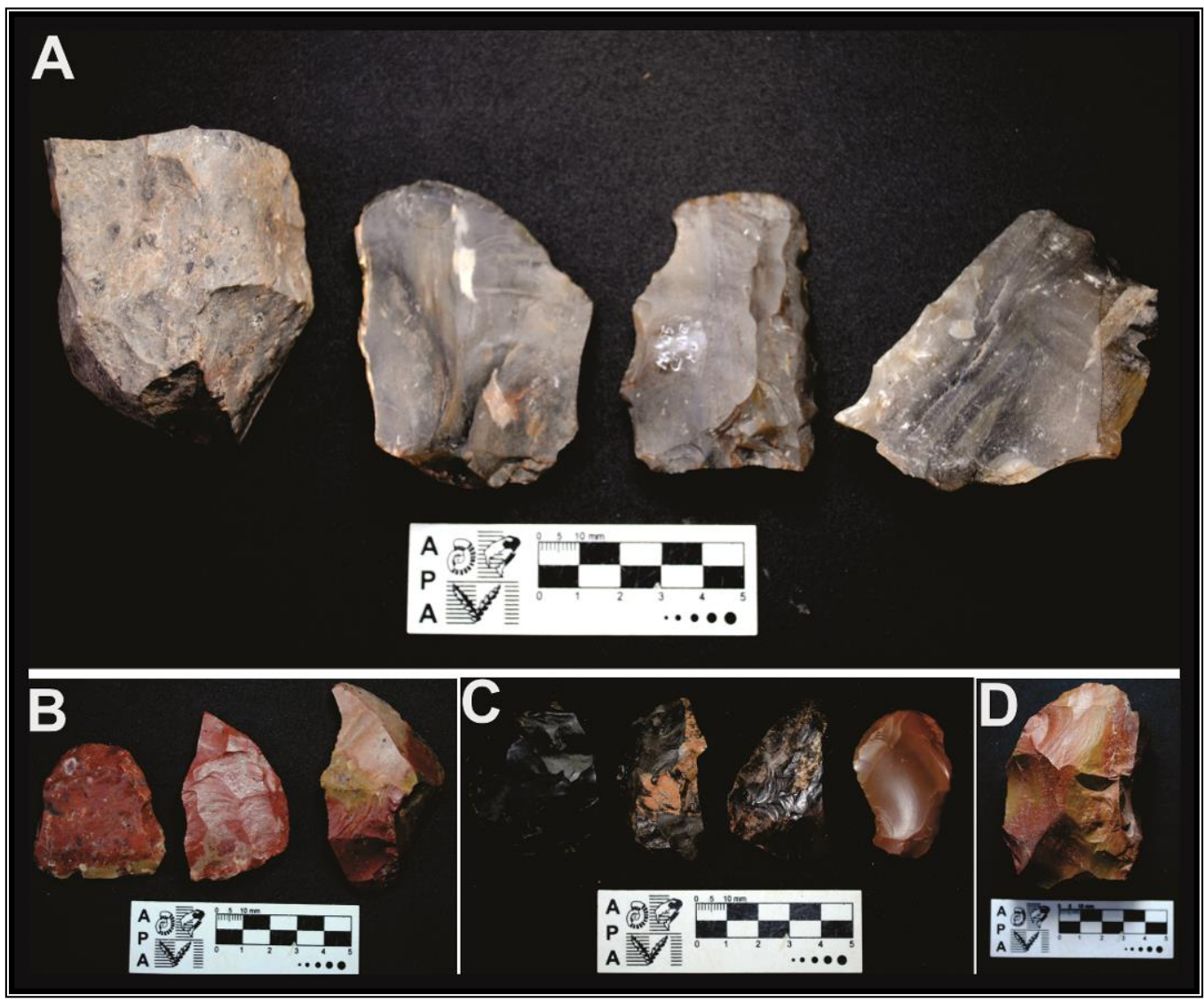

Figura 19: Materiales recuperados de la Capa 5 de CN de Cueva Maripe. A-B) Materiales de la cuadrícula C5, cepillo de filo latero-frontal, raederas de filo lateral largo y frontal, bifaz, cuchillo de filo retocado y raspador de filo frontal corto. C) Materiales de la cuadrícula D5; raedera de filo lateral, pieza

bifacial y raspador de filo frontal corto. D) Pieza recuperada de la cuadrícula D6 de talla bifacial.

\section{VI.4.1.2. Artefactos no formatizados de Capa 5}

El conjunto de artefactos no formatizado de la capa 5 constituye el $48 \%$ del total de la muestra y consta de 115 piezas con 121 filos observados bajo microscopia óptica. El mayor porcentaje de materiales fue recuperado, al igual que en el caso de los artefactos formatizados, en la cuadrícula D6 (48\%) sector SW (Figura 20).
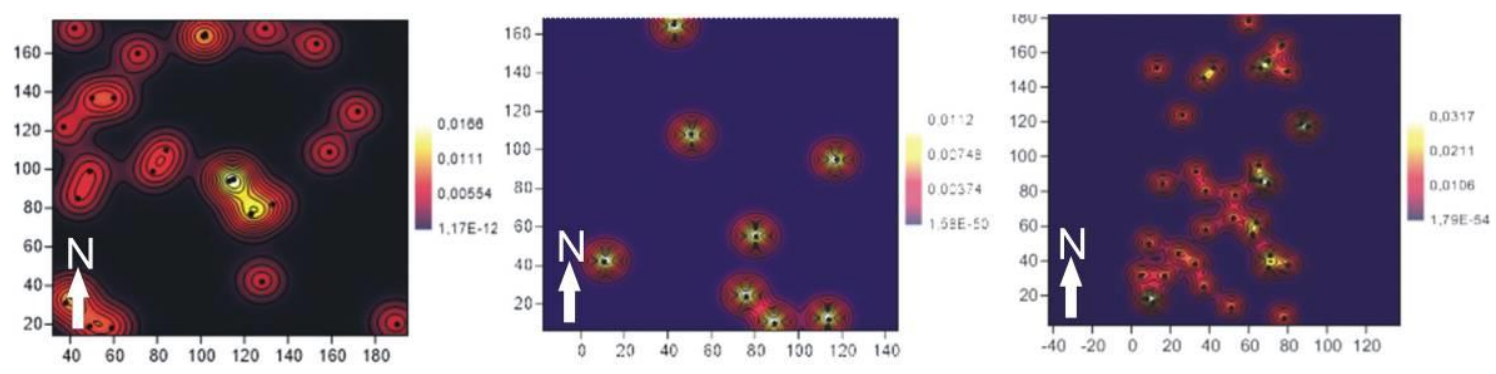

Figura 20: Distribución de densidades de ANF en Capa 5, cuadrículas C5, D5 y D6. 
La muestra a analizar ha sido seleccionada en relación al tamaño (mayor a 4) y a la presencia de filos potencialmente utilizables (de delineación rectilínea mayor a $30 \mathrm{~mm}$ ). Estas variables han sido consideradas en la totalidad del conjunto de artefactos no formatizados.

Respecto a la integridad de la muestra el mayor porcentaje lo ocupan las piezas fracturadas sin talón $(\mathrm{N}=62,54 \%)$, seguido por piezas fracturadas con talón $(\mathrm{N}=37$, $32 \%)$ y en menor medida piezas enteras $(\mathrm{N}=16,14 \%)$.

En cuanto a las materias primas utilizadas en su elaboración corresponde, al igual que en el caso de los artefactos formatizados, a rocas de procedencia local principalmente criptocristalinas y de alto contenido silíceo. Las variedades identificadas en esta capa incluyen mayores porcentajes de ópalo (PG1, $\mathrm{N}=18,16 \%)$ y roca silicificada grupo 2 (RSG2, $\mathrm{N}=17,15 \%)$ y en menor medida las variedades BS $(\mathrm{N}=2,2 \%), \mathrm{CG} 1(\mathrm{~N}=7$, $6 \%)$, ISG1 (N=3, 3\%), ISG2 (N=1; 1\%), RSG1 ( $=6,5 \%)$ y RSG3 (N=5, 4\%) (Figura 18).

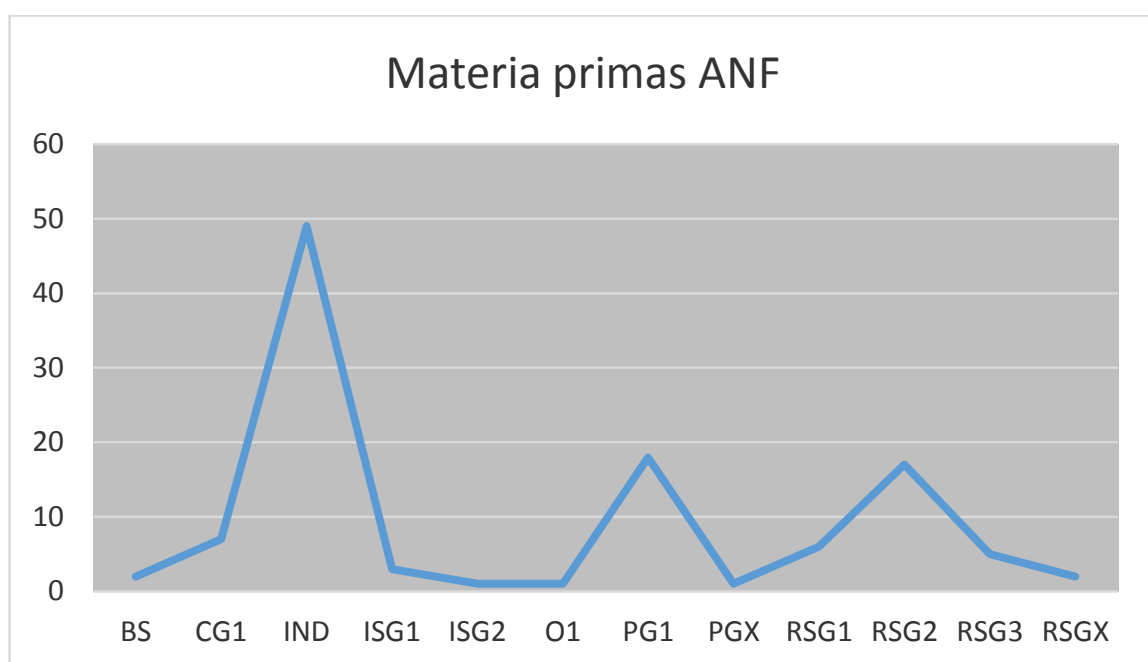

Figura 21: Histograma de materias primas identificadas en los ANF de capa 5.

El tamaño mayormente representado corresponde al mediano-grande y módulo de longitud anchura mediano normal $(\mathrm{N}=32,39 \%)$.

En cuanto a los tipos de lascas identificados se pudo observar que en la capa 5 la presencia de lascas $(\mathrm{N}=75,50 \%)$ supera a las hojas $(\mathrm{N}=21,33 \%)$, presentando una amplia variedad, donde las lascas angulares $(\mathrm{N}=47,50 \%)$ y de arista $(\mathrm{N}=27,29 \%)$ corresponden a las más representadas. En cuanto a la producción de hojas, se observa principalmente la variedad de arista simple. 
En relación a la cantidad de filos, se registró que, en su mayoría las piezas presentan un único filo potencialmente funcional, mientras que una muestra menor de piezas presentaban al menos un filo complementario $(\mathrm{N}=17)$ y en ningún caso superó este número de filos complementarios. En cuanto a la forma secundaria de los filos se registró un mayor porcentaje de filos convexos $(\mathrm{N}=44,42 \%)$ y rectilíneos $(\mathrm{N}=43,41 \%)$, mientras que la sección longitudinal o delineación de los filos en su mayoría fue rectilíneo $(\mathrm{N}=96,92 \%)$ seguido por proporciones iguales y menores de cóncavos y sinuosos $(\mathrm{N}=4,4 \%$ respectivamente $)$.

Si bien no se pudo determinar algún tipo de correlación entre la longitud (Prueba de Mann-Whitney $=\mathrm{U}=217$; $\mathrm{p}=0,94$ ) y el ángulo del filo (Prueba de Mann-Whitney= $U=151,5 ; p=0,12)$ en relación con la forma secundaria de estos; se pudo observar cierta tendencia en donde los filos con forma secundaria cóncava presentaron un ángulo de filo promedio de $40^{\circ}$, mayores que el resto de la muestra.

\section{VI.4.1.3. Resultados del análisis funcional de base microscópica}

Los datos obtenidos del análisis funcional se han dividido por ocupaciones y se las presenta de manera comparativa. El fin es identificar cambios en cuanto a los procesos productivos y las alteraciones tafonómicas en los conjuntos líticos recuperados. En lo referente a la inferencia funcional, materiales procesados, cinemáticas implementadas y actividades desarrolladas, los resultados de los filos retocados y no retocados se presentan de manera separada. Este criterio tiene como objetivo identificar diferencias o similitudes en el uso de ambas categorías artefactuales. En contraposición, en los resultados de los procesos de formación de sitio los filos retocados y no retocados se toman de manera conjunta, dado que provienen del mismo contexto de depositación y el manejo de ambas categorías artefactuales fue similar en el laboratorio.

\section{VI.4.1.3. Integridad del conjunto e identificación de alteraciones tafonómicas}

Las piezas recuperadas de la capa 5 de cámara norte incluyen un total de 153, de las cuales fueron identificados y observados bajo microscopio metalográfico un total de 179 filos. Los artefactos recuperados presentaron distintos grados y tipos de alteración sobre su superficie lo que permitió, pese a esto, la identificación del material trabajado al igual que la cinemática empleada, en algunos casos. En este sentido, se pudo observar 
que del total de la muestra de AF un 35\% (N=16) no fue determinado por alteración. Las piezas incluidas en esta categoría incluyeron un intenso grado de alteración, que impidió la observación de potenciales rastros de uso. Los tipos de alteración identificados en esta capa para los AF, corresponde principalmente a la abrasión sedimentaria $(\mathrm{N}=11,73 \%)$, seguido por termo-alteración y lustre $(\mathrm{N}=2,13 \%)$ y en menor medida por el desarrollo de pátinas $(\mathrm{N}=1,7 \%)$ y consecuencias ocasionadas por mal tratamiento de las piezas en condiciones de laboratorio (rotulado del material con PVAC, resina de acetato de polivinilo, $\mathrm{N}=1,7 \%$ ). En el caso de los ANF las piezas no determinadas por alteración intensa ocupa el 35\% (N=13) del total de la muestra. Dentro de las alteraciones más importantes reconocidas sobre los materiales se identificó: abrasión sedimentaria $(\mathrm{N}=9,69 \%)$, termoalteracion y lustre $(\mathrm{N}=2,16 \%)$ y playas de abrasión (N=2, 15\%) (Figura 22).

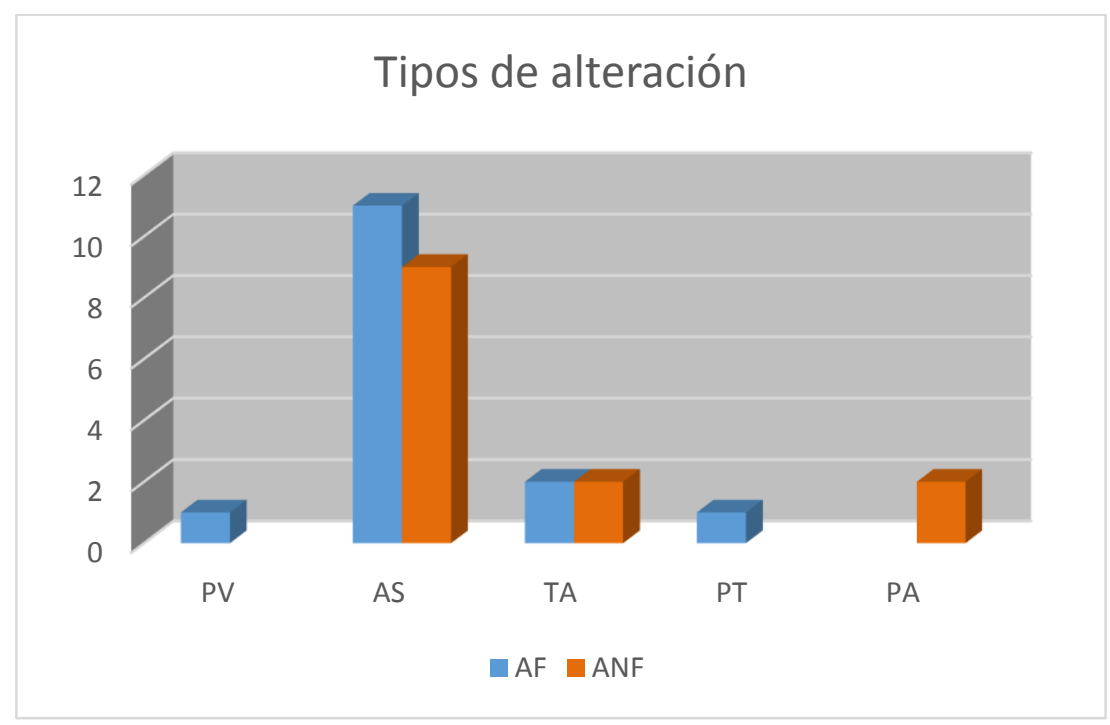

Figura 22: Tipos de alteración reconocidas en los artefactos formatizados de la capa 5 de CN. PV: alteraciones ocasionadas por el siglado en laboratorio; AS: abrasión sedimentaria; TA: termoalteración; PT: formación de pátina blanca y PA: playas de abrasión.

En relación a las características composicionales de las materias primas utilizadas en capa 5 (en su mayoría criptocristalinas u homogénea), no se observaron diferencias respecto al grado e intensidad de las alteraciones. Sin embargo, durante su estudio se pudo observar diferencias en la formación y distribución de las mismas. La abrasión por sedimento presentó un intenso desarrollo de estrías sin una determinada orientación y distribución sobre la superficie de las piezas. Mientras que en los casos donde se observó el desarrollo de pátinas de coloración blanca, estuvieron asociadas a la presencia de grietas o sectores de fractura en la microtopografía de las piezas. En cuanto 
a las playas de abrasión, estas se relacionan a un intenso desarrollo de abrasión por sedimento y en la mayoría de estos casos éstas se generaron en sectores de mayor contacto (aristas, superficies altas de la microtopografía y sectores del filo) (Figura 23).

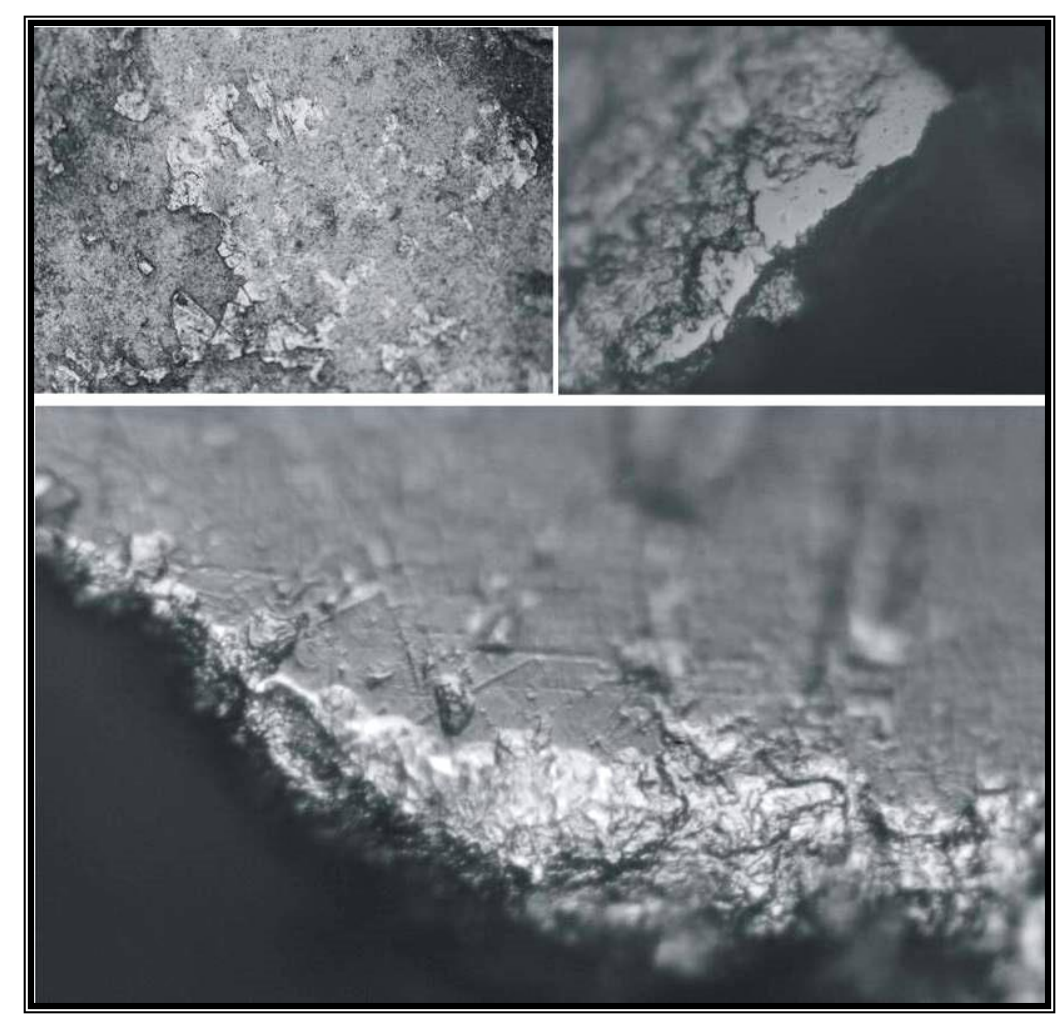

Figura 23: Fotos de alteraciones identificadas sobre los materiales recuperados en capa 5 de $\mathrm{CN}$. Abrasión sedimentaria que en algunos casos llega a formar playas de abrasión y puntos en espejo.

\section{VI.4.1.4. Inferencia funcional de las modalidades de uso}

Los resultados obtenidos del análisis funcional difieren entre los AF y los ANF en capa 5. En este sentido, el conjunto de AF presenta un 35\% ( $\mathrm{N}=21)$ de elementos con rastros de utilización, aunque el mayor porcentaje corresponde a piezas no determinadas (ND, $\mathrm{N}=24,39 \%$ ) y menores proporciones a no determinadas por alteración (NDA, $\mathrm{N}=16$, 16\%). Cabe aclarar que la categoría no determinado incluye aquellas piezas que pudieran haber sido utilizadas pero que, debido al escaso tiempo de utilización o al material trabajado, imposibilitaron un buen desarrollo de micropulidos que permitiera identificar su uso.

En cuanto a la cantidad de filos identificados por pieza se registró que en la mayoría de los casos las piezas presentaban filos simples $(\mathrm{N}=22,58 \%)$ y en menor medida dobles $(\mathrm{N}=11,29 \%)$ o múltiples $(\mathrm{N}=5,13 \%)$. Dentro de las piezas con rastros de uso 
identificado, se observó que de las piezas con un único filo un 36\% presentaron rastros de uso. En cuanto a las piezas con dos filos funcionales, el 36\% de la muestra presentaban al menos un filo con rastros de uso y $18 \%$ con dos filos. Mientras que los AF con tres filos potencialmente utilizables, presentaron un $57 \%$ de piezas con rastros de uso, $14 \%$ con dos filos usados, mientras que el $29 \%$ restante, de los tres filos identificados, no se reconocieron rastros de utilización (Figura 24).

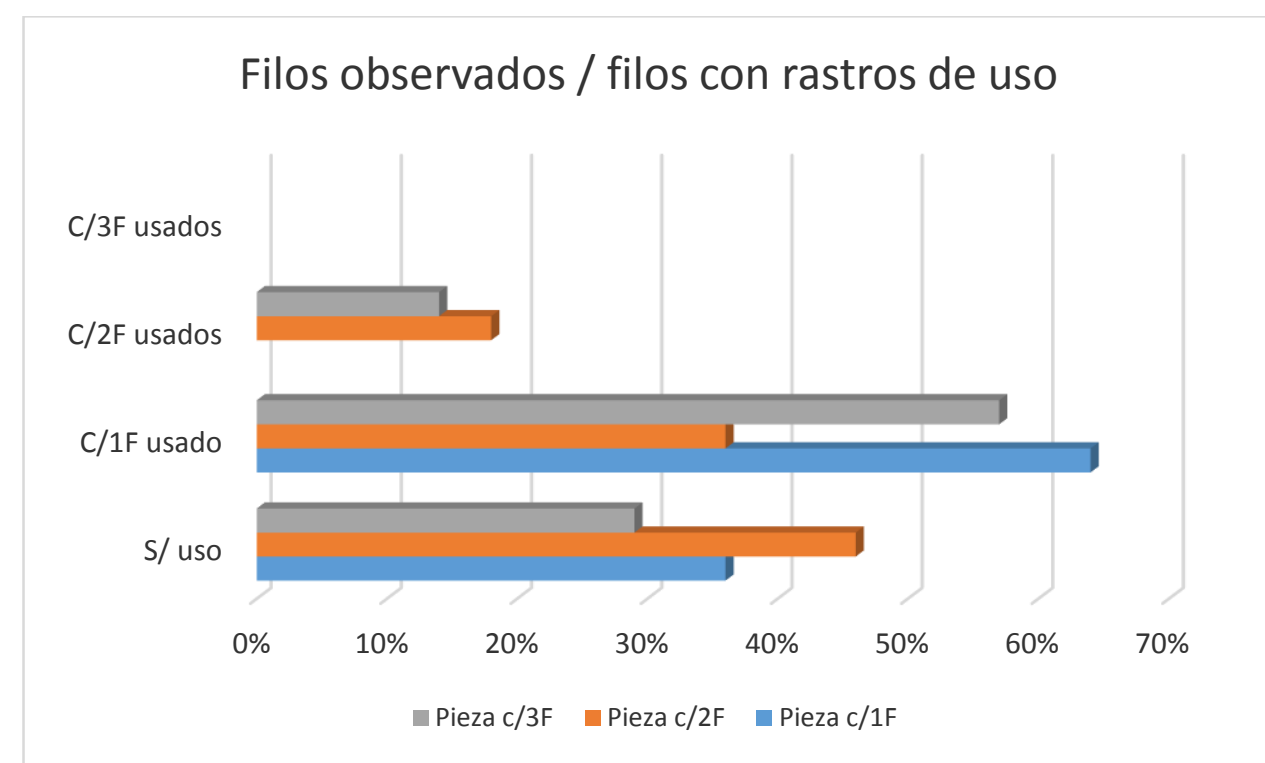

Figura 24: Relación de filos potencialmente funcionales por pieza y rastros de uso identificados en la capa 5.

En relación con los ANF de capa 5 el porcentaje más elevado (41\%) corresponde a piezas con rastros de utilización $(\mathrm{N}=15)$, seguido por pieza no determinadas por alteración $(\mathrm{N}=13,35 \%)$ y no determinadas $(\mathrm{N}=6,16 \%)$. Sin embargo en su mayoría, corresponde a piezas con filo simple $(\mathrm{N}=90,78 \%)$ y menores proporciones de filos dobles $(\mathrm{N}=25,22 \%)$. Dentro de las piezas con filo simple un $40 \%$ presentaron rastros de uso; mientras que en las piezas con filos dobles un 29\% ocupa este lugar (Figura 24). 


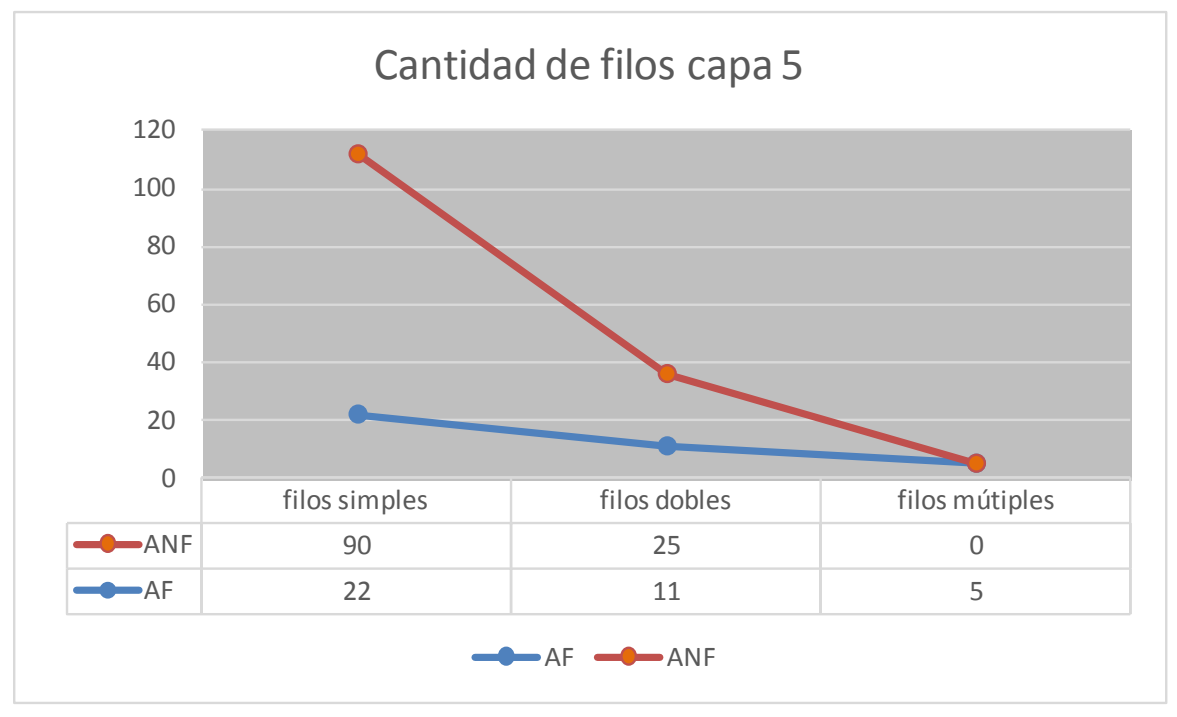

Figura 25: Cantidad de filos potencialmente funcionales en capa 5. AF: artefactos formatizados y ANF: artefactos no formatizados.

En relación con la materia prima empleada y la presencia de huellas de uso, se observó que un $32 \%$ de las materias primas identificadas de los AF presentaron algún tipo de rastros que permitiera identificar su uso. Si bien no se encontraron grandes diferencias debido a sus características composiciones (en su mayoría rocas homogéneas) se pudo determinar que las variedades ISG1 (33\%) y RSG3 (22\%) presentaban un mayor número de piezas con rastros de utilización (Figura 25).

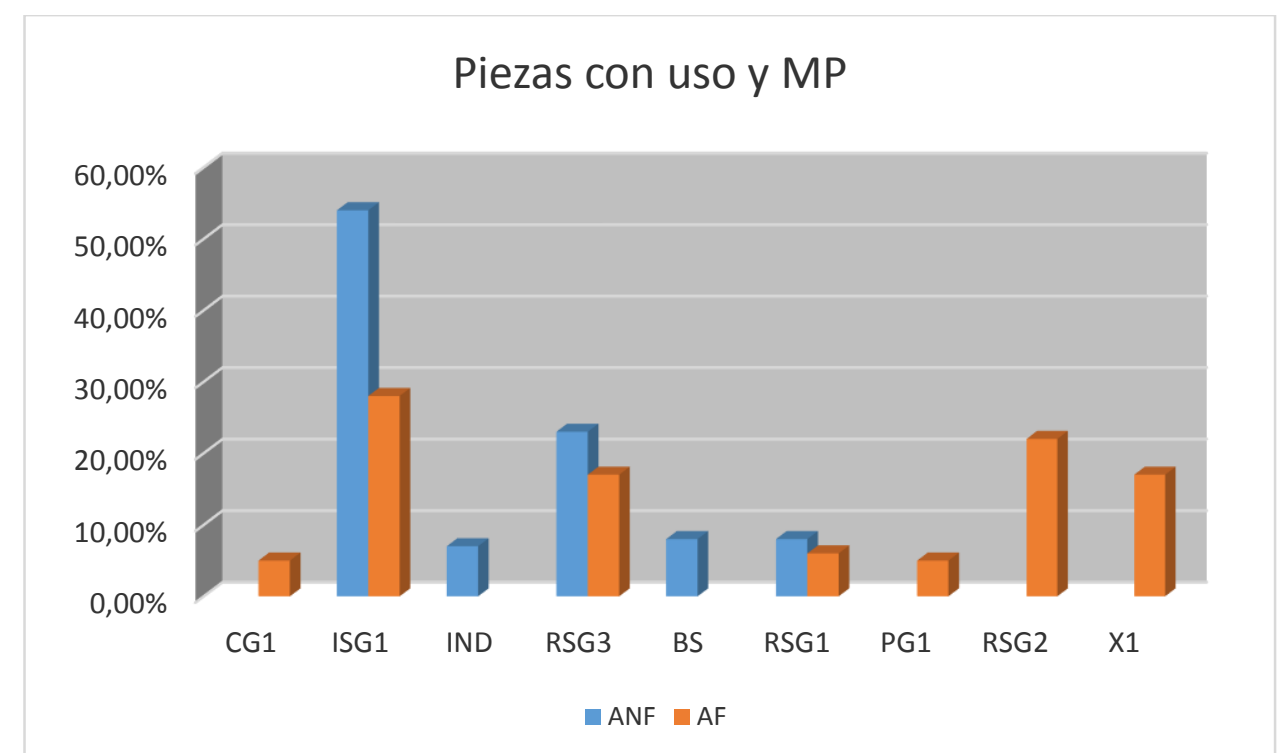

Figura 26: Variedad de materias primas con rastros de utilización en capa 5 de Cueva Maripe. 
Mientras que en los ANF el 10\% del total de la muestra presentó algún tipo de rastro que permitiera identificar su uso. Al igual que en el caso anterior, la variedad ISG1 (54\%) corresponde a la materia prima con mayor cantidad de rastros identificados y en menores proporciones se localizan las variedades RSG3 (23\%), BS (8\%), RSG1 (8\%) y por último materias primas indeterminadas (7\%) (Figura 26).

\section{VI.4.1.5. Materiales trabajados}

Los materiales identificados en los AF incluyen un mayor porcentaje de material duro $(\mathrm{N}=11,52 \%)$, seguido por el trabajo sobre hueso $(\mathrm{N}=3,14 \%)$ y menores proporciones del trabajo de cuero $(\mathrm{N}=4,19 \%)$ y material duro de origen vegetal $(\mathrm{N}=2,10 \%)$, mientras que el $5 \%$ restante $(\mathrm{N}=1)$ corresponde a una pieza donde el material trabajado no pudo ser determinado pero sí la cinemática empleada. En ninguno de los casos se identificó el estado del material (estacionado, fresco o seco) como sí ocurrió en la serie experimental de referencia.

En cuanto a los artefactos no formatizados, se pudo observar ciertas diferencias en el empleo de los materiales trabajados. Se registró el uso de material duro ( $\mathrm{N}=9,75 \%)$, seguido por el trabajo sobre hueso $(\mathrm{N}=1,9 \%)$ y menores e iguales proporciones de material duro vegetal e indeterminado. A diferencia de los artefactos con formatización el trabajo sobre cuero no pudo ser reconocido en los ANF de capa 5 (Figura 27).

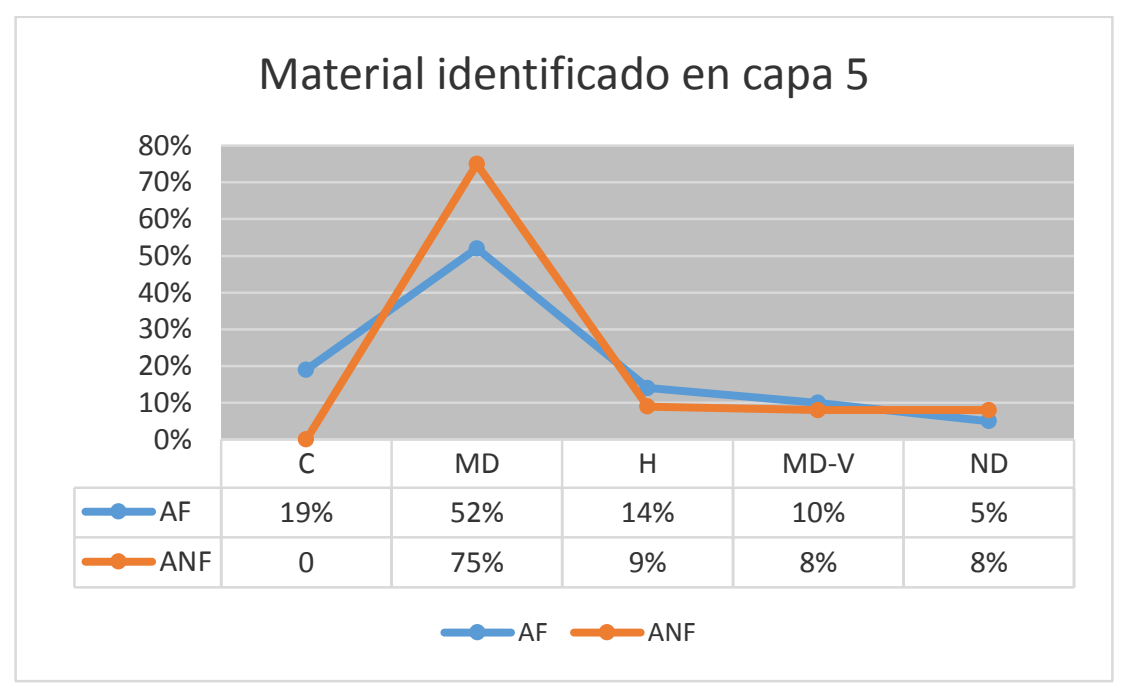

Figura 27: Material identificado en la capa 5 de Cueva Maripe. C: cuero; MD: material duro; H: hueso; MD-V: material duro vegetal y ND: no determinado. 


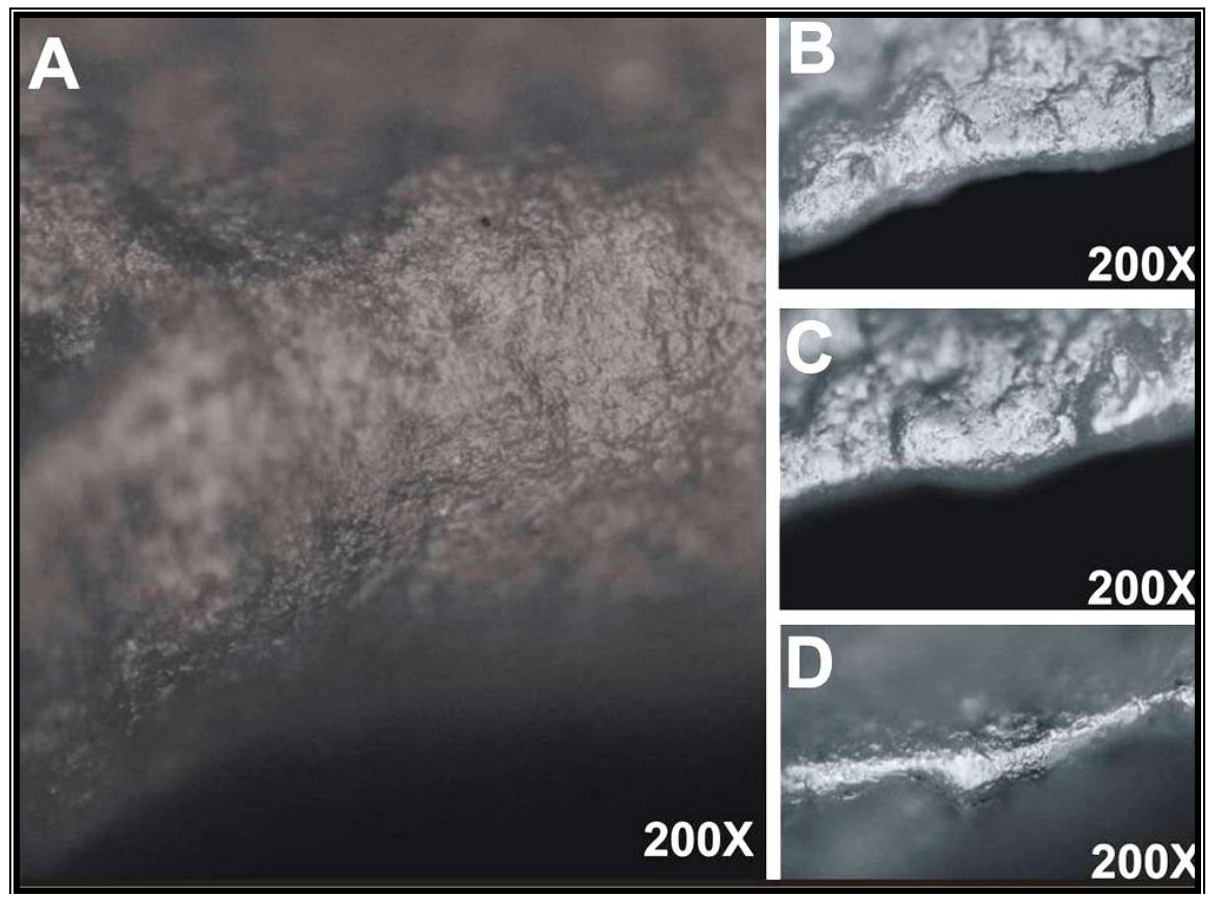

Figura 28: Fotomicrografías de los materiales trabajados capa 5 de $\mathrm{CN}$ en Cueva Maripe. A) Pieza $\mathrm{N}^{\circ}$ : MA06'D6437 (raspador de filo frontal), acción de raspado sobre material blando animal (cuero), B) Pieza $\mathrm{N}^{\mathrm{o}}$ : MA05'C535 (raedera de filo frontal largo), raspado sobre material duro vegetal (madera), C) Pieza $\mathrm{N}^{\mathrm{o}}$ : MA05'C580 (raedera de filo frontal largo), acción de raspado sobre material duro de origen animal (hueso).

\section{VI.4.1.6. Cinemática empleada}

A partir de la identificación del material empleado se han podido reconocer los movimientos efectuados por los artefactos correspondientes a esta capa.

Los modos de empleo y acciones desarrolladas para los AF incluyeron movimientos transversales como también longitudinales o mixtos. El primer caso corresponde a un $62 \%(\mathrm{~N}=13)$ de las piezas con rastros de utilización, seguido por acciones longitudinales $(\mathrm{N}=5,24 \%)$ y mixtas (longitudinales y transversales, $\mathrm{N}=1,5 \%$ ). Mientras que el porcentaje restante corresponde a indeterminados $(\mathrm{N}=2,9 \%)$.

Si bien no se pudo observar ninguna relación estadísticamente significativa [prueba de Chi-cuadrado $\left.\left(\chi^{2}=2,34 ; \mathrm{df}=1 ; \mathrm{p}=0,12\right)\right]$ en cuanto a los materiales trabajados identificados y los movimientos efectuados, se registraron ciertas tendencia en la muestra. El trabajo sobre material blando (cuero) incluyó únicamente acciones transversales $(\mathrm{N}=4)$. Mientras que en el caso del material duro se pudo observar cierta diversidad en cuanto a la cinemática empleada. Se realizaron acciones longitudinales (33\%) como así también transversales (50\%) y mixtas (6\%). 
En el caso de los ANF fueron identificados movimientos transversales (33\%) como también longitudinales (67\%). En relación con el material identificado, se observó que las piezas trabajadas sobre material duro fueron mayormente empleadas a partir de acciones longitudinales o de corte $(67 \%)$. En cuanto a las características principales de los filos (forma secundaria, longitud y ángulo) se observó una relación estadísticamente significativa entre el material trabajado y el ángulo del filo utilizado (Prueba de MannWhitney; $\mathrm{U}=17,5 ; \mathrm{p}=0,05)^{2}$, las piezas empleadas en acciones longitudinales presentaron ángulos mayormente agudos con un promedio de $48^{\circ}$; mientras que las empleadas en acciones transversales más rectos con un promedio de $64^{\circ}$. En cuanto a la longitud no se pudo determinar ningún tipo de correlación estadística (Prueba de MannWhitney; $U=30 ; p=0,42$ ).

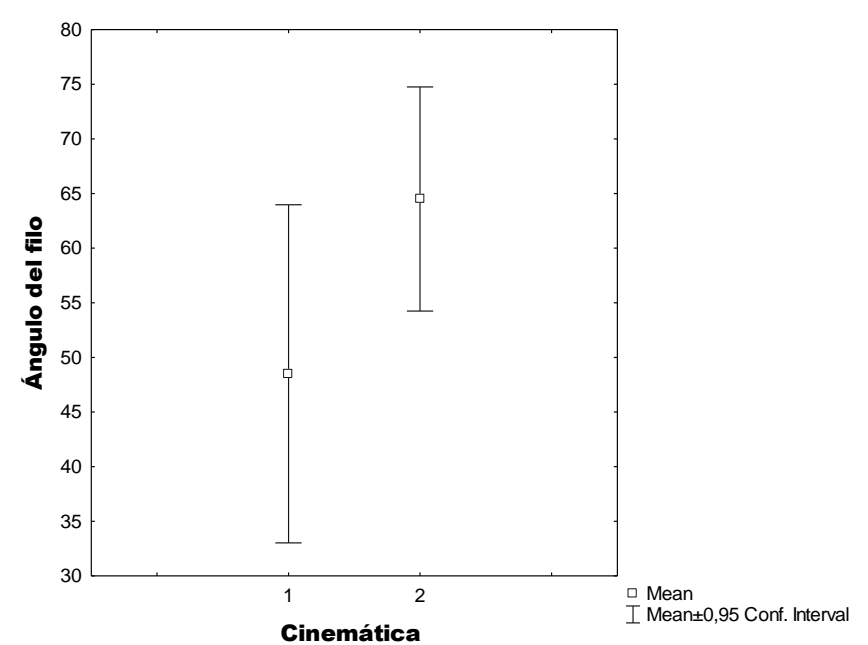

Figura 29: Correlación entre la cinemática empleada y el material trabajado en AF de la capa 5. 1) Acciones transversales 2) Acciones longitudinales.

En relación con la forma secundaria de los filos se registró que para las acciones longitudinales sobre materiales duros, se utilizaron filos de morfología rectilínea principalmente $(\mathrm{N}=5,83 \%)$ y en menor medida convexos atenuados $(\mathrm{N}=1,17 \%)$. Mientras que las acciones transversales emplearon filos de morfología variable. En los casos donde se trabajó material blando se utilizaron filos convexos, como también atenuados $(\mathrm{N}=4,25 \%)$ y en su mayoría se disponían de manera extendida. Mientras que los filos que trabajaron material duro de manera transversal también presentaron filos convexos pero, las variedades convexas atenuadas $(\mathrm{N}=5,34 \%)$ y muy atenuadas $(\mathrm{N}=2$, $33 \%)$, estuvieron mayormente representados.

${ }^{2}$ Prueba U de Mann-Whitney, corresponde a un test no paramétrico que contrasta la igualdad de medias entre dos poblaciones. 
Por otro lado, y en relación con las características principales de los filos identificados en los ANF de capa 5, se registró una correlación estadísticamente significativa entre la cinemática empleada y la longitud del filo (Prueba de Mann-Whitney; $U=2,5 ; p=0,02$ ). Las piezas trabajadas longitudinalmente presentaron un promedio mayor de $47 \mathrm{~mm}$, mientras que las empleadas en acciones transversales una longitud de $31 \mathrm{~mm}$ promedio. En cuanto al ángulo empleado no se pudo determinar una correlación significativa (Prueba de Mann-Whitney; $\mathrm{U}=12,5 ; \mathrm{p}=0,7$ ).

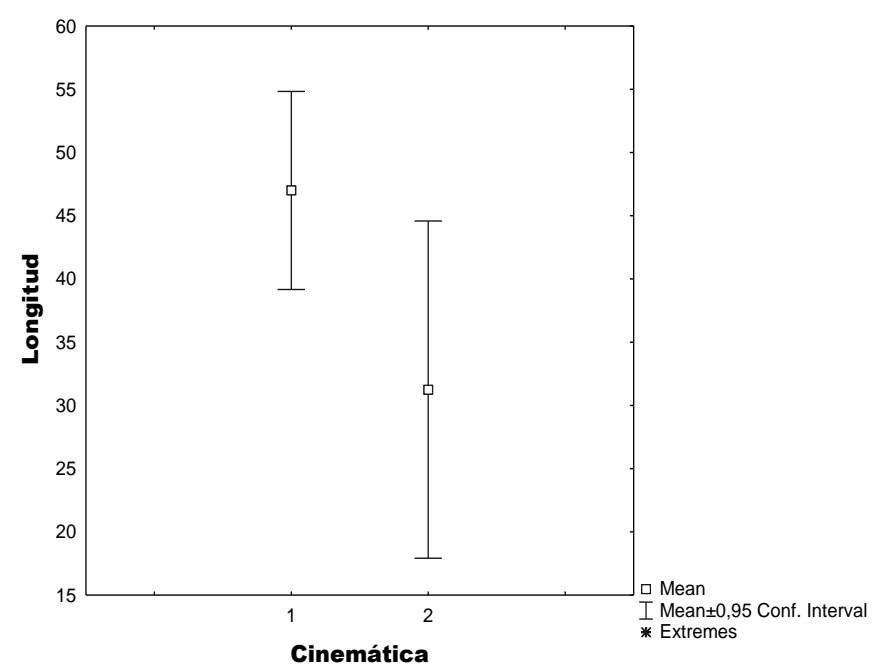

Figura 30: Relación entre la cinemática efectuada y la longitud de los filos empleados: 1) Acciones longitudinales sobre material duro y 2) Acciones transversales sobre material duro.

En relación con la forma secundaria se registró, para aquellos trabajados longitudinalmente sobre materiales duros, un mayor porcentaje de filos rectos $(\mathrm{N}=5$, $71 \%)$ y en menor medida convexos $(\mathrm{N}=2,29 \%)$; mientras que las piezas empleadas transversalmente presentaron filos sinuosos $(\mathrm{N}=2,50 \%)$, rectilíneos y convexos en iguales proporciones $(\mathrm{N}=1,25 \%$ respectivamente).

\section{VI.4.1.7. Actividades desarrolladas}

De acuerdo a los resultados obtenidos a partir del análisis funcional de base microscópica efectuado, se logró inferir para los AF de la capa 5 el desarrollo de distintas actividades. Entre estas, se encuentran el raspado de material duro ( $\mathrm{N}=5,24 \%)$, de piel $(\mathrm{N}=1,19 \%)$, madera $(\mathrm{N}=2,9 \%)$, hueso $(\mathrm{N}=1,5 \%)$ e indeterminado $(\mathrm{N}=1,5 \%)$; como también el corte de material duro $(\mathrm{N}=4,19 \%)$ y material duro animal (hueso, $\mathrm{N}=1,5 \%$ ). Un solo caso presentó dos tipos de acciones, de corte y raspado, sobre 
material duro animal $(\mathrm{N}=1,5 \%)$ y otro caso incluyó cinemática indeterminada sobre material duro ( $\mathrm{N}=2,9 \%)$ (Figura 31).

El análisis realizado sobre los ANF permitió inferir distintas actividades relacionadas principalmente al corte sobre material duro $(\mathrm{N}=11,48 \%)$, material duro animal (hueso, $\mathrm{N}=1,5 \%)$ y madera $(\mathrm{N}=1,4 \%)$. También se identificó actividades de raspado igualmente sobre material duro $(\mathrm{N}=7,31 \%)$, madera $(\mathrm{N}=1,4 \%)$ e indeterminado $(\mathrm{N}=1$, 4\%). Mientras que en dos piezas se identificaron movimientos tanto transversales o de raspado y longitudinales o de corte sobre material duro (4\%) (Figura 28), esto estaría asociados probablemente al desarrollo de actividades de procesamiento de presas hacia el interior de la cueva o de manufactura de instrumentos, sin embargo, esta discusión será retomada más adelante con los resultados del análisis funcional total de la cueva por componente identificado.

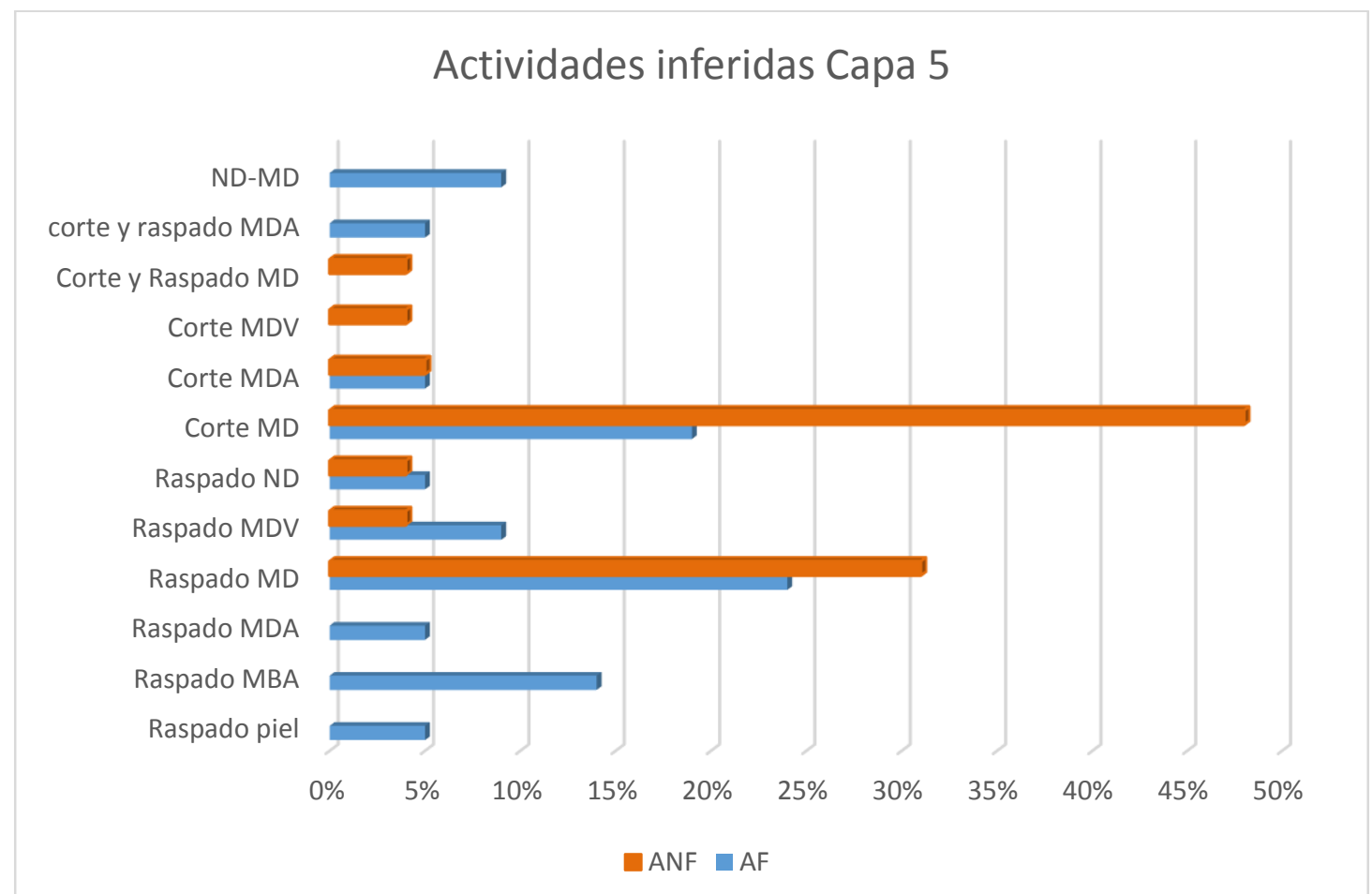

Figura 31: Actividades inferidas a partir de las huellas de uso identificadas sobre los AF y ANF de capa 5. MD: material duro; MDA: material duro animal; MDV: material duro vegetal; MBA: material blando animal y ND: no determinado.

En cuanto a los materiales procesados se registraron ciertas diferencias en los AF, si bien estos se utilizaron mayormente sobre materiales duros, también lo hicieron sobre material blando como el cuero. Sin embargo, en los artefactos con filos naturales no se registraron rastros asociados al trabajo sobre material blando; la mayoría de los casos 
trabajaron exclusivamente material duro de origen animal como así también vegetal (Figura 31).

\section{VI.4.2 Conjunto lítico de Capa 4: artefactos formatizados}

Los artefactos líticos recuperados de esta capa se encuentran en asociación a fechados de alrededor de $c a$. 5.376 a 3.535 años AP, lo que permitiría correlacionarlo con el bloque temporal del Holoceno Medio.

En relación con los rasgos e indicadores tafonómicos, se pudo identificar una estructura de combustión hacia la pared E de las cuadrícula D5, que se extiende hacia el sector SE de C5. Otra de estas estructuras se registró hacia el centro de la pared S, cuadrícula D5 que se extiende en el sector central de la pared N de D6 (Figura 32).

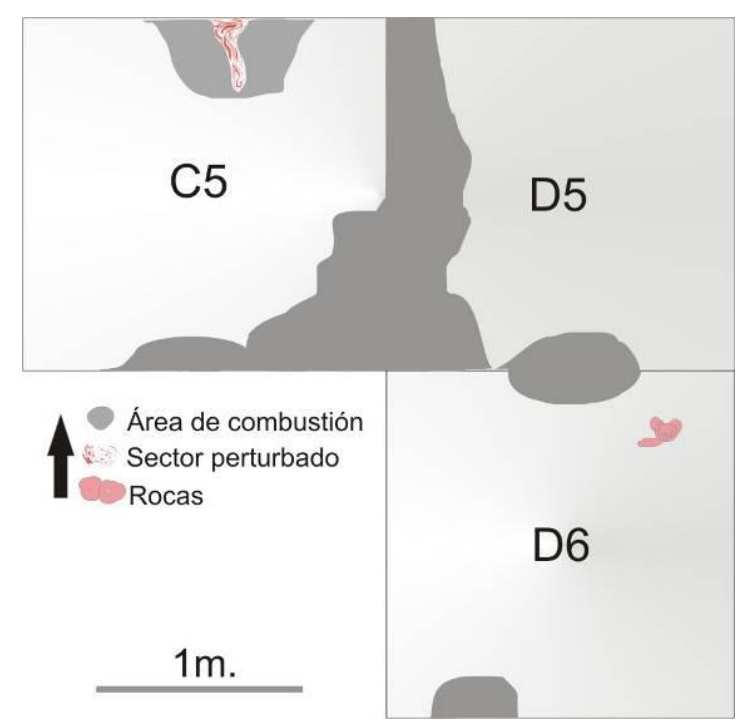

Figura 32: Dibujo en planta de capa 4 CN (modificado de Marchionni 2013).

De esta capa fue recuperado un $40 \%$ del total de AF formatizado, en especial de la cuadrícula D5 sector NE de donde se recuperaron un total de 18 piezas. La capa 4 presenta 93 elementos entre los que se encuentra 42 AF y 51 ANF. De los AF se observaron bajo microscopia óptica un total de 90 filos; mientras que de los ANF fueron analizados 58 filos (Figura 33). 

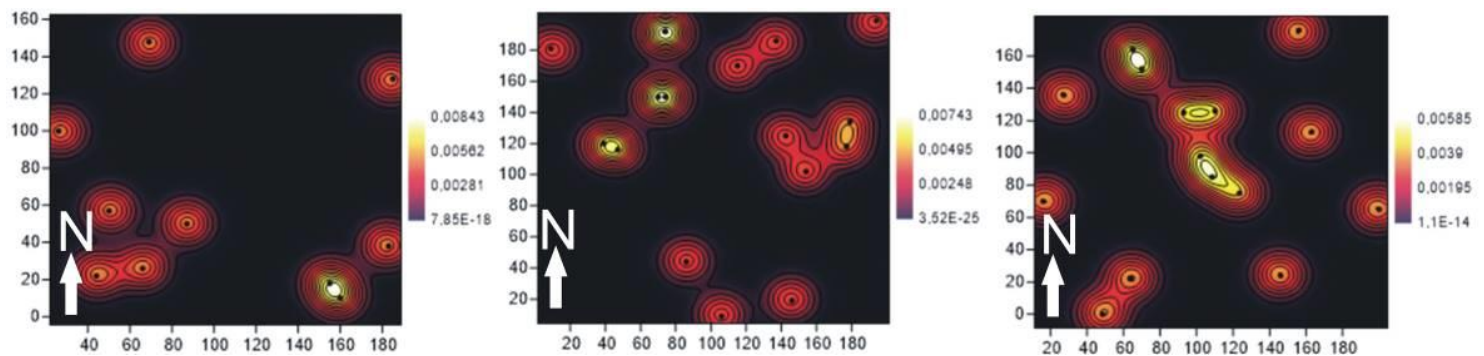

Figura 33: Distribución de densidades artefactuales en capa 4 (AF) de las cuadrículas C5, D5, y D6 en

$\mathrm{CN}$.

En cuanto al estado de los AF, en su mayoría corresponden a piezas enteras $(\mathrm{N}=18$, $43 \%$ ), mientras que, al igual que en la capa anterior, el grupo tipológico más representado corresponde a los raspadores $(\mathrm{N}=25,62 \%)$, seguido por láminas retocadas $(\mathrm{N}=6,14 \%)$, raederas $(\mathrm{N}=5,11 \%)$, filos no diferenciados $(\mathrm{N}=4,10 \%)$, piezas unifaciales y limaces $(\mathrm{N}=1,2 \%$ respectivamente) (Tabla 6$)$.

\begin{tabular}{|c|c|c|c|c|c|c|c|c|}
\hline $\mathbf{A F}$ & FND & LI & LR & $\mathrm{RD}$ & $\mathrm{RP}$ & UF & FNRC & MUR \\
\hline $\begin{array}{c}\text { Capa } 4 \\
\text { Piezas } N=42\end{array}$ & 4 & 1 & 6 & 5 & 25 & 1 & - & - \\
\hline \begin{tabular}{|c|} 
Total filos \\
$(N=90)$
\end{tabular} & 7 & 1 & 8 & 6 & 36 & 1 & 27 & 4 \\
\hline
\end{tabular}

Tabla 6: Grupos tipológicos identificados en la capa 4 de CN. FND: filos no diferenciados; LI: limaces; LR: lámina retocada; RD: raedera; RP: raspador; UF: unifaz; FNRC: filo natural con rastros complementario; MUR: muesca retocada.

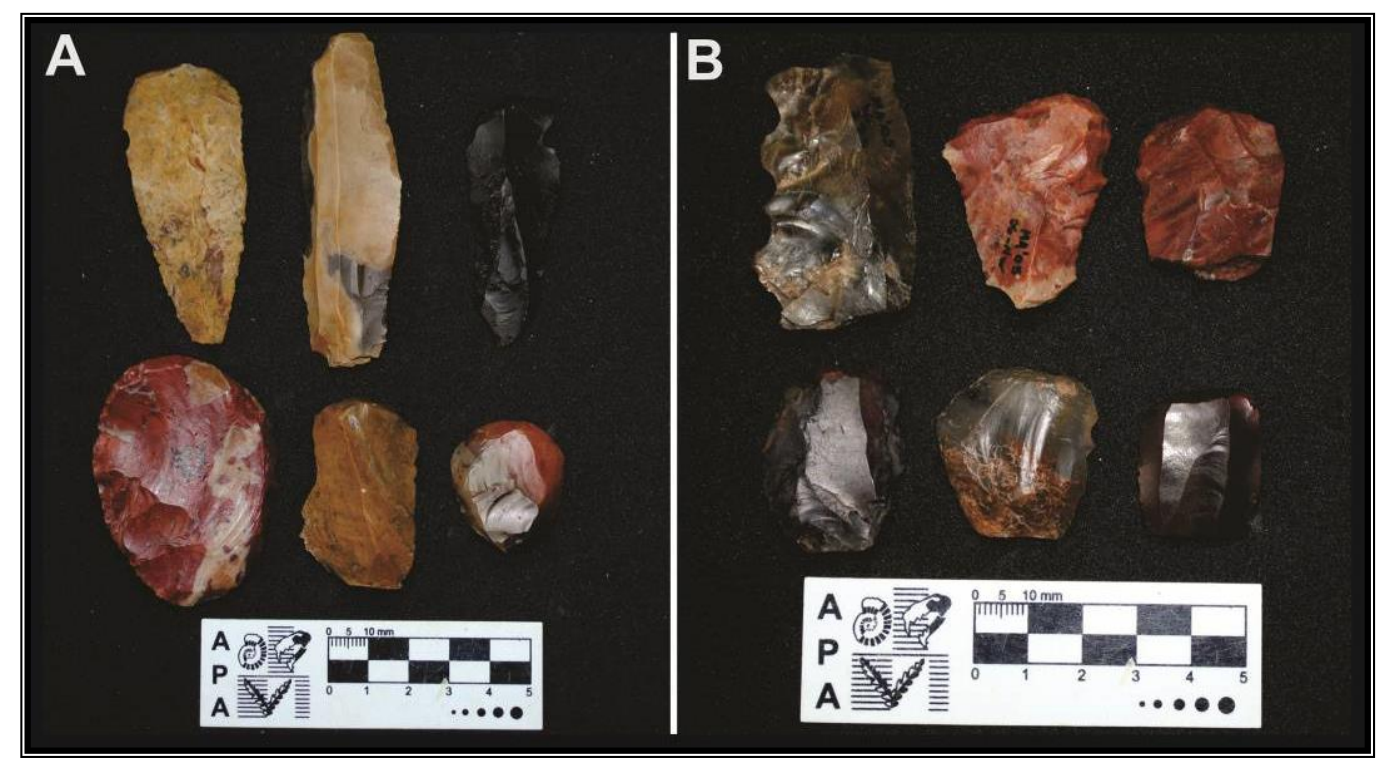

Figura 34: Materiales recuperados de Capa 4 de Cueva Maripe. A) Artefactos formatizados de la cuadrícula D5 (láminas retocadas de filo lateral largo, readera de filo lateral largo y raspadores de filo frontal corto). B) Artefactos formatizados de la cuadrícula D6 (raspadores de filo frontal corto y denticulado). 
Al igual que en la capa 5, se encuentran elaborados en su mayoría sobre rocas ígneas con alto contenido silíceo. Dentro las variedad identificadas las más representadas corresponden a la ISG1 $(\mathrm{N}=12,32 \%)$ y CG1 $(\mathrm{N}=6,16 \%)$.

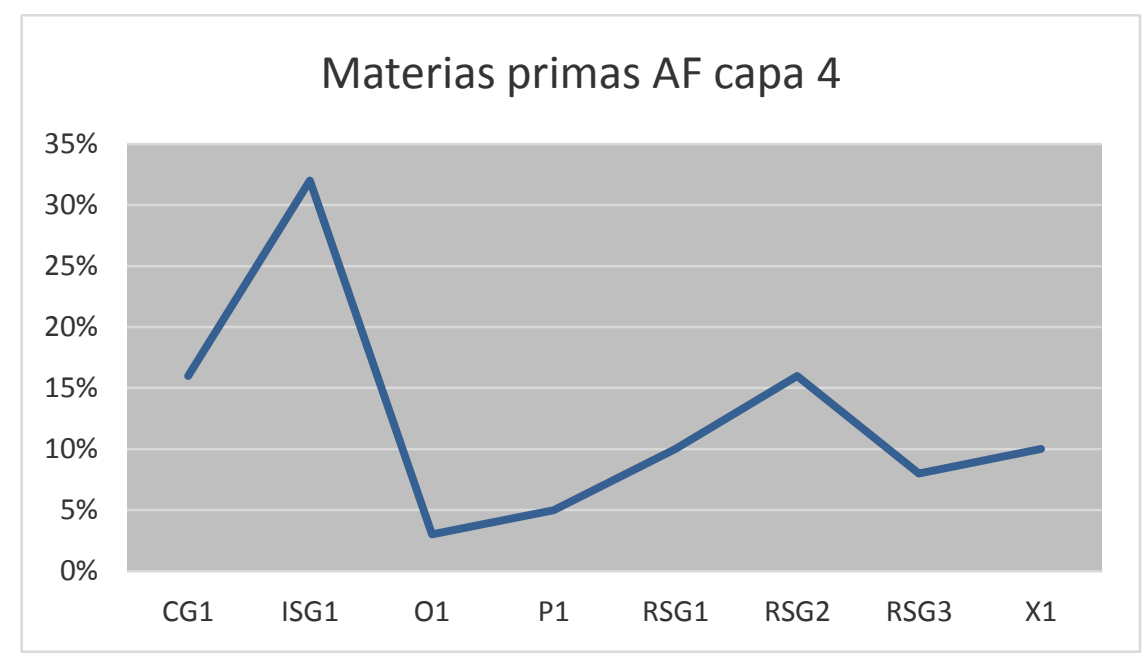

Figura 35: Variedad de materias primas en AF de capa 4.

\section{-Filos no diferenciados}

Este grupo presenta dos piezas elaboradas sobre RSG2 y un solo caso sobre X1. En dos casos se registraron filos complementarios naturales con microlascados aislados y en su mayoría presentaron un tamaño grande y en menor medida mediano-pequeño. Las formas bases seleccionadas para su elaboración incluyeron lascas primarias y secundarias y proporciones menores de hojas.

\section{-Laminas retocadas}

Un total de 6 elementos fueron identificados dentro de este grupo, de los cuales 5 presentaron al menos un filo complementario. La materia prima seleccionada para su producción fue mayormente la variedad ISG1 (50\%), mientras que el tamaño de la muestra en su mayoría corresponde a piezas mediano-pequeñas (42\%) y elaboradas principalmente sobre hojas $(50 \%)$ como formas bases. En cuanto a los filos complementarios, dos piezas presentaron al menos uno que correspondía a filos naturales con microlascados aislados. 


\section{-Limaces}

El grupo de los limaces se encuentra representado en esta capa por un único elemento elaborado sobre la variedad ISG1 de coloración roja. Esta pieza fue realizada sobre una lasca indeterminada como forma base, presentando una longitud de 40,2 mm y una anchura de $26,3 \mathrm{~mm}$. No se registraron filos complementarios.

\section{-Raederas}

Esta clase incluye 5 elementos, elaborados sobre las variedades CG1 (40\%), ISG1 (40\%) y en menor medida RSG2 de coloración marrón (20\%). En cuanto al tamaño de las piezas se registró grandes a medianos-grandes en iguales proporciones (40\%) y en menor medida piezas mediano-pequeñas (20\%). Mientras que en relación con las formas bases utilizadas en su elaboración incluyó exclusivamente lascas, angulares y de arista en iguales proporciones (40\% respectivamente) y en menor medida lasca indeterminada (20\%). En 3 casos se observó la presencia de un filo complementario natural con microlascados aislados. En cuanto a las variables métricas las piezas presentaron una longitud promedio de 44,3mm y una anchura de $37,2 \mathrm{~mm}$.

\section{-Raspadores}

Este grupo incluyó la mayor cantidad de piezas de capa $4(\mathrm{~N}=27)$ con 36 filos complementarios. En cuanto a las materias primas utilizadas para su confección se seleccionaron una amplia variedad; la más representada, corresponde a la ISG1 (42\%), seguida por ISG2 (19\%) y menores proporciones de PG1 (11\%), CG1 (8\%), X1 (8\%), RSG2, CG2 y O1 (4\% respectivamente).

El tamaño de la muestra incluyó piezas principalmente mediano-grandes (50\%) seguido por mediano-pequeñas (35\%) y grandes (15\%). Mientras que el módulo de longitud anchura más representado corresponde al mediano normal (66\%) (Figura 36). 


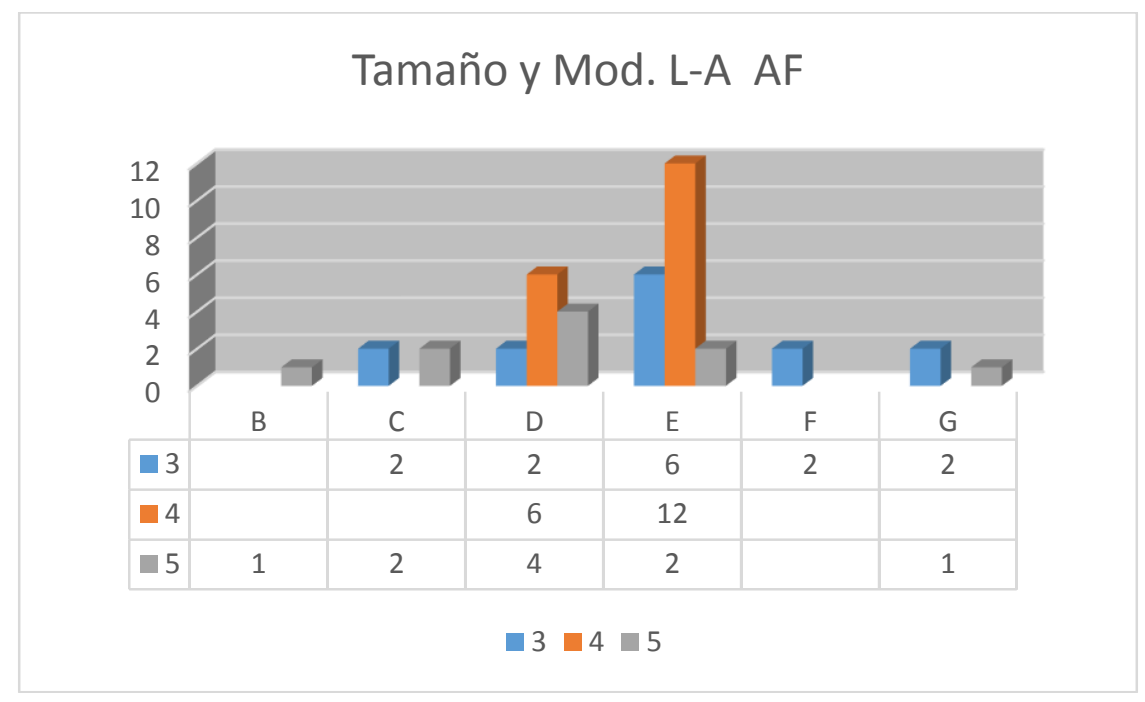

Figura 36: Tamaños y módulos de longitud-anchura de AF en capa 4.

\section{VI.4.2.1. Artefactos no formatizados (ANF) de Capa 4}

El total de artefactos no formatizados en esta capa incluye 51 piezas con 7 filos complementarios; siendo observados bajo microscopía óptica un total de 58 filos. La mayor cantidad de elementos fueron recuperados de la cuadrícula D6 (N=26) principalmente del sector SE que incluyó el 35\% del total de la muestra de esta cuadrícula (Figura 37).
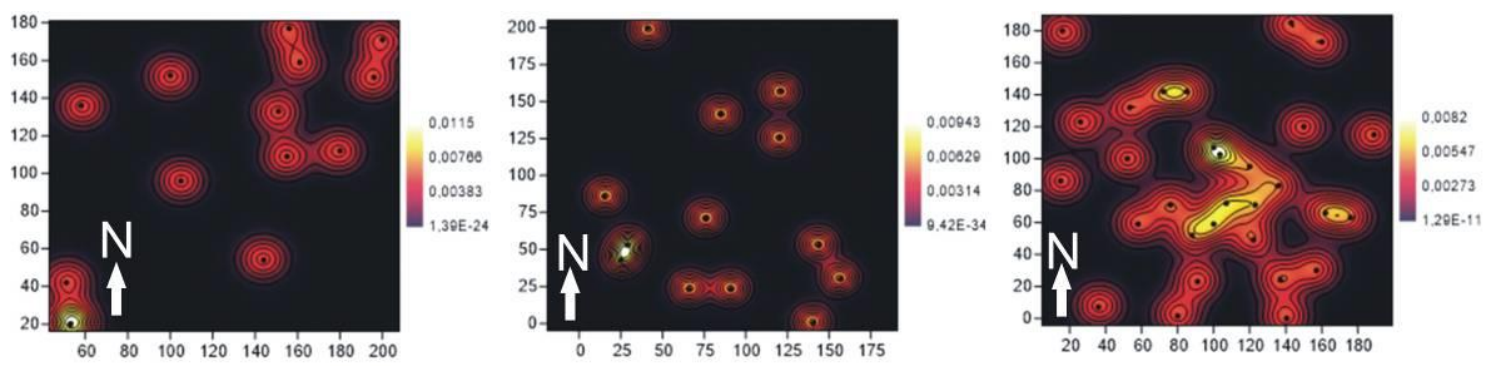

Figura 37: Distribución de densidades artefactuales (ANF) de capa 4 en las cuadrículas C5, D5 y D6 de CN.

En cuanto a las características y estados generales de la muestra, se identificó que la mayoría de las piezas estaban fracturadas sin talón $(\mathrm{N}=23,45 \%)$, seguidas por piezas enteras $(\mathrm{N}=16,31 \%)$ y menores proporciones de piezas fracturadas con talón $(\mathrm{N}=12$, $24 \%)$. 
El grupo de ANF se encuentra elaborado sobre una amplia variedad de materias primas, siendo la variedad ISG1 (N=28, 43\%) la más representada. En menores proporciones se encuentran PG1, X1 y RSG2 (N=7, 11\% respectivamente) y variedades con porcentajes aún menores que incluye basalto, calcedonia y otros grupos de rocas. Como se puede observar en el apartado anterior la distribución de materias primas es similar al de los AF de capa 4 , a excepción de la presencia de $\mathrm{BS}(\mathrm{N}=5,8 \%)$, que se da únicamente en los ANF (Figura 38).

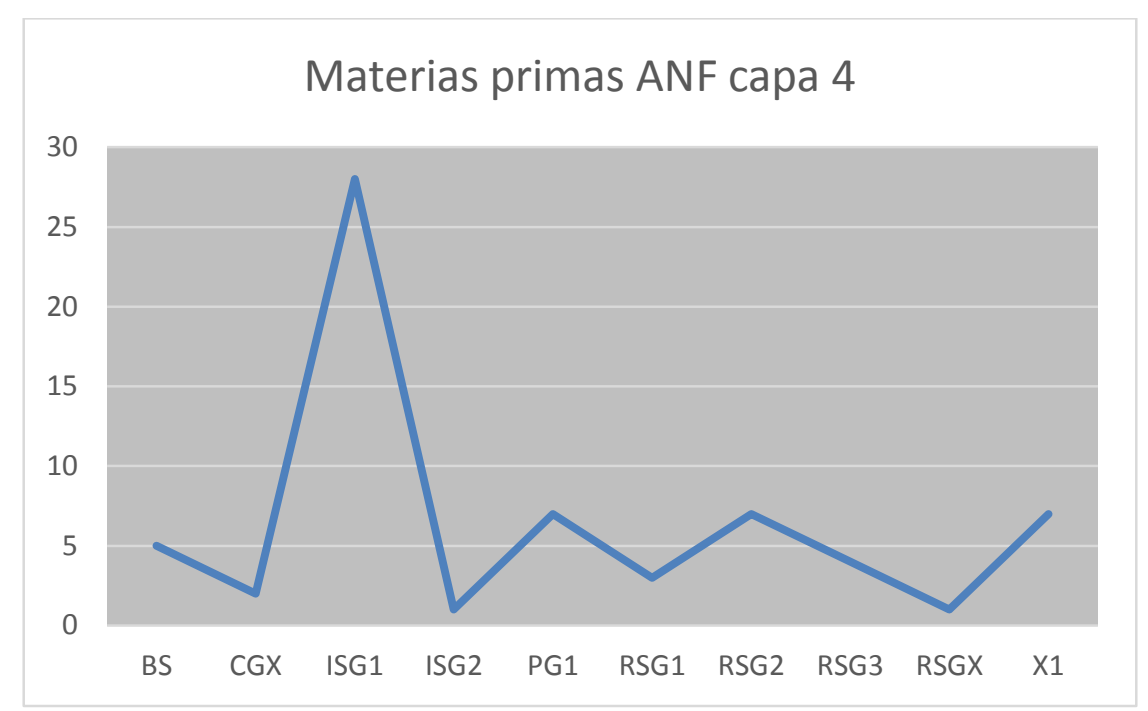

Figura 38: Distribución de las variedades de materias primas utilizadas en ANF de capa 4 de CN.

En cuanto al tamaño de la muestra el mayor porcentaje consistió en piezas de tamaño medianos grandes $(\mathrm{N}=35,40 \%)$, mientras que el módulo de longitud anchura más representando fue el laminar normal (Figura 39).

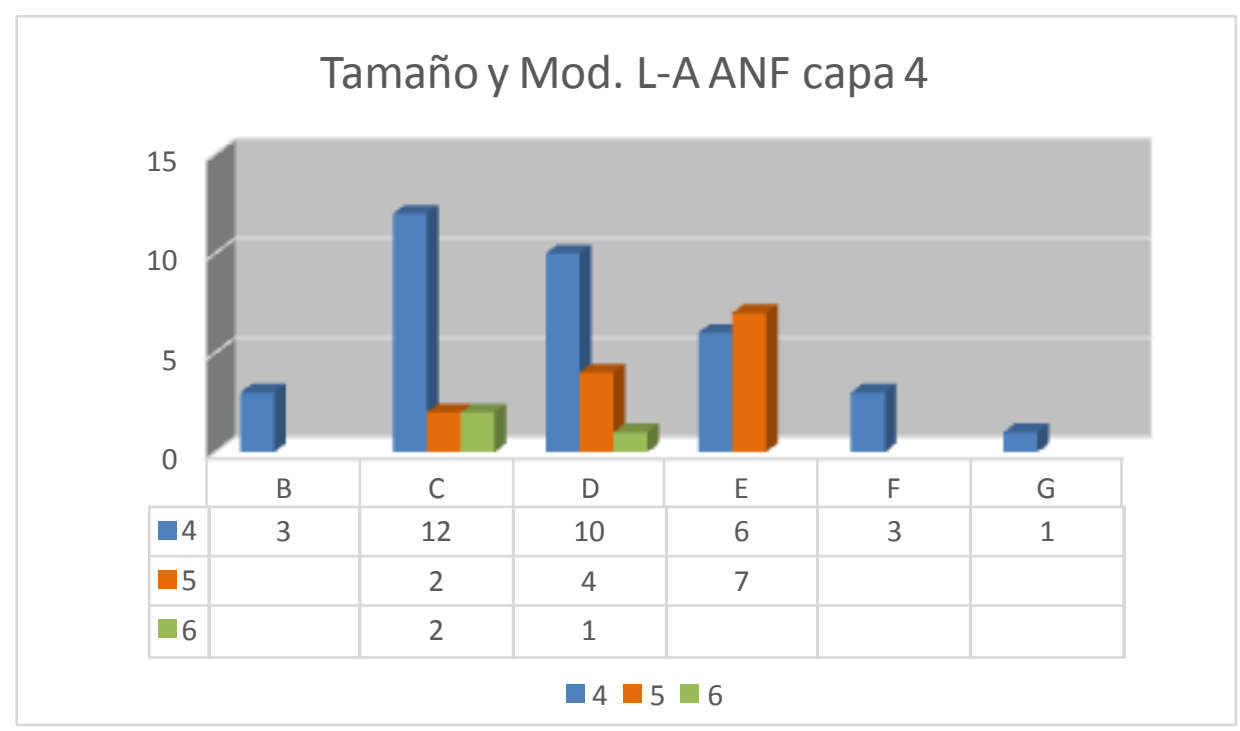

Figura 39: Distribución de tamaños en ANF de capa 4 de CN. 
En relación a los tipos de lascas identificadas se registró una mayor cantidad de lascas angulares $(\mathrm{N}=20,39 \%)$ y de aristas $(\mathrm{N}=11,21 \%)$, seguido por hojas de aristas simples $(\mathrm{N}=9,18 \%)$ y dobles $(\mathrm{N}=6,12 \%)$. El tipo de lascas extraídas es similar a las identificadas en los ANF de capa 5, ya que las proporciones más elevadas igualmente corresponden a lascas angulares y de aristas. En capa 4 la presencia de lascas $(\mathrm{N}=36$, $95 \%)$ es mayor que la de hojas $(\mathrm{N}=15,5 \%)$. Las diferencias de ocurrencia de lascas y hojas en relación con la capa 5, no fueron estadísticamente significativas, para esto se realizó un test de Chi-cuadrado $\left(\chi^{2}=1,02 ; \mathrm{df}=1 ; \mathrm{p}=0,31\right)$, observándose que las proporciones de lascas $v s$. hojas no difieren significativamente entre esta dos capas.

\section{VI.4.2.2. Resultados del análisis funcional de base microscópica}

El total de filos analizados en esta capa es de 148, de los cuales 90 corresponden a AF (61\%) y 58 a ANF (39\%). En los AF se registró que el 43\% (N=39) presentó algún tipo de rastro de utilización. El resto de la muestra estuvo compuesta por piezas no determinadas $(\mathrm{N}=33,37 \%)$, no determinadas por alteración $(\mathrm{N}=16,18 \%)$ y dos casos sin uso observable, que conformó el $2 \%$ restante de las muestra. Mientras que de los ANF el mayor porcentaje estuvo representado por piezas con rastros de uso seguro en un $35 \%(\mathrm{~N}=23), 30 \%$ no determinadas $(\mathrm{N}=20)$ y $27 \%$ no determinadas por alteración $(\mathrm{N}=18)$.

\section{VI.4.2.3. Integridad del conjunto y alteraciones tafonómicas}

Debido a las características composicionales de las materias primas utilizadas en la elaboración de los artefactos líticos de capa 4, la mayoría de las piezas presentaron abrasión sedimentaria leve. Sin embargo, en pocas piezas estas alteraciones imposibilitaron la identificación funcional.

En el caso de los AF, la abrasión de la superficie lítica por el contacto con el sedimento, ha sido una de las causas principales. Este tipo de alteración se encuentra representado en la muestra por un $75 \%(\mathrm{~N}=12)$ del total de filos observados, seguido por alteraciones ocasionadas debido al tratamiento de las piezas en laboratorio (siglado con PVAC, N=3, $19 \%)$ y en menor medida por termoalteración $(\mathrm{N}=1,6 \%)$. 
En cuanto a los $\mathrm{ANF}$, se pudo observar que un 27\% (N=18) de los artefactos presentaban al menos un tipo de alteración que impedía su identificación. Entre estas alteraciones se registró piezas con abrasión sedimentaria $(\mathrm{N}=7,44 \%)$ que en algunos casos llegaron a formar puntos brillantes sobre las superficies $(\mathrm{N}=2,12 \%)$, piezas con termoalteración $(\mathrm{N}=4,25 \%)$ y en menor medida formación de pátina blanca acompañado, en una sola pieza, por concreciones carbonáticas ( $\mathrm{N}=3,19 \%)$ (Figura 40).

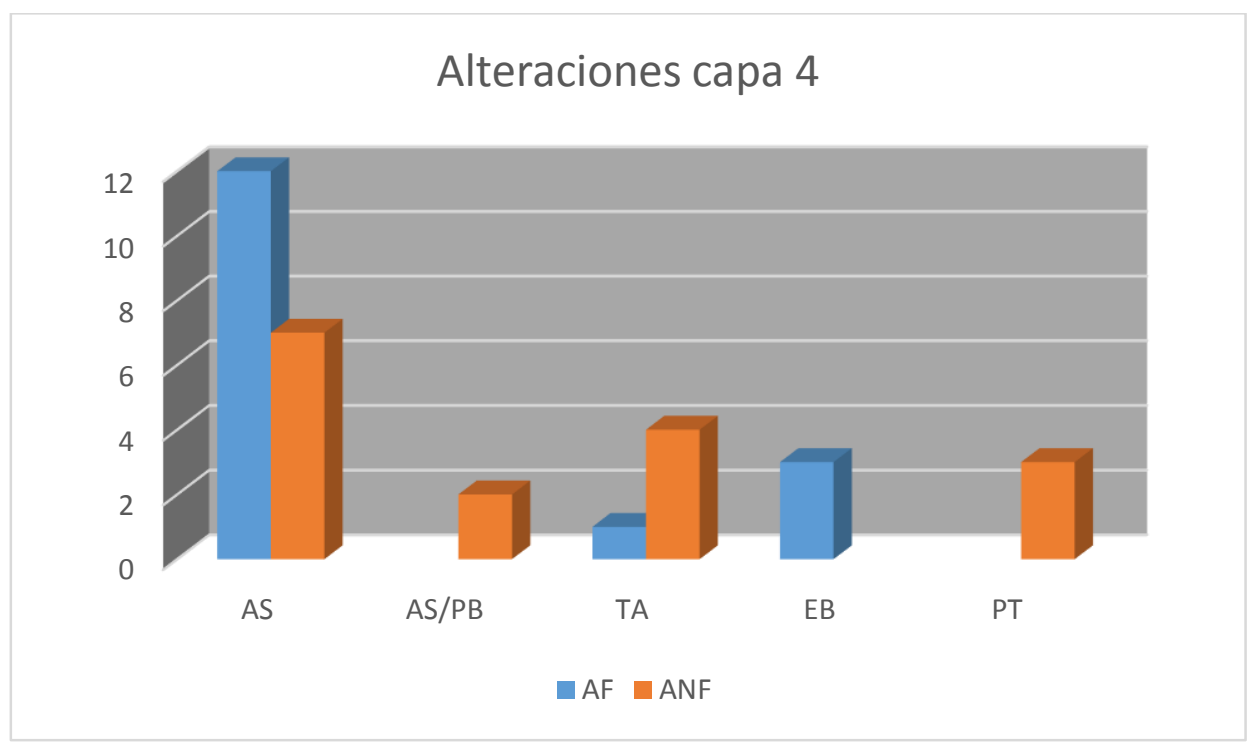

Figura 40: Alteraciones identificadas en la capa 4 de CN de Cueva Maripe. AS: abrasión sedimentaria; TA: termoalteración; EB: alteración ocasionada en laboratorio por siglado y PT: pátina blanca.

\section{VI.4.2.4. Inferencia funcional de las modalidades de uso}

El análisis realizado registró en los AF un mayor porcentaje de piezas con un solo filo potencialmente utilizable, de los cuales el 17\% $(\mathrm{N}=7)$ no registró rastros de utilización. Le siguen piezas con dos filos potencialmente utilizables con al menos uno con microhuellas de uso $(\mathrm{N}=6,15 \%)$. El resto del conjunto se comporta de manera variable. Mientras que en los ANF las piezas presentaban en su mayoría un sólo filo potencialmente utilizable de los cuales $44 \%(\mathrm{~N}=22)$ no presentó rastros de uso; mientras que el 32\% ( $\mathrm{N}=16)$ restante de estas piezas, registraron algún tipo de huella que permitiera inferir su utilización. El resto de los artefactos se comportan igualmente de manera variable aunque le siguen las piezas con dos filos de los cuales al menos uno presentó rastros de haber sido usado $(\mathrm{N}=3,6 \%)$ (Figura 41). 


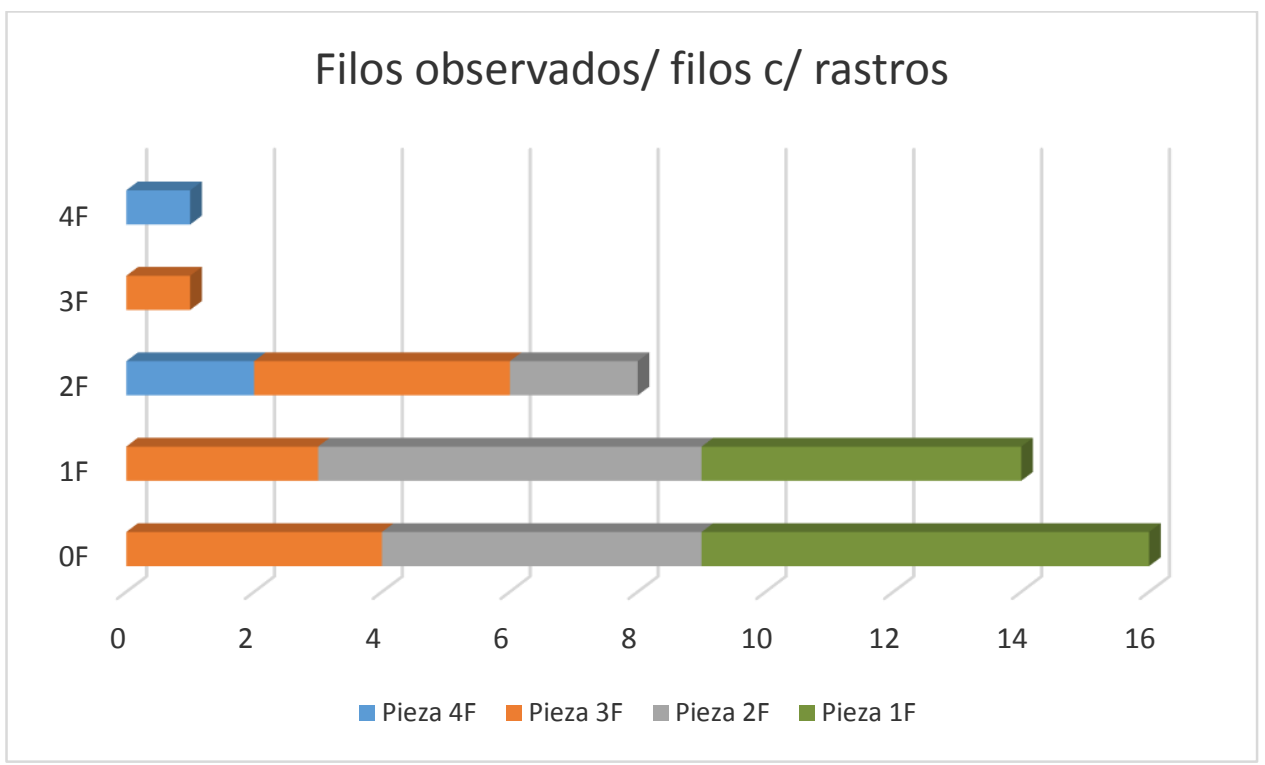

Figura 41: Relación de los filos observados y la presencia/ausencia de rastros de uso en AF de capa 4.

En cuanto a la relación presencia de rastros de utilización y materias primas seleccionadas, no se pudo determinar diferencias significativas, ya que un solo caso corresponde a un tipo de materia prima de grano mediano a grueso (basalto).

Aun así, resulta interesante dentro de esta amplia variedad de materias primas silíceas, poder observar ciertas diferencias en cuantos a la presencia/ausencia de estos rastros. En este sentido, se reconoció que la materia prima con mayor cantidad en los AF corresponde a la variedad $\mathrm{RSG} 2(\mathrm{~N}=7,35 \%)$, lo que llama la atención debido a que la materia prima más representada en la muestra es la ISG1. En proporciones menores se observa las variedades ISG1 (N=4, 20\%), CG1 (N=3, 15\%), RSG1, RSG3 (N=2, 10\% respectivamente) y PG1, $\mathrm{X} 1(\mathrm{~N}=1,5 \%$ respectivamente).

Mientras que en los ANF la variedad RSG2, se encuentra mayormente representado $(\mathrm{N}=6,26 \%)$. Le siguen en orden las variedades ISG1 y $\mathrm{X} 1$ ( $\mathrm{N}=5,22 \%$ respectivamente), RSG3 (N=3,13\%), RSG1 ( $\mathrm{N}=2,9 \%)$ y menores e iguales proporciones de PG1 y BS $(\mathrm{N}=1,4 \%$ respectivamente) (Figura 42$)$. 


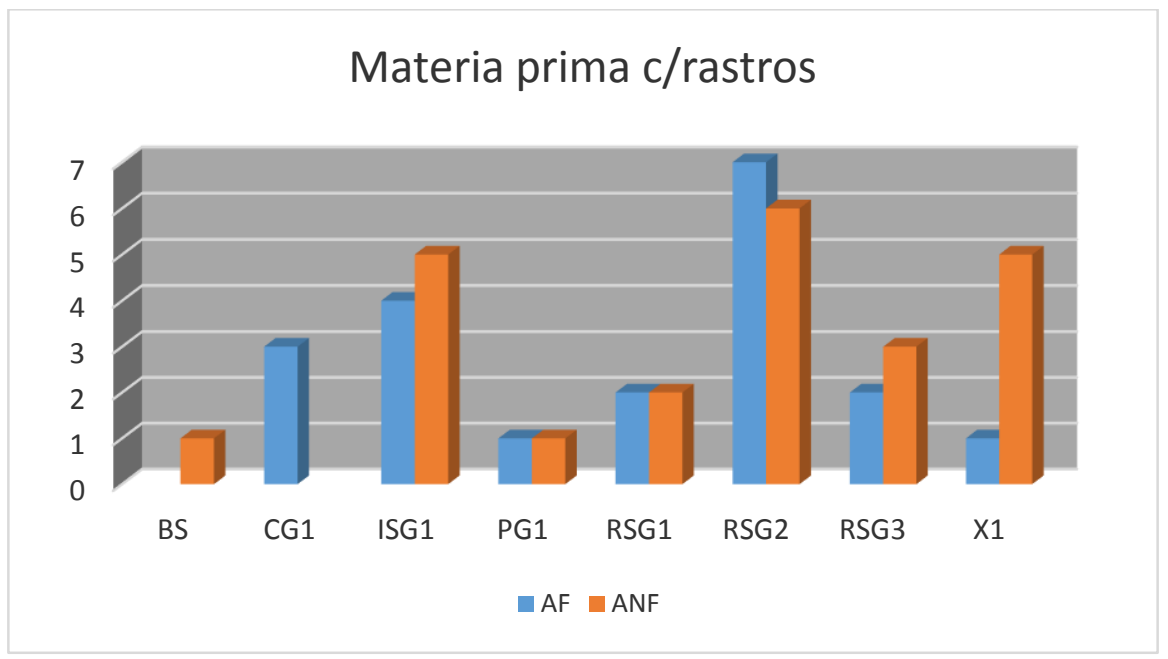

Figura 42: Distribución de las distintas variedades de materias primas en AF y ANF con rastros de uso en capa 4 de $\mathrm{CN}$.

\section{VI.4.2.5. Materiales trabajados}

Los materiales trabajados identificados en la capa 4 presentan una distribución similar tanto en los AF como en los ANF. En el primero, se reconoció el uso de material duro por sobre los demás $(\mathrm{N}=17,44 \%)$, en menores proporciones se reconoció el trabajo sobre material duro vegetal (madera, $\mathrm{N}=13,33 \%$ ), animal (hueso, $\mathrm{N}=3,5 \%$ ) y sobre material blando $(\mathrm{N}=3,5 \%)$. El porcentaje restante estuvo ocupado por aquellas piezas que presentaron signos de haber sido trabajadas pero no pudieron ser adscriptas a algún tipo de material específico $(\mathrm{N}=2,5 \%)$.

Mientras que en los ANF se identifico, al igual que los AF, un mayor uso de material duro $(\mathrm{N}=13,54 \%)$, seguido por el trabajo sobre material duro vegetal (madera, $\mathrm{N}=4$, $13 \%$ ), menores e iguales proporciones de cuero, material blando y duro a la vez y material duro animal $(\mathrm{N}=3,12 \%$ respectivamente) y por último el trabajo sobre material blando $(\mathrm{N}=1,4 \%)$. En este caso no se reconoció el trabajo sobre cuero que si ocurre en los AF (Figura 43). 


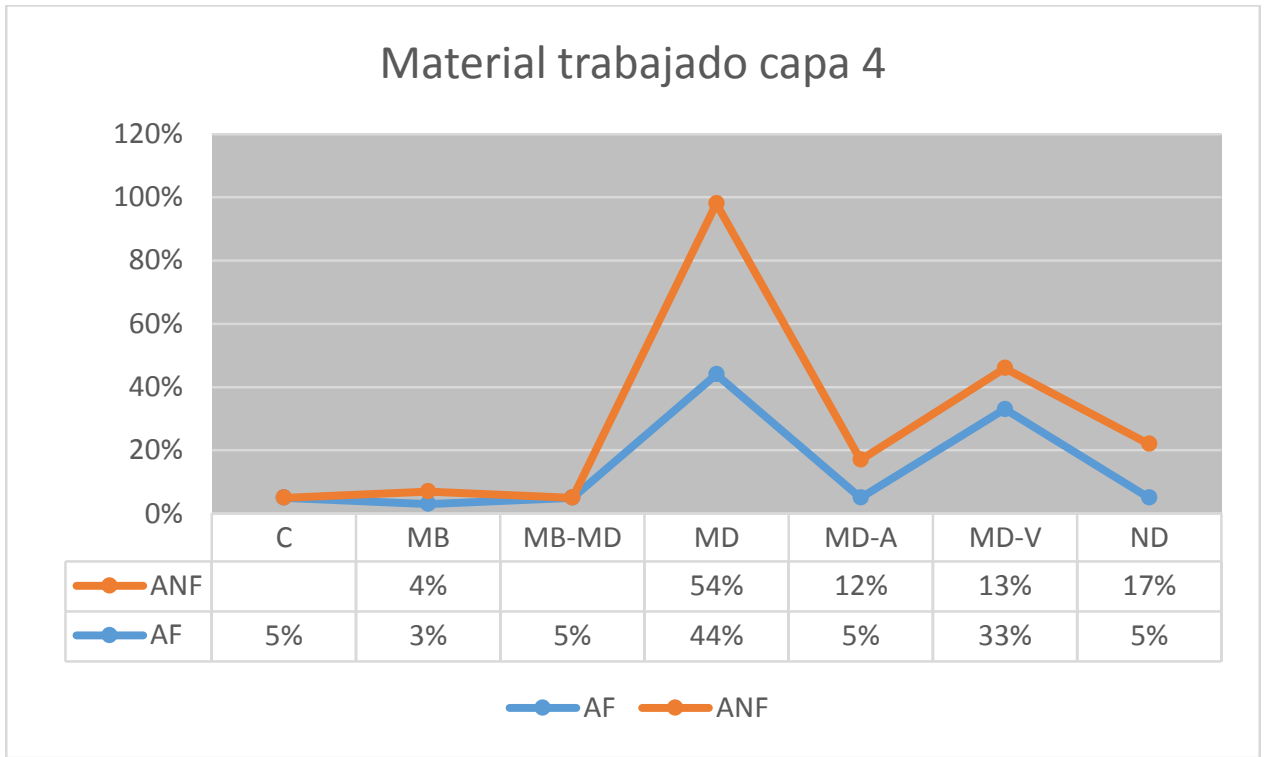

Figura 43: Materiales trabajados identificados en los artefactos líticos de capa 4 en CN. C: cuero; MB: material blando; MD: material duro; MD-A: material duro animal; MD-V: material duro vegetal y ND: no determinable.

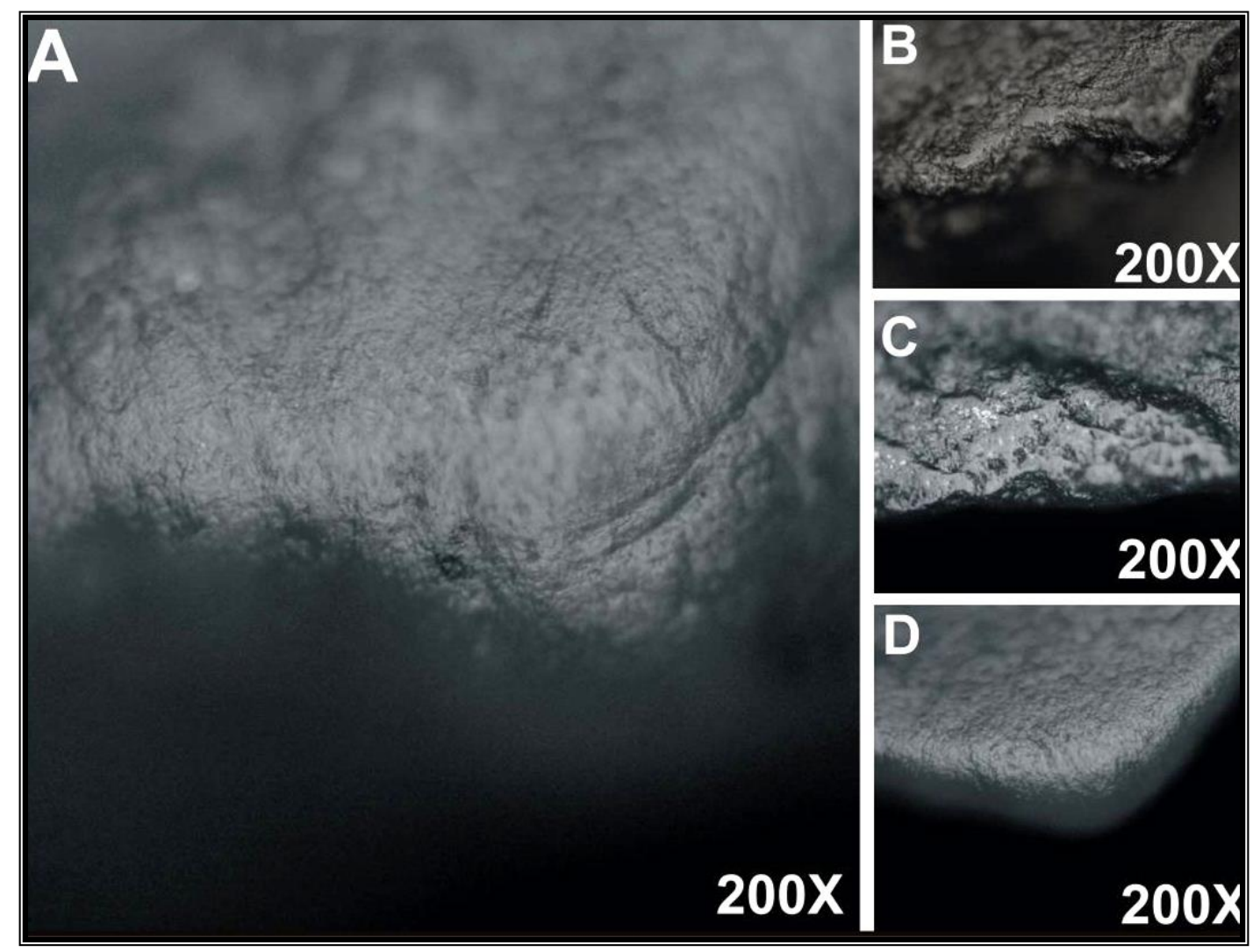

Figura 44: Materiales trabajados identificados en capa $4 \mathrm{CN}$ de Cueva Maripe. A/D) Pieza No: MA04'D5338 (raedera de filo lateral largo), raspado de piel. B) Pieza No: MA04'D5318 (raspador de filo frontal corto), raspado de material duro vegetal. C) Pieza $N^{o}:$ MA05 'C5134 (raspador de filo frontal corto) raspado de material duro vegetal (madera). 


\section{VI.4.2.6. Cinemática empleada}

En relación con los modos de uso y la cinemática empleada para el trabajo sobre distintos materiales, se observó que en los AF la mayoría de las actividades desarrolladas se efectuaron a partir de movimientos transversales ( $\mathrm{N}=27,69 \%)$, mientras que los ANF incluyeron una mayor cantidad de acciones longitudinales $(\mathrm{N}=12$, $52 \%)$ y en menor medida transversales $(\mathrm{N}=10,44 \%)$.

Por otro lado, se registró una relación estadísticamente significativa entre la cinemática empleada y el trabajo sobre material duro. Se observó una diferencia entre la longitud de filos y las acciones desarrolladas (transversales o longitudinales) (Prueba de MannWhitney; $U=19,5 ; p=0,01$ ) (Figura 45). Los filos que trabajaron de manera transversal presentaron una longitud promedio menor de $31 \mathrm{~mm}$; mientras que las piezas empleadas longitudinalmente $46 \mathrm{~mm}$ promedio.

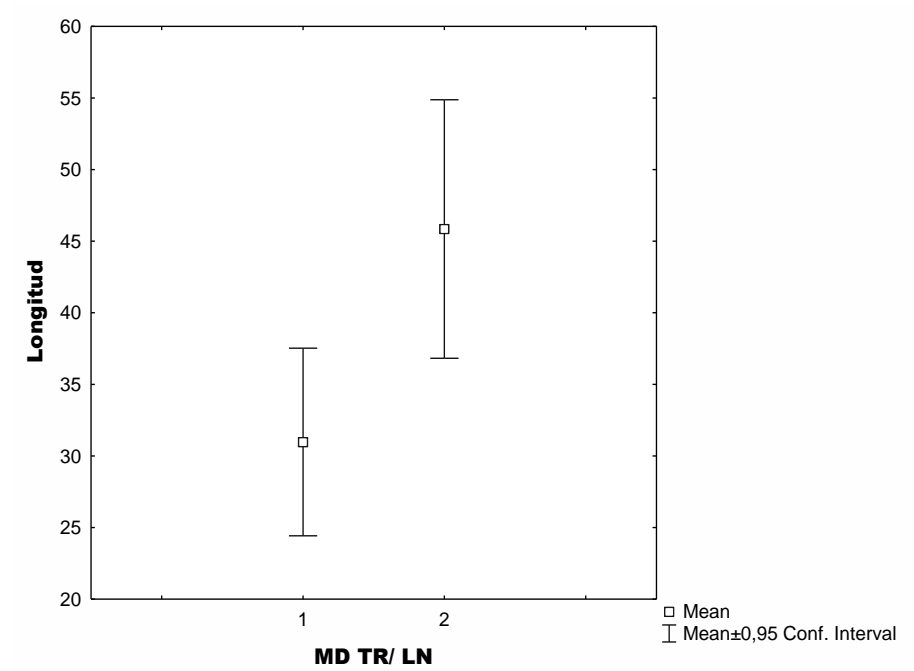

Figura 45: Expresa la diferencia significativa entre la longitud de los filos empleados en distintas cinemáticas sobre material duro (TR: acciones transversales y LN: acciones longitudinales).

Por otro lado y en relación con el ángulo de los filos trabajados sobre material duro, se observó, al igual que en el caso anterior, una diferencia significativa (Prueba de MannWhitney; $U=17,5 ; p=0,007$ ) (Figura 46). Los filos trabajados sobre material duro de manera transversal presentaron un ángulo más recto con un promedio de $61^{\circ}$, mientras que los que se emplearon de manera longitudinal tuvieron un ángulo de $36^{\circ}$. 


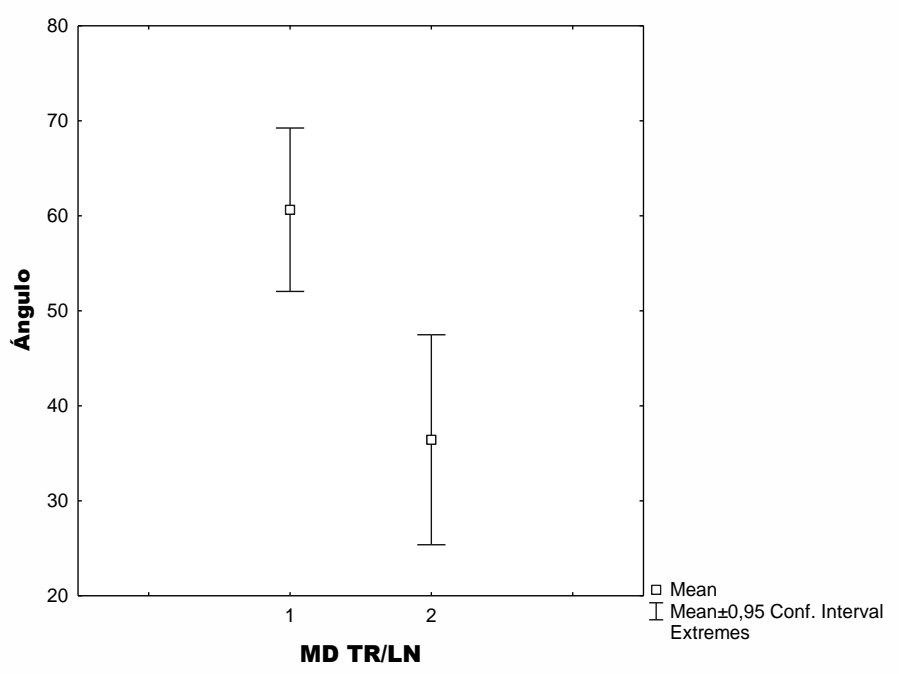

Figura 46: Relación entre diferentes cinemáticas empleadas en el trabajo sobre material duro y el ángulo de los filos utilizados. 1) Acciones transversales y 2) Acciones longitudinales.

No se registró diferencias significativas en relación con las acciones transversales y el material trabajado (duro o blando), tanto en relación con la longitud (Prueba de MannWhitney; $U=11 ; p=0,12$ ) como también en el ángulo de los filos utilizados (Prueba de Mann-Whitney; $U=19,5 ; p=0,52)$.

\section{VI.4.2.7. Actividades desarrolladas}

A partir de los materiales y movimientos identificados en capa 4 , se ha podido inferir diferentes actividades que se desarrollaron en cámara norte. Estas incluyeron el uso de los AF principalmente para el raspado sobre materiales duros $(\mathrm{N}=10,26 \%)$ y materiales duros de origen vegetal (madera, $\mathrm{N}=9,23 \%$ ). También habrían raspado otras sustancias en menores proporciones, como el cuero $(\mathrm{N}=2,5 \%)$ o materiales blandos $(\mathrm{N}=1,2 \%)$ y hueso $(\mathrm{N}=1,3 \%)$.

Las acciones de corte se llevaron a cabo igualmente sobre materiales duros $(\mathrm{N}=6,15 \%)$, con menores proporciones de corte de hueso $(\mathrm{N}=1,3 \%)$ y materiales de dureza intermedia como la madera $(\mathrm{N}=2,5 \%)$.

En los ANF la actividad más representada dentro de la muestra corresponde, al igual que en los AF, al raspado sobre material duro (madera o hueso, $\mathrm{N}=6,26 \%$ ). También se reconoció esta misma actividad sobre materiales de dureza intermedia como la madera $(\mathrm{N}=1,5 \%)$.

En cuanto a las actividades de corte se identificó principalmente sobre materiales duros $(\mathrm{N}=5,22 \%)$ y menores proporciones de hueso $(\mathrm{N}=3,13 \%)$, madera $(\mathrm{N}=2,9 \%)$ y 
material indeterminado $(\mathrm{N}=1,4 \%)$. Mientras que en un solo caso no se pudo determinar el movimiento empleado pero si el trabajo sobre material duro ( $\mathrm{N}=1,4 \%)$ (Figura 47).

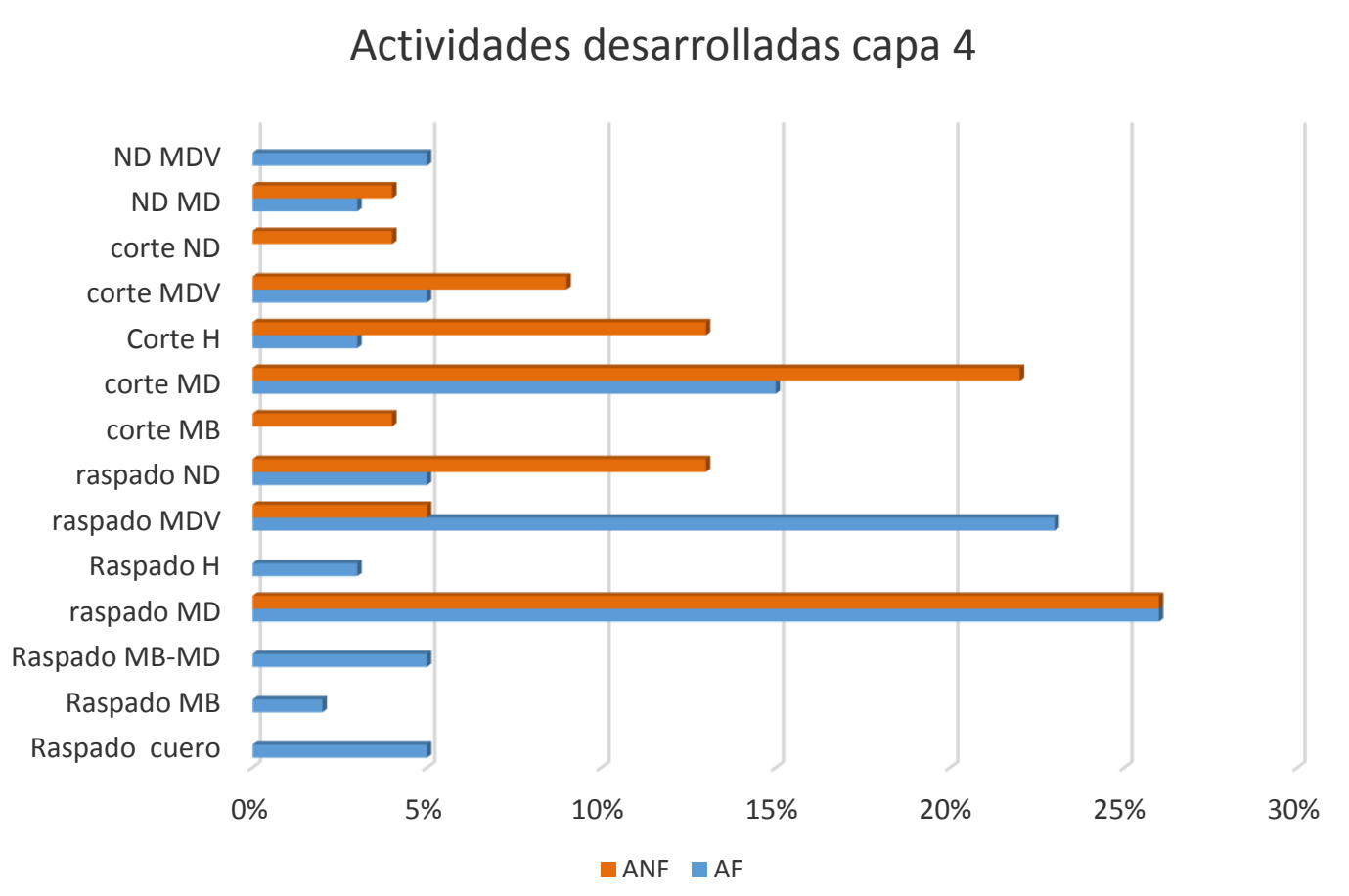

Figura 47: Actividades inferidas mediante el análisis funcional desarrollado en AF y ANF de capa 4 en $\mathrm{CN}$.

\section{VI.4.3. Conjunto lítico de Capa 3 y 2: Artefactos formatizados}

Durante la excavación de la capa 3 se reconocieron dos áreas de combustión en la cuadrícula D6, al igual que tres sectores circulares donde el sedimento interior se presentaba suelto y que podría estar asociado a cuevas de animales cavadores. En el sector NW de esta misma cuadrícula, fue mapeada una concentración de fragmentos de cáscara de huevo de rheidos. Por otro lado, en la cuadrícula D5 sector NE, se registraron dos concentraciones de gramíneas o vegetales, estas también pueden ser vistas en el perfil de la cuadrícula. Mientras que en el sector SE de la cuadrícula D5, se registró una concentración de restos óseos más densa que en el resto de la excavación, contabilizándose una mayor cantidad de restos apendiculares de guanaco (Marcchioni 2013).

La capa 2 presenta una menor cantidad de materiales en relación con la totalidad del conjunto. En el vértice SE de la cuadrícula D6, se registró un área de combustión y en el sector central, un hoyo con sedimento suelto posiblemente consecuencia de animales 
cavadores. De su interior se recuperaron escasos materiales que fueron analizados por separado del conjunto total (Marcchioni 2013) (Figura 48).

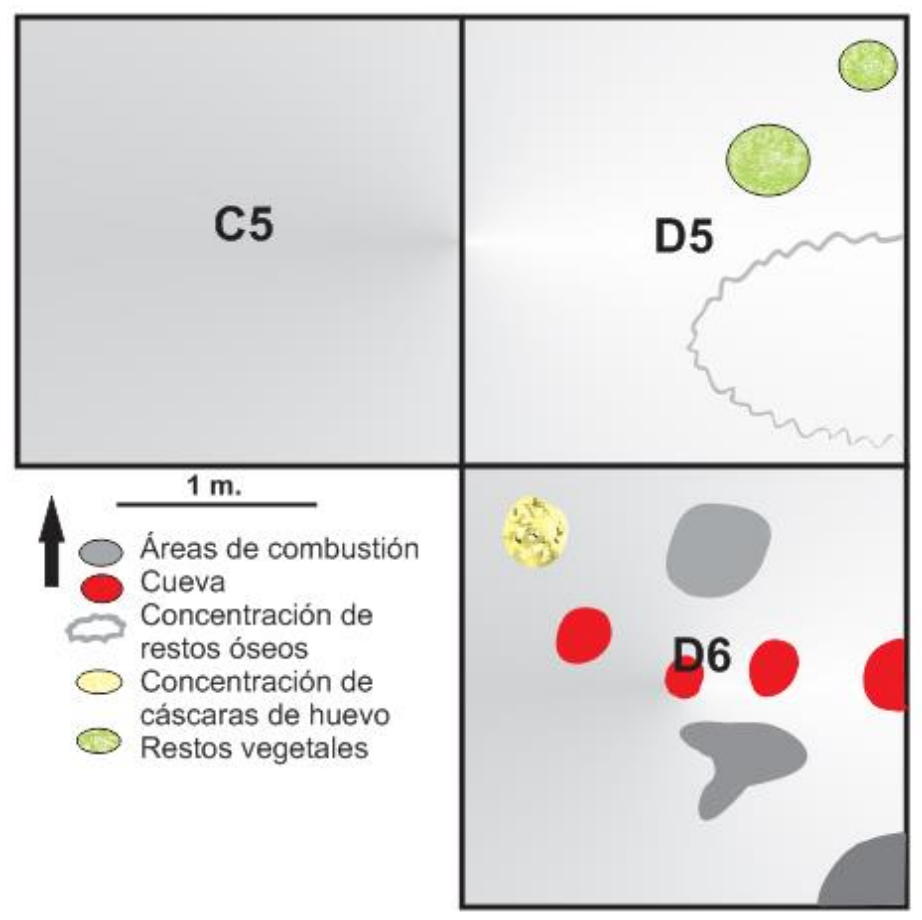

Figura 48: Dibujo en planta de capa 3 y 2 de CN (modificado de Marchionni 2013).

Estas capas constituyen el $32 \%$ del total de la muestras de artefactos formatizados y de donde se recuperó 35 piezas con 64 filos, los cuales fueron observados y analizados en su totalidad, mientras que 65 piezas (con 71 filos) corresponde a los ANF. La distribución tridimensional de estas piezas registró que la mayor concentración de materiales se encuentra en la cuadrícula D6 $(\mathrm{N}=21,62 \%)$ principalmente en el sector SE. En menor medida las cuadriculas D5 $(\mathrm{N}=7,20 \%)$ y C5 $(\mathrm{N}=6,18 \%)$ le siguen en orden (Figura 49).
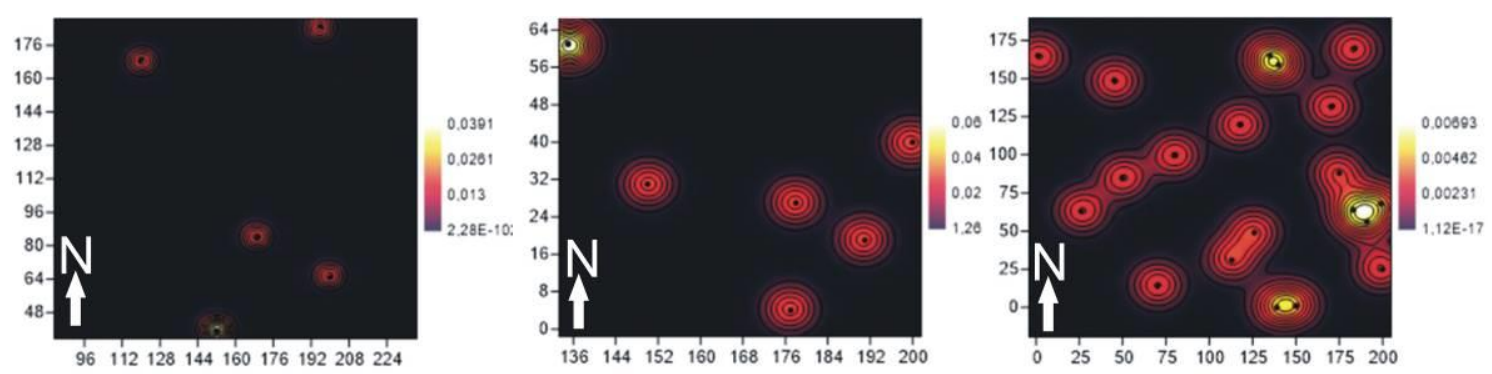

Figura 49: Distribución de densidad artefactual (AF) en las capas 3 y 2 de CN, cuadrículas C5, D5 y D6. 
En cuanto a las características principales y generales del conjunto de AF de estas capas, se observó que en su mayoría las piezas estaban fracturadas sin talón $(\mathrm{N}=21$, $60 \%)$, mientras que el resto se encuentran enteras $(\mathrm{N}=9,26 \%)$ o fracturadas con talón $(\mathrm{N}=5,14 \%)$.

En relación con las materias primas seleccionadas para la producción de estos artefactos se observó un porcentaje elevado de ISG1 (N=10, 34\%); le siguen las variedades RSG2 $(\mathrm{N}=8,27 \%)$, RSG3 $(\mathrm{N}=4,13 \%)$ y CG1 $(\mathrm{N}=3,10 \%)$. En proporciones menores se encuentran ISG2 (N=2, 7\%) y PG1, X1 y RSG1 (N=1, 3\% respectivamente) (Figura $50)$.

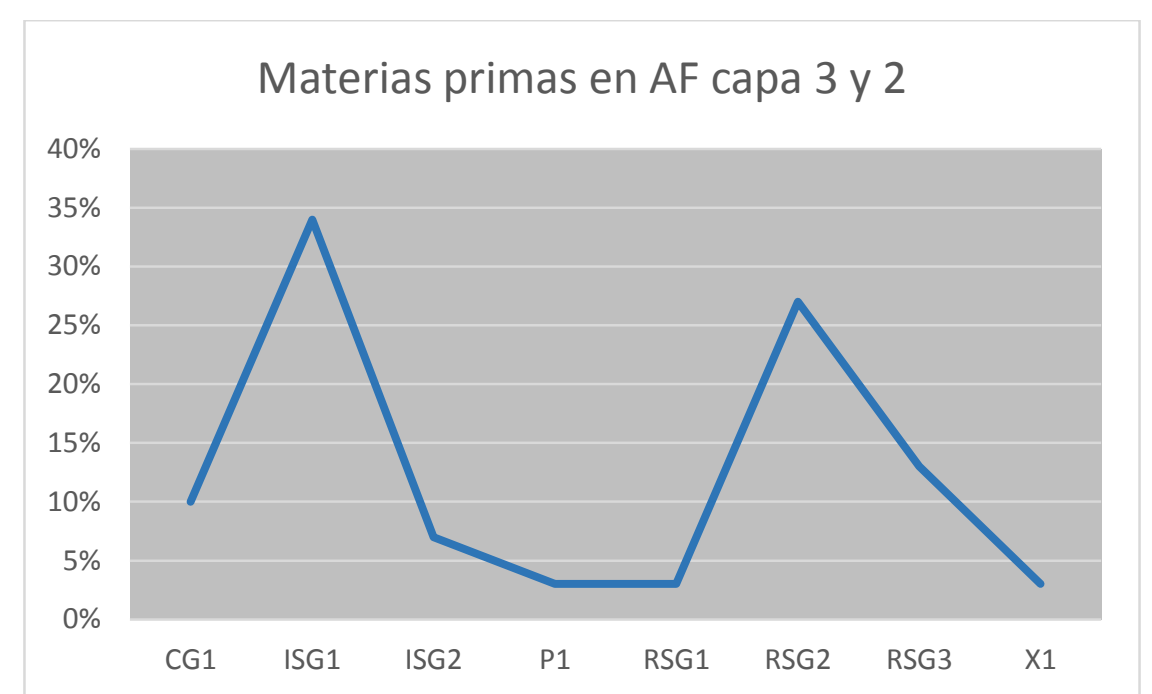

Figura 50: Distribución de las materias primas seleccionadas en la producción de AF de capa 3 y 2 CN.

Se pudieron identificar 6 grupos tipológicos y al igual que en las capas anteriores, el grupo de raspadores (RP), estuvo ampliamente representado en la muestra (Tabla 7).

\begin{tabular}{|c|cccccccc|}
\hline AF & FND & LR & MUR & RD & RP & PE & PP & FNRC \\
\hline $\begin{array}{c}\text { Capa 3/2 } \\
\text { Piezas } \text { N=35 }\end{array}$ & 8 & 5 & 2 & 2 & 16 & 1 & 1 & - \\
\hline $\begin{array}{c}\text { Total filos } \\
(\mathbf{N = 6 4})\end{array}$ & 10 & 6 & 5 & 3 & 23 & 1 & 1 & 15 \\
\hline
\end{tabular}

Tabla 7: Grupos tipológicos identificados en las capas 3 y 2 de CN. FND: filo no diferenciado; LR: lámina retocada; MUR: muesca retocada; RD: raedera; RP: raspador; PE: perforador; PP: punta de proyectil; FNRC: filo natural con rastros complementarios. 


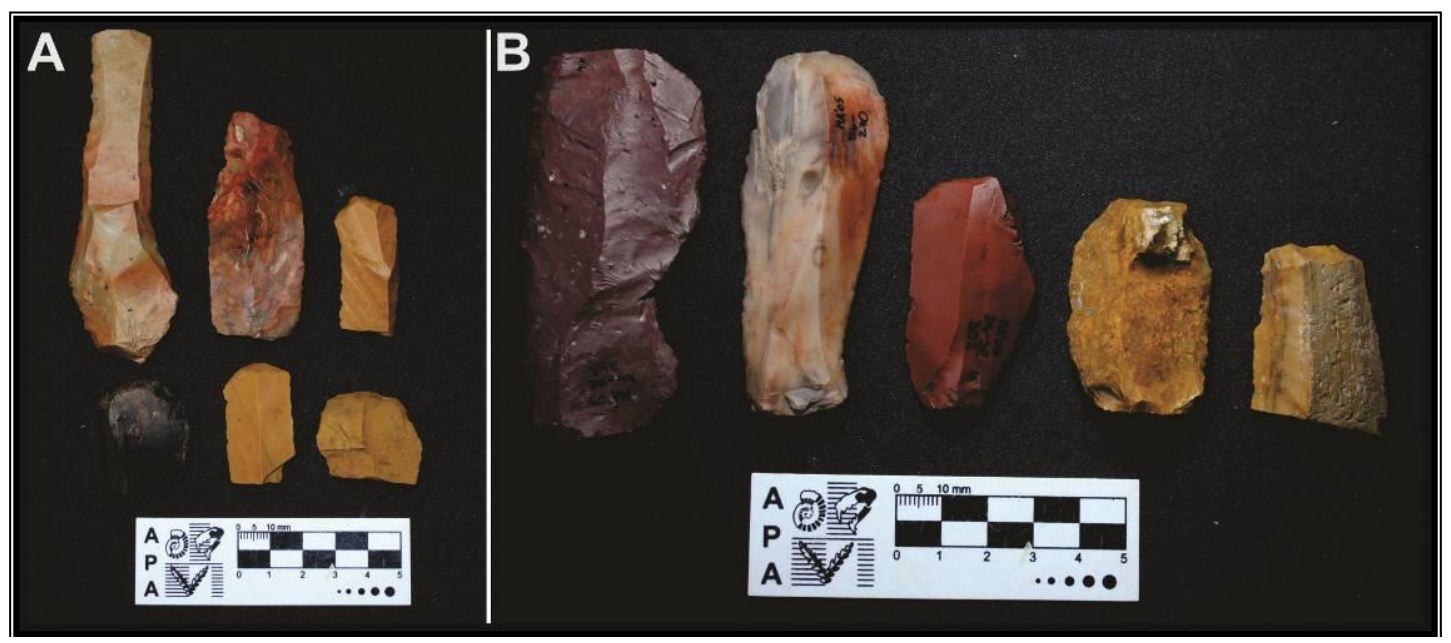

Figura 51: Materiales recuperados de la Capa 3 y 2 de Cueva Maripe. A) Artefactos formatizados de la cuadrícula D5 (lámina retocada, raspadores de filo frontal corto y lateral). B) Artefactos formatizado de la cuadrícula D6 (lámina retocada y raspadores de filo frontal corto y largo lateral).

\section{-Filos no diferenciados (FND)}

Se encuentra caracterizado por un único elemento, elaborado sobre obsidiana de coloración negra. En cuanto a las variables métricas, presentó un tamaño mediano grande y un módulo de longitud-anchura mediano alargado, elaborado sobre una lasca secundaria como forma base y con dos filos naturales complementarios con microlascados aislados.

\section{-Láminas retocadas (LR)}

El conjunto de láminas retocadas corresponde al 14\% (N=5) del total de AF, compuesto principalmente por piezas FCT $(60 \%)$ y elaboradas en su mayoría sobre la variedad ISG1 (80\%) y menores proporciones en CG1 (20\%). En cuanto a la selección de las formas bases se utilizaron en la producción hojas de aristas dobles (60\%) y simples (40\%), mientras que en relación con el tamaño se registró un mayor porcentaje de piezas grandes (33\%) y de módulo de longitud anchura laminar normal.

En todos los casos se registró al menos un filo natural complementario con microlascados aislados. 


\section{-Muesca retocada (MUR)}

Este grupo estuvo compuesto por dos piezas y constituye el $8 \%$ del total de AF. Las materias primas utilizadas para su producción incluyeron dos variedades RSG2 y X1 de coloración marrón, mientras que las formas bases seleccionadas, incluyeron una lasca indeterminada y una hoja de arista simple. En relación al tamaño de las piezas fueron mediano-pequeño y mediano grande y módulo de longitud anchura mediano alargado.

\section{-Raedera (RD)}

El conjunto de raederas está compuesto por un número reducido de elementos de filo lateral largo y corto, conformando un $6 \%$ de la muestra total. La variedad de materias primas utilizadas en su elaboración incluyó al grupo RSG2 y X1 de coloración marrón; se seleccionaron como formas bases lascas angulares y de aristas dobles. En un solo caso se identificó un filo complementario natural con microlascados. El tamaño de las piezas fue grande y mediano-pequeño, presentando una longitud promedio de $48 \mathrm{~mm}$, anchura de $33 \mathrm{~mm}$ y espesor de $10 \mathrm{~mm}$.

\section{-Raspadores (RP)}

Este grupo está ampliamente representado a lo largo de toda la secuencia de cámara norte, en las capas 3 y 2 ocurre lo mismo, constituyendo un $46 \%(\mathrm{~N}=16)$ del total de la muestra de AF. En su mayoría se encuentran FCT (56\%) y están elaborados sobre una amplia variedad de materias primas silíceas, donde ISG1 (30\%) y RSG2 (25\%) están ampliamente representadas.

En relación con la selección de formas bases se registró un mayor uso de lascas $(65 \%)$ sobre hojas (35\%), siendo las angulares las que presentaron proporciones mayores (64\%). Sin embargo, se observa un incremento en el uso de hojas en la producción de AF en estas capas.

En cuanto al tamaño y módulo de longitud anchura, se registró mayor cantidad de pieza de tamaños mediano-pequeño a mediano grande (45\% respectivamente) y menor cantidad de piezas grandes (10\%), mientras que el módulo más representado corresponde al mediano normal $(78 \%)$. 
En relación con las variables métricas las piezas presentaron una longitud promedio de $38 \mathrm{~mm}$, anchura $27 \mathrm{~mm}$ y espesor $9 \mathrm{~mm}$.

\section{-Perforador (PE)}

Este grupo está caracterizado por un único elemento por lo que presenta un porcentaje menor en la totalidad del conjunto de AF (3\%). Está elaborado sobre una RSG2 de coloración marrón. Esta pieza presenta un tamaño mediano-grande con módulo cortoancho y presenta un sólo filo complementario natural con microlascados.

\section{VI.4.3.1. Artefactos no formatizados (ANF) de Capa 3 y 2}

Este conjunto está compuesto por un total de 65 piezas de las cuales se observaron bajo microscopía óptica 71 filos. La distribución tridimensional de los ANF en esta capa registró que la cuadrícula D6 presentaba una mayor concentración de materiales $(\mathrm{N}=49$, $73 \%$ ), en relación con las demás cuadrículas ( $\mathrm{D} 5, \mathrm{~N}=9,16 \%$ y C5, N=5, 11\%), principalmente hacia el sector SE (Figura 52).
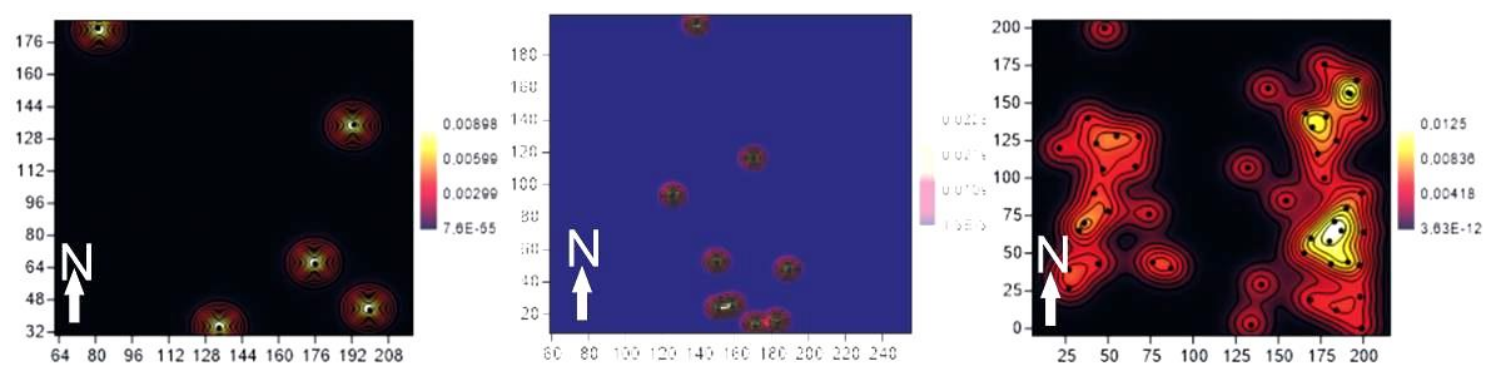

Figura 52: Densidad artefactual (ANF) capas 3 y 2 de CN, cuadrículas C5, D5 y D6.

La mayor cantidad de artefactos se encuentran FST ( $\mathrm{N}=26,38 \%)$, sin embargo, las proporciones de piezas FCT $(\mathrm{N}=24,35 \%)$ y $\mathrm{E}(\mathrm{N}=19,27 \%)$, no difieren ampliamente de las primeras.

En cuanto a las selección de materias primas para su producción, se registró al igual que en las capas anteriores, porcentaje elevado de ISG1 ( $\mathrm{N}=20,30 \%)$, sin embargo a diferencia de estas también se utilizó la RSG3, representada en un 24\% (N=16). Mientras que la RSG2, que con anterioridad constituía porcentajes elevados, en esta capa se encuentra presente a partir de un único elemento (1\%) (Gráfico 30). Por otro lado, también se registró el uso de basalto (materia prima igualmente representada en 
los ANF de capa 4), que en las capas 3 y 2 está representado en un 6\% (N=4) (Figura $53)$.

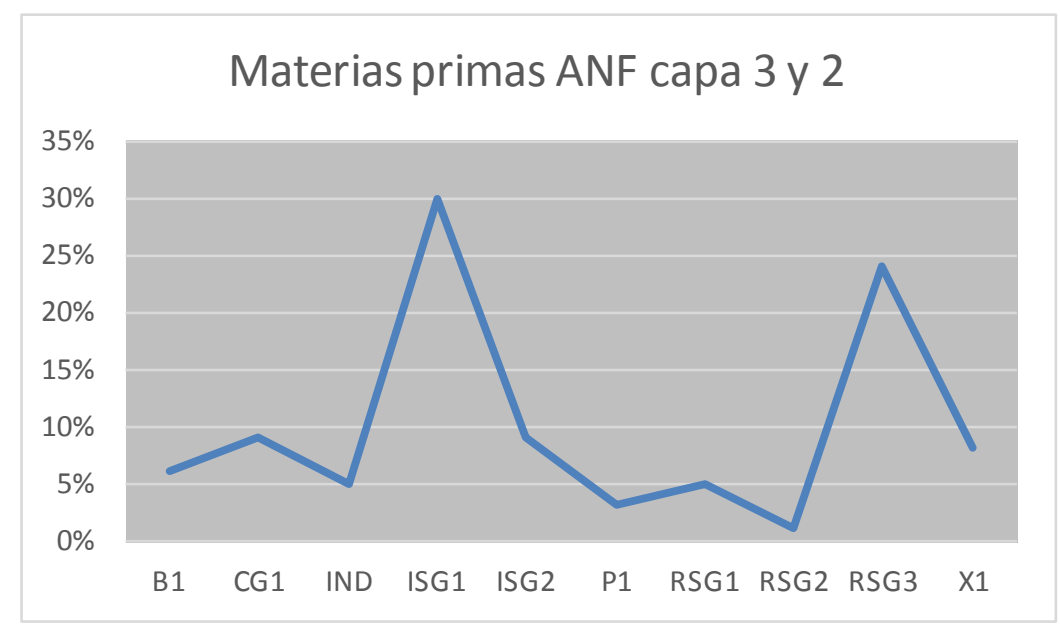

Figura 53: Distribución de materias primas de ANF en capas 3 y 2 de CN.

En relación con el tamaño de la muestra se puede observar mayor cantidad de piezas de tamaño mediano grandes $(\mathrm{N}=40,56 \%)$ y módulo de longitud anchura mediano alargado $(\mathrm{N}=23,32 \%)$. Por otro lado, se registró iguales cantidad de lascas y hojas como formas bases ( $\mathrm{N}=33$ respectivamente); sin embargo, la diferencia en la frecuencia de ocurrencia de lascas y hojas entre las capas de $\mathrm{CN}(5,4,3$ y 2) es estadísticamente significativa $\left(\chi^{2}=14,5 ; \mathrm{df}=2 ; \mathrm{p}=0,001\right)$, observándose que en las capas más profundas la frecuencia de ocurrencia de lascas es mayor, con un incremento en la producción de hojas hacia los niveles superiores (Figura 54).

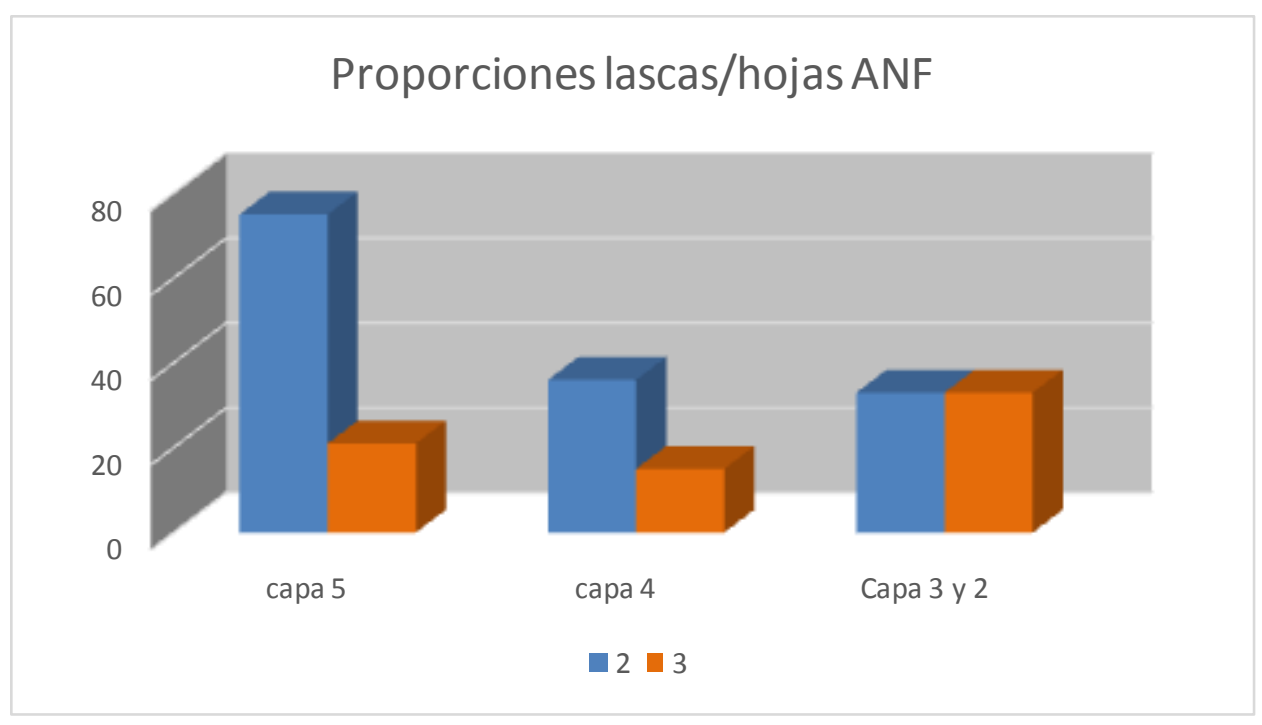

Figura 54: Frecuencia de ocurrencia de lascas/hojas entre las capas (5, $43 \mathrm{y}$ 2) de CN (2: lascas y 3: hojas) 


\section{VI.4.3.2. Resultados del análisis funcional de base microscópica}

Los resultados obtenidos a partir del análisis funcional realizado sobre los filos identificados de las capas 3 y $2(\mathrm{~N}=138)$, ha permitido identificar el trabajo sobre distintos materiales al igual que diferentes modos de uso. En cuanto a la integridad funcional, se registró un $42 \%(\mathrm{~N}=28)$ de piezas que presentaron rastros de utilización sobre diversos materiales. En menor medida se observó piezas sin rastros identificables $(\mathrm{N}=25,37 \%)$ y piezas con alteraciones intensas que imposibilitó la determinación funcional $(\mathrm{N}=14,21 \%)$.

En los ANF las proporciones entre piezas con rastros de uso y no determinadas se disponen de manera similar al de los AF (41\% y 39\%, 29 y 28 elementos respectivamente). Mientras que el resto incluye un $16 \%(\mathrm{~N}=11)$ no determinada por alteración y 4\% (N=3) sin microhuellas de uso identificables.

\section{VI.4.3.3. Integridad del conjunto e identificación de alteraciones tafonómicas}

En cuanto a los distintos tipos de alteración identificadas sobre los artefactos se reconoció un mayor porcentaje de abrasión sedimentaria $(\mathrm{N}=7,50 \%)$ en las piezas con formatización, seguido por procesos de termoalteración que en algunos casos presentaban lustre $(\mathrm{N}=5,36 \%)$ y en menor medida abrasión sedimentaria muy intensa con formación de puntos brillantes $(\mathrm{N}=2,14 \%)$.

Mientras que en los ANF la abrasión sedimentaria ocupa, al igual que en el caso anterior, el mayor porcentaje de las piezas con alteraciones intensas $(\mathrm{N}=4,34 \%)$; $\sin$ embargo, se registraron proporciones de piezas que estaban alteradas por tratamientos en laboratorio (siglado y contacto con metal, $\mathrm{N}=3,33 \%$ ) y en menor medida procesos de termoalteración $(\mathrm{N}=2,22 \%)$ y formación de pátinas $(\mathrm{N}=1,11 \%)$.

\section{VI.4.3.4. Inferencia funcional de las modalidades de uso}

En los AF la relación de filos observados y filos con rastros de utilización registró que en la mayoría de las piezas que presentaban dos filos potencialmente utilizable, al menos uno presentaba rastros de uso $(\mathrm{N}=10,29 \%)$.

Mientras que en los ANF, se observó que la mayoría de las piezas presentaba un solo filo potencialmente utilizable, de los cuales un $34 \%(\mathrm{~N}=24)$ presentaron signo de 
utilización sobre distintos materiales. De las piezas que presentaron 2 filos funcionales al menos 1 registró rastros de utilización $(\mathrm{N}=2,3 \%)$; mientras que el 4\% ( $\mathrm{N}=3)$ no registraron rastros de uso. En los artefactos que presentaron 3 filos, un solo caso presentó dos filos utilizados $(1 \%)$ y el resto $(\mathrm{N}=2,3 \%)$ no registró rastros de uso identificables (Figura 55).

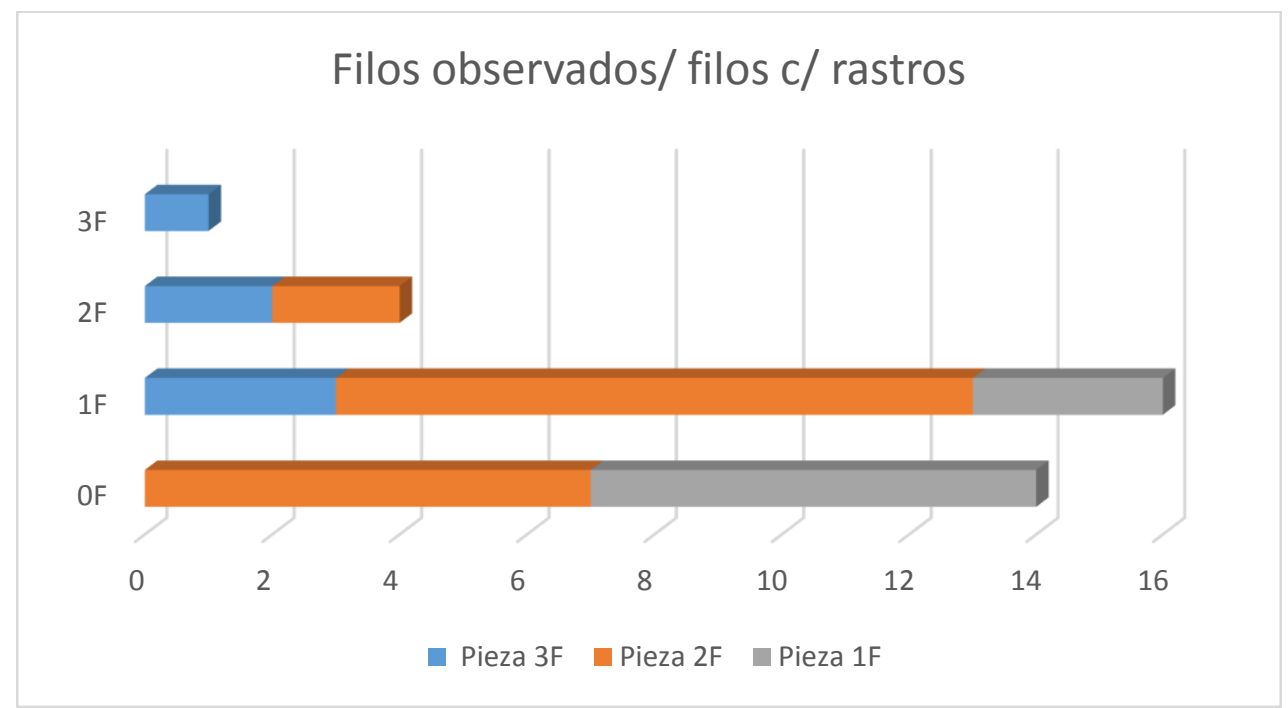

Figura 55: Relación de los filos observados y la presencia/ausencia de rastros de uso en AF de las capas 3 y 2 en $\mathrm{CN}$.

De acuerdo a las materias primas reconocidas en el conjunto de AF, si bien la variedad ISG1 es la que se encuentra más representada en la muestra, las proporciones en relación con la presencia de rastros de uso es igual que la variedad $\mathrm{RSG} 2$ ( $\mathrm{N}=7,33 \%$ respectivamente). Las materias primas RSG3 e ISG2 registraron porcentajes menores de piezas con uso identificable ( $10 \%$ y $9 \%, \mathrm{~N}=2$ respectivamente), mientras que le siguen las variedades $\mathrm{CG} 1$ y $\mathrm{X} 1$ ( $\mathrm{N}=1$ en cada caso).

En cuanto a los $\mathrm{ANF}$, la materia prima que registró un mayor número de piezas con rastros de uso fue la RSG3 (N=9, 32\%), siendo la ISG1, al igual que en los AF, la más representada del conjunto. Mientras que la RSG2 está presente en porcentajes menores $(\mathrm{N}=1,4 \%)$ en conjunto con otras variedades que no se registraron en la manufactura de AF, BS (N=2, 7\%) y PG1 (N=1, 4\%) (Figura 56). 


\section{Materias primas $\mathrm{c} /$ rastros}

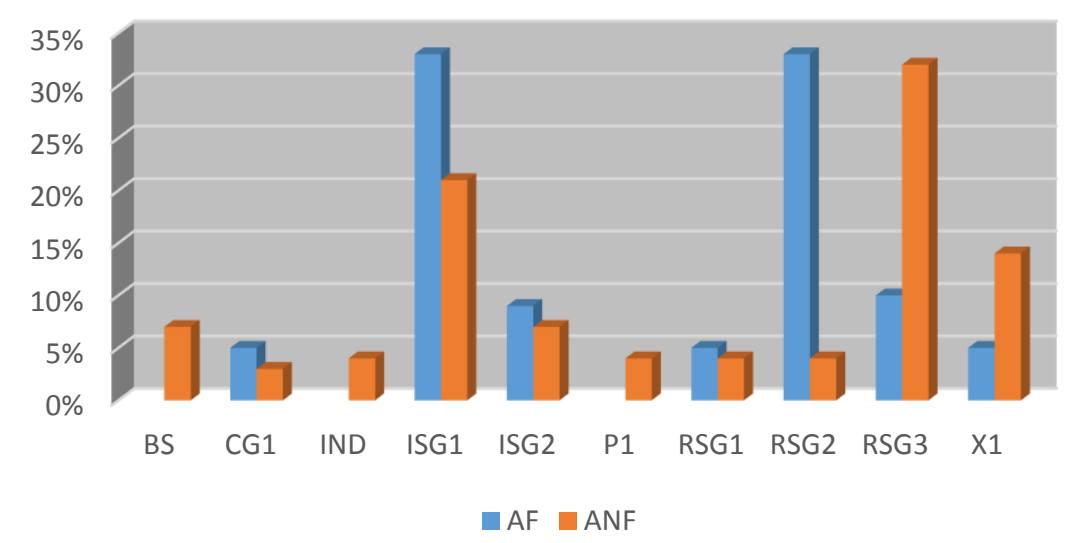

Figura 56: Distribución de las materias primas con rastros de uso identificables en las capas $\mathbf{3}$ y 2 de CN.

\section{VI.4.3.5. Materiales trabajados}

En cuanto a la identificación de los materiales trabajados en las capas 3 y 2, se observa una amplia variedad de materiales. Sin embargo, la diferencia de estados (fresco, seco, estacionado, etc.) no fue reconocido en los artefactos. Las características composicionales de las materias primas utilizadas en su manufactura estuvieron en mayor o menor grado afectadas por alteraciones postdepositacionales. No obstante, la determinación de dureza y movimientos empleados han podido ser inferidos a partir de su análisis.

Tanto en artefactos con filos naturales como también formatizados predomina el trabajo sobre material duro $(\mathrm{AF}=64 \%, \mathrm{~N}=18$ y $\mathrm{ANF}=55 \%, \mathrm{~N}=16)$. Sin embargo, en los AF el análisis efectuado permitió identificar otros materiales como hueso y madera $(\mathrm{N}=2,7 \%$ respectivamente) y en menor medida el trabajo sobre material blando $(\mathrm{N}=1,4 \%)$. Un solo caso registró trabajo sobre material blando y duro a la vez. Cabe aclarar, en este caso en particular, el desarrollo de micropulido identificado como material blando (probablemente piel) en algunos sectores presentaba micropulido de material duro. Si bien el desarrollo de este micropulido no permitió identificar con certeza el trabajo sobre hueso, la inferencia de la actividad desarrollada con esta pieza estaría relacionada a las etapas de procesamiento de presas y tratamiento inicial del cuero (extracción y limpieza). 
En los ANF incluyó igualmente el trabajo sobre material duro animal (hueso, $\mathrm{N}=5$, $17 \%$ ) y vegetal (madera, $\mathrm{N}=3,10 \%$ ) y menores proporciones de material blando y cuero $(\mathrm{N}=2,4 \%$ respectivamente) (Figura 57).

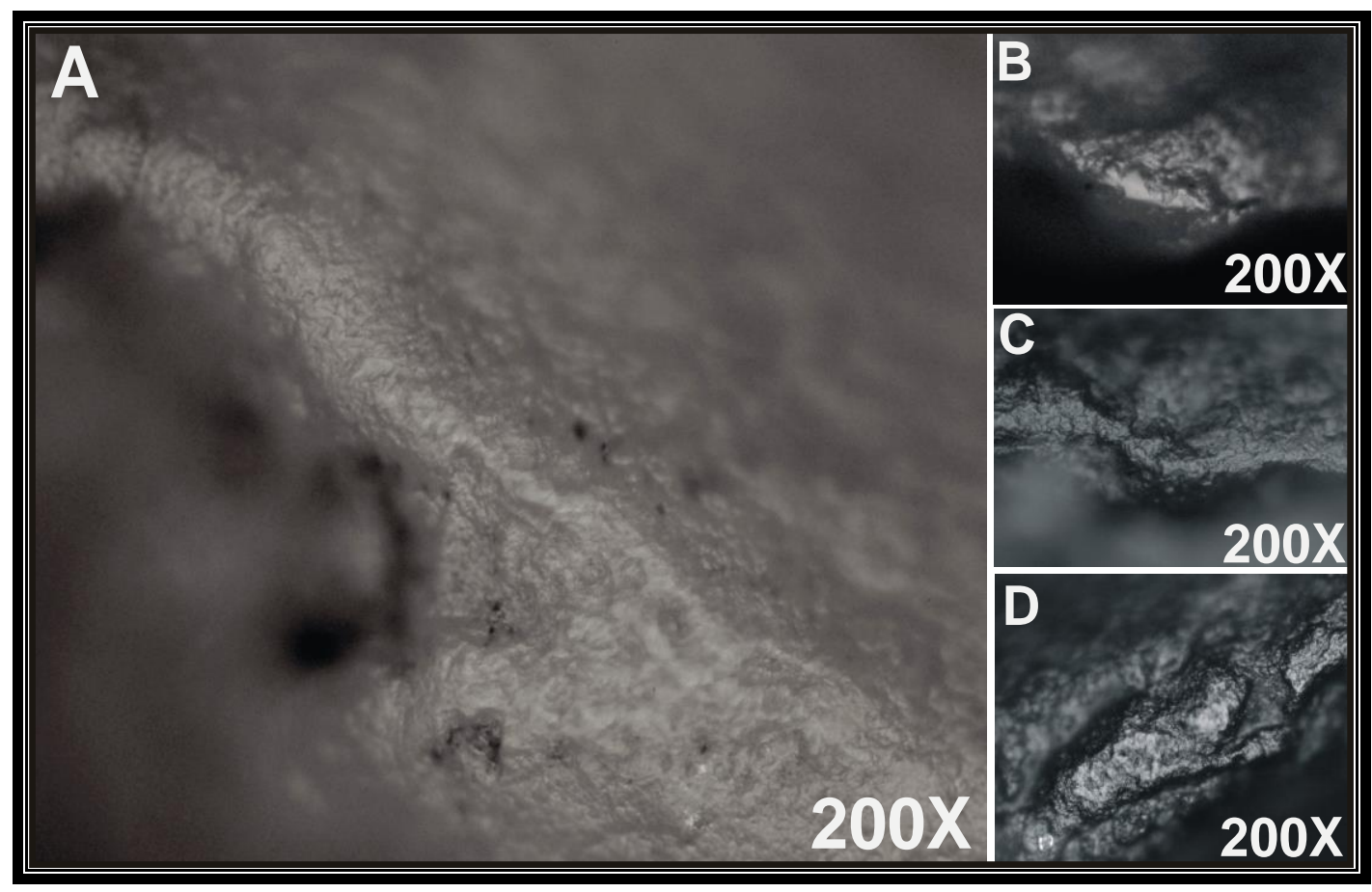

Figura 57: Materiales identificados en las capas 3 y 2 CN. A) Pieza No: MA06’ 6200 (raspador filo frontal corto), raspado de material duro. B/C) Pieza No: MA04'D5150 (lámina retocada), corte de material duro animal. D) Pieza No: MA03 'C562a (lámina retocada), raspado de material duro animal (hueso).

\section{VI.4.3.6. Cinemática empleada}

En relación con los movimientos empleados, se identificó una mayor cantidad de actividades inferidas a partir de acciones transversales y en menor medida longitudinal e indeterminada.

En los AF la cinemática empleada incluyó un $68 \%(\mathrm{~N}=19)$ de piezas trabajadas transversalmente, un 29\% ( $\mathrm{N}=8)$ empleadas en acciones longitudinales y el porcentaje restante incluyó una única pieza cuyo movimiento no pudo ser determinado (3\%).

En los ANF las piezas fueron trabajadas mayormente de manera longitudinal $(\mathrm{N}=21$, $72 \%)$ y en menor medida empleadas en acciones transversales ( $\mathrm{N}=7,24 \%)$ e indeterminadas $(\mathrm{N}=1,4 \%)$.

En cuanto a las variables de longitud y ángulo del filo, se pudo identificar una relación estadísticamente significativa entre la cinemática empleada y ángulo de los filos utilizados en piezas trabajadas sobre material duro (Prueba de Mann-Whitney; $U=21$; 
$\mathrm{p}=0,01)$. Las piezas que trabajaron transversalmente presentaron ángulos más rectos (promedio de $62^{\circ}$ ) que aquellas que lo hicieron de manera longitudinal con un ángulo de $42^{\circ}$ promedio (Figura 58).

Sin embargo, esta relación, no pudo establecerse entre la cinemática empleada y la longitud de los filos trabajados sobre este mismo material (Prueba de Mann-Whitney; $\mathrm{U}=39 ; \mathrm{p}=0,24)$.

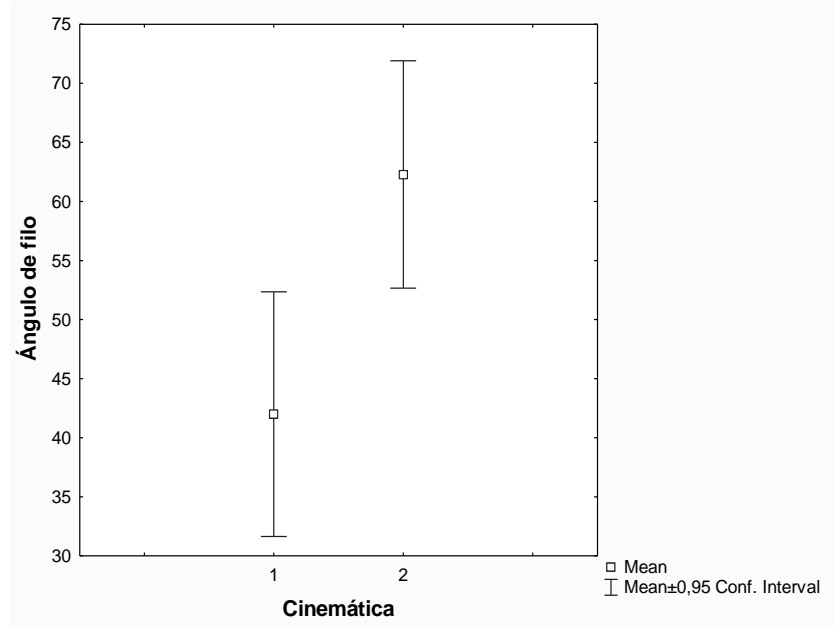

Figura 58: Diferencia estadísticamente significativa entre la cinemática empleada y el trabajo sobre material duro ( $\mathrm{AF}$ de capa 3 y 2 de $\mathrm{CN}$ ). 1) Acciones longitudinales. 2) Acciones transversales.

En el caso de las piezas empleadas sobre material blando, no pudo ser aplicado ningún test estadístico debido al tamaño de la muestra.

En los ANF no se registró ninguna relación estadísticamente significativa entre la cinemática empleada y el ángulo (Prueba de Mann-Whitney; $U=36 ; p=0,87$ ) y longitud del filo utilizado (Prueba de Mann-Whitney; $U=37,5 ; p=0,96$ ).

\section{VI.4.3.7. Actividades desarrolladas}

Los resultados obtenidos del análisis funcional de base microscópica han permitido plantear inferencias acerca de las actividades desarrolladas a partir de los conjuntos líticos de las capas 3 y 2 en $\mathrm{CN}$.

Tanto los AF como los ANF fueron empleados mayormente en actividades de raspado y corte sobre material duro $(\mathrm{N}=9,31 \%$ y $\mathrm{N}=8,28 \%$ respectivamente en el primer caso, mientras que $\mathrm{N}=3,10 \%$ y $\mathrm{N}=12,32 \%$ en el segundo). 
El resto de las actividades desarrolladas por los AF incluyó el corte sobre material duro animal (hueso) y material duro vegetal (madera) 7\% respectivamente, y menores proporciones $(4 \%)$ del raspado de cuero y material blando.

Mientras que los ANF estuvieron empleados, al igual que los AF, en actividades de raspado de hueso y madera en un $7 \%(\mathrm{~N}=3)$ cada uno, raspado sobre material duro y blando a la vez $(\mathrm{N}=1,4 \%)$ y raspado sobre material blando únicamente $(\mathrm{N}=1,3 \%)$.

Cabe aclarar que el porcentaje restante incluye piezas cuya cinemática ha sido identificada pero no se ha podido determinar con exactitud el material trabajado (Figura 59).

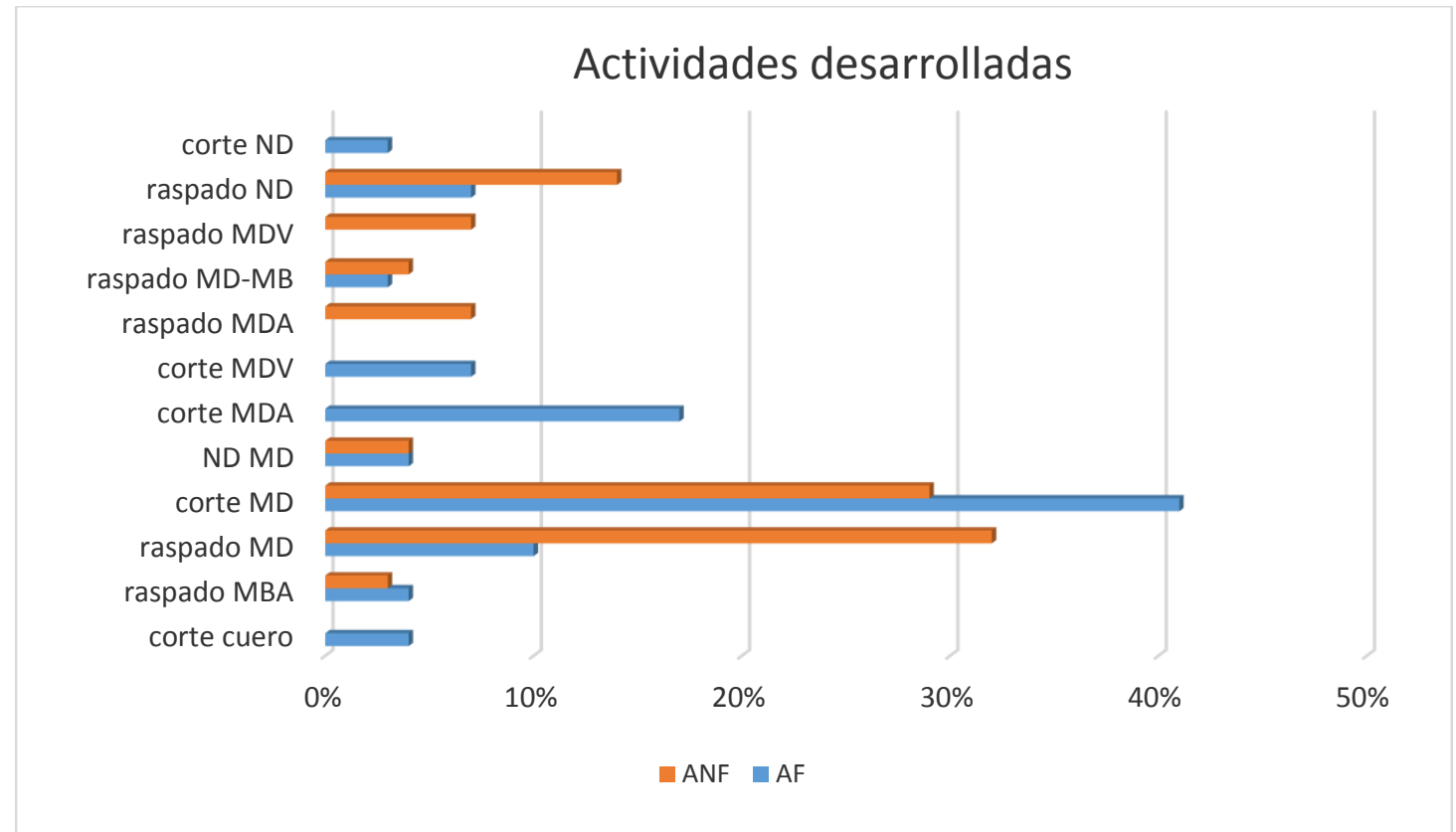

Figura 59: Inferencias de las actividades desarrolladas por los AF y ANF de capa 3 y 2 en CN.

\section{VI.5. Cámara Sur (CS):}

El sector sur de Cueva Maripe comprende los materiales analizados de las cuadrículas A12 y B12, las cuales han sido excavadas hasta la roca de caja conformando un área de $8 \mathrm{~m}^{2}$. En esta cámara han sido recuperados un total de 206 AF con 446 filos identificados y 348 ANF (con 499 filos), de las cuales 283 (339 filos) constituyen la muestra a analizar mediante microscopía óptica.

Los materiales proceden de 7 niveles artificiales de excavación, que de acuerdo a los fechados obtenidos (Tabla 4) han sido agrupados en 3 unidades analíticas o capas 
(Marchionni 2013). Estas unidades han sido definidas a partir de las principales características del sector sur de Cueva Maripe, con una menor tasa de depositación que genera una secuencia más comprimida. Esta particularidad, (menor potencia sedimentaria) le otorga, a este sector, un menor grado de resolución arqueológica en comparación con cámara norte (Miotti et al. 2007; Miotti et al. 2011).

Por otro lado, en la pared posterior de la cueva se reconoce una filtración intermitente de agua, que escurre a través de la roca de caja y humedece los sedimentos depositados. Esto ha generado una configuración particular, en especial en la capas 3 y 4.

En relación a las capas que presentaron evidencia ocupacional, se puede mencionar ciertas diferencias estructurales entre cada una de ellas.

La unidad analítica 4 (UA4) corresponde a la más profunda de la secuencia con dos fechados radiocarbónicos (ca. 9500 y 8300 años AP). Los fechados obtenidos permiten asociar esta unidad a los momentos iniciales de ocupación del área durante la transición Pleistoceno-Holoceno.

La unidad analítica 3 (UA3) incluye igualmente dos fechados radiocarbónicos ( ca. 7700 y 4100 años AP) y corresponde al bloque temporal del Holoceno medio.

Mientras que la unidad analítica 2 (UA2) corresponde a la más superficial de la secuencia, presentando fechados de ca.1100 años AP en su base, lo que permite una asignación del Holoceno tardío. De este nivel fueron también recuperados materiales históricos que evidenciarían la ocupación de la familia Maripe en la cueva hasta mediados del $s$. XX.

\section{VI.5.1. Conjunto lítico de la UA4: Artefactos formatizados}

Durante las excavaciones se pudieron identificar dos áreas de fogones en esta capa, una hacia el SW de la cuadrícula B12 y otra hacia el SE de la A12. En el sector sur de la cuadrícula A12 se reconoció a su vez, un área con presencia de raíces hacia la roca de caja; al igual que un sector con sedimento perturbado relacionado posiblemente a actividades de animales cavadores en el sector NW. Esta área comprendía de 8 a $10 \mathrm{~cm}$ de ancho y 1,10 m de largo en sentido NW-SE. Los materiales obtenidos fueron analizados por separado debido a su dudosa procedencia (Marchionni 2013).

En cuanto a los materiales recuperados de esta unidad, constituyen el 6\% ( $=29)$ del total de artefactos líticos de CS; con una mayor concentración de materiales hacia la cuadrícula A12 principalmente en los sectores SW y NW. La cuadrícula B12 presenta 
un $41 \%$ de los materiales recuperados de esta capa, con una mayor densidad hacia el sector NW (Figura 60).
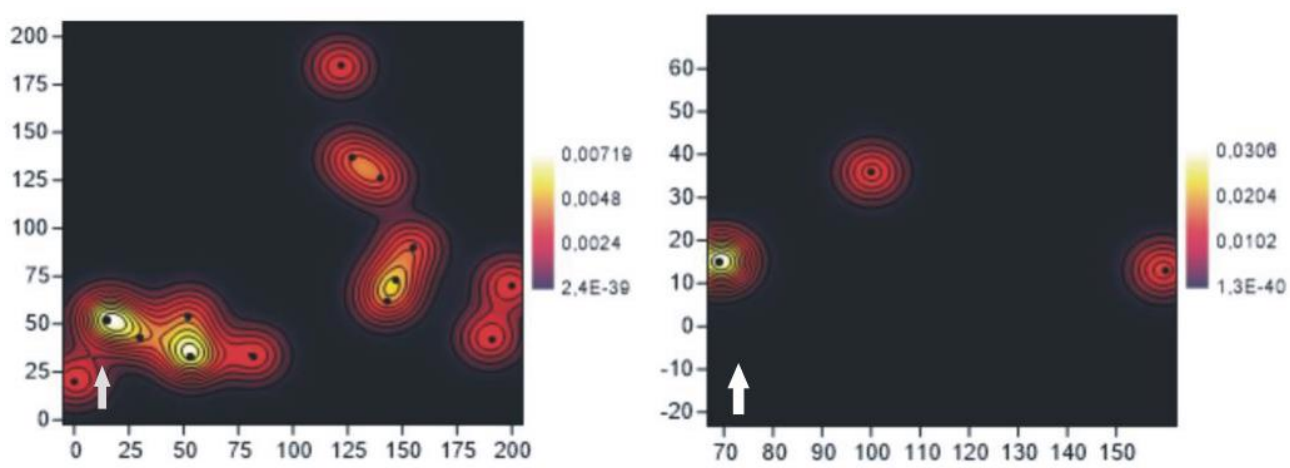

Figura 60: Distribución de la densidad de materiales líticos formatizados en sentido S-O en UA4 de CS, cuadrículas A12 y B12.

El conjunto de artefactos formatizados está constituido por un total de 12 piezas (con 25 filos), de las cuales fueron identificados 7 grupos tipológicos.

Mientras que los ANF está compuesto por 17 piezas con 18 filos analizados bajo microscopía óptica.

En lo que respecta al grupo de los AF y a las características generales de estos, se pudo reconocer la utilización de materias primas homogéneas para su producción. En su mayoría estuvieron elaboradas sobre la variedad ISG1 (19\%) al igual que en el caso de CN. Sin embargo, las proporciones con el resto de las materias primas identificadas, no varían en gran cantidad; el X1, RSG1 y RSG3 se encuentran representadas igualmente en altas proporciones (18\% cada una), mientras que en menor cantidad se registró el uso de obsidiana, ópalo y calcedonia (9\%) representados con una sola pieza cada una (Figura 61).

En relación con los grupos tipológicos identificados, los raspadores, que en las demás capas están ampliamente representados, constituyen en este caso únicamente el $18 \%$ $(\mathrm{N}=2)$ del conjunto de $\mathrm{AF}$, mientras que las raederas registraron un mayor número de piezas $(\mathrm{N}=3,28 \%)$. La variedad de artefactos formatizados está complementado por los siguientes grupos: cepillo, bifaz, cuña, filos no diferenciados y cuchillos retocados con una pieza cada uno (9\%).

En cuanto al tamaño y módulos de longitud anchura registrada en este conjunto, se observó que en su mayoría correspondían a piezas de tamaño grandes $(\mathrm{N}=3,27 \%)$ a muy grandes $(\mathrm{N}=4,28 \%)$ y módulo de longitud anchura mediano normal $(\mathrm{N}=4,46 \%)$. 
Para la elaboración de estos artefactos se reconoció la utilización únicamente de lascas como formas bases siendo las lascas no diferenciadas las mayormente representadas en el conjunto $(\mathrm{N}=3,34 \%)$. Mientras que otras variedades como lascas primarias $\mathrm{y}$ angulares fueron igualmente utilizadas pero en menores proporciones $(22 \%$ respectivamente).

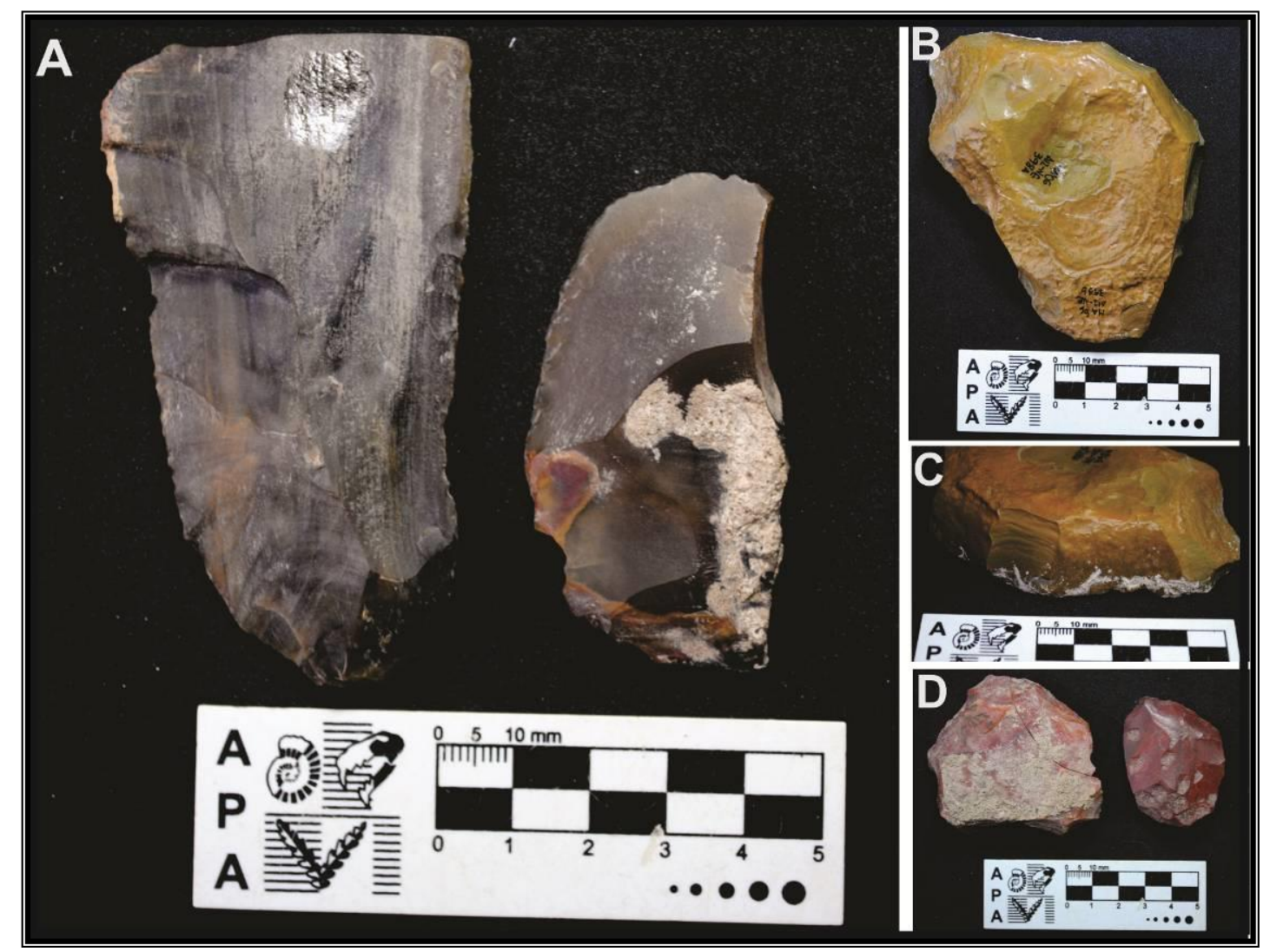

Figura 61: Materiales recuperados de la UA4 de CS de Cueva Maripe. A) Raedera y cuchillo retocado de filo lateral largo, elaborados sobre xilópalo. B-C) Cepillo elaborado sobre sílex de coloración marrón, presenta depositación de carbonato sobre lacara ventral y filo. D) Piezas con restos de carbonatos y termoalteradas.

\section{VI.5.1.1. Artefactos no formatizados (ANF) de UA4}

El conjunto de artefactos no formatizados de esta unidad, están distribuidos principalmente en la cuadrícula A12 (53\%) hacia el sector NW.

En su mayoría se compone de piezas enteras $(\mathrm{N}=8,44 \%)$ y en menores medidas fracturadas con talón $(\mathrm{N}=6,37 \%)$ y sin talón $(\mathrm{N}=3,19 \%)$.

En cuanto a las materias primas utilizadas se seleccionaron rocas de procedencia local (variedad de sílices de buena calidad para la talla) en especial el tipo ISG1 ( $\mathrm{N}=9,56 \%)$, 
seguido por el uso de calcedonias CG1 (N=3, 19\%) y en menor medida RSG2, RSG3 y $\mathrm{X} 1(\mathrm{~N}=1,6 \%$ cada una).

El tamaño de las piezas estuvo representado principalmente por artefactos mediano grandes $(\mathrm{N}=11,69 \%)$ y con módulo de longitud-anchura mediano alargado. Al igual que en $\mathrm{CN}$, esta capa no registró piezas de tamaño pequeñas a muy pequeñas observándose cierta tendencia en la distribución del tamaño de las piezas, en relación a su disposición en la secuencia ocupacional.

El uso de lascas como formas bases estuvo representado en un $75 \%(\mathrm{~N}=12)$, mientras que las hojas un $25 \%(\mathrm{~N}=4)$, siendo las lascas angulares las más representadas en el conjunto $(\mathrm{N}=6,50 \%)$. En menor medida se utilizaron lascas de arista $(\mathrm{N}=4,34 \%)$, primarias y secundarias $(\mathrm{N}=2,8 \%$ respectivamente).

\section{VI.5.1.2. Resultados del análisis funcional de base microscópica}

El total de filos analizados bajo microscopía óptica fue de 22 en AF y 18 en ANF. En el segundo caso se observó que en su mayoría las piezas presentaban un único filo potencialmente utilizables.

Los resultados obtenidos del análisis funcional arrojó en $\mathrm{AF}$ un $40 \%(\mathrm{~N}=8)$ de filos con rastros de utilización, mientras que en menor medida se identificaron piezas no determinadas por alteración $(\mathrm{N}=6,30 \%)$, no determinadas $(\mathrm{N}=5,25 \%)$ y $\sin$ rastros de utilización en menores proporciones $(\mathrm{N}=1,5 \%)$.

En el caso de los ANF el mayor porcentaje $(\mathrm{N}=8,44 \%)$ estuvo ocupado por piezas no determinables, probablemente debido al tiempo o al tipo de material en el que fue empleado. En iguales y menores proporciones se registraron piezas con huellas de uso y piezas que no fueron determinadas debido a alteraciones intensas sobre su superficies $(\mathrm{N}=5,28 \%$ cada una).

\section{VI.5.1.3. Integridad del conjunto e identificación de alteraciones tafonómicas}

El análisis realizado en el conjunto de la UA4 de CS registró ciertas diferencias en relación con la $\mathrm{CN}$. En primera instancia se observó que, si bien el número de piezas analizadas en CS era mayor que en $\mathrm{CN}$, el porcentaje de piezas con alteraciones intensas $(\mathrm{N}=6,30 \%)$ fue mayor que en la capa 5 de este sector (16\%). Las alteraciones mayormente identificadas en los AF incluyó porcentaje elevados de piezas con lustre de 
suelo y playas de abrasión $(\mathrm{N}=4,67 \%)$ y en menor medida piezas con depósitos de carbonato sobre su superficies, que en algunos casos, iba acompañado con el desarrollo de pátina de coloración blanca o grisácea. Estas concreciones se extendían sobre la superficie de las piezas, en especial en la cara dorsal, que presentaban una mayor irregularidad y aristas, llegando en algunos casos a cubrir la totalidad de la pieza.

En relación a la integridad artefactual de los ANF, se registró un 28\% ( $\mathrm{N}=5)$ de piezas no determinadas por alteración. Las alteraciones identificadas fueron mayormente ocasionadas por procesos de termoalteración intensos, con cambios de coloración de la roca, que en algunos casos llegaban a presentar abundantes hoyuelos sobre su superficie. Asimismo, se registró la presencia de pátina blanca en forma de costra, extendiéndose sobre los filos e imposibilitando su observación (Figura 62).

Por otro lado, en cuanto a la variedad de materias primas utilizadas en relación con la presencia de rastro de uso se identificó que en los AF la variedad RSG3 (N=4, 60\%) registró mayor cantidad de rastros de utilización a diferencia de las materias primas ISG1 y X1 (N=2, 20\% respectivamente). Mientras que en los ANF ocurre lo contrario, la ISG1 (57\%) presenta una mayor cantidad de piezas con huellas de utilización, seguido por la variedad CG1 (19\%). Le siguen la RSG3 y X1 en menores proporciones $(6 \%)$.

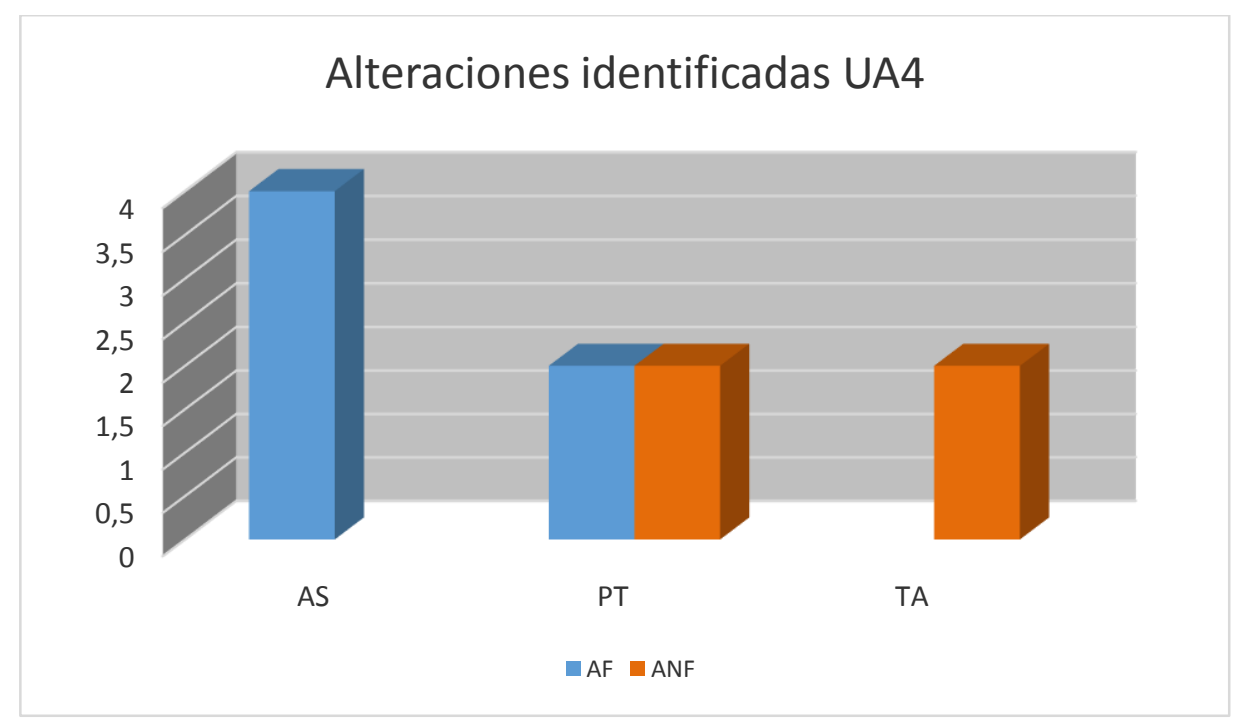

Figura 62: Tipo de alteraciones identificadas en la UA4 de CS (AF y ANF). AS: abrasión sedimentaria; PT: formación de pátina blanca y TA: termoalteración. 


\section{VI.5.1.4. Inferencia funcional de las modalidades de uso}

En esta unidad se pudo observar ciertas diferencias en cuanto a la determinación funcional de los artefactos en relación a los filos retocados y no retocados. En los AF el $40 \%(\mathrm{~N}=8)$ presentó signos de utilización mientras que los ANF el 28\% (N=5) de los filos analizados registraron algún tipo de rastro que permitiera identificar su uso. Por otro lado, en los AF, el $25 \%(\mathrm{~N}=5)$ de los filos fueron no determinados, mientras que en los filos sin formatización este porcentaje se incrementó con un $44 \%(\mathrm{~N}=8)$. Asimismo, en los AF se reconocieron filos sin uso (5\%), que en los ANF no pudo ser reconocido, incluyendo un $28 \%$ de filos no determinados por alteración (Figura 63).

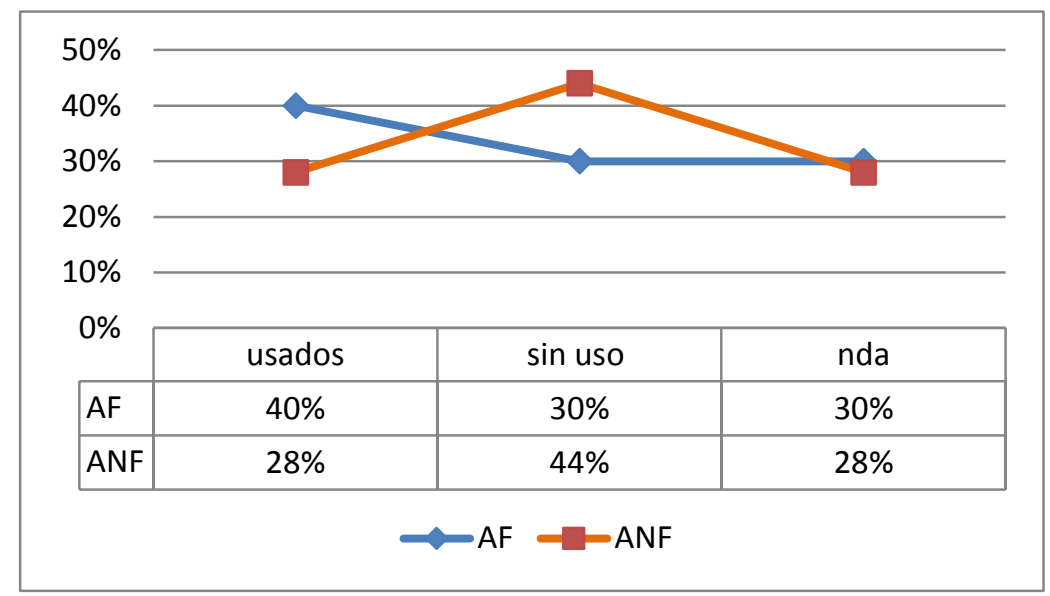

Figura 63: Integridad artefactual de la UA4 en CS. AF: artefactos formatizados y ANF: artefactos no formatizados.

En cuanto a la cantidad de filos identificados por pieza se observó que si bien en su mayoría los AF presentaban un único filo potencialmente utilizables (50\%), se registraron piezas con filos dobles y múltiples $(\mathrm{N}=6,25 \%$ respectivamente). Las piezas con filos múltiples presentaron al menos 2 filos con rastros de utilización en mayor medida. Mientras que el porcentaje más elevado corresponde a piezas con filos simple de las cuales un $34 \%(\mathrm{~N}=4)$ no registraron rastros de uso.

En el caso de los ANF, la mayoría presentaron filos simples $(\mathrm{N}=14,82 \%)$ y dobles en menores proporciones $(\mathrm{N}=3,18 \%)$. Las lascas con filos simples fueron usadas en un $23 \%$ sobre distintos materiales, mientras que un $6 \%$ de piezas con filos dobles presentaron rastros de utilización (Figura 64). 


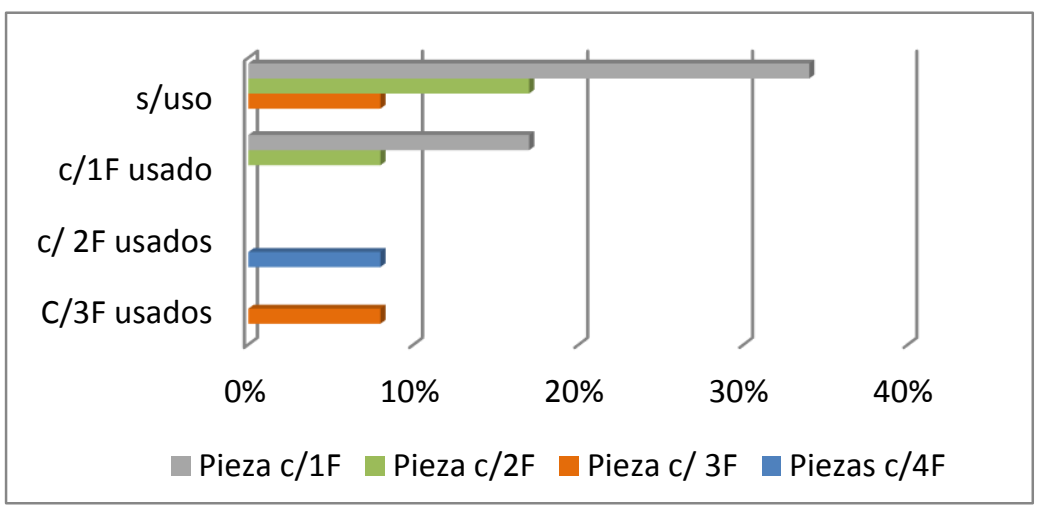

Figura 64: Relación de los filos observados y la presencia/ausencia de rastros de uso en AF de UA4 de CS.

\section{VI.5.1.5. Materiales trabajados}

En esta unidad se reconocieron ciertas diferencias en relación con el uso de los filos formatizados de aquéllos sin formatización. En el primer caso, las piezas fueron empleadas sobre distintos materiales, siendo el trabajo sobre cuero el más representado dentro de la muestra $(\mathrm{N}=4,50 \%)$. Le siguen el trabajo sobre material duro animal (hueso, 38\%) y material duro (tanto de origen vegetal como animal, 12\%).

El uso de lascas estuvo relacionado principalmente al trabajo sobre material duro tanto de origen animal como vegetal (50\%), mientras que en iguales y menores proporciones se registró el trabajo sobre madera y hueso (25\%) (Figura 65).

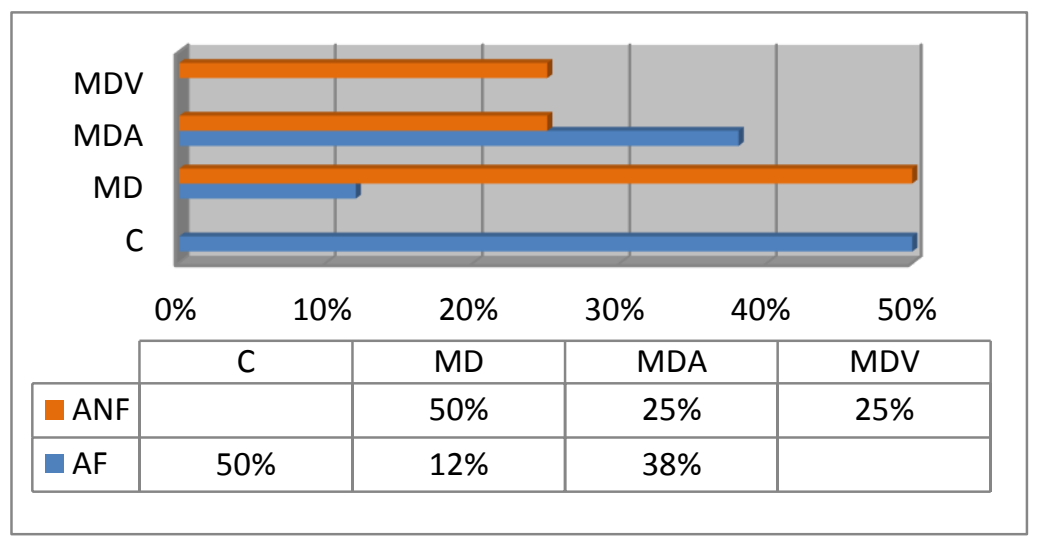

Figura 65: Materiales trabajados identificados en la UA4 de CS. C: Cuero; MD: material duro; MD-A: material duro animal y MD-V: material duro animal. 


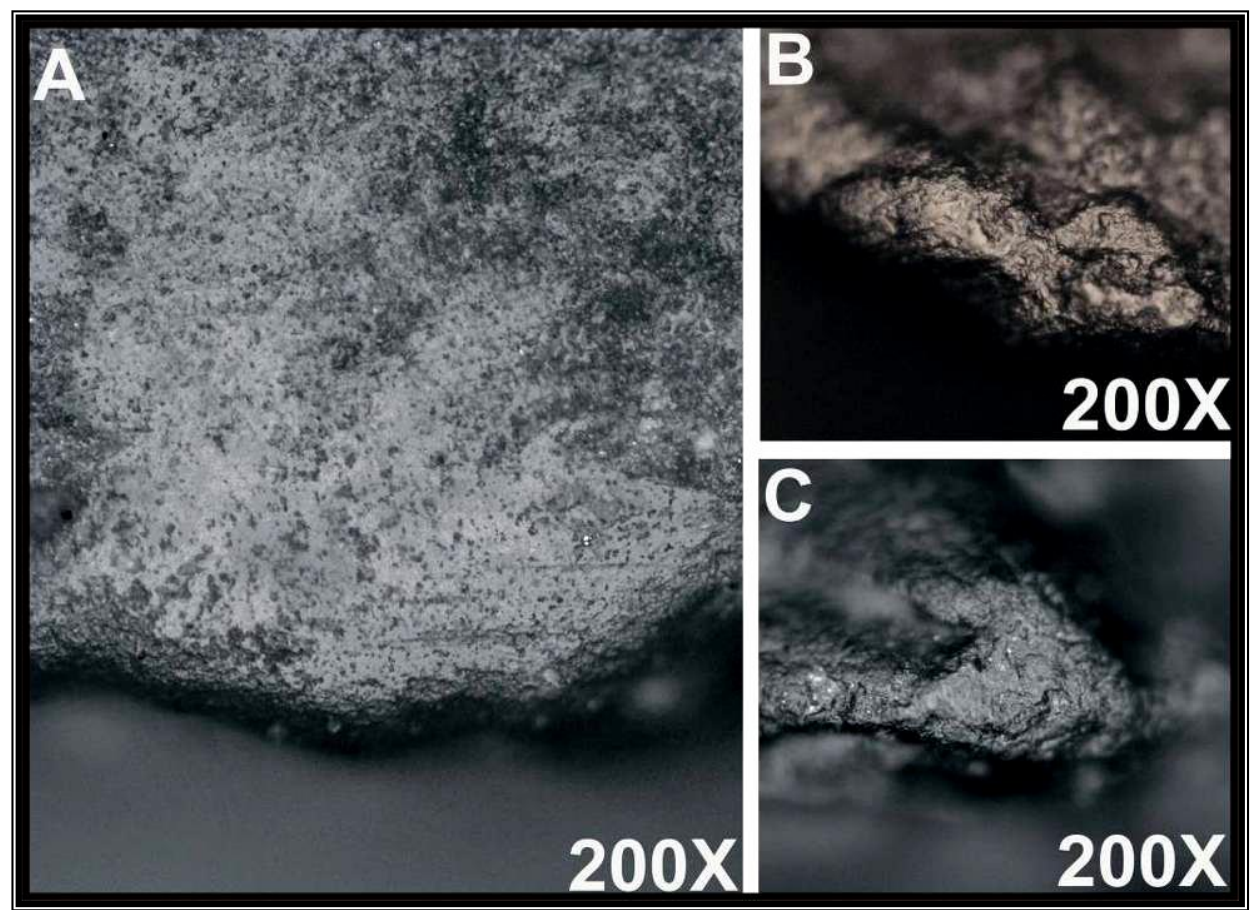

Figura 66: Materiales trabajados identificados en la UA4 CS. A) Pieza No: MA04'A12398a, (raedera de filo lateral corto), corte de material duro vegetal. B) Pieza $\mathrm{N}^{\mathrm{o}}: M A 04$ 'A12284a, (cepillo filo lateral largo), raspado de material duro animal (hueso). C) Pieza $\mathrm{N}^{\mathrm{o}}$ : $M A 06$ 'B12413, (artefacto formatizado no diferenciado), raspado de material duro animal (hueso).

\section{VI.5.1.6. Cinemática empleada}

En relación con los movimientos identificados, las acciones transversales fueron reconocidas mayormente tanto en los AF como en los ANF, en el trabajo sobre materiales blandos como también material duro (hueso y madera).

Debido al tamaño de la muestra no pudo realizarse ningún test estadístico, sin embargo se observaron ciertas diferencias en cuanto a las características principales de los filos que trabajaron transversalmente en relación a la dureza del material utilizado. Las piezas empleadas sobre material duro presentaron ángulos más agudos (promedio de $50^{\circ}$ ), que los filos trabajados sobre material blando (ángulo promedio de $78^{\circ}$ ). Mientras que en relación a la longitud de estos filos, se observó que los trabajados sobre material duro presentaron filos más cortos (longitud promedio de $42 \mathrm{~mm}$ ) que los empleados en material blando (longitud promedio de $56 \mathrm{~mm}$ ). Respecto a este punto cabe hacer una aclaración, los resultados obtenidos de la serie experimental y trabajos publicados con anterioridad (Mansur-Franchomme 1983, Castro de Aguilar 1994, Álvarez 2003, Leipus 2006) evidenciaron una mayor efectividad del uso de ángulos agudos para favorecen una mejor penetración en el material trabajado, por lo que sería esperable el uso de este tipo de ángulos en las actividades realizadas. 
Por otro lado, los movimientos longitudinales fueron efectuados, al igual que en el caso anterior, sobre material blando como también material duro (hueso o cuero). No se registraron diferencias significativas, tanto en la longitud como en el ángulo de los filos utilizados.

\section{VI.5.1.7. Actividades desarrolladas}

El análisis funcional realizado sobre los artefactos líticos recuperados de la UA4 de CS ha permitido inferir el desarrollo de una serie de actividades sobre diversos materiales. Sin embargo, algunas diferencias en cuanto al diseño y formatización de los filos fueron registrados en el análisis llevado a cabo.

Los trabajos inferidos a partir del uso de artefactos formatizados incluyeron iguales porcentajes del raspado y corte de cuero y de hueso ( $25 \%$ cada una), mientras que en menores proporciones se identificó el corte de hueso (13\%) y de material duro (tanto de origen animal como vegetal, 12\%) (Figura 67).

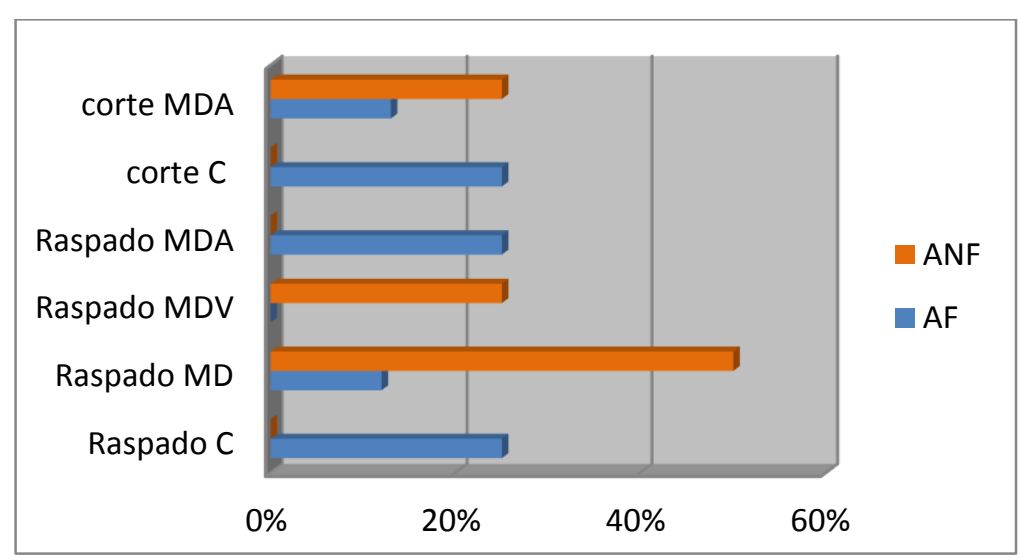

Figura 67: Actividades inferidas a partir del análisis efectuado en los artefactos recuperados de la UA4 de CS.

Por otro lado, los filos naturales fueron empleados principalmente para el raspado de material duro (vegetal o animal, 50\%) y en porcentajes menores raspado de madera y corte de hueso (25\% respectivamente). El trabajo sobre cuero fue realizado principalmente con filos formatizados al igual que una amplia variedad de actividades sobre distintos materiales (Figura 64).

Cabe mencionar, que la cantidad de filos observados en los AF (N=22) se asemeja a los ANF $(\mathrm{N}=18)$, por lo que el incremento en la variedad de actividades desarrolladas por los AF no se encuentra influenciado por el tamaño de la muestra. Mientras que en 
cuanto a las materias primas utilizadas en su producción se asemeja en ambos casos, por lo que no se considera una variable influyente en la preservación de los rastros identificados. Tanto en artefactos formatizados como en lascas, las rocas utilizadas fueron homogéneas y de grano fino a diferencia de lo que ocurre en los artefactos no formatizados de capa 5 en $\mathrm{CN}$, donde fue registrado el uso de basalto (roca de grano intermedio a grueso y heterogénea) y obsidiana en la manufactura de lascas.

Para finalizar, y dado el poco número de materiales con rastros de uso, no se llevará a cabo el cruce de las variables morfológicas con las funciones identificadas. Esta situación se debe a que los resultados serían pocos significativos. No obstante esto, serán tenidos en cuenta y discutidos en relación con el conjunto de la capa 5 de $\mathrm{CN}$ que conforman el componente inferior de ocupación en Cueva Maripe.

\section{VI.5.2. Conjunto lítico de la UA3: Artefactos formatizados}

El total de artefactos líticos recuperado de la UA3 de CS fue de 233 piezas entre las que se incluyen 92 AF (con 181 filos analizados) y 141 ANF (152 filos observados). La mayor cantidad de material tridimensional proviene de la cuadrícula A12 (65\%) principalmente del sector SE, el 35\% restante de los materiales fueron recuperados de la cuadrícula B12 con una mayor concentración hacia el sector NW (Figura 68).
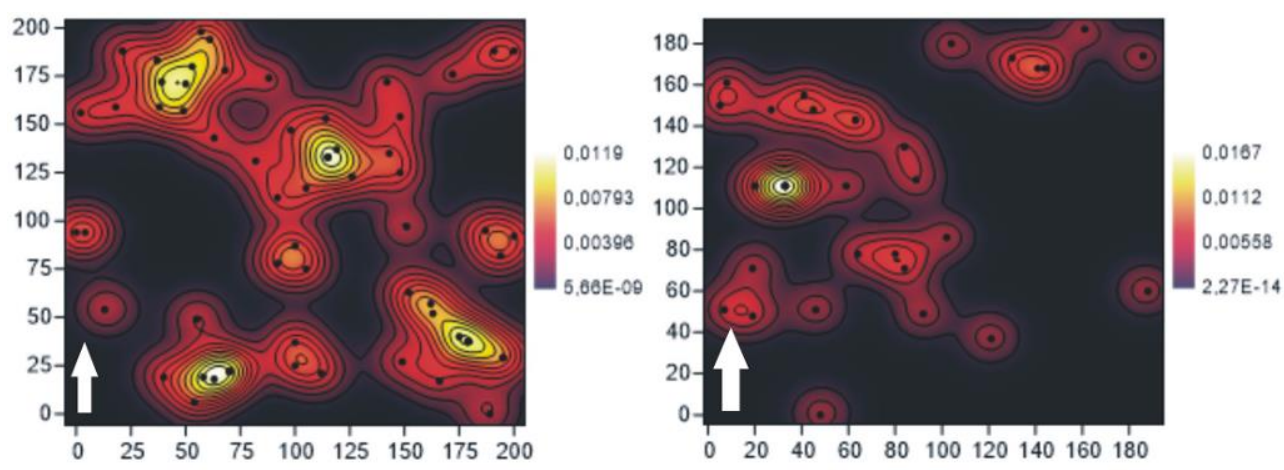

Figura 68: Distribución de AF en la UA3 de CS, sentido O-S (cuadrículas A12 y B12).

El conjunto de artefactos con formatización estuvo caracterizado por 12 grupos tipológicos, siendo los raspadores, al igual que en la capa 4 de $\mathrm{CN}$, el grupo más representado en la muestra $(\mathrm{N}=52,57 \%)$. Le siguen en orden y con porcentajes elevados el grupo de láminas retocadas $(\mathrm{N}=12,13 \%)$ y raederas $(\mathrm{N}=10,11 \%)$. 
En cuanto al estado de la muestra, se registró una gran cantidad de piezas que estaban fracturadas sin talón $(\mathrm{N}=50,55 \%)$, mientras que un número más reducido correspondía a piezas enteras $(\mathrm{N}=27,30 \%)$ y fracturadas con talón $(\mathrm{N}=14,15 \%)$. A continuación se describen los grupos más representados en la muestra de AF en la UA3 de CS (Figura $69)$.

\section{-Artefactos con formatización sumaria (AFS)}

Este grupo comprende el $6 \%$ del total de la muestra de artefactos formatizados $(\mathrm{N}=5)$ siendo en su mayoría elaborados sobre la variedad ISG1 (50\%). El resto de las muestra está confeccionadas sobre otros grupos de rocas silicificadas (RSGX y RSG3, 25\% cada una).

En cuanto al tamaño de los artefactos se reconoció iguales proporciones de piezas con tamaños mediano grandes a grandes (25\% respectivamente) y módulos de longitud anchura de dos tipos: mediano alargado y mediano normal.

\section{-Cuñas ( $\mathbf{C N})$}

Las piezas incluidas en este grupo corresponden únicamente a dos elementos elaborados, al igual que las anteriores, en materia prima de origen local (ISG1) de coloración marrón rojizo. El tamaño de estas piezas fue mediano pequeñas y con módulo de longitud anchura mediano alargado y normal.

\section{-Espolones (ES)}

Este grupo incluye dos piezas con 4 filos complementarios. La materia prima utilizada en su producción corresponde a la variedad ISG1, la más representada en la UA3, de color rojo. En cuanto al tamaño de las piezas corresponde exclusivamente a mediano pequeñas y con módulo de longitud anchura laminar normal y mediano alargado.

\section{-Filos no diferenciados (FND)}

Incluye 4 elementos con 1 filo complementario. Están elaborados principalmente sobre una materia prima indeterminada y en menores proporciones por ópalo e ISG1 con 
coloración negra y rojiza. En su totalidad los artefactos presentaron tamaño mediano pequeño, mientras que el módulo de longitud anchura incluyó la variedad mediana normal, mediana alargada y laminar normal.

\section{-Puntas de proyectil (PP)}

Este grupo incluye 4 elementos, dos puntas de proyectil apedunculadas de base recta y limbo triangular simétrico, 1 de limbo triangular con pedúnculo y otra fracturada sin pedúnculo. En cuanto al tamaño corresponden en su mayoría a mediano grande y pequeño con módulo de longitud anchura mediano normal a mediano-alargado. Dos de estas puntas se encuentran enteras mientras que las dos restantes están fracturadas, una en el sector del ápice y la otra presenta una fractura longitudinal al eje morfológico de la pieza. En cuanto a la morfología de los lascados estos son en su mayoría paralelos laminares.

\section{-Raspadores (RP)}

$\mathrm{Al}$ igual que en $\mathrm{CN}$ el grupo de raspadores en la UA3 de CS presenta un mayor número de piezas del total del conjunto de $\mathrm{AF}(\mathrm{N}=52,57 \%)$. En su mayoría se encuentran enteros (46\%) y elaborados sobre una amplia variedad de materias primas silíceas, siendo las más representadas la ISG1 (20\%) seguido por proporciones más altas de las variedades RSG2 (14\%), PG1 e IND (13\% cada una).

En relación al tamaño de este grupo, presenta una amplia variedad, desde elementos pequeños hasta muy grandes. Sin embargo, el más representado corresponde a piezas de tamaño mediano pequeña (42\%) y mediano grande (36\%). Mientras que los módulos más representados incluyen mediano normal (47\%) y mediano alargado (24\%). En su mayoría los raspadores presentaron filos complementarios siendo, los naturales con rastros complementarios los más representados en el conjunto (42\%) y en menor medida los raspadores dobles $(21 \%)$.

\section{-Raederas (RD)}

El conjunto de raederas identificado en la UA3 de CS corresponde al 11\% (N=10) del total de AF. Este grupo está caracterizado en su mayoría por piezas fracturadas sin talón 
(45\%) y en menor medida enteras (33\%), siendo el grupo ISG1 la principal materia prima para su producción. En menores e iguales proporciones se encuentran las variedades PG1, RSG1, RSG3 y CG1 (12\% respectivamente).

El tamaño de este grupo estuvo constituido principalmente por piezas de tamaño grande y módulo de longitud anchura mediano normal (50\%).

\section{-Láminas retocadas (LR)}

Este grupo le sigue en representación al grupo de raspadores y conforma un $13 \%$ $(\mathrm{N}=12)$ del total de AF de CS. Un alto porcentaje de estas piezas se encuentran fracturadas sin talón (64\%) y en menor medida fracturadas con talón (27\%) y enteras $(9 \%)$.

En cuanto a la selección de materias primas para su producción la más representada al igual que en lo demás grupos corresponde a la ISG1 (50\%), sin embargo, otras rocas fueron utilizadas para su producción tales como la CG1 (30\%) y RSG3 (10\%).

En su mayoría las raederas fueron de tamaño mediano grande (67\%), seguido por grandes $(22 \%)$ y mediano pequeña (11\%), presentando mayormente un módulo de longitud anchura mediano alargado.

En cuanto a los filos complementarios las piezas presentaron al menos un filo, con un total de 10 filos identificados. Los filos de láminas retocadas dobles constituyó el mayor porcentaje identificado $(67 \%)$. 


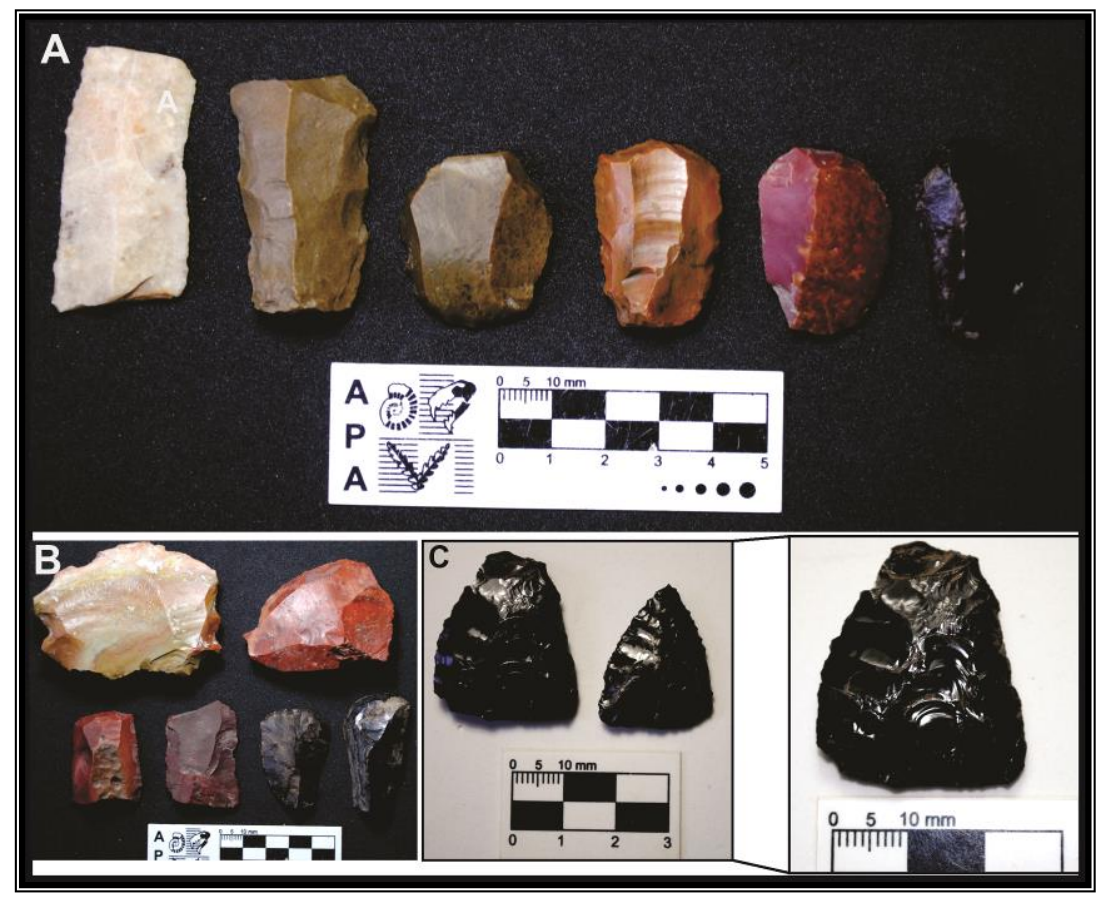

Figura 69: Materiales recuperados de la UA3 CS de Cueva Maripe. A-C) Artefactos formatizados de la cuadrícula A12 (raspadores de filo frontal corto y dobles de filo lateral largo, láminas retocadas y puntas de proyectil elaboradas sobre obsidiana, una fracturada en el ápice). B) Artefactos formatizados de la cuadrícula B12 (raspadores, lámina retocada y raederas).

\section{VI.5.2.1. Artefactos no formatizados (ANF) de UA3}

El conjunto de ANF de la UA3 se encuentra formado por 138 artefactos de los cuales fueron observados bajo microscopía óptica un total de 152 filos.

Los materiales registrados fueron recuperados en su mayoría de la cuadrícula A12 (58\%, N=81) principalmente del sector NE. El porcentaje restante corresponde a la cuadrícula B12 (N=60) en especial hacia el NW (Figura 70).
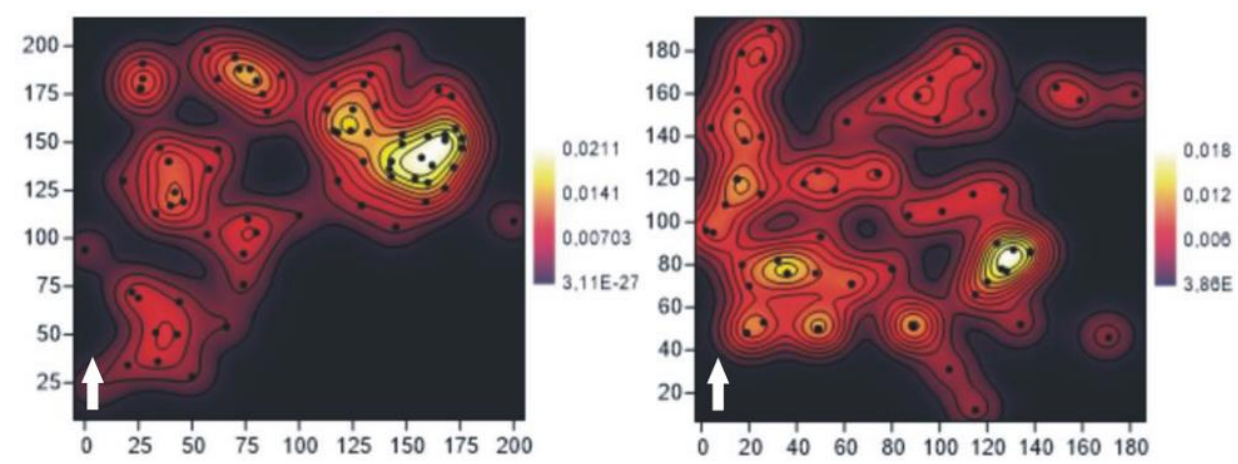

Figura 70: Distribución de ANF en la UA3 CS (cuadrículas A12 y B12), sentido O-S. 
En cuanto al estado de las piezas se registró, al igual que en los artefactos con formatización, un mayor porcentaje de piezas fracturadas sin talón ( $\mathrm{N}=53,38 \%)$ y menores proporciones enteras $(\mathrm{N}=45,32 \%)$ y fracturadas con talón $(\mathrm{N}=43,30 \%)$.

El tamaño de la muestra estuvo representada en su mayoría por piezas mediano grandes $(\mathrm{N}=85,40 \%)$, grandes y muy grandes en un $33 \% \quad(\mathrm{~N}=38)$ y $27 \% \quad(\mathrm{~N}=18)$ respectivamente. Los módulos de longitud anchura incluyó mediano normal y mediano alargado en mayores proporciones (41 y 27\% cada una). Mientras que los módulos corto ancho y muy ancho junto con los laminares angosto y laminares normales tuvieron una menor representación en los artefactos sin formatización.

Si bien las materias primas más utilizadas en la elaboración de lascas u hojas incluyeron las mismas variedades de rocas silicificadas identificadas en $\mathrm{CN}$, las proporciones de cada una de estas difieren. Al igual que en los AF la presencia de ISG1 está ampliamente representada en la muestra de $\operatorname{ANF}(\mathrm{N}=41,28 \%)$, sin embargo, las proporciones de ISG2 disminuye en relación a la $\mathrm{CN}$. Por otro lado, se observa un incremento en cuanto a las proporciones del uso de basalto (B1, 15\%) y de RSG2 (12\%) al igual que la producción de lascas u hojas a partir de CG1 (8\%), RSG3 (8\%) y X1 (7\%). Las demás variedades de materias primas se disponen de manera homogénea en el resto de la muestra (Figura 71$)$.

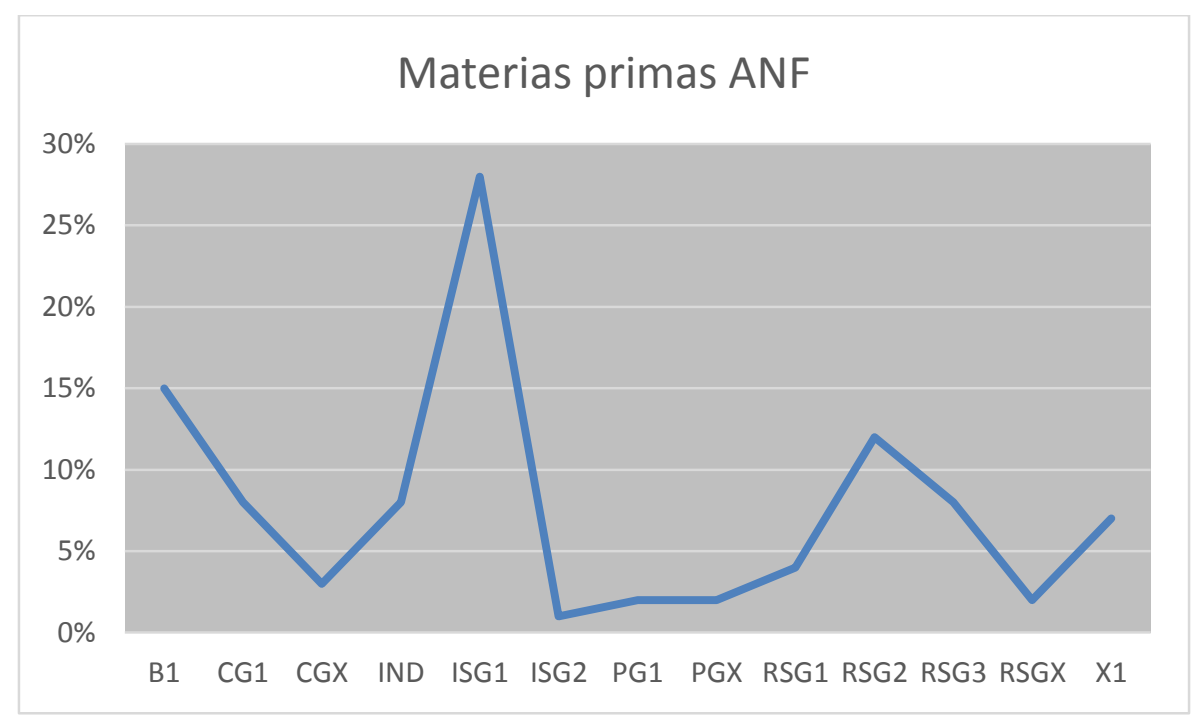

Figura 71: Distribución de las materias primas seleccionadas en la producción de ANF en la UA3 de CS.

En cuanto a la selección de formas bases en los ANF fue registrado un alto porcentaje de lascas $(\mathrm{N}=125,91 \%)$ en relación con las hojas $(\mathrm{N}=13,9 \%)$. Por otro lado, en cuanto a los tipos de lascas identificados se registró porcentajes elevados de lascas angulares 
(42\%), secundarias (27\%) y de arista (17\%). Mientras que las hojas estuvieron representadas en menores proporciones.

\section{VI.5.2.2. Resultados del análisis funcional de base microscópica}

El total de filos analizados bajo microscopía óptica incluyó 181 filos con formatización y 152 filos naturales. En el segundo caso se observó que en su mayoría las piezas presentaban un único filo potencialmente utilizable.

Los artefactos recuperados presentan diferentes grados y tipos de alteración, que dificultaron la identificación de los rastros de utilización tanto en artefactos formatizados como en no formatizados.

El análisis realizado en los AF registró un mayor porcentaje de piezas no determinadas por alteración $(\mathrm{N}=76,39 \%)$, en menor medida se identificaron piezas sin rastros de uso $(\mathrm{N}=62,31 \%)$ y el porcentaje restante incluyó piezas con huellas de uso identificables $(\mathrm{N}=60,30 \%)$.

En los artefactos sin formatización los filos potencialmente utilizables presentaron un alto porcentaje de piezas sin rastros de uso $(\mathrm{N}=59,40 \%)$, mientras que en porcentajes menores se ubican las piezas no determinadas por alteración $(\mathrm{N}=49,32 \%)$ y con rastros de uso identificables $(\mathrm{N}=44,28 \%)$.

\section{VI.5.2.3. Integridad del conjunto e identificación de alteraciones tafonómicas}

Con respecto a los tipos de alteración identificada sobre los materiales, incluyó en su mayoría alteraciones intensas que influyeron en la observación e identificación de los rastros de uso.

Durante el estudio de estas alteraciones se registró variabilidad en sus efectos sobre las piezas líticas, sin embargo, la más representada en la capa corresponde a la abrasión sedimentaria ( $\mathrm{N}=34,52 \%$ en $\mathrm{AF}$ y $\mathrm{N}=17,47 \%$ en $\mathrm{ANF})$, que estuvo presente en un grado intermedio a leve en todas las piezas no identificadas por alteración.

Asimismo en los AF se observaron playas de abrasión y puntos en espejo ( $\mathrm{N}=6,9 \%$ en AF y $\mathrm{N}=1,3 \%$ en $\mathrm{ANF}$ ), alteraciones severas que impidieron en la mayoría de los caso la identificación de los rastros de uso e igualmente tecnológicos, principalmente sobre la variedad ISG1. 
Por otro lado, se reconoció la formación de pátinas blancas acompañado por concreciones carbonáticas sobre la superficie de las piezas en porcentajes menores $(\mathrm{N}=3,5 \%$ en $\mathrm{AF}$ y $\mathrm{N}=5,14 \%$ en $\mathrm{ANF})$. Es sabido que la presencia de pátinas sobre la superficie de artefactos líticos está relacionada con cambios en la composición del pH en el sedimento que contiene los materiales, por lo tanto la presencia de este tipo alteración permite inferir los procesos que intervinieron en la formación del depósito. Además, se identificaron otros tipos de alteraciones relacionadas con procesos de termoalteración, que en muchos casos estaba acompañado por otras modificaciones de la superficie de las piezas (hoyuelos, fracturas internas y cambio de coloración). Este tipo de alteración se registró en un 28\% (N=23) de los AF y 36\% (N=13) de los ANF.

Mientras que en menor medida, se reconoció efectos vinculados con la manipulación de los materiales en condiciones de laboratorio dentro de las cuales se incluye las marcas dejadas durante el rotulado del material por uso de PVAC (N=4, 6\% en AF) (Figura 72).

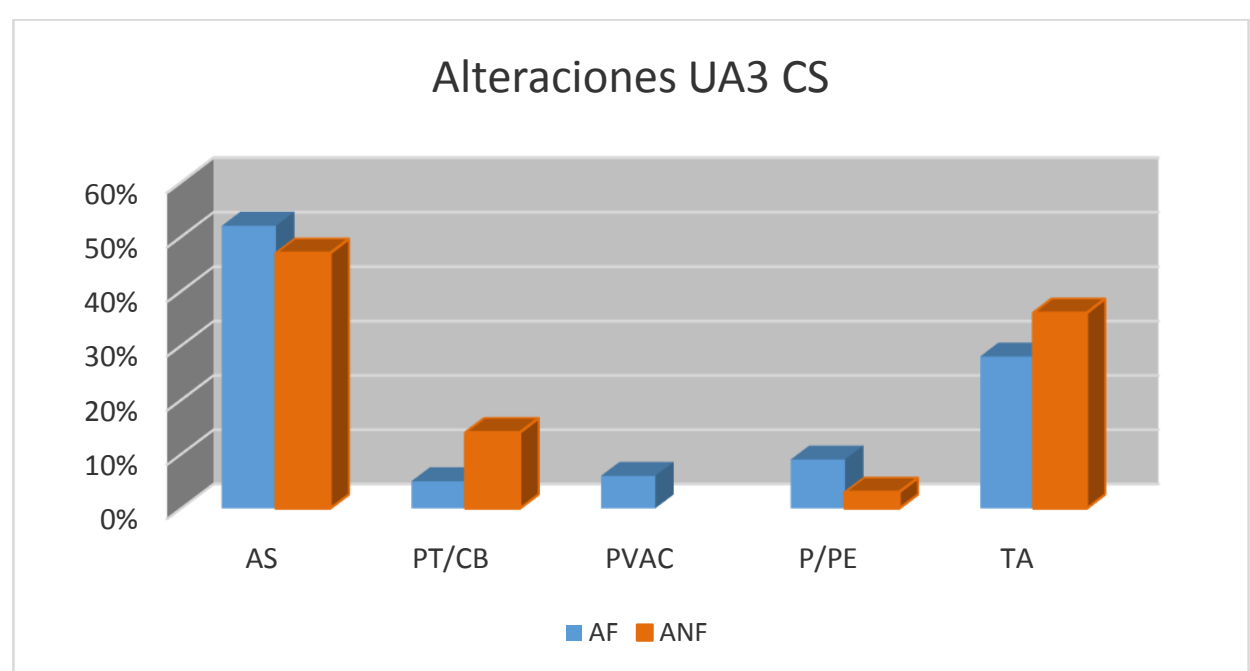

Figura 72: Alteraciones identificadas sobre los artefactos recuperados de la UA3 en CS. PT/CB: pátina blanca con carbonato; P/PE: playas de abrasión con puntos en espejo; TA: termoalteración.

En relación con el tipo de materia prima y rastros de utilización identificados en cada una, se reconoció que si bien en su mayoría las piezas estaban elaboradas sobre rocas homogéneas, las variedades de otras rocas silicificadas presentaron mayor cantidad de piezas con rastros de uso que la ISG1, materia prima altamente representada en la producción de AF en la UA3.

Para realizar una mejor interpretación de los resultados y analizar si estas diferencias se deben al tamaño de la muestra por materia prima se realizó el índice de riqueza. Los 
resultados indicaron que la variabilidad de materias primas con rastros de uso no está relacionado con el tamaño de la muestra de cada una (Figura 73).

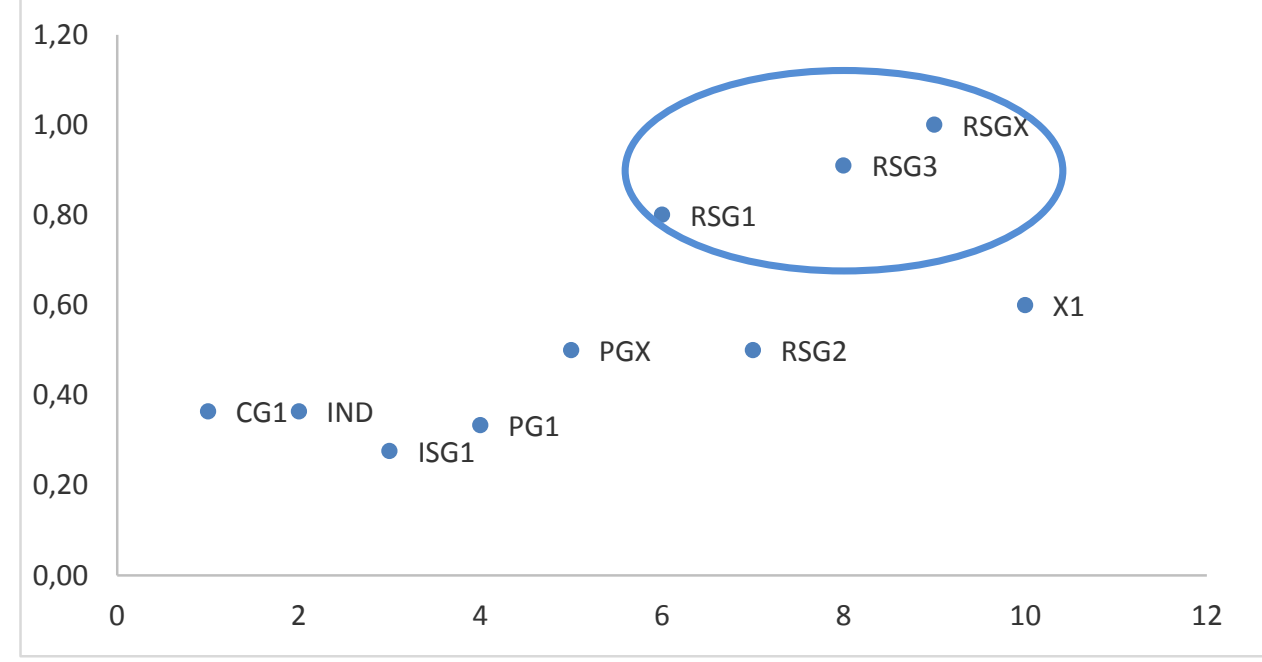

Figura 73: Diagrama de dispersión del tamaño de la muestra y riqueza (materias primas con rastros de utilización) en AF de la UA3 CS.

En los ANF el basalto y la variedad RSGX corresponden a las materias primas que presentaron mayor cantidad de rastros de uso identificados. Este resultado en conjunto con los datos obtenidos por otro autores (Mansur-Franchomme 1983, 1999; Levi Sala 1986,1993) y la serie experimental realizada (ver capítulo IV), concuerda con una mejor preservación de los rastros de uso sobre materias primas heterogéneas (Figura 74).

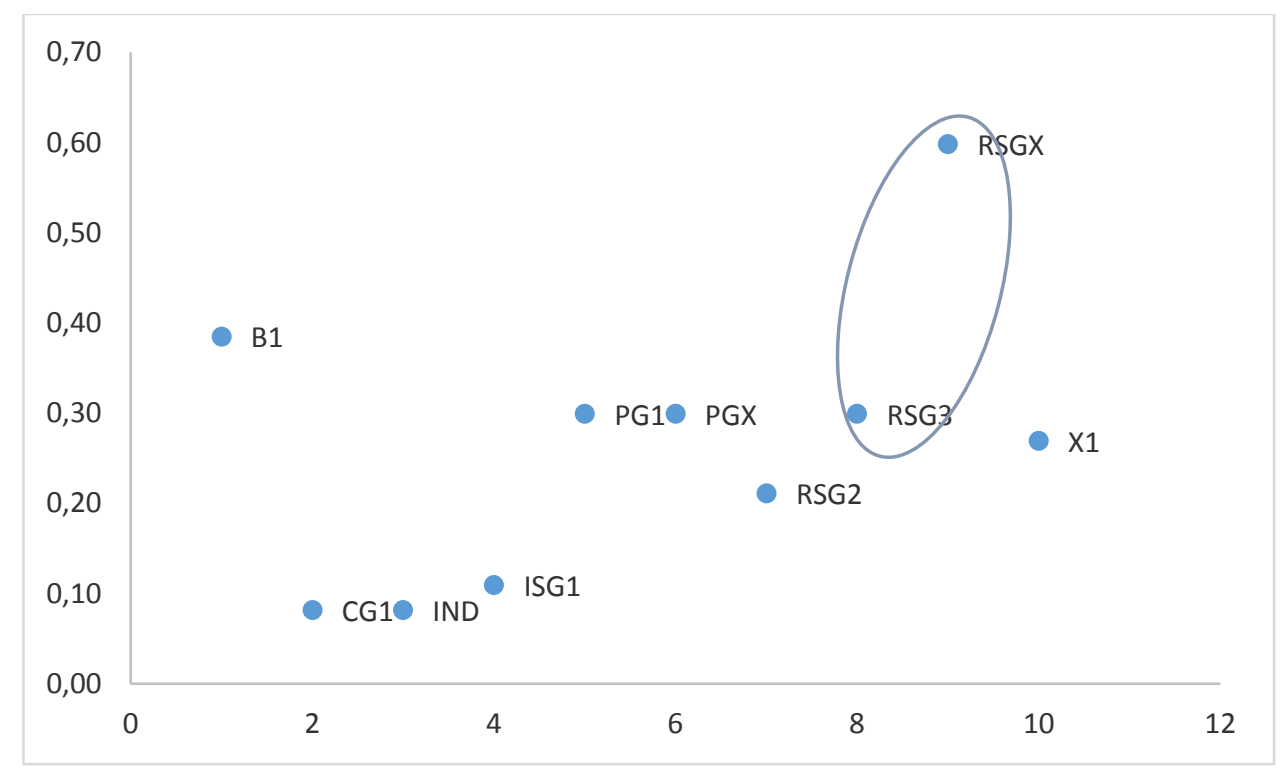


Figura 74: Gráfico de dispersión del tamaño de la muestra y riqueza en relación con las materias primas identificadas con rastros de uso en los ANF de UA3.

\section{VI.5.2.4. Inferencia funcional de las modalidades de uso}

Los resultados obtenidos del análisis funcional difieren entre los AF y ANF, ya que en los primeros los porcentajes elevados de piezas con algún tipo de alteración no permitieron su identificación funcional; mientras que en los ANF las piezas sin rastros de utilización ocupan este lugar.

Por otro lado, en los AF la cantidad de piezas con filos dobles y múltiples es superior que en los ANF donde la mayoría de las piezas presentan un único filo potencialmente utilizable.

En cuanto a la relación de filos observados con rastros de uso identificados se determinó que en los AF las piezas con filos dobles en su mayoría presentaron al menos un filo complementario utilizado constituyendo un $18 \%(\mathrm{~N}=15)$ del total del conjunto. En menor medida se encuentran piezas con un único filo utilizado $(\mathrm{N}=6,7 \%)$ y piezas con filos múltiples (3 o 4 filos identificados) que presentaron 1 y 2 filos complementarios con rastros de uso (Figura 75).

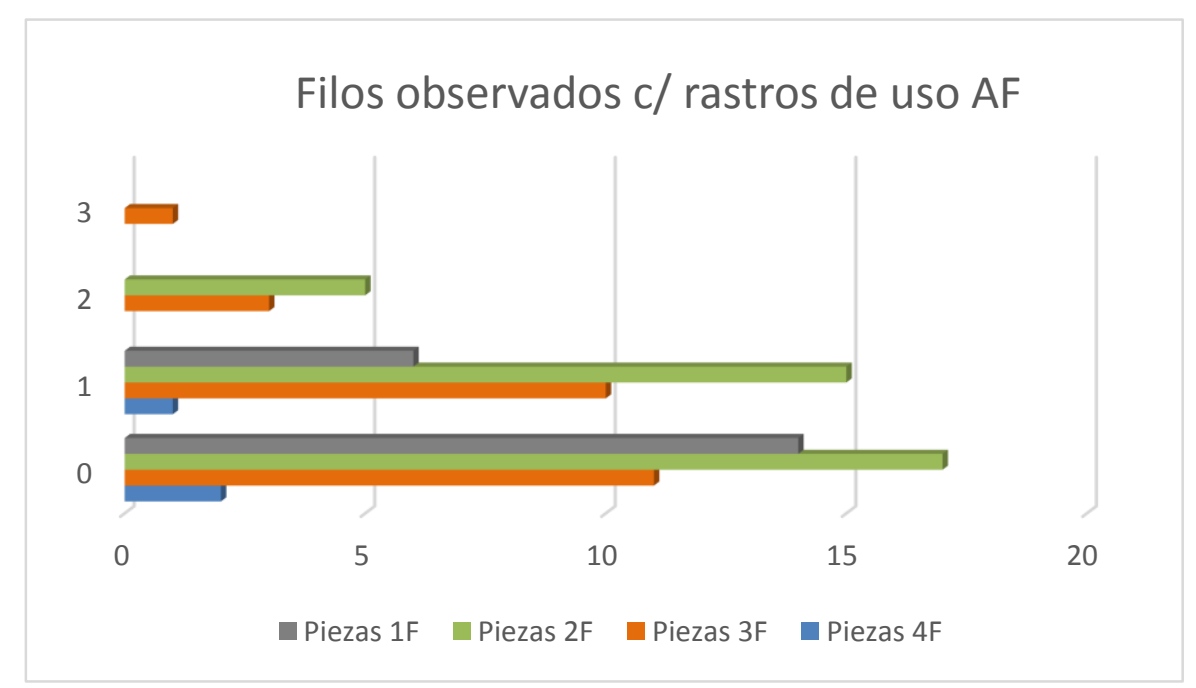

Figura 75: Relación de los filos observados y la presencia/ausencia de rastros de uso en AF de

UA3 CS.

En los ANF la mayoría de las piezas presentaron un solo filo potencialmente utilizable y en menor medida dos filos con potencialidad de uso. Sin embargo, en muy pocos casos $(\mathrm{N}=4)$ se registró rastros de utilización y en los casos donde se pudo identificar el uso, 
este estuvo relacionado principalmente al trabajo sobre material duro (animal o vegetal) con acciones longitudinales como también transversales.

\section{VI.5.2.5. Materiales trabajados}

El estudio de los rastros identificados sobre los materiales de la UA3, permitió reconocer cierta diversidad en los materiales trabajados al igual que en la cinemática empleada.

Los $\mathrm{AF}$ fueron utilizados en su mayoría sobre material duro $(\mathrm{N}=22,41 \%)$, lo que incluye materiales de origen animal como también vegetal, sólo que debido al estado o al tiempo trabajado no se pudo establecer con exactitud su origen. También se pudo inferir el trabajo sobre hueso $(\mathrm{N}=15,28 \%)$ y material duro vegetal (madera) en un $14 \%$ $(\mathrm{N}=7)$ de los filos analizados. Igualmente se reconoció el trabajo sobre materiales blandos $(\mathrm{N}=4,8 \%)$, cuero $(\mathrm{N}=3,6 \%)$ y material blando vegetal no leñoso (gramíneas, $\mathrm{N}=1,2 \%$ ).

En los ANF la variedad de materiales trabajados incluyó materiales duros en altas proporciones $(\mathrm{N}=18,53 \%)$, hueso y madera en iguales y menores proporciones $(\mathrm{N}=2$, $6 \%$ ). Mientras que el material blando estuvo representado por el trabajo sobre cuero en un $9 \%(\mathrm{~N}=3)$ del total de la muestra analizada. El 26\% restante corresponde a piezas que se identificaron con acciones transversales pero no se pudo adscribir a ningún material específico (Figura 76).

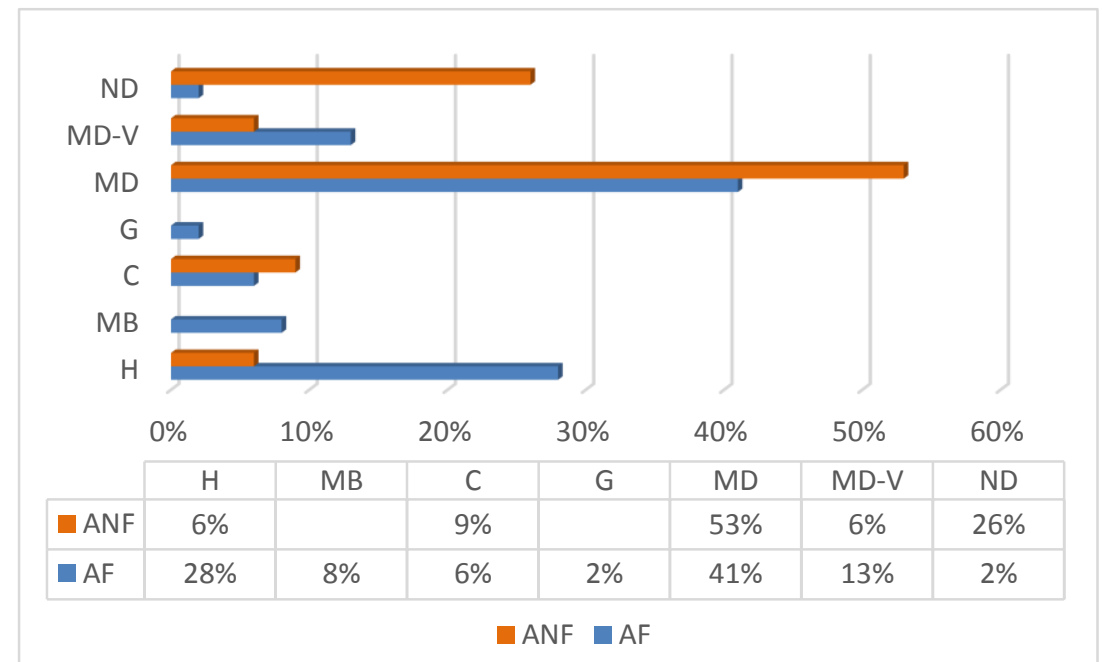

Figura 76: Materiales trabajados identificados en la UA3 de CS. H: hueso; MB: material blando; C: cuero; G: gramíneas; MD: material duro; MD-V: material duro vegetal y ND: no determinable. 


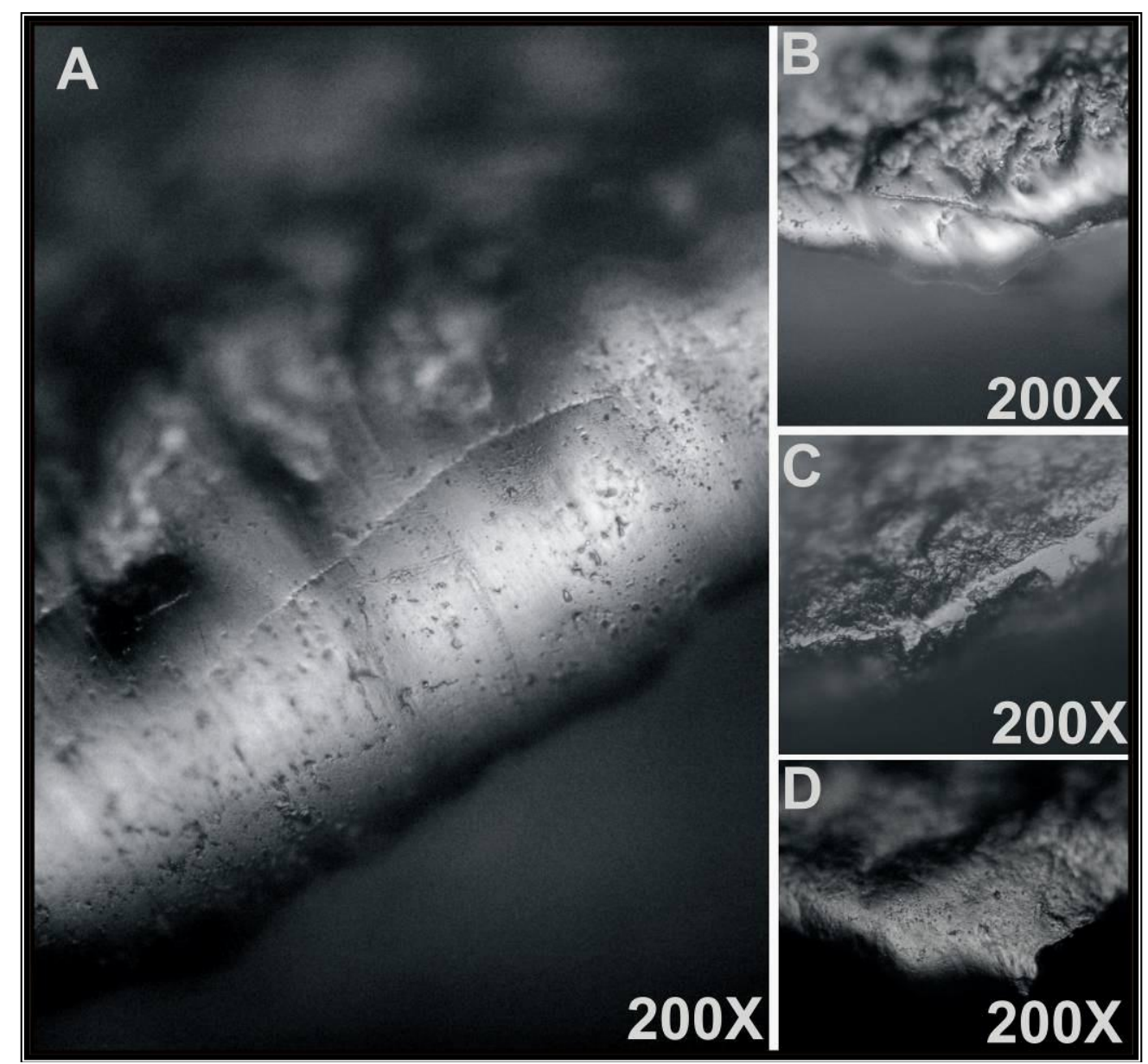

Figura 77: Materiales identificados en la UA3 de CS. A/B) Pieza No: MA05'B12 156 (raspador de filo frontal corto), raspado de material duro vegetal (madera). C) Pieza $\mathrm{N}^{\mathrm{o}}$ : MA05'B12382 (raspador de filo frontal corto), raspado de material duro animal (hueso). D) Pieza $\mathrm{N}^{\mathrm{o}}$ : MA06'A12351 (raspador filo frontal corto), raspado de material duro vegetal (madera).

\section{VI.5.2.6. Cinemática empleada}

La mayoría de las actividades identificadas en los filos trabajos estuvieron relacionadas a acciones transversales, sin embargo, acciones longitudinales y mixtas fueron igualmente reconocidas. En algunos casos la cinemática utilizada no pudo ser identificada debido a la ausencia de estrías o del escaso desarrollo del micropulido, ya sea por el tiempo empleado de la pieza o por el material trabajado.

Los AF en su mayoría fueron utilizados a partir de acciones transversales constituyendo un $72 \%$ de la muestra y en menor medida a partir de acciones longitudinales (20\%) y $\operatorname{mixtas}(6 \%)$. 
Mientras que en los ANF, si bien ocurre lo mismo, donde las acciones transversales ocupan porcentajes elevados (53\%), el resto de los filos fueron empleado en acciones longitudinales únicamente $(47 \%)$.

En cuanto a las variables métricas, se pudo identificar diferencias estadísticamente significativas en los filos trabajados sobre material duro en relación con la cinemática empleada. Se registró que los filos usados longitudinalmente eran significativamente más largos que los utilizados en acciones transversales (Prueba de Mann-Whitney; $\mathrm{U}=52 ; \mathrm{p}=0,007)$. Los filos empleados longitudinalmente presentaron una mayor longitud con un promedio de 47,6 mm; mientras que los filos reconocidos en acciones transversales un promedio de 35,6 mm (Figura 78).

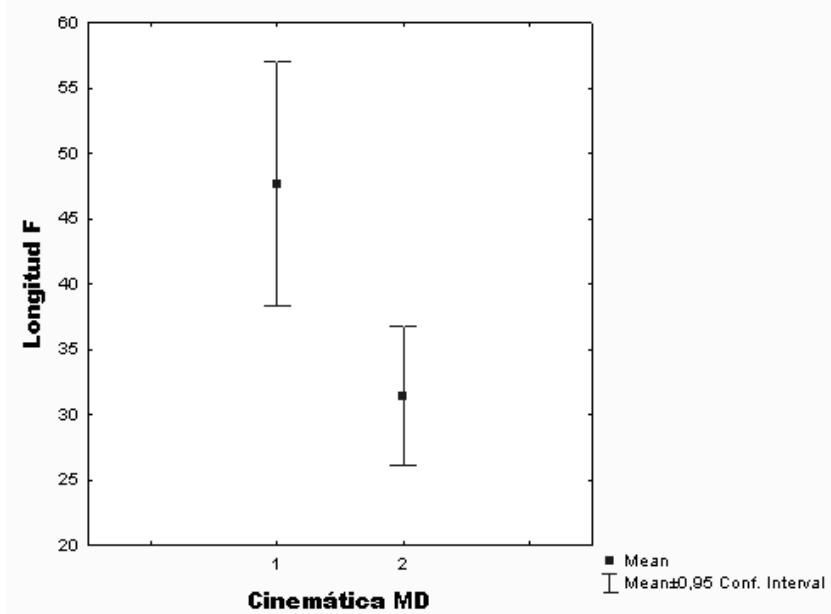

Figura 78: Diagrama de correlación entre la longitud de los filos utilizados sobre material duro y la cinemática empleada. 1) Acciones longitudinales y 2) Acciones transversales.

Esta diferencia fue igualmente registrada en el ángulo de los filos trabajados, observándose que los ángulos empleados en acciones transversales eran significativamente más rectos que los utilizados en acciones longitudinales (Prueba de Mann-Whitney; $U=10,50 ; \mathrm{p}=0,00$ ). Las piezas trabajadas longitudinalmente presentaron ángulos más agudos (promedio de $37^{\circ}$ ) que aquellas que lo hicieron transversalmente (ángulo promedio de $57^{\circ}$ ) (Figura 79). 


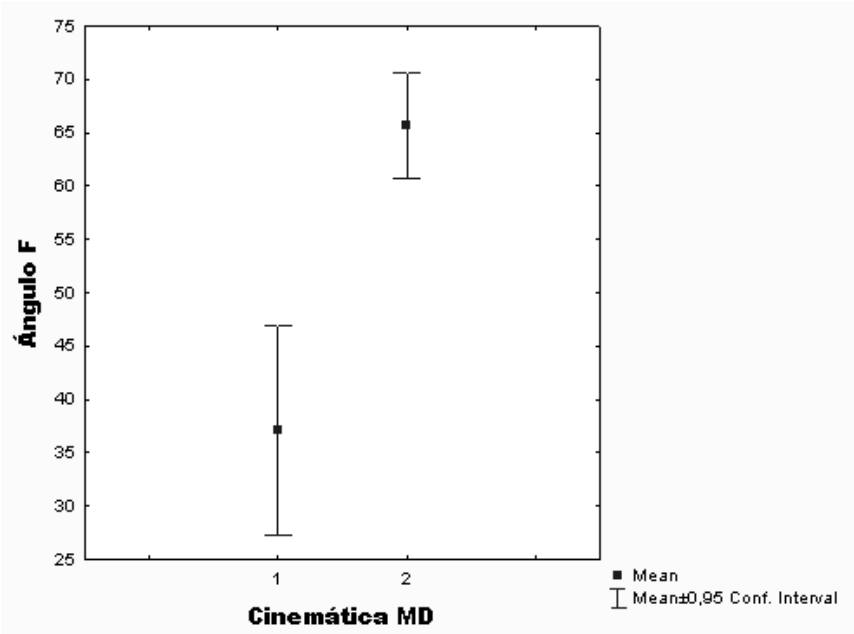

Figura 79: Diagrama de correlación entre la cinemática empleada y el ángulo de los filos utilizados. 1) Acciones longitudinales y 2) Acciones transversales.

Mientras que en relación al material identificado, se pudo determinar diferencias significativas entre el material y la longitud de los filos (Prueba de Mann-Whitney; U= $119 ; \mathrm{p}=0,19)$ y el ángulo empleado en materiales blandos y duros (Prueba de MannWhitney; $U=142 ; p=0,49)$.

\section{VI.5.2.7. Actividades desarrolladas}

Los resultados obtenidos a partir del análisis funcional realizado sobre los AF de la UA 3 en CS, permitieron inferir el trabajo sobre una amplia variedad de materiales y durezas (Figura 80).

El raspado sobre material duro (origen animal o vegetal) estuvo altamente representado $(\mathrm{N}=17,51 \%)$ en la muestra. Le siguen el raspado y corte sobre hueso y madera, con porcentajes igualmente elevados $(\mathrm{N}=8,15 \%$ y $\mathrm{N}=6,11 \%$ respectivamente). En menor medida se pudo inferir el raspado de cuero $(\mathrm{N}=3,6 \%)$ y material blando $(\mathrm{N}=3,5 \%)$. Cabe aclarar que el trabajo sobre material blando incluyó piezas que no estuvieron asociadas a un origen vegetal, pero debido al grado de desarrollo del micropulido, no se llegó más allá de su dureza.

En menores proporciones ( $2 \%$ cada una) fue inferido el desarrollo de otro tipo de actividades, como corte de material duro, raspado y corte de material vegetal no leñoso y hueso. Además en porcentajes menores se registraron acciones no determinables sobre material duro, hueso y material blando (Figura 80). 
En cuanto a los ANF los filos naturales fueron empleado principalmente para el desarrollo de actividades de corte y raspado sobre material duro (de origen vegetal o animal, $\mathrm{N}=10,29 \%$ y $\mathrm{N}=8,23 \%$ respectivamente). Mientras que, al igual que en los $\mathrm{AF}$, los filos sin retoque fueron utilizados en menores proporciones para el raspado $(\mathrm{N}=2,6 \%)$ y corte $(\mathrm{N}=1,3 \%)$ de cuero, raspado de madera $(\mathrm{N}=2,6 \%)$ y corte sobre material no determinado $(\mathrm{N}=3,9 \%)$.

A diferencia de los AF, los filos naturales no fueron empleados en acciones mixtas (longitudinales y transversales); mientras que el raspado y corte de material blando no leñoso, tampoco fue registrado en el análisis funcional realizado sobre estos filos (Figura 80).

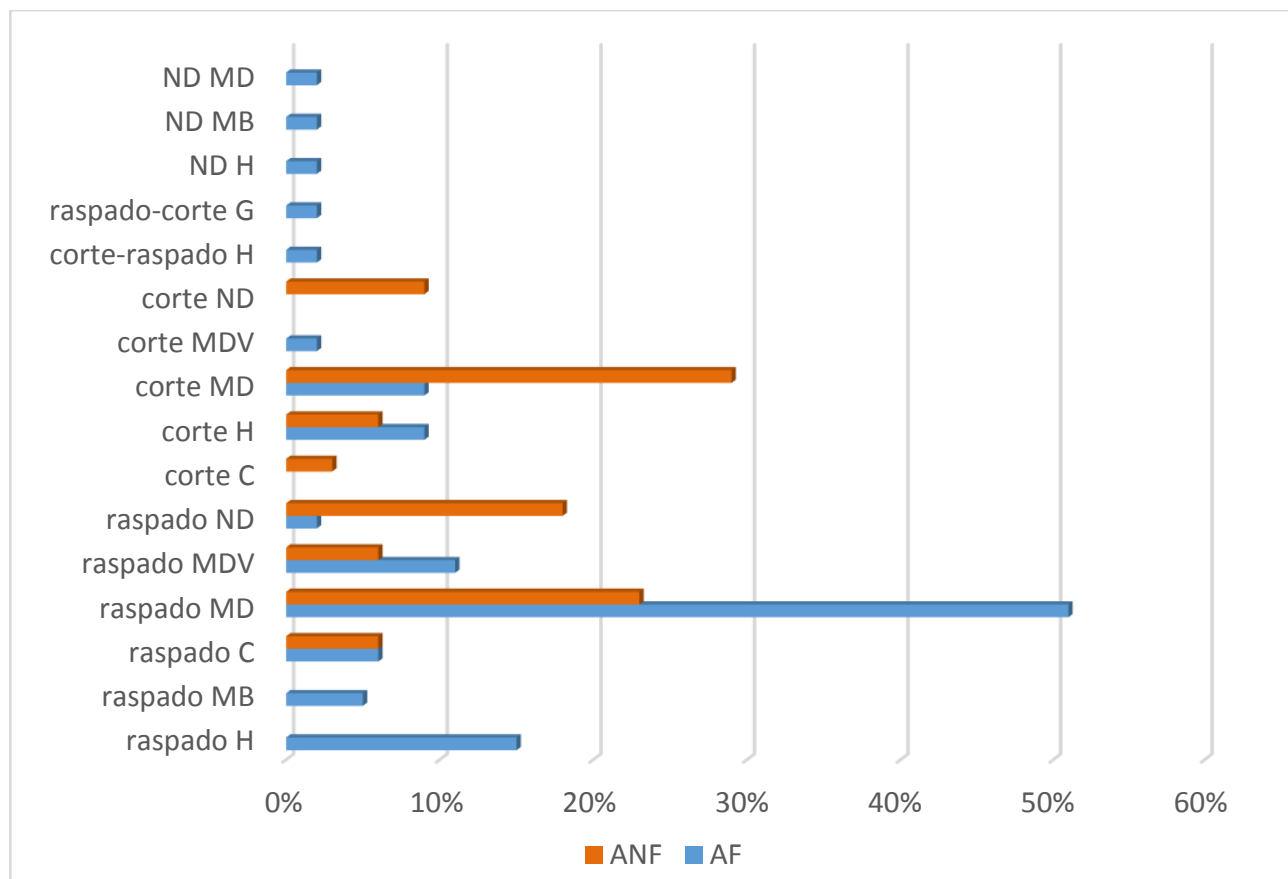

Figura 80: Porcentajes de materiales trabajados identificados en el conjunto lítico de la UA3 de CS.

\section{VI.5.3. Conjunto lítico de la UA2: Artefactos formatizados}

El conjunto lítico recuperado de esta unidad incluye un total de 223 piezas con 339 filos identificados. Dentro de estas se registraron 98 AF (204 filos) y 125 ANF (135 filos). La distribución a partir de medidas tridimensionales arrojó que la cuadrícula B12 presentaba una mayor cantidad de elemento $(\mathrm{N}=57)$ que la $\mathrm{A} 12$, principalmente hacia el sector SE donde se identificó un 33\% (N=19) del total de materiales recuperados en ella. 
En la cuadrícula A12 se recuperó un 42\% (N=41) del total de AF en la UA2, con una mayor densidad hacia los sectores NE y SE (Figura 81).
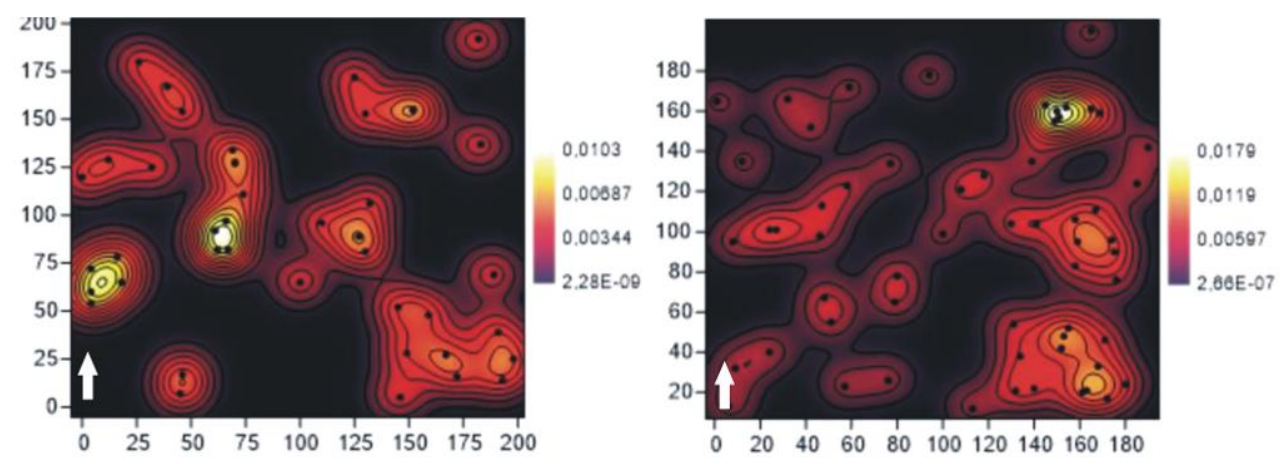

Figura 81: Distribución de los AF en UA2 de CS (cuadrículas A12 y B12) sentido O-S.

Esta unidad registró un total de 9 grupos tipológicos elaborados, al igual que en la capa anterior, sobre rocas homogéneas que incluyó variedades de ignimbritas y rocas silicificadas de variadas tonalidades (26\% y $23 \%$ del total de AF).

La mayoría de las piezas se presentaban fracturadas sin talón $(\mathrm{N}=55,56 \%)$, mientras que en menor medida estaban enteras $(\mathrm{N}=29,30 \%)$ y fracturadas con talón $(\mathrm{N}=14$, $14 \%)$.

A continuación se describe con más detalle los grupos tipológicos identificados y los diseños empleados en su producción.

\section{-Artefactos con formatización sumaria (AFS)}

Este grupo constituye el 9\% ( $\mathrm{N}=8)$ del total de AF en esta unidad e incluye 8 piezas con 10 filos complementarios. En su mayoría se encuentran enteras y elaboradas sobre ISG1 y RSGX en iguales proporciones (40\%), mientras que el resto está representado por la variedad CG1 (20\%).

En relación al tamaño de la muestra la mayor cantidad de piezas corresponden al tamaño grande $(60 \%)$, mientras que en menor medida presentaron tamaño mediano grande y pequeño, mientras que el módulo más representado corresponde al mediano normal.

En cuanto a la selección de formas bases para su manufactura, los artefactos con formatización sumaria estuvieron elaborados en iguales proporciones de lascas u hojas. 


\section{-Láminas retocadas (LR)}

El grupo de láminas con retoques constituye un porcentaje menor $(\mathrm{N}=6,6 \%)$ del total de AF, presentado 6 piezas con 8 filos complementarios. En su mayoría se encuentran fracturados sin talón (40\%) seguido por fracturados con talón (33\%) y piezas enteras $(17 \%)$.

Las materias primas utilizadas en su producción incluyen mayores porcentajes de otras variedades de rocas silíceas (RSG2:33\%, RSG1: 17\%, RSGX: 17\%) y en menor medida basalto gris y obsidiana de coloración negra (16 y 17\% respectivamente).

En cuanto a la selección de las formas bases utilizadas para su producción incluyó hojas de aristas y en un solo caso una lasca angular.

Mientras que los tamaños más representados corresponden a piezas mediano grandes y mediano pequeñas (43\% respectivamente) y en menor medida grandes (14\%) y los módulos laminar normal y mediano alargados los más representados en la muestra.

\section{-Raederas (RD)}

Este grupo incluye el $4 \%(\mathrm{~N}=4)$ del total de AF y en su mayoría se encuentran fracturadas con talón (50\%). Las materias primas utilizadas en su manufactura incluyen las variedades ISG1 y RSG3. Mientras que el tamaño mediano grande y en menor medida grande fue el más representado en este grupo. En relación con el módulo de longitud-anchura los módulos mediano alargados y mediano normales fueron los únicos registrados en este grupo.

Las formas bases utilizadas en su producción incluyeron tanto lascas como hojas siendo las de arista y secundarias las más utilizadas.

\section{-Raspadores (RP)}

Al igual que en la unidad anterior este grupo presenta una gran cantidad de piezas constituyendo el 69\% (N=67) del total de AF. Se encuentran elaborados sobre una amplia variedad de materias primas siendo la ISG1 (24\%) y las no determinadas (23\%) las más representadas en este grupo. 
La mayoría de las piezas se encuentran fracturadas sin talón (60\%), sin embargo, se observa un porcentajes elevado de piezas enteras (38\%) y en menor medida fracturadas con talón $(2 \%)$.

En general las piezas analizadas presentaron al menos un filo complementario, siendo los filos naturales con microlascados aislados (33\%) altamente representados en este conjunto. Le siguen en menor medida los raspadores con filos de formatización sumaria $(17 \%)$ y raederas $(10 \%)$ como complementarios.

En cuanto al tamaño y módulo identificados se reconoció, en gran medida, piezas mediano pequeñas y mediano grandes (46\% respectivamente) e iguales y menores proporciones de los tamaños pequeño y grandes (4\% cada uno). Los módulos más representados corresponden a mediano normal y alargados.

\section{-Grupos menores}

Incluye aquellos grupos con número de piezas reducido que constituyen un porcentaje menor a 3\% del total de AF. Los grupos identificados incluyen piezas bifaciales y unifaciales, cuchillos retocados, gubias y filos no diferenciados.

En su mayoría se encuentra fracturados sin talón (67\%) y elaborados principalmente sobre lascadas indiferenciadas. Mientras que las materias primas seleccionadas en su producción constituyen una amplia variedad de rocas silíceas siendo la más representada la roca silicificada del grupo 3 (RSG3, 25\%). 


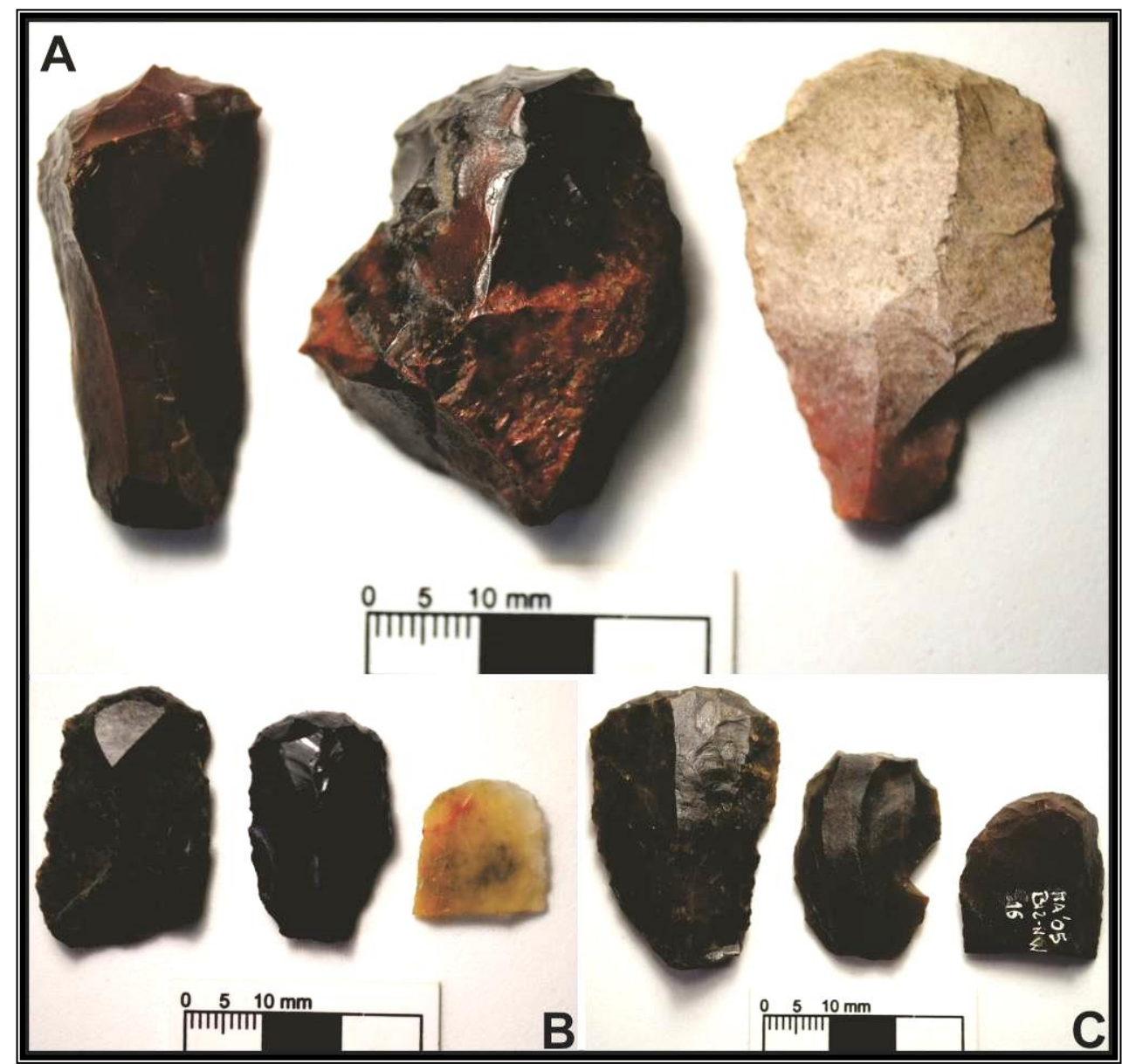

Figura 82: Materiales recuperados de la UA2 CS de Cueva Maripe. A) Raspadores con filo frontal corto y evidencia de termoalteración (cambio de coloración, hoyuelos y lustre intenso). B-C) Raspadores recuperados de la cuadrícula B12 de tamaño mediano pequeño a pequeño y elaborados sobre ópalo, calcedonia y obsidiana.

\section{VI.5.3.1. Artefactos no formatizados (ANF) de UA2}

Incluyó un total de 125 piezas con 135 filos observados bajo microscopía óptica. La mayoría de las piezas estuvieron localizadas tridimensionalmente en la cuadrícula B12 principalmente hacia el sector $\mathrm{NE}(\mathrm{N}=28,34 \%)$. El porcentaje restante fue recuperado de la cuadrícula A12 en el sector $\mathrm{NE}(\mathrm{N}=16,38 \%)$ (Figura 83).
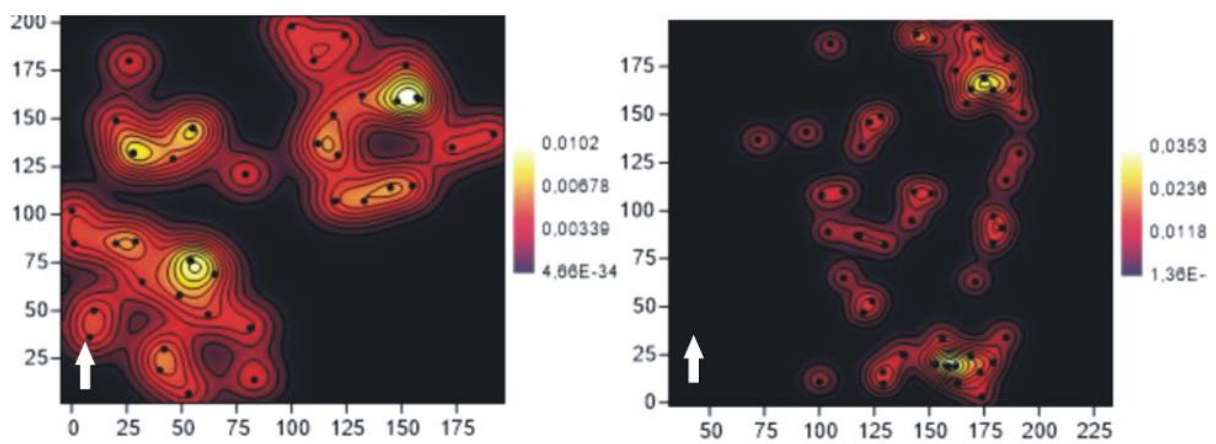

Figura 83: Distribución de ANF en la UA2 de CS (cuadrículas A12 y B2), sentido O-S. 
Las piezas se encontraban mayormente fracturadas sin talón $(\mathrm{N}=48,38 \%)$ y en menor medida fracturadas con talón $(\mathrm{N}=45,36 \%)$ y enteras $(\mathrm{N}=32,26 \%)$.

En cuanto a las materias primas utilizadas para su manufactura se observó las mismas variedades que las utilizadas en la producción de AF. Sin embargo, las proporciones de cada una difieren, al igual que la ausencia de la variedad PGx en la producción de los ANF de esta unidad.

Aun así, se puede observar en el diagrama dos picos que incluyen las variedades de ISG1 $(\mathrm{N}=40,32 \%)$ y RSG3 $(\mathrm{N}=38,31 \%)$ como las más representadas en este tipo de artefactos (Figura 84).

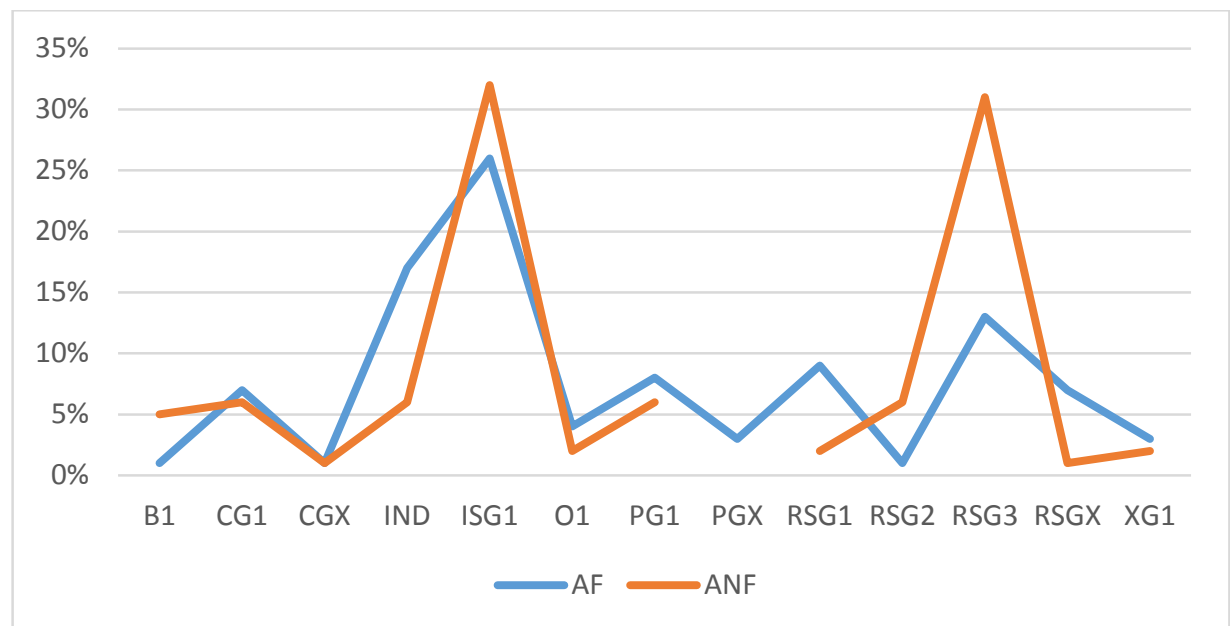

Figura 84: Distribución de materias primas con rastros de uso identificables de los artefactos recuperados en la UA2 de CS.

Por otro lado y en relación a los tamaños identificados se reconoció que las piezas en su mayoría eran mediano grande $(\mathrm{N}=43,43 \%)$ y mediano pequeña $(\mathrm{N}=40,40 \%)$, aunque se encontraron grandes en porcentaje elevados $(\mathrm{N}=13,13 \%)$.

Los módulos mediano normal $(\mathrm{N}=45,45 \%)$ y mediano alargado $(\mathrm{N}=27,27 \%)$ estuvieron mayormente representados en la muestra, seguido por porcentajes menores de corto muy ancho $(\mathrm{N}=14,14 \%)$, laminar normal $(\mathrm{N}=11,11 \%)$ y corto ancho $(\mathrm{N}=3$, $3 \%)$.

La selección de lascas sobre hojas fue altamente representativa en la muestra con un $71 \%$, siendo las lascas angulares las más representadas del conjunto (37\%).

\section{VI.5.3.2. Resultados del análisis funcional de base microscópica}

El análisis funcional realizado en los artefactos que componente la UA2, fue llevado a cabo considerando un total de 223 piezas con 339 filos identificados. 
En los AF si bien el mayor porcentaje de piezas fue no determinado por alteración $(\mathrm{N}=76,37 \%)$ las diferencias proporcionales entre piezas $\sin$ rastros de uso $(\mathrm{N}=65,32 \%)$ y con uso seguro $(\mathrm{N}=63,31 \%)$ no fueron amplias.

A diferencia de esto, en los artefactos sin formatización, la mayoría de las piezas no presentaron rastros de haber sido utilizadas ocupando un $39 \%(\mathrm{~N}=60)$ del total del conjunto. Le siguen en orden las piezas no determinadas por alteraciones intensas (lustres de suelo, playas de abrasión, procesos de termoalteración, etc.) con un 33\% $(\mathrm{N}=50)$ del total, mientras que en menor medida se reconocieron piezas con uso identificable sobre distintos materiales y durezas $(\mathrm{N}=43,28 \%)$.

\section{VI.5.3.3. Integridad del conjunto e identificación de alteraciones tafonómicas}

Como se observó con anterioridad un alto porcentaje de los artefactos analizados con microscopía óptica no pudieron ser adscriptos al trabajo sobre algún tipo de material debido a las alteraciones que sufrieron luego de su depositación. En este sentido, es importante mencionar, que el grado de estas alteraciones fue intenso afectando en algunos caso los filos y/o aristas (sectores más sobresalientes de las piezas) y en menor medida el total de la superficies de los artefactos.

Las alteraciones reconocidas incluyeron elevados porcentajes de piezas con lustre de suelo (58\%, N=41 en AF y 26\%, N=10 en ANF) que en algunos caso llegaban a formar verdaderas playas de abrasión o puntos en espejo acompañados con redondeamiento de aristas y filos.

En menor medidas, pero altamente representado, se reconoció alteraciones ocasionadas por procesos de termoalteración tanto en $\operatorname{AF}(\mathrm{N}=7,10 \%)$ como en $\mathrm{ANF}(\mathrm{N}=17,45 \%)$; incluyendo piezas con fracturas internas, escamas y cambios de coloración debido a una exposición directa al fuego (Figura 79).

Mientras que únicamente en los ANF fue reconocido, en proporciones menores $(\mathrm{N}=6$, 16\%), piezas con formación de pátinas blancas.

En menor medida varios artefactos (AF 17\%, N=12 y ANF 10\%, N=4) sufrieron altas consecuencias de su tratamiento en condiciones de laboratorio a partir del uso de PVAC durante el proceso de siglado y numeración de las piezas durante su inventariado. En este caso los filos no pudieron ser observados ya que esta sustancia se expresa a nivel microscópico en forma de brillo intenso y dispuesto en capa sobre los sectores 
aplicados, que en algunos casos se extiende afectando una microárea de mayor tamaño (Figura 85).

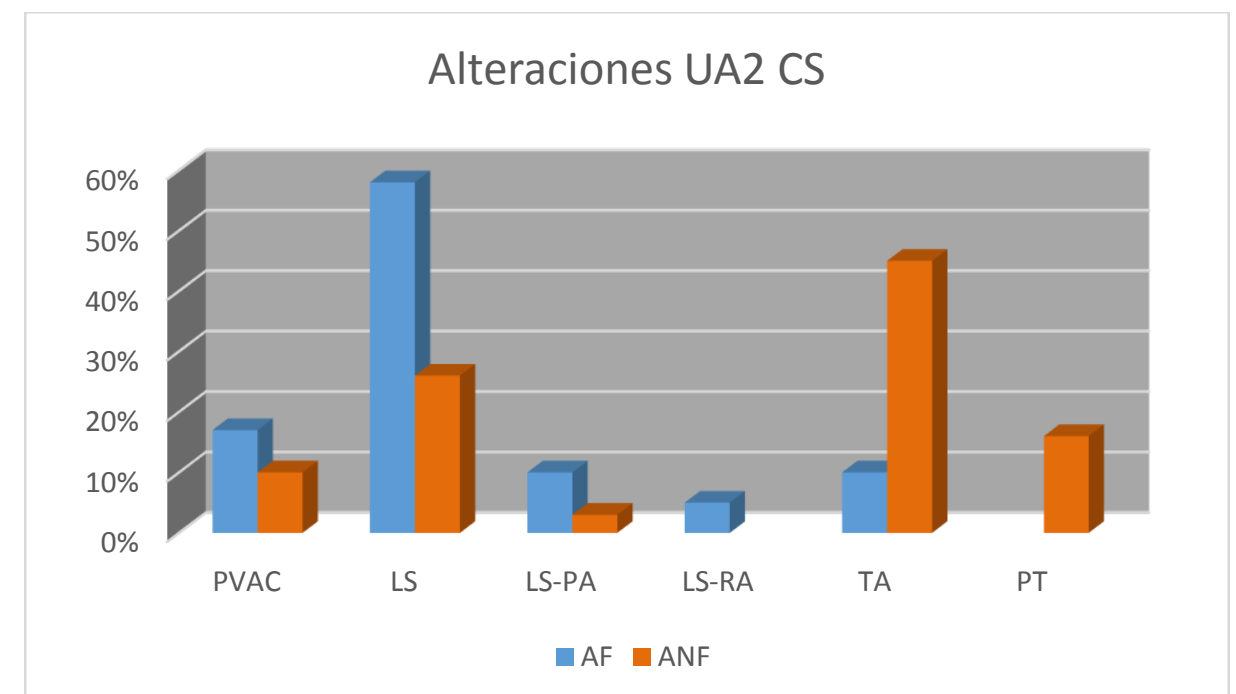

Figura 85: Tipos de alteraciones reconocidas sobre las piezas recuperadas de la UA2 de CS. LS-PA: de suelo y playas de abrasión. LS-RA: lustre de suelo con redondeamiento de aristas y filos.

\section{VI.5.3.4. Inferencia funcional de las modalidades de uso}

Los resultados obtenidos a partir del análisis realizado permitieron observar ciertas diferencias entre los AF y los ANF. En los primeros el mayor porcentaje está representado por piezas no determinadas por alteración, mientras que en los segundos este lugar lo ocupa las piezas no determinadas, ya sea consecuencia del tiempo empleado como también debido al material trabajado.

En este sentido los AF presentaron asimismo diferencias respecto a la cantidad de filos observados por piezas. En su mayoría presentaron 1 o 2 filo complementarios de los cuales por lo menos 1 presentó rastros de utilización (13\%). En menor medida se reconocieron piezas con 2 filos identificables de los cuales 1 fue usado (12\%). Mientras que el resto de la muestra incluye porcentajes menores de piezas con 3 y 2 filos identificables de los cuales $1,2 \mathrm{u}$ el total de estos filos fueron usados.

$\mathrm{Al}$ igual que en las unidades anteriores los ANF presentaron en su mayoría piezas con un único filo y en menor medida (11\%) un filo complementario.

Por otro lado, ciertas diferencias fueron registradas en relación a las materias primas utilizadas en la manufactura de los artefactos en esta unidad. Si bien la mayoría de las piezas estuvieron manufacturadas sobre materias primas homogéneas (variedades ISG1 y RSG3 con los porcentajes más elevados de la muestra), se identificó en los AF una mayor cantidad de piezas de materia prima RSG1 y RSG3 con rastros de uso, mientras 
que el basalto (materia prima no homogénea) y xilópalo se comportan de manera similar (Gráfico 57). En los ANF ocurre algo semejante, la variedad RSG3 es la materia primas más representada con rastros de utilización (42\%) y en menor medida le siguen la ISG1 $(23 \%)$ y BS (10\%) (Figura 86).

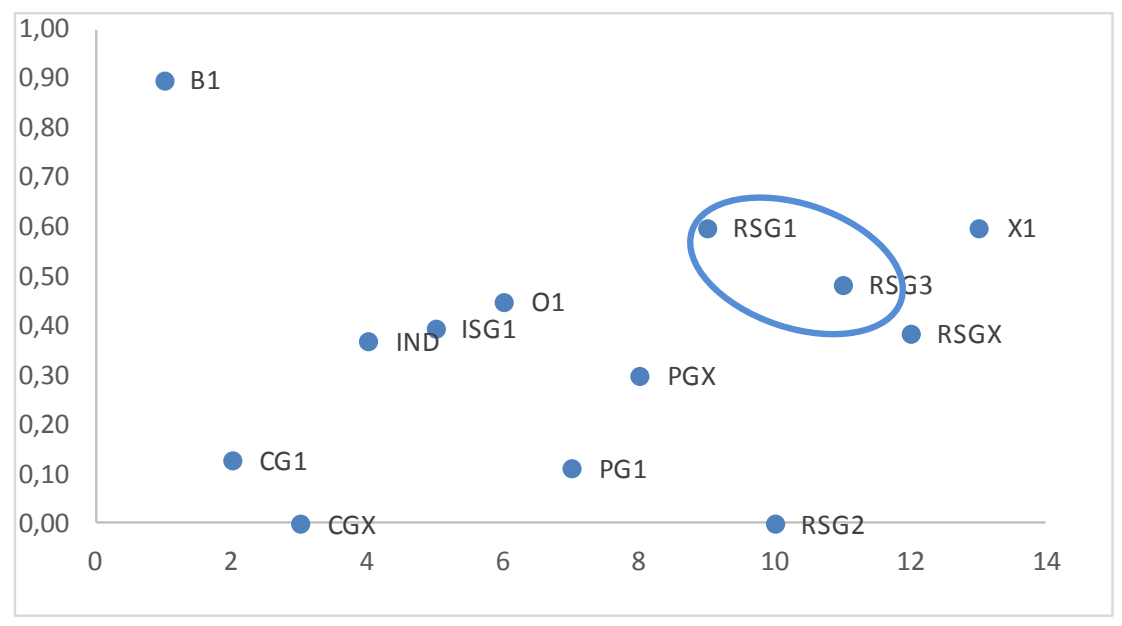

Figura 86: Diagrama de distribución de materias primas con rastros de uso en relación al tamaño de la muestra y riqueza en los AF de UA2 de CS.

\section{VI.5.3.5. Materiales trabajados}

Los materiales trabajados por los artefactos recuperados de la UA2 incluyen variedad de dureza y movimientos empleados.

Si bien un gran porcentaje de los filos observados en los AF presentaron alteraciones intensas, que imposibilitó su observación a nivel funcional, el porcentaje elevado de piezas con uso seguro permitió reconocer el trabajo principalmente de material duro (de origen vegetal o animal, $\mathrm{N}=26,48 \%$ ). En menor medida se identificó el trabajo de material óseo $(\mathrm{N}=9,17 \%)$ y porcentaje menor de madera $(\mathrm{N}=3,6 \%)$ como material duro. Asimismo se reconoció el empleo de las piezas sobre materiales blandos $(\mathrm{N}=5$, $9 \%)$ y cuero $(\mathrm{N}=3,5 \%)$. $\mathrm{Y}$ en dos casos se reconoció en un mismo filo el trabajo sobre material blando y duro a la vez (4\%).

En lo que respecta a los usos identificados de los ANF, el mayor porcentaje corresponde al igual que en el caso anterior, al trabajo sobre materia duro (vegetal o animal, $\mathrm{N}=12$, $35 \%)$. Le sigue en iguales proporciones el trabajo sobre madera y hueso $(\mathrm{N}=5,15 \%$ respectivamente) y en menores proporciones el trabajo sobre material blando $(\mathrm{N}=2,6 \%)$ 
y cuero $(\mathrm{N}=1,3 \%)$. El $26 \%$ restante incluye aquellas piezas cuya cinemática pudo ser inferida pero el material trabajado no determinado (Figura 87).

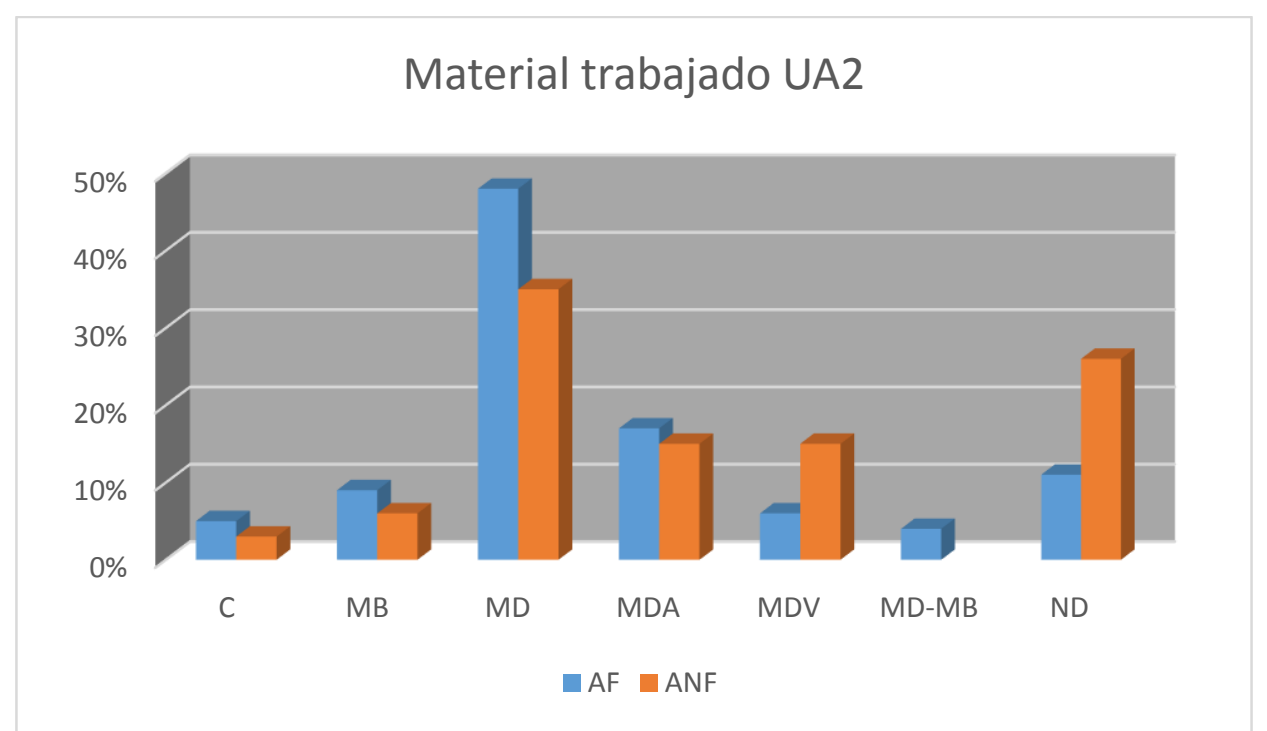

Figura 87: Materiales identificados en la UA2 de CS. C: cuero; MB: material blando; MD: material duro; MD-A: material duro animal; MD-V: material duro vegetal y ND: no determinable.

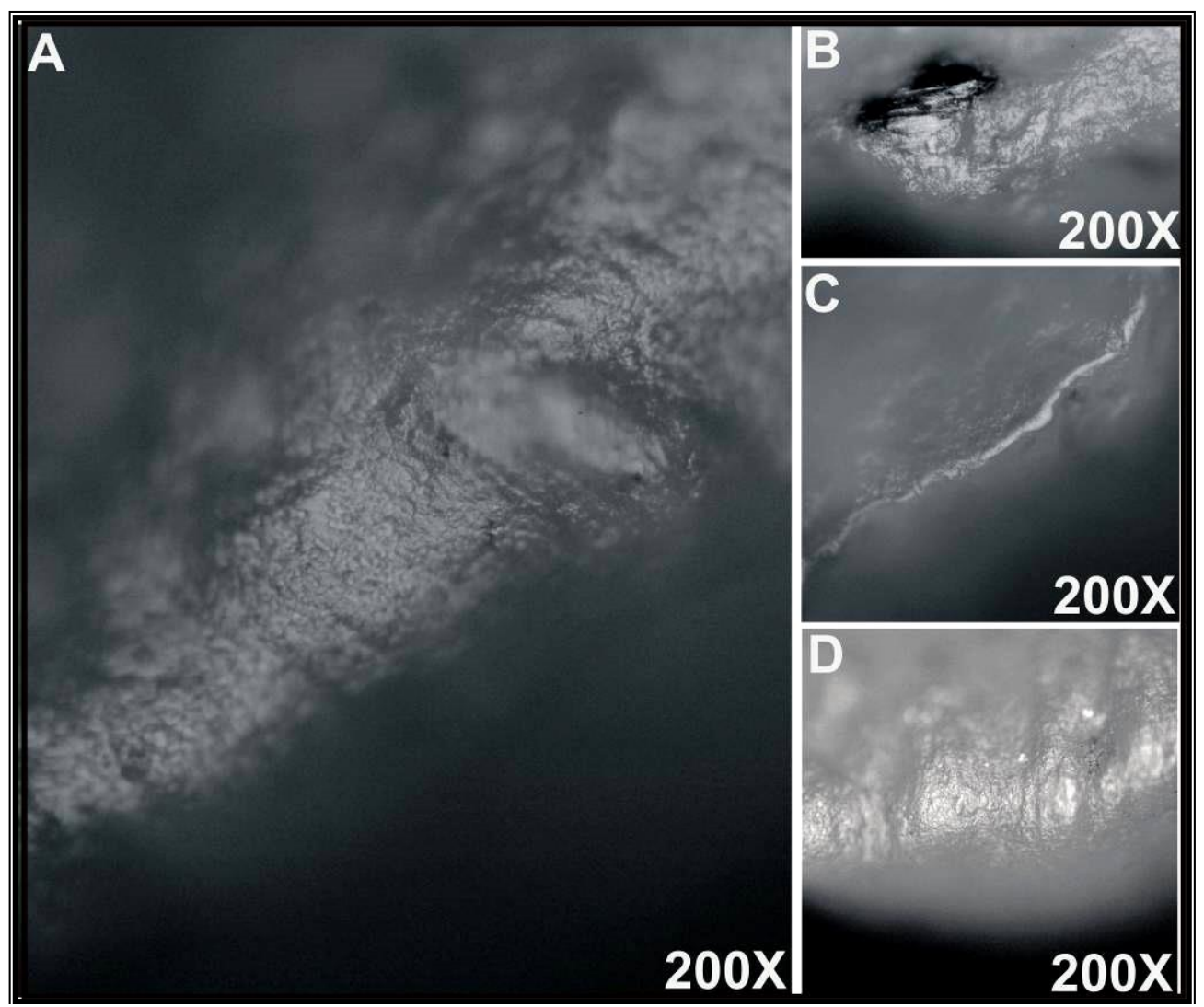

Figura 88: Materiales trabajados identificados en la UA2 CM. A) Pieza No: MA06'B1289 (raspador de filo frontal extendido) acción de raspado sobre material blando animal (piel). B) Pieza $\mathrm{N}^{\circ}$ : MA05 'B1214 (raedera de filo lateral) acción de corte sobre material duro animal (hueso). C) Pieza $\mathrm{N}^{\circ}$ : MA06'B1254 
(raspador de filo frontal corto) raspado sobre material duro (vegetal). D) Pieza $\mathrm{N}^{\mathrm{o}}$ : MA06'A12238 (raspador filo frontal corto) raspado sobre cuero.

\section{VI.5.3.6. Cinemática empleada}

La mayoría de las piezas en la UA2 fueron empleadas en acciones transversales, sin embargo, en menor medida también se registraron acciones longitudinales y en algunos casos no determinadas.

En los artefactos con formatización las piezas empleadas en acciones transversales o de raspado incluyeron un $72 \%(\mathrm{~N}=39)$ del conjunto, mientras que un $22 \%(\mathrm{~N}=12)$ en longitudinales o de corte; el porcentaje restante incluyó piezas cuya cinemática no pudo ser inferida $(\mathrm{N}=3,6 \%)$. En los ANF ocurre la misma situación, las piezas con filos naturales fueron mayormente empleadas en acciones transversales $(\mathrm{N}=18,53 \%)$ sobre las longitudinales $(\mathrm{N}=14,41 \%)$.

En relación con las variables métricas de los filos, se reconoció diferencias estadísticamente significativas en los AF (Prueba de Mann-Whitney; U=6,0; $\mathrm{p}=0,00$ ), donde las piezas empleadas en acciones longitudinales presentaron filos más agudos (ángulo promedio de $34^{\circ}$ ) que los que trabajaron transversalmente el material duro (promedio de $65^{\circ}$ ) (Figura 89).

No se reconocieron estas diferencias entre la cinemática empleada y el trabajo sobre material duro en relación con la longitud del filo (Prueba de Mann-Whitney; U=53; $\mathrm{p}=0,11$ ), al igual que entre el tipo de material (blando o duro) y la longitud (Prueba de Mann-Whitney; $U=136 ; \mathrm{p}=0,64$ ) y ángulo de los filos empleados (Prueba de MannWhitney; $\mathrm{U}=132 ; \mathrm{p}=0,56)$.

Mientras que en los ANF, no se reconoció diferencias significativas entre la cinemática empleada y el trabajo sobre material duro en relación con la longitud (Prueba de MannWhitney; $U=30,5 ; p=0,23$ ) y ángulo del filo utilizado (Prueba de Mann-Whitney; $\mathrm{U}=27 ; \mathrm{p}=0,14)$. 


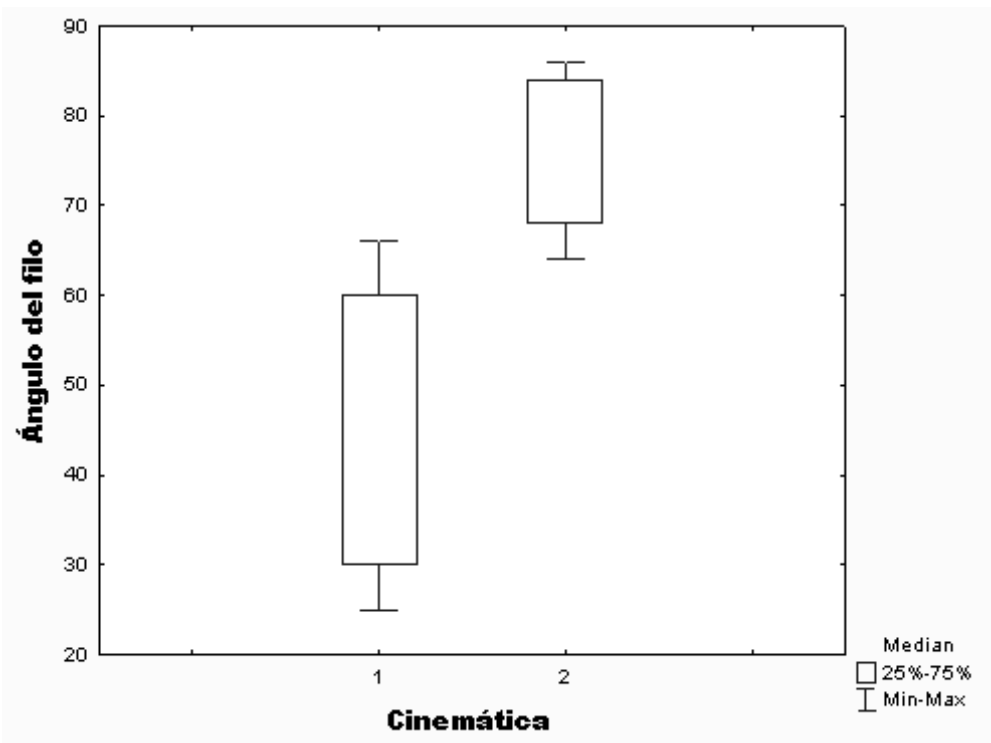

Figura 89: Diagrama de diferencias de media, ángulos de filos identificados en AF de UA2 en relación con la cinemática empleada y el trabajo sobre material duro. 1) Acciones longitudinales y 2) Acciones transversales.

\section{VI.5.3.7. Actividades desarrolladas}

El análisis funcional realizado sobre los materiales permitió inferir una amplia variedad de actividades realizada por los grupos humanos que ocuparon este sector de la cueva. La actividad más representada fue el raspado sobre material duro (de origen vegetal o animal) con un porcentaje más elevado en los artefactos sin formatización (37\%), mientras que en los formatizados este porcentaje se encuentra reducido (14\%).

Por otro lado, también se llevaron a cabo otras actividades sobre materiales duros más específicamente raspado de madera o hueso, sin embargo, el primero solamente fue realizado con piezas formatizadas; caso contrario ocurre con el raspado sobre material blando inferido únicamente en los artefactos con filos naturales.

También se registró el raspado sobre cuero en proporciones menores, tanto en AF como en $\operatorname{ANF}(3 \%$ y $5 \%$ respectivamente).

Además se reconoció en los ANF, el raspado sobre un material duro, pero que a su vez en algunos sectores se observó contacto con algún tipo de material blando, el análisis realizado no permitió especificar el material trabajado más allá de estas categorías (4\%). Los porcentajes menores corresponde a piezas cuyo material fue reconocido pero la cinemática empleada indeterminada (material duro, hueso y material duro vegetal, $2 \%$ cada uno).

En los usos reconocidos sobre material duro vegetal y hueso, como ocurrió en las unidades anteriores, no se pudo identificar el estado del material trabajado, sin embargo 
el reconocimiento de un material específico permite una mejor interpretación de los trabajos realizados en este sector de la cueva para las ocupaciones más tardías (Figura 90).

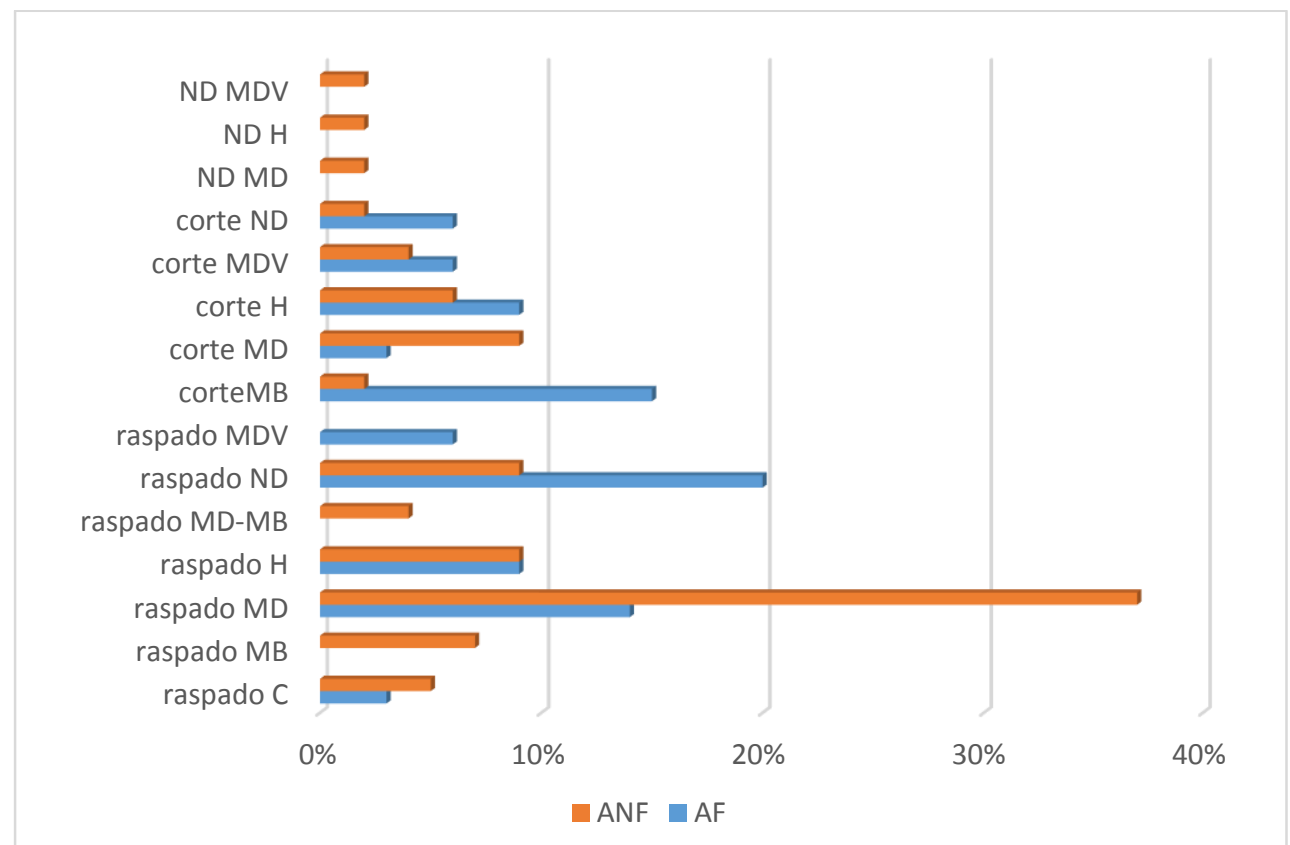

Figura 90: Distribución de las actividades desarrolladas inferidas a través del análisis de los artefactos líticos de la UA2 de CS.

\section{VI.6. Consideraciones generales}

Los estudios realizados en ambas cámaras de Cueva Maripe, permitieron generar un mejor conocimiento acerca del contexto de uso (materiales trabajados y modo de empleo) de los conjuntos líticos recuperados en el sitio.

A partir de distintas líneas de investigación realizadas a la par de este estudio específico de los materiales líticos (estudios zooarqueológicos, de arte rupestre, tafonómicos, georaqueológicos y de SIG intrasitio), la secuencia estratigráfica de Maripe ha sido divida en tres componentes arqueológicos incluyendo tres bloques temporales.

En este apartado se presentan los resultados obtenidos a nivel comparativo de las distintas unidades analíticas o capas de estos componentes.

\section{VI.6.1.Componente 1}

Incluye las etapas iniciales de ocupación de la cueva, que se da entre la transición Pleistoceno-Holoceno y Holoceno temprano, 11.100 años cal AP (9518 $\left.{ }^{14} \mathrm{C}\right)$, en CS 
hasta $c a .8000$ años cal $\left(7153{ }^{14} \mathrm{C}\right)$. Estratigráficamente incluye la capa 5 de CN y UA4 en CS.

En relación con los estudios realizados de restos faunísticos, en este bloque temporal no fueron registrados megamamíferos pleistocénicos, pese a que estuvieron disponibles para el área (como El Ceibo, La María, Piedra Museo y Cerro Bombero) (Marchionni 2013).

A nivel macroscoscópico la cultura material está caracterizada por una tecnología principalmente unifacial sobre lascas y con filos largos. Entre los grupos tipológicos identificados se incluyen principalmente cepillos, raederas y puntas de proyectil apedunculadas. Las materias primas identificadas corresponden en su mayoría a un origen local dentro de un radio de $15 \mathrm{~km}$, con excepción de la obsidiana (solamente en dos $\mathrm{AF}$ ), cuyas fuentes conocidas se sitúan en sector de cordillera más específicamente en Pampa del Asador (Belardi et al. 2006; Stern et al. 2012). Esto estaría sugiriendo un aprovisionamiento por intercambio a escala regional (Hermo y Miotti 2011 y Hermo y Lynch en prensa; bibliografía allí citada).

En cuanto a los resultados obtenidos del análisis funcional permitió discutir y analizar tendencias respecto a: 1) las alteraciones tafonómicas y el grado de integridad de este componente indagando en la génesis del depósito arqueológico, 2) a las prácticas de consumo de las poblaciones que habitaron la cueva en este bloque temporal y 3) al contexto de uso de los conjuntos líticos (usos identificados y modos de empleo).

\section{VI.6.1.1. Integridad y alteraciones tafonómicas}

El estudio de las alteraciones registradas en los artefactos se focalizó tanto en el grado o intensidad como en los efectos que ocasionan sobre las piezas observadas.

En este sentido, el grado de alteración en ambas cámaras fue moderado a intenso. Si bien en ambos sectores de la cueva se registraron piezas no determinadas por alteración, el grado de preservación en $\mathrm{CN}$ es moderado con efectos menos severos que en CS, donde se registró un mayor número de artefactos no determinados por alteración. Los restos óseos recuperados de la UA4 de esta cámara, también sufrieron modificaciones sobre su superficie, específicamente presencia de depósitos de carbonatos (Marchionni 2013). Según esta autora, podría deberse a la disolución de rocas o sedimentos carbonaticos, dado que este nivel se encuentra cercano a la roca de caja (ignimbrita) y por lo tanto es posible pensarla como fuente de su procedencia. 
Con respecto a las materias primas utilizadas en la producción, si bien en su mayoría fueron elaborados sobre rocas criptocristalinas u homogéneas, la presencia de basalto en los ANF de $\mathrm{CN}$ marca notablemente algunas diferencias por ser una roca heterogénea. Sin embargo, en un solo caso se registró rastros de utilización a partir de acciones transversales sobre material duro. En cuanto a los rastros identificados en CS, las piezas elaboradas sobre la variedad RSG3, presentaron una mayor cantidad de piezas usadas que la ISG1.

En cuanto a los tipos de alteración las más representadas en los materiales líticos son, la abrasión sedimentaria, playas de abrasión, puntos en espejo y lustre de suelo. Debido a que son consecuencia de la fricción de las partículas sedimentarias que entra en contacto con la superficie de los artefactos (Mansur 1999, Levi Sala 1986, 1993), las principales causas de su formación estuvieron relacionadas a distintos agentes como el pisoteo, acción hídrica y movimiento del suelo.

Asimismo el lustre de suelo y las playas de abrasión son consecuencia de alteraciones químicas o cambios en el pH del suelo. Ambos afectan la observación de rastros de uso llegando en algunos casos hacer desaparecer los micropulidos (Mansur 1983; Álvarez 2003; Leipus 2006). En este sentido, ambientes muy alcalinos, pueden alterar la presencia de micropulidos. Estudios relacionados a la determinación del $\mathrm{pH}$ fueron realizados en la $\mathrm{CN}$ a partir de muestras de sedimento solicitado al Lic. Bruno Mosquera, quien actualmente se encuentra realizando la geoarqueología de la cueva, tema de su tesis doctoral. Los resultados obtenidos permitieron identificar que en los niveles inferiores el $\mathrm{pH}$ era más alcalino $(\mathrm{pH}=8,4)$ que en los niveles más superficiales en $\mathrm{CN}(\mathrm{pH}=7,6)$.

En conclusión, las piezas analizadas de ambas cámaras presentaron altos porcentajes de abrasión sedimentaria acompañado por estrías y puntos en espejo. En menor medida se reconoció piezas con lustre de suelo y playas de abrasión en especial hacia el sector norte de la cueva, mientras que en CS se registró una mayor cantidad de piezas con pátinas de coloración blanca y depositación de carbonatos.

\section{VI.6.1.2. Prácticas de consumo}

A pesar del bajo número de filos con rastros de uso identificados en el componente 1, los datos obtenidos del análisis funcional en conjunto con otras líneas de evidencia, posibilitaron explicar los procesos productivos desarrollados en el sitio. 
En cuanto a los materiales procesados por los AF y ANF de $\mathrm{CN}$, trabajaron principalmente materiales duros (i.e. hueso). En menor medida se identificó el trabajo sobre materiales blandos (i.e. cuero), actividad únicamente realizada con filos formatizados pertenecientes al grupo de raspadores y cepillos. Mientras que en CS el material más representado corresponde al trabajo sobre cuero, actividad realizada únicamente con filos formatizados (grupo de raederas y cepillos). El material duro se encuentra representado en altas proporciones pero no supera al trabajo sobre cuero.

Asimismo en este sector, se identificó el trabajo sobre madera, únicamente en filos naturales; ocupando las mismas proporciones que el trabajo sobre hueso.

Cabe aclarar que en los AF se registró un mayor número de materiales procesados, tales como material duro, cuero, vegetal, material duro animal. Sin embargo, las diferencias en las proporciones de estos materiales no son tan marcadas en relación con los filos naturales. Es decir, existe una correlación por cámara en la frecuencia de los recursos procesados por los artefactos, más allá de su formatización.

Los filos naturales trabajaron principalmente material duro (hueso, pigmentos o madera) mientras que los filos retocados trabajaron materiales duros, madera, hueso y cuero.

Por otro lado, tanto en los filos formatizados como los naturales, se registró el trabajo de un único material, ya que no hubo superposición de rastros, restringiendo el uso de los filos. Sin embargo, esto no ocurre con las acciones empleadas, se identificaron diferentes cinemáticas para un único material, desarrollándose actividades de raspado y corte sobre material duro en proporciones menores.

Sin embargo, en su mayoría las piezas fueron empleadas en acciones transversales aunque también fueron reconocidos movimientos longitudinales.

Con respecto a los recursos utilizados, el trabajo sobre cuero fue realizado únicamente con filos retocados a partir de movimientos transversales. Los rastros identificados corresponden al trabajo sobre piel seca y en algunos casos a las etapas iniciales de procesamiento del cuero. El análisis de estos rastros no permitió identificar ningún tipo de aditivo (pigmentos u otros) en el tratamiento.

La evidencia del trabajo sobre material duro vegetal se encuentra registrado en especial en $\mathrm{CN}$ a partir de filos naturales como retocados. Mientras que en CS un único exponente presenta rastros de este tipo. El trabajo sobre madera estaría asociado a la producción y manufactura de mangos o elementos cortantes, que debido a su naturaleza no se conservaron en el registro. Sin embargo, esto no ocurre con el trabajo de hueso, identificado en ambas cámaras. Los rastros atribuibles a este tipo de material estuvieron 
asociados a acciones de raspado y corte. El análisis de restos óseos realizado en la cueva arrojó porcentajes elevados de hueso de guanaco con fracturas helicoidales y marcas de corte: “... La presencia de distintos atributos tecnológicos asociados como puntos de impacto y huellas de corte, sumado a la ausencia de modificaciones atribuibles a carnívoros, nos permiten interpretar este patrón como resultado de la aplicación de una fuerza dinámica sobre el hueso en estado fresco y, en este sentido, producto de la intencionalidad humana..." (Marchionni 2013).

Para los momentos iniciales de ocupación en la cueva se registró un número menor de piezas empleadas sobre material blando en general (i.e. piel y cuero) esto podría deberse a los efectos de procesos postdepositacionales y al grado de preservación de este tipo de material (Keeley 1980; Mansur- Franchomme 1983; Álvarez 2003; Leipus 2006). Aún así el reconocimiento de este material en ambos sectores estarían asociados a actividades relacionadas al cuereo de presas o a su tratamientos inicial (limpieza). Las actividades de consumo de animales en el sitio no fueron registrados a partir del análisis funcional de los artefactos líticos recuperados (corte y trozamiento de carne), para los momentos iniciales de ocupación. Aún así, otras líneas de evidencia complementan los análisis efectuados e indican procesamiento secundario y consumo de guanaco en el sector sur de Cueva Maripe (Marchionni 2013).

\section{VI.6.1.3. Contexto de uso}

Los trabajos previos realizados (Hermo 2008, Miotti y Marchionni 2012; Marchionni 2013 y Miotti y Marchionni 2013) formularon que en los momentos iniciales de ocupación, el sitio habría funcionado como un lugar de procesamiento primario, secundario y probablemente de consumo con uso diferencial de las cámaras. Es así que en cámara norte, se habrían realizado actividades más específicas de procesamiento secundario; trozamiento, cocción y manufactura de adornos e instrumentos utilizados también en la producción de pinturas (restos de pigmentos en material óseo). Mientras que en CS se realizarían actividades de consumo y descarte. El análisis funcional realizado sobre los materiales líticos recuperados de ambos sectores estaría avalando esta hipótesis, a partir de la identificación de un mayor número de actividades en CN relacionadas al trabajo sobre material duro (mayormente con filos naturales) y hueso (principalmente con filos retocados), al igual que rastros del trabajo sobre madera, para la producción de otro tipo de elementos (mangos, elementos contenedores, etc.) y 
trabajo sobre material blando (piel) consecuencia de las etapas iniciales de su tratamiento.

En CS se reconocieron proporciones menores del trabajo sobre material duro y hueso, con porcentajes más elevados del trabajo sobre cuero, realizado únicamente a partir de filos retocados. El mayor porcentaje del trabajo en cuero estaría indicando actividades relacionadas al tratamiento de este material para vestimenta $\mathrm{u}$ otros objetos del quehacer cotidiano. Por otro lado, es importante mencionar, la ausencia de rastros de uso sobre material blando animal en CS (carne y tendones), por lo que es difícil plantear, a nivel funcional, el uso de los materiales líticos en el desarrollo de actividades de consumo en el sector mencionado. Esto podría deberse a una mala preservación del micropulido generado sobre este tipo de material blando (carne). A nivel experimental, se ha comprobado que el micropulido generado por el trabajo sobre este material es difícil de reproducir y a su vez ha sido escasamente identificado en el registro arqueológico (Mansur-Franchomme 1983, Álvarez 2003).

\section{VI.6.2.Componente 2}

Está comprendido por la capa 4 en CN y la UA3 en CS y abarca el bloque temporal del Holoceno medio, con fechados radiocarbónicos que marcan su límite desde el 8584 ca. $\left(7700{ }^{14} \mathrm{C}\right)$ a $3272 \mathrm{ca} .\left(3210{ }^{14} \mathrm{C}\right)$ AP. Sin embargo, en base a los fechados radiocarbónicos de estas ocupaciones se observan ciertas discontinuidades, que en la CN se expresan a partir de la ausencia de fechados entre el 7100 y 5400 años AP, lapso menor que en CS, donde de 7700 pasa a nuevas ocupaciones en 4100 años AP. Es decir, en CS no se registran ocupaciones humana en un lapso de 3600 años, hiato ocupacional que podría deberse a condiciones microambientales, por lo cual dicha cámara no habría estado disponible para la ocupación humana, mientras que la $\mathrm{CN}$ si podría haber estado en condiciones, de acuerdo al lapso con fechados disponibles para este sector (Miotti et al. 2013).

A diferencia de la unidad anterior, la tecnología lítica del componente 2 está representada por la producción de hojas sobre el de lascas y aparecen por primera vez las bolas de boleadora, generando la incorporación de nuevos sistemas de armas con cadenas operativas específicas (Hermo y Magnin 2012). 
El uso de materias primas muestra diferencias en relación a la variabilidad, incluyendo mayormente rocas de trayectoria local y en menor medida no locales (obsidiana) (Miotti 2008; Hermo y Miotti 2011).

La incorporación e incremento de materiales no locales como la obsidiana, proveniente de la cordillera y otros elementos de origen marino, avalaría la idea de cambios de circuitos de movilidad (Miotti 2008; Salemme y Miotti 2008).

Las estrategias de apropiación de recursos faunísticos no varían en relación con el componente anterior, ya que el guanaco sigue siendo el recurso más utilizado por estos grupos, complementado con el uso de rheidos, evidenciado por fragmentos de cascara de huevo en las unidades correspondientes al Holoceno Medio (Miotti 2012).

El análisis funcional realizado al conjunto lítico recuperado de este componente permitió reconocer igualmente ciertas diferencias en el uso de los instrumentos, como también en relación a su estado e integridad, permitiendo avanzar en la interpretación de los procesos que afectaron a los materiales luego de su depositación.

\section{VI.6.2.1. Integridad y alteraciones tafonómicas}

El grado de alteración en CS es mayor que en CN debido a un incremento en la cantidad de piezas alteradas que no pudieron ser analizadas bajo técnicas de microscopía. El grado de alteración de estas piezas fue moderado a intenso, llegando a cubrir la superficie total de la pieza.

En cuanto a los tipos de alteración, se observó que en ambas cámaras, la mayor cantidad de piezas se vieron afectadas por abrasión sedimentaria y formación de lustre de suelo, acompañado en algunos casos, por puntos en espejo y playas de abrasión. Los procesos de formación de estas alteraciones se encuentran explicados en el apartado anterior por lo que aquí sólo se enumeran. Sin embargo, es importante mencionar que en la UA3 los restos óseo también se vieron afectados por alteraciones como la presencia de manganeso, probablemente ocasionado por la descomposición de la roca de caja como ocurre en la UA4 o por la liberación de materia orgánica. Asimismo, Rabassa et al. (2007) describen la presencia de moteados negros resultado de la alteración de raíces y guano y hacia la parte superior observan precipitación de sales que estarían indicando condiciones de humedad local. Sería esperable que estos procesos hayan ocasionado cambios en la composición del pH en esta unidad, afectando a la preservación de los micropulidos en el sector sur de la cueva. 
Otro factor que imposibilitó la observación de rastros de uso en ambos sectores del sitio, corresponde a procesos de termoalteración (daño térmico), presentando cambios de coloración, fracturas internas, escamas u hoyuelos consecuencia de la exposición directa al fuego. Cabe mencionar que tanto en $\mathrm{CN}$ como en CS la presencia de estructuras de combustión fue registrada y probablemente hayan intervenido en la formación de estas alteraciones, relacionado a técnicas específicas de producción o como desecho al ser arrojadas al fuego directo (Frank 2012).

En relación con las materias primas utilizadas y rastro de uso identificados, se observó que en su mayoría correspondían a materias primas locales homogéneas a excepción de lascas de basalto, materia prima de grano intermedio a grueso.

La variabilidad de materias primas se asemeja en ambas cámaras con un leve incremento del uso de basalto en CN. En ambos sectores de la cueva la roca ISG1 estuvo más representada; sin embargo, llama la atención ya que los resultados obtenidos del análisis funcional concluyeron que la materia prima con mayor cantidad de rastros de uso corresponde, en ambos sectores, a las variedades RSG2 y RSG3 junto con el basalto. En este sentido sería esperable que el basalto presentara una mejor preservación de rastros debido a su composición litológica (roca de grano más grueso con menor porcentaje de sílice) que le otorga una mayor dureza. Estudios previos observaron que este tipo de rocas emplean más tiempo para la formación de micropulidos diferenciables de acuerdo al material trabajado, pero el grado de conservación es mayor, al igual que en otras variedades de rocas como el cuarzo y la cuarcita (Mansur-Franchomme 1983; Levi Sala 1993; Álvarez 2003; Leipus 2006). Aun así, resta por explicar los porcentajes elevados de las variedades RSG2 y RSG3 con rastros de uso por sobre el de ISG1; estos grupos incluyen otras variedades de rocas silíceas, por lo que probablemente su composición litológica y tamaño de grano, sean variables que intervengan en el grado de preservación de los rastros de uso, aunque estudios más específicos permitirán profundizar esta temática.

\section{VI.6.2.2. Prácticas de consumo}

En relación con los materiales trabajados identificados y las actividades desarrolladas en el componente 2 de Cueva Maripe, se pudieron observar ciertas diferencias entre cámaras y en relación al uso de filos retocados o naturales. 
Los $\mathrm{AF}$ de $\mathrm{CN}$ fueron empleados en una amplia variedad de actividades, aunque se registró mayormente el trabajo sobre material duro (madera o hueso) a partir de movimientos transversales. A diferencia del componente anterior se observó un incremento del trabajo sobre material duro vegetal (madera), principalmente mediante acciones transversales y en menor medida longitudinal o de corte.

También se reconoció el trabajo sobre hueso y sustancias blandas (cuero y piel) empleados de manera transversal y longitudinalmente.

En CS la mayoría de los AF presentaron dos filos potencialmente utilizables de los cuales al menos en uno fue reconocido su uso. Entre los materiales identificados se registró al igual que en $\mathrm{CN}$, el trabajo sobre material duro (madera o hueso) en porcentajes mayores; las acciones transversales sobre este material estuvieron realizados principalmente con filos retocados; mientras que las de corte, se efectuaron en su mayoría con filos naturales de ángulos más agudos. Esto sería esperable ya que a nivel experimental se comprobó un uso más efectivo de filos naturales para acciones de corte e incisión. Sin embargo, estarían más expuestos a roturas o esquirlamientos que a nivel arqueológico no se registraron de manera intensa y continua. Esto podría indicar que el material trabajado presentaría una dureza intermedia o habría sido utilizado en estado fresco, en el caso de la madera, brindando una mayor flexibilidad del material y menor resistencia durante el trabajo.

Por otro lado, algunos AF de CN (del grupo de raspadores) presentaron micropulido generado por el contacto con material duro en la porción proximal, lo que permitiría plantear su uso a partir de algún tipo de dispositivo u enmangue. Trabajos experimentales previos (Castro y Moreno 1994, Forlano y Dolce 2006-2007, Lynch y Hermo 2011) permitieron identificar estos rastros en conjunto con fuentes etnohistóricas que confirmaría este modo de uso (Mansur-Franchomme 1983, 1987). Sin embargo, la colección experimental realizada incluye un número de piezas reducido por lo que sería conveniente profundizar en esta temática ampliando la serie experimental con una mayor variedad de dispositivos de enmangues.

En cuanto a los ANF de $\mathrm{CN}$, las actividades desarrolladas estuvieron restringidas principalmente al trabajo sobre material duro, al igual que en AF, tanto en acciones de raspado como de corte. Sin embargo, se observó un alto porcentaje de piezas que cortaron hueso y acciones de raspado y corte de madera. El raspado sobre cuero no fue reconocido en los ANF de CN, sin embargo se identificó el corte sobre material blando (piel). 
Mientras que los ANF de CS, en su mayoría presentaron un solo filo potencialmente utilizable, donde el material más representado corresponde al material duro (madera o hueso) en acciones de raspado y corte y en menor medida al trabajo sobre hueso y material duro vegetal (madera). A diferencia de $\mathrm{CN}$, se reconoció el raspado de cuero y corte de piel, sin uso de pigmentos u algún otro aditivo para su tratamiento. El corte de piel a partir de filos naturales, estaría asociado al procesamiento inicial de guanacos en este sector, probablemente a las etapas de descarne y cuereo de las presas introducidas al sitio. Las condiciones microambientales de mayor reparo y protección en este sector, probablemente hayan favorecido al desarrollo de estas actividades.

El trabajo sobre madera se encuentra más representando en el sector norte de la cueva lo que estaría indicando que probablemente allí se llevaran a cabo la elaboración de mangos, astiles u otros elementos como contenedores, que por su naturaleza no hayan sido preservados en el registro arqueológico.

\section{VI.6.2.3. Contexto de uso}

Los trabajos previos realizados en el componente 2, permitieron plantear para este bloque temporal, que los recursos faunísticos más representados corresponden al uso de guanaco y un mayor incremento de rheidos, expresado a partir de restos de cáscara de huevo. El empleo de artefactos líticos sobre hueso o material duro, junto con otra variedad de materiales trabajados, ha sido identificado a partir del análisis funcional realizado sobre los artefactos líticos recuperados en estratigrafía. Los elevados porcentajes del trabajo sobre material duro, en especial el hueso, junto con marcas de corte antrópico sobre los materiales óseos, estarían indicando que en el interior del sitio y en ambos sectores, se habrían realizado actividades de procesamiento secundario de presas. Por otro lado, se habrían desarrollado actividades complementarias, tales como el cuereo y tratamiento inicial de estos cueros, principalmente hacia el sector sur de la cueva. El trabajo sobre este material estaría relacionado a la vestimenta, abrigo y a la elaboración de otros elementos tales como cuerdas y tensores.

Los materiales trabajados no difieren en los distintos sectores de la cueva, por lo que a partir del análisis realizado, no se podría sostener la hipótesis de uso diferencial de las cámaras para este bloque temporal. Sin embargo, la identificación de un mayor desarrollo de actividades para $\mathrm{CN}$ podría deberse a un hiato ocupacional identificado 
que abarcó unos 3600 años, donde CS probablemente no haya estado disponible para la ocupación humana, momentos en donde si lo estaba $\mathrm{CN}$ que registró fechados para el lapso en cuestión. A nivel funcional, esto se vería expresado, a partir del desarrollo de actividades variadas que incluyeran procesamiento de presas y otro tipo de actividades del quehacer cotidiano en un mismo sector de la cueva.

\section{VI.6.3.Componente 3}

Este componente se distribuye en las capas 3 y 2 de CN y en la UA2 de CS, con una cronología de $3535{ }^{14} \mathrm{C}$ a $1907{ }^{14} \mathrm{C}$ años AP en $\mathrm{CN}$ y de 2849 cal $\left(2655{ }^{14} \mathrm{C}\right)$ a 928 cal $\left(1078{ }^{14} \mathrm{C}\right)$ años AP en CS, correspondiente al Holoceno Tardío. En cuanto a la tecnología lítica, a nivel macroscópico, se observa una disminución en la selección de hojas como formas bases (raspadores, láminas retocadas) y un incremento de grupos con filos de morfología que permiten el desarrollo de actividades específicas como gubias, cuñas y escoplos, con uso variado de materias primas. En cuanto a los recursos faunísticos se evidencia un mayor uso de rheidos y de aves medianas, con la incorporación de animales de porte pequeño como armadillos; aun así, el guanaco continúa siendo el recurso principal (Miotti et al. 2011, Miotti et al. en prensa).

Los resultados obtenidos del análisis funcional de los materiales líticos asociados a este bloque temporal, han permitido determinar ciertas diferencias en ambos sectores de la cueva.

\section{VI.6.3.1. Integridad y alteraciones tafonómicas}

El análisis realizado en este componente registró ciertas diferencias en el grado de integridad de los conjuntos observados. Los materiales recuperados de $\mathrm{CN}$ presentaron una mayor cantidad de piezas con rastros de uso que en el caso de CS donde el mayor porcentaje estuvo representado por piezas no determinadas por alteración. En estos casos el grado de alteración fue intenso e imposibilitó la determinación funcional.

La abrasión sedimentaria y lustre de suelo fueron las alteraciones tafonómicas más representadas en ambos sectores, al igual que en los componentes anteriores, sin embargo, en algunos casos, se encontraban acompañados por playas de abrasión y estrías generadas por el contacto con el sedimento. 
Por otro lado en CS y en especial en los ANF, se registró un incremento de piezas con formación de pátina sobre la superficie de los artefactos. Esto podría deberse a alteraciones químicas ocasionadas por cambios en el pH del sedimento, ya que es en este sector donde se evidencia filtración de agua semipermanente. Sin embargo, aún resta por realizar estudio específicos de composición de sedimento y $\mathrm{pH}$ en este sector de la cueva.

Otro factor que imposibilitó la observación de las piezas al microscopio en ambos sectores fue la termoalteración, que en algunos casos estuvo acompañado por cambio de coloración, hoyuelos, lustre y fracturas internas consecuencia de una exposición intensa al fuego.

\section{VI.6.3.2. Prácticas de consumo}

En cuanto a los recursos utilizados por los grupos que habitaron Cueva Maripe hacia el Holoceno Tardío, se reconoció un mayor uso de material blando con artefactos formatizados en CS, mientras que los filos naturales fueron mayormente empleados en material duro (madera o hueso) a partir de acciones transversales o de raspado. En menores porciones se reconoció también el trabajo sobre hueso y madera longitudinal y transversalmente, tanto con filos formatizados como naturales. A diferencia de este sector, en $\mathrm{CN}$, se habría registrado mayor cantidad de piezas trabajadas sobre material duro (madera o hueso) con AF como con ANF y ambos empleados en acciones de raspado como de corte. El trabajo sobre material blando y cuero fue igualmente identificado pero en menores proporciones, únicamente en acciones transversales.

El aserrado de hueso en $\mathrm{CN}$ fue identificado exclusivamente en $\mathrm{AF}$, mientras que el raspado se habría realizado a partir de lascas con filos naturales. Esto sería esperable ya que los filos formatizados presentan una mejor resistencia a las fracturas, por lo que brindaría un mayor tiempo de utilización por pieza durante su empleo. Mientras que los filos naturales serían más efectivos durante el proceso de limpieza.

En cuanto al trabajo sobre madera se reconoció su empleo en proporciones menores y utilizadas de la misma manera que para el caso del trabajo sobre hueso. Los artefactos formatizados con filos largos fueron empleados para el corte de madera, mientras que las lascas con filos naturales y cortos para acciones transversales o de raspado. 


\section{VI.6.3.3. Contexto de uso}

Respecto a las ocupaciones identificadas para el Holoceno tardío, los estudios realizados hasta el momento estarían indicando que la cueva habría funcionado como lugar de actividades domésticas y consumo de presas. El análisis de restos faunísticos reconoció el uso de guanaco como principal elemento de consumo de estos grupos y en menor medida aves de tamaño mediano en CN y rheidos en CS lo que indicaría un uso diferencial del espacio intrasitio (Marchionni 2013). A nivel funcional esta diferencia no puede ser reconocida mediante el análisis de los artefactos líticos realizado, sin embargo, se registra un incremento del trabajo sobre material blando en CS contrario a la $\mathrm{CN}$, donde se identificó un mayor empleo de los artefactos sobre materiales duros (madera o hueso). En este sentido, si se podría hablar de un uso diferencial de estos dos sectores de la cueva, en donde se habrían llevado a cabo actividades complementarias pero diferentes a la vez. En $\mathrm{CN}$ se registró una mayor frecuencia de modificaciones antrópicas en los materiales óseos que en CS; esto habría estado relacionado a actividades de procesamiento, junto con huellas de corte, puntos de impacto, marcas de raspado y percusión presente en ambos sectores (Marchionni 2013).

Los rastros identificados de aserrado y raspado sobre hueso probablemente expresen el uso de los artefactos líticos en estas actividades de procesamiento de las presas y en algunos casos para la obtención de fracturas controladas para extracción de médula ósea.

En cuanto al trabajo sobre madera en CN, podría estar relacionado a la producción de mangos, al igual que en el componente anterior, la determinación de micropulidos de material duro en sectores proximales de las piezas, podría estar indicando el uso de instrumentos a partir de distintos dispositivos de enmangue.

Por otro lado, en cuanto a las alteraciones postdepositacionales, la CS evidenció un menor grado de integridad que $\mathrm{CN}$, a partir de la determinación de distintos procesos (pisoteo, acción hídrica, movimientos de la matriz sedimentaria, cambios de $\mathrm{pH}$ ), que habrían generado las alteraciones identificadas en las piezas. Esto estaría igualmente evidenciado a partir del análisis realizado en los resto faunísticos, ya que presentaron un mayor grado de meteorización y depósitos de manganeso (Marchionni 2013).

En cuanto al uso diferencial de ambas cámaras, los resultados del análisis funcional realizado sobre la tecnología lítica recuperada de este componente, permitiría sostener la hipótesis de uso diferencial para el Holoceno tardío a partir de las distintas 
actividades identificadas y en base a los resultados de otras investigaciones realizadas con anterioridad (Hermo 2008, Carden 2009, Marchionni 2013). Para ese entonces CS habría sido utilizado como área de consumo y sector de procesamiento primario de piel y cuero, mientras que $\mathrm{CN}$ se habrían realizados otras actividades relacionadas al trabajo sobre material duro, madera o hueso. A su vez, el mayor número de piezas que componen la UA2 de CS en relación con las capas 3 y 2 de $\mathrm{CN}$, es notoriamente mayor, sumado a que el volumen excavado es semejante en ambos sectores, serían elementos que permitirían sostener la hipótesis de uso diferencial de la cueva. Sin embargo, la evidencia material de la excavaciones más recientes realizadas en Cueva Maripe, que aún están siendo procesadas, permitirán esclarecer algunas de las preguntas referentes a los recursos utilizados y el uso del espacio interior de la cueva. 



\section{CAPÍTULO 7}

Sitio

\section{Piedra Museo}

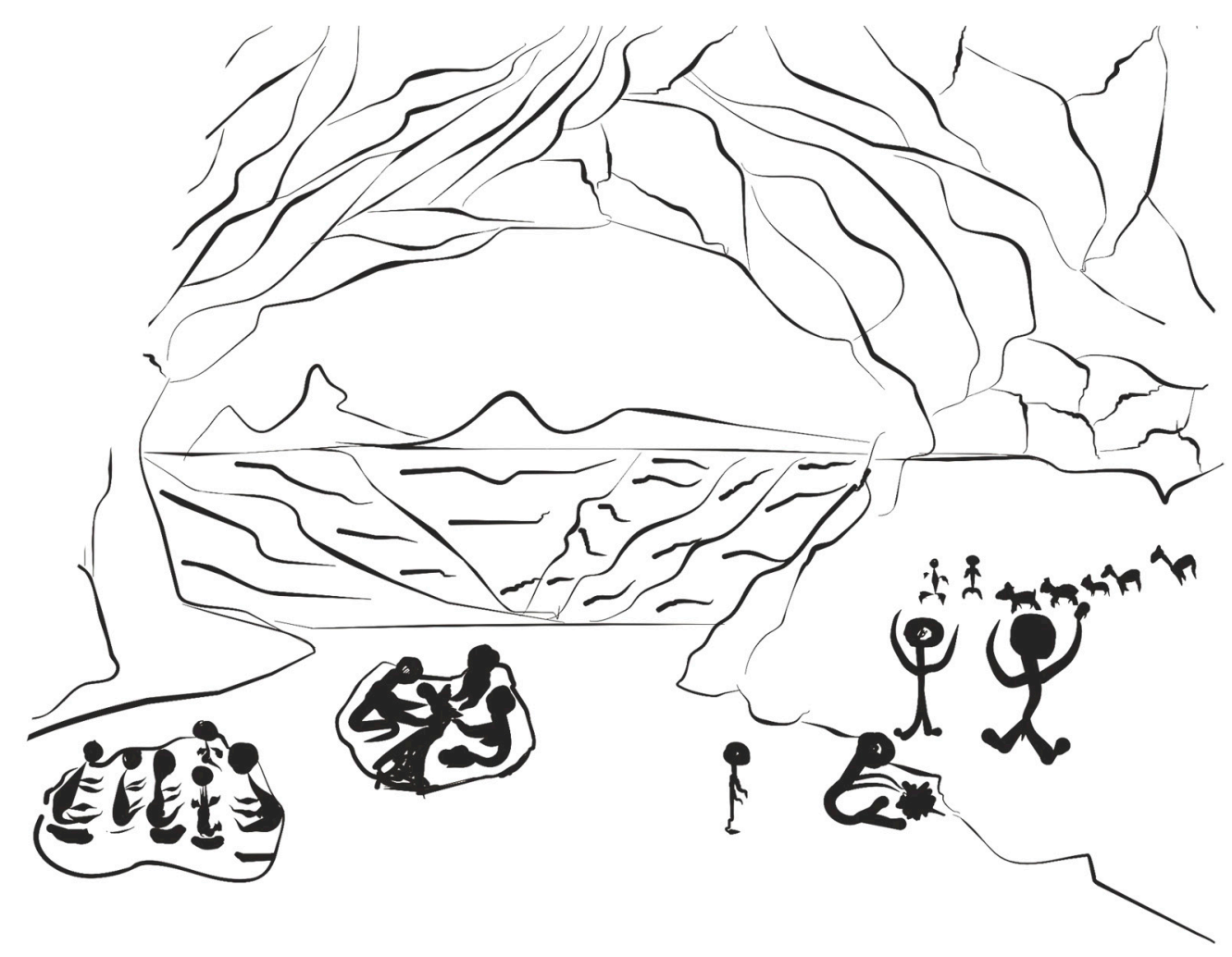





\section{ANÁLISIS FUNCIONAL DEL INSTRUMENTAL LÍTICO DE LA LOCALIDAD ARQUEOLÓGICA PIEDRA MUSEO}

En este capítulo se exponen los resultados obtenidos a partir del análisis funcional de base microscópica de los conjuntos recuperados del sitio AEP1, de la Localidad arqueológica Piedra Museo.

Con anterioridad a estos estudios una muestra menor fue analizada a partir de diferente metodología y marco de referencia (Miotti y Cattáneo 1997; Miotti et al. 1999; Cattáneo 2002) por lo que en esta tesis se amplía la muestra analizada y se discute la información generada en base a los nuevos resultados obtenidos a partir del análisis funcional de base microscópica de los materiales líticos.

Los criterios utilizados para llevar a cabo este estudio son los establecidos con anterioridad en el Capítulo V, siendo los mismos criterios aplicados en el análisis realizado a los conjuntos líticos del sitio Cueva Maripe (Capítulo VI).

\section{VII.1. Características principales del sitio}

Piedra museo es una de las localidades arqueológicas más importante de la Meseta Central de Santa Cruz, debido a que presenta evidencia confiable de una alta redundancia ocupacional desde la transición Pleistoceno-Holoceno hasta el Holoceno tardío. Este sitio se encuentra localizado en el curso inferior del zanjón Rojo, a una altura de $150 \mathrm{msnm}$, próximo a un extenso salitral, antiguamente un paleolago, con importante caudal de agua durante la transición Pleistoceno-Holoceno (Miotti 1995). Este paleolago se encuentra interrumpido por el zanjón Rojo o también denominado Elornia, con un nivel de base ubicado a $30 \mathrm{~km}$ al noroeste de este lugar, en la Laguna Grande del Monumento Natural Bosques Petrificados (MNBP).

La localidad mencionada presenta 3 sitios arqueológicos: Alero El Puesto 1 (AEP1), Alero El Galpón 2 (AEG2) y Cueva Grande (CG), emplazados en un extenso afloramiento de areniscas coquinoides, relicto de una antigua ingresión marina durante el Terciario (Formación Puesto el Museo, Panza 2001).

El mayor cúmulo de información arqueológica de esta localidad proviene de los sitios AEP1 y AEG2. Ambos son contiguos, AEG2 es un alero de $11 \mathrm{~m}$ de boca y $4 \mathrm{~m}$ de 
profundidad, mientras que AEP1 corresponde a un paredón que habría funcionado como alero para momentos anteriores a $c a .9 \mathrm{ka} \mathrm{AP}$, que se produjo el derrumbe masivo del techo (Miotti et al. 1999) (Figura 91).

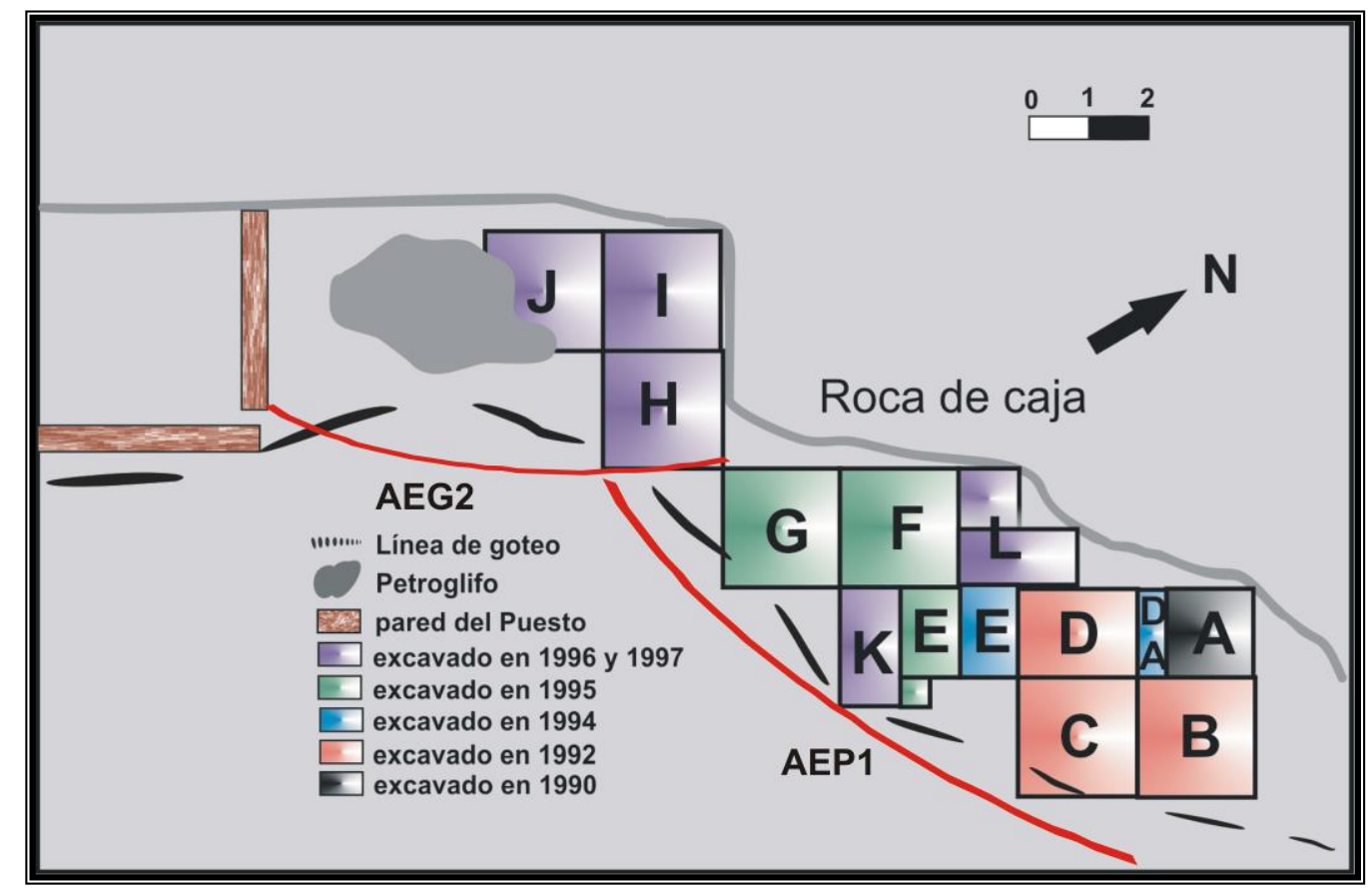

Figura 91: Planta de los sitios AEP1 y AEG2, donde se observan las cuadrículas excavadas por año, sectores con grabados y pinturas, sin embargo de ahora en más se referirá únicamente a AEP1, como se conoce en la literatura (modificado de Miotti et al. 1999).

\section{VII.2. Antecedentes de investigación}

\section{Geoarqueología}

Las excavaciones realizadas en ambos sitios se llevaron a cabo entre los años 19901999, dirigido por la Dra. Miotti, que incluyó una superficie total de 41,25 m². Se realizó a partir de capas naturales, pudiéndose identificar seis unidades depositacionales distribuidas en dos estratos principales. El estrato superior es de origen eólico y contiene una única unidad de ocupación (UE1), mientras que el estrato inferior o unidad estratigráfica 2 (UE2) corresponde a un suelo enterrado o paleosuelo integrado por Capa 2 a 6. El límite inferior de UE1 es neto lineal, en desarrollo vertical y continuo en sentido lateral, ya que se trata de una discordancia erosiva; mientras que los límites entre la Capa 2 a la 6 son transicionales debido a que corresponden a horizontes pedogénicos (Miotti et al. 2003; Zárate et al. 2000). 
Las características estratigráficas del sitio fueron planteadas a partir del perfil ubicado en la pared NE de la cuadrícula L; de donde también se extrajeron muestras sedimentológicas, para análisis mineralógicos y polínicos (Borromei 2003; Miotti et al. 2003; Zárate et al. 2000).

La UE1 presenta una granulometría diferente al resto de las capas reconocidas en la secuencia y corresponde a una arena de color castaño de gravas finas. La UE2 corresponde a la morfología de un perfil de suelo desarrollado a partir de material parental de aporte mixto, cuencal-eólico de granulometría constante (Blasi et al. 1997; Miotti et al. 1999; Zárate et al. 2000).

La Capa 2 pertenece al horizonte IIA del suelo truncado parcialmente por erosión. Arena fina de color castaño amarillento con un espesor de $15 \mathrm{~cm}$. No hay evidencia de erosión eólica o hídrica en el límite inferior y corresponde a un fango arenoso; sin embargo se ha identificado gran cantidad de bioturbaciones (raíces e insectos) con importante porosidad (Miotti y Marchionni 2011). La Capa 3 constituye el horizonte IIBt del perfil del suelo, compuesto por limo arcilloso de color castaño y un promedio de $20 \mathrm{~cm}$ de espesor. En la parte inferior de esta capa se observan nódulos calcáreos y algo de carbonatación sobretodo en las cuadrículas más sobresalientes del alero. La Capa 4 es el horizonte II31 del perfil del suelo, limo areno arcilloso de coloración castaño grisáceo y espesor de $20 \mathrm{~cm}$. Se observa abundante bioturbaciones de invertebrados y macroporos. La Capa 5 conforma el horizonte II32, de textura limo arcillosa y color castaño oscuro con un espesor de $15 \mathrm{~cm}$. Presenta clastos de la roca de caja. Texturalmente corresponde a una arena fangosa. Y por último la Capa 6 pertenece al horizonte IIIC del perfil del suelo, arena castaño oscura amarillenta que pasa a sedimentita coquinoide de la roca de base. Texturalmente es una arena limosa.

Todas las unidades estratigráficas se reconocieron en la mayoría de la superficie excavada del sitio, siendo la única excepción la Capa 6, que no aparece en el sector bajo del alero debido a la altura de la roca de base, principalmente en las cuadrículas H, I y J. También se realizaron estudios polínicos en la secuencia de ocupación, que reconocieron cambios vegetacionales en las fechas de 12.890 y 7670 años AP, indicando un reemplazo de la estepa graminosa por estepa arbustiva (Ephedra y Asteraeceae) vegetación de ambiente semidesértico, con menor humedad disponible, menores precipitaciones y temperaturas más altas. Hacia el Holoceno tardío las condiciones ambientales irían adoptando los escenarios actuales de aridez, estos 
cambios también habrían sido reconocidos en otras localidades arqueológicas cercanas al sitio bajo estudio (Páez et al. 1999; Borromei 2000).

\section{Dataciones obtenidas}

En el sitio AEP1 fueron identificadas dos unidades estratigráficas. La primera de estas unidades incluye la Capa 1 de la secuencia de ocupación (Miotti et al. 1999). Esta capa carece de fechados radiocarbónicos, sin embargo, los resultados obtenidos a partir de los materiales recuperados han permitido otorgarle una asignación temporal del Holoceno tardío.

La segunda unidad estratigráfica incluye dos componentes (superior e inferior). El primero de estos componentes incluye la Capa 2 con ocupaciones del Holoceno medio (Miotti 1996; Miotti et al. 2000), mientras que la Capa 3 corresponde a un hiato ocupacional. El componente inferior incluye las Capa 4/5 y 6 y las ocupaciones humanas más tempranas identificadas en el sitio. Este componente contiene al menos dos resoluciones temporales; una relacionada a las primeras ocupaciones del alero y contenida en la Capa 6 y otra correspondiente a las ocupaciones más tardías del intervalo Pleistoceno final/Holoceno temprano, con fechados que abarcan desde $c a$. 10.500 hasta 9200 años AP (Capa 4/5) (Tabla 8).

\begin{tabular}{|c|c|c|c|c|c|}
\hline$\overline{U E}$ & Código & Tipo & $A \tilde{n} o s C^{14} A P$ & $\delta 13 C$ & Material \\
\hline 2-media & NSRL-11167 & AMS & $7470 \pm 140$ & $-23,1$ & Carbón \\
\hline 2- base & LP 450 & estándar & $7670 \pm 110$ & $S / D$ & óseo-L.guanicoe \\
\hline 4- techo & LP 949 & estándar & $9230 \pm 105$ & $-22,2$ & óseo-L.guanicoe \\
\hline 4- base & LP 859 & estándar & $9710 \pm 105$ & $-20,2$ & óseo-L.guanicoe \\
\hline 5 & AA- 8428 & AMS & $10400 \pm 80$ & $-25,8$ & óseo-Camelidae \\
\hline 5 & OXA 9249 & AMS & $10470 \pm 65$ & $-26,6$ & Carbón \\
\hline 6 & OXA 8527 & AMS & $10390 \pm 70$ & $-18,1$ & óseo- L.guanicoe \\
\hline 6 & GRA 9837 & AMS & $10470 \pm 60$ & $S / D$ & Carbón \\
\hline 6 & OXA 8528 & AMS & $10925 \pm 65$ & $-19,3$ & óseo-Hippidion saldiasi \\
\hline 6 & AA- 27950 & AMS & $11000 \pm 65$ & $-23,4$ & Carbón \\
\hline 6 & AA- 20125 & AMS & $12890 \pm 90$ & $-25,8$ & Carbón \\
\hline
\end{tabular}

Tabla 8: Fechados radiocarbónicos obtenidos de AEP1 (modificado de Miotti et al. 2003). 
Arte rupestre

Las manifestaciones rupestres de Piedra Museo incluyen dos de los 3 sitios identificados en la localidad (AEG2 y CG). Estas manifestaciones fueron dadas a conocer por De Aparicio en 1933, publicando los grabados del alero junto con los reconocidos en la Cueva Grande (De Aparicio 1935). En rasgos generales el arte de Piedra Museo se podría dividir en representaciones pintadas, por un lado y en grabados por el otro. Las pinturas consisten principalmente en negativos de manos en tonos rojo, ocre, blanco y amarillo, muchas de estas superpuestas. Mientras que los grabados ofrecen una mayor variedad de motivos e incluyen figuras de pisadas de animales y otros motivos geométricos (circulares, curvilíneos y rectilíneos), realizados mediante la técnica de incisión y raspado. La baja dureza del soporte ofreció escasa resistencia a las distintas técnicas aplicadas (Carden 2009; Blanco y Lynch 2011).

\section{Zooarqueología}

El análisis de los recursos faunísticos a partir de los materiales recuperados del componente inferior de Piedra Museo registró ciertas diferencias entre las Capa 4/ 5 y 6. Los estudios de remontaje permitieron reconocer un único evento ocupacional en las Capas 4 y 5, ya desde los primeros trabajos, Miotti las ubicaba como de límites transicionales (Miotti 1996), que luego se mantendría así con los análisis geoarqueológicos (Blasi et al. 1997; Rabassa et al. 2007; Zárate et al. 2000) y en el trabajo de 1999 (Miotti et al. 1999) demostrarían que debían ser interpretadas como una única Capa 4/5 (Giardina et al. 2000). A diferencia de esto, los materiales de la Capa 6 tratada como una ocupación independiente y previa, tal vez haya correspondido a los primeros momentos de ocupación humana de la región (Miotti 2010). Esta capa corresponde al primer evento ocupacional del alero, con 2.500 años más de antigüedad que las capas subyacentes. Por otro lado, la estructura faunística de las Capas 4/5 y 6, difieren en cuanto a diversidad taxonómica, con un incremento de fauna pleistocénica en la Capa 6 y una significativa reducción de la misma en la Capa 4/5. Estas unidades corresponderían a varios eventos de caza y descarte de las presas en el mismo lugar hacia los 10.470 \pm 65 años AP y $9.230 \pm 105$ años AP (Miotti y Salemme 2005). Este componente habría sido interpretado como resultado de actividades limitadas y procesamiento primario de grandes animales (Miotti et al. 1999). 
Los trabajos realizados sobre los restos faunísticos indican que el principal taxón como en el resto de la secuencia corresponde al guanaco (Lama guanicoe), mientras que el segundo incluye las aves corredoras (rheidos) (Miotti y Salemme 1999; 2005; Miotti et al. 1999; Marchionni 2013).

Asimismo, se registraron para ambas ocupaciones (Capa 4/5 y 6), dos géneros diferentes de rehidos: Rhea (ñandú de las pampas o grande) y Pterocnemia (ñandú petiso o choique), el primero pertenece a una especie que no habita en el área de estudio, mientras que la segunda es la especie más endémica y que durante el Holoceno habitó en toda Patagonia y en Los Andes desde Mendoza hasta el NOA (Miotti 1998; Miotti y Salemme 2005; Miotti et al. 1999).

En cuanto a la megafauna identificada en Capa 6 las especies de Hippidion saldiasi y Lama gracilis presentan evidencia de uso antrópico (huellas de corte y fractura helicoidal con punto de impacto), reconocido como complementario en la Capa 4/5 (Miotti y Cattáneo 1997; Miotti et al. 1999; Marchionni 2013).

Por otro lado, Miotti (2003) nota que el grado de fragmentación ósea es bajo y que los materiales presentan manchas de manganeso y acreciones carbonáticas abundantes en la superficie de los especímenes. También reconoce que la distribución de los materiales en la Capa 4/5 se dispone en pilas de descarte, sobre todo en las cuadrículas C, D y F; donde las patas y la columna vertebral se encuentran articuladas (Miotti y Salemme 2005).

La Capa 6 habría sido interpretada como un evento ocupacional reducido, donde el uso del sitio para esos momentos correspondería un lugar de trozamiento primario de presas, posiblemente de guanacos, caballos y camélidos extintos, junto con prácticas de aprovechamiento oportunista de ciertas partes de mylodontinos (Miotti et al. 1999). Esta estrategia difiere de la interpretada para la Capa 4/5 que serían eventos de caza programada, por acecho, de guanacos complementado con ñandúes (Miotti et al. 1999). Los estudios más actuales del sitio incorporaron los análisis tafonómicos y taxonómicos de ambos componentes. El superior estaría caracterizado por fauna autóctona viviente como el guanaco, ñandú petiso, cánidos y armadillos, evidenciando actividades de caza y procesamiento, con uso del hueso como materia prima en la elaboración de instrumentos. Para ese entonces, el sitio habría sido usado como área de actividades múltiples incluyendo procesamiento, descarte, extracción de médula y consumo de alimentos (Marchionni 2013; Miotti y Marchionni 2013). 


\section{Análisis lítico}

El primer estudio detallado de los materiales líticos recuperado de AEP1 fue tratado con anterioridad, en la tesis doctoral de la Dra. Cattáneo (2002). Allí se discute la disponibilidad de materias primas y recursos líticos en el área del Macizo central de Santa Cruz, al igual que los diseños elegidos en la producción y manufactura de los instrumentos a lo largo de las distintas ocupaciones arriba mencionadas. También en este trabajo se realiza una primera aproximación al análisis de rastros de uso, pero a partir de un número reducido de piezas experimentales y arqueológicas y mediante una metodología diferente a la aquí aplicada. En este sentido, se vio la necesidad de ampliar la muestra e incorporar materiales correspondientes al bloque temporal asignado como Holoceno tardío, realizando un análisis funcional de base microscópica más profundo de los materiales líticos recuperados de Piedra Museo que son los presentados en esta tesis. Este análisis se llevó a cabo teniendo en consideración los fundamentos teóricosmetodológicos formulados por Mansur Franchomme (1983, 1986) y otros estudios generados en base microscópica para el área bajo estudio (Castro de Aguilar 1994; Álvarez 2003).

En cuanto al análisis macroscópico efectuado, se pudo distinguir cierta diferencia en la UE2, específicamente entre las Capas $4 / 5$ y la 6 , que constituyen el componente inferior del sitio, correspondientes al Pleistoceno final.

El número de piezas líticas de estas unidades es relativamente pequeño comparado con los restos óseos recuperados durante las excavaciones realizadas (Miotti 1992, Miotti y Cattáneo 2003; Miotti et al. 1999; Cattáneo 2000), en especial en la Capa 6. Sin embargo, los resultados obtenidos de su análisis, han permitido discutir algunos aspectos de la organización tecnológica, en especial aquéllos vinculados al aprovisionamiento de materias primas y estrategias de producción relacionados con la caza y procesamiento primario de presas (Cattáneo 2002; Miotti y Cattáneo 2003; Miotti et al. 2003). Mientras que en el componente superior, contenido en la Capa 2 y correspondiente al Holoceno medio, el sitio habría funcionado como lugar de actividades múltiples evidenciando procesamiento de presas, descarte y consumo. El análisis de distribución de los materiales líticos muestra que la mayoría se encuentran depositados en un sector del alero, principalmente en las cuadriculas $\mathrm{H}$, I y J y que si bien no se reconocieron fogones estructurados para este componente, en las cuadrículas 
F y G, se habrían identificado sectores de descarte de productos líticos térmicamente alterados (Cattáneo 2002).

\section{VII.3. Unidad estratigráfica 2}

Como fue mencionado con anterioridad esta unidad comprende las primeras ocupaciones humanas desde la transición Pleistoceno-Holoceno hasta el Holoceno medio e incluye los materiales recuperados de las Capas 6, 4/5 y 2.

A continuación se describen los artefactos recuperados de cada unidad y los resultados obtenidos del análisis funcional realizado en relación con el diseño elegido.

\section{VII.3.1. Componente inferior: materiales de Capa 6}

El conjunto de artefactos líticos de esta capa constituye un 5\% (N=11) del total de materiales líticos recuperados. Los fechados obtenidos de esta unidad incluyen dataciones de 12.890 y 10.470 años AP, por lo tanto corresponde al bloque temporal transicional Pleistoceno-Holocénico.

El análisis efectuado en esta capa consta de un número reducido de piezas que incluye artefactos formatizados como también con filos naturales (22 filos observados en total). Los artefactos con formatización fueron elaborados sobre materias primas de muy buena calidad para la talla, utilizando rocas criptocristalinas o de grano fino (ópalo, xilópalo y calcedonia de coloración blanco translúcido a marrón translúcido). Dentro del grupo de artefactos formatizados se incluyen 3 raederas de filo lateral largo, 1 artefactos con formatización sumaria y una muesca retocada. El grupo de artefactos no formatizados incluyó 4 cuchillos con filos naturales, confeccionados sobre lascas grandes de adelgazamiento de bifaces. Junto con estos artefactos fue recuperado un instrumento elaborado sobre hueso que podría haber funcionado como retocador o perforador.

\begin{tabular}{|c|c|c|}
\hline UE2 & Piezas observadas & Total \\
\hline Grupos tip. & $\begin{array}{llll}\text { RD } & \text { MUR } & \text { AFS } & \text { CU }\end{array}$ & Total capa \\
\hline Capa 6 & $3(33 \%) \quad 1(11 \%) \quad 1(11 \%) \quad 4(45 \%)$ & 9 (18 filos) \\
\hline Grupos tip. & $\begin{array}{lllll}\text { AFS } & \text { CP } & \text { PP } & \text { RD } & \text { RP }\end{array}$ & Total capa \\
\hline
\end{tabular}




\begin{tabular}{|c|c|c|}
\hline Capa $4 / 5$ & $1(7 \%) 1(7 \%) 1(7 \%) 5(33 \%) 7(46 \%)$ & 15 (25 filos) \\
\hline Grupos tip. & $\begin{array}{lllllll}\text { AFS } & \text { BF } & \text { LR } & \text { PP } & \text { RD } & \text { RP } & \text { UF }\end{array}$ & Total capa \\
\hline Capa 2 & $3(9 \%) \quad 3(9 \%) \quad 1(3 \%) \quad 2(6 \%) 10(29 \%) 14(41 \%) 1(3 \%)$ & 34 (66 filos) \\
\hline UE1 & Piezas observadas & \\
\hline Grupos tip. & MUR & Total capa \\
\hline Capa 1 & $4(18 \%) 1(4 \%) 2(9 \%) 4(17 \%) 11(48 \%) 1(4 \%)$ & $\mathbf{2 3}(46$ filos $)$ \\
\hline Total filos & & 155 \\
\hline
\end{tabular}

Tabla 9: Artefactos formatizados recuperados de AEP1. AFS: artefacto con formatización sumaria; BF: bifaz; CP: cepillo; CU: cuchillo de filo natural; LR: lámina retocada; MUR: muesca retocada; PP: punta de proyectil; RD: raedera; RP: raspador; UF: unifaz.

\section{VII.3.1.1. Resultados del análisis funcional de base microscópica}

El análisis realizado incluyó un total de 22 filos observados y 11 piezas (artefactos formatizados y sin formatización). Las piezas en su mayoría estaban fracturadas sin talón, salvo un solo caso fracturado con talón. Los tamaños identificados son en su totalidad grandes y con módulos de longitud anchura corto ancho y mediano normal. En cuanto a la selección de formas bases para su elaboración, se reconoció el uso de lascas internas angulares o de aristas.

La mayoría de las piezas presentaron al menos un filo complementario que en general incluía filos naturales con microlascados continuos y en algunos casos aislados.

En cuanto a los filos identificados como raederas, presentaron en su mayoría ángulos agudos con un promedio de $27^{\circ}$ y una longitud promedio de $36 \mathrm{~mm}$.

Debido a la escasa cantidad de materiales de este conjunto no se pudo realizar el análisis funcional teniendo en cuenta su relación con variables del diseño a nivel estadístico, ya que podría influir en los resultados obtenidos. Sin embargo se pudieron plantear algunas consideraciones al respecto:

\section{VII.3.1.2 Integridad del conjunto e identificación de alteraciones tafonómicas}

En cuanto al estado de preservación de los materiales, las piezas evidenciaron porcentajes menores de uso; el $40 \%$ de los AF pudo ser atribuido al trabajo sobre distintos materiales, mientras que en los ANF únicamente el $31 \%$ lo fue. El resto de los materiales se disponen en proporciones mayores no determinados por alteración $(60 \%$ 
en los AF y $39 \%$ en los ANF) y en algunas piezas no pudo ser determinado su uso, debido al tiempo empleado o al material sobre el cual se trabajó.

Sin embargo, en la mayoría de las piezas se pudo observar un grado de alteración alto a moderado, presentando lustre de suelo y abrasión sedimentaria en su superficie, que en algunos casos, iban acompañadas por playas de abrasión o puntos en espejo. No se determinó modificaciones por procesos de termoalteración en la muestra analizada, sin embargo, Cattáneo (2002) infiere la presencia de fogones en el sector este de la cuadrícula D y oeste de la $\mathrm{B}$, debido a la presencia de acumulaciones de productos de talla termoalterados; además se recuperaron restos de carbón vegetal y un hueso que permitió obtener dos fechados radiocarbónicos (Miotti et al. 1999). Cabe aclarar que los fechados sobre carbón se dieron a conocer en Miotti et al. 2003; sin embargo, lamentablemente las muestras del límite superior de Capa 6 y base de la Capa 5 , correspondientes a una posible estructura de combustión obtenida de un pan de sustancia carbonosa, no ha sido posible fechar en Southampton (Steele com pers.). Los

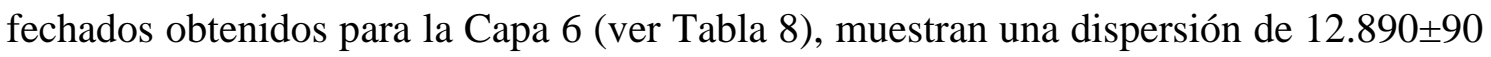
años a 10.390 \pm 70 años AP, pudiendo ser ambos outliers estadísticos (Prates et al. 2009; Steele y Politis 2009), aún así corresponden a un fogón y los fechados obtenidos son acordes al Pleistoceno final.

Así mismo, debido a las características particulares de esta unidad el estado de los materiales recuperados presenta un elevado porcentaje de no determinados por alteración, ya que la intensidad de los procesos que afectaron a los artefactos fue alta y en muchos casos imposibilitó su determinación funcional a nivel microscópico. Cabe mencionar además, que los restos óseos recuperados de esta unidad también presentaron modificaciones sobre su superficie, principalmente óxido de manganeso, que habría llegado a cubrir la superficie cortical y medular de los huesos, indicadores de condiciones de humedad y cambios de pH (Marchionni 2013). Probablemente estos factores hayan afectado a los conjuntos líticos de esta capa, en especial los cambios de $\mathrm{pH}$ del sedimento como consecuencia de la disolución de la roca de base, que apoya el horizonte IIIC del suelo enterrado y debido a fluctuaciones del nivel freático en el alero (Zárate et al. 2000).

Aún así, el porcentaje restante permitió inferir el uso de estos artefactos sobre distintos materiales. 


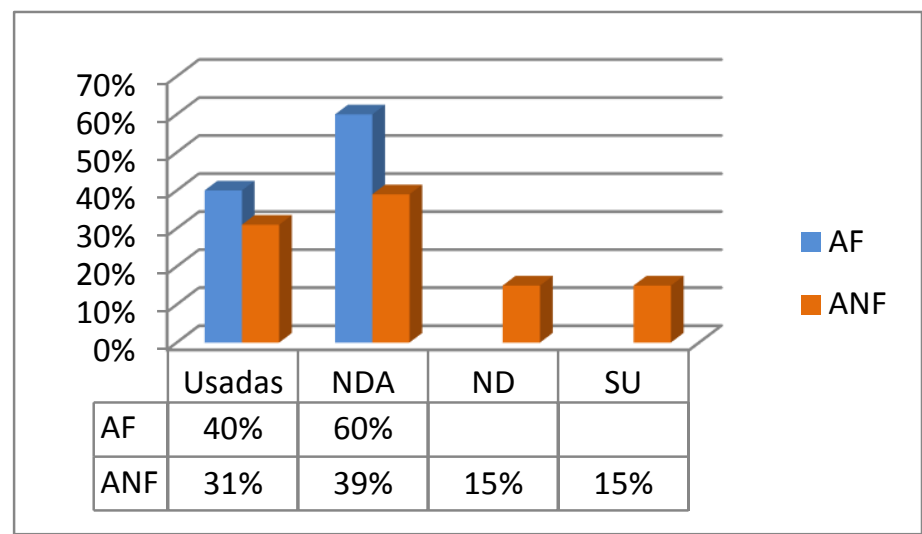

Figura 92: Integridad de los artefactos en la Capa 6 de AEP1. NDA: no determinadas por alteración postdepositacional; ND: no determinadas y $\mathbf{S U}$ : sin uso.

En cuanto a las materias primas utilizadas en su producción, corresponden en su totalidad a rocas homogéneas o de grano fino (ópalo, xilópalo, calcedonia, sílex), por lo que el estado de integridad del conjunto no varía en relación a las materias primas utilizadas. Debido a sus características litológicas de menor dureza, este tipo de roca se encuentra más expuesto a distintos agentes y procesos (contacto con partículas sedimentarias, pisoteo, cambios de composición del $\mathrm{pH}$ ) en mayor grado que aquellas no homogéneas (Levi-Sala 1986, 1993; Shea y Klenck 1993; Mansur 1999; Álvarez 2003), expresado en el alto porcentaje de piezas alteradas y en la intensidad de estos procesos. 


\section{Piedra Museo (AEP1 y AEG2)}

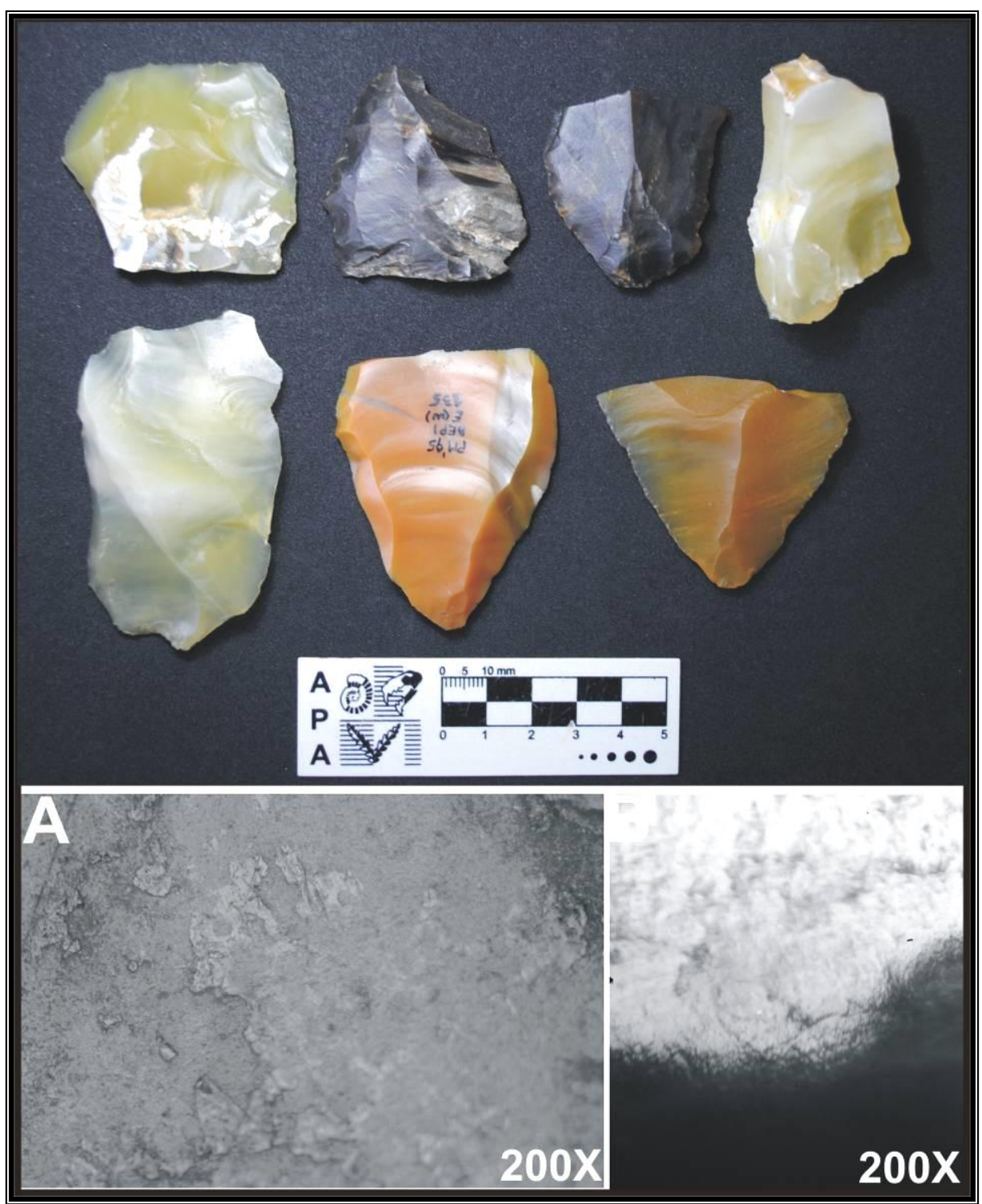

Figura 93: Artefactos recuperados de la Capa 6 de AEP1. A-B) Alteraciones identificadas sobre la superficie de los artefactos, A) playas de abrasión y B) abrasión sedimentaria.

\section{VII.3.1.3 Materiales trabajados}

Las piezas recuperadas de esta unidad registraron el uso de AF únicamente sobre materiales duros, principalmente el trabajo sobre hueso $(\mathrm{N}=4,57 \%)$, menores proporciones sobre material duro $(\mathrm{N}=2,29 \%)$ y un solo caso donde la cinemática empleada pudo ser inferida pero el material indeterminado.

En los ANF las piezas presentaron un menor porcentaje de microhuellas de uso, pero una mayor variabilidad de los materiales utilizados. Se reconoció el uso sobre material duro, hueso y material blando (probablemente piel) en iguales proporciones $(25 \%)$ (Figura 94). 
Mientras que en relación a la cinemática empleada se registró que en los AF el total de las piezas fueron empleadas a partir de acciones transversales (raspado), mientras que los ANF fueron utilizados en acciones transversales y en algunos casos no pudo ser determinado el movimiento efectuado.

El uso de dispositivos de enmangue no pudo ser inferido a partir del análisis realizado en AF como tampoco en ANF. Por lo que sugiere un uso manual de las piezas observadas.

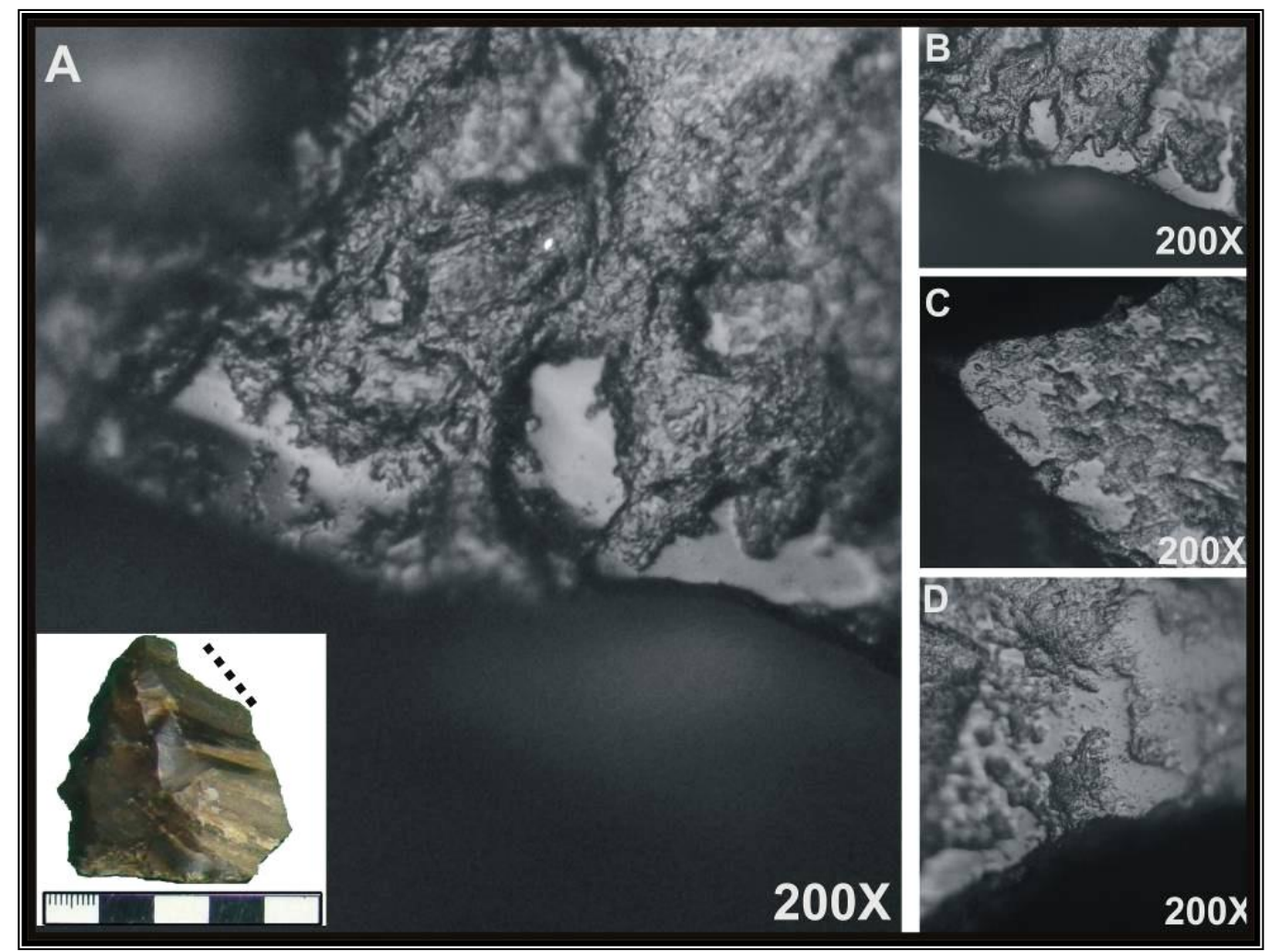

Figura 94: Materiales identificados en la Capa 6 de la UE2 de AEP1. A/B) Pieza No: AEP1K59 (raedera de filo lateral largo y muesca retocada) raspado sobre material duro animal (hueso). C/D) Pieza $\mathrm{N}^{\circ}$ : AEPIE130 (raedera de filo lateral largo) corte de material duro animal.

\section{VII.3.1.4 Actividades desarrolladas}

A partir del análisis realizado se ha podido inferir ciertas actividades mediante el registro de huellas de uso.

Las piezas recuperadas de las primeras ocupaciones de Piedra Museo, habrían sido empleadas en acciones de raspado tanto con filos formatizados como naturales.

Los AF fueron empleados únicamente sobre materiales duros, raspado y corte sobre hueso $(\mathrm{N}=4,67 \%)$, raspado y corte sobre material duro indiferenciado $(\mathrm{N}=2,16 \%)$ y un 
solo caso no determinado (17\%). Esto sería esperable ya que el proceso de formatización de los filos ofrece mayor resistencia durante el empleo sobre este tipo de material, generando gran cantidad de esquirlamiento y en algunos casos llegando a fracturar los filos de las piezas utilizadas. Los ANF, registraron filos empleados en actividades de raspado de material duro y material indiferenciado (Figura 95). El uso de estos filos sobre material duro podría ser explicado a partir de las etapas de limpiezas y procesamiento secundario de presas, donde se removería parte del material blando (cartílago y remanentes de carne) entrando en contacto con material duro. Sin embargo, debido a las alteraciones leves y moderadas de las piezas, el análisis realizado no permitió ir más allá de la identificación de material duro, por lo que sería anticipado hacer esta inferencia.

Por otro lado, es importante mencionar que los resultados obtenidos del análisis de restos óseos en esta capa, habría registrado marcas de corte de origen antrópico, en especies de camélidos actuales (Lama guanicoe), como también en mamíferos pleistocénicos (Hippidion sp. y Lama gracilis). Estas especies habrían sido utilizadas como recursos complementarios a la caza del guanaco y probablemente el material lítico habría sido empleado en estas actividades de procesamiento y cuereo de las presas (Miotti 1998; Miotti et al. 1999; Miotti y Salemme 2005). Este modelo de expectativas arqueológicas fue también aplicado con los mismos resultados en otras áreas de Patagonia, principalmente en última esperanza (Borrero 1995).

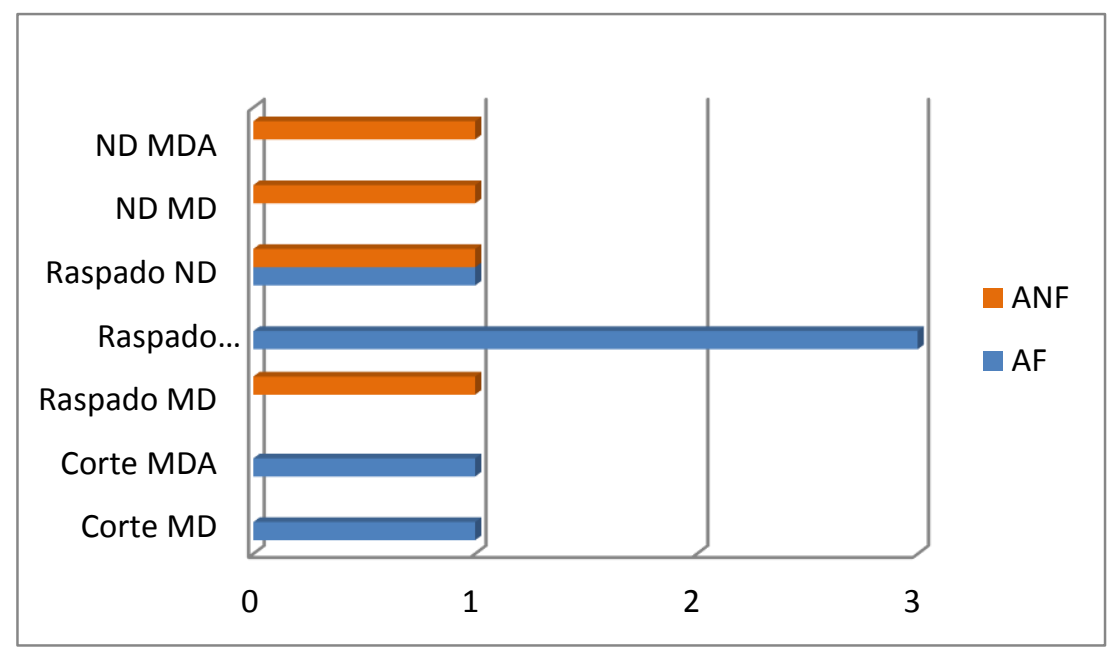

Figura 95: Actividades desarrolladas e identificadas en los materiales recuperados de la Capa 6 de AEP1. MD: material duro; MDA: material duro animal; ND: no determinado. 


\section{3.2. Materiales de Capa 4/5}

El conjunto de artefactos de esta capa constituye el 14\% (N=28) del total de materiales líticos recuperados en el sitio y corresponde a las ocupaciones identificadas para el bloque temporal de la transición Pleistoceno/Holoceno temprano, con fechados de 10.400 a 9200 años AP (ver Tabla 8).

La mayor cantidad de materiales fueron recuperados en la cuadrícula $\mathrm{C}$, de donde se registró un $43 \%$ del total de conjunto.

El análisis microscópico fue realizado a partir del estudio de 28 piezas de esta unidad, 15 artefactos con formatización con 25 filos observados y 13 artefactos con filos naturales. El conjunto de AF está representado por 7 grupos tipológicos, de los cuales el grupo de los raspadores con filos complementarios de raederas se encuentra mayormente representado en el conjunto (46\%) (Ver Tabla 9). En menor medida le siguen el grupo de raederas (33\%) y proporciones menores de artefactos con formatización sumaria, cepillos, muescas retocadas y puntas de proyectil, sumado a una pieza discoidal recuperado de esta capa (Tabla 9).

En cuanto a los tamaños identificados la mayoría de las piezas presentaron tamaños muy grandes $(\mathrm{N}=7,40 \%)$ y grandes $(\mathrm{N}=3,33 \%)$; con módulos de longitud anchura mediano normal $(\mathrm{N}=6,46 \%)$ y corto ancho $(\mathrm{N}=4,31 \%)$ como los más representados.

Las materias primas utilizadas en su manufactura, en su mayoría corresponden, al igual que la capa anterior, a rocas criptocritalinas o de grano fino de buena calidad para la talla. La más representada en el conjunto, a diferencia de la anterior, es el sílex con un $73 \%(\mathrm{~N}=11)$ de representación en la muestra. En menor medida se reconoce el uso de otras materias primas locales como la calcedonia, toba silicificada y uso de granito en la producción de discos pulidos (Figura 96). Estas materias primas son de procedencia local e inmediatamente disponibles, ya que varias fuentes identificadas se encuentran en los alrededores del sitio (sitio cantera-taller 17 de Enero, Cattáneo 2000, 2002, 2004). 


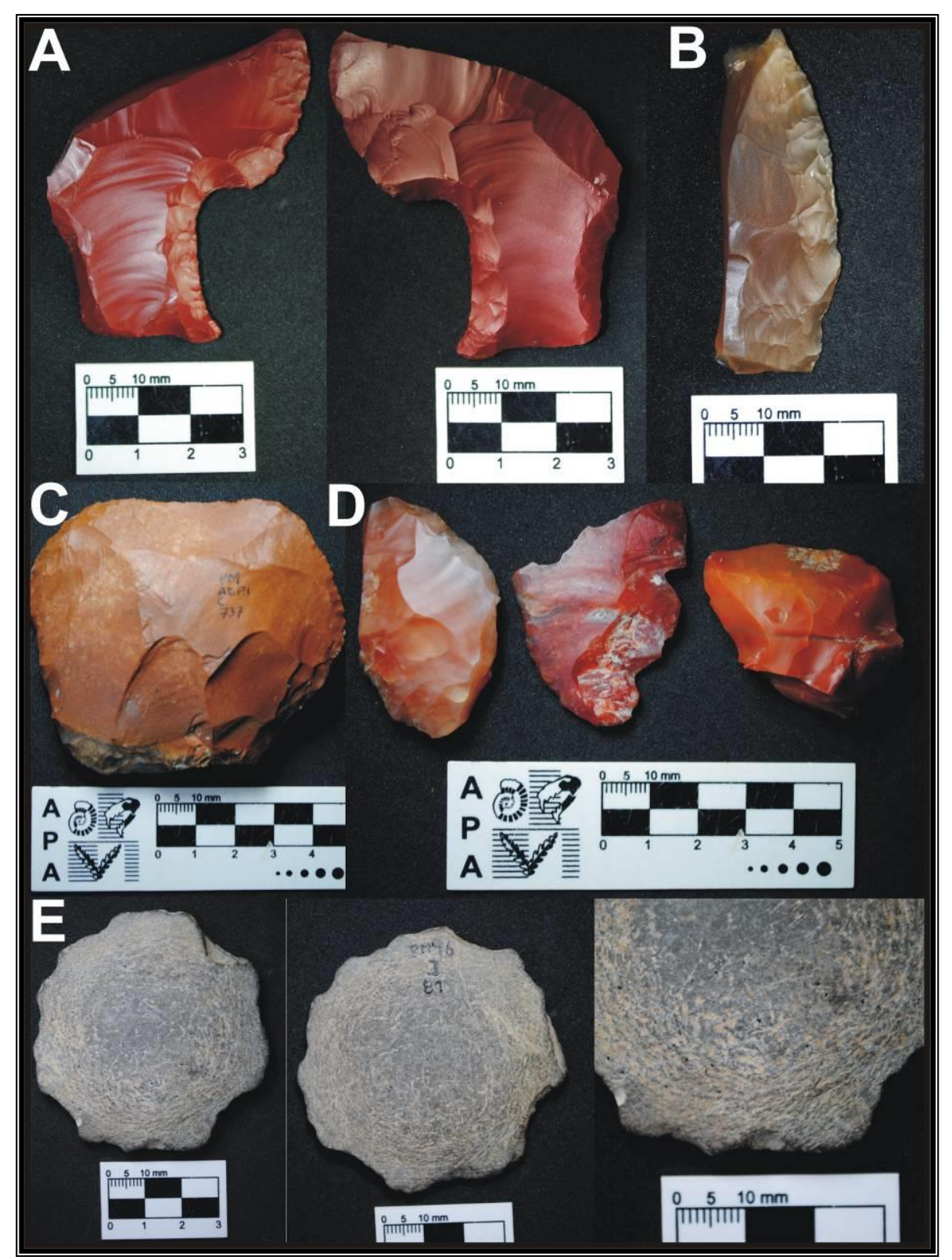

Figura 96: Artefactos recuperados de la Capa 4/5 de AEP1. A) Fragmento de puntas de proyectil "cola de pescado", elaborado sobre sílex rojo. B) Fragmento de raedera elaborado sobre xilópalo. C) Artefacto formatizado con filo de raspador y complementario de raedera elaborado sobre materia prima silícea. D)

Artefactos con daño térmico (cambio de coloración, craquelados y hoyuelos). E) Pieza discoidal elaborada sobre granito.

\section{VII.3.1.1 Integridad del conjunto e identificación de alteraciones tafonómicas}

La mayoría de las piezas observadas al microscopio registraron lustre de suelo y en algunos casos abrasión sedimentaria. Sin embargo, el grado e intensidad en la que actuaron, difiere en los materiales recuperados. En este sentido se pudo registrar un grado de alteración moderado a leve, ya que la cantidad de piezas no determinadas por alteración no es tan elevada en comparación con la Capa 6. 
En los AF se reconoció un mayor porcentaje de piezas con uso identificable incluyendo un 56\% ( $\mathrm{N}=14)$ del total de la muestra. En menor medida están las piezas no determinadas $(\mathrm{N}=7,28 \%)$ y no determinadas por alteración $(\mathrm{N}=4,16 \%)$. En cuanto a los ANF se registró una sola pieza con rastros de uso identificable y el resto se presentó como no determinables por alteración (Figura 97).

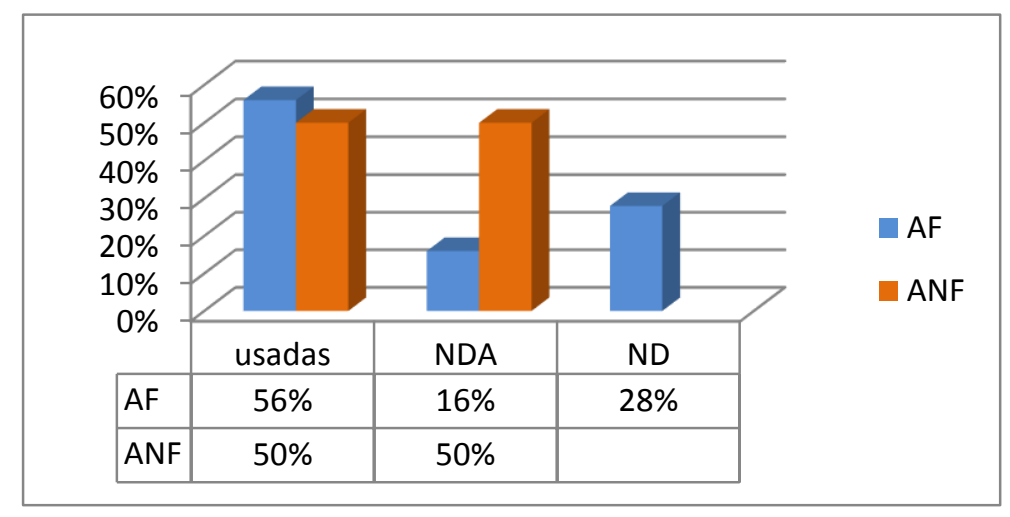

Figura 97: Integridad artefactual de los materiales recuperados en la Capa 4/5 de AEP1.

El tipo y grado de alteración en estos casos fue intensa y los procesos que afectaron a las piezas estuvieron evidenciados a partir de la formación de lustres de suelo, que en ciertos originaron playas de abrasión (Ver Capítulo V). También se registraron depósitos de carbonato que llegaron a cubrir una extensa superficie de la pieza.

Otra alteración identificada corresponde a la exposición de las piezas al fuego, estos procesos de termoalteración ocasionaron un intenso lustre sobre las superficies dificultando la inferencia funcional de las mismas a nivel microscópico. En algunos casos, estas alteraciones fueron identificadas como daño térmico, debido al registro de hoyuelos, descamaciones o craquelado, mientras que en otros, se reconoció únicamente un intenso lustre que podría haber estado asociado a mejoras en la calidad de la talla (Frank 2012).

En los AF las piezas no determinadas por alteración sufrieron únicamente termoalteración que debido a su intensidad ocasionó un lustre intenso sobre las superficies e imposibilitó su determinación funcional (Figura 97).

\section{VII.3.1.2 Inferencia funcional de las modalidades de uso}

El análisis realizado sobre los artefactos permitió determinar ciertas diferencias entre los AF y ANF. En primer lugar los artefactos con filos naturales presentaron un único filo potencialmente utilizable y en su mayoría no registraron rastros de utilización. Mientras 
que en los artefactos con formatización las piezas registraron al menos dos filos potencialmente funcionales de los cuales al menos uno presentó rastros de uso.

Por otro lado y en relación a las materias primas utilizadas en la producción de estos artefactos no se reconoció diferencias respecto a los rastros de uso identificados, ya que en su totalidad las piezas estuvieron elaboradas en rocas de grano fino de muy buena calidad para la talla, debido a esto, a nivel funcional los rastros de uso identificados no registraron diferencias en cuanto a las materias primas utilizadas.

\section{VII.3.1.3 Materiales trabajados}

Los artefactos recuperados de la Capa 4/5 registraron cierta variabilidad en los materiales trabajados. Es así que se pudo determinar el empleo de los artefactos con formatización en materiales duros como blandos.

El trabajo principalmente sobre material duro fue inferido en un $43 \% \quad(\mathrm{~N}=6)$ de las piezas e iguales proporciones del trabajo sobre hueso y madera ( $\mathrm{N}=2,7 \%$ respectivamente). En cuanto a los materiales blandos se reconoció el uso sobre cuero y en algunos casos piel $(\mathrm{N}=5)$. Sin embargo, no pudo determinarse la presencia de aditivos en su tratamiento.

En los ANF la mayoría de las piezas no registraron microhuellas de uso, debido al grado de alteración que presentaron los materiales. Sin embargo, un solo caso presentó rastros de uso consecuencia del contacto con material duro a partir de acciones transversales o de raspado (Figura 98).

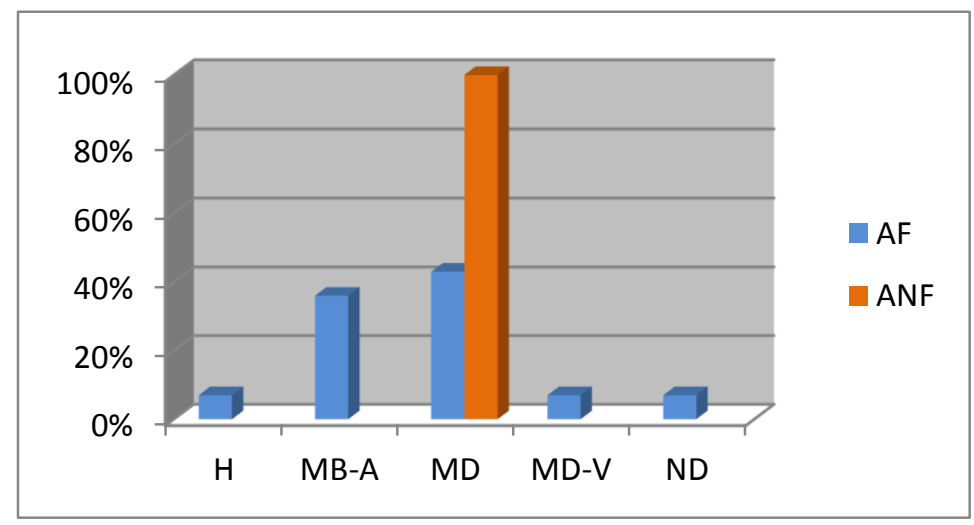

Figura 98: Materiales identificados a partir del análisis efectuado en los material recuperados de la Capa 4/5. H: hueso; MB-A: material blando animal; MD: material duro; MD-V: material duro vegetal y ND: no determinable.

En cuanto a la cinemática empleada, si bien en la mayoría de las piezas no hubo superposición de rastros (trabajo de dos materiales a la vez con el mismo filo), si se 
pudo reconocer el empleo sobre igual material a partir de distintas cinemáticas (acciones longitudinales y transversales en un mismo filo). El trabajo transversal y longitudinal sobre material duro fue inferido en una raedera de filo lateral largo en esta unidad.

Sin embargo, el resto de las piezas recuperadas fueron empleadas en acciones transversales (Figura 99).

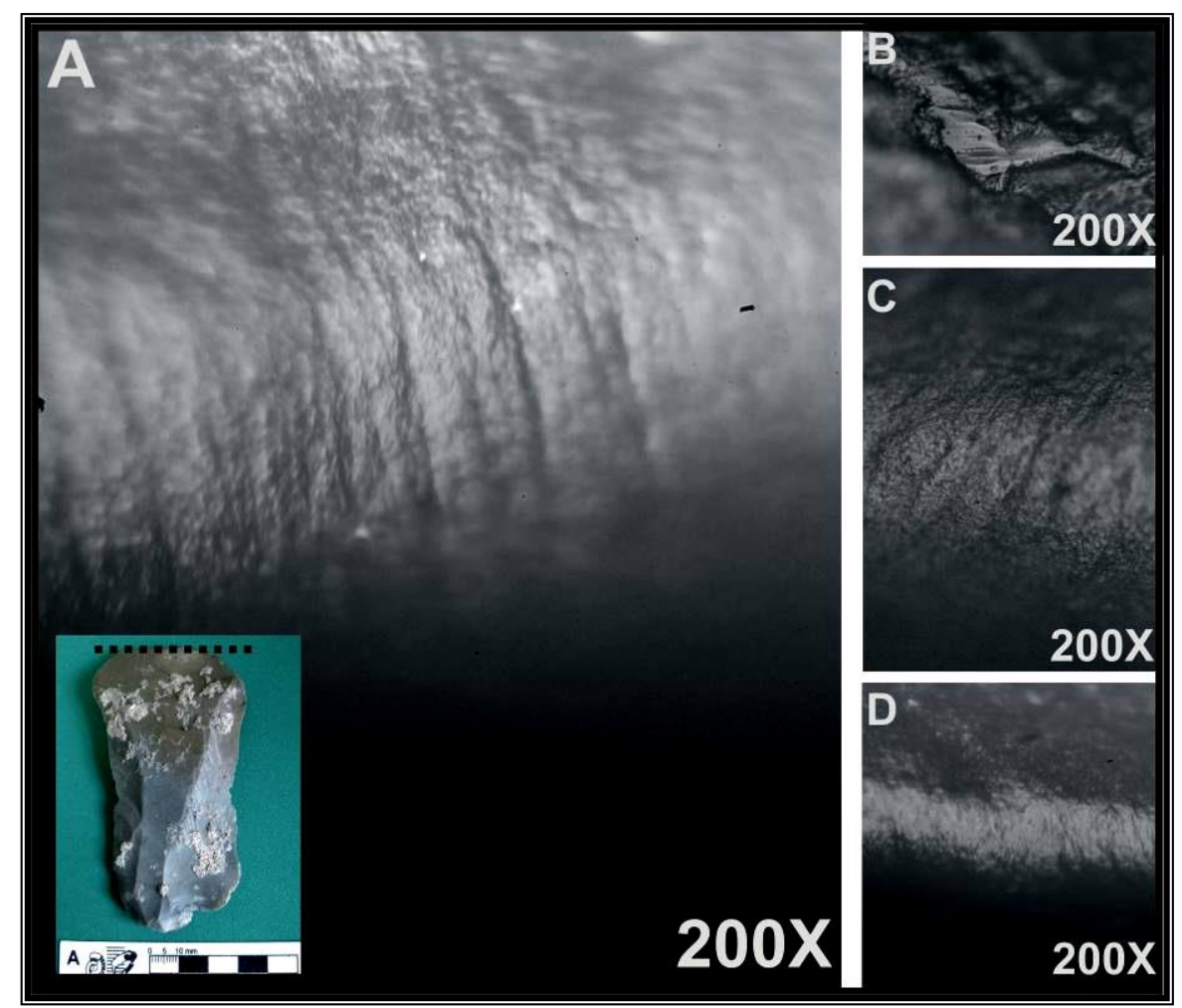

Figura 99: Materiales identificados en la Capa 4/5 de la UE2 de AEP1. A-C) Pieza No ${ }^{\circ}$ AEP1L642 (lámina retocada filo frontal corto) raspado sobre material blando (cuero). B) Pieza $\mathrm{N}^{\circ}$ : $\boldsymbol{A E P 1 F 3 5 2 ,}$ micropulido sobre cristal, corte sobre material duro. D) Pieza $N^{\circ}$ : AEP1 D690, raspado sobre material duro animal (hueso).

\section{VII.3.1.5 Actividades desarrolladas}

El análisis funcional microscópico efectuado sobre las piezas de la Capa 4/5 permitió inferir así el desarrollo de distintas actividades. Se reconoció el raspado sobre material duro (madera o hueso) en elevados porcentajes y en menor medida el raspado sobre hueso y madera en iguales proporciones.

El análisis zooarqueológico realizado en esta unidad, evidenció que el recurso faunístico más utilizado correspondía, al igual que en la capa anterior, al guanaco (Lama guanicoe), sin embargo a diferencia de la anterior, las especies de mamíferos pleistocénicos habrían disminuido para ese entonces. Si bien, las frecuencias de 
modificaciones culturales (marcas de corte) obtenidas de análisis de restos óseos de Lama guanicoe son bajos, debido al deterioro de las superficies por procesos postdepositacionales químicos (Miotti et al. 1999; Marchionni 2013), el trabajo sobre material óseo ha sido reconocido a través del análisis funcional de los artefactos líticos y probablemente sea consecuencia de actividades de procesamiento primario con cuereado y desmembramiento de las grandes unidades de trozamiento. Estos materiales podrían haber intervenido en los proceso de limpieza del hueso (extracción de cartílagos y periostio), y en la obtención de médula ósea como consumo ocasional, ya que también se identificaron puntos de impacto en algunos huesos largos de guanaco (Marchionni 2013).

Por otro lado, para este bloque temporal se pudo identificar el desarrollo de otras actividades complementarias sobre material blando animal, como el raspado de cuero y piel. Los rastros observados no permitieron inferir el uso de otros elementos para el tratamiento de este material; sin embargo esta actividad habría estado relacionada a las etapas iniciales de cuereo de presas y limpieza de huesos largos. Esta idea fue planteada en los primeros estudios zooarqueológico del sitio, infiriendo que la alta proporción de huesos largos completos, la evidencia de porciones articuladas de la columna vertebral y de las patas, indicarían que en el sitio se podrían haber realizado el cuereado de animales cazados a orillas del paleolago, seleccionando las partes anatómicas que fueron sacadas del sitio con el propósito de ser trasladadas al campamento residencial y que para tal fin se podrían haber usado los cueros, a modo de "bolsa" para el transporte de las unidades faenadas de las presas cazadas (Borrero et al. 1998; Miotti 1996; Miotti et al. 1999b).

El bajo número de artefactos recuperados de esta unidad con diseños y usos específicos avala, desde esta nueva línea de investigación, la hipótesis de funcionalidad propuesta para el sitio hacia la transición Pleistoceno/Holoceno (sensu Broecker y Denton 1990; Eriksen y Straus 1998 y que a su vez para el área patagónica se utilizan con los mismos criterios en los trabajos de Borrero et al. 1998; Miotti 1996; 1998; 2012; Miotti y Salemme 1999; Miotti et al. 1999; Salemme y Miotti 2008; entre otros), como sitio de actividades limitadas, donde se habrían realizado procesamiento de presas junto con el tratamiento inicial de cueros, posiblemente empleados en vestimenta y otros elementos como bolsas o tensores, que debido a su naturaleza no han podido ser conservados en el registro arqueológico. 
En cuanto al estado de integridad del conjunto lítico, si bien se reconocieron piezas no determinadas por alteración de sus superficies y filos debido a distintos agentes y procesos, el grado de estas alteraciones fue moderado a leve, expresado a partir de un menor porcentaje de piezas con alteraciones. La presencia de lustres de suelo y playas de abrasión sobre las superficies de los artefactos, probablemente haya estado relacionada a cambios del $\mathrm{pH}$ del sedimento y la disolución de la roca de caja de base carbonática.

\section{3.3 Componente superior: materiales de Capa 2}

El conjunto de artefactos líticos recuperados de esta unidad corresponden al bloque temporal del Holoceno medio, con fechados radiocarbónicos de ca. 7700 y 7400 años AP. Los materiales están ubicados en el horizonte IIA del suelo local, irrumpido por una discordancia erosiva que marca el cambio abrupto de las condiciones ambientales en la cuenca. Esa discordancia indica que a partir de allí las condiciones se volvieron más áridas y su presencia como límite neto entre el eólico de la UE1 y el paleosuelo de la UE2, termina con las condiciones de estabilidad ambiental y a partir de allí, los procesos de erosión fueron más marcados y decapitaron el horizonte A del paleosuelo. Estas condiciones de aridez se habrían conservado en el área hasta momentos actuales (Zárate et al. 2000). Las ocupaciones humanas hacia el interior del sitio habrían ocurrido mientras los procesos pedogenéticos eran más activos, denotando una estabilidad ambiental con mayor humedad efectiva que habría propiciado una cobertura vegetal más continua y disminución en la tasa de erosión/depositación. Esto podría ocasionar una mayor exposición subáerea de los materiales arqueológicos en un perfil de suelo de contexto alcalino (Zárate et al. 2000).

Los materiales recuperados de esta capa corresponden al 48\% (N=99) del total del conjunto analizado e incluyen un mayor número de piezas que el componente inferior.

Los artefactos con formatización corresponden a 34 piezas con 66 filos observados, recuperados, en su mayoría, de la cuadrícula I, con un $31 \%$ del total de esta unidad principalmente hacia el sector Oeste. Los artefactos con filos naturales estuvieron representados por 65 piezas con 133 filos identificables y una mayor concentración de estos en el mismo sector y cuadrícula que para el caso de los AF.

En cuanto a estos últimos, se registraron 7 grupos tipológicos de los cuales los raspadores estaban mayormente representados en esta unidad ( $\mathrm{N}=14,41 \%)$, (ver Tabla 
9). En general las piezas se encontraban fracturadas sin talón $(\mathrm{N}=18,53 \%)$ y en menor medida enteras $(\mathrm{N}=12,35 \%)$ y fracturadas con talón $(\mathrm{N}=4,12 \%)$.

Las materias primas utilizadas en su producción incluyó porcentajes mayores de ignimbritas y riolitas silicificadas $(\mathrm{N}=23,67 \%)$ y en menor medida otras variedades de rocas criptocristalinas de muy buena calidad para la talla (calcedonia, toba silicificada, xilópalo y obsidiana) (Figura 99). La selección de formas bases para la producción de este tipo de artefactos incluyó un mayor uso de lascas sobre láminas, principalmente secundarias ( $\mathrm{N}=10,29 \%)$; sin embargo, la selección de guijarros en la producción de artefactos formatizados también registró elevados porcentajes $(\mathrm{N}=4,11 \%)$. En menores proporciones se registraron lascas angulares y de aristas como formas bases.

En cuanto al tamaño de la muestra se observó cierta variedad en los artefactos formatizados, el mayor porcentaje corresponde a piezas de tamaño grande $(\mathrm{N}=14) \mathrm{y}$ mediano grande $(\mathrm{N}=8)$; con módulos medianos normales $(\mathrm{N}=13)$ y medianos alargados $(\mathrm{N}=9)$ como los más representados en el conjunto observado. Los artefactos con filos naturales estuvieron en su mayoría fracturados sin talón $(\mathrm{N}=36,56 \%)$ y en menor medida enteros $(\mathrm{N}=21,32 \%)$ y fracturados con talón $(\mathrm{N}=8,12 \%)$, al igual que los $\mathrm{AF}$ (Figura 100).

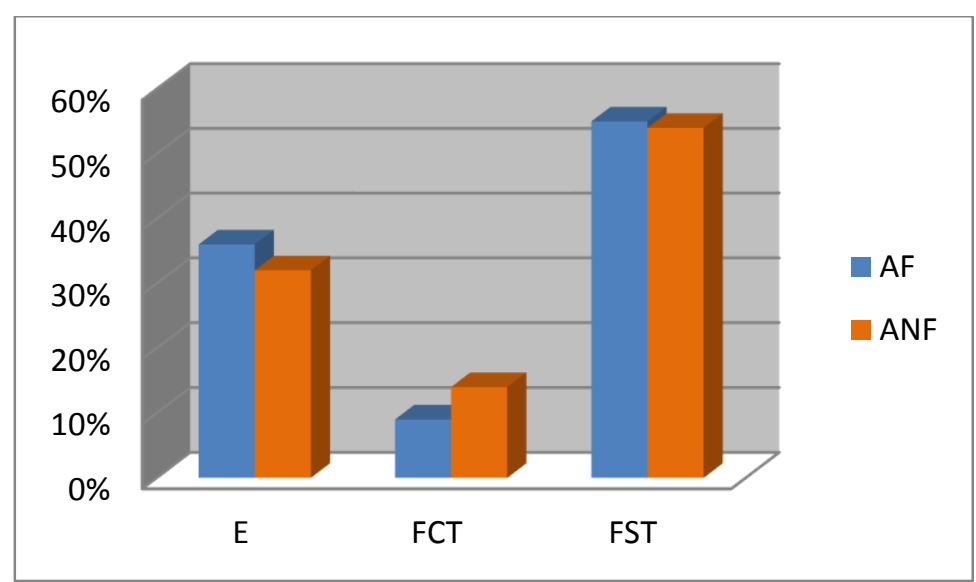

Figura 100: Estado de los materiales recuperados de la Capa 2 de AEP1. E: entero; FCT: fracturado con talón; FST: fracturado sin talón.

En relación al tamaño de la muestra la mayor cantidad de piezas presentaron tamaños mediano normal (63\%), seguido por grandes (33\%) y en muy pocos casos muy grandes (4\%). Las lascas son las formas bases más representadas en la Capa 2 con un mayor incremento en la producción de lascas secundarias $(\mathrm{N}=9,22 \%)$, angulares $(\mathrm{N}=5,16 \%)$ y de $\operatorname{aristas}(\mathrm{N}=4,10 \%)$. Si bien las láminas están también presentes en esta capa, se 
registran en menores proporciones, siendo las de arista simple las más representadas $(\mathrm{N}=5,8 \%$ del total).

En cuanto a las selección de materias primas utilizadas en la producción de artefactos con filos naturales, se observó al igual que en el caso de los AF, un alto porcentaje del uso de rocas silicificadas como ignimbritas y riolitas $(\mathrm{N}=28,51 \%)$ y en menor medida xilópalo $(\mathrm{N}=10,20 \%)$, toba silicificada $(\mathrm{N}=8,15 \%)$ y calcedonia $(\mathrm{N}=4,13 \%)$. A diferencia de los AF, se reconoció igualmente el uso de basalto (1\%), roca de grano grueso y de calidad regular para la talla (Figura 101).

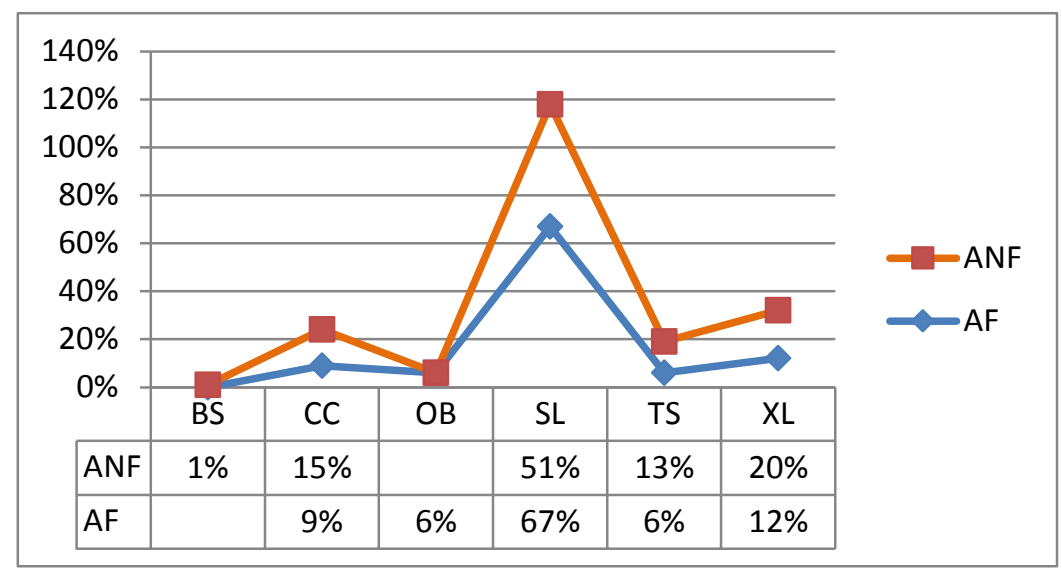

Figura 101: Representación de materias primas utilizadas en los conjuntos observados de la Capa 2 de AEP1. BS: basalto; CC: calcedonia; OB: obsidiana; SL: sílex; TS: toba silicificada y XL: xilópalo. 


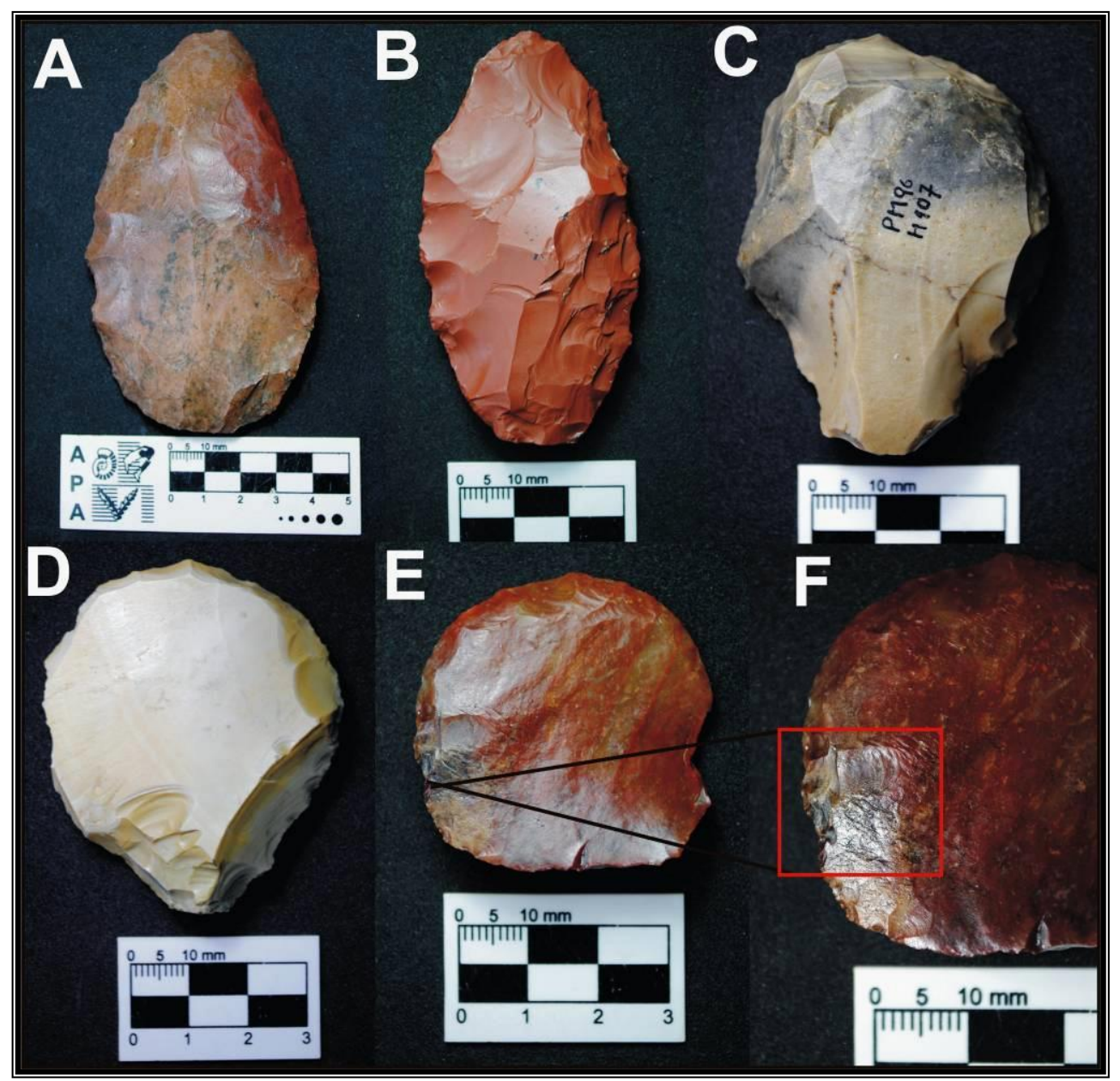

Figura 102: Materiales recuperados de la Capa 2 de AEP1. A) Bifaz recuperado de la capa 2, con características de haber sido retomado de niveles inferiores (pátina y lustre diferencial sobre su superficie). B) Bifaz elaborado sobre sílex de muy buena calidad. C-D) Raspadores de filo extendido y retoque alterno. E) Raspador de filo extendido y con signos de termoalteración (lustre y hoyuelos), probablemente para mejoras en la técnica de talla y restos de residuos de coloración negra en la porción medial.

\section{VII.3.1.1 Integridad del conjunto e identificación de alteraciones tafonómicas}

El conjunto de AF recuperado de la Capa 2 presentó un mayor grado de integridad que el resto de las capas analizadas. Esto se ve expresado en un menor porcentaje de piezas no determinables por alteración. En este sentido, las piezas con uso identificable constituyeron el $38 \%(\mathrm{~N}=28)$ de la muestra y en menor medida se disponen las piezas no determinables por alteración $(\mathrm{N}=24,33 \%)$ y no determinables $(\mathrm{N}=21,29 \%)$. Las piezas no determinables se deben a la falta del desarrollo de micropulidos diagnósticos que permiten identificar el material trabajado.

En los ANF esta proporción no se mantiene, debido a que un porcentaje menor de las piezas $(\mathrm{N}=34,26 \%)$ presentó rastros de uso adscriptos a un material específico. El resto de los elementos se disponen también de manera diferencial, las piezas no 
determinables se identificaron en un $35 \%(\mathrm{~N}=47)$, las no determinables por alteración constituyeron un $24 \%(\mathrm{~N}=32)$ y piezas con aristas frescas que fueron identificadas sin uso el $15 \%(\mathrm{~N}=20)$ restante (Figura 103).

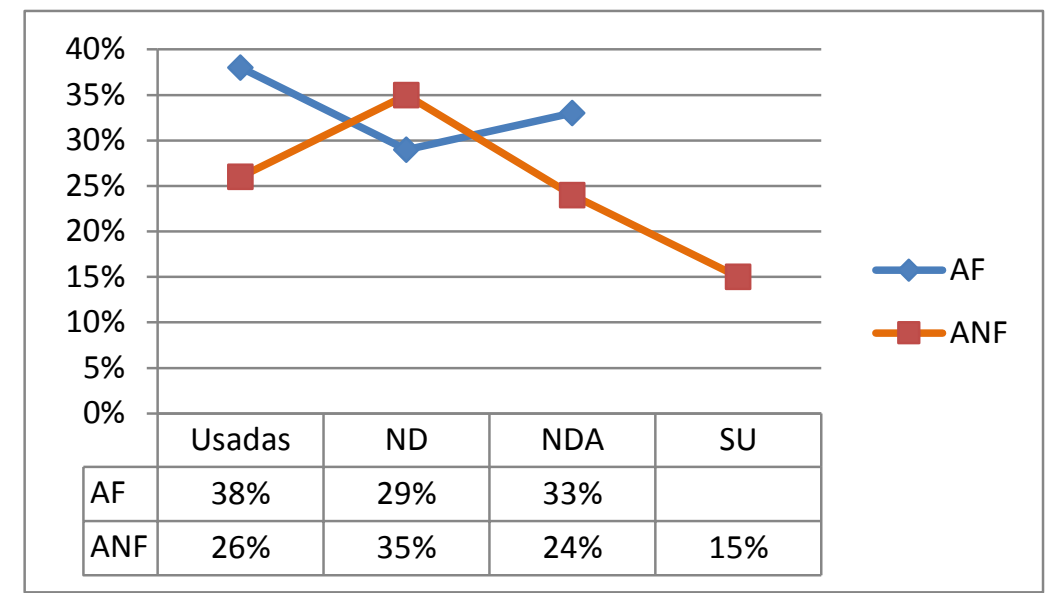

Figura 103: Resultado del análisis funcional realizado sobre los artefactos recuperados del componente superior de AEP1 (Capa 2).

En cuanto a las alteraciones registradas, se reconoció un grado de alteración moderado a leve con desarrollo de lustre de suelo como el tipo de alteración más recurrente en el conjunto. Este lustre iba acompañado en algunos casos por la formación de playas de abrasión y puntos en espejo. En los AF se identificó además otras alteraciones como la depositación de carbonatos, sobre la superficie de las piezas. Esta depositación fue igualmente registrada en el análisis de restos faunísticos realizados en esta unidad (Marchionni 2013). Esto podría deberse a las sales dispuestas en el sedimento o a la roca de afloramiento (coquina), cuya disolución se habría visto favorecida por los procesos pedogenéticos como el identificado en el sitio (Zárate et al. 2000). Sin embargo, el trabajo realizado por Miotti y Marchionni (2011), adjudica estas alteraciones también a encharcamientos y deshidratación de los materiales óseos. Esto podría haber originado leves películas de carbonatos disueltos en los huesos, pero no como verdaderas incrustaciones, como se observa en los materiales de la Capa 4/5, donde la incidencia de estos procesos es mayor sobre las superficies de los materiales recuperados, tanto en restos óseos como en líticos.

Por otro lado, también se reconoció la exposición de piezas a proceso de termoalteración que produjo cambios de coloración, escamas y hoyuelos sobre sus superficies. En los ANF además de elevados porcentajes de lustre de suelo $(\mathrm{N}=21$, $66 \%$ ), se reconoció, al igual que en los formatizados, otras alteraciones como 
termoalteración $(\mathrm{N}=5,16 \%)$, formación de pátinas de coloración blanca y abrasión sedimentaria $(\mathrm{N}=1,3 \%$ respectivamente) (Figura 104 y 105).

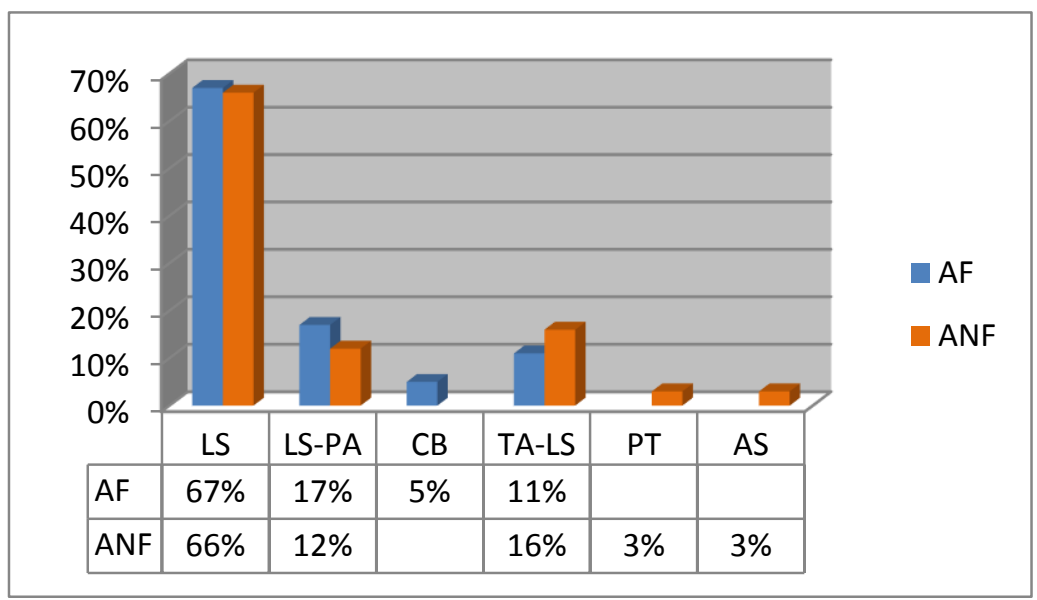

Figura 104: Alteraciones registradas en el componente superior de AEP1, Capa 2. LS: lustre de suelo; LS-PA: lustre de suelo con playas de abrasión; CB: carbonatos; TA-LS: termoalteración con lustre intenso y PT: formación de pátina blanca y AS: abrasión sedimentaria.

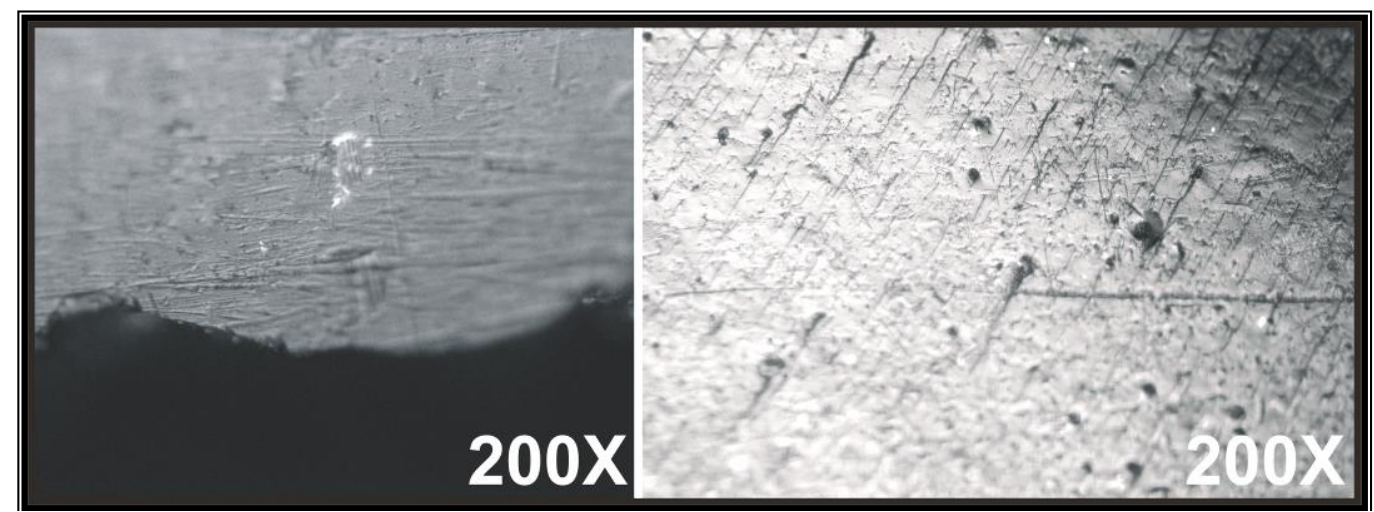

Figura 105: Alteraciones identificadas en las piezas recuperadas de Capa 2 de AEP1 (principalmente abrasión sedimentaria y lustre de suelo).

\section{VII.3.1.2 Inferencia funcional de las modalidades de uso}

Los resultados obtenidos del análisis funcional realizado sobre los AF y los ANF de Capa 2, registraron ciertas diferencias.

La cantidad de filos identificados en los AF es mayor que en los ANF, donde la mayoría de las piezas presentan un único filo complementario y en menores proporciones. En los artefactos con formatización se observan piezas con hasta 3 filos identificables, de los cuales se registró iguales proporciones de dos y un filo con rastros de utilización $(\mathrm{N}=2$, $4 \%$ ). También se identificaron piezas con dos filos observados y al menos un filo con rastros de uso $(\mathrm{N}=5,11 \%)$ y en menor medida se reconoció piezas con dos filos con uso 
seguro $(\mathrm{N}=4,9 \%)$. El porcentaje restante corresponde a piezas con un solo filo potencialmente utilizables de los cuales un 17\% ( $=8)$ presentó signos de utilización sobre distintos materiales.

En general los filos complementarios coincidían con la identificación tipológica del filo principal descripto.

Salvo en algunos casos, donde el filo principal identificado como raspador presentó un filo complementario de raedera, en estos el material trabajado fue diverso al filo principal. Sin embargo, en la totalidad de los casos no hubo superposición de rastros (no se trabajó con un mismo filo diversos materiales), al igual que ocurrió con la cinemática empleada, no se registró el uso de un mismo filo en acciones transversales y longitudinales a la vez (Figura 106).

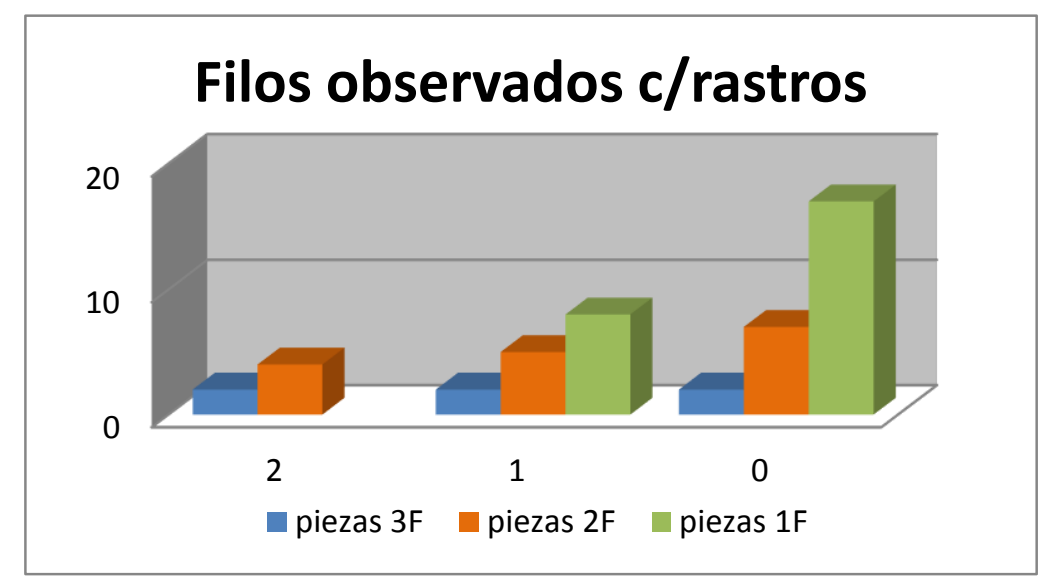

Figura 106: Relación entre los filos observados y los rastros de uso identificados en los AF del componente superior de AEP1 (Capa 2).

\section{VII.3.1.3 Materiales trabajados}

En cuanto a los materiales reconocidos a partir del análisis efectuado, se observó ciertas diferencias entre los AF y los ANF. Se identificó una mayor variedad en los materiales trabajados con filos naturales o sin formatización, donde el porcentaje de filos observados con rastros de uso fue menor. Sin embargo, el uso sobre material duro (madera o hueso), tanto en AF como en ANF, presentaron elevados porcentajes. En los AF también se reconoció el trabajo sobre hueso específicamente $(\mathrm{N}=8,29 \%)$ y en menor medida el trabajo sobre material blando $(\mathrm{N}=2,7 \%)$.

En los ANF se reconoció principalmente el empleo sobre material duro, pero a diferencia de los AF, se registró el uso sobre material duro de origen vegetal (madera, 
$\mathrm{N}=5,15 \%)$ y hueso $(\mathrm{N}=3,9 \%)$. El porcentaje restante incluyó piezas cuya cinemática fue reconocida pero el material trabajado indeterminado, un $11 \%(\mathrm{~N}=3)$ en $\operatorname{los} \mathrm{AF} y$ $17 \%(\mathrm{~N}=6)$ en ANF (Figura 107).

En cuanto al trabajo sobre material blando identificado, se reconoció un origen animal por lo que estaría asociado al trabajo sobre piel, cuero o tendones. Sin embargo, el análisis efectuado no permitió realizar una mayor especificación más allá de la dureza del material utilizado (Figura 107).

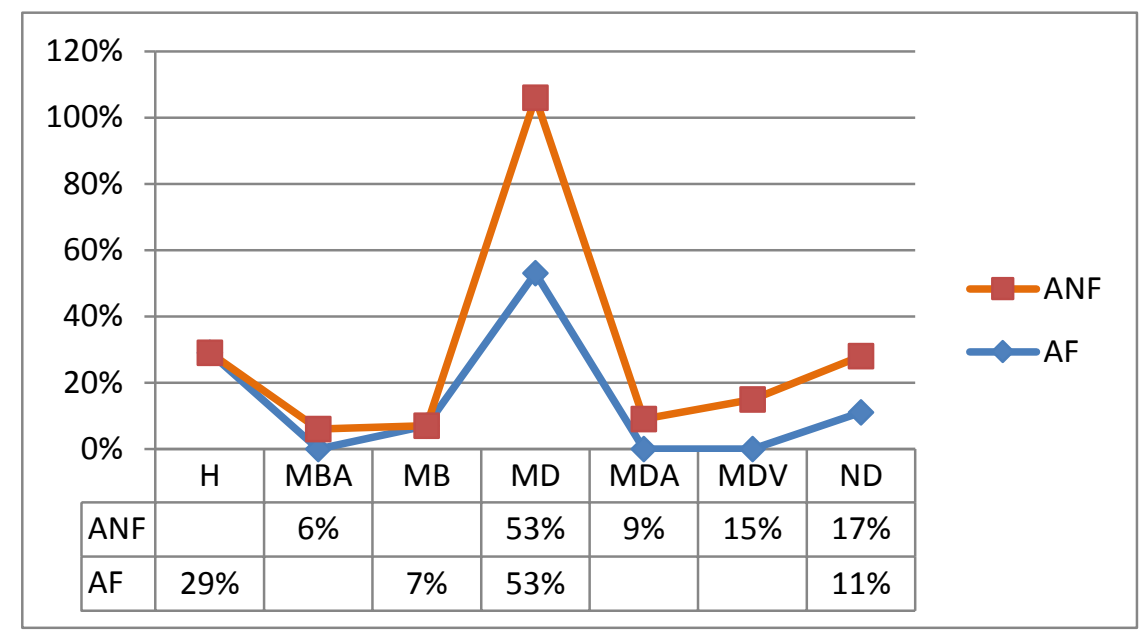

Figura 107: Materiales identificados en los artefactos recuperados del componente superior de AEP1 (Capa 2). H: hueso; MBA: material blando animal; MB: material blando; MD: material duro; MDA: material duro animal; MDV: material duro vegetal; MDV: material duro vegetal y ND: no determinado.

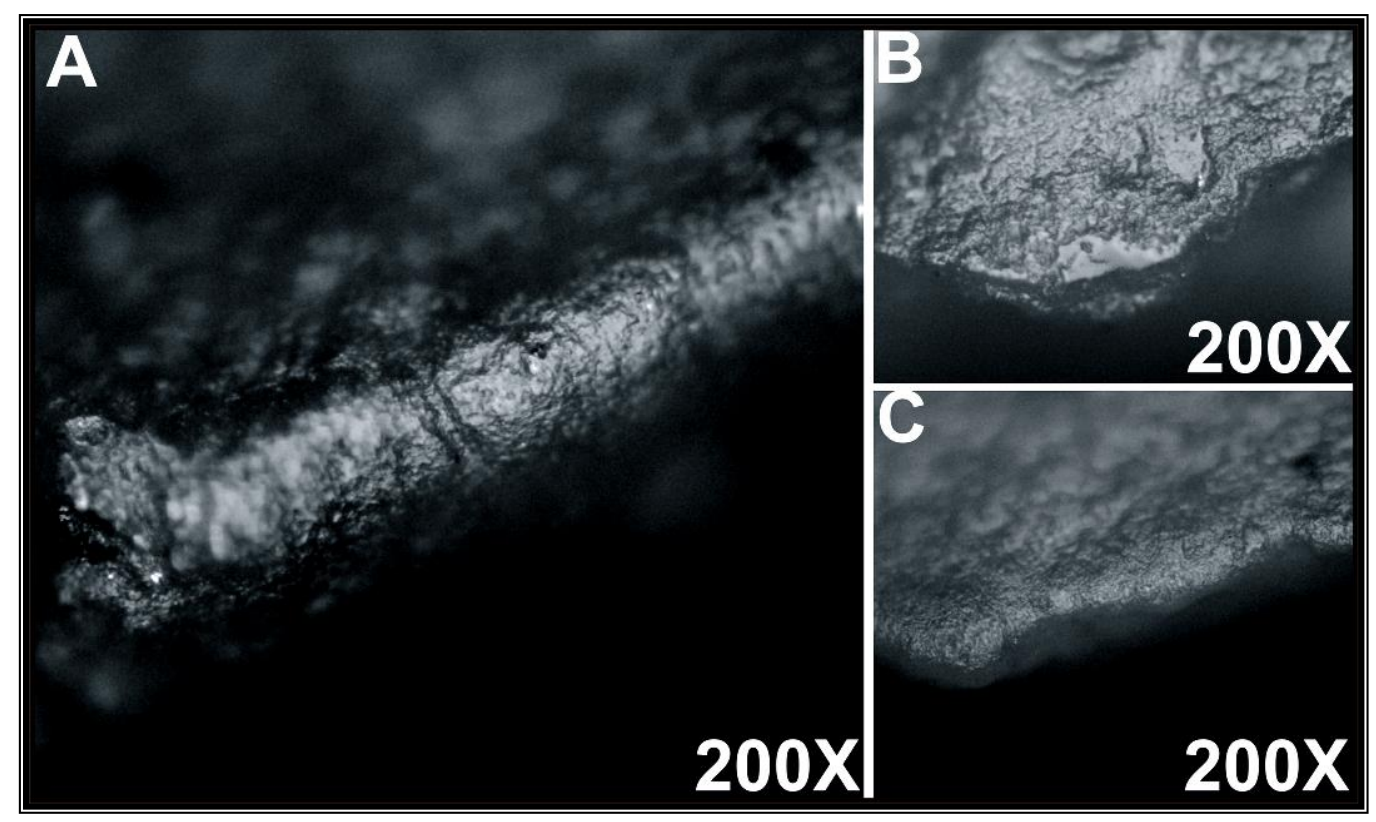

Figura 108: Materiales identificados en la Capa 2 de la UE2 de AEP1. A) Pieza No: $\boldsymbol{A E P 1 / 1 J .}$ Micropulido de material duro animal, acción transversal o de raspado. B) Pieza $\mathrm{N}^{\mathrm{o}}$ : $\boldsymbol{A E P 1 / 1 0 2 F}$.

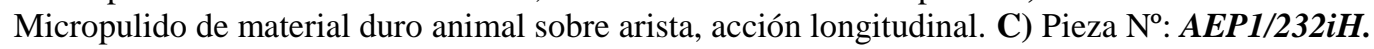
Micropulido de material blando, acción transversal. 


\section{VII.3.1.4 Cinemática empleada}

En cuanto a los movimientos efectuados a partir del trabajo realizado se pudo inferir un mayor número de piezas utilizadas en acciones transversales por sobre acciones longitudinales. Tanto en los AF como en los ANF no se reconoció el empleo de un mismo filos a partir de distintas acciones, al igual que no se reconoció superposición de rastros. De acuerdo al análisis realizado los filos habrían trabajado sobre un mismo material y de igual manera con cada filo utilizado.

Por otro lado, debido a la baja cantidad de AF empleados sobre material blando, no se pudo realizar una correlación entre las variables métricas (medidas de ángulo y longitud) de los filos utilizados en relación con el tipo de material trabajado (material blando y duro). En cuanto a la cinemática empleada sobre material duro, no se pudo determinar una diferencia estadísticamente significativa entre las piezas empleadas longitudinalmente y las que intervinieron en acciones transversales en relación al ángulo (Prueba de Mann-Whitney; U= 29,5; $\mathrm{p}=0,5$ ) y a la longitud de los filos utilizados (Prueba de Mann-Whitney; $U=25,5 ; p=0,3$ ).

\section{VII.3.1.5 Actividades desarrolladas}

El análisis realizado permitió identificar el desarrollo de distintas actividades para el bloque temporal del Holoceno medio en Piedra Museo. Se reconoció principalmente el trabajo sobre material duro (madera o hueso) en acciones de raspado como de corte; al igual que raspado y corte sobre hueso, a partir de artefactos formatizados como también sin formatización. Esta actividad probablemente haya estado relacionada con el procesamiento de presas hacia el interior del sitio. También se reconoció el empleo sobre otro tipo de material duro, corte y raspado sobre madera en menores proporciones (9\%); pero en este caso fue desarrollado únicamente con filos naturales. La serie experimental realizada a lo largo de esta tesis, demostró un uso más efectivo de lascas con filos naturales durante el proceso de descortezamiento de la madera, por lo que los resultados registrados a nivel arqueológico, podrían coincidir con estas observaciones, y probablemente hayan estado asociados a la manufactura de elementos en madera (enmangues o astiles), que por sus características particulares no se preservan en el registro arqueológico (Ver Apéndice). 
Por otro lado, se reconoció bajas proporciones del empleo de AF sobre material blando $(\mathrm{N}=2,7 \%)$ y de ANF sobre material blando animal (piel o cuero, $\mathrm{N}=2,6 \%$ ). En este sentido llama la atención la baja proporción del trabajo sobre este tipo de material a lo largo de toda la secuencia de Piedra Museo y especialmente en esta unidad (Figura 106). Esto podría estar relacionado al elevado porcentaje de piezas no determinables principalmente en los ANF, quizás consecuencia de efectos postdepositacionales que hayan alterado diferencialmente el grado de preservación de este tipo de micropulido. Aún así, resta por comprender con mayor detalle los efectos ocasionados como consecuencia de alteraciones químicas sobre microhuellas de uso, que probablemente se hayan producido en el registro arqueológico de Piedra Museo.

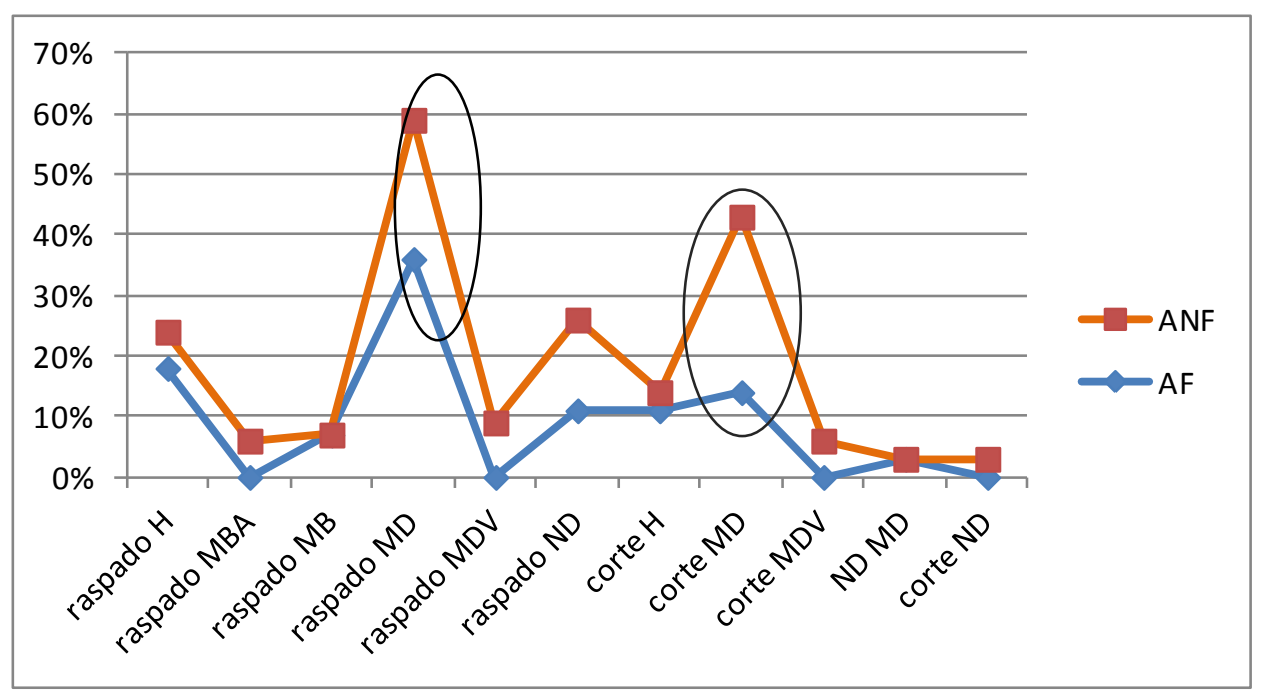

Figura 109: Detalle de las actividades realizadas en el componente superior de AEP1 (Capa 2).

\section{VII.4. Unidad estratigráfica 1}

Esta unidad corresponde a la última etapa de ocupación del sitio y se encuentra constituida por los materiales recuperados de la Capa 1. La misma está compuesta por arenas de color castaño que corresponden a los sedimentos de la superficie actual de Piedra Museo, sin rasgos pedológicos. Su límite inferior es una superficie irregular que ha sido interpretada como una discordancia erosiva (Zárate et al. 2000). Esta unidad no presenta fechados radiocarbónicos, sin embargo, los resultados obtenidos hasta el momento a partir de los materiales recuperados le darían una asignación temporal del Holoceno tardío. Los resultados polínicos obtenidos para esta unidad arrojan condiciones de vegetación similares a las actuales (Borromei 2000). 


\section{VII.4.1 Materiales de Capa 1}

Los materiales recuperados de Capa 1 están conformados por 23 AF con 46 filos identificados y 46 ANF con 68 filos. Este conjunto constituye el 33\% (N=69 con 114 filos observados) del total de la muestra analizada. La mayoría de las piezas fueron recuperadas de las cuadrículas $\mathrm{C}$ y D con un $22 \%$ del conjunto recuperado de estas unidades, principalmente hacia el sector Norte.

En cuanto a los AF se reconoció 7 grupos tipológicos, de los cuales el grupo de los raspadores está mayormente representado (48\%). Le siguen en menor medida la producción de raederas (18\%), bifaces (17\%), perforadores (4\%), puntas de proyectil pedunculadas $(9 \%)$ y muescas $(4 \%)$, (Tabla 9). En su mayoría las piezas se encuentran fracturadas sin talón $(\mathrm{N}=12,55 \%)$ y en menores proporciones enteras $(\mathrm{N}=9,36 \%)$ y fracturadas con talón $(\mathrm{N}=2,9 \%)$.

El tamaño más representado en la producción de AF corresponde a piezas de tamaños grandes $(\mathrm{N}=14,58 \%)$ y muy grandes $(\mathrm{N}=6,25 \%)$ con porcentajes elevados. Los módulos de longitud-anchura más representados corresponde a mediano-alargados $(\mathrm{N}=11,50 \%)$ y mediano- normal $(\mathrm{N}=6,27 \%)$.

Al igual que en el resto de la secuencia, la producción de estos artefactos evidenció un gran uso de rocas silíceas $(\mathrm{N}=14,64 \%)$ principalmente de coloración marrón-rojizas y en menor medida el uso de calcedonias $(\mathrm{N}=4,18 \%)$, xilópalo $(\mathrm{N}=3,14 \%)$ y cuarzo $(\mathrm{N}=1,4 \%)$.

Las formas bases más recurrentes están representadas por la selección de lascas $(\mathrm{N}=14$, $64 \%$ ), principalmente de aristas dobles y simples, y en menor medida lascas primarias. La producción de láminas como formas bases estuvo representado en el registro en porcentajes menores al uso de lascas $(\mathrm{N}=5,23 \%)$, al igual que los guijarros $(\mathrm{N}=2,9 \%)$. Los artefactos no formatizados incluyen un total de 46 piezas (68 filos observados) y en su mayoría fueron recuperados de la cuadrícula $\mathrm{H}$ en el sector Norte.

$\mathrm{Al}$ igual que los $\mathrm{AF}$, las piezas se encuentran mayormente fracturados sin talón $(\mathrm{N}=22$, $48 \%)$, y en menor medida enteros $(\mathrm{N}=17,37 \%)$ y fracturados con talón $(\mathrm{N}=7,15 \%)$.

A diferencia de los artefactos con formatización, la variabilidad de materias primas seleccionadas en su producción es mayor, debido a que se incluyeron otras rocas de grano grueso como el basalto en bajas proporciones $(\mathrm{N}=2,5 \%)$, cuarzo $(\mathrm{N}=2,4 \%)$ y ópalo $(\mathrm{N}=1,2 \%)$. Sin embargo, al igual que los anteriores, las rocas silíceas fueron las más utilizadas $(\mathrm{N}=23,50 \%)$ junto con la toba silicificada $(\mathrm{N}=9,20 \%)$ (Figura 107). Los 
tamaños más representados en la muestra fueron mediano grande $(\mathrm{N}=26,57 \%)$, grande $(\mathrm{N}=18,39 \%)$ y en menor medida muy grande $(\mathrm{N}=2,4 \%)$; mientras que el módulo más representado corresponde al mediano alargado $(\mathrm{N}=18,39 \%)$.

Al igual que en la capa anterior, la producción de lascas sobre láminas fue mayor, siendo las lascas angulares las más representadas en la muestra $(\mathrm{N}=12,33 \%)$; sin embargo, las lascas secundarias presentaron porcentajes elevados $(\mathrm{N}=11,31 \%)$.

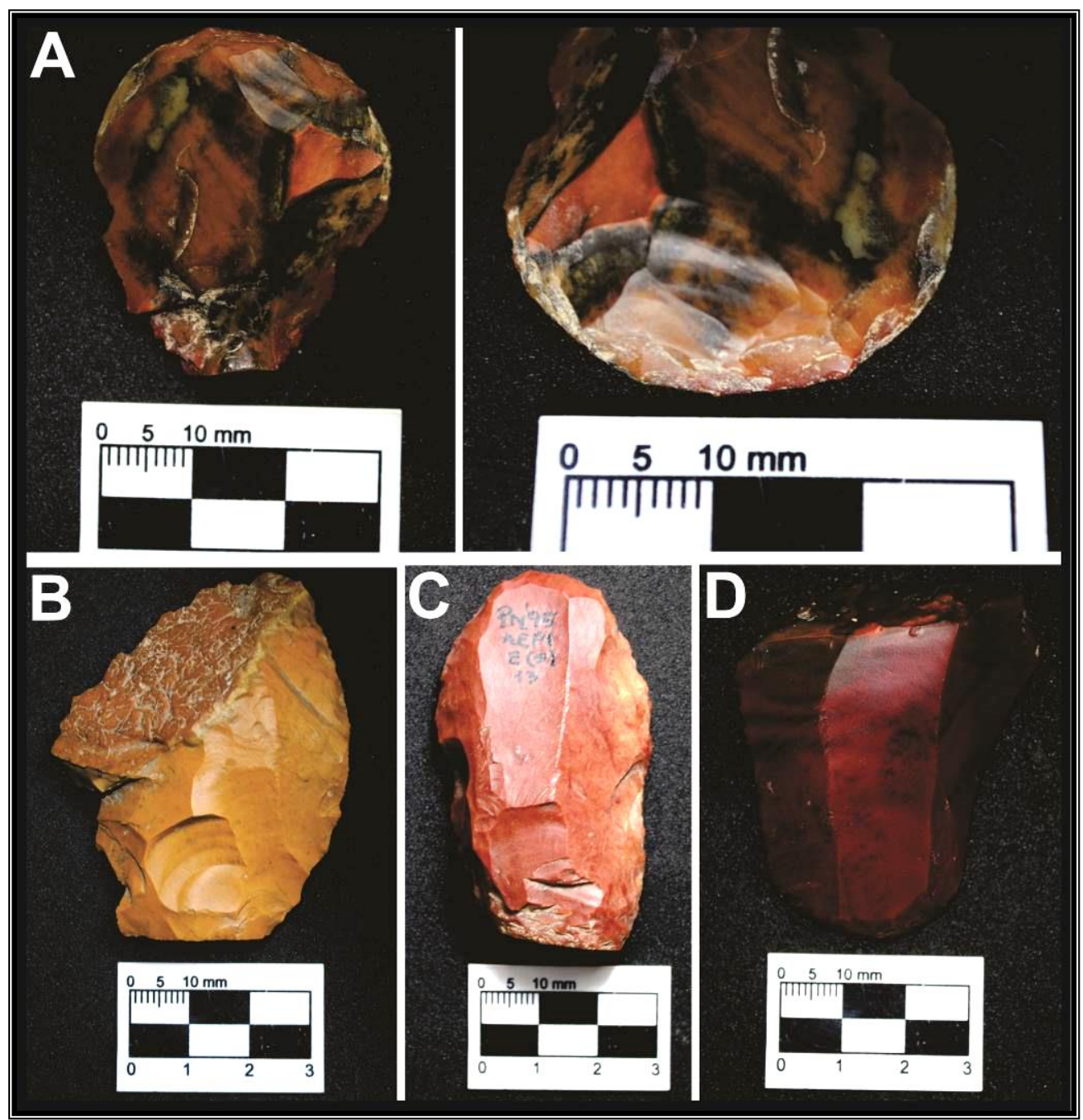

Figura 110: Materiales recuperados de la capa 1 UE1 de AEP1. A) Raspador de filo frontal extendido. B) Raedera de filo lateral largo. C-D) Raspadores de filo frontal extendido elaborado sobre materia prima silícea.

\section{VII.3.1.1 Integridad del conjunto e identificación de alteraciones tafonómicas}

En la Capa 1 el grado de integridad es semejante a la Capa 2 del componente superior de la UE2. La cantidad de AF con rastros de uso identificables es igual a las piezas no determinadas por alteración $(\mathrm{N}=18,39 \%)$ y en menor medida se ubican las piezas no 
determinadas $(\mathrm{N}=10,22 \%)$. En los artefactos con filos naturales estas proporciones no se mantienen, ya que se observó un mayor número de piezas con rastros de uso identificables $(\mathrm{N}=29,40 \%)$ y le siguen las piezas no determinadas con alteración $(\mathrm{N}=23,31 \%)$ y no determinadas $(\mathrm{N}=21,29 \%)$.

El grado de alteración identificado en esta capa corresponde a moderado a leve, identificándose distintos tipos de alteraciones. Al igual que en las demás capas de la secuencia, las más representadas corresponden a la abrasión sedimentaria y el desarrollo de lustre de suelo, que en los casos donde los efectos fueron más intensos, registró playas de abrasión y puntos en espejo.

A diferencia de la UE2, no se registró depositación de carbonatos sobre la superficie de las piezas. Sin embargo, algunos ANF presentaron formación de pátina blanca en muy bajas proporciones $(\mathrm{N}=2,9 \%)$

Otro tipo de alteración registrada en este conjunto incluyó piezas con exposición a fuego intenso que genero descamación, cambios de coloración y en algunos caso hoyuelos (AF: N=5, 28\% y ANF: N=4, 17\%) (Figura 111). En los casos donde se registraron estas modificaciones no se reconoció rastros de uso identificables, probablemente como consecuencia de la extracción y desprendimiento de varios sectores del potencial filo utilizado. Mientras que en los casos con cambios de coloración, se observó un intenso lustre que imposibilitó su observación a nivel microscópico, ya que cubría gran parte de la microtografía.

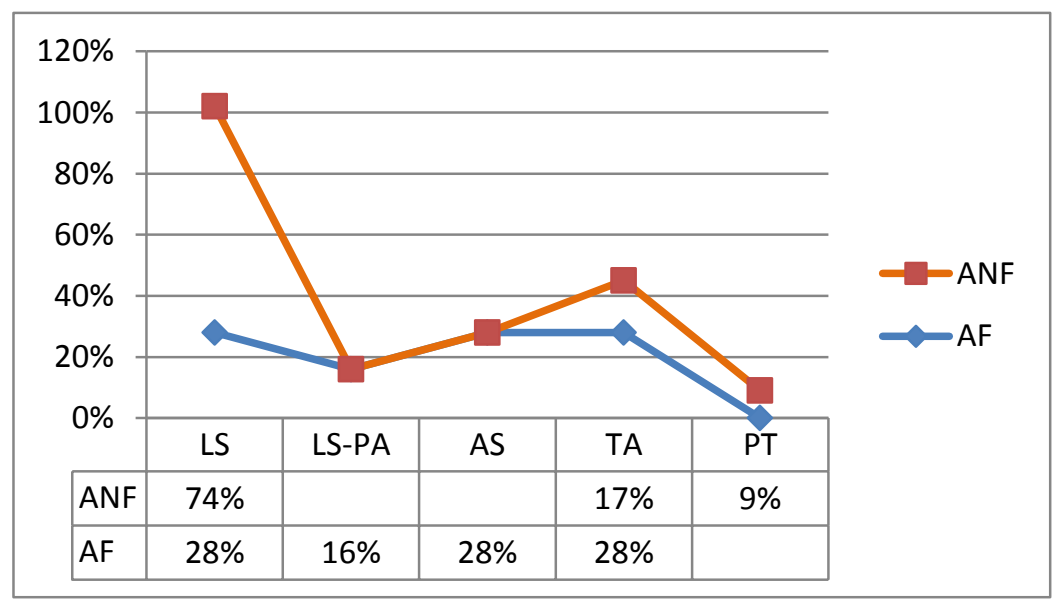

Figura 111: Tipos de alteraciones identificadas en la UE1 (Capa 1 de AEP1). LS: Lustre de suelo; LSPA: lustre de suelo y formación de pátina; AS: abrasión sedimentaria; TA: termoalteración y PT: formación de pátina blanca. 


\section{VII.3.1.2 Inferencia funcional de las modalidades de uso}

El análisis realizado permitió observar ciertas diferencias entre los AF y los ANF y en relación con la cantidad filos observados por pieza con rastros de uso. En los artefactos con formatización la mayoría de las piezas presentaron un único filo complementario, entre los cuales un $14 \%(\mathrm{~N}=4)$ presentaron rastros de haber sido utilizados.

En menor medida se disponen las piezas con dos filos identificados, de los cuales uno $(\mathrm{N}=2,7 \%)$ y dos filos $(\mathrm{N}=2,7 \%)$ presentaron rastros de uso. En menor medida se registraron piezas con tres filos potencialmente funcionales, de los cuales el mayor porcentaje estuvo representado por un solo filo con rastros de utilización ( $\mathrm{N}=4,15 \%)$. En los artefactos con filos naturales las piezas presentaron un filo complementario de los cuales el $40 \%$ registró rastros de uso.

\section{VII.3.1.3 Materiales trabajados}

El registro de las microhuellas permitió identificar el trabajo sobre distintos materiales del conjunto lítico recuperado en la Capa 1 de Piedra Museo. Estos materiales representaron distintas durezas, ya que se reconoció el trabajo principalmente de material duro, en altas proporciones y en menor medida el trabajo sobre material blando, tanto en AF como en ANF.

El trabajo sobre material duro estuvo representado en los AF en elevados porcentajes sin embargo, el trabajo sobre hueso fue el más representado $(\mathrm{N}=10,56 \%)$, seguido por el trabajo sobre material duro indiferenciado (madera o hueso, $\mathrm{N}=4,22 \%$ ) y en menor medida material blando $(\mathrm{N}=3,17 \%)$. El porcentaje restante incluyó piezas donde se pudo determinar la cinemática empleada pero no pudo ser inferido el material utilizado. A diferencia de estos, en los ANF las piezas fueron empleadas principalmente sobre material duro (madera o hueso, $\mathrm{N}=15,52 \%$ ) y en menor medida hueso $(\mathrm{N}=7,24 \%)$ y material blando ( $\mathrm{N}=2,7 \%)$ (Figura 112). En los filos observados no se reconoció la superposición de rastros, por lo que se asume que los artefactos no fueron empleado a partir de un mismo filo sobre distintos materiales. Por otro lado, no se pudo diferenciar el estado de los materiales trabajados (fresco, estacionado, no estacionado, seco), como sí ocurrió en la serie experimental de referencia realizada para esta tesis. 


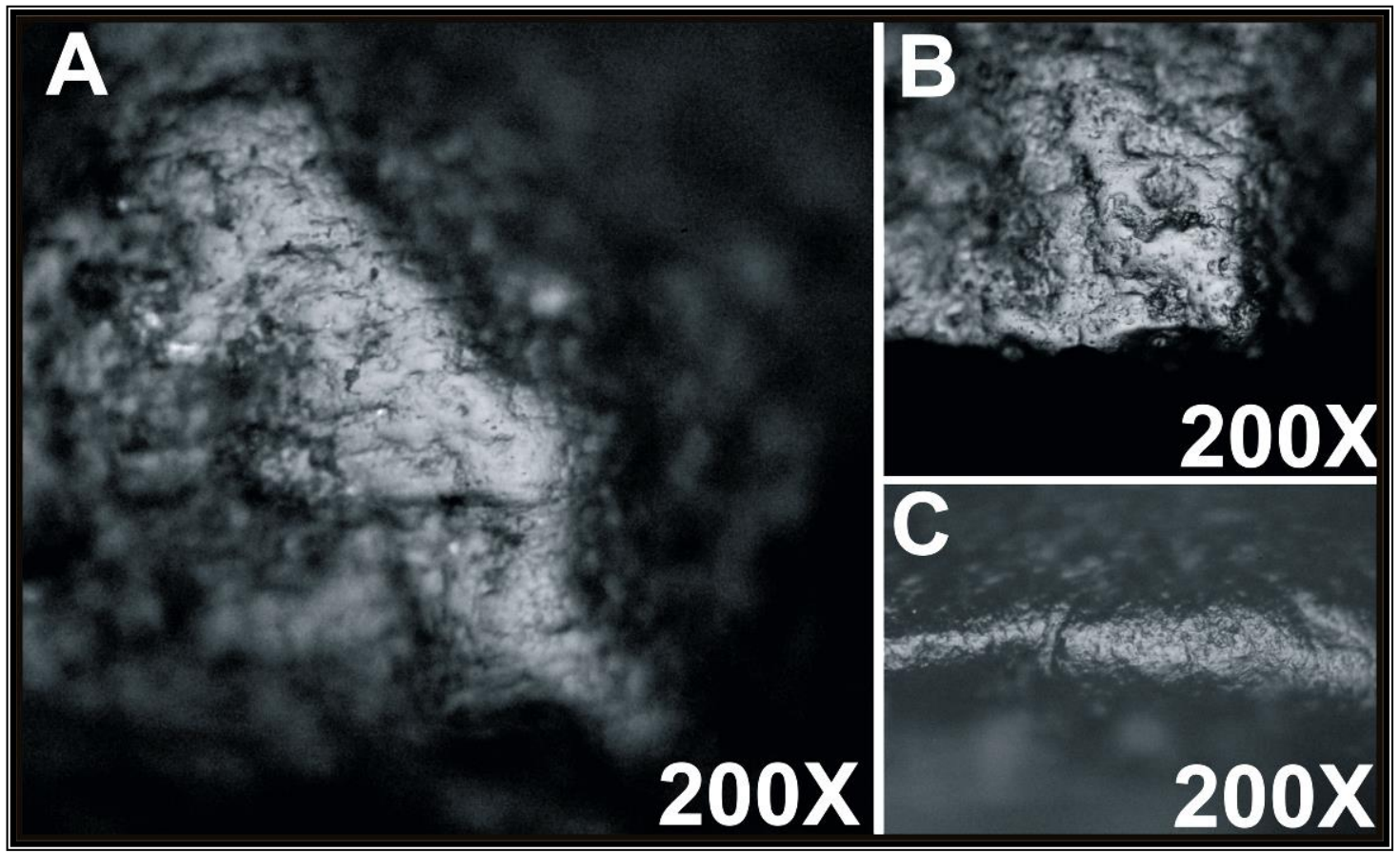

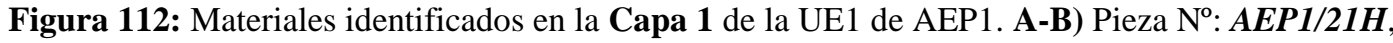
micropulido de material duro animal, acción longitudinal. C) Pieza $\mathrm{N}^{\mathbf{o}}$ : $\boldsymbol{A E P 1 / 3 5 2 D}$, micropulido de material duro animal, acción transversal o de raspado.

\section{VII.3.1.4 Cinemática empleada}

Los resultados obtenidos a partir del análisis efectuado, arrojaron que exclusivamente en los $\mathrm{AF}$ varias piezas fueron empleadas con un mismo filo mediante acciones mixtas (transversales y longitudinales). Sin embargo, tanto en los AF como en los ANF, en su mayoría fueron usados a partir de acciones transversales (o de raspado) y en menores proporciones se registraron acciones longitudinales.

El análisis de los AF dio como resultado que muchas piezas habrían sido utilizadas para el raspado sobre diversos materiales y durezas $(\mathrm{N}=10,56 \%)$, mientras que un elevado porcentaje corresponde a acciones mixtas $(\mathrm{N}=5,28 \%)$. El empleo de las piezas en acciones transversales y longitudinales a la vez, estuvo relacionado a piezas asignadas a nivel tipológico al grupo de raederas y cuchillos retocados, elementos que en muchos casos se creyó habrían intervenido en actividades de procesamiento de presas. Los movimientos inferidos en esta capa a partir del análisis funcional, confirmaría el modo de empleo de estos instrumentos.

En lo ANF ocurre de manera similar a los artefactos con formatización, aun así, no se registraron movimientos mixtos y las proporciones entre artefactos empleados transversal y longitudinalmente no difieren ampliamente; las acciones transversales 
estuvieron representados por un $48 \%(\mathrm{~N}=14)$, mientras que las longitudinales por un $45 \%(\mathrm{~N}=13)$.

\section{VII.3.1.5 Actividades desarrolladas}

De acuerdo a lo observado a nivel microscópico varias piezas de la Capa 1 de Piedra Museo, habrían servido para el raspado y corte de material duro, más específicamente el trabajo sobre hueso. Sin embargo, la identificación de microhuellas exclusivamente sobre material duro, podrían estar indicando el desarrollo de otro tipo de actividades hacia el interior del sitio para ese bloque temporal. Por otro lado, el trabajo sobre material blando estuvo apenas representado en la muestra, a partir de filos formatizados como también naturales $(\mathrm{N}=2,13 \%$ y $\mathrm{N}=2,7 \%$, respectivamente) y empleados en acciones transversales exclusivamente (Figura 113).

En general, la curva de distribución de las acciones inferidas a partir del análisis efectuado no difieren entre los artefactos con filos formatizados y naturales, a excepción de acciones de corte sobre material duro representado en porcentajes mayores a partir de filos naturales (Figura 110). Como fue explicado en apartados anteriores, este tipo filo sería propicio para llevara a cabo actividades de limpieza, ya sea en madera (para la extracción de corteza) como en hueso (limpieza de cartílagos y periostio entrando en contacto con el hueso), (para más detalle ver Apéndice).

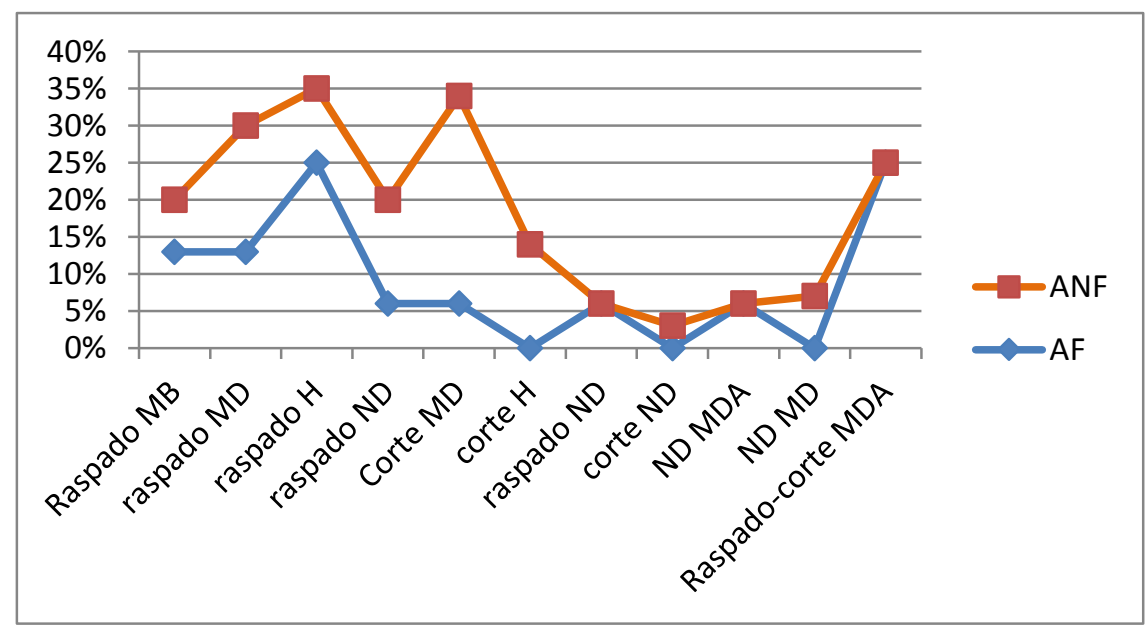

Figura 113: Actividades inferidas a partir del análisis funcional realizado en la UE1 (Capa 1 de AEP1). 


\section{VII.5. Consideraciones generales}

Los resultados obtenidos a partir del análisis funcional realizado sobre los conjuntos líticos recuperados del sitio Piedra Museo permiten discutir temas y tendencias respecto a: 1) la intensidad y tipos de alteraciones identificadas en las distintas unidades estratigráficas del sitio, permitiendo profundizar el conocimiento acerca de la génesis del depósito arqueológico, 2) las prácticas de uso de los artefactos líticos por parte de los grupos que habitaron el alero en los distintos bloques temporales establecidos y 3) al contexto de uso de los materiales recuperados.

\section{Unidad estratigráfica 2:}

Corresponde a los momentos de ocupación inicial del sitio y abarcan el bloque temporal que va desde la Transición Pleistoceno-Holoceno ( $c a .13 .000$ al 8500 años AP) y Holoceno temprano (de 8.5 a 7.5 ka AP) al Holoceno medio ( $c a .7500$ al 3500 años AP). Esta unidad presenta la mayor cantidad de materiales recuperados de Piedra Museo y es de gran importancia para comprender los momentos de colonización inicial del área bajo estudio (Borrero 1989-90; Borrero et al. 1998; Franco 2002; Miotti 1998 (1989); Miotti y Salemme 1999, 2003, 2005; Salemme y Miotti 2008).

\section{5.1.1. Grado de intensidad y tipos de alteraciones}

El análisis de las alteraciones identificadas a lo largo de la secuencia se basó tanto en el grado de su intensidad como en los efectos ocasionados. En cuanto a la integridad se observó ciertas diferencias entre las distintas unidades estratigráficas, y en especial entre el componente superior (Capa 2) e inferior (Capa 6 y 4/5). Además del bajo número de piezas recuperadas del componente inferior, se registró un grado de integridad "bajo" a "moderado", ya que la mayoría de las piezas se vieron afectadas por distintos proceso postdepositacionales (e.g., abrasión sedimentaria y lustre de suelo). Además se registró depósitos de carbonatos sobre las superficies de algunos artefactos principalmente en la Capa 4/5. Estos depósitos también fueron observados en los restos faunísticos analizados, lo que fue marcado como una de las modificaciones naturales más importantes de los especímenes óseos, llegando a cubrir parcialmente la superficie de los huesos (Marchionni 2013). En el caso del material lítico, estos depósitos se disponen 
en su mayoría de manera parcial, sobre una de las caras de los artefactos y en algunos casos llegando a cubrirla en su totalidad.

Debe recordarse que el techo de la Capa 4 está afectado por el derrumbe masivo del alero, en amplios sectores de la excavación (cuadrículas C, D, E, L están cubiertos por el mismo, incluso llegando hasta la base de la Capa 2). Esto es lo que pudo haber afectado doblemente a los materiales de las Capas 6 y 4/5, debido a la roca de caja (coquina) tanto arriba como en la base del alero. Mientras que en la Capa 2, la intensidad fue posiblemente menos severa y haya estado relacionado con los lugares inmediatos a las áreas de derrumbes

Por otro lado, la formación de abrasión sedimentaria, playas de abrasión y puntos en espejo son los tipos de alteración más representados en todas las distintas capas de AEP1. Estas se generan por las partículas de sedimento que entran en contacto con la superficie de los artefactos líticos y vinculados con el accionar de diferentes agentes como el pisoteo, acción hídrica y movimientos del suelo (Mansur 1984; Levi Sala 1993; Shea y Klenck 1993).

A diferencia de estos agentes, la génesis del lustre del suelo y de las playas de abrasión es diversa, ya que implica distintos procesos de formación, debido a cambios en la composición del pH del sedimento (Mansur 1986; Levi Sala 1986, 1996). Así las capas más profundas de AEP1, como consecuencia de la disolución de la roca de base (coquina), difieren de las capas más superficiales, y probablemente estos procesos hayan intervenido en la formación de lustres afectando el grado de preservación de los micropulidos en las distintas unidades.

Muchas veces, si la formación de estos lustres es intensa llegan a borrar, enmascarar o en algunos casos a "imitar" los distintos micropulidos ocasionados por el uso de los artefactos. Es por esta razón, que es de fundamental importancia comprender los procesos de formación del depósito arqueológico, que en general son complejos y difíciles de interpretar.

En cuanto a los tipos de materias primas y la preservación de rastros de uso, se observaron ciertas diferencias en la selección de materias primas de muy buenas calidad para la talla, principalmente ópalo, calcedonia y xilópalo en la Capa 6, mientras que en la Capa 4/5 variedades de sílex, toba silicificada e igualmente calcedonia. Sin embargo, todas estas rocas son similares en cuanto a su composición litológica y a nivel textural de grano fino. De acuerdo a esto no se observaron diferencias en el grado de preservación de microhuellas de uso. Mientras que en los niveles superiores (Capa 2 del 
componente superior y Capa 1) se reconoció el uso de basalto en la producción de ANF. Aún así y debido al bajo número de piezas identificadas para este tipo de materia prima, no se podría plantear una hipótesis de preservación diferencial de rastros de uso en relación a las rocas utilizadas a través del registro arqueológico de AEP1.

Asimismo, otras alteraciones identificadas a lo largo de la secuencia corresponden a procesos de termoalteración ocasionados por la exposición directa al fuego. Estas alteraciones estuvieron acompañadas por la formación de lustre y en muchos casos por cambios de coloración de la roca y formación de hoyuelos y/o escamaciones. Este tipo de alteración a nivel microscópico se ve expresado en la remoción de sectores del filo observado y en un lustre intenso que impide la observación de rastros de uso. El tratamiento y daño térmico, ya ha sido registrado en otros conjuntos de la Meseta Central, técnica de manufactura utilizada por los grupos que habitaron la Patagonia a lo largo del tiempo (Hermo 2008; Nami 1992; Paunero 2009; Cueto y Frank 2008; Frank 2009, 2012). Estas mismas alteraciones habían sido mencionadas y registradas con anterioridad por Cattáneo (2002; et al. 1997-1998); no obstante esto, su influencia sobre rastros de uso microscópicos de los materiales recuperados en AEP1 se detalla por primera vez en este estudio.

Por lo tanto y a diferencia de las propuestas realizadas por Cattáneo (2002), se cree necesario ser más cautos con las inferencias sobre el uso de los artefactos líticos ya que, hasta el momento, los resultados obtenidos a nivel microscópico permiten plantear diferentes grados de alteración e integridad en los materiales líticos recuperados de los distintos componentes. Los tipos y grados de alteración se vinculan principalmente al accionar de diferentes procesos de formación del sitio y a la exposición de los materiales a condiciones ambientales específicas. Todo esto conforma una serie de factores que minimizan la preservación de las huellas de uso en los filos y por lo tanto, gran parte de los materiales observados presentan señales bajas o nulas de su trabajo en el pasado.

Sin embargo, se cree que estos estudios son una contribución al avance de los procesos tafonómicos que actuaron en esta compleja estratigrafía con una secuencia ocupacional tan extensa. 


\section{VII.5.1.2. Prácticas de uso}

A pesar del bajo número de piezas recuperadas del componente inferior de Piedra Museo se ha podido explicar, junto con otras líneas de evidencia, algunos procesos productivos llevados a cabo en el sitio. En cuanto a los materiales procesados, se ha encontrado ciertas diferencias en relación a las distintas unidades estratigráficas identificadas. En la unidad 2, se registró una menor variedad de actividades realizadas por los artefactos recuperados del componente inferior (Capa 6 y 4/5). Los instrumentos retocados de la Capa 6 trabajaron básicamente materiales duros (i.e., hueso), mientras que en la Capa 4/5, se registró el uso de otros materiales duros (i.e., hueso y madera) como también blandos (piel). A diferencia de este componente en el superior (Capa 2) se registró, una mayor cantidad de piezas, al igual que el desarrollo de distintas actividades, donde se observa el trabajo sobre diferentes materiales y durezas. Los instrumentos retocados registraron principalmente el trabajo sobre material duro indiferenciado y hueso y en menor medida material blando. En los filos naturales, se identificó el trabajo sobre madera en mayores proporciones, mientras que hueso y piel se trabajaron en proporciones menores. En ambos componentes el movimiento más representado corresponde al transversal, que implica actividades de desbaste y raspado, tanto en filos formatizados como en naturales. Sin embargo, el porcentaje de piezas empleadas longitudinalmente se incrementa en los filos naturales y abarca acciones de aserrado y corte.

\section{VII.5.1.3. Contexto de uso}

Los trabajos previos realizados para este bloque temporal en Piedra Museo, han mencionado el desarrollo de distintas prácticas tecnológicas, donde la Capa 6 estaría relacionada a la producción de instrumentos generalizados o informales (Cattáneo 2002; 2005) que habrían intervenido en actividades de procesamiento de animales de gran porte, básicamente équidos y camélidos (Miotti y Salemme 1999, 2005). A su vez, la selección de materias primas de muy buena calidad para la talla (ópalo, calcedonia y xilópalo), en conjunto con la identificación de raederas y cuchillos de filos naturales como grupos tipológicos más representados, marca importantes diferencias en comparación con la Capa 4/5. Sin embargo, a nivel funcional y en base a los resultados obtenidos microscópicamente, la diferencia se encuentra marcada exclusivamente en el 
uso de estos instrumentos sobre material duro animal (hueso) y material duro indiferenciado. Aún así, la escasa cantidad de materiales líticos recuperados, sumado a la baja integridad de los artefactos en esta unidad, no serían, por sí solos, indicadores fuertes para sostener la hipótesis del uso de estos artefactos en actividades de procesamiento primario de presas exclusivamente. El trabajo sobre material duro indiferenciado podría estar indicando el desarrollo de otras actividades además del faenamiento de grandes animales, como ha sido expresado en estudios anteriores. Sin embargo, los resultados obtenidos a partir del análisis de restos óseo (Miotti 1993, 1996; Miotti et al. 1999; Miotti y Salemme 1999; Marchionni 2013) y del contexto arqueológico en general (menor superficie utilizada en el sitio que coincidiría con los modelos existentes para el área, Borrero 1989-90; Miotti y Salemme 1999, 2004), indican que para ese entonces, este sector de la meseta habría sido ocupada por grupos con pocos individuos donde no sería esperable una redundancia marcada en el uso de los sitios, generando contextos arqueológicos con baja concentración de materiales y desarrollo de actividades específicas (procesamiento primario y secundario de presas).

A diferencia de la Capa 6, en los niveles superiores, se produce un incremento del número de artefactos recuperados, con mayor diversidad de materias primas y grupos tipológicos identificados. Es así que, en la Capa 4/5 se registró variedad de materiales trabajados (duro y blando), al igual que cinemáticas empleadas (acciones transversales y longitudinales). Probablemente esto iría acompañado al uso más repetitivo del sitio (Borrero 1989-90), que a nivel microscópico estaría expresado a partir del desarrollo de distintas actividades y variedades de los materiales empleados (material duro, madera, hueso y cuero).

A finales de esta ocupación, es decir después de 9.200 años AP, se habría producido el colapso del sector más externo del alero (cuadrículas C, D, E), ya que a partir de ese entonces y en base al análisis óseo realizado con anterioridad, se observan cambios en el área de descarte de presas (Marchionni 2013). Esto coincide con los resultados obtenidos del análisis lítico donde se observa un notable uso del alero hacia el sector oeste del sitio, corroborado a partir de una mayor cantidad de artefactos en las cuadrículas H, I y J, e indicando mayor disponibilidad del sector de reparo del alero para las ocupaciones correspondientes al Holoceno medio.

Para ese entonces, el sitio habría sido usado como área de actividades múltiple, donde se habrían desarrollado actividades de procesamiento y consumo hacia el interior del sitio. Esto se vería expresado en la identificación de rastros de uso sobre materiales duros 
(hueso) y blandos (cuero y piel), a partir de diversas acciones que incluyen el raspado, corte y/o aserrado de los materiales identificados. Por otro lado, el registro del trabajo sobre material duro vegetal, permitiría sostener el desarrollo de diferentes actividades relacionadas a la producción de otros elementos (mangos, astiles, contenedores) y actividades como el tratamiento inicial del cuero, hacia el interior del sitio para ese entonces. La información arqueozoológica de este contexto avala estas ideas del uso de diferentes materiales, es decir, coincidiendo con un área de base residencial donde se habrían realizado múltiples actividades, incluyendo el procesamiento y consumo de los alimentos. En este último caso las áreas de estructuras de combustión avalan esta idea (Marchionni 2013; Marchionni et al. 2010; Miotti y Marchionni 2011).

\section{Unidad Estratigráfica 1:}

Esta unidad corresponde al bloque temporal del Holoceno tardío e incluye materiales de cazadores recolectores tanto pre como posthispánicos; estos últimos no han sido analizados en esta tesis. Sin embargo, los resultados obtenidos a partir del análisis lítico han permitido plantear diferencias en relación al componente inferior.

\section{VII.5.2.1. Grado de intensidad y tipos de alteraciones}

El grado de integridad de los artefactos recuperados de la Capa 1 de AEP1 es moderado a leve, expresado en un mayor porcentaje de piezas con rastros de uso identificables. Sin embargo, en comparación con la Capa 2, los porcentajes de piezas no determinadas por alteración son similares, pero teniendo en consideración que el número de piezas analizadas es mayor, el grado de alteración se incrementa hacia los niveles superiores. Probablemente esto sea consecuencia de una mayor exposición de los materiales en superficie, debido a que gran parte de estos fueron recuperados del sector más externo del alero. Por lo tanto, los materiales habrían estado más expuestos, expresado a partir de piezas con abrasión sedimentaria y formación de lustres, alteraciones más frecuentes en esta unidad de análisis. Sin embargo, las piezas con termoalteración se encuentran igualmente representadas en porcentajes elevados. Este tipo de alteración se ve acompañado, en algunos casos, por un intenso lustre que llega a ocultar y desaparecer los micropulidos generados durante el empleo de un artefacto. A diferencia del resto de la secuencia, la formación de pátinas sobre las superficies de los artefactos recuperados 
es menor, al igual que la depositación de carbonatos, que en este caso se encuentran ausentes. Los procesos de formación de estas alteraciones ya fueron explicados anteriormente, por lo que en este apartado solo se mencionan haciendo hincapié en las diferencias con la unidad estratigráfica 2 (UE2).

\section{VII.5.2.2.Prácticas de uso}

En cuanto a las actividades desarrolladas no se observan grandes diferencias en relación con la Capa 2. Se reconoció el empleo de los artefactos sobre material duro (principalmente hueso) y en menor medida material blando animal (piel o cuero). El trabajo sobre madera no fue reconocido en los materiales analizados. Sin embargo, se identificó el uso de los artefactos sobre material duro indiferenciado, que podría estar indicando su utilización sobre este tipo de material. En cuanto a los movimientos empleados se registraron porcentajes similares de acciones transversales $y$ longitudinales. En este sentido, se podría indicar que en los momentos finales de ocupación del sitio, los artefactos intervinieron en acciones de raspado y corte o aserrado de manera similar sobre materiales duros principalmente.

\section{VII.5.2.3.Contexto de uso}

En relación a la distribución de los materiales recuperados de la Capa 1, se reconoció su disposición principalmente en las cuadrículas C y D. Estas cuadrículas, como ha sido indicado anteriormente, corresponde a los sectores más externos del alero, sector que para el Holoceno medio no habría estado utilizable, producto del derrumbe de una parte del techo del alero que habría generado cambios en los sectores de ocupación disponibles del sitio, a lo largo de los bloques temporales de ocupación establecidos para AEP1. Probablemente hacia el Holoceno tardío, pudo haber una reutilización de este sector más externo del alero, donde se habrían llevado a cabo distintas actividades, desde el procesamiento de presas hasta las etapas de cuereo y tratamiento inicial del cuero.

Por otro lado, el trabajo sobre materiales duros (hueso) y blandos (cuero y piel) estaría indicando que para ese entonces, el sitio continuaría siendo utilizado para el desarrollo de actividades domésticas, pero debido a la disminución de materiales recuperados de este capa, es probable que haya habido un cambio en la distribución del espacio por 
parte de los grupos que habitaron el alero hacia el Holoceno tardío. Los modelos propuestos para el área de estudio (Borrero 1989-90; Franco 2002; Miotti 1998; Miotti y Salemme 1999, 2003, 2005; Salemme y Miotti 2008) indican que para estos momentos, habría una mayor densidad de distribución poblacional y cambios en los modos de subsistencia y en las estrategias de apropiación de los recursos, marcado ya desde el Holoceno medio y que se iría acentuado hacia el Holoceno tardío (Miotti 2012). En este trabajo la autora propone que para ese entonces los grupos habrían utilizado una estrategia de intensificación o focalización de los recursos, con una mayor complejidad en las tareas de procesamiento, almacenamiento, y tal vez intercambios, con el intento de potenciar recursos de bajo retorno. Por otro lado, se pone hincapié en el aprendizaje socialmente transmitido y en las redes sociales. Estos cambios se verían expresados en la producción tecnológica de AEP1, a través de la manufactura de artefactos para tareas específicas tales como gubias, espolones y perforados. El análisis funcional realizado a partir de los materiales líticos recuperados en Capa 1, no permitió inferir cambios significativos en los recursos procesados y modos de utilización; sin embargo los resultados obtenidos permitieron realizar un análisis más detallado de los usos específicos a los cuales fueron destinados estos materiales. 


\section{CAPÍTULO 8}

\section{Discusión y Conclusiones}

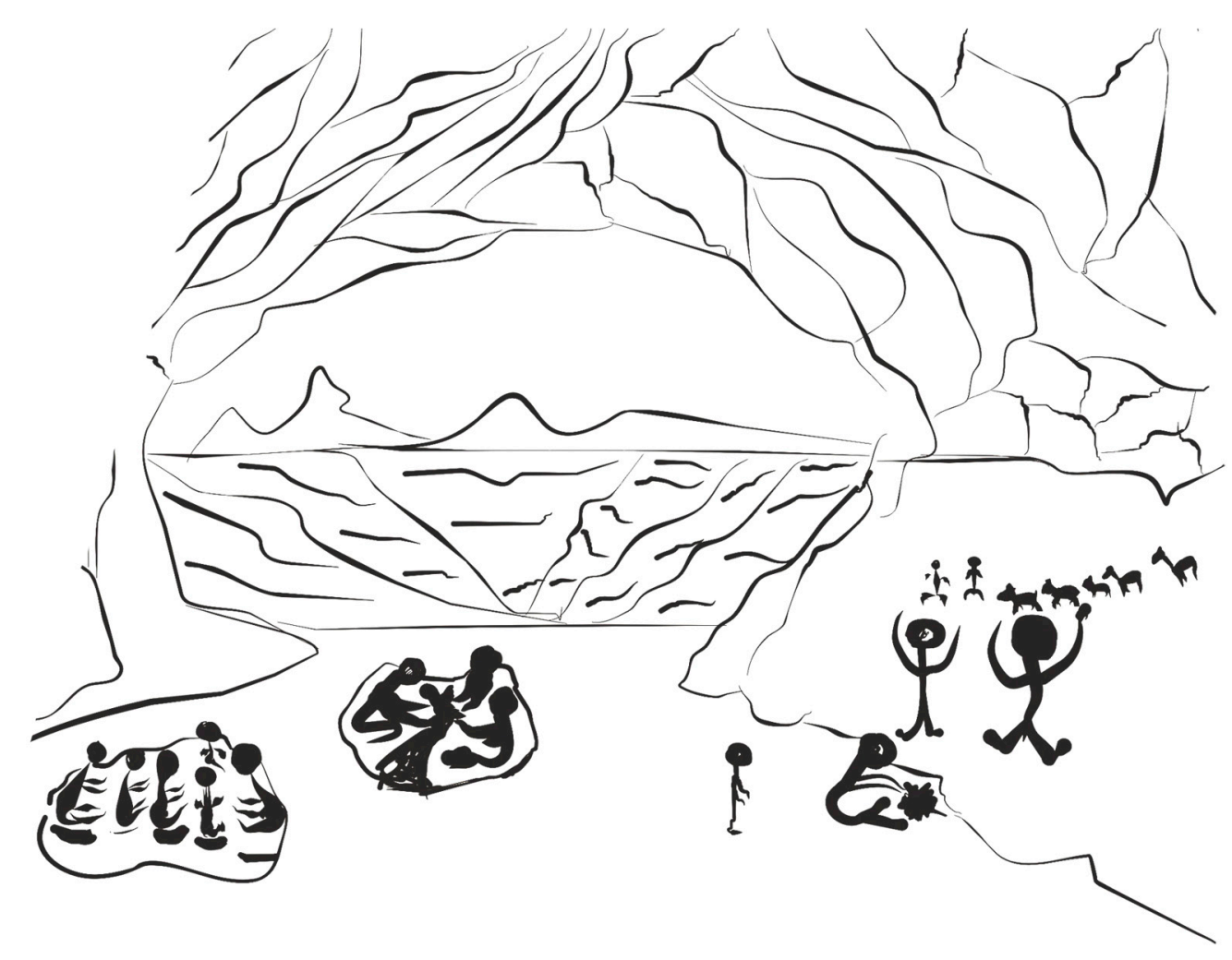





\section{DISCUSIÓN FINAL Y CONCLUSIONES}

Desde la ocupación inicial de la Meseta Central de Santa Cruz por parte de sociedades cazadoras-recolectoras y su posterior dispersión, los modos de vida de estos grupos estuvieron acompañados por posibles cambios socio-económicos y reajustes a diferentes condiciones ambientales. Las variaciones climáticas ocasionadas a finales del Pleistoceno, afectaron la diversidad ambiental, favoreciendo la explotación de diferentes recursos a partir de distintas estrategias.

La presencia de artefactos tallados en rocas ha ido acompañando este proceso de desarrollo cultural, de allí que su estudio puede ser considerado de suma importancia para evaluar e indagar, mediante su uso, las temáticas relacionadas a la explotación de los recursos disponibles en el área mencionada.

Las distintas actividades desarrolladas en un sitio pueden estar expresadas en el uso de los artefactos recuperados del contexto arqueológico y es a través de este mismo contexto, que le otorga significado como parte más general de un sistema de conductas definidas por los individuos que lo generaron.

En este sentido, el objetivo principal de esta tesis incluyó el estudio de la tecnología lítica de grupos cazadores-recolectores que habitaron desde finales del Pleistoceno la Meseta Central de Santa Cruz. Se focalizó principalmente en el análisis de las prácticas de uso y consumo desarrolladas a lo largo de tres bloques temporales identificados en los sitios bajo estudio (desde la transición Pleistoceno-Holoceno al Holoceno tardío).

Esta temática no había sido tratada con anterioridad de manera sistemática, por lo que su aporte al estudio de las prácticas tecnológicas contribuye con el avance del conocimiento acerca de las conductas y toma de decisiones de los grupos humanos que habitaron en el pasado. Esto fue realizado a partir del desarrollo del análisis funcional de base microscópica, que hasta el momento, constituye la mejor herramienta para poder determinar los modos de uso de los artefactos líticos recuperados del registro arqueológico.

En este capítulo se discutirán e integrarán los resultados obtenidos en los análisis realizados, teniendo en consideración los objetivos e hipótesis propuestas al inicio de este trabajo de tesis. Esto se realizará a partir de tres ejes fundamentales: 
VIII. 1. Análisis de los mecanismos de formación de rastros de uso e integridad artefactual en los sitios identificados.

VIII. 2. Estudio de las estrategias de uso, prácticas de consumo y los diseños elegidos en la manufactura de los artefactos empleados para los distintos bloques temporales establecidos.

VIII. 3. Análisis comparativo de los conjuntos líticos para determinar tendencias en las estrategias de producción tecnológica. Esto permitirá un mejor conocimiento acerca de la funcionalidad de los sitios a lo largo de las distintas ocupaciones establecidas, teniendo en consideración los modelos de poblamiento formulados para el área (Borrero 1989-90, 1994-95; Miotti 1998; Miotti y Salemme 2004).

Los puntos mencionados con anterioridad podrán ser discutidos a partir de distintas escalas de análisis. En este sentido, se discutirá a nivel artefactual los diseños elegidos y las variables morfológicas relacionadas al uso establecido (punto VIII.1.). A nivel intrasitio, se discutirá la integridad artefactual de los distintos componentes y los procesos de formación de los sitios que afectaron a la integridad de los conjuntos líticos recuperados (punto VIII.2.). Por último, a escala microrregional, se discutirá e integrará los datos obtenidos en relación con las hipótesis propuestas respecto a la funcionalidad de los sitios con otros identificados en la Meseta Central de Santa Cruz (punto VIII.3.).

\section{1. ANÁLISIS DE LOS MECANISMOS DE FORMACIÓN DE RASTROS DE USO Y ALTERACIONES IDENTIFICADAS EN LOS SITIOS.}

Dentro de los objetivos específicos planteados al inicio de esta tesis, se incluyó poder comprender los mecanismos de formación y deformación de los rastros de uso en relación con distintos tipos de materias primas (homogéneas y heterogéneas) identificadas en los sitios analizados. Para esto se desarrolló un extenso programa experimental que abarcó distintas actividades y materiales trabajados, al igual que el empleo de los artefactos a partir de dispositivos de enmangue y una pequeña serie para determinar los factores y modificaciones que generan las alteraciones químicas.

Los resultados obtenidos se presentan a partir de dos criterios considerados clave: 1) los mecanismos de formación de los rastros de uso y 2) de las alteraciones de las superficies y filos líticos. 


\section{VIII.1.1. Mecanismo de formación de rastros de uso}

Varios factores son los que intervienen en la formación de los rastros de uso, sin embargo, los principales corresponden a la materia prima utilizada para la producción de los artefactos líticos y al estado y tipo de material sobre el cual se trabajó.

Respecto a este primer punto, las materias primas identificadas en los sitios analizados corresponden principalmente a distintos tipos de rocas con alto contenido silíceo (homogéneas), a excepción del basalto. El uso de basalto habría estado vinculado, en un principio, con la manufactura de boleadoras, específicamente en el sitio Cueva Maripe (Hermo 2008). Los altos porcentajes de rocas silíceas utilizadas en la producción de artefactos, se debe a la alta disponibilidad de este tipo de materia prima en los sectores cercanos a los sitios estudiados, además de su buena calidad para la talla, que en algunos casos no presentan impurezas (Cattáneo 2005; Miotti et al. 2007; Hermo y Miotti 2003; Hermo 2008; Hermo 2009). Se destaca que no sólo en los sitios aquí investigados las rocas silíceas son abundantes en los contextos arqueológicos, sino que desde la cordillera o su piedemonte, hasta la costa atlántica, la disponibilidad de rocas silíceas de bueno a excelentes cualidades para la talla es alta. Esto se debe fundamentalmente al afloramiento de formaciones del Grupo Bahía Laura (Miotti 1998; Hermo 2009; Moreira 2005; Hermo y Miotti 2011).

En este sentido, la serie experimental incluyó estas dos variedades de materias primas, junto con la observación de otras piezas experimentales elaboradas sobre obsidiana. Los datos obtenidos han permitido identificar ciertas diferencias (ver Apéndice).

Estas están relacionadas principalmente con el tiempo de formación de rastros de uso diagnósticos en materias primas heterogéneas (basalto) y la disposición de estos rastros generados en relación con la microtopografía observada.

El basalto presenta distinta composición litológica (pasta afanítica con cristales de mayor tamaño) que las rocas silíceas, característica que le brinda una mayor dureza y resistencia a la deformación. Esto se vio expresado en un mayor tiempo de utilización para generar rastros de uso diagnósticos del material trabajado. A su vez, las características de la microtopografía de este tipo de materia prima, de matriz heterogénea, hace que los rastros se generen principalmente sobre la superficie alta de la microtopografía, aún en micropulidos bien desarrollados y diagnósticos del material trabajado. Según Mansur (1999) estos se generan más rápido sobre la superficie de fractura de los cristales antes que en la matriz. 
Trabajos anteriores referentes a este tipo de materia prima (Odell 1980; Jones 1980; Plisson 1985) han indicado estas diferencias en artefactos líticos arqueológicos y experimentales sobre basalto, mencionando que las piezas utilizadas, además presentarían tamaños más grandes y filos más redondeados.

El alto grado de redondeamiento de los filos, identificado en las piezas experimentales también coincidiría con estas observaciones, aún en el empleo de materiales duros, capaces de generar un intenso esquirlamiento del filo. También, se observó que los filos generados sobre basalto, se embotaban más rápidamente y son menos efectivos para acciones de corte, ya que presentan ángulos menos agudos y filosos que los obtenidos a partir de materias primas homogéneas, que a su vez evidencian mayor cantidad de esquirlamientos de morfología variable dependiendo del material trabajado.

Las rocas homogéneas o de grano fino (sílex) se caracterizan por formar rápidamente micropulidos diagnósticos, mientras que las materias primas heterogéneas, utilizan más tiempo para generarlos (alrededor de $1 \mathrm{hr}$. 30', mientras que a iguales condiciones en las silíceas es de 60'), debido a su composición mineralógica, compactación y microtopografía más irregular. Estos resultados, a su vez coinciden con los obtenidos por otros investigadores (Castro 1994; Mansur 1999; Álvarez 2003; Leipus 2006; Leipus y Mansur 2007).

De esta manera, la serie experimental de referencia permitió indagar en la formación de rastros de uso a través del empleo de distintos tipos de materias primas (homogéneas y heterogéneas), al igual que la formación de los rastros generados por el empleo sobre diferentes materiales y estados. Se observaron variaciones en la formación de micropulidos en relación con el estado del material trabajado, sobretodo en materias primas homogéneas, donde se discriminó el empleo de materiales en estado fresco de aquellos en estado seco. El trabajo sobre madera no estacionada, generó un micropulido espeso, más brillante y homogéneo que aquel producto del trabajo sobre madera estacionada, donde presentó una mayor cantidad de estrías pero menor brillo que en estado fresco. Esto mismo ocurrió para el trabajo sobre piel, donde se pudo identificar mayor brillo (grasoso) y menor cantidad de estrías que el trabajo realizado sobre piel seca o cuero (ver Figuras 41, Apéndice). Sin embargo, estas diferencias no pudieron ser observadas en las piezas elaboradas sobre basalto. Variaciones en cuanto al estado del material trabajado (fresco, seco, estacionado o no estacionado), no fue registrado debido a las características microtopográficas y litológicas de este tipo de materia prima (ver Figuras 47 y 48, Apéndice). 


\section{VIII.1.2. Integridad artefactual y alteraciones identificadas}

Los materiales recuperados de excavaciones arqueológicas han sido afectados por diversos procesos postdepositacionales; ya sean de carácter natural como así también antrópico. Estos procesos ocasionan traslados y reorganización de los objetos alterando, en gran medida, la integridad de los mismos. En tal sentido, la evaluación de los múltiples procesos culturales y naturales que intervienen en la formación de los depósitos arqueológicos, es una herramienta fundamental para inferir las condiciones que contribuyeron a la formación de los sitios arqueológicos en general.

Dentro de los objetivos específicos planteados al inicio de esta tesis, se incluyó el estudio de las alteraciones identificadas en los conjuntos líticos observados. En los casos que se generan con mayor intensidad, estas alteraciones pueden enmascarar o hasta imitar el desarrollo de micropulidos (Kaminska et al. 1993; Burroni et al. 2002; Araujo 2013), por lo que su estudio a nivel arqueológico y experimental es de fundamental importancia a la hora de aplicar el análisis funcional de base microscópica a los sitios bajo estudio.

A nivel arqueológico, los conjuntos analizados presentaron diferentes grados de integridad, que va desde buena a regular dependiendo de la intensidad en la que actuaron estos procesos. Sin embargo, dentro de los conjuntos observados un gran porcentaje de las piezas permitió identificar el material trabajado.

En el sitio Cueva Maripe, el grado de integridad de los artefactos recuperados varía en relación a la distribución de los materiales tanto en tiempo como en el espacio dentro de la cueva. Los niveles más profundos del sitio, presentaron una mayor cantidad de piezas con formación de pátinas blancas y concreciones carbonáticas sobre su superficie (Lynch et al. 2012). Esto podría deberse a la disolución de la roca de caja y a un aporte de humedad efectiva que tiende a ser mayor en la cámara sur de la cueva. Esta disolución de la roca de caja generaría aportes a la matriz sedimentaria e igualmente al registro arqueológico, ocasionando cambios en la composición del pH del sedimento, que podría a su vez, provocar modificaciones en los micropulidos generados por el uso de los artefactos.

Los estudios químicos realizados hasta el momento indican un $\mathrm{pH}$ alcalino en los niveles inferiores del sector norte de la cueva, mientras que hacia los niveles más superficiales el pH tiende a ser neutro. Es esperable que los cambios de alcalinidad del 
sedimento en la cámara sur de Cueva Maripe sean similares a los de este sector de la cueva, lo que deberá ser confirmado con futuras mediciones.

El resto de las piezas analizadas presentaron principalmente abrasión sedimentaria y lustre de suelo. En algunos casos, estas alteraciones iban acompañadas por otras como puntos en espejos y playas de abrasión, alteraciones que podían llegar a cubrir grandes extensiones de los filos observados.

Según Mansur (1999) el lustre de suelo es un tipo de alteración que permite distinguir las piezas experimentales de las arqueológicas y no plantean problemas en la observación de los rastros de uso. Sin embargo, en las piezas observadas de los niveles inferiores de Piedra Museo, este tipo de alteración es tan intensa que llega a cubrir completamente la superficie de los artefactos, y en algunos casos alterar el desarrollo de micropulidos, siendo perceptible a ojo desnudo (brillo intenso de la pieza).

En los niveles superiores de ambos sitios, el grado de integridad es bueno a muy bueno, permitiendo observar una mayor cantidad de piezas con rastros de uso identificables.

Aún así, las alteraciones más representadas en todos los niveles, tanto en Piedra Museo como en Cueva Maripe, corresponden a la abrasión sedimentaria y al lustre de suelo. La abrasión sedimentaria habría sido consecuencia de la acción hídrica y/o sedimentaria, generando el contacto de las piezas con las partículas más finas del sedimento, mientras que el lustre de suelo se habría ocasionado por cambios en la composición del pH del sedimento (Mansur 1999; Levi Sala 1993). Los análisis diatomológicos realizados en Cueva Maripe, brindaron mayor sustento a esta hipótesis, ya que las muestras sedimentarias tomadas en el perfil Este de la cuadrícula D5 de la cámara norte (capa más profunda de la excavación - capa 5d-) y en la superficie actual del fondo (parte más interna de la cueva), se encontró abundancia y diversidad de diferentes especies de diatomeas. Entre estas especies fueron identificadas H. amphioxys, Nitzschia párvula, Pinnularia borealis y Denticula elegans que colonizan lugares húmedos o con encharcamientos someros y temporarios (Fernández 2013; Lynch et al. 2012). Sin embargo, la gran cantidad de valvas fragmentadas dificultó la caracterización de posibles microambientes durante los momentos de ocupación de la cueva, tanto en la cámara norte como en la sur. Esto podría estar vinculado con el grado de preservación de las valvas de diatomeas. Si bien, es difícil definir esta causa probable para la alta fragmentación de los restos silíceos, varios procesos postdepositacionales como percolaciones, derrumbes del techo, encharcamientos, actividad de roedores y ganado (capas de estiércol de vacas- que producen acidificación en los sustratos superficiales-, 
pisoteo, etc.) pueden haber afectado la preservación, tanto de las diatomeas como de los materiales arqueológicos (Miotti et al. 2007; Fernández y Salemme 2012; Fernández 2013).

En suma, los diferentes contextos analizados presentaron los mismos tipos de alteraciones; no obstante, se identificaron variaciones en su representatividad y en los grados de alteración a lo largo de las secuencias de ocupación. Los resultados obtenidos a nivel arqueológico como experimental, han permitido profundizar en relación a los tipos y procesos de formación de las alteraciones identificadas, permitiendo un mejor conocimiento de los efectos que generan en las microhuellas de uso (ver Apéndice).

Además cabe mencionar, que si bien la materia prima más utilizada en la manufactura de los artefactos recuperados corresponde principalmente a rocas homogéneas, se observó en proporciones menores el uso de basalto (roca heterogénea o de grano grueso). En el caso de Cueva Maripe, las ignimbritas silicificadas incluyen los porcentajes más elevados de materias primas utilizadas; este tipo de roca genera micropulidos diagnósticos de manera más rápida que las rocas heterogéneas. Sin embargo, el grado de preservación es menor que las mencionadas anteriormente (Mansur 1999).

El análisis realizado de los rastros de uso identificables en los distintos tipos de materias primas registradas en Cueva Maripe, permitió determinar ciertas diferencias en cuanto al grado de preservación. Si bien, la variedad ISG1 es la más representada dentro del conjunto, las materias primas RSG3, RSG2 y el basalto presentaron mayores porcentajes de piezas con rastros de uso. Cabe aclarar que las dos primeras son al igual que la ISG1, rocas homogéneas; sin embargo, la composición litológica específica de cada una de estas (otras variedades de sílices que incluyen diferencias en el tamaño de los cristales y grano más grueso), podría haber sido alguno de los factores que generaron un mayor grado de integridad en este tipo de rocas. Estas observaciones ya habrían sido mencionadas por otros autores, que indican que el sílex de grano grueso presenta una formación más lenta de los rastros de uso pero un mejor grado de preservación (Mansur-Franchomme 1983; Plisson 1985; Vaughan 1985; Caspar 1988; Clemente y Gibaja 1998). Aún así, estudios específicos relacionados a esta temática darán un mayor sustento a esta hipótesis.

Por otro lado, si bien el uso de basalto está representado en menores proporciones, el grado de integridad de este tipo de materia prima es mayor en comparación con las otras variedades de rocas utilizadas. Los estudios realizados con anterioridad ya han 
planteado esto, proponiendo que las rocas de grano grueso, si bien tardan en formar micropulidos diagnósticos, se ven menos afectadas por los procesos postdepositacionales (Castro de Aguilar 1987/1988; Mansur 1999; Leipus 2004, 2006; Flegenheimer y Leipus 2007). Los resultados obtenidos del análisis realizado en los conjuntos de las capas superiores de Cueva Maripe estarían reflejando esta hipótesis, a diferencia de lo que ocurre en Piedra Museo, donde el uso exclusivamente de materias primas homogéneas (sin diferenciación en el tamaño de los cristales) en la producción de los artefactos líticos, no permitiría sostener esta variabilidad.

Otra de las hipótesis que se planteó en cuanto al grado de integridad de las piezas, está relacionada a la preservación diferencial de los micropulidos registrados. El estudio realizado en los contextos líticos de las distintas ocupaciones de ambos sitios observados, arrojó un bajo porcentaje del trabajo sobre cuero y material blando. Los estudios experimentales efectuados mediante alteraciones químicas (Ver Apéndice), y los realizados por otros investigadores (Mansur 1986; Plisson y Mauger 1988; Levi Sala 1993), sostienen que los micropulidos generados por el trabajo sobre materiales blandos como la piel, cuero, carne y tendones, tienen menor grado de preservación que aquellos generados por el contacto con material duro (hueso, madera, mineral). Los bajos porcentajes registrados de micropulidos sobre material blando animal, podrían estar relacionados con esta hipótesis de preservación diferencial. Dicha hipótesis será tratada en próximos trabajos y considerada como parte de los nuevos objetivos para el reconocimiento de las microhuellas de uso. Aún así, los bajos porcentajes identificados sobre material blando animal y las otras variedades de materiales identificados, brinda información de suma importancia para comprender e indagar en las prácticas de consumo utilizadas por los grupos cazadores-recolectores que habitaron la Meseta Central de Santa Cruz desde inicios del Holoceno.

\section{2. PRÁCTICAS DE CONSUMO Y DISEÑOS ELEGIDOS EN LA MANUFACTURA DE LOS ARTEFACTOS EMPLEADOS}

Este apartado se relaciona con el estudio de las estrategias de uso de los artefactos líticos, que orientan la toma de decisiones en los diseños utilizados y manufacturados.

El estudio de las prácticas de consumo permite vincular la producción de objetos materiales y los modos de uso a los cuales serán destinados estos objetos. El análisis funcional de base microscópica brinda una herramienta fundamental a la hora de 
indagar en las prácticas de consumo utilizadas por sociedades cazadores-recolectores del pasado. Este análisis permite determinar el material utilizado, al igual que los movimientos empleados mediante los trabajos desarrollados a partir de artefactos líticos. El estudio de las prácticas de consumo incluye dos ejes fundamentales: 1) los recursos empleados junto con las actividades desarrolladas y 2) las opciones técnicas seleccionadas durante los procesos productivos, las cuales se podrían expresar a partir de los diseños elegidos, teniendo en consideración su relación entre el valor de producción y el uso específico destinado (Pfaffemberger 1992; Ingold 1997, 2001; Risch 2002; Álvarez 2003,2011; Briz 2010).

\section{VIII.2.1. Materiales trabajados y actividades desarrolladas}

\section{-Transición Pleistoceno/Holoceno y Holoceno temprano (Capa 5 de CN y UA4 de CS en Cueva Maripe y Capas 6 y 4/5 de AEP1)}

Los momentos iniciales de ocupación de los dos sitios (CM y AEP1) estuvieron caracterizados por condiciones ambientales diferentes a las actuales (ver Capítulo 2 y bibliografía allí citada). Esto generó que los recursos disponibles y utilizados por los grupos cazadores-recolectores que habitaron en el pasado la Meseta Central, hayan variado con el paso del tiempo. Sin embargo, los estudios zooarqueológicos realizados en los sitios mencionados indican que el guanaco habría sido el recurso animal más utilizado para los distintos momentos de ocupación (Marchionni 2013). Esto concuerda con otros sitios cercanos al área estudiada (Aguerre y Pagano 2003; Borrero 1990; Borrero et al. 1998; Mengoni 1999; Miotti y Salemme 1999; Paunero 2009b; Rindel 2009). El sitio AEP1 de Piedra Museo evidencia estas propuestas en sus contextos de ocupación inicial, donde el guanaco constituía el principal recurso, sin embargo, también se habría complementado por el consumo de fauna pleistocénica extinta (Marchionni 2013; Miotti et al. 1999), congruente con lo que ocurre en otros sitios de la zona (Cardich 1987; Cardich y Miotti 1983; Borrero 1989-90; Miotti 1989; Miotti y Salemme 2004; Paunero et al. 2000, 2003, 2005; Paunero y Castro 2001).

Los numerosos estudios realizados en los conjuntos arqueofaunísticos de AEP1 identificaron la presencia de fauna pleistocénica extinta en coexistencia con recursos actuales y a su vez, al igual que en algunos sitios de la región, se reconocieron marcas de procesamiento y alteración térmica sobre los restos óseos recuperados de estas 
primeras ocupaciones [Miotti 1989 (1998); Miotti 1996, 1999; Miotti y Tonni 1996; Miotti y Salemme 1999; Miotti y Marchionni 2009; Marchionni et al. 2010; Marchionni 2013).

De acuerdo al análisis funcional realizado en los conjuntos líticos de los componentes inferiores, el recurso trabajado más representado corresponde al material duro indiferenciado (madera o hueso), tanto con filos formatizados $(41 \%)$ como naturales (72\%). Aún así, se reconoció el empleo de otros materiales como el trabajo sobre cuero, que fue realizado exclusivamente a partir de filos formatizados. También se observó el empleo de los artefactos sobre hueso y madera. Para el trabajo sobre hueso se utilizaron principalmente filos retocados, mientras que para las actividades desarrolladas sobre madera, filos naturales. Esto probablemente se deba a su efectividad para la extracción de corteza y alisado de este material de dureza intermedia (ver Capítulo 6).

\section{-Trabajo sobre piel y hueso}

Como se mencionó anteriormente, los resultados obtenidos a partir del análisis funcional, concuerdan en que en la microrregión estudiada y en los momentos iniciales de ocupación del área, los recursos más utilizados corresponden al trabajo sobre piel/cuero y hueso. En el caso de la piel, la actividad más representada incluye acciones transversales, realizadas a partir del raspado y sobado de pieles. El desarrollo de esta actividad habría incluido principalmente el uso de filos retocados. Los filos naturales habrían intervenido principalmente en las etapas de extracción de la piel del animal, ya que en su mayoría se registraron piezas empleadas longitudinalmente. Además, y debido a los resultados obtenidos de la serie experimental de referencia, es posible suponer que los filos naturales no habrían intervenido en las demás etapas del tratamiento de este material, debido a un ángulo más agudo que genera un excesivo filo, capaz de producir roturas al realizar el trabajo más fino sobre este material luego del secado.

Los rastros del trabajo sobre piel y cuero identificados en filos retocados se encuentran desarrollados de manera marginal a partir de su distribución en el filo y en algunas piezas se reconocieron surcos profundos paralelos entre sí, lo que podría estar indicando la presencia de ciertos aditivos para su tratamiento.

Sin embargo, para el caso de los filos naturales, no se registró este aditivo e intervinieron mayormente en acciones longitudinales. Cabe aclarar que el trabajo sobre 
cuero implica distintas etapas durante el proceso productivo. La primera de ellas consiste en el cuereo (extracción de la piel del animal). Algunas crónicas (Claraz 1864; Muster 1964) detallan este proceso llevado a cabo por los Tehuelches meridionales, indicando que la extracción de la piel se realizaba a partir de unos pequeños cortes en sectores puntuales del animal (patas y vientre). Las etapas siguientes consisten en el secado, limpieza (extracción de restos de carne, grasa y/o pequeños capilares adheridos al cuero) y por último, su conservación en soluciones (orina, ocre y/o aceite), los taninos vegetales favorecen esta etapa permitiendo incrementar la flexibilidad y extender la vida útil de este material.

Por lo tanto, los rastros observados podrían estar indicando las distintas etapas de acondicionamiento, preparación de pieles y producción de bienes de consumo como vestimenta, contenedores, etc. Por otro lado, el tamaño de las piezas líticas (grande a muy grande) y la ausencia de rastros asociados a dispositivos de enmangue en el bloque temporal establecido, permitiría plantear una utilización manual de estos instrumentos.

Además del trabajo sobre piel y cuero, se reconoció el empleo sobre hueso de los artefactos en los componentes inferiores de los sitios bajo estudio. La capa 6 de AEP1 (Pleistoceno final) presenta evidencia exclusivamente del trabajo sobre este material en grupos de raederas y cuchillos de filos naturales. Mientras que en los conjuntos de la capa 4/5 (transición Pleistoceno-Holoceno), se observó mayor variedad en los grupos tipológicos identificados, al igual que en los materiales trabajados; distinguiéndose su utilización sobre hueso y material blando como el cuero y/o piel. En el sitio Cueva Maripe no se observan estas diferencias, la capa 5 de $\mathrm{CN}$ y la UA4 de CS, registran variabilidad en los grupos identificados al igual que en los recursos procesados.

La identificación de marcas de corte sobre los conjuntos arqueofaunísicos recuperados de estas unidades en ambos sitios, estarían indicando actividades de procesamiento primario y secundario (Marchionni 2013). Los rastros del trabajo sobre hueso habrían sido realizados a partir de acciones transversales principalmente con filos retocados. Mientras que las acciones longitudinales habrían sido realizadas a partir de filos naturales alargados y en menores proporciones. Los resultados obtenidos a nivel experimental indican que los filos naturales no son propicios para actividades de corte o aserrado, ya que generan abundante esquirlamiento (eliminando a su vez los micropulidos generados por el mismo uso) y en algunos casos, llegando a fracturar parcialmente el filo utilizado. Sin embargo, el raspado sería una actividad efectiva que, si bien generaría abundantes esquirlamientos (similares en algunos casos a retoques 
intencionales), permitiría la extracción del periostio y limpieza efectiva del hueso, que en el caso de realizarse este procedimiento sobre huesos largos, podría estar relacionado a la posible extracción de médula [Miotti 1989 (1998)]. Las marcas de corte identificadas sobre restos de Hippidion saldiasi y especímenes de camélidos, tanto $L$. gracilis como L. guanicoe, (Alberdi et al. 2001; Miotti 2003; Miotti y Cattáneo 2003; Miotti y Salemme 2005; Miotti et al. 1999), junto con huellas de corte en un fragmento de costilla de Mylodon sp. (Marchionni y Vázquez 2012), estarían avalando las hipótesis previamente establecidas para AEP1, acerca del procesamiento de camélidos y el aprovechamiento oportunístico de los caballos para los momentos iniciales de ocupación del sitio (Miotti 1996; Miotti y Salemme 2005; Miotti et al. 1999). Si bien la representación de milodontinos es escasa en el conjunto de Capa 6 de AEP1, se sugiere igualmente una explotación ocasional posiblemente por carroñeo (Borrero 2009; Borrero y Franco 1997; Borrero y Martin 2012; Miotti y Salemme 1999, Marchionni 2013). Los rastros de uso identificados en los artefactos líticos sobre hueso, podrían estar relacionados a estas actividades de procesamiento identificadas tanto en AEP1 como en Cueva Maripe, al igual que en la manufactura de instrumentos elaborados sobre hueso (Miotti 1998; Miotti et al. 2007; Miotti y Marchionni 2010, 2013).

Los instrumentos formales recuperados del componente temprano en AEP1 (capa 4/5) y Componente 1 de Cueva Maripe, junto con la producción de artefactos informales elaborados sobre restos óseos, permitirían sostener estas afirmaciones (Miotti y Marchionni 2013).

\section{-Trabajo sobre madera}

En la cuenca estudiada, el trabajo sobre madera esta igualmente representado pero en menores proporciones. Cabe aclarar que los resultados obtenidos del trabajo sobre material duro vegetal incluye, en el caso de AEP1, solamente la capa 4/5, implicando un momento posterior de ocupación del alero diferente al identificado en la capa 6. Para el caso de Cueva Maripe los materiales corresponden exclusivamente al Componente 1, definido como el bloque temporal del Pleistoceno final/Holoceno temprano.

Las actividades desarrolladas incluyeron principalmente acciones transversales, probablemente el raspado, descortezamiento y/o alisado de la superficie sobre este material. Estas actividades estuvieron realizadas, en su mayoría, a partir de filos formatizados, mientras que las acciones longitudinales fueron identificadas en 
porcentaje menores y específicamente a partir de filos naturales (Capítulo VII, figura 34).

Las actividades inferidas permiten plantear que este recurso habría sido utilizado como materia prima para la manufactura de otros objetos (corte de leña, astiles u otros elementos relacionados con la captura de presas), que debido a sus características particulares no han podido ser conservadas en el registro arqueológico.

Dentro de las actividades identificadas en los filos formatizados se incluyó principalmente acciones transversales, con un desarrollo marginal del micropulido sobre el filo. Esto estaría indicando un ángulo de trabajo más recto y, debido a las características observables de los micropulidos identificados (muy brillante y homogéneo sobre la superficie), indicarían que el trabajo se habría realizado sobre el material en estado fresco. Las piezas empleadas longitudinalmente, incluyeron en su mayoría filos naturales y el desarrollo del micropulido en ambas caras del filo de manera más extendida, lo que implica un ángulo de trabajo más recto.

El registro del trabajo de madera en contextos tempranos habría sido registrado igualmente en sitios cercanos al área estudiada. Tal es el caso de los instrumentos analizados del nivel 11 del sitio Los Toldos (cueva 3) y del Ceibo (cueva 7), siendo los únicos que registran rastros de trabajo sobre material vegetal (Mansur-Franchomme 1983). En los demás sitios de la Meseta Central se habrían identificado únicamente actividades de procesamiento derivados de productos animales (Mansur-Franchomme 1983, 1986; Castro de Aguilar 1994) (Figura 114).

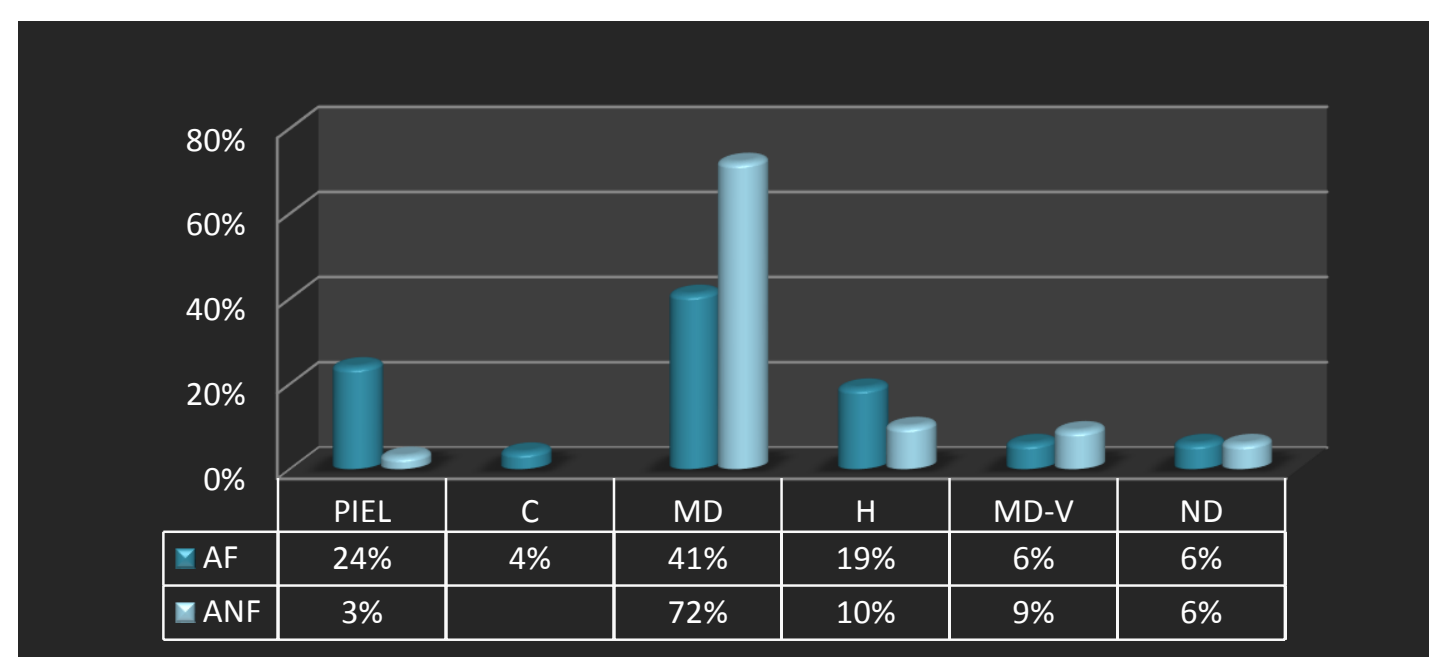

Figura 114: Recursos utilizados en el componente 1 de Cueva Maripe (Capa 5 CN y UA4 CS) y componente inferior de AEP1, Piedra Museo (Capa 6 y 4/5). C: cuero; MD: material duro; H: hueso; MD-V: material duro vegetal; ND: no determinable. 
Si bien hasta el momento existen pocos trabajos a partir de la metodología de análisis funcional en sitios de contextos tan tempranos como los estudiados en esta tesis, los resultados obtenidos en áreas cercanas concuerdan con los recursos identificados para este bloque temporal. En este sentido, cabe mencionar el trabajo realizado en el sitio El Ceibo (cueva 7) por Mansur (1983, 1986,1987), donde los conjuntos líticos recuperados coinciden con las características mencionadas para las etapas iniciales de exploración y/o colonización de la Meseta Central de Santa Cruz (Borrero 1989-90, 1994-95; Borrero y Franco 1997; Franco 2002; Miotti y Salemme 1999, 2003, 2004). Los instrumentos recuperados son escasos, sin embargo, las características principales de estos (sobre lascas anchas con retoques unifaciales, marginales y escamosos) han permitido plantear cierta semejanza con los del nivel 11 de Los Toldos (Cardich et al. 1987). Los resultados obtenidos a partir de este análisis en El Ceibo, sugirió usos mediante prehensión manual de los artefactos sobre pieles (frescas o secas) y en algunos casos para corte de carne y un número reducido en trabajo sobre madera.

En el sitio Cerro Tres Tetas (cueva 1) el análisis funcional y de distribución espacial de los artefactos, indicó igualmente la existencia de áreas de corte y de raspado, como actividades de procesamiento secundario de productos animales o derivados, principalmente cuero y en menor medida hueso (Paunero y Castro 2001). Sin embargo, en este caso, no se reconoció el trabajo sobre madera, como si ocurre en los sitios mencionados anteriormente y en los estudiados en este trabajo de tesis.

También es importante señalar que en el componente temprano (U4) del sitio Casa del Minero 1 (Cueto et al. 2012), con características diagnósticas de la fase colonizadora como ocurre en la capa 6 de AEP1, especies de camélidos extintos y evidencia de procesamiento primario y consumo (fractura helicoidal y marcas de corte), los recursos identificados a partir de los conjuntos líticos analizados, corresponden al trabajo sobre cuero y hueso exclusivamente.

Sin embargo, más allá de que exista una congruencia en los materiales trabajados por los conjuntos líticos, la importancia reside en que para la transición Pleistoceno/Holoceno, ya habría claras evidencias de la etapa de colonización en distintas localidades de la Meseta Central y se mantienen las hipótesis planteadas acerca de la funcionalidad de AEP1, como un sitio de procesamiento dentro de lo que sería una estación de caza, tanto para la capa 6 como para la 4/5 y CM como área de actividades de base residencial desde el principio de su ocupación. 
-Holoceno medio (capa 4 de CN y UA2 de CS de Cueva Maripe y Capa 2 de AEP1, Piedra Museo)

El Holoceno medio está caracterizado por un período de mejoramiento climático que se vería reflejado en el desarrollo de una estepa herbácea en áreas de Patagonia (Miotti et al. 1999; Miotti y Salemme 2004; Paunero 2003; Borromei 2003; Salemme y Miotti 2008; Mancini et al. 2002). También se habría producido la etapa de consolidación territorial por parte de los grupos cazadores-recolectores que habitaban la Meseta Central (Coronato et al. 1999; Miotti y Salemme 2004), con una disminución en la continentalidad provocado por el incremento del nivel del mar consecuencia del deshielo (Borrero 1999; Miotti 2003, 2010; Miotti y Salemme 1999; Fernández 2012).

Los resultados obtenidos del análisis funcional, evidencian para este bloque temporal un incremento en el número de piezas, en los grupos tipológicos y en los recursos utilizados en las ocupaciones identificadas (Capa $4 \mathrm{CN}$ y UA3 de CS en Cueva Maripe y Capa 2 de AEP1).

Los recursos establecidos a partir del análisis efectuado, registraron principalmente el trabajo sobre materiales duros indeterminados, madera y hueso en menores proporciones; mientras que el trabajo sobre materiales blandos estuvo representado a partir del registro de actividades desarrolladas sobre cuero, piel y material no leñoso vegetal.

\section{-Trabajo sobre material duro: hueso y madera}

Los conjuntos observados del Componente 2 de CM y Capa 2 de AEP1, evidencian un mayor uso de los artefactos en actividades sobre materiales duros principalmente. En algunos casos se pudo especificar el tipo de material trabajado más allá de su dureza, identificando un incremento en el uso de recursos vegetales (i.e. madera) y en menor cantidad sobre material óseo.

El trabajo sobre madera estuvo realizado en su mayoría a partir de acciones transversales y posiblemente haya incluido actividades de descortezamiento, raspado y/o alisado del material mencionado. El empleo de madera estuvo relacionado principalmente a filos formatizados y en menor medida filos naturales, que incluyeron, igualmente, mayores porcentajes de acciones transversales durante su empleo. Muy pocas piezas (tanto artefactos formatizados como no formatizados) fueron empleadas de 
manera longitudinal sobre este tipo de material. Los resultados obtenidos a nivel experimental sugieren un uso poco efectivo de los filos naturales en el desarrollo de acciones longitudinales, debido a que produce un excesivo esquirlamiento del filo.

En algunas de las piezas analizadas, se reconoció además micropulido de material duro en sectores proximales. Los casos identificados corresponden al grupo tipológico de los raspadores, grupo que se encuentra representado a lo largo de toda la secuencia de los sitios estudiados. Sin embargo, hacia el Holoceno medio se produce un incremento en la aparición de estos artefactos (Hermo 2008). En los casos estudiados donde se reconoció micropulido en sectores proximales, sumado al tamaño (mediano-pequeño) de las piezas observadas y a un uso intensivo de sus filos, permitiría sugerir el empleo de estos instrumentos a partir de distintos dispositivos de enmangue.

Probablemente, el marcado incremento del trabajo sobre material duro vegetal estuvo relacionado a la manufactura de estos elementos u otros utilizados durante la captura de presas.

El trabajo sobre hueso se encuentra menos representado en los conjuntos observados; sin embargo, en este caso, se observa su empleo a partir de acciones transversales y longitudinales en artefactos formatizados y con filos naturales mayormente en acciones longitudinales.

La utilización de los artefactos sobre este tipo de material, estaría asociado a las actividades de procesamiento primario y secundario de presas y manufactura de instrumental óseos. Durante estas ocupaciones los recursos faunísticos disponibles fueron semejantes a los actuales, y los estudios zooarqueológicos realizados reconocen porcentajes elevados del consumo del guanaco complementado por rheidos, evidenciado a partir de un incremento de restos de cáscara de huevo en el registro arqueológico, que habría sido un uso estacional de este recurso (primavera-verano) (Marchionni 2013). En el caso de las aves de tamaño mediano, están representadas en menores proporciones y si bien no se sabe con certeza que hayan sido utilizados como alimento en primera instancia, sí se identificó su uso en la producción y manufactura de instrumentos y adornos (Carden 2009; Marchionni 2013; Miotti 1996; Miotti et al. 1999; Miotti y Marchionni 2013). Los rastros del trabajo sobre hueso en los artefactos líticos recuperados de estas unidades, podrían haber estado relacionados al desarrollo de estas actividades y probablemente también hayan incluido el uso de artefactos elaborados sobre materias primas óseas (Miotti y Marchionni 2013). El análisis y reconocimiento de la producción de tecnología ósea y su potencial uso, podrían ser incorporados como 
agenda a futuro a partir de la realización de una serie experimental adecuada para la identificación de rastros de uso de este tipo de artefactos.

\section{-Trabajo sobre material blando: cuero/ piel y recursos vegetales no leñosos}

Al igual que en el componente anterior, el trabajo sobre piel y cuero fue reconocido como recurso utilizado a partir de artefactos formatizados y con filos naturales. Sin embargo, la presencia de micropulidos relacionados al trabajo sobre este tipo de material blando, se encuentra representado en bajas proporciones. Algunas de las hipótesis planteadas en relación con el grado de integridad de los conjuntos analizados, sugerirían que los procesos postdepositacionales habrían actuado en la preservación de este tipo de rastros. Sin embargo, los materiales recuperados de las últimas excavaciones y que están siendo procesados, aportarían nuevos datos que permitirán sostener o rechazar esta hipótesis.

Los artefactos que trabajaron este tipo de material en su mayoría estuvieron formatizados, los cuales fueron empleados principalmente a partir de acciones transversales y posiblemente hayan incluido actividades de raspado y sobado del cuero. Mientras que las acciones longitudinales estuvieron identificadas en un número menor de piezas y realizadas a partir de filos naturales. Debido al poco desarrollo de caracteres que permiten identificar la presencia de aditivos, se cree que estos no fueron utilizados en su tratamiento, salvo en pocas excepciones, entre las que se puede mencionar la identificación de una sustancia de coloración rojiza sobre la cara ventral de un raspador de filo frontal corto. Por otro lado, en relación a las características principales de los micropulidos observados sobre este material, no se registró su desarrollo de manera extendida hacia el interior del filo. En este sentido, se sugiere que habrían sido utilizados con un ángulo de ataque más recto o en algunos casos a partir de algún tipo de intermediario que permitiera el desarrollo de esta actividad.

En cuanto a los recursos vegetales no leñosos, fueron reconocidos únicamente en el Componente 2 de Cueva Maripe. El trabajo sobre este tipo de material estuvo realizado exclusivamente sobre lascas con filos naturales e incluyó únicamente acciones longitudinales. Los restos de vegetales identificados en la secuencia del sitio, podría estar asociado al uso de este recurso. Su disposición en forma de camada, sugeriría algún tipo de acondicionamiento de la cueva en determinados momentos de su ocupación (Miotti et al. 2005; 2007). Estas actividades ya habrían sido identificadas en 
otros sectores cercanos al área bajo estudio. Las investigaciones realizadas por Gradín (1987) mencionan, en el sitio Cueva de las Manos (nivel 1 capa 6), la presencia de camadas de restos vegetales en la secuencia de ocupación; del mismo modo las investigaciones realizadas por Paunero y Castro (2001), registran restos vegetales dispuestos en la estratigrafía del sitio Cerro Tres Tetas (CTT). Los artefactos no formatizados podrían haber intervenido en este proceso de acondicionamiento de Cueva Maripe, en momentos donde algunos sectores no hayan estado del todo disponibles para su ocupación (Miotti et al. 2011) (Figura 115).

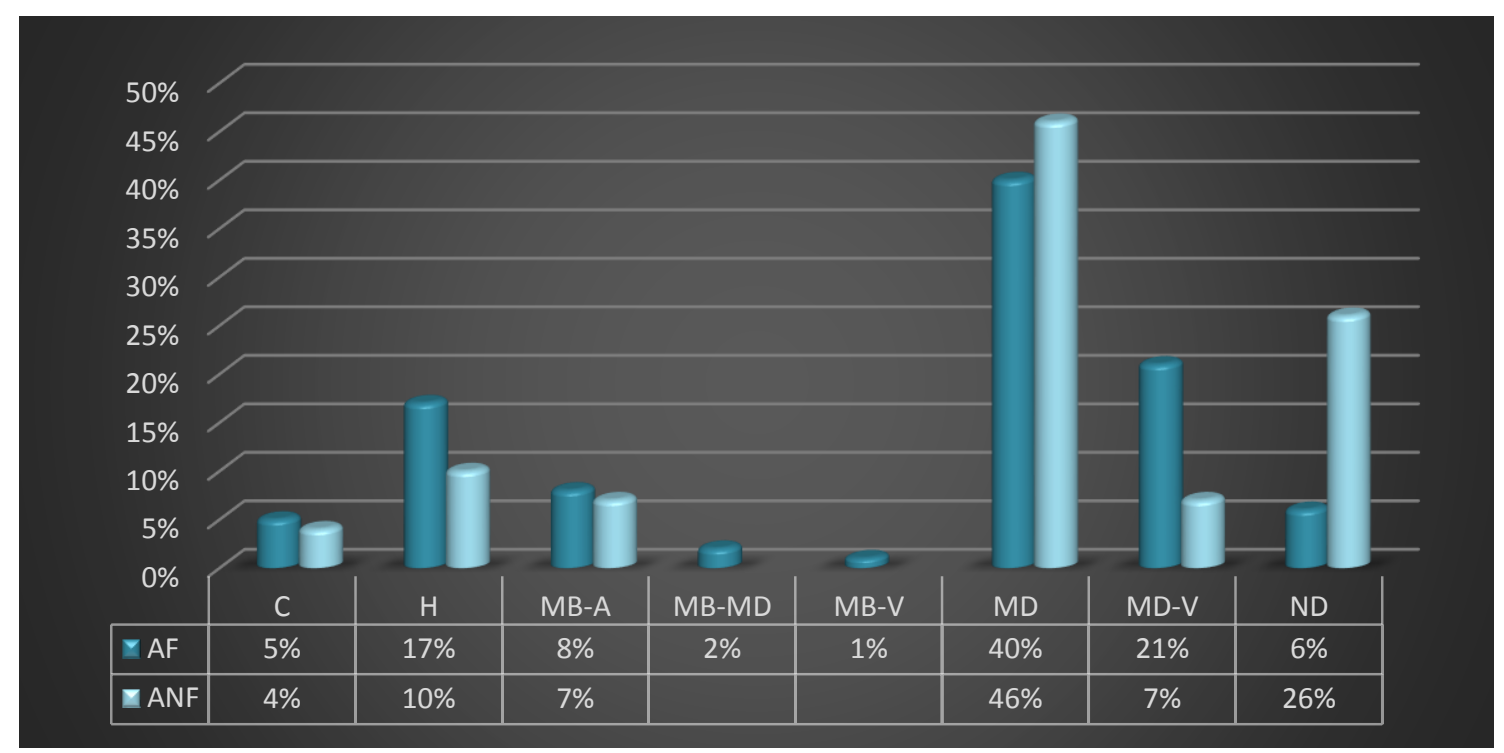

Figura 115: Recursos identificados en el Componente 2 de Cueva Maripe y componente superior de AEP1 (Capa 2).

En síntesis, la alta frecuencia del trabajo sobre material vegetal, evidencia la importancia que tuvo este recurso en las sociedades cazadoras-recolectoras hacia el Holoceno medio. Los recursos vegetales brindarían, por lo tanto, la materia prima para la manufactura de diferentes artefactos, que sumado al consumo de otros materiales (piel, cuero, hueso, vegetal no leñoso) se habrían incrementado para ese entonces, permitiendo inferir que hacia el Holoceno medio las sociedades de cazadores recolectores definen una creciente estructuración de los espacios de las bases residenciales, con diferenciación de áreas de actividad. 


\section{-Holoceno tardio (Capa 3 y 2 de CN y UA2 de CS de Cueva Maripe y Capa 1 de} AEP1, Piedra Museo).

Este período incluye los últimos 3000 años A.P. y corresponde al inicio de la configuración actual de la región Patagónica, con ocupaciones más estables para algunos sectores (Miotti y Salemme 2004; Salemme y Miotti 2008; Cassiodoro 2009; Goñi 2010). Este bloque temporal está comprendido por el Componente 3 de Cueva Maripe (Capas 3 y 2 de CN y UA2 de CS) y la UE1 de AEP1 (Capa 1).

Los resultados obtenidos del análisis funcional difieren de los registrados en el componente anterior. Los recursos identificados corresponden principalmente al uso sobre materiales duros, hueso y menores proporciones de trabajo sobre madera. Los materiales blandos identificados en el registro están representados en bajas frecuencias, donde se reconoció el trabajo sobre material blando indeterminado y cuero.

\section{-Trabajo sobre materiales duros: hueso y madera}

El empleo sobre material duro animal (hueso) se vió incrementado en los conjuntos identificados para el último bloque temporal en las secuencias establecidas. El trabajo sobre este material habría sido efectuado a partir de artefactos formatizados como también con filos naturales. Sin embargo, las cinemáticas empleadas varían en cada caso. Las acciones transversales estuvieron relacionadas principalmente a filos formatizados, mientras que las longitudinales realizadas en su mayoría por filos naturales. Las actividades desarrolladas a partir de acciones transversales probablemente hayan incluido el raspado y limpieza de restos óseo; mientras que las longitudinales hayan intervenido en el aserrado de este material. También se pudo reconocer una frecuencia menor de artefactos con distintas cinemáticas realizadas a partir de un mismo filo (acciones longitudinales y transversales a la vez). Si bien en estos niveles no se pudo identificar la manufactura de tecnología ósea, se sugiere que los artefactos líticos probablemente hayan intervenido en diferentes actividades de procesamiento de este recurso. Para ese entonces, al igual que en el bloque anterior, el consumo de guanaco y rheidos se encuentra representado en el registro; a partir de marcas de corte y alteración térmica en los conjuntos zooarqueológicos analizados. Sin embargo, también se observa un incremento en el uso de recursos faunísticos de menor porte, como el caso de dasipódidos, presentes en el registro de Cueva Maripe, a partir de la identificación de 
placas dérmicas quemadas y que probablemente habrían formado parte de la dieta de estos grupos en el pasado [(Miotti 1989 (1998); Marchionni 2013]. El consumo de dasipódidos es asimismo registrado en casi todos los sitios de Patagonia para el Holoceno tardío, lo que es interpretado como un cambio en las estrategias de consumo por varios autores y que se relaciona con la intensificación, diversificación o potenciación de los recursos (Miotti 2012 y bibliografía allí citada).

Por otra parte, algunas crónicas detallan las cacerías comunales de dasipódidos y otros pequeños animales, como los Ctenomys (tucu tucu o cururos) actividades desarrolladas principalmente por grupos de mujeres y/o niños [Miotti 1989 (1998)].

Asimismo, se reconoció en menores proporciones el uso de artefactos sobre material duro de origen vegetal (madera). En este caso, los recursos vegetales registran una disminución en su uso. Los artefactos que trabajaron este recurso, consisten en su mayoría en filos naturales empleados a partir de acciones longitudinales.

Sin embargo, en este bloque temporal se observan altas frecuencias del trabajo sobre material duro indeterminado. El análisis de las piezas utilizadas sobre material duro incluiría casos donde no se pudo determinar el material trabajado específicamente, ya sea por el tiempo empleado o el estado del recurso utilizado. Esto produjo que no se generaran rastros diagnósticos que permitieran identificar el material de manera concreta como en los casos anteriores y que sólo se haya podido determinar la dureza relativa de los materiales procesados. Estos corresponden a artefactos con filos formatizados como también naturales y fueron utilizados para llevar a cabo acciones transversales como longitudinales, que indicarían corte o aserrado.

El trabajo sobre materiales duros podría incluir recursos vegetales, óseos, o minerales (pigmentos), abriendo paso a la incorporación de ciertos conocimientos acerca de otras esferas de orden social como la producción de pinturas y grabados rupestres identificados en los contextos arqueológicos estudiados (Carden 2009; Miotti et al. 2010).

-Trabajo sobre materiales blandos: cuero y piel

El trabajo sobre cuero estuvo realizado a partir de filos formatizados como también naturales y en su mayoría empleados mediante acciones transversales; lo que probablemente haya incluido actividades de limpieza, raspado y/o alisado sobre este material. Además de este recurso, se identificó el trabajo sobre material blando 
indiferenciado. En este caso, si bien no se pudo determinar más allá de la dureza relativa, se cree podría haber estado relacionado con el trabajo sobre material blando de origen animal (i.e. carne, tendones), rastros que demoran en formarse y que en pocas ocasiones ha podido ser identificado a nivel arqueológico (Keeley 1980; AndersonGerfaud 1981; Mansur-Franchomme 1983).

Por otro lado, al igual que en el componente anterior, se cree que para este bloque temporal se habrían realizado actividades iniciales del tratamiento del cuero, además del resto de las etapas incluidas para la manufactura de elementos elaborados sobre este tipo de material (vestimenta, tensores, elementos contenedores, etc.). Sin embargo, los bajos porcentajes identificados del uso de este recurso, podrían estar relacionado a los efectos de procesos postdepositacionales que hayan actuado en el registro arqueológico para los momentos más tardíos de ocupación. Aún así, la identificación del trabajo sobre cuero es un fuerte indicador de las actividades propuestas anteriormente (Figura 116). Los datos obtenidos a partir de crónicas de viajeros, mencionan el uso de este recurso en la manufactura de distintos elementos, que formaron parte de la vida cotidiana de los grupos que habitaron la Meseta Central hacia el Holoceno tardío. El cuero era obtenido mediante la caza del guanaco: “...se le sacaba la piel [en general de chulengos y juveniles] para hacer mantas, reservando la carne para alimento, y el cuero [de animales grandes]... para reparar el toldo...” (Musters 1964:164).

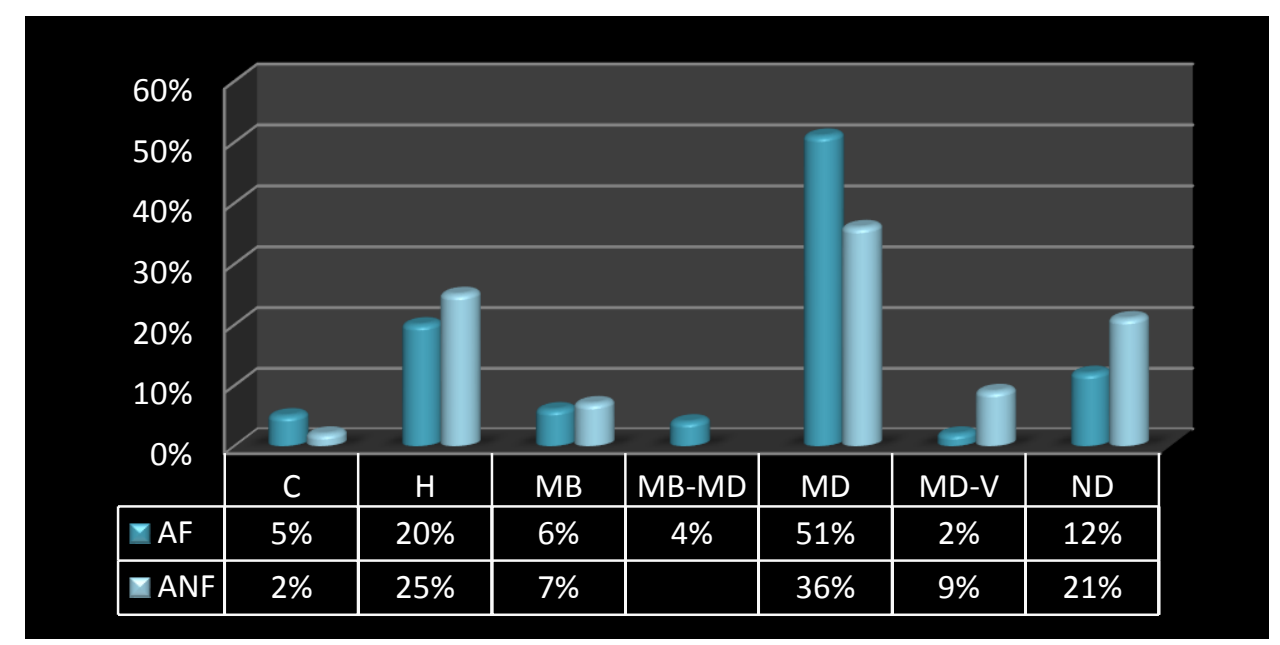

Figura 116: Recursos identificados en el Componente 3 de Cueva Maripe y capa 1 de AEP1, bloque temporal definido como Holoceno tardío. 


\section{VIII.2.2. Opciones técnicas seleccionadas durante los procesos productivos y los} diseños elegidos.

Si bien la tecnología debe ajustarse a objetivos y limitaciones del ambiente físico y social, la producción de formas específicas implica una elección resultado de las necesidades funcionales y tecnológicas en un contexto social determinado (Bradley y Giria 1996; Schiffer y Skibo 1997; Hocsman y Escola 2006/2007). Las diferencias en los filos de los artefactos pueden estar relacionadas a determinados aspectos funcionales, debido a que la variación que presentan estas formas implica un modo de contacto diferente entre el filo y el material a procesar, y en este sentido el diseño particular de un filo, ha sido pensado para el desarrollo de funciones independientes (Hocsman 2006). Las opciones técnicas incluyen así ciertas variables del diseño de los artefactos manufacturados para ese uso (largo del filo, forma del borde, etc.) y la aplicación exitosa de un instrumento depende, por lo tanto, de su efectividad durante la etapa de producción y por ende, de ciertos atributos formales que faciliten distintos requerimientos (ángulo del filo, longitud, tipo de materia prima, etc.). El diseño de un artefacto es establecido a partir de un conjunto de variables que definen una determinada forma mediante el uso de materias primas líticas.

En este apartado se consideran algunas de estas variables en relación a las prácticas de uso identificadas a partir del análisis funcional.

De acuerdo a lo desarrollado hasta el momento, las opciones técnicas podrían considerarse, a partir de grupos cerrados (Aschero 1975, 1983), pero teniendo en consideración las características principales de los filos utilizados. Las categorías tecnomorfológicas preestablecidas han adjudicado cierta funcionalidad a los artefactos, sin embargo, los usos a los cuales fueron destinados no presentan una correlación directa con estas categorías (Aschero y Hocsman 2004; Hocsman 2006). Las variables que intervienen en la determinación de usos está relacionado principalmente a las distintas características de los filos utilizados (Álvarez 2003, Álvarez et al. 2010; Briz 2002; Pal 2012; Risch 2002). En este apartado se discute este punto teniendo en consideración los grupos tipológicos y los usos establecidos en los conjuntos líticos analizados. Hasta el momento, se ha podido determinar el uso de estos filos en actividades relacionadas a la dieta de los grupos, como también, a la manufactura de otras tecnologías como la producción de artefactos de madera, cuero y material óseo. A continuación, se discute la relación entre el desarrollo de las diferentes actividades y las opciones técnicas 
identificadas, a partir de las categorías morfotécnicas analizadas en las distintas ocupaciones registradas.

\section{Grupo de raspadores}

Este grupo corresponde a una de las categorías más representadas a lo largo de la secuencia de ocupación de los sitios analizados. Sin embargo, la frecuencia de ocurrencia y las características principales de este grupo varía en los distintos bloques temporales establecidos. En su mayoría, se encuentran elaborados sobre materias primas silíceas de buena calidad para la talla y de procedencia local. No obstante, y como ha sido mencionado en el Capítulo VI, la ausencia de este grupo en la capa 6 de AEP1, marca ciertas diferencias en la producción tecnológica para este sitio en momentos iniciales de ocupación. Por otro lado, se registra un uso diferencial de materias primas en la manufactura de estos artefactos. En los componentes inferiores se observa un mayor uso de otras variedades de rocas como el xilópalo y calcedonia de muy buena calidad para la talla. Además, se registra una reducción en los tamaños de las formas bases seleccionadas, ya que en los componentes inferiores se identificaron tamaños de piezas muy grandes, que para momentos más tardíos se encuentran ausentes.

Por otro lado, en el Holoceno se registra cierta homogeneidad interna en este grupo tipológico, donde se observa la selección principalmente de lascas angulares y de arista para su manufactura y en el caso particular del Componente 2 de CM, su producción a partir de hojas, tema tratado más adelante en este capítulo.

Los resultados obtenidos del análisis funcional de este grupo han permitido asociarlo al trabajo sobre diversos materiales (cuero, piel, madera, hueso, material duro indiferenciado). Sin embargo, en cuanto a la cinemática empleada se reconoció, en los casos identificados como filos frontales cortos, un modo de empleo exclusivamente a partir de acciones transversales, mientras que los filos laterales largos presentaron cinemáticas diversas. Por otro lado, se observó hacia el Holoceno medio un incremento en el uso de estos artefactos sobre material duro vegetal y su disminución en momentos posteriores. Probablemente, esto estaría relacionado a la producción de ciertos elementos que habrían intervenido en actividades de consumo como también relacionado a otras tecnologías, que por sus características no han podido ser reconocidas en el registro arqueológico. 
Además, se registró evidencia del uso de sustancias adherentes (posiblemente resinas) en estos artefactos, lo que refiere por la ubicación de las mismas, a posibles dispositivos de enmangue (Lynch y Hermo 2011). Si bien otros autores han planteado el uso de estos instrumentos mediante el empleo de mangos y su posible determinación a nivel arqueológico (Castro 1987; González Urquijo e Ibáñez Estévez 1994; MansurFranchomme 1983; Mansur y Lasa 2005; Rots 2002, 2006) su reconocimiento es una tarea dificultosa, esto se debe en general, a que en los casos donde las piezas se encuentran bien sujetas y no hay un continuo movimiento, no se generan rastros bien desarrollados que permitan su identificación; sumado a los efectos ocasionados por los procesos postdepositacionales que afectan a los artefactos en contextos arqueológicos. Aún así, los rastros reconocidos en los casos estudiados permitirían sostener este modo de empleo en algunas de las piezas analizadas (Lynch y Hermo 2011).

Por otro lado, se examinó con mayor detenimiento las variables que intervienen en el diseño de los filos utilizados, considerando cierta variabilidad observada en cuanto a los materiales trabajados.

Aquellos empleados sobre materiales blandos presentaron filos menos espesos que los utilizados sobre materiales duros (prueba de Mann-Whitney $U=216 ; p=0,02$ ). Mientras que en relación con las variables de longitud, anchura y ángulo del filo usado, no se pudieron determinar diferencias significativas entre las medias, respecto al material trabajado. Sin embargo, en cuanto a la forma secundaria de los filos, se reconoció el empleo de filos convexos (atenuados, medios y semicirculares) exclusivamente en materiales blandos, mientras que los filos empleados sobre materiales duros presentaron formas secundarias más variadas (rectilíneos, cóncavos, convexos muy atenuados). En este sentido, se pueden mencionar trabajos anteriores que expresan las cualidades que tienen los filos convexos sin salientes en actividades desarrolladas sobre material blando como el cuero, ya que proveen de una mayor flexibilidad durante su uso, evitando accidentes y roturas del material (Hayden 1990; Álvarez 2003).

Igualmente se consideraron las variables de longitud, anchura y espesor de las piezas, con el fin de observar diferencias en cuanto a la dureza del material trabajado en los distintos bloques temporales establecidos. Si bien los resultados estadísticos no fueron significativos (considerando un 95\% de significancia), se observó una tendencia entre las medias de la longitud (prueba de Kruskal Wallis; $\mathrm{H}=4,83$; $\mathrm{p}=0,08$ ) y anchura (prueba de Kruskal Wallis; $\mathrm{H}=4,9 ; \mathrm{p}=0,08$ ) de las piezas que trabajaron materiales duros. Hacia los momentos iniciales de ocupación de los sitios las piezas presentaron 
una mayor longitud y anchura que en el resto de la secuencia con un promedio de $58 \mathrm{y}$ $46 \mathrm{~mm}$. respectivamente (Tabla 10 ).

\begin{tabular}{|c|c|c|c|c|c|c|c|c|}
\hline \multirow[b]{2}{*}{ Raspadores } & \multicolumn{4}{|c|}{ Material blando } & \multicolumn{4}{|c|}{ Material duro } \\
\hline & Long. & Anch. & Esp. & Mod. A-E & Long. & Anch. & Esp. & Mod. A-E \\
\hline $\begin{array}{c}\text { Holoceno } \\
\text { temprano } \\
\text { (Capa } 5 \text { y } \\
\text { UA4) }\end{array}$ & $\begin{array}{l}60,9 \pm 20 \\
(33-55)\end{array}$ & $\begin{array}{l}32,5 \pm 12 \\
(16-44)\end{array}$ & $\begin{array}{l}9,9 \pm 5,6 \\
(7-18,5)\end{array}$ & $\begin{array}{l}3,9 \pm 3,9 \\
(1,7-6,3)\end{array}$ & $\begin{array}{l}58 \pm 26,7 \\
(32,7-114)\end{array}$ & $\begin{array}{l}46 \pm 21,5 \\
(19,2-81)\end{array}$ & $\begin{array}{l}18,5 \pm 14,1 \\
(5-27,1)\end{array}$ & $\begin{array}{l}3,2 \pm 1,76 \\
(1,6-6,7)\end{array}$ \\
\hline $\begin{array}{c}\text { Holoceno } \\
\text { medio } \\
\text { (Capa } 4 \text { y } \\
\text { UA3) }\end{array}$ & $\begin{array}{l}42,8 \pm 11 \\
(31-69)\end{array}$ & $\begin{array}{c}28,8 \pm 4,4 \\
(20-39)\end{array}$ & $\begin{array}{l}9,8 \pm 2,9 \\
(2,92)\end{array}$ & $\begin{array}{l}3,2 \pm 1,15 \\
(32-82)\end{array}$ & $\begin{array}{l}40,6 \pm 12,4 \\
(21,2-85,6)\end{array}$ & $\begin{array}{l}30,7 \pm 12,4 \\
(21,8-87)\end{array}$ & $\begin{array}{l}9,2 \pm 2,4 \\
(4-13,5)\end{array}$ & $\begin{array}{l}3,5 \pm 1,6 \\
(2,1-9,5)\end{array}$ \\
\hline $\begin{array}{c}\text { Holoceno } \\
\text { tardío } \\
\text { (Capa } 3 \text { y } 2 \\
\text { y UA2) }\end{array}$ & $\begin{array}{l}47,6 \pm 20 \\
(32-82)\end{array}$ & $\begin{array}{l}30 \pm 3,7 \\
(26-36)\end{array}$ & $\begin{array}{l}10,7 \pm 2,8 \\
(6-14)\end{array}$ & $\begin{array}{l}3 \pm 0,8 \\
(2,1-4,3)\end{array}$ & $\begin{array}{l}39,9 \pm 8,2 \\
(31,2-54,7)\end{array}$ & $\begin{array}{l}28,6 \pm 3,8 \\
(20-32,5)\end{array}$ & $\begin{array}{l}9,2 \pm 1,9 \\
(5,3-11,7)\end{array}$ & $\begin{array}{l}3,3 \pm 1,0 \\
(2,2-5,7)\end{array}$ \\
\hline
\end{tabular}

Tabla 10: Medida centrales y de dispersión del grupo de raspadores, a partir del material trabajado, en los distintos bloques temporales identificados en Cueva Maripe. L: longitud en mm.; A: ancho en mm.; E: pesor en mm.; Mod. A-E: módulo de longitud-anchura.

En conclusión y debido a los resultados obtenidos a partir del análisis de ciertas variables del diseño y de los cambios identificados en bloques temporales definidos, se podría establecer que, en los sitios estudiados, este grupo presenta poca especialización funcional acompañado de cierta variabilidad en los diseños, a pesar de una tendencia hacia la estandarización de su forma, comenzada en las ocupaciones del Holoceno medio y acentuada hacia el Holoceno tardío.

\section{Grupo de raederas}

Estas se encuentran representadas en toda la secuencia de ocupación de los sitios analizados y en la capa 6 de Piedra Museo, constituye el único tipo de artefacto formal (Andrefsky 1994, 2001) en esta unidad. Sin embargo, la frecuencia de aparición de este grupo es menor que los artefactos definidos como raspadores, aunque en muchos casos los filos de raederas se presentan como complementarios del grupo mencionado.

En cuanto a las materias primas utilizadas, se registraron diferencias a lo largo de las distintas ocupaciones. Hacia el Pleistoceno final y Holoceno temprano el grupo de raederas estuvo elaborado principalmente sobre materias primas de muy buena calidad para la talla, incluyendo porcentajes mayores de xilópalo y calcedonia en su producción. 
En momentos posteriores, las variedades de materias primas utilizadas disminuyen junto con el xilópalo y se mantiene la utilización del sílex y calcedonia, rocas igualmente de buena calidad para la talla en su manufactura. Por otro lado, se observa un incremento en su producción hacia los niveles inferiores y una disminución en su frecuencia hacia los momentos más tardíos, donde se reconoce el incremento de otros grupos tipológicos, como los raspadores, caracterizados por cierta variabilidad tecnológica.

Los resultados del análisis tecno-morfológico de este grupo evidencian cierta homogeneidad en algunos de los atributos que las definen (selección de formas bases preferentemente de lascas internas, angulares y de arista, tamaños mediano grandes y grandes y retoques unifaciales directos). En trabajos anteriores se ha planteado que este grupo presenta cierta diversidad tecnológica en su manufactura y que esto podría deberse a usos específicos (Paunero y Castro 2001; Álvarez 2003; Leipus 2006). En contextos tempranos cercanos al área de estudio, como en el sitio Casa del Minero 1 y Cueva Túnel; se definió el uso de estos instrumentos en actividades de procesamiento de recursos de origen animal, principalmente el trabajo sobre piel o cuero, al igual que el uso sobre materiales duros como la madera (Castro 1994; Paunero y Castro 2001; Cueto y Castro 2012; Cueto 2013). Esto mismo ocurre en los conjuntos líticos recuperados de otros contextos arqueológicos, donde el uso de las raederas estuvo asociado al trabajo sobre material duro vegetal pero en menores proporciones (Leipus 2006).

En los contextos bajo estudio y con el fin de determinar ciertas diferencias en este grupo tipológico a lo largo de los bloques temporales establecidos, se consignaron las variables de longitud, anchura y espesor para ser sometidos a test estadísticos (prueba de Kruskal-Wallis). Los resultados obtenidos no fueron estadísticamente significativos entre las medias de cada una de estas variables, esto permitiría plantear que no existen grandes diferencias en relación a los tamaños en la producción de estos artefactos. Sin embargo, se registraron ciertas particularidades en los filos utilizados que estarían relacionados a usos específicos. El análisis funcional realizado al grupo de raederas presentó cierta variabilidad en los recursos procesados. Se reconoció su empleo principalmente sobre materiales duros indiferenciados, hueso y madera, y en menores proporciones sobre materiales blandos, cuero y piel.

En cuanto a las características principales de los filos utilizados, se reconoció en su mayoría la producción de filos largos. Los empleados sobre materiales duros presentaban formas secundarias rectilíneas o convexo muy atenuado; mientras que los 
filos empleados sobre materiales blandos únicamente convexos atenuados. En cuanto a la conformación de los bordes, se reconocieron ciertas diferencias en los momentos iniciales de ocupación, donde se registraron filos principalmente dentados o normales con espolones. Mientras que en momentos posteriores, los bordes utilizados fueron normales o normales con dentado sumario, donde a su vez también se observó, un mayor uso de este grupo sobre materiales blandos (i.e. cuero o piel). Mientras que en relación al ángulo y la longitud de los filos utilizados, estos fueron en su mayoría agudos y con una longitud promedio de $44 \mathrm{~mm}$.

En cuanto a los modos de empleo, se reconoció el uso de estos instrumentos sobre materiales blandos a partir de acciones transversales y en un solo caso mediante acciones longitudinales o de corte. Mientras que las utilizadas sobre materiales duros presentaron distintos modos de empleo, a partir de acciones transversales, longitudinales, y en un solo caso ambas acciones a la vez sobre un mismo filo. Debido a que no se registraron rastros de posible asociación al uso de enmangues y en relación al tamaño de las piezas (mediano grandes y grandes), se sugiere un empleo manual de estos artefactos.

De acuerdo a los resultados obtenidos del análisis efectuado, podemos concluir que en los conjuntos estudiados, este grupo tipológico no presenta grandes diferencias en su producción; sin embargo algunas de estas diferencias se reconocen principalmente en los filos observados y en la diversidad de los recursos procesados. Podríamos concluir que las piezas representativas de este grupo tipológico presentan cierta especialización funcional con baja variabilidad en los diseños y que habrían estado vinculadas principalmente al procesamiento primario y consumo, junto a la manufactura de bienes e intermediarios (herramientas, sistemas de armas, vestimenta, abrigos, etc.) a partir de la explotación de recursos disponibles en el ambiente.

\section{Grupo de cepillos y muescas retocadas}

En los sitios analizados estos grupos se encuentran representados en bajas proporciones, sin embargo, estudios anteriores identificaron el grupo de cepillos en asociación a ocupaciones tempranas, principalmente hacia finales del Pleistoceno (Borrazzo 2006, 2011; Cattáneo 2005; Charlin y Borrero 2012; Civalero et al. 2005; Franco 2002). En sitios cercanos al área estudiada se han recuperado este tipo de artefactos y en muchos casos se estableció una posible asociación al trabajo sobre materiales blandos, 
principalmente al raspado de cuero o piel. Aún así, en pocos casos se efectuó el análisis funcional para corroborar las afirmaciones propuestas y en los casos concretos donde se realizó permitió afirmar estas asociaciones, sumado a otros posibles usos como el trabajo sobre madera y material duro animal (Castro 1987/88; 1994; Cattáneo y Aguerre 2009; Leipus 2006; Paunero y Castro 2001). Lo mismo ocurrió en el sitio Casa del Minero 1 (CD1), donde se recuperó un ejemplar de este grupo y el análisis funcional realizado en sus filos evidenció el trabajo sobre material blando, específicamente piel (Cueto 2013).

En otros países, como por ejemplo el área peninsular de España, el análisis funcional realizado sobre este tipo de instrumentos en contextos relacionados al Holoceno (con una cronología de 8.500 años AP.), habría permitido identificar un uso específico de manera manual y a partir de acciones de raspado sobre material duro de origen vegetal (madera) (Risco Zorita 2010).

En los sitios analizados en esta tesis, el grupo de cepillos fue igualmente reconocido en las ocupaciones identificadas para el bloque temporal del Pleistoceno final, mientras que las muescas retocadas presentaron una mayor extensión temporal siendo registradas hasta momentos posteriores del Holoceno tardío y al igual que en sectores cercanos, representados por un número reducido de piezas. En los conjuntos observados, el grupo de cepillos se encuentra elaborado en su mayoría, sobre materias primas de buena calidad para la talla, variedades de sílex y un solo caso de xilópalo, con reserva de corteza. Mientras que en relación a los atributos que los definen están caracterizados por el uso de nódulos o lascas primarias y angulares espesas como formas bases, de tamaños exclusivamente muy grandes y pesados (en algunos casos mayores a 150 grs.). En cuanto a las características principales de sus filos, se disponen principalmente de manera perimetral o fronto-lateral y se pudo observar evidencia de reactivación. Presentan, además, una sección longitudinal normal irregular o sinuosa, de forma primaria dentada irregular, generado a partir de retalla extendida y forma secundaria principalmente convexa.

El análisis funcional realizado en este grupo permitió determinar su uso sobre material blando animal (piel) al igual que materiales duros (hueso). Mientras que la cinemática desarrollada a partir de los filos analizados corresponden exclusivamente a actividades de raspado. Debido a su "robustez" (piezas de tamaños muy grandes y pesadas), y a la falta de rastros asignables a algún modo específico de empleo, se cree un uso principalmente manual de estos instrumentos. 
Sin embargo, las diferencias establecidas en los filos analizados (de morfología convexa y conformación del borde dentado o normal con dentado sumario), permitirían plantear cierta variabilidad en las actividades desarrolladas por este grupo. El trabajo sobre material blando animal podría haber estado relacionado a las primeras etapas del tratamiento y limpieza de los cueros en estado fresco, lo que permitiría mayor flexibilidad y menor tendencia a roturas durante el trabajo realizado. En el caso identificado sobre material duro animal, también estaría relacionado a las etapas de limpieza, ya que las características principales de los filos de estos instrumentos realizarían de manera efectiva el trabajo sobre este tipo de material. Los filos identificados en este grupo tipológico, con ángulos más rectos y espesos, serían variables que favorecerían al desarrollo de esta actividad, evitando posibles fracturas en sus filos y particularmente en las piezas.

En cuanto a las muescas retocadas, estas estuvieron elaboradas a partir de retoques marginales, con la producción de filos restringidos de morfología cóncava o cóncava atenuada. En cuanto al análisis realizado (Capítulo VI), se reconoció su utilización principalmente sobre material duro animal (hueso) mediante acciones transversales o de raspado.

En conclusión, estos grupos estarían relacionados con la realización de tareas específicas [raspado de hueso y material blando animal (i.e. piel y cuero)] y esta especialización en los usos se vería plasmado en la producción de sus diseños.

\section{Grupo de cuchillos con filos naturales o retocados}

La identificación de este grupo tipológico en distintos contextos arqueológicos ha permitido plantear cierta variabilidad en su producción. En sitios localizados en el noreste de la península Ibérica, la manufactura de estos artefactos incluye otras materias primas como la madera y el hueso, sin embargo, su inferencia funcional está relacionada principalmente a distintas actividades de procesamiento de presas (Gibaja Bao et al. 2002). En nuestro país, la información disponible indica que la producción de estos artefactos estuvo relacionada al trabajo sobre material duro indiferenciado y en algunos casos sobre madera, a partir de acciones longitudinales (Álvarez 2003; Leipus 2006; Paunero y Castro 2001). En el sitio Cueva Túnel (Cueto 2013), con fechados tempranos y cercano al área estudiada, el análisis funcional realizado sobre un cuchillo con filo 
complementario de raedera, habría determinado el uso de este grupo sobre material duro y blando a la vez.

En los sitios analizados, este grupo está representado por un número reducido de piezas, no obstante, incluye una amplia distribución temporal, ya que se localizan desde los momentos iniciales de ocupación hasta los más tardíos. En muchas ocasiones el reconocimiento de este tipo de artefactos ha sido dificultoso, en especial en los casos definidos a partir de filos naturales (Cattáneo 2002, 2005).

En la capa 6 del sitio AEP1, los cuchillos identificados relacionados a este tipo, se encuentran elaborados sobre lascas grandes de adelgazamiento de bifaces, de módulos de espesor delgados y en algunos muy delgados, con filos largos y microlascados aislados como rastros complementarios de los filos identificados. El grupo de cuchillos definidos en los momentos iniciales de ocupación del sitio AEP1 de Piedra Museo, registró pocos casos con rastros de utilización, debido al desarrollo de lustres de suelo que presentaban las piezas en la superficie de sus caras, con un grado de alteración intenso. Aún así, en algunos casos se pudo reconocer el empleo de estos artefactos sobre materiales duros probablemente de origen animal y en un solo caso sobre material blando indiferenciado. El trabajo sobre material duro empleó acciones longitudinales mientras que el único caso definido sobre material blando, acciones transversales o de raspado. A pesar de esto, el desarrollo de rastros de uso se vio afectado por alteraciones postdepositacionales intensas, que en muchos casos, imposibilitó el análisis funcional de las piezas. En este sentido y debido a la baja evidencia de rastros de uso observados, sería demasiado arriesgado definirlas como cuchillos. Por lo tanto se considera más conveniente definirlos como artefactos expeditivos que cubrieron un espectro de tareas generalizadas.

En los componentes superiores de los sitios analizados se identificaron exclusivamente cuchillos con filos retocados. La distribución de los filos fue lateral de retoque marginal e inverso. El grado de integridad en estos elementos fue moderado y en algunos casos se pudo identificar el material trabajado. Se reconoció el empleo de este grupo principalmente sobre materiales duros de origen animal (i.e. hueso) y únicamente a partir de acciones longitudinales.

Los rastros identificados y las características principales de los filos observados (filos largos de ángulos agudos, rectilíneos y conformación del borde dentado regular o normal con dentado sumario), permitiría suponer en los sitios analizados cierta especialización en su uso, específicamente sobre material duro animal, sumado a una 
manufactura a partir de formas bases alargadas (lascas grandes u hojas), que serían propicias para la obtención de este tipo de filos.

\section{Grupo de bifaces y unifaces}

La producción de estas piezas implica distintas etapas de su manufactura y una serie de estadios de reducción y afinamiento de la pieza a través de sucesivas formatizaciones (Álvarez 1999; Böeda et al. 1990; Hocsman 2006). En este apartado se menciona exclusivamente la producción bifacial y unifacial de piezas en el primer estadio de reducción.

Estos grupos se encuentran identificados principalmente en los bloques temporales definidos como Holoceno temprano y medio. Hacia el tardío si bien se registra la presencia de estos artefactos en los conjuntos observados, se reconoce cierta disminución en su producción. La mayoría de las piezas presentan filos perimetrales de morfología convexa atenuado, de arista sinuosa irregular de talla extendida y retoque marginal.

Los resultados obtenidos del análisis funcional realizado permitieron determinar un número reducido de piezas con rastros de uso asignables en los distintos bloques temporales establecidos. En su mayoría, se infirió un uso de manera transversal sobre material duro animal, aunque en algunos casos simplemente se pudo determinar su dureza relativa. En cuanto a la cinemática empleada se reconoció su empleo de manera transversal al material trabajado (raspado), y en uno de los casos no se pudo determinar el movimiento aplicado. El bajo número de piezas con rastros de uso podría estar relacionado a la reactivación de sus filos o las distintas etapas de reducción, donde posibles rastros asignables a su utilización hayan sido removidos de la pieza.

En este sentido, el análisis funcional realizado no permite esclarecer con certeza la funcionalidad de este tipo de instrumentos, debido a la baja cantidad de piezas presentes en el registro y específicamente a un número aún más reducido de piezas con rastros diagnósticos de uso. Sin embargo, y de acuerdo a lo establecido hasta el momento, en relación con las características tecno-morfológicas y funcionales de estos instrumentos, se considera que habrían sido manufacturados para un uso específico en actividades de procesamiento y que debido al tamaño y espesor de estas piezas tendrían cierta flexibilidad en sus diseños. 


\section{Grupo de perforadores, cuñas y gubias}

Los grupos mencionados se encuentran identificados en los componentes superiores de ocupación y están presentes con un bajo grado de representatividad en los conjuntos analizados. Estos grupos corresponden a instrumentos de retoques marginales o extendidos, obtenidos a partir de lascas internas, angulares o de aristas y hojas como formas bases y de tamaño mediano pequeño a mediano grande. En los casos identificados como perforados se reconoció su utilización sobre material duro animal, pero no se pudo determinar la cinemática empleada en ninguno de los casos analizados. El trabajo exclusivamente sobre materiales duros de estos instrumentos y la falta de determinación respecto a la cinemática empleada, podría deberse a la realización de distintos movimientos superpuestos sobre estos materiales. Las variables reconocidas en la producción tecnológica de estos grupos sumado al análisis funcional efectuado, sugeriría cierta especialización en el uso expresado a través de los diseños utilizados en la manufactura.

\section{Artefactos con filos naturales}

Algunos autores han mencionado que el procesamiento de diferentes recursos no necesariamente requiere de filos formatizados (Álvarez 2003; Leipus 2006; Pal 2013). Esto ya habría sido mencionado igualmente en otros países, como en el nivel V del Sitio Tres Arroyos 1 (Jackson 1987), donde se propuso que varios filos naturales de los artefactos líticos habrían sido empleados en tareas de corte y raspado. Sin embargo, estos resultados contrastan con los obtenidos del análisis funcional realizado sobre los conjuntos de Patagonia, donde se encuentra escasa utilización de filos naturales (Castro 1994; Cueto y Castro 2012).

En los sitios estudiados estos artefactos incluyen productos de talla (lascas u hojas) con filos naturales, de diferentes tamaños con predominio de módulos mediano-normales y mediano-grandes elaborados en materias primas con alto contenido silíceo. A partir del análisis funcional realizado sobre estos artefactos, se determinó un número reducido de piezas con uso asignable.

Los resultados obtenidos han sido analizados en los Capítulos VI y VII de esta tesis, sin embargo, a continuación se discuten algunas de las variables del diseño de los filos con rastros de uso identificable para cada uno de los bloques temporales establecidos. 
Los análisis realizados permitieron determinar diferencias en los momentos iniciales de ocupación de los sitios. Los artefactos no formatizados utilizados sobre material duro de manera longitudinal presentaban filos significativamente más largos (prueba de MannWhitney $=\mathrm{U}=40,5 ; \mathrm{p}=0,02$ ) y piezas menos espesas (prueba de Mann-Whitney= $\mathrm{U}=37,5 ; \mathrm{p}=0,01)$ que los empleados de manera transversal. Con una longitud de filo promedio de $48 \pm 13 \mathrm{~mm}$. y espesor $8,8 \pm 5,4 \mathrm{~mm}$. en acciones longitudinales, mientras que las empleadas de manera transversal presentaron una longitud de filo promedio de $36 \pm 9,5 \mathrm{~mm}$. y espesor promedio de la pieza de 9,5 $\pm 6,2 \mathrm{~mm}$.

En relación a las formas secundarias de los filos, se reconoció una mayor cantidad de filos rectilíneos para el trabajo longitudinal, mientras que las piezas empleadas de manera transversal presentaron una mayor variedad en las formas secundarias de los filos utilizados (convexos, cóncavos, sinuosos y rectilíneos).

Los artefactos empleados sobre materiales blandos de origen animal, estuvieron escasamente representados y presentaron ángulos agudos a rectos de morfología convexa atenuada (Tabla 11).

\begin{tabular}{|c|c|c|c|c|c|c|c|c|c|c|c|}
\hline & \multirow{2}{*}{\multicolumn{3}{|c|}{$\begin{array}{c}\text { Material blando } \\
\text { Filo }\end{array}$}} & \multicolumn{8}{|c|}{ Material duro } \\
\hline & & & & \multirow{2}{*}{\multicolumn{4}{|c|}{$\frac{\text { Filo }}{L N}$}} & \multicolumn{4}{|c|}{ Filo } \\
\hline & \multicolumn{3}{|c|}{$T R$} & & & & & \multicolumn{4}{|c|}{$T R$} \\
\hline & $F S$ & $S L$ & $L$ & $F S$ & $S L$ & $L$ & $A$ & $F S$ & $S L$ & $L$ & $A$ \\
\hline $\begin{array}{c}\text { H.T. } \\
\text { (Capa } \\
5 y \\
\text { UA4) }\end{array}$ & $\begin{array}{l}\text { CX: } \\
\text { N=1 } \\
\text { CXA: } \\
\text { N=1 }\end{array}$ & $\mathrm{R}: \mathrm{N}=2$ & 43 & $\begin{array}{l}\mathrm{R}: 47 \%(\mathrm{~N}=8) \\
\text { CX:29\% } \\
\text { (N=5) } \\
\text { CXA:12\% } \\
\text { (N=2) } \\
\text { CVA: } 12 \% \\
(\mathrm{~N}=2)\end{array}$ & $\begin{array}{l}\mathrm{R}: 85 \% \\
(\mathrm{~N}=13) \\
\mathrm{CV}: 15 \% \\
(\mathrm{~N}=4)\end{array}$ & $\begin{array}{l}34,1 \\
\pm 13,7 \\
(20-70)\end{array}$ & $\begin{array}{l}48,07 \\
\pm 13,4 \\
(30-86)\end{array}$ & $\begin{array}{l}S: 21 \% \\
(N=3) \\
C X: 36 \% \\
(N=5) \\
C V A: 14 \% \\
(N=2) \\
R: 29 \% \\
(N=4)\end{array}$ & $\begin{array}{l}C V: 15 \% \\
(N=2) \\
C V A: 8 \% \\
(N=1) \\
R: 62 \% \\
(N=8) \\
S: 15 \% \\
(N=2)\end{array}$ & $\begin{array}{l}30,8 \\
\pm 13,2 \\
(15-59)\end{array}$ & $\begin{array}{l}36,5 \\
\pm 9,6 \\
(20-56)\end{array}$ \\
\hline
\end{tabular}

Tabla 11: Características principales de artefactos con filos naturales del Componente 1 (Pleistoceno final) de CM. TR: acciones transversales; LN: acciones longitudinales; FS: forma secundaria; SL: sección longitudinal; L: longitud en mm.; A: ancho en mm.

En momentos posteriores y específicamente hacia el Holoceno medio, se reconoce en Cueva Maripe (ver Capítulo VI) un incremento en la producción de hojas, con filos naturales y que también habrían sido utilizadas como formas bases para artefactos formatizados (Hermo 2008). En cuanto a los materiales trabajados, no se reconocieron grandes diferencias (ángulo y longitud del filo) entre estos y las cinemáticas empleadas. Sin embargo, los filos utilizados sobre materiales blandos se presentaron en su mayoría con morfologías convexas y convexas extendidas, mientras que los filos trabajados sobre materiales duros, presentaron una mayor variedad que incluyen rectilíneos, 
cóncavos atenuados, sinuosos y en menores proporciones convexos. Si bien no se pudieron determinar diferencias significativas entre el empleo sobre materiales blandos y duros a partir de distintas cinemáticas, se cree que las diferencias registradas en los filos, hayan sido factores decisivos en las elecciones tecnológicas durante su producción y en la selección de estos artefactos para el uso al cual fueron destinados.

\section{VIII.2.3. Variabilidad de los conjuntos observados y su relación con la funcionalidad de las ocupaciones arqueológicas.}

Al inicio de esta tesis se había propuesto como objetivo específico aplicar el método del análisis funcional de base microscópica a los materiales líticos procedentes de los sitios Cueva Maripe y Alero El Puesto 1, con el fin de corroborar las hipótesis formuladas hasta el momento respecto a la funcionalidad de los sitios en las distintas ocupaciones arqueológicas identificadas. Por mucho tiempo se ha considerado que la variabilidad en la composición de los grupos tipológicos, conformaban el punto de partida para brindar una explicación en relación a la funcionalidad de un determinado sitio. Estas propuestas dejan de lado otras posibles causas capaces de generar variabilidad en los conjuntos observados; ya sea diferencias culturales, cuestiones de índole estilística o áreas específicas de actividades (Andrefsky 1994; Dunnell 1978; Nelson 1991). Algunos autores, han planteado la necesidad de incorporar estos factores a los análisis ya que son capaces de generar variabilidad en el registro arqueológico. Los estudios realizados por Álvarez 2003; Álvarez et al. 2000; Castro de Aguilar 1994, 1996; Mansur-Franchomme 1983; Mansur y Lasa 2005; Mansur y Vila 1993; Paunero y Castro 2001, plantean algunas de estas cuestiones al respecto en áreas cercanas a la estudiada.

En este sentido, la metodología del análisis funcional aplicado a conjuntos líticos, ha demostrado que la relación entre forma y función no siempre es directa, ya que diseños semejantes pueden haber tenido funciones diferentes. Igualmente se ha observado que, inclusive en grupos con cierta homogeneidad en el modo de producción tecnológica, han sido utilizados sobre distintos materiales. Tal es el caso del grupo de raspadores que si bien presentan cierta similitud en su producción, los usos a los cuales fueron destinados, han sido identificados a partir de distintos materiales y durezas (Álvarez et al. 2000; Calvo et al. 2011; Mansur y Lasa 2005; De Angelis 2012).

Por lo tanto, podemos plantear que la búsqueda de relaciones forma-función en el instrumental lítico no es algo novedoso (Calvo 1999, 2002; Juel Jensen 1988; Landini 
et al. 2000; Leipus 2006; Mansur y Lasa 2005; Odell 1981; entre otros) y debido a las dificultades que presentan, los esfuerzos de investigación en esta línea han ido paulatinamente decayendo sobre todo por la ausencia de resultados evidentes. En primer lugar, uno de los puntos claves en esta cuestión incluye el uso de procedimientos de clasificación inadecuados para los objetivos que se habían planteado. El segundo factor es, el mantenimiento de las categorías tipológicas como unidades básicas de análisis, en donde se fuerza a la identificación de posibles vinculaciones entre forma y función. Al enfrentar los datos proporcionados por el análisis funcional con la caracterización morfológico-tipológica, los resultados presentaban una elevada diversidad de posibles usos, sin identificar una posible correlación forma-función. Trabajos posteriores han tenido que enfrentarse al mismo problema desde diferentes posicionamientos teóricos, y con mayor o menor grado de resolución (Calvo 1999 y 2002; Briz 2007, 2010; Debert y Sherriff 2007; Hardy et al. 2008; Landini et al. 2000; Leipus 2006).

Sin embargo, las capacidades que brinda el análisis funcional de microhuellas de uso permite superar las analogías etnográficas y morfológicas, aún a partir de categorías preestablecida, siempre y cuando se considere como punto de partida ciertas variables que permitan interpretar los modos de empleo de los conjuntos líticos; sin un sesgo $a$ priori respecto a su posibilidad funcional.

En este sentido, los resultados obtenidos a partir del análisis efectuado permitieron plantear algunas de estas cuestiones y determinar otras con mayor detalle, relacionadas con la organización espacial de ciertas actividades que difieren de la manufactura de instrumentos, como la identificación de áreas de actividades diferentes a nivel intrasitio (Cahen et al. 1979; Clemente et al. 1997; Mansur y Vila Mitja 1993; Paunero y Castro 2001). Esto permite a su vez confirmar interrogantes respecto a las posibles causas de las diferencias observadas en los conjuntos analizados y su relación con modos específicos de uso y funcionalidad de los artefactos.

La aplicación de la metodología de análisis funcional de base microscópica junto con el análisis morfo-tecnológico, permitieron generar información novedosa en cuanto a la caracterización funcional de cada una de las ocupaciones arqueológicas identificadas en los dos sitios investigados. Los modelos propuestos en el Capítulo III de esta tesis y las hipótesis formuladas en relación a la producción de la tecnología lítica en los distintos bloques temporales definidos en los sitios analizados (Capítulos VI y VII), plantean ciertas diferencias identificables en la producción y uso de los distintos conjuntos observados. 
En las ocupaciones iniciales, los grupos tendrían que afrontar las particularidades de un área desconocida, con condiciones ambientales y recursos diferentes a las actuales (Borrero 1994-95; Borrero y Franco 1996; Franco 2002; Marchionni et al. 2012; Marchionni 2013; Miotti 1996, 2003; Miotti y Salemme 2004, 2008; Miotti y Marchionni 2013). Las decisiones en la producción de los artefactos líticos habrían sido esenciales en la supervivencia y desplazamiento de estos primeros grupos. Al inicio de este trabajo de investigación se sostiene que para ese entonces la tecnología lítica, sujeta a variables ambientales y sociales, habrían favorecido la producción de diseños versátiles capaces de cumplir distintas tareas (Civalero y Franco 2003; Franco 2002; Khun 1994; Nelson 1991). En este sentido serían esperables diferencias en la producción tecnológica como en los usos a los cuales fueron destinados para momentos posteriores.

Los resultados obtenidos en relación al análisis funcional y de ciertas variables del diseño realizado, han permitido corroborar esta hipótesis; a pesar de esto, no siempre se ve acompañado por cierta diversidad en los usos destinados. Los datos obtenidos de la capa 6 de AEP1, con pocos artefactos formales elaborados sobre materias primas de muy buena calidad para la talla, registran poca variabilidad funcional y en general está relacionada principalmente a actividades de procesamiento de presas. Esto permitiría sostener las hipótesis propuestas en relación con la funcionalidad del sitio durante los momentos iniciales de ocupación del área (Franco 2002; Miottti 1996; Miotti et al. 1999; Miotti y Salemme 2004), al igual que se condice con la función específica asignada (Miotti et al. 1999) como parte de un área de despostamiento cercano al sitio de matanza. Sin embargo y considerando los conjuntos zooarqueológicos estudiados, también sería posible asignarlo a un momento de aprendizaje inicial en un ambiente desconocido (en el sentido de Miotti et al. 2011).

A diferencia de esta primera ocupación, los conjuntos recuperados del Componente 1 de Cueva Maripe y capa 4/5 de Piedra Museo, relacionados al Pleistoceno final y Holoceno temprano, registran un incremento en la producción de artefactos formatizados, con materias de buena calidad para la talla y cierta versatilidad en los diseños utilizados, expresado a partir del tamaño de las piezas, grandes a muy grandes (algunas de talla bifacial), que permitiría realizar modificaciones parciales o totales de la forma establecida en el caso de ser necesario. Los modos de uso y recursos identificados para ese bloque, estarían relacionados a diferentes actividades, como el procesamiento de presas, manufactura de instrumentos o tratamientos de pieles para vestimenta o abrigos. 
En momentos posteriores, con condiciones ambientales y recursos disponibles semejantes a las actuales y un mayor conocimiento del ambiente (Borrero 1994-95; Miotti 2003; Miotti y Salemme 2004; Miotti y Marchionni 2011), las estrategias tecnológicas habrían estado focalizadas a la realización de tareas específicas, mediante artefactos formatizados como también a partir de lascas u hojas con filos naturales.

El incremento en el número de piezas recuperadas para estas ocupaciones y las concentraciones identificadas en relación con usos específicos, permitirían sostener las hipótesis propuestas en relación a la funcionalidad de los sitios para ese entonces. Esta habría sido definida como lugares de actividades múltiples o domésticas, donde se llevarían a cabo actividades relacionadas a la subsistencia al igual que otras de índole simbólica, como la producción de grabados y pinturas rupestres.

También, se sugiere que para ese entonces se habrían generado cambios en la distribución de los asentamientos de los grupos que habitaron la Meseta Central, acompañado por una marcada redundancia en el uso de los sitios (Borrero 1989-90, Miotti y Salemme 2004). Estos cambios incluirían además, una mayor circulación y posible intercambio de bienes, que en los casos estudiados habría comenzado hacia el Holoceno medio (identificación de obsidiana en la manufactura de artefactos líticos como materia prima de procedencia no local y restos de moluscos identificados en el registro arqueológico) (Hermo 2011; Hermo y Miotti 2011; Miotti y Salemme 2004; Miotti et al. 2007).

Estos cambios en la distribución de los asentamientos y posible redundancia ocupacional se verían expresados en la producción de un mayor número de artefactos, sumado a una mayor especificidad en los usos. Respecto a esta temática, los recursos identificados en los últimos bloques temporales difieren de los momentos iniciales de ocupación, con una producción de diseños con cierta especialización funcional, que darían sustento a estas propuestas. 


\section{CONCLUSIONES}

A lo largo de esta tesis se plantea el estudio de los conjuntos líticos recuperados de la Meseta Central de Santa Cruz. Esta investigación se realizó a partir del análisis funcional de base microscópica, que permitió indagar con mayor profundidad cuestiones respecto a los procesos de consumo y producción por parte de los grupos cazadores-recolectores que habitaron en el pasado.

El análisis efectuado en los conjuntos líticos recuperados de las distintas ocupaciones identificadas en los sitios Cueva Maripe y Alero El Puesto 1, brindaron información más acabada acerca de los procesos de formación de sitio a partir de la determinación de distintos tipos de alteraciones identificadas en las diferentes ocupaciones. El grado de integridad de los conjuntos observados no está relacionado exclusivamente a los procesos capaces de generar estas alteraciones; sino también en relación con las materias primas utilizadas en la manufactura de los artefactos.

Si bien trabajos anteriores indagaron en esta temática en los sitios mencionados, lo hicieron a partir de los conjuntos zooarqueológicos recuperados (Miotti y Marchionni 2011; Miotti et al. 2011; Marchionni 2013), los estudios referidos a esta temática realizados en este trabajo de tesis incluyen específicamente el análisis del material lítico. En este sentido, los resultados alcanzados complementan los datos obtenidos a partir de otros materiales, con características composicionales muy diferentes de aquellos producidos a partir de materias primas líticas.

Por otro lado, la serie experimental realizada en relación con alteraciones químicas, permite abarcar con mayor solidez el accionar de estos procesos en relación con las diferentes microhuellas de uso y testear algunas de las hipótesis propuestas con anterioridad, por otros autores (Levi-Sala 1993; Mansur 1983,1987, 1999; Plisson y Mauger 1988), acerca de la preservación diferencial de micropulidos generados por el uso de los artefactos. Aún así, pese a esta primera aproximación a nivel experimental, resta por analizar los efectos ocasionados por procesos mecánicos, que podrían formar parte de investigaciones a futuro.

Cabe establecer también, que en esta tesis se analizaron los procesos de consumo de los cuales formaron parte los conjuntos líticos recuperados. Los análisis cualitativos y cuantitativos de los conjuntos mencionados han permitido determinar diferencias en los 
modos de producción y uso de la tecnología lítica recuperada de los diferentes contextos arqueológicos. Los recursos disponibles en los distintos momentos de ocupación (materias primas líticas, recursos animales y vegetales) y los conocimientos adquiridos habrían jugado un rol fundamental en la producción tecnológica. La selección de determinadas formas y diseños en relación con usos específicos, habrían favorecido el desarrollo de distintas actividades en los sitios analizados. La obtención de materias primas no habría sido una tarea dificultosa para los grupos que habitaron la meseta desde momentos temprano, debido a la localización de fuentes primarias de buena calidad para la talla en áreas cercanas a los sitios analizados. Sin embargo, los usos a los cuales fueron destinados y la obtención de los recursos, habrían sido factores condicionantes respecto a la toma de decisiones en relación a la producción tecnológica. Si bien en los diferentes sectores de la cuenca las estrategias de consumo estuvieron focalizadas en la caza del guanaco (Lama guanicoe), como recurso principal, también estuvo complementada por rheidos, al igual que de otras especies de menor porte que habrían formado parte de la dieta de los diferentes grupos. En este sentido, sería esperable que estos grupos hayan utilizado diferentes estrategias tecnológicas para el desarrollo de estas actividades relacionadas con la subsistencia.

Como ha sido mencionado con anterioridad, el uso de fauna pleistocénica en la capa 6 y su reducción hacia la capa 4/5 de AEP1 y la presencia de elementos con marcas de corte, habrían permitido formular que, para ese entonces, el sitio habría sido utilizado como lugar de matanza y procesamiento primario de presas, con prácticas de consumo relacionadas a la extracción de médula ósea en el sitio hacia los $c a$. 10.400 años AP (Miotti 1996, Miotti et al. 1999). A nivel tecnológico, se observan cambios en la producción lítica y en el uso de los artefactos recuperados para este primer momento de ocupación. En este sentido se confirma la hipótesis propuesta anteriormente.

En momentos más tardíos, habría cierta especialización en el consumo del guanaco, expresado en las ocupaciones identificadas hacia el Holoceno medio de la capa 2 (Marchionni 2013). Esta especialización iría acompañada por la producción de artefactos capaces de cumplir con los requerimientos necesarios para las diferentes actividades. Estas diferencias en los usos al igual que en los diseños con cierta homogeneidad interna en la producción de la tecnología lítica, confirmarían la funcionalidad propuesta para estos momentos, donde se lo define como un lugar de actividades múltiples. Los rastros identificados a partir del trabajo sobre materiales 
duros (hueso, madera) y blandos (cuero, piel) y los diferentes modos de uso permitirían complementar la información obtenida y dar un mayor sustento a esta hipótesis.

En relación con el sitio Cueva Maripe, las prácticas de consumo difieren de acuerdo a los distintos momentos de ocupación. Si bien las actividades de subsistencia estuvieron focalizadas en la caza de guanaco como recurso principal, el sitio habría funcionado como un locus de actividades domésticas (Hermo 2008; Marchionni 2013; Miotti et al. 2005, 2007; ) con un uso diferencial de los distintos sectores de la cueva. Por lo tanto, se habría propuesto que la cámara Sur habría funcionado como lugar para el desarrollo de actividades de consumo y descarte principalmente, mientras que en el sector Norte, se habrían desarrollado actividades específicas relacionadas a la producción y uso de diferentes tecnologías y materias primas (producción de artefactos elaborados sobre material lítico como óseo), al igual que el uso de pigmentos naturales (Carden 2009; Miotti et al. 2010). El análisis realizado sobre los artefactos líticos permitió reconocer algunas de estas actividades, sin embargo, el consumo sobre materiales blandos, como la carne, no pudo ser reconocido en los conjuntos observados y esto probablemente se deba a un escaso desarrollo de los rastros definidos para estas actividades o al efecto de los procesos postdepositacionales identificados en los conjuntos observados. Aún así, el empleo de los artefactos estuvo relacionado tanto a actividades de procesamiento de presas (trabajo sobre material duro animal, hueso), como también al desarrollo de otros elementos que formaron parte de las diferentes tecnologías (mangos, astiles, etc.) y otros necesarios para afrontar las condiciones ambientales en los distintos momentos de ocupación del sitio.

En síntesis, la confrontación de la información contextual de los conjuntos líticos analizados, datos ambientales y disponibilidad de diferentes recursos, sumado a los datos derivados del análisis morfotécnico y funcional, permitió postular ciertas consideraciones generales en cuanto a las opciones tecnológicas particulares adoptadas en los diferentes contextos, generando datos que permitieron contribuir al estudio de la organización tecnológica en general.

El trabajo realizado en esta tesis, constituye una primera aproximación sistemática en el estudio del análisis funcional de base microscópica de componentes diacrónicos de dos secuencias culturales, aplicado a los conjuntos líticos recuperados de sitios localizados en las cuencas de los zanjones Blanco y Rojo del Macizo Central de Santa Cruz. Los estudios realizados brindaron información respecto a las prácticas de consumo, uso y producción de estos conjuntos y en este sentido sería propicio realizar este tipo de 
análisis en otros sectores de la cuenca, para determinar posibles diferencias en los recursos procesados, como también en los modos de uso y diseños utilizados en otros conjuntos líticos.

Por otro lado, los resultados aquí expuestos serían complementados a partir de nuevos materiales recuperados de las últimas excavaciones realizadas en el sitio Cueva Maripe, al igual que de otros sectores de la cuenca, para poder evaluar la variabilidad en las muestras analizadas. El estudio de estos materiales y de los ya analizados, podrá ser abordado a partir de nuevas técnicas o metodologías relacionadas a la identificación de posibles residuos sobre los filos utilizados. Esto incluiría otras técnicas de microscopía, como el uso del microscopio electrónico de barrido y obtención de curvas de EDAX, para la determinación de componentes químicos específicos que permitan su identificación.

También resta por completar la serie experimental de referencia, en especial al estudio de procesos postdepositacionales ocasionados a partir de acciones mecánicas (pisoteo, movimientos, redepositación, etc.), que pueden haber afectado a los conjuntos analizados y a nivel general a otros conjuntos líticos, modificando la identificación de posibles microhuellas generadas por el uso de los artefactos. En este sentido, los estudios actualísticos permitirán abordar nuevas cuestiones en relación con los procesos que afectan a los conjuntos recuperados del registro arqueológico y brindarán, junto con el análisis funcional, un conocimiento más sólido en relación a la tecnología lítica, producto de sociedades cazadoras-recolectoras que habitaron la Meseta Central de Santa Cruz. 



\section{Bibliografía, Apéndice y Planillas}

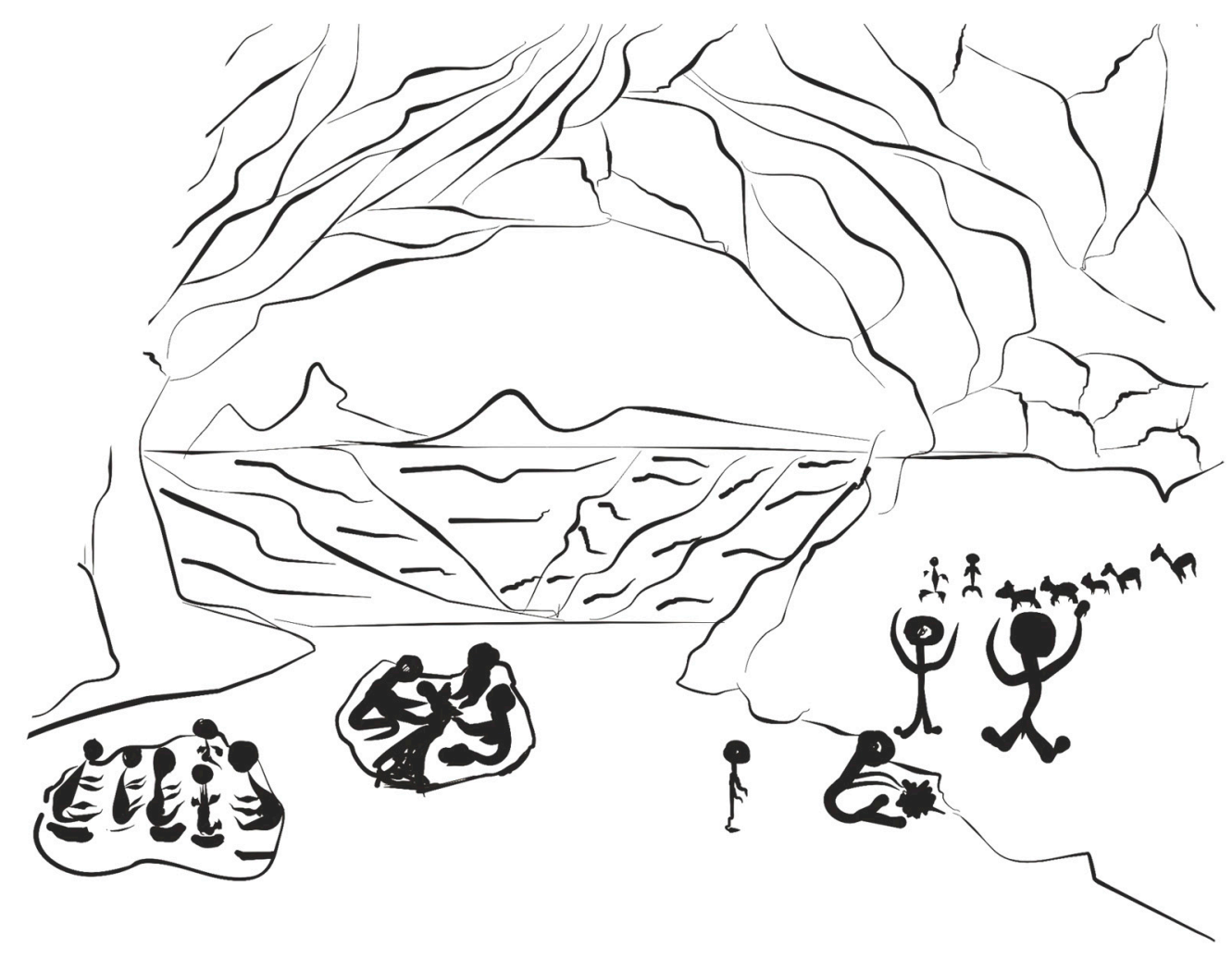





\section{BIBLIOGRAFÍA}

Adams, KR y VL Bohrer. 1998. Archaeobotanical indicators of seasonality: Examples from arid southwestern United States. Seasonality and Sedentism, Archaeological Perspectives from Old and New World Sites 6: 129-141.

Aguerre, AM. 1977. A propósito de un nuevo fechado radiocarbónico para la Cueva de las Manos, Alto río Pinturas, provincia de Santa Cruz. Relaciones de la Sociedad Argentina de Antropología 11: 129-142.

Aguerre, AM. 1982. Informe preliminar de las excavaciones de la Cueva 4 de La Martita, Departamento de Magallanes, Provincia de Santa Cruz. VII Congreso de Arqueología Argentina, San Luis, Argentina.

Aguerre, AM. 1987. Investigaciones arqueológicas en el área de La Martita, Dto. Magallanes, Provincia de Santa Cruz. I Jornadas de Arqueología de la Patagonia. Gobierno de la Provincia de Chubut, Rawson, Argentina.

Aguerre, AM. 2000. Las vidas de Pati en la toldería Tehuelche del Río Pinturas y después. Universidad Nacional de Buenos Aires, Argentina.

Aguerre, AM. 2003. La Martita: ocupaciones de 8.000 años en la Cueva 4. En Aguerre AM (Comp.). Arqueología y Paleoambiente en la Patagonia Santacruceña Argentina. Nuevo Offset, Buenos Aires, Argentina.

Aguerre, AM y MI Pagano. 2003. Fauna de las ocupaciones de 8.000 años de la cueva de La Martita: Guanaco. En Aguerre AM (Comp.). Arqueología y Paleoambiente en la Patagonia Santacruceña Argentina. Nuevo Offset, Buenos Aires, Argentina.

Alberdi, MT, AN Menegaz y JL Prado. 1987. Formas terminales de Hippidion (Mammalia, Perissodactyla) de los yacimientos del Pleistoceno tardío Holoceno de la Patagonia (Argentina y Chile). Estudios Geológicos 43: 107-115.

Alberdi, MT, L Miotti y JL Prado. 2001. Hippidion saldiasi Roth, 1899 (Equidae, Perissodactyla), at the Piedra Museo Site (Santa Cruz, Argentina): Its Implication for the Regional Economy and Environmental Reconstruction. Journal of Archaeological Science 28: 411-419.

Álvarez, M. 2003. Organización Tecnológica en el Canal Beagle. El caso de Túnel I (Tierra del Fuego, Argentina). Tesis doctoral. Universidad de Buenos Aires, Argentina.

Álvarez, M. 2004. Estrategias tecnológicas en los grupos canoeros tempranos del área Fuego-Patagónica. Magallania 32: 191-208.

Álvarez, M. 2011. Puntas de arma del extremo sur de Patagonia: algunas consideraciones sobre diseño y contexto de uso. En Bozzuto, D y J Martínez (Eds.). Armas prehíspánícas: múltiples enfoques para su estudio en Sudamérica. Editorial Fundación Azara, Buenos Aires, Argentina.

Álvarez, MR y D Fiore. 1995. Recreando imágenes: diseño de experimentación acerca de las técnicas y los artefactos para realizar grabados de arte rupestre. Cuadernos del Instituto Nacional de Antropología y Pensamiento Latinoamericano 16: 215-240. 
Alvarez, MR, D Fiore, E Favret y R Castillo-Guerra. 1998. El uso de artefactos líticos para la ejecución de grabados rupestres: observación y análisis de los rastros de utilización mediante las técnicas de microscopía óptica. Actas del XII Congreso Nacional de Arqueología Argentina: 55-62.

Álvarez, MR, A. Lasa y ME Mansur. 2000. La explotación de recursos naturales perecederos: análisis funcional de los raspadores de la costa norte del canal Beagle. Relaciones 25: 275-294.

Álvarez, ME y I Brizi-Godino. 2006 Organización tecnológica en el proceso de poblamiento del extremo sur de Sudamérica. Habitus 4: 771-795.

Álvarez, ME, I Briz-Godino, N Pal y L Salvatelli. 2010. Contextos de uso y diseños: Una propuesta metodológica para el análisis de la variabilidad de los conjuntos líticos. En Bárcena, J y H Chiavaza (Eds.). Arqueología Argentina en el Bicentenario de la revolución de Mayo, Mendoza, Argentina.

Anderson-Gerfaud, P. 1980. Etude d'utilisation d'outils préhistoriques para analyse des résidus au M.E.B. Colloque "Préhistoire et technologie litique", Tervüren, Bélgica.

Anderson-Gerfaud, P. 1981. Contribution methodologique a l'analyse des microtraces d'utilisation sur les outils prehistoriques. Tesis Doctoral, Universidad de Bordeaux, Francia.

Anderson-Gerfaud, P y D Helmer. 1987. Líenmanchement au MoustĖrien. VVAA: Le Main et líoutil. Manches et enmanchements prèhistoriques. CNRS Travaux de la Maison de LíOrient 15: 38-44.

Andrefksky, W. 1994. Raw material availability and the organization of technology. American Antiquity 59: 21-34.

Andrefksky, W. 1998. Lithics: Macroscopic Approaches to Analysis. Cambridge University Press. Cambridge, Inglaterra.

Andrefksky, W. 2001. Emerging Directions in Debitage Analysis. En Andrefsky, W (Ed.). Lithic Debitage: context, form, meaning. University of Utah Press, Utah, Estados Unidos.

Andrefsky Jr, W. 2006. Experimental and archaeological verification of an index of retouch for hafted bifaces. American antiquity 71: 743-757.

Andrefsky Jr, W. 2009. The analysis of stone tool procurement, production, and maintenance. Journal of archaeological research, 17: 65-103.

Aoyama, K. 1995 Microwear analysis in the southeast Maya Lowlands: two case studies at Copan, Honduras. Latin American Antiquity 6: 129-144.

Araujo, AG. 2013. Bioturbation and the upward movement of sediment particles and archaeological materials: comments on Bueno et al. Journal of Archaeological Science, 40: 2124-2127.

Argelés, T, A Bonet, I Clemente, J Estévez, JF Gibaja, LG Lumbreras, R Piqué, M Ríos, MA Taulé, X Terradas, A Vila y G Wünsch. 1995.Teoría para una praxis "splendorrealitatis". Trabalhos de Antropologia e Etnologia 35: 501-507.

Aschero, CA. 1975. Ensayo para una clasificación morfológica de artefactos líticos aplicada a estudios tipológicos comparativos. Informe CONICET. MS.

Aschero, CA. 1983 Registro de códigos para atributos descriptivos aplicados a artefactos líticos. Informe CONICET. MS. 
Aschero, CA. 1996. El área Río Belgrano-Lago Posadas (Santa Cruz): problemas y estado de problemas. En Gómez, J (Ed.). Arqueología, Sólo Patagonia. CENPAT-CONICET, Puerto Madryn, Argentina.

Aschero, CA y S Hocsman. 2004. Revisando cuestiones tipológicas en torno a la clasificación de artefactos bifaciales. En Acosta, A, D Loponte y M Ramos (Eds). Temas de arqueología, análisis lítico. Universidad Nacional de Luján, Argentina.

Aschero, CA, C Bellelli, MT Civalero de Biset, R Goñi, AG Guraieb y R. Molinari. 1992. Cronología y Tecnología en el Parque Nacional Perito Moreno: ¿Continuidad o reemplazos? Arqueología 2: 89-105.

Ariztegui, D, MM Bianchi, J Masaferro, E Lafargue y F Niessen. 1997. Interhemispheric synchrony of lateglacial climatic instability as recorded in proglacial Lake Mascardi, Argentina. Journal of Quaternary Science 12: 333-338.

Ariztegui, D, A Gilli, FS Anselmetti, RA Goñi, JB Belardi y S Espinosa. 2010. Lake-level changes in central Patagonia (Argentina): crossing environmental thresholds for Lateglacial and Holocene human occupation. Journal of Quaternary Science 25: 1092-1099.

Arnold, JL y WF Libby. 1951. Radiocarbon Dates. Science 113: 111-120.

Bamforth, D. 1986. Technological efficiency and tool curation. American Antiquity 51: 38-50.

Bamforth, D. 1992. Quarries in context: a regional perspective on lithic procurement: En Arnold JE (Ed.). Stone tool procurement, production and distribution in California prehistory. Universidad de California. Estados Unidos.

Barceló, JA. 2007. Arqueología y estadística: Introducción al estudio de la variabilidad de las evidencias arqueológicas. Universidad Autónoma de Barcelona, España.

Bate, LF. 1998. El Proceso de Investigación en Arqueología. Crítica, Barcelona, España.

Bayón, C y N Flegenheimer. 2004. Cambio de planes a través del tiempo para el traslado de roca en la pampa bonaerense. Estudios Atacameños 28: 59-70.

Bayón, C, P Escola y N Flegenheimer. 1995. Organización tecnológica: usos y abusos de esta perspectiva. Arqueología 5: 179-186.

Bayón, C, P Escola y N Flegenheimer. 2001. La expeditividad y su registro arqueológico, un tema olvidado. Arqueología 11: 261-270.

Belardi, J. B. y L. A. Borrero. 1999. El paisaje arqueológico de la margen norte del lago Argentino (Pcia. de Santa Cruz, Argentina). Prehistoria 3: 35-64.

Belardi, J y R Goñi. 2006. Representaciones rupestres y convergencia poblacional durante momentos tardíos en Santa Cruz (Patagonia argentina). El caso de la meseta del Strobel. En Fiore, D y MM Podestá (Eds.). Tramas en la piedra. Producción y usos del arte rupestre. WAC, AINA and SAA, Argentina.

Belardi, J, P Tiberi, C Stern y A Súnico. 2006. Al Este del Cerro Pampa: ampliación del área de disponibilidad de obsidiana de la Pampa del Asador (Santa Cruz). Intersecciones en Antropología 7: 27-36. 
Bellelli, C, V Scheinsohn y MM Podestá. 2008. Arqueología de pasos cordilleranos: un caso de estudio en Patagonia Norte durante el Holoceno Tardío. Boletín del museo chileno de arte precolombino 13: $37-$ 55.

Berón, MA y GG Politis. 1997. Arqueología pampeana en la década de los'90. Estado de las investigaciones y perspectivas. En Berón, MA y GG Politis (Eds.). Arqueología de la Región Pampeana en la Década de los'90. Museo de Historia Natural de San Rafael e INCUAPA-UNCPBA, Argentina.

Binford, L. 1962. Archaeology as Anthropology. American Antiquity 28: 217-225.

Binford, L. 1973. Interassemblage variability - the Mousterian and the "functional" argument. En Renfrew, C (Ed.). The Explanation of Culture Change. Duckworth Press, Londres, Inglaterra.

Binford, L. 1976. Forty-seven trips. A case study in the character of some formation processes of the Archaeological Record. En Hall, ES (Ed.). Contributions to Anthropology: The Interior Peoples of Northern Alaska, Archaeological Survey of Canada. National Museum of Canada, Ottawa, Estados Unidos.

Binford, L. 1979. Organization and formation processes: Looking at curated technologies. Journal of Archaeological Research 35: 255-273.

Binford, L. 1980 Willow smoke and dogs'tails: hunter-gatherer settlement systems and archaeological site formation. American Antiquity 45: 4-20.

Binford, L. 1981. Bones: Ancient Men and Modern Myths. Academic Press, Nueva York, Estados Unidos.

Binford, L. 1982. The archaeology of place. Journal of Anthropological Archaeology 1: 5-31.

Bird, JB. 1938. Antiquity and migrations of the early inhabitants of Patagonia. Geographical Review 28: 250-275.

Bird, JB. 1993. Viajes y arqueología en Chile Austral. Universidad de Magallanes, Punta Arenas, Chile.

Blanco, RV y V Lynch. 2011. Experimentos replicativos de grabados en piedra. Implicancias en el arte rupestre de la localidad Arqueológica de Piedra Museo (Santa Cruz, Argentina). Boletín Museo Chileno de Arte Precolombino 16: 9-21.

Blasi, A, J Rabassa, L Miotti y R Cattáneo. 1997. Investigación geoarqueológica en la localidad Piedra Museo. XII Congreso Nacional de Arqueología Argentina, pp. 9. Universidad Nacional de La Plata, Argentina.

Bleed, P. 1986. The optimal design of hunting weapons: maintainability or reliability. American Antiquity 51: 737-747.

Böeda, E, JM Geneste y L Meignen. 1990. Identification de Chaînes Opératoires Lithiques du Paléolithique Ancien et Moyen. Paléo 2: 43-80.

Borrazzo, K. 2004. Hacia una tafonomía lítica: el análisis tafonómico y tecnológico de los conjuntos artefactuales líticos de superficie provenientes de los loci San Genaro 3 y 4 (Bahía San Sebastián Tierra del Fuego, Argentina). Tesis de Licenciatura, Universidad de Buenos Aires, Argentina. 
Borrazzo, K. 2006. Tafonomía lítica en dunas: una propuesta para el análisis de los artefactos líticos. Intersecciones en Antropología 7: 247-261.

Borrazzo, K. 2011. Tafonomía lítica en la estepa patagónica: experimentación y registro arqueológico. En Borrero, LA y K Borrazzo (Eds.). Bosques, Montañas y cazadores: investigaciones arqueológicas en Patagonia Meridional. CONICET-IMHICIHU, Buenos Aires, Argentina.

Borrero, LA. 1988. Tafonomía regional. En Ratto N y A. Haber (Eds.). De Procesos, contextos y otros huesos. Universidad Nacional de Buenos Aires, Argentina.

Borrero, LA. 1989. Replanteo de la arqueología patagónica. Interciencia 14: 127-135.

Borrero, LA. 1989-90. Evolución cultural divergente en la Patagonia Austral. Anales del Instituto de la Patagonia (Serie Ciencias Sociales) 19: 133-140.

Borrero, LA. 1990. Fuego-Patagonia bone assemblages and the problem of comunal guanaco hunting. En Davis L y B Reeves (Eds.). Hunters of the recent past. Unwin Hyman, Londres, Inglaterra.

Borrero, LA. 1994-95. Arqueología de la Patagonia. Palimpsesto 4: 9-69.

Borrero, LA. 2001. Cambios, continuidades, discontinuidades: discusiones sobre arqueología Fuego Patagónica. En Berberián, E y A Nielsen (Eds.). Historia Argentina Prehispánica. Editorial Brujas, Córdoba, Argentina.

Borrero, LA. 2009. The elusive evidence: The archaeological record of the South American extinct megafauna. En Haynes, G (Ed.). American Megafaunal Extinctions at the end of the Pleistocene. Springer Science, Estados Unidos.

Borrero, LA y N Franco. 1997. Early Patagonian hunter-gatherers: subsistence and technology. Journal of Anthropological Research 53: 219-239.

Borrero, L. A. y N. V. Franco. 2000. Cuenca superior del río Santa Cruz: perspectivas temporales. En: Desde el País de los Gigantes. Perspectivas arqueológicas en Patagonia. Tomo II: 345-356.

Borrero, LA y N Franco. 2001. Las colecciones líticas del Museo Británico. Anales del Instituto de la Patagonia (Serie Ciencias Humanas) 29: 207-210.

Borrero, LA y L Miotti. 2007. La tercera esfinge indiana: la edad del poblamiento de Argentina. En Politis, et. al. (Eds.). Sociedad Argentina de Antropología, Buenos Aires, Argentina.

Borrero, LA y F Martin. 2012. Ground sloths and humans in southern Fuego-Patagonia: taphonomy and archaeology. Word Archeology 44: 102-117.

Borrero, LA, M Zárate, L Miotti y M. Massone. 1998. The Pleistocene-Holocene transition and human occupations in the Southern Cone of South America. Quaternary International 49/59: 191-199.

Borrero, LA, FM Martin y J Vargas. 2005. Tafonomía de la interacción entre pumas y guanacos en el Parque Nacional Torres del Paine, Chile. Magallania 33: 95-114.

Borromei, AM. 2003. Palynology at Piedra Museo Locality, Santa Cruz Province, Argentina. En Miotti, L, M Salemme y N Flegenheimer (Eds.). Where the South Winds Blow: Ancient Evidence of Paleo South Americans. A\&M University Press, Texas, Estados Unidos. 
Bousman, CB. 1993. Hunter-gatherer adaptations, economic risk and tool design. Lithic Technology 18: $59-86$.

Bradley, B y Y Giria. 1996. Concepts of technological analysis of flaked stone: a case study from the High Arctic. Lithic Technology 21: 23-47.

Briz, I. 2002. Producción y consumo. En Clemente, I, R Risch y J Gibaja (Eds.). Análisis Funcional: su aplicación al estudio de sociedades prehistóricas. BAR International Series 1073, Oxford, Inglaterra.

Briz, I. 2004. Dinàmiques econòmiques de producció-consum en el registre lític caçador-recolector de l'extrem sud americà. La societat yàmana. Tesis doctoral. Universidad Autónoma de Barcelona, España.

Briz, I. 2007. Piedras dinámicas, producciones y consumos: propuesta desde la Dialéctica para el análisis de conjuntos líticos. Krei 9: 27-46.

Briz, I. 2010. Dinámicas producción-consumo en conjuntos líticos: El análisis de los conjuntos líticos de la sociedad Yámana. Magallania 38: 189-211.

Briz, I, I Clemente, J Pijoan, X Terradas y A Vila. 2002. Contextos etnorqueológics i l'estudi de Conjunts Lítics. Cota Zero. Revista de Ciencia i Arqueología 17: 12-20.

Briz, I, I Clemente, J Pijoan, X Terradas y A Vila. 2005. Stone tools in etnoarchaeological contexts: theoretical-methodological inferences. En Terradas, X (Ed.). Lithic Toolkits in Ethnoarchaeological Contexts. Archeopress, Oxford, Inglaterra.

Briz, I y L Vietri. 2011. L'analogia in etnoarcheologia: la chiusura del cerchio. Logica, "contrastazione", archeologia,Quaderni di Thule. Rivista d'Americanistica 10: 169-178.

Briz, I, JI Santos, JM Galán, J Caro, M Álvarez y D Zurro. 2013. Social Cooperation and Resource Management Dynamics Among Late Hunter-Fisher-Gatherer Societies in Tierra del Fuego (South America). Journal of Archaeological Method and Theory: 1-21.

Briuer, F. 1976. New clues to stone tool function: plant and animal residues. American antiquity 41: 478484.

Broecker, W y G Denton. 1990. What drives glacial cycles? Scientific American 262(1): 42-50.

Buc, N. 2005. Análisis de microdesgaste en tecnología ósea. El caso de punzones y alisadores en el noreste de la provincia de Buenos Aires (humedal del Paraná inferior). Tesis de licenciatura. Universidad de Buenos Aires, Argentina.

Burroni, D, R Donahue, M Pollard y M Mussi. 2002. The Surface Alteration Features of Flint Artefacts as a Record of Environmental Processes. Journal of Archaeological Science 29: 1277-1287.

Cabrera, AL. 1976. Fitogeografía de la República Argentina. Boletín de la Serie Botánica 14: 1-42.

Cabrera, AL y A Willink. 1980. Biogeografía de América latina. Programa regional de desarrollo científico y tecnológico-OEA, Washington, Estados Unidos.

Cahen, D, LH Keeley y FL Van Noten. 1979. Stone tools, toolkits and human behavior in prehistory. Current Anthropology 20: 661-683. 
Calvo, M. 1999. Reflexiones en torno al concepto de útil, forma, función y su relación con los análisis funcionales. Pyrenae 30: 17-38.

Calvo, M. 2002. Útiles líticos prehistóricos. Forma, función y uso. Ariel Prehistoria, Barcelona, España.

Calvo, M, JM Fullola, X Mangado y MA Petit. 2011. Los raspadores y el procesado de la piel en la cueva del Parco. Veleia: 24-25.

Carden, N. 2008. Imágenes a través del tiempo. Arte rupestre y construcción social del paisaje en la Meseta Central de Santa Cruz. Sociedad Argentina de Antropología, Buenos Aires, Argentina.

Carden, N, L Magnin y L Miotti. 2009. Distribución de figuras animales y dinámica poblacional: un estudio comparativo en Patagonia (provincia de Santa Cruz, Argentina). En Sepúlveda, M, L Briones y J Chacama (Eds.). Crónicas sobre la piedra: Arte Rupestre de las Américas. Ediciones Universidad de Tarapacá, Chile.

Cardich, A. 1987. Arqueología de Los Toldos y El Ceibo (Prov. de Santa Cruz, Argentina). Estudios Atacameños 8: 95-113.

Cardich, A, L Cardich y A Hadjuk. 1973. Secuencia arqueológica y cronología radiocarbónica de la cueva 3 de Los Toldos (Santa Cruz, Argentina). Relaciones 7: 85-123.

Cardich, A y N Flegenheimer. 1978. Descripción y tipología de las industrias líticas más antiguas de Los Toldos. Relaciones 12: 225-242.

Cardich, A y L Miotti. 1983. Recursos faunisticos en la economia de los cazadores de Los Toldos (Santa Cruz, Argentina). Relaciones 15: 145-157.

Cardich, A, E Tonni y N Kriskautzky. 1977. Presencia de Canis Familiaris en restos arqueológicos de Los Toldos (Provincia de Santa Cruz, Argentina. Relaciones 11: 115-119.

Carr, P. 1994. The Organization of Prehistoric North American Chipped Stone Technologies. International Monographs in Prehistory, Archaeology Series 7. Ann Arbor, Michigan, Estados Unidos.

Coronato, A, M. Salemme y J Rabassa. 1999. Paleoenvironmental conditions during the early peopling of Southernmost South America (Late Glacial-Early Holocene, 14-8 ka B.P.). Quaternary International 53/54: 77-92.

Casamiquela, R. 1978. Temas patagónicos de interés arqueológico III. La técnica de la talla del vidrio Relaciones 12: 213-233.

Caspar, JP. 1988. Contribution à la tracéologie de l'industrie lithique du Néolithique Ancien dans l'Europe Nord-Occidentale. Tesis Doctoral. Université Catholique, Francia.

Cassiodoro, G, D Rindel, R Goñi, A Re, A Tessone, S García-Guraieb y S Pasqualini. 2013. Arqueología del Holoceno medio y Tardío en Patagonia meridional: Poblamiento Humano y fluctuaciones climáticas. Diálogo andino 41: 5-23.

Castro de Aguilar, A. 1987/88. Análisis microscópico de huellas de utilización en artefactos líticos de Fortín Necochea. Paleoetnológica 4: 65-77.

Castro de Aguilar, A. 1994. Estudios de Análisis Funcional de material lítico: Un modelo alternativo de clasificación tipológica. Tesis Doctoral. Universidad Nacional de La Plata, Argentina. 
Castro, A. 1996a. El análisis funcional de material lítico: un punto de vista. Revista del Museo de La Plata (NS) 9: 318-326.

Castro, A. 1996b. El análisis funcional del material lítico: Su importancia. Jornadas de Antropología de la Cuenca del Plata. Rosario, Argentina.

Castro, A y E Moreno. 1994. Determinación de enmangues en instrumentos líticos por medio del análisis de huellas de utilización. Paleoetnológica 7: 7-20.

Cattáneo, R. 2000. El paisaje y la distribución de recursos líticos en el Nesocratón del Deseado. En Miotti, L, R Paunero, M Salemme y G Cattáneo (eds.). Guía de campo de la visita a las localidades arqueológicas. La colonización del Sur de América durante la transiciel Sur de América durante la Transición Pleistoceno/Holoceno. Servicoop, Argentina.

Cattáneo, R. 2002. Una aproximación a la organización de la tecnología lítica entre los cazadores recolectores del Holoceno medio/Pleistoceno final en la Patagonia austral (Argentina). Tesis Doctoral. Universidad Nacional de La Plata, Argentina.

Cattáneo, R. 2005. Tecnología lítica en la localidad arqueológica Piedra Museo (Santa Cruz, Argentina). Relaciones 30: 79-103.

Cattáneo, R. 2006. Tecnología Lítica del Pleistoceno Final/Holoceno Medio. Un Estudio de los CazadoresRecolectores de la Patagonia Austral (Argentina). Archaeopress Oxford, Inglaterra.

Cattáneo, R, A Pupio, M Valente y A Barna. 1997/98. Alteración térmica en dos tipos de rocas silíceas: resultados experimentales y aporte de datos para el análisis arqueológico. Relaciones 22/23: 343-361.

Cattáneo, R, C Di Lello y JC Gómez. 2004. Cuantificación y análisis de la distribución de rocas útiles para la manufactura de instrumentos a través del uso de sistema de información geográfica (SIG) en el área de Piedra Museo, Santa cruz, Argentina. XV Congreso Nacional de Arqueología Argentina, Río Cuarto, Argentina.

Cattáneo, R y AM Aguerre. 2009. Estudios funcionales de artefactos líticos de Cueva de las Manos, Río Pinturas, Santa Cruz, Argentina. Revista del Museo de Antropología 2: 3-22.

Ceraso, A. 2011. SIG y estadística espacial en el contexto arqueológico de Cueva Maripe (Santa Cruz). Informe de Beca de Experiencia Laboral para Graduados, FCNyM- UNLP.

Charlin, J y LA Borrero. 2012. Rock Art, Inherited Landscapes, and Human Populations in Southern Patagonia. En McDonald, J y P Veth (eds.). A Companion to Rock Art (IV). John Wiley \& Sons, Chichester, Inglaterra..

Civalero, MT. 1999. Obsidiana en Santa Cruz, una problemática a resolver. III Terceras Jornadas de Arqueología de la Patagonia. Instituto Nacional de Antropología y Pensamiento Latinoamericano y Universidad Nacional del Comahue, Argentina.

Civalero, MT y NV Franco. 2003. Early human occupations in Western Santa Cruz Province, Southernmost South America. Quaternary International 109: 77-86.

Civalero, MT y ME De Nigris. 2005. Explotación de fauna y tecnología lítica en Cerro Casa de Piedra 7 (Santa Cruz, Argentina). Relaciones 30: 105-122. 
Claraz, J. 1988. Diario de viaje de exploración al Chubut 1865-1866. Marymar, Buenos Aires, Argentina.

Clemente Conte, I. 1997. Los instrumentos líticos de Túnel VII: una aproximación etnoarqueológica. Treballs D'Etnoarqueologia 2, CSIC-UAB, Madrid, España.

Clemente, I y JF Gibaj. 1998. Working processes on cereals: an approach through microwear analysis. Journal of archaeological Science 25: 457-464.

Clemente, I, ME Mansur, X Terradas y A Vila. 1996. Al Cesar lo que es del Cesar o los "instrumentos" líticos como instrumentos de trabajo. En Gómez Otero, J (Ed.). Arqueología solo Patagonia. CENPAT-CONICET, Argentina.

Clop, X. 2002: La ceràmica del nivell arqueològic III.4. Anàlisi petrográfica. En Alcalde, G, M Molist y M Saña (Eds.). Procés d'ocupacióde la Bauma del Serrat del Pont entre 5480 i 2900 cal AC. Museu Comarcal de la Garrotxa, España.

Clop, X, JF Gibaja, A Palomo y X Terradas (en prensa). Un utillaje lítico especializado: las "grandes láminas" de sílex del noreste de la Península Ibérica. XXVII Congreso Nacional de Arqueología. Instituto de Estudios Altoaragoneses, Huesca 6-8 Mayo 2003.

Cooper, JM. 1946. The Araucanians. Handbook of South American Indians. Bulletin 143: 687-766.

Cosgrove, R. 1985. New evidence for early Holocene Aboriginal occupation in northeast Tasmania. Australian Archaeology 21: 19-36.

Criado Boado, F. 1993. Límites y posibilidades de la Arqueología del paisaje. Revista de Prehistoria y Arqueología 2: 9-55.

Crivelli Montero, E, M Fernández, N Franco, U Pardiñas y Z Tavella, 1990/1992. Prospecciones arqueológicas en el partido de Tapalqué (provincia de Buenos Aires). Paleoetnológica 6: 31-46.

Cueto, M. 2012. Manufactura, utilización y análisis de huellas de uso sobre artefactos líticos tallados enrocas silíceas de la meseta central de Santa Cruz. Diseño y desarrollo del Programa Experimental. En Kuperszmit, N, M Lagos, L Mucciolo y M Sacchi (Eds.). Entre pasados y presentes III. Estudios contemporáneos en ciencias antropológicas. Instituto Nacional de Antropología y Pensamiento Latinoamericano, Buenos Aires, Argentina.

Cueto, M. 2013. Estudio comparativo forma-función de artefactos líticos. Evidencias de las ocupaciones iniciales de la localidad arqueológica La María. En Zangrando et al. (Eds.). Tendencias teóricometodológicas y casos de estudio en la arqueología de la Patagonia. Buenos Aires, Argentina.

Cueto, M y A Frank. 2008. Tratamiento térmico de artefactos líticos: estudios experimentales. En Austral, A y M Tamagnini (Eds.). Problemáticas de la Arqueología Contemporánea. Universidad Nacional de Río Cuarto, Argentina.

Cueto, M, R Paunero y A Castro. 2012. La aplicación del análisis funcional sobre el conjunto artefactual lítico del componente temprano del sitio Casa del Minero I para la determinación de operaciones técnicas. XVIII Congreso Nacional de Arqueología Chilena, Chile. 
Cueto M y A Castro. 2012. Technological and Functional Analysis on Pleistocene Components from La María Locality, Santa Cruz, Argentina. En Goebel, T, L Miotti, N Flegenheimer y M Salemme (Eds.). Current Research in the Pleistocene. Center Texas A\&M University, Estados Unidos.

De Angelis, H. 2012. Materias primas lejanas. Explotación de recursos líticos no locales para la confección de micro-raspadores en el centro de Tierra del Fuego: el caso arqueológico Kami. Magallania 40: 247257.

De Angelis, H. 2013. Arqueología de la faja central de Tierra del Fuego: una aproximación funcionalespacial. Tesis Doctoral. Universidad Nacional de La Plata, Argentina.

De Aparicio, F. 1933-35. Viaje preliminar de exploración en el territorio de Santa Cruz. Museo Antropológico y Etnográfico de la FFyL (Serie A) 3:71-92.

Debert, J y BL Sherriff. 2007. Raspadita: a new lithic tool from the Isthmus of Rivas, Nicaragua. Journal of Archaeologica Science 34: 1889-1901.

D’Errico, F, P Jardón y B Soler. 1993. Techniques de perforation des coquillages et usures de suspension: critères d'analyse à base expérimentale. ERAUL 50: 243-254.

Deetz, J. 1990. Landscapes as cultural statements. En Kelso, WM y R Most (Eds.). Earth Patterns: Essays in Landscape Archaeology. University Press, Inglaterra.

De Giusto, J, C Di Persia y E Pezzi. 1980. Nesocratón del Deseado. II Simposio de Geología Regional Argentina: 1390-1430.

Dillehay, TD, GA Calderón, G Politis, MC de Beltrao. 1992. Earliest hunters and gatherers of South America. Journal of World Prehistory 6: 145-204.

Di Lello, C, JC Gómez y GR Cattáneo. 2005. Herramientas geomáticas aplicadas al estudio de los recursos minerales no industriales en tiempos prehistóricos en el área de Piedra Museo, Santa Cruz, Argentina. XVI Congreso Nacional de Geología Argentina. Universidad Nacional de la Plata, Argentina.

Dobres, MA y C Hoffman. 1994. Social Agency and the Dynamics of Prehistoric Technology. Journal of Archaological Method and Theory 1: 211-258.

Dunnell, RC. 1989. Aspects of the application of evolutionary theory in archaeology. En LambergKarlovsky, CC (Ed.). Archaeological thought in America, Cambridge University Press, Inglaterra.

Dunnell, RC. 1992. The notion site. Space, time, and archaeological landscapes. Springer, Estados Unidos.

Durán, V, A Gil, G Neme y A Gasco. 2003. El Verano: Ocupaciones de 8.900 años en la Cueva 1 (Santa Cruz, Argentina). En Aguerre, A (Ed.). Arqueología y Paleoambiente en Patagonia Santacruceña Argentina. Nuevo Offset, Argentina.

Escola, PS. 2004. La expeditividad y el registro arqueológico. Chungará 36: 49-60.

Estevez, J y A Vila. 1996. Encuentros en los conchales fueguinos, Treballs d'Etnoarqueologia 1. CSIC$\mathrm{UAB}$, Barcelona, España.

Estevez, J y A Vila. 2000. Estratigrafías en contexto. Krei 5: 29-61.

Evans J. 1872. The ancient stone implements, weapons and ornaments of Great Britain. Longmans, Green, Reader and Dyer. Londres, Inglaterra. 
Favier Dubois, CM. 2001. Análisis geoarqueológico de los procesos de formación del registro, cronología y paleoambientes en sitios arqueológicos de Fuego-Patagonia. Tesis Doctoral. Universidad de Buenos Aires, Argentina.

Fernández, M. 2013. Los paleoambientes de Patagonia meridional, Tierra del Fuego e Isla de los Estados en los tiempos de las primeras ocupaciones humanas. Estudio basado en el análisis de diatomeas. Tesis doctoral. Universidad Nacional de La Plata, Argentina.

Fernández, M y M Salemme. 2012. Diatom analysis in Santa Cruz central massif (Patagonia, Argentina): Preliminary results. En Miotti et al. (Eds.). Southbound. Late Pleistocene Peopling of Latin America. Texas A\&M University Press, Texas, Estados Unidos.

Fiore, D. 2004. Arte rupestre y mobiliar en Fuego-Patagonia. Distribución espacial, movilidad y tecnologías de producción artística. X Congreso Nacional de Arqueología Argentina, Río Cuarto, Argentina.

Fiore, D, M Maier, SD Parera, LA Orquera y EL Piana. 2008. Chemical analysis of the earliest Pigments residues from the uttermost Part of the Planet (Beagle Channel region, Tierra del Fuego, southern South America). Journal of Archaeological Science 35: 3047-3056.

Flegenheimer, N y M Leipus. 2007. Trabajar en un espacio reducido, Cerro El Sombrero. XVI Congreso Nacional de Arqueología Argentina, Jujuy, Argentina.

Flegenheimer, N y R Cattáneo. 2013. Análisis comparativo de desechos de talla en Contextos del Pleistoceno final/Holoceno temprano de Chile y Argentina. Magallania 41: 171-192.

Flegenheimer, N, N Mazzia y MP Babot. 2013. Estudios de detalle sobre una piedra discoidal pampeana. Intersecciones en Antropología 14: 499-506.

Foley, R. 1981. A model of regional archaeological structure. Proceedings of the Prehistoric Society 47:117.

Forlano, A y MV Dolce. 2006-2007. Experimentación con raspadores enmangados de la Patagonia Argentina. Boletín de arqueología experimental 7:100-113.

Franco, VN. 2002. ¿Es posible diferenciar los conjuntos líticos atribuidos a la exploración de un espacio de los correspondientes a otras etapas del poblamiento? Werken 3: 119-132.

Franco, NV, P Ambrústolo, M Martucci, G Brook, MV Mancini y N Ccirigliano. 2010a. Early human occupation in the southern part of the Deseado Massif (Patagonia, Argentina). Current Research in the Pleistocene 7: 13-16.

Franco NV, M Martucci, P Ambrústolo, G Brook, MV Mancini y N Cirigliano. 2010b. Ocupaciones humanas correspondientes a la transición pleistoceno-holoceno al sur del macizo del deseado: El área de la Gruta (provincia de Santa Cruz, Argentina). Relaciones 35: 301-308.

Franco NV, P Ambrústolo y N Cirigliano. 2012. Disponibilidad de materias primas líticas silíceas en el extremo sur del maciso del Deseado: Los casos de La Gruta y Viuda Quenzana (Provincia de Santa Cruz, Argentina). Magallania 40: 279-286. 
Frank, AD. 2009. El daño térmico en artefactos líticos: estudios experimentales. En Bourlot et al. (Eds.). Entre Pasados y Presentes II. Estudios Contemporáneos en Ciencias Antropológicas. Fundación de Historia Natural Félix de Azara, Buenos Aires, Argentina.

Frank, AD. 2012. Tratamiento y daño térmico de artefactos líticos en los componentes tempranos del sitio Casa del Minero 1, Santa Cruz, Argentina. Chungará 44: 25-37.

Frenguelli, J. 1933. Situación estratigráfica y edad de la "zona con araucaria" al sur del curso inferior del río Deseado. Boletín de Informaciones Petrolíferas 112: 843-900.

Giardina, M, D Hermo, L Miotti y M Vázquez. 2000. Resolución e integridad arqueológica del Componente inferior de Piedra Museo. En Miotti, L, R Paunero, M Salemme y R Cattáneo (Eds.). Guía de Campo de la visita a las Localidades arqueológicas. Servicoop, La Plata, Argentina.

Gibaja, FJ, I Clemente y A Mir. 2002. Análisis funcional en instrumentos de cuarcita: el yacimiento del Paleolítico superior de la Cueva de la Fuente Trucho Colungo, Huesca). En Clemente, I, R Risch y JF Gibaja. Análisis funcional: su aplicación al estudio de sociedades prehistóricas. Arqueopress, Inglaterra.

Gifford González D. 1989. Ethnographic analogues for interpreting modified bones. Some cases from East Africa. En Bonnichsen, R y M Sorg (Eds.). Bone Modification. Center for the Study of the First Americans, Estados Unidos.

Gilli, A, D Aristegui, FS Anselmetti, JA Mckenzie, V Markgraf, I Hajda y RD Mcculloch. 2005. MidHolocene strengthening of the Southern Westerlies in South America-Sedimentological evidences from lago Cardiel, Argentina (49 ${ }^{\circ}$ ). Global and Planetary Change 49: 75-93.

Gómez Otero, J. 1996. Arqueología de cazadores-recolectores en Península Valdés, costa central de Patagonia. Informe CONICET.

González, MA. 1992. Paleoambientes del Pleistoceno Tardío/Holoceno Temprano en la cuenca de los Lagos Belgrano y Burrneister (Santa Cruz). Informe Técnico, Fundación Carl, Buenos Aires, Argentina.

Goñi, R. 2010. Cambio climático y poblamiento humano durante el Holoceno tardío en Patagonia meridional. Una perspectiva arqueológica. Tesis doctoral. Universidad de Buenos Aires, Argentina.

Goñi, R y G Barrientos. 2004. Poblamiento tardío y movilidad en la cuenca del Lago Salitroso. En Civalero, T, P Fernández y GGuraieb (Eds.). Contra Viento y Marea. Arqueología de Patagonia. Sociedad Argentina de Antropología, Buenos Aires.

Goñi, R, G Barrientos, H Panarello, S Valencio L Luna. 2000. Cazadores de Patagonia Austral: aspectos poblacionales y análisis isotópicos. VI Congreso Latinoamericano de Antropología Biológica. Pirlápolis, Uruguay.

Coronato, A, M Salemme J Rabassa. 1999. Paleoenvironmental conditions during the early peopling of Southern most South America (Late Glacial-Early Holocene, 14-8 ka B.P.). Quaternary International 53/54: 77-92. 
González Urquijo, J y J Ibáñez Estévez. 1994. Metodología de análisis funcional de instrumentos tallados en sílex. Universidad de Deusto. Bilbao, España.

González Urquijo, J y J Ibáñez Estévez. 2003. The quantification of use-wear polish using image analysis. First results. Journal of Archaeological Science 30: 481-489.

Gosden, C y Y Marshall. 1999. The cultural biography of objects. World archaeology 31: 169-178.

Gradin, C. 1980. Secuencias radiocarbónicas del sur de la Patagonia Argentina. Relaciones 14: 177-194.

Gradin C y A Aguerre. 1983. Arte rupestre del área La Martita (Provincia de Santa Cruz). Relaciones 15: 195-223.

Gradin C y A Aguerre. 1992. Nuevo aporte al conocimiento de la dinámica poblacional en la cuenca del Río Pinturas (Santa Cruz, Argentina). En Borrero, LA y JL Lanata (Eds.). Análisis espacial en arqueología patagónica. Buenos Aires, Argentina.

Gradin, C, C Aschero y A Aguerre. 1976. Investigaciones arqueológicas en la Cueva de Las Manos, Estancia Alto Río Pinturas (Santa Cruz). Relaciones 10: 201-250.

Gradin, C, C Aschero y A Aguerre. 1979. Arqueología del área Río Pinturas (Santa Cruz). Relaciones 13: $183-227$.

Gusinde, M. 1982. Los indios de Tierra del Fuego. Los Selk’nam. Centro Argentino de Etnología Americana, Buenos Aires, Argentina.

Gutiérrez, M. 2004 Análisis tafonómicos en el Área Interserrana (Provincia de Buenos Aires). Tesis Doctoral. Universidad Nacional de La Plata, Argentina.

Gutiérrez Sáez, C. 1990. Introducción a las huellas de uso: los resultados de la experimentación. Espacio Tiempo y Forma (I), Prehistoria y Arqueología: 15-54.

Hadjuk, A y MJ Lezcano. 2005. Un" nuevo-viejo" integrante del elenco de instrumentos óseos de Patagonia: los machacadores óseos. Magallania 33: 63-80.

Hammer, O y DA Harper. 2006. Paleontological Data Analysis. Blackwell. Estados Unidos.

Hardy, B, M Bolus y N Conrad. 2008. Hammer or crescent wrench? Stone-tool form and function in the aurignacian of southwest Germany. Journal of Human Evolution 54: 648-662.

Hayden, B. 1979. Lithic Use-Wear Analysis. Academic Press, Estados Unidos.

Hayden, B. 1995. Pathways to Power: Principles for creating Socioeconomic Inequalities. En Price, D y G Feinman (Eds.). Foundations of social inequality. Plenum Press, Estados Unidos.

Hayden, B. 1998. Practical and Prestige Technologies: The Evolution of Material Systems. Journal of Archaeological Method and Theory 5: 1-55.

Hayden, B. 2009. The Proof Is in the Pudding. Current Anthropology 50: 597-601.

Hayden, B, N Franco y J Spafford. 1996. Evaluating lithic strategies and design criteria. En Odell, G (Ed.). Stone Tools: Theroretical insights into Human Prehistory. Plenum Press, Estados Unidos.

Hermo, D. 2005. Acerca del aprovechamiento de xilópalo en el Monumento Natural Bosque Petrificado, por parte de los cazadores-recolectores de la meseta central de Santa Cruz. VI Jornadas de Jóvenes Investigadores en Ciencias Antropológicas, Argentina. 
Hermo, D. 2008. Los cambios en la circulación de las materias primas líticas en ambientes mesetarios de Patagonia. Una aproximación para la construcción de los paisajes arqueológicos de las sociedades cazadoras-recolectoras. Tesis doctoral. Universidad Nacional de La Plata, Argentina.

Hermo, D. 2009. Estructura de los recursos líticos y paisajes arqueológicos en el Nesocratón del Deseado (Santa Cruz, Argentina). Revista Arqueología Suramericana/Arqueología Sul-americana 5: 178-203.

Hermo, D y L Miotti. 2003. El efecto zoom para relacionar los desechos líticos de un sitio y los paisajes arqueológicos de cazadores - recolectores del Holoceno en la meseta central de Santa Cruz. Intersecciones en Antropología 4: 111-120.

Hermo, D y L Miotti. 2011. La Obsidiana en el Nesocratón del Deseado (Santa Cruz, Argentina): extractos de una oscura biografía. Biografías de paisajes y seres. Visiones desde la arqueología sudamericana. Córdoba, Argentina.

Hermo, D y L Magnin. 2012. Blade and bifacial technology in Mid-Holocene occupations at Deseado Massif, Santa Cruz province, Argentina. Quaternary International 256: 71-77.

Hermo D y V Lynch (en prensa). Analysis of core technology from Maripe Cave site (Santa Cruz, Argentina): Implications on the rocks provisioning process and lithic production. Quaternary International.

Heusser, CJ. 1989a. Late Quaternary vegetation and climate of Southern Tierra del Fuego. Quaternary Research 31: 396-406.

Heusser, CJ. 1989b. Southern westerlies during the Last Glacial Maximum. Quaternary Research 31: 423425.

Heusser, CJ y J Rabassa. 1995. Late Holocene forest steppe interaction at Cabo San Pablo, Isla Grande de Tierra del Fuego, Argentina. Quaternary of South America and Antarctic Peninsula 9: 179-188.

Hocsman, S. 2006. Producción lítica, variabilidad y cambio en Antofagasta de la Sierra (ca 5500-1500 AP). Tesis doctoral. Universidad Nacional de La Plata, Argentina.

Hocsman, S y P Escola. 2006-2007. Inversión de trabajo y diseño en contextos líticos agro-pastoriles (Antofagasta de la Sierra, Catamarca). Cuadernos del Instituto de Antropología y Pensamiento Latinoamericano 21: 75-90.

Hubert, J. 1994. Sacred beliefs and beliefs of sacredness. En Carmichael, DL, J Hubert, B Reeves y A Schanche (Eds.). One World Archaeology. Routledge, Inglaterra.

Hugill, PJ y KE Foote. 1995. Re-reading cultural geography. En Foote, KE, PJ Hugill, K Mathewson y JM Smith (Eds.). Re-Reading Cultural Geography. University of Texas Press, Estados Unidos.

Hyland, DC, JM Tersak, JM Adovasio y MI Siegel. 1990. Identification of the Species of Origin of Residual Blood on Lithic Material. American Antiquity 55: 104-112.

Ingold, T. 1997. Eight themes in the Anthropology of technology. Techology as skilled practice. Social Analysis 41: 106-138.

Ingold, T. 2005. Comments on Christopher Tilley: The Materiality of Stone: Explorations in Landscape Phenomenology. Norwegian Archaeological Review 38: 122-129. 
Jahren, A, N Toth, K Schick, J Clark y R Amundson. 1997. Determining stone tool use: Chemical and morphological analyses of residues on experimentally manufactured stone tools. Journal of Archaeological Science 24: 245-250.

Jackson, D. 1987. Componente lítico del sitio arqueológico Tres Arroyos. Anales del Instituto de la Patagonia 17: 67-72.

Johnson, E, G Politis y M Gutiérrez. 2000. Early Holocene Bone technology at the La Olla 1 site, Atlantic coast of the Argentine Pampas. Journal of Archaeological Science 27: 463-477.

Jones, S. 1980. Experimental butchery with modern stone tools and in relevance for archaeology. World Archaeology 12: 153-165.

Jones, S. 2002. The archaeology of ethnicity: constructing identities in the past and present. Routledge, Inglaterra.

Jones, A y N Boivin. 2010. The malice of inanimate objects, material agency. En Hicks, D y M Beaudry (Eds.). The Oxford Handbook of Material Cultural Studies. Oxford University Press, Inglaterra.

Juel Jense, H. 1988. Functional analysis of prehistoric flint tools by high-power microscopy: A review of west European research. Journal of World Prehistory 2: 53-88.

Kaminska, J. 1982. Over de edge. University of Qeensland, Australia.

Kaminska, J, E Mycielska-Dowgiallo y K Szymczak. 1993. Postdepositional changes on surfaces of fint artefact as observed under scanning electron microscope. En Anderson, P, S Beyries, M Otte y H Plisson (Eds.). Traces et fonction. Les gestes retrouves. Universidad de Liège, Bélgica.

Kardulias, N y R Yerkes. 1996. Microwear and Metric Analysis of Threshing Sledge Flintsfrom Greece and Cyprus. Journal of Archaeological Science 23: 657-666.

Keeley, L. 1974. Technique and methodology in microwear analysis, World Archaeology 5: 323-336.

Keeley, L. 1977. An experimental study of Microwear traces on selected British Paleolithic implements. Tesis doctoral. Universidad de Oxford, Inglaterra.

Keeley, L. 1978. Prelimimary micorwear analysis of the Meer assemblage. En Les chasseurs de Meer. Dissertationes Archaeologicae Gandenses 18: 73-99.

Keeley, L. 1980. Experimental Determination of Stone Tool Uses: a Microwear Analysis. University of Chicago Press, Estados Unidos.

Keeley, L. 1982. Hafting and Re-tooling; Effect on the archaeological record. American Antiquity 47: 798805.

Keeley, L y M Newcomer. 1977. Microwear analysis of experimental flint tools: A test case. Journal of Archaeological Science 4: 29-62.

Kelly, R. 1988. Hunter-gatherer Land Use and Regional Geomorphology: Implications for Archaeological Survey. American Archaeology 7: 49-57.

Kelly, R. 1992. Mobility/sedentism: concepts, archaeological measures, and effects. Annual Review of Anthropology 21: 43-66. 
Kelly, R. 1999. Hunter-gatherer foraging and colonization of the Western Hemisphere. Anthropologie 37: 143-153.

Kelly, R. 2003. Colonization of New Land by hunter-gatherers. Expectations and implications based on ethnographic data. En Rockman, M y J Steel (Eds.). Colonization of Unfamiliar Landscapes. Routledge, Inglaterra.

Knutsson, K. 1986. SEM-analysis of wear features on experimental quartz tools. En Owen, L y G Unrath (Eds.). Technical aspect of microwear studies on stone tools. Part I. Tübingen, Alemania.

Knutsson, K. 1990. A new lithic scene. The archaeological context of used tools. Societas Archaeologica Upsaliensis: $15-30$.

Koldehoff, B. 1987. The Cahokia flake tool industry: socioeconomic implications for Late Prehistory in the Central Mississippi Valley. En Johnson, JK y CA Morrow (Eds.). The Organization of Core Technology. Westview Press, Estados Unidos.

Kopnin, PV. 1969. Hipótesis y Verdad. Juan Grijalbo Editor, México.

Kuhn, S. 1994. A formal approach to the design and assembly of mobile toolkits. American Antiquity 59 (3): 426-442.

Landini, C, M Bonomo, M Leipus y G Martínez. 2000. Forma y función de los instrumentos líticos del sitio Paso Otero 3 (Pdo. de Necochea. Pcia. De Buenos Aires, Argentina): un estudio comparativo. Espacio, Tiempo y Forma, Serie 1. Prehistoria y Arqueología 13: 161-187.

Leipus, M. 2004. Tendencias en el uso de los artefactos líticos en la Subregión Pampa Húmeda: relación entre morfología y función a partir del análisis de microrrastros de utilización. En Gradín, CF y F Oliva (Eds.). El Área Pampeana: Su Pasado Arqueológico. Laborde Editor, Argentina.

Leipus, M. 2006. Análisis de los modos de uso prehispánicos de las materias primas líticas en el Sudeste de la Región Pampeana. Una aproximación funcional. Tesis Doctoral. Universidad Nacional de La Plata, Argentina.

Leipus, M y ME Mansur. 2007. El análisis funcional de base microscópica aplicado a materiales heterogéneos. Perspectivas metodológicas para el estudio de las cuarcitas de la región pampeana. En Bayón et al. (Eds.). Arqueología en las Pampas Tomo I. Sociedad Argentina de Antropología, Argentina.

Levi-Sala, I. 1986. Experimental replication of postdepositational surface modification on flint. En Owen, L y G Unrath (Eds.). Technical aspect of microwear studies on stone tools. Part I. Tübingen, Alemania.

Levi-Sala, I. 1993. Use wear traces: processes of development and post-depositional alterations. En Anderson et al. (Eds.). Traces et fonction. Les gestes retrouves. Universidad de Liège, Bélgica.

Levi-Sala, I. 1996. A study of microscopic polish on flint implements. British Archaeological Reports, Inglaterra.

Lewenstein, S. 1981. Mesoamerican obsidian blades: An experimental approach to function. Journal of Field Archaeology 8: 175-188. 
Loy, TH. 1993. The artifact as site: biomolecular analysis of organic residues on prehistoric tools. World of Archaeology 25: 44-63.

Loy, TH y Nelson DE. 1986. Potential applications of the organic residues on ancient tools. Smithsonian Institution Press, Estados Unidos.

Lubbock, J. 1872. Pre-Historic times. Williams and Norgate, Londres, Inglaterra.

Lull, V. 2005. Marx, producción, sociedad y arqueología. Trabajos de Prehistoria 62: 7- 26.

Lumbreras, LG. 1981. La Arqueología como Ciencia Social. Peisa, Lima, Perú.

Lupo, KD. 1994. Butchering marks and carcass acquisition strategies: distinguishing hunting form scavenging in archaeological context. Journal of Archaeological Science 21: 827-837.

Lynch, T. 1990. Quaternary climate, environment and the human occupation of the South American Andes. Geoarchaeology 5: 199-228.

Lynch, V. 2013. Analisis morfologico-funcional de raspadores líticos del sitio Cueva Maripe (Santa Cruz, Argentina). En Zangrando et al. (Eds.). Tendencias teórico-metodológicas y casos de estudio en la arqueología de Patagonia. Sociedad Argentina de Antropología, Argentina.

Lynch, V y D Hermo. 2011. ¿Es posible la detección de huellas de enmangue? Evidencias macro y microscópicas en instrumentos líticos experimentales. Magallania 39: 241-252.

Lynch V, M Fernández y L Miotti. 2012. Estudio experimental sobre la dinámica postdepositacional en rastros de uso: integridad artefactual del sitio Cueva Maripe (Santa Cruz, Argentina). VI Simposio del Hombre Temprano en América, Colombia.

Magnin, L. 2004. Los datos espaciales y la arqueología de grupos móviles de la Meseta Central de Santa Cruz. XV Congreso Nacional de Arqueología Argentina, Argentina.

Magnin, L. 2006. Herbario de la Flora de la Estancia Aguada del Cuero, Departamento del Deseado, Santa Cruz. 17 pp.

Magnin, L. 2010. Distribuciones arqueológicas en la Meseta Central de Santa Cruz. Implicancias para los estudios del uso del espacio y movilidad de sociedades cazadoras-recolectoras. Tesis doctoral. Universidad Nacional de La Plata, Argentina.

Mancini, MV. 1998. Vegetational changes during the Holocene in Extra-Andean Patagonia, Santa Cruz Province, Argentina. Palaeogeography, Palaeoclimatology, Palaeoecology 138: 207-219.

Mancini, MV, M Paez y A Prieto. 2002. Cambios paleoambientales durante los últimos $700014 \mathrm{C}$ en el ecotono bosque estepa, 47-48 S, Santa Cruz, Argentina. Ameghiniana 39: 151-162.

Mansur-Franchomme, ME. 1981. Las estrías como microrrastros de utilización: clasificación y mecanismos de formación. Antropología y Paleoecología Humana 2: 221-236.

Mansur-Franchomme, ME. 1983. Traces d'utilisation et technologie lithique: Exemples de la Patagonia. Tesis Doctoral. Universidad de Bordeux, Francia.

Mansur-Franchomme, ME. 1986. Microscopie du materiel lithique préhistorique: traces d'utilisation, altérations naturelles, accidentelles et technologiques. Cahiers du Quaternarie 9, Bordeaux, Francia. 
Mansur-Franchomme, ME. 1986/1990. Instrumentos líticos: Aspectos da análise funcional. Arquivos do Museu de Historia Natural 11: 115-169.

Mansur-Franchomme, ME. 1987a. El análisis funcional de artefactos líticos (I). Secretaría de Cultura, Dirección Nacional de Antropología y Folklore, Instituto Nacional de Antropología. Argentina.

Mansur-Franchomme, ME. 1987b. Outils etnographiques de Patagonie enmanchement et traces d'utilisation. La main et l'outil: manches et enmanchements préhistoriques. Travaux de la maison de l'Orient, Lyon, Francia.

Mansur-Franchomme, ME. 1990. Quelques observations sur les altérations naturelles des microtraces d'usage des outillages lithiques. Le silex de sa genése á l'outil. Cahiers du Quaternarie 17, Bordeaux, Francia.

Mansur, ME. 1992. Aspectos del análisis microscópico de instrumentos de piedra. Arquivos do Museu de Historia Natural. UFMG, Brasil.

Mansur, ME. 1999. Análisis funcional de instrumental lítico: Problemas de formación y deformación de rastros de uso. XII Congreso Nacional de Arqueología Argentina, Argentina.

Mansur, ME y A Lasa. 2005. Diversidad artefactual vs. especialización funcional. Análisis del IV componente de Tunel I (Tierra del Fuego, Argentina). Magallania 33: 69-91.

Mansur, ME, R Piqué y A Vila. 2004. Sociedad y Ritual en Tierra del Fuego. Excavaciones Arqueológicas en un Sitio Ceremonial del Corazón de la Isla. XV Congreso Nacional de Arqueología Argentina, Argentina.

Mansur, ME, A Castro y M Álvarez. 2005. Perspectivas en el análisis de conjuntos líticos. Teoría, metodología, nuevas tendencias. XVI Congreso Nacional de Arqueología Argentina, Argentina.

Marchionni L. 2013. Comparación de las distintas historias tafonómicas en conjuntos zooarqueológicos provenientes de la Meseta Central de la provincia de Santa Cruz. Tesis Doctoral. Universidad Nacional de La Plata, Argentina.

Marchionni, L y M Vázquez. 2012. New data on exploited Pleistocene fauna at Piedra Museo (Central Plateau of Santa Cruz Province, Argentina). En Miotti et al. (Eds.). Southbound. Late Pleistocene Peopling of Latin America. Texas A\&M University Press, Texas, Estados Unidos.

Marchionni, L, L Miotti y B Mosquera. 2010. El uso de la fauna entre el Pleistoceno final y el Holoceno medio en la Patagonia extra-andina. En Gutiérrez et al. (Eds.). Zooarqueología a principios del siglo XXI: aportes teórico, metodológicos y casos de estudio. Ediciones del Espinillo, Argentina.

Markgraf, V. 1991. Younger Dryas in South America? Boreas 20: 63-69.

Markgraf, V. 1993. Paleoenvironments and paleoclimates in Tierra del Fuego and Southernmost Patagonia, South America. Palaeogeography, Palaeoclimatology, Palaeoecology 102: 53-68.

Markgraf, V, J Platt-Bradbury, A Schwalb, S Burns, C Starn, D Araiztegui, A Gilli, F Anselmetti, S Stine y N Maidana. 2003. Holocene palaeoclimates of southern Patagonia: limnological and environmental history of Lago Cardiel, Argentina. The Holocene 13: 581-591.

Martinic, M. 1995. Los Aonikenk: historia y cultura. Universidad de Magallanes, Chile. 
Martin, FM. 2008. Tafonomía y Paleoecología de la transición Pleistoceno-Holoceno en Fuego-Patagonia. Interacción entre poblaciones humanas y de carnívoros y su importancia como agentes en la formación del registro fósil. Tesis Doctoral. Universidad Nacional de La Plata, Argentina.

Massigoge A y N Pal. 2011. Producción y uso de artefactos líticos en contextos cazadores-recolectores del Área Interserrana (Argentina): análisis integral de la diversidad tecno-morfológica y funcional. Revista Española de Antropología Americana 41: 51-73.

Meltzer, D. 2003. Lessons in Landscape Learning. En Rockman, M y J Steele (Eds.). Colonization of Un familiar Landscapes. The Archaeology of Adaptation. Routledge, Inglaterra.

Mena, F y D Jackson. 1991. Tecnología y subsistencia en el Alero Entrada Baker, Región de Aisén, Chile. Anales del Instituto de la Patagonia 20: 169-203.

Menghin, OFA. 1952. Las pinturas rupestres de Patagonia. Runa 5: 5-22.

Menghin, OFA. 1957. Estilos del arte rupestre de Patagonia. Acta Prehistorica 1, Buenos Aires, Argentina.

Mengoni Goñalons, GL. 1982. Notas zooarqueológicas I: fracturas en hueso. VII Congreso Nacional de Arqueología, Uruguay.

Mengoni Goñalons, GL y M Silveira. 1976. Análisis e interpretación de los restos faunísticos de la cueva de las Manos Estancia Alto Río Pinturas (Provincia de Santa Cruz). Relaciones 10: 261-270.

Miotti, L. 1992. Paleoindian occupation at Piedra Museo Locality, Patagonian Region,

Argentina. Current Research in the Pleistocene 9: 30-32.

Miotti, L. 1995. Piedra Museo Locality: a special place in the New World. Current Research in the Pleistocene 12: 37-40.

Miotti, L. 1996. Piedra Museo (Santa Cruz): nuevos datos para el debate de la ocupación Pleistocénica en Patagonia. En Gómez Otero, J (Ed.). Arqueología, sólo Patagonia. Secretaría de Cultura de ChubutCONICET, Chubut, Argentina.

Miotti, L. 1998. Zooarqueología de la Meseta Central y Costa de la Prov. de Santa Cruz: Un enfoque de las estrategias adaptativas aborígenes y los paleoambientes. Imprenta del Museo de Ciencias Naturales de San Rafael, San Rafael, Argentina.

Miotti, L. 2003. Patagonia: a paradox for building images of the first Americans during the Pleistocene/Holocene transition. Quaternary International 109-110: 147-173.

Miotti, L. 2006. Paisajes domésticos y sagrados desde la arqueología de los cazadoresrecolectores en el macizo del Deseado, provincia de Santa Cruz. Cazadores Recolectores Del Cono Sur. Revista De Arqueología 1: 13-42.

Miotti, L. 2011. La potenciación de los recursos entre los cazadores-recolectores de Patagonia. Factores, procesos e implicancia arqueológica. II Congreso Argentino de Zooarqueología. Olavarría, Argentina.

Miotti, L. 2012. El uso de los recursos faunísticos entre los cazadores-recolectores de Patagonia: tendencias espacio/temporales de las estrategias durante el Holoceno. Archaeofauna 21: 137-160. 
Miotti, L y N Carden. 2007. The relationships between rock art and archaeofaunas in the Central Patagonian Plateau. En Gutiérrez et al. (Eds.). Taphonomy and Archaeology in Argentina. BAR International Series, Inglaterra.

Miotti, L y G Cattáneo. 1997. Lithic technology at 13.000 years ago in southern Patagonia. Current Research in the Pleistocene 14: 62-65.

Miotti, L y G Cattáneo. 2003. Pleistocene/Holocene transition at Piedra Museo and surrounding region. En Miotti, L, M Salemme y N Flegenheimer (Eds.). Ancient evidences for paleo South Americans: From where the south wind blow. Center for the studies of the first Americans and Texas A\&M University Press, Estados Unidos.

Miotti, L y D Hermo. 2000. Áreas de Estudio. En Miotti et al. (Eds.). Guía de Campo de la visita a las localidades arqueológicas. Servicoop, La Plata, Argentina.

Miotti, L y L Magnin. 2012. South America 18,000 years ago: topographic accessibility and human spread. En Miotti et al. (Eds.). Southbound. Late Pleistocene Peopling of Latin America. Texas A\&M University Press, Texas, Estados Unidos.

Miotti, L y L Marchionni. 2009. Procesando huesos: entre la Etnografía y la Arqueología. En Salemme et al. (Eds.). Arqueología de la Patagonia. Una mirada desde el confín del mundo. Editorial Utopía, Argentina.

Miotti, L y L Marchionni. 2012. Autopodios de guanacos: un caso de equifinalidad entre lo palatable y lo preservado del registro zooarqueológico. II Encuentro Latinoamericano de Arqueozoología. Santiago de Chile, Chile.

Miotti, L y L Marchionni. 2013. Beyond tools: bone as raw material for tools in Central Plateau of Santa Cruz, Argentinian Patagonia. En Choyke, A, S O'Connor y C Vercoutère (Eds.). Raw and work osseous materials. Oxbow, Inglaterra.

Miotti, L y M Salemme. 1999. Biodiversity, Taxonomic Richness and Generalist-Specialists economical systems in Pampa and Patagonia Regions, Southern South America. Quaternary International 53-54: 53-68.

Miotti, L y M Salemme. 2004. Poblamiento, movilidad y territorios entre las sociedades cazadorasrecolectoras de Patagonia: cambios desde la transición Pleistoceno/ Holoceno al Holoceno medio. Complutum 15: 177-206.

Miotti, L y M Salemme. 2005. Hunting and butchering events at the Pleistocene/ Holocene transition in Piedra Museo: An example of adaptation strategies of the first colonizers of Patagonia. En Bonnichsen et al. (Eds.). Paleoamerican origins: Beyond Clovis. Texas A\&M University Press, Estados Unidos.

Miotti, L y E Tonni. 1996. Rheidos del sitio arqueológico AEP-1 de Piedra Museo y la meseta central de Santa Cruz y sus implicancias paleoambientales. III Jornadas de Arqueología de Patagonia, Argentina.

Miotti, L, N Carden y MJ Canosa. 1999a. Paisajes arqueológicos de Cazadores-recolectores, Arte rupestre y Lagunas. XII Congreso Nacional de Arqueología Argentina, La Plata, Argentina. 
Miotti, L, M Vázquez y D Hermo. 1999b. Piedra Museo un Yamnagoo Pleistocénico en la colonización de la meseta de Santa Cruz. En Belardi et al. (Eds.). Soplando en el Viento. INALP, Buenos Aires, Argentina.

Miotti, L, M Salemme y J Rabassa. 2003. Radiocarbon chronology at Piedra Museo Locality. En Miotti, L, M Salemme y N Flegenheimer (Eds.). Where the South Winds Blow: Ancient Evidence of Paleo South Americans. Center for the Studies of the First Americans-Texas A \& M University Press, Estados Unidos.

Miotti, L, M Salemme, D Hermo, M Vázquez, N Carden, M Giardina y L Magnin. 2005. Aguada del Cuero, un nuevo escalón en la arqueología de la Meseta Central de Santa Cruz. En Berberián, E (Ed.). XIII Congreso Nacional de Arqueología Argentina, Córdoba, Argentina.

Miotti, L, D Hermo, L Magnin, N Carden, L Marchionni, A Alcaraz, B Mosquera, E Terranova y M Salemme. 2007. Resolución arqueológica en la Cueva Maripe (Santa Cruz, Argentina). En Morello et al. (Eds.). Arqueología de Fuego-Patagonia: Levantando piedras, desenterrando huesos...y develando arcanos. Ediciones CEQUA, Punta Arenas, Chile.

Miotti, L, D Hermo, M Salemme, L Magnin y L Marchionni. 2009. Cueva Maripe y su excavación. Implicancias en los Estudios Regionales del Macizo del Deseado. En Austral, A y Tamagnini (Eds.). Problemática de arqueología contemporánea, Universidad Nacional de Río Cuarto, Argentina.

Miotti, L, L Marchionni, B Mosquera, D Hermo y M Fernández. 2011. Aportes metodológicos para el ajuste temporal de las ocupaciones humanas de la Cueva Maripe, Santa Cruz, Argentina. En Zangrando et al. (Eds.). VIII Jornadas de Arqueología de la Patagonia. Centro de Convenciones y Exposiciones Thesaurus, Museo de Historia Natural de San Rafael, Malargüe, Argentina.

Miotti, L, N Carden, R Blanco y J Clottes. 2012. Las manifestaciones artísticas de la transición Pleistoceno/Holoceno: la Eevidencia de la Meseta Central de Santa Cruz (Patagonia Argentina). Préhistoire, art et societies 65-66: 851-866.

Miotti, L, L Marchionni, B Mosquera, D Hermo y A Ceraso. Fechados radiocarbónicos y delimitación temporal de los conjuntos arqueológicos de Cueva Maripe, Santa Cruz (Argentina). En prensa.

Mosquera, B. 2012. Análisis geoarqueológicos del sitio Cueva Maripe: primeros resultados. IX Jornadas de Jovenes Investigadores. INAPL, Buenos Aires, Argentina.

Moss, E. 1983. The functional analysis of flint implements. Pincevent and Pont D`Ambon: two case studies form the French Final Palaeolithic. BAR International Series 177.

Moss, E y M Newcomer. 1982. Reconstruction of tool use al Pincevent: Microwear and Experiments. Studia Praehistorica Belgica 2: 289-312.

Moreira, P. 2005. Geología y metalogénesis del distrito La Josefina, macizo del Deseado, Santa Cruz. Tesis Doctoral. Universidad Nacional de La Plata, Argentina.

Muñoz, AS y JB Belardi. 1998. El marcado perimetral en los huesos largos de guanaco de Cañadón Leona (Colección Junius Bird): implicaciones arqueofaunísticas para Patagonia Meridional. Anales del Instituto de la Patagonia 26: 107-117. 
Musters, GC. 1964. Vida entre los Patagones. Un año de excursiones por tierras no frecuentadas desde el Estrecho de Magallanes hasta el Río Negro. Ediciones Solar-Hachette, Buenos Aires, Argentina.

Myers A. 1989. Reliable and maintainable technological strategies in the Mesolithic of mainland Britain. Time energy and stone tools. Cambridge, Inglaterra.

Nacuzzi, L y C Pérez de Micou. 1983/85. Los Recursos vegetales de los cazadores de la cuenca del río Chubut. Cuaderno del Instituto Nacional de Antropología 10: 407-424.

Nami, HG. 1992. El subsistema tecnológico de la confección de instrumentos líticos y la explotación de los recursos del ambiente. Shincal 2: 13-53.

Nami, HG. 1998. Arqueología experimental, talla de la piedra contemporánea, arte moderno y técnicas tradicionales: observaciones actualísticas para discutir estilo en tecnología lítica. Relaciones 22/23: 363-388.

Nami, HG y VG Scheinsohn. 1997. Use-wear patterns on bone experimental flakers: a preliminary report. En Hannus, LA, L Rossum y RP Winhan (Eds.). Proceedings of the 1993 Bone Modification Conference, HotSprings, Estados Unidos.

Naranjo, JA y C Stern. 1998. Holocene explosive activity of Hudson volcano, southern Andes. Bulletin of Volcanology 59: 291-306.

Narosky T y D Yzurieta. 2010. Guía de identificación Aves de Argentina y Uruguay. Vázquez Mazzini Editores, Buenos Aires, Argentina.

Nelson, M. 1991. The Study of Technological Organization. Archaeological Method and Theory 3: 57-100.

Díaz, NI, Prieto A y G Bahamonde. 2007. Guanacos tímidos, huemules confiados: el límite occidental de los cazadores terrestres australes. Magallania 35: 133-138.

Núñez, L, J Varela, R Casamiquela, V Schiappacasse, H Niemeyer y C Villagrán. 1994. Cuenca de Taguatagua en Chile: el ambiente del Pleistoceno superior y ocupaciones humanas. Revista Chilena de Historia Natural 67: 503-519.

Odell, GH. 1981. The Morphological express at function junction: searching for meaning in Lithic tool types. Journal of Anthropological Research 37: 319-342.

Odell, GH. 1994. Prehistoric hafting and mobility in the North American Midcontinent: Examples from Illinois. Journal of Anthropological Archaeology 13: 51-73.

Odell, GH. 1996. Stone tools: theoretical insights into human prehistory. Plenum, Estados Unidos.

Odell, GH y F Odell-Vereecken. 1980. Verifying the reliability of lithic use-wear assessments by 'blind tests': the low-power approach. Journal of field Archaeology 7: 87-120.

Olsen, S. 1979. A study of Bone Artifacts fom Grasshopper Pueblo, Kiva 44: 341-371.

Osterrieth, M. 2000. Silicofitolitos, una herramienta para la comprensión de procesos pedológicos del Cuaternario. XVII Congreso Argentino de la Ciencia del Suelo, Argentina.

Osterrieth, M, G Martínez, D Zurro, A Zucol, M Brea y D Mazzantti. 2002. Procesos de formación del sitio 2 de la localidad arqueológica Amalia: evolución paleoambiental. En: Mazzantti et al. (Eds.). Del mar 
a los salitrales: Diez mil años de historia pampeana en el umbral del tercer milenio. Sociedad Argentina de Arqueología, Argentina.

Oubiña, CP, F Criado-Boado y M Santos-Estévez. 1998. Rewriting landscape: incorporating sacred landscapes into cultural traditions. World Archaeology 30: 159-176.

Páez, MM, AR Prieto y MV Mancini. 1999. Fossil pollen from Los Toldos locality: a record of the LateGlacial transition in the Extra-Andean Patagonia. Quaternary International 53-54: 69-76.

Pal, N. 2008. Aportes al estudio de la integridad del sitio Laguna La Barrancosa 1 (Partido de Benito Juárez, Provincia de Buenos Aires): Análisis de los microdesechos líticos. Intersecciones en Antropología 9: 59-75.

Pal, N. 2009. Análisis funcional: programa experimental sobre Ftanitas, Dolomías Silicificadas y Cuarcitas (Sector Noroccidental de Tandilla). En Bourlot et al. (Eds.). Entre Pasados y Presentes II. Estudios contemporáneos en ciencias antropológicas. Editorial Azara, Buenos Aires, Argentina.

Pal, N. 2010. Correlación entre forma-función de los conjuntos líticos recuperados en la cuenca superior del arroyo Tapalqué: Su vinculación con otros sitios de la región pampeana. En Berón et al. (Eds.). Mamül Mapu: Pasado y presente desde la arqueología pampeana Tomo II. Editorial Libros del Espinillo, Ayacucho, Argentina.

Pal, N. 2013. Tendencias temporales en las estrategias de explotación y uso de los materiales líticos de la cuenca superior del arroyo Tapalqué: Una perspectiva desde el Análisis Funcional. Tesis Doctoral. Universidad Nacional del Centro de la Provincia De Buenos Aires, Argentina.

Pal, N y P Messineo. 2012. Producción y uso de los artefactos líticos en la Laguna Barrancosa. Centro Austral de Investigaciones Científicas, Ushuaia, Argentina.

Panza, JL. 1982. Descripción geológica de las Hojas 53e "Gobernador Moyano" y 54e "Cerro Vanguardia", Santa Cruz. Servicio Geológico Nacional, Argentina.

Panza, JL. 2001. Hoja Geológica 4769-IV. Monumento Natural Bosques Petrificados, Santa Cruz. Instituto de Geología y Recursos Minerales, Buenos Aires, Argentina.

Panza, JL y M Genini. 1998. Hoja Geológica 4969-IV. Monumento Natural Bosques petrificados, Santa Cruz. Servicio Geológico Minero Argentino, Argentina.

Paunero, RS. 2000a. Relevamiento, arte rupestre y sectorización de la localidad La María. En Miotti et al. (Eds.). Guía de Campo de la visita a las Localidades arqueológicas. Servicoop, Argentina.

Paunero, RS. 2000b. Cañadón de La Mina: Sitio Casa del Minero 1. En Miotti et al. (Eds.). Guía de Campo de la visita a las Localidades arqueológicas. Servicoop, Argentina.

Paunero, RS. 2000c. Localidad arqueológica Cerro Tres Tetas. En Miotti et al. (Eds.). Guía de Campo de la visita a las Localidades arqueológicas. Servicoop, Argentina.

Paunero, RS. 2003a. The Cerro Tres Tetas (C3T) locality in the Central Plateau of Santa Cruz, Argentina. En Miotti, L, M Salemme y N Flegenheimer (Eds.). Where the South Winds Blow: Ancient Evidence of Paleo South Americans. A\&M University Press, Texas, Estados Unidos. 
Paunero, RS. 2003b. The presence of a Pleistocene colonizing culture in La Maria archaeological locality, Casa del Minero 1. En Miotti, L, M Salemme y N Flegenheimer (Eds.). Where the South Winds Blow: Ancient Evidence of Paleo South Americans. A\&M University Press, Texas, Estados Unidos.

Paunero, RS. 2009a. Fogones, conjuntos líticos y funcionalidad en el componente pleistocénico del sitio Cueva 1 de Cerro Tres Tetas, Santa Cruz. En Oliva, F, N de Grandis y J Rodríguez (Eds.). Arqueología Argentina en los inicios de un nuevo siglo. Universidad Nacional de Rosario, Argentina.

Paunero, RS. 2009b. La colonización humana de la Meseta Central de Santa Cruz durante el Pleistoceno final: indicadores arqueológicos, referentes estratigráficos y nuevas evidencias. En Salemme et al. (Eds.). Arqueología de la Patagonia. Una mirada desde el último confín. Editorial Utopia, Argentina.

Paunero, RS y A Castro. 2001. Análisis lítico y funcionalidad del componente inferior del sitio Cueva 1, localidad arqueológica Cerro Tres Tetas, Santa Cruz. Anales del Instituto de la Patagonia (Serie Ciencias Sociales) 29: 189-206.

Paunero, RS, ME Cueto, A Frank, G Rosales, F Skarbun, MF Paunero y G Zapata. 2004. Localidad Arqueológica La María en la Meseta Central de Santa Cruz. XV Congreso Nacional de Arqueología Argentina, Río Cuarto, Argentina.

Paunero, RS, A Frank, F Skarbun, G Rosales, G Zapata, ME Cueto, MF Paunero, DG Martínez, R López, N Lunazzi y M Del Giorgio. 2005. Arte rupestre en Estancia La María, Meseta Central de Santa Cruz: sectorización y contextos arqueológicos. Relaciones 30: 147-168.

Paunero, RS, P Albertengo, M Cueto, A Dávila, A Frank, A Olivera y C Piva. 2007. Sitio Casa del Minero 1, localidad arqueológica La María: nuevas evidencias sobre ocupación humana pleistocénica en Santa Cruz. En Oliva, F, N de Grandis y J Rodríguez (Eds.). Arqueología Argentina en los inicios de un nuevo siglo. Laborde Editor, Argentina.

Peltier, A y H Plisson. 1989. Microtraceologie fonctionnelle sur l'os. Quel ques resultats experimentaux. Artefacts 3: 69-79.

Pérez de Micou, C, C Belleli y C Aschero. 1992. Vestigios minerales y vegetales en la determinación del territorio de explotación de un sitio. En Borrero, LA y JL Lanata (Eds.). Análisis espacial en la Arqueología Patagónica. Ediciones Ayllu, Argentina.

Pfaffenberger, B. 1988. Fetishised Objects and Humanised Nature: Towards an Anthropology of Technology. Man 23: 236-252.

Pfaffenberger, B. 1992. Social anthropology of technology. Annual review of Anthropology 21: 491-516.

Plisson, H. 1985. Etude fonctionnelle d'outillages lithiques préhistoriques par l'analyse des micro usures: Recherche méthodologique et archéologique. Université de Paris, Francia.

Plisson, H. 1987. L'emmanchement dans l'habitation no de Pincevent, La Main et routil. Mancheset emmanchements préhistoriques. Travaux de la Maison de l'Orient 15: 75-88.

Plisson, H y M Mauger. 1988. Chemical and mechanical alteration of microwear polishes: An experimental approach. Helinium 28: 3-16. 
Politis, G. 1999. La estructura del debate sobre el poblamiento de América. Boletín de Arqueología 14: 2552.

Politis, G y M Salemme. 1990. Pre-hispanic mammal exploitation and hunting strategies in the Eastern Pampa Subregion of Argentina. En Davis, LB y BOK Reeves (Eds.). Hunters of the Recent Past. Unwin Hyman, Inglaterra.

Politis G, PG Messinero y CA Kaufmann. 2004. El poblamiento temprano de las llanuras pampeanas de Argentina y Uruguay. Complutum 15: 207-224.

Ponce, JF, J Rabassa, A Coronato y A Borromei. 2011. Palaeogeographical evolution of the Atlantic coast of Pampa and Patagonia from the last glacial maximum to the Middle Holocene. Biological Journal of the Linnean Society 103: 363-379.

Prates, L, G Politis y J Steele. 2013. Radiocarbon Chronology of the Early Human Occupation of Argentina. Quaternary International XXX 1-19.

Rabassa, J, L Miotti, L Marchionni, RV Blanco y M Salemme. 2007. Informe de campaña arqueológica 2007. Excavación y geoarqueología del sitio Cueva Maripe. Informe de campaña inédito en posesión de los autores.

Ratto, S. 1994. Indios amigos e indios aliados. Orígenes del "negocio pacífico" en la provincia de Buenos Aires (1829-1832). Cuadernos del Instituto Ravignani 5: 5-34.

Ratto, N. 2003. Estrategias de caza y propiedades del registro arqueológico en la Puna de Chaschuil (Departamento de Tinogasta, Catamarca, Argentina). Tesis Doctoral. Universidad de Buenos Aires, Argentina.

Ricciardi, A y E Rolleri. 1980. Cordillera Patagónica austral. En Turner, JCM (Ed.). II Simposio de Geología Regional Argentina. Academia Nacional de Ciencias, Argentina.

Rindel, D. 2009. Arqueología de momentos tardíos en el noroeste de la provincia de Santa Cruz (Argentina): una perspectiva faunística. Tesis Doctoral. Universidad de Buenos Aires, Argentina.

Risch, R. 2002. Recursos naturales, medios de producción y explotación social. Un análisis económico de la industria lítica de Fuente Alamo. Philipp von Zabern, Alemania.

Rockman, M y J Steele. 2003. Colonization of unfamiliar landscapes. En Rockman, M y Steele (EDs.). The Archaeology of Adaptation. Routledge, Inglaterra.

Rots, V. 2002. Hafting traces on flint tools: possibilities and limitations of macro- and microscopic approaches. Tesis Doctoral. Katholieke Universiteit Leuven, Bélgica.

Rots, V. 2003.Towards an understanding of hafting: the macro- and microscopic evidence Antiquity 77 : 805-815.

Rots, V y B Williamson. 2004. Microwear and residue analyses in perspective: the contribution of ethnoarchaeological evidence. J. Archaeological Science 31: 1287-1299.

Rots, V, L Pirnay, P Pirson y O Baudoux. 2006. Blind tests shed light on possibilities and limitations for identifying stone tool prehension and hafting.Journal of Archaeological Science 33: 935-952.

Rottländer, R. 1975. The formation of patina on flint. Archaeometry 17: 106-111. 
Salemme, M y L Miotti. 1998. The status of rheids in Patagonia: environmental approach and economic interpretation at the transition Late Pleistocene/Early Holocene. VII International Conference of the International Council for Archaeozoology, Canadá.

Salemme, M y L Miotti. 2008. Archaeological hunter-gatherer landscapes since the latest Pleistocene in Fuego-Patagonia. En Rabassa, J (Ed.). Late Cenozoic of Patagonia and Tierra Del Fuego. Elsevier, Estados Unidos.

Sanguinetti, N. 1969. Un petroglifo de Hierro Viejo. Anales del Museo de Historia Natural de Valparaíso 2: 25-236.

Sanguinetti de Bórmida, MA y LA Borrero. 1977. Los niveles con fauna extinta de la cueva de las Buitreras. Relaciones 11: 167-175.

Scheinsohn, V. 1997. Explotación de materias primas óseas en la Isla grande de Tierra del Fuego. Tesis Doctoral. Universidad de Buenos Aires, Argentina.

Schiffer, M. 1987. Formation processes of archaeological record. University of New Mexico Press, Mexico.

Schiffer, M y J Skibo. 1987. Theory and Experiment in the Study of Technological Change. Current Anthropology 28: 595-622.

Schmid, T. [1858/65] 1964. Misionando por Patagonia austral, Buenos Aires, Academia Nacional de la Historia.

Schobinger, J. 1969. Prehistoria de Sudamérica. Editorial Labor, España.

Siegel, S y NJ Castellan Jr. 1988. Nonparametric statistics for the behavioral sciences. McGraw-Hill, Estados Unidos.

Semenov, S. 1964. Prehistoric technology. Adams y Dart, Inglaterra.

Semenov, S. 1981. Tecnología Prehistórica. Akal Universitaria Press, España.

Shafer, F y R Holloway. 1979. Organic residues analysis in determining stone tools function. En Hayden, B (Ed.). Lithic Use-Wear Analysis. Academic Press, Estados Unidos.

Shea, J y J Klenck. 1993. An experimental investigation of the effects of trampling on the results of lithic microwear analysis. Journal of Archaeological Science 20: 175-194.

Sruoga, P, A Busteros, R Giacosa, H Martínez, L Kleiman, S Japas, A Maloberti y MR

Gayone. 2008. Análisis litofacial y estructural del complejo volcánico Bahía Laura en el área El DoradoMontserrat, Santa Cruz. Revista de la Asociación Geológica Argentina 63: 653-664.

Stapert, D. 1976. Some natural surface modifications on Flint in the Netherlands. Palaeohistoria 18I: 7-41.

Steele, J y G Politis. 2009. AMS 14C dating of early human occupation in southern South America. Journal of Archaeological Science 36: 419-439.

Stein, JK. 1992. Organic Matter in Archaeological Contexts. En Holliday, V (Ed.). Soils in Archaeology. Smithsonian Institution Press, Estados Unidos.

Stein, JK. 2001. A review of site formation processes and their relevance to geoarchaeology. Earth sciences and archaeology. Springer, Estados Unidos. 
Stern, RC. 1999. Black obsidian from central-south Patagonia; chemical characteristics, sources and regional distribution of artifacts. III Jornadas de Arqueología de la Patagonia. Universidad Nacional del Comahue e Instituto Nacional de Antropología y Pensamiento Latinoamericano, Argentina.

Stern, RC. 2000. Sources of obsidian artefacts from the Pali Aike, Fell's Cave and Cañadón La Leona archaeological sites in southernmost Patagonia. Río Gallegos, Argentina.

Stern, RC. 2004. Obsidian in Southern Patagonia: Review of the Current Information. En Civalero, P, P Fernández y AG Guráieb (Eds.). Contra viento y marea. Arqueología de Patagonia. Instituto Nacional de Antropología y Pensamiento Latinoamericano y Sociedad Argentina de Antropología, Argentina.

Stern, CR, S Caracotche, I Cruz y J Charlin. 2012. Obsidiana gris porfírica calco-alcalina del volcán Chaitén sitios arqueológicos al sur del río Santa Cruz. Magallania 40: 137-144.

Stine, S. 1994. Extreme and persistent drought in California and Patagonia during medieval time. Nature 369: 546-549.

Stine, S y M Stine. 1990. A record from Lake Cardiel of climate change in southern South America. Nature 345: 705-708.

Stordeur, D. 1987. Manches et emmanchements préhistoriques: quelques propositions préliminaires. En Stordeur, D (Ed.). La main et l'outil: manches et mmanchements préhistoriques. Maison de l'Orient Mediterranéen, Francia.

Stordeur, D y P Anderson-Gerfaud. 1985. Les omoplates enconchées néolithiques de Ganj Dar eh (Iran). Étude morphologique et fonctionnelle. Cahiers de l'Euphrates 4: 199-313.

Symens, N. 1986. A functional analysis of selected stone artefacts from the Magdalenian site al Verberie, France. Journal of Field Archaoelogy 13: 213-222.

Torrence, R. 1983. Time budgeting and hunter-gatherer technology. En Bailey, G (Ed.). Hunter- Gatherer Economy in Prehistory. Cambridge University Press. Inglaterra.

Torrence, R. 1986. Production and Exchange of Stone Tools: Prehistoric Obsidian in the Aegean. Cambridge University Press, Inglaterra.

Torrence, R. 1989. Tools as optimal solutions. En Torrence, R (Ed.). Time, Energy and Stone Tools. Cambridge University Press, Inglaterra.

Tringham, R, G Cooper, G Odell, B Voytek y A Whitman. 1974. Experimentation in the formation of edge damages: a new approach to lithic analysis. Jounal of Field Archaeology 1: 171-196.

Unger Hamilton, R. 1988. Method in Microwear Analysis. Prehistoric Sickles and other stone tools from Arjoune, Syria. BAR International Serie, 435.

Unrath, G, LR Owen, A van Gijn, EH Moss, H Plisson y P Vaughan. 1986. An evaluation of micro-wear studies: a multi-analyst approach. En Unrath, G y L Owen (Eds.). Technical Aspects of Micro-wear Studies on Stone Tools. Archaeologica Venatoria, Alemania.

Vaughan, P. 1981. Lithic Microwear Experimentation and the functional analysis of the Lower Magdalenian stone tool assemblage. Tesis Doctoral. University of Pennsylvania. Estados Unidos. 
Vaughan, P. 1985. Use-wear analysis of flaked stone tools. University of Arizona Press. Estados Unidos.

Viedma, A. [1780/83] 1972. Diario y Descripción de la costa meridional del sur llamada vulgarmente patagónica. Colección P. de Angelis, Plus Ultra, Buenos Aires, Argentina.

Vignati, MA. 1938. Cráneos pintados del cementerio indígena de San Blas. Revista del Museo de La Plata $1: 35-52$.

Vila, A. 1986. Determinació del caràcter d'un lloc d'ocupació per les activitats que s'hi desenvolupen, Arqueología Espacial 8: 61-71.

Villa, P y F D`Errico. 2001. Bone and ivory points in the Lower and Middle Paleolithic of Europe. Journal of Human Evolution 41: 69-112.

Weitzel, C y MI González. 2012. Técnicas y decisiones sociales para el empleo de las rocas. Relaciones 37: 243-264.

Witthoft, J. 1967. Glazed polish on flint tools. American Antiquity 32: 383-388.

Yacobaccio, H. 1987. Los raspadores de Patagonia: un problema multifunción. I Jornadas de Arqueología de la Patagonia, Rawson, Argentina.

Yerkes, RW, R Barkai, A Gopher y O Bar Yosef. 2003. Microwear analysis of early Neolithic (PPNA) axes and bifacial tools from Netiv Hagdud in the Jordan Valley, Israel. Journal of Archaeological Science, 30: 1051-1066.

Zárate, M, A Blasi, y J Rabassa. 2000. Geoarqueología de la localidad Piedra Museo. En Miotti et al. (Eds.). Guía de Campo de la visita a las localidades arqueológicas. La Colonización del Sur de América durante la Transición Pleistoceno/Holoceno. Servicoop, Argentina. 


\section{Apéndice}

\section{Resultados obtenidos de la serie experimental de uso}

La determinación de los rastros generados a partir del uso de los artefactos de la serie experimental fue observada siguiendo los criterios establecidos por MansurFranchomme 1983 y Álvarez 2003, pasando a formar parte de la colección lítica experimental del equipo de trabajo. La serie estuvo constituida por 163 lascas sigladas desde EU1 (EU: Experimento unidad $\mathrm{N}^{\circ}$ ) hasta EU163. Desde la EU135 hasta la EU140 se realizaron raspadores de sílice para experiencias relacionadas a la identificación de rastros generados por el uso de enmangues. Asimismo, desde la EU150 a la EU163 fueron piezas empleadas para comprender los procesos postdepositacionales que pudieron haber afectado y ocasionado modificaciones en los materiales arqueológicos.

La materia prima utilizada en mayor proporción fueron rocas silíceas de distintas coloraciones, principalmente rojo y marrón. Asimismo, se realizó una serie menor en basalto $(n=11)$, cuya procedencia corresponde igualmente al área estudiada.

Las lascas utilizadas en los distintos experimentos fueron registradas a partir de variables morfológicas y funcionales (con especial atención a los filos activos), fotografiadas (macro y fotomicrografías), medidas y dibujadas con el fin de realizar una correcta toma de datos. Los resultados obtenidos a partir de la serie experimental realizada fueron los siguientes:

\section{-Materia prima Homogénea: Ignimbrita y riolita silicificada}

Este tipo de materia prima tiene una amplia representatividad en los sitios de estudio. Su procedencia ya ha sido mencionada con anterioridad (Capítulos II y V) y su buena calidad para la talla ha permitido extraer abundante cantidad de lascas experimentales mediante percusión directa. En consecuencia, los filos obtenidos fueron filosos y aptos de ser utilizados pero, dependiendo del material trabajado, en algunos casos sufrían embotamiento. 
Debido a las características que presenta el área de estudio (zona fitogeográfica de estepa arbustiva), la disponibilidad de este tipo de recurso no se encuentra ampliamente disperso a lo largo de la meseta.

En sus viajes a Tierra del Fuego, el etnólogo austríaco Gusinde (1982-1989), observó el uso del calafate (Barberis buxifolia) como astiles para la inserción de puntas de proyectil. Por otro lado, también ha sido conocido su uso, como varillas para el secado de cueros y "tenazas" para el fuego (Ratto 1994; 2003).

Otro recurso igualmente utilizado como madera debido a su tamaño corresponde al molle (Schinus marchandii), la altura alcanzada por estos árboles (3 metros), al igual que en el caso del duraznillo (Colliguaja integerrina) y Yoayin (Lycium Chilense) con 2 metros de altura y sin espinas, han sido utilizados como postes en la elaboración de viviendas (Magnin 2010). El uso del molle fue registrado arqueológicamente en el sitio Campo Mancada por Perez de Micou (1992), donde se menciona el uso de la resina de este árbol como ligante de instrumentos elaborados en piedra sobre madera (astiles o mangos), e igualmente utilizado como goma de mascar durante la higiene bucal (Musters [1871] 1997). También fue registrado como leña en sitios arqueológicos como Piedra Museo y Cerro Tres Tetas, con dataciones de ca. 11.000 AP (Steel y Politis 2009).

\section{-Madera Dura (Estacionada- Piquillín)}

El primer material empleado fue el de madera dura estacionada (Piquillín). Las lascas utilizadas fueron sigladas desde EU1 hasta EU20, y se realizaron las siguientes actividades: descortezamiento, raspado, alisado y aserrado. Se seleccionaron 4 lascas para cada actividad por lo que en total fueron utilizadas 16 lascas. En pocos casos (piezas trabajadas en período de tiempo prolongado - 45' y 60'-) fue necesaria la reactivación de los filos y en estos casos se utilizaron dos lascas más con el fin de conservar las embotadas para su posterior observación. 


\section{Descortezamiento:}

Se utilizaron 4 lascas, de la EU1 a la EU5. La actividad de descortezamiento se realizó con dificultad; ya que las lascas sufrían numerosos esquirlamientos. La corteza de la madera utilizada en la experimentación se adhería con fuerza excesiva generando inconvenientes al realizar esta actividad y por lo tanto implicó mayor inversión de esfuerzo. En cuanto al desarrollo de los rastros de uso, el filo observado sin haber sido utilizado presentaba caras planas y relativamente lisas. Una vez que entraron en contacto con el material trabajado las lascas empleadas en 5', 15' y 30' presentaron abundantes negativos de esquirlamientos, mayormente sobre la cara dorsal, con rasgos tecnológicos característicos: ondas, estrías de percusión, etc. En cuanto al desarrollo de estrías y micropulidos, en estas mismas piezas, se observaron abundantes estrías debido al desprendimiento de microlascados del filo utilizado. Mientras que en relación a los micropulidos desarrollados; las lascas trabajadas $5^{\prime}$ y $15^{\prime}$ presentaron redondeamiento del filo y escaso desarrollo en grado indiferenciado (sensu Mansur 1999). A los 30' comenzó a desarrollarse micropulido con algunos rasgos que caracterizan al trabajo sobre madera; brillante, continuo, de espesor intermedio y desarrollo en superficies altas de las microtopografía de la pieza. El micropulido se desarrolló en relación al filo de extensión intermedia; ya que el ángulo de trabajo fue extremadamente agudo (entre $20^{\circ}$ $35^{\circ}$ ). En cuanto a las piezas trabajadas $45^{\prime}$ y $60^{\prime}$, los filos presentaron mayor redondeamiento y buen desarrollo de micropulido permitiendo identificar el material trabajado. Las características principales del mismo fueron: espeso, desarrollo sobre superficies altas y bajas de la microtopografía del filo, continuo, con poco brillo (debido a al estado de la materia trabajada - estacionada-) y de extensión intermedia debido a un ángulo de trabajo agudo que permitió su desarrollo hacia el interior del filo.

\section{Raspado:}

Resultó dificultoso definir esta actividad en relación con la actividad de alisado. A pesar de esto, la diferenciación se dio por el ángulo de trabajo en relación con el material utilizado; ángulo que va de agudo a recto, entre $80^{\circ}$ y $90^{\circ}$. Ya sin corteza, el material trabajado no presentó mucha resistencia durante el desarrollo de la actividad realizada. En cuanto a los macrorrastros, el filo siguió presentando abundantes esquirlamientos, sobre todo en aquellas piezas trabajadas pocos minutos (5'y 15'). El desarrollo de 
estrías se dio con orientación perpendicular al filo trabajado y en cuanto al micropulido siguió las mismas etapas de formación que en el caso de la actividad anterior. La pieza trabajada $15^{\prime}$ presentó únicamente redondeamiento del filo; mientras que a los $30^{\prime}$ comenzó el desarrollo del micropulido indeferenciado (brillo y espesor intermedio en superficies altas de la microtopografía de la pieza). A los 45’ y $60^{\prime}$ se observó los caracteres diagnósticos que permiten definir el material trabajado.

\section{Alisado:}

El ángulo de trabajo en esta actividad, a diferencia del anterior fue agudo (entre $45^{\circ}$ y $50^{\circ}$ ). La lasca utilizada para el bloque temporal de $15^{\prime}$ se embotó rápidamente (a los 10') debido a las características que presentaba el filo; extremadamente agudo, dando como resultado una gran continuidad de negativos de microesquirlamientos y que el filo quedara inutilizable. El esfuerzo en la realización de esta actividad, no fue excesivo, ya que la extracción de la corteza fue el momento de mayor resistencia. La mayoría de los filos utilizados para alisar se embotaron a los $30^{\prime}$ por lo que fue necesario la confección de nuevas piezas para los períodos de $45^{\prime}$ y $60^{\prime}$. Probablemente el embotamiento de estas lascas haya sido consecuencia de la mala elección de filos al momento de su utilización (extremadamente agudos).

\section{Aserrado:}

El trabajo de aserrar implicó un ángulo de ataque de $90^{\circ}$ en la mayoría de los experimentos destinados a ésta actividad. La dificultad no fue excesiva pero se necesitó ejercer mucha presión para lograr el fin deseado. En cuanto a los rastros de uso generados se pudo observar abundantes negativos de esquirlamientos en ambas caras de las piezas utilizadas. El desarrollo de los microrrastros se generaron a partir de los 30' de iniciada la actividad y ambas caras de las piezas entraron en contacto. El esquirlamiento continuo se produjo en las piezas trabajadas $5^{\prime}$ y $15^{\prime}$ impidiendo el desarrollo de micropulidos. Una vez estabilizado el filo, a los 30', se observó el desarrollo de micropulido inicial, sobre todo en aristas y superficies altas de la microtopografía. Las lascas empleadas por más tiempo, desarrollaron un grado diferenciado, con rasgos característicos del trabajo de madera en ambas caras y estrías que permitieron definir el movimiento empleado (longitudinales al filo utilizado). 


\section{-Madera Dura (No estacionada- Piquillín)}

Las lascas utilizadas para este material fueron sigladas desde EU119 hasta EU134. Se trabajó en los mismos períodos de tiempo y actividades establecidas que en el caso de madera dura estacionada.

Los resultados obtenidos mediante la observación microscópica no presentan diferencias significativas en relación con los experimentos anteriores. Esto podría deberse a que el material trabajado no era lo suficientemente fresco como para permitir el desarrollo de micropulido diagnóstico en menor tiempo que el caso anterior.

\section{-Madera Blanda (No estacionada-molle y pino)}

Las actividades realizadas coincidieron con aquellas elegidas para el trabajo de madera anteriormente descripta (descortezamiento, raspado, alisado y aserrado) y en los mismos períodos de tiempo establecidos.

El tipo de madera utilizada (pinus silvestris y Schinus marchandii), presentaba abundante resina (estado fresco), por lo que generó micropulido bien desarrollado y brillante en corto período de tiempo (35').

Durante la actividad de descortezamiento, la extracción de corteza, implicó menor esfuerzo que en el caso de la madera dura estacionada.

En los momentos iniciales de cada actividad, se desarrolló gran cantidad de esquirlamientos de morfología variables y escalonados. En cuanto al micropulido y estrías, los rasgos característicos del trabajo sobre madera (micropulido muy brillante, espeso, sobre superficies altas y bajas de la microtopografía, y estrías en forma de cometas) fueron vistos a los $45^{\prime}$ de iniciada la actividad. La presencia de estrías dispuestas en forma transversal y longitudinal al filo utilizado, permitió identificar con facilidad el movimiento empleado (en el primer caso acciones transversalesdescortezamiento, raspado o alisado- mientras que en el segundo acciones longitudinales- aserrado-)

\section{-Madera Blanda (Estacionada)}


Se realizaron las mismas actividades e igual período de tiempo que en el caso anterior. Las lascas con filo natural utilizadas fueron sigladas desde EU76 hasta EU88.

Los rastros de uso generados permitieron observar micropulidos característicos del trabajo sobre madera a partir de los $45^{\prime}$ de iniciada la actividad. Asimismo, la presencia de rasgos diagnósticos para su identificación, se estableció a los 60' de iniciada la actividad y sin embargo, en este caso el micropulido desarrollado no presentó un brillo intenso como en el caso de la madera blanda no estacionada. Probablemente esto se deba a la presencia de abundante resina y mayor humedad durante el proceso de trabajo.

\section{Resultados del trabajo de madera}

Las características principales de los distintos estadios del desarrollo de micropulidos de madera han sido enumeradas con anterioridad. Sin embargo, en este apartado se plantean las características principales que permitirá su posterior identificación en el registro arqueológico.

El redondeamiento del filo se originó en piezas trabajadas poco minutos (15' a $\left.20^{\prime}\right)$ asociado al desarrollo de micropulido en estadio inicial. Al inicio del trabajo las piezas presentaron abundantes esquirlamientos de morfologías variadas y escalonadas que disminuyeron posteriormente al estabilizarse el filo.

El desarrollo de micropulido presentó las características mencionadas con anterioridad por Mansur-Franchomme $(1983,1986,1999)$ en relación a los tres estadios de formación.

En la etapa inicial, el micropulido, presentó un brillo mate sobre superficies altas de la microtopografía y de extensión marginal. A medida que iba avanzando el tiempo de utilización, el micropulido comenzó a ser más brillante, espeso, sobre superficies altas y bajas de la microtopografía y sobre todo, en los casos donde el ángulo de ataque era agudo de extensión intermedia. En cuanto a la presencia de estrías fue registrado hacia inicios de la actividad y posteriormente junto con el micropulido bien desarrollado se identificaron estrías en forma de cometas, rasgo característico del trabajo de madera. 


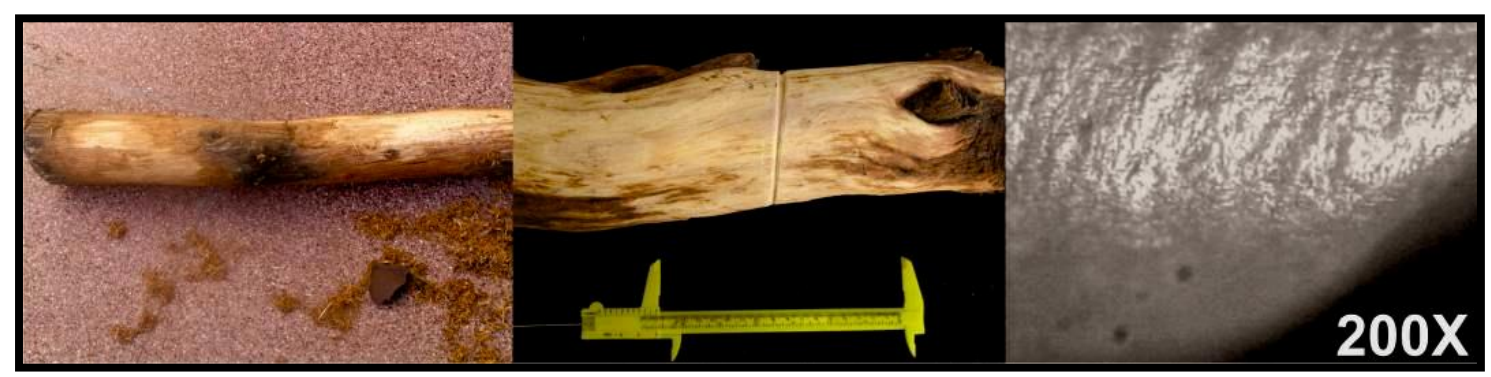

Figura 117: Trabajo sobre madera dura (estacionada) de manera transversal (raspado) 60’ de trabajo.

\section{Trabajo sobre cuero y piel}

El recurso alimenticio más importante por los grupos que habitaron la región estudiada corresponde al guanaco (Lama guanicoe), seguido en proporciones menores por la caza del ñandú (Rhea american y Pterocnemia pennata). De estos animales ninguna de sus partes era tratada con desprecio; se utilizaba la carne, grasa, visceras, sangre, huesos y sobretodo su cuero (Musters [1869-1879] en 1964; Schmid [1858/65] en 1964.

El cuero era utilizado en varias funciones, existen crónicas que indican la estrategia de almacenamiento de grasa de ñandú como provisión para ser utilizada en épocas de escasez de la misma y es posible que éstas se guardaran en bolsas de piel, permitiendo una mayor potenciación de los recursos obtenidos. Las características de esas bolsas coinciden con los datos etnohitóricos en cuanto al almacenamiento de grasa de avestruz que realizaban las mujeres y que cada una llevaba consigo para disponer de la misma durante sus largos viajes, o cuando lo deseasen (Miotti 1998).

Muchas veces el cuero se extraía del guanaco y era reservado para reparar el toldo, se extraía a mano luego de realizar los cortes necesarios con el cuchillo (Musters, 1964:199).

“...En el paso vi varios pedazos grandes de obsidiana... las mujeres recogieron algunos de esos pedazos, para usarlos como rascadores en la limpieza de cueros de guanacos..." Musters [1869-1879] en 1964).

La vestimenta también se realizaba con este material, de dos varas de cuadro, el pelo hacia dentro y en algunos casos pintados de color amarillo, verde o colorado (Viedma, [1780/83] 1972). 


\section{Trabajo sobre Cuero seco}

Luego de las experimentaciones realizadas sobre madera se utilizó cuero seco sin tratamiento especial, simplemente secado al sol. Las actividades que se realizaron sobre este material fueron: raspado y alisado.

\section{Raspado:}

Este tipo de actividad no presentó ninguna dificultad, se extrajeron capas finas de piel seca que permitió dejar bien limpio el cuero y en algunos casos más finos. El ángulo de ataque en esta actividad fue de $90^{\circ}$ y la fuerza ejercida mínima. Sin embargo, las lascas se embotaban con facilidad debido al contacto con la grasa; por lo que algunas de las lascas no superaron los 30 minutos de trabajo debido a un fuerte redondeamiento del filo. En estos casos en particular se continuó con el trabajo hasta llegar al tiempo establecido para cada una de las piezas utilizadas (45' y 60 ' respectivamente).

\section{Alisado:}

La presión ejercida en esta actividad fue mínima y el trabajo continuó siendo cada vez más fino (extrayendo capas aún más delgadas de piel). Esto produjo que el cuero fuera más suave y flexible. El ángulo de ataque empleado fue agudo de $45^{\circ}$.

\section{Trabajo sobre cuero fresco}

Se realizaron lascas para raspado de cuero fresco, y se trabajó en bloques temporales ya establecidos con anterioridad, lasca sigladas EU89-EU91. A medida que se realizaba el trabajo fue necesario limpiar constantemente las piezas debido a que se adherían residuos de piel y restos de grasa sobre el filo de las mismas, lo que hacía dificultoso el trabajo.

Las actividades realizadas sobre este material se diferencian en relación con el ángulo de trabajo, generando que el micropulido se extienda hacia el interior del filo. Por otro lado, en cuanto a los rastros registrados de este tipo de material, se pudo observar ciertas diferencias en relación al cuero seco, con mayor brillo sobre la superficie donde se desarrolló el micropulido. En cuanto a las estrías y los demás rasgos diagnósticos, se 
observó surcos profundos, paralelos entre sí y un intenso redondeamiento del filo. Asimismo el desarrollo del micropulido se dio tanto en superficies altas como bajas de la microtopografía de las piezas.

\section{Resultados del trabajo sobre cuero}

Luego de las experiencias realizadas a partir del trabajo sobre este tipo de material se pudo observar como rasgos característicos para su identificación, un fuerte redondeamiento del filo, a partir de $15^{\prime}$ a $20^{\prime}$ de iniciada la actividad. En cuanto a la presencia de estrías, su desarrollo estuvo asociado a microesquirlas desprendidas del filo durante el trabajo. Este rastro permitió, como en los casos anteriores, identificar el movimiento empleado y en otros el ángulo de ataque utilizado al realizar la actividad.

En cuanto al desarrollo del micropulido, las piezas presentaron características principales del trabajo sobre cuero: brillo mate a levemente brillante, homogéneo, fuerte redondeamiento del filo y surcos profundos paralelos entre sí como rasgo diagnóstico.

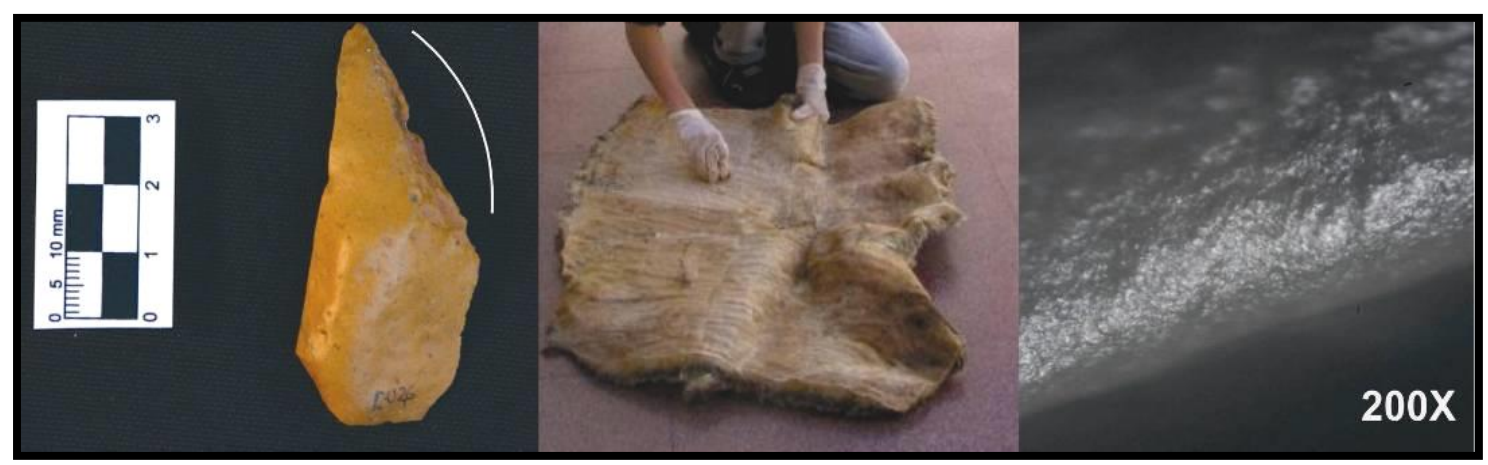

Figura 118: Pieza de sílice trabajada sobre cuero seco de manera transversal (raspado) 60’ de trabajo.

\section{$>\quad$ Trabajo sobre hueso}

La información faunística proveniente de diferentes sitios arqueológicos (cuevas, aleros y sitios a cielo abierto) en el sector patagónico, ha señalado recurrentemente la presencia de un tipo de modificación antrópica denominada fractura perimetral marcada. Algunos investigadores han vinculado la función de este rasgo de fragmentación ósea con una serie de hipótesis alternativas: acceder a las cavidades medulares, facilitar el transporte, procesar carcasas congeladas y/o con rigor mortis, obtener formas base para instrumentos o bien una combinación de varias de estas 
posibilidades (Mengoni y Silveira 1976; Mengoni Goñalons 1982; Miotti 1989; Mena y Jackson 1991; Lupo 1994; Muñoz y Belardi 1998; Hadjuk y Lezcano 2005).

Algunas de estas fracturas presentan un marcado perimetral que involucra la preparación de los huesos mediante un surco completo o incompleto que rodea su contorno, técnica de procesamiento que se encuentra diseminada por el amplio territorio patagónico (Mengoni Goñalons y Silveira 1976; Mengoni Goñalons 1982; Muñoz y Belardi 1998; Mena y Jackson 1991; Hajduk y Lezcano 2005) y en grupos humanos de otras regiones del mundo (Gifford-González 1989 y Lupo 1994).

Teniendo en cuenta estos datos, la experimentación llevada a cabo consignó generar un marcado perimetral a partir de los bloques de tiempo establecidos con anterioridad para los demás materiales. Por lo tanto, el trabajo sobre hueso, incluyó dos etapas fundamentales: limpieza y extracción del periostio y el trabajo propiamente dicho (raspado y aserrado/corte) sobre hueso.

El proceso de limpieza primaria se realizó mediante lascas de filo natural, donde se extrajeron tendones y tejidos conectivos del hueso, incluyendo aquellos de las extremidades, siendo removido parte del periostio. Este procedimiento dejó marcas de corte en las extremidades articulares sobretodo en sectores con cartílago. La función de esta limpieza y raspado meticuloso ha sido realizado para un mejor control del proceso de ruptura del hueso (Binford 1981).

\section{Hueso Fresco}

Fueron utilizadas tres lascas (EU45, EU46, EU48) durante el proceso de limpieza profunda del hueso, extracción de cartílagos y tejido conectivo, principalmente ubicados en las extremidades distales del mismo. La extracción del periostio presentó cierta dificultad ya que la mayoría de las lascas utilizadas en esta labor se embotaban rápidamente. El periostio se extrajo en su totalidad, excepto en las extremidades de las diáfisis en donde quedaron remanentes de los mismos. De acuerdo al trabajo etnoarqueológico realizado por Binford en los Nunamiut, el hecho de haber cortado el cartílago y todo el tejido conectivo, permite tener una mayor precisión en el momento de dar el golpe para la extracción de la médula. Antes del golpe final numerosos estudios demostraron, que el hecho de realizar un marcado perimetral antes del mismo, brinda una mayor precisión en el corte transversal y una menor cantidad de astillas al 
extraer la médula (Miotti 1998, Marcchioni et al. 2010). Para este marcado se utilizaron las siguientes lascas: EU41, EU42, EU43, EU44.

Mientras que para el raspado de hueso propiamente dicho se utilizaron cuatro lascas más (EU37, EU38, EU39, EU16), al igual que para el corte o aserrado (EU10, EU26, EU30 y EU31).

\section{Hueso Cocido}

En este procedimiento se cocinó el hueso por dos horas. Durante la cocción, gran parte de grasa y cartílagos fueron desprendiéndose del hueso, por lo que facilitó el trabajo a realizar en momentos posteriores (raspado y aserrado) en los mismos bloques de tiempo (desde 5' a 60') estipulados anteriormente.

El hueso cocido presentó una consistencia más dura en relación con el hueso fresco, provocando que durante su trabajo las piezas utilizadas presentaran mayor número de esquirlamientos sobre los filos.

\section{Hueso Húmedo}

Se sumergió en agua a temperatura ambiente un hueso de fémur durante 24 horas y luego se trabajó de igual manera que en los casos anteriores.

No se observaron diferencias entre el hueso fresco y húmedo, ambos presentaban la misma resistencia y dureza, a diferencia del hueso cocido que generó abundantes esquirlamientos sobre los filos utilizados. Las lascas empleadas fueron sigladas con los siguientes números: desde las EU92 a la EU100.

\section{Resultados del trabajo sobre hueso}

En cuanto al desarrollo de los rastros de uso generados por este material se pudo observar un fuerte esquirlamiento a inicios de cada actividad y sobretodo en estado cocido. Una vez estabilizado el filo comenzó el desarrollo de micropulido. En momentos iniciales el mismo presentó un brillo mate, poco espeso y sobre superficies altas de la microtopografía. A los 30’ de iniciada la actividad el micropulido comenzó a ser más brillantes y espeso y continuó su desarrollo en sectores altos de las superficies del filo. En el estadio bien diferenciado el micropulido presentó brillo muy brillante, 
espeso, sobre superficies altas de la microtopografía y desarrollo de craquelé como rasgo característico. En cuanto a la presencia de estrías, podemos mencionar que las mismas fueron abundantes en los momentos iniciales de trabajo, junto con esquirlamientos en forma de medialuna y de terminación simple. Por otro lado, la orientación tanto de las estrías como del micropulido, permitió la identificación de la cinemática empleada. Estrías paralelas al filo utilizado y micropulido desarrollado sobre ambas caras del filo corresponde a acciones longitudinales (aserrado/corte). Mientras que la observación de estrías transversales y micropulido sobre una única cara del filo utilizado, permitió determinar acciones transversales como el raspado sobre hueso.

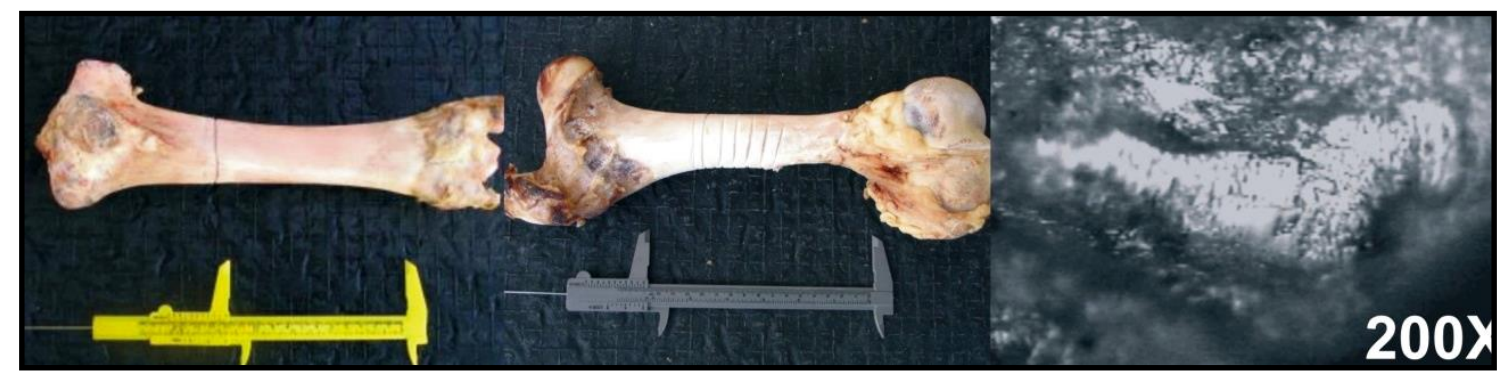

Figura 119: Trabajo sobre hueso fresco y formación del surco perimetral. Micropulido generado luego de 60 ’ de trabajo realizado mediante acción transversal (raspado).

Posteriormente y con el fin de observar a mayor aumento la presencia de residuos sobre el filo utilizado, algunas de las piezas trabajadas sobre hueso fueron observadas bajo un microscopio electrónico de barrido (modo ambiental bajo aumentos de 2000 a 5000X). Esto permitió observar en mayor detalle el desarrollo del micropulido y las estrías que permitieron identificar el movimiento empleado, mientras que la curva de EDAX registró los elementos constituyentes (con un incremento de $\mathrm{Ca}$ exclusivamente en sectores con desarrollo de micropulido). 


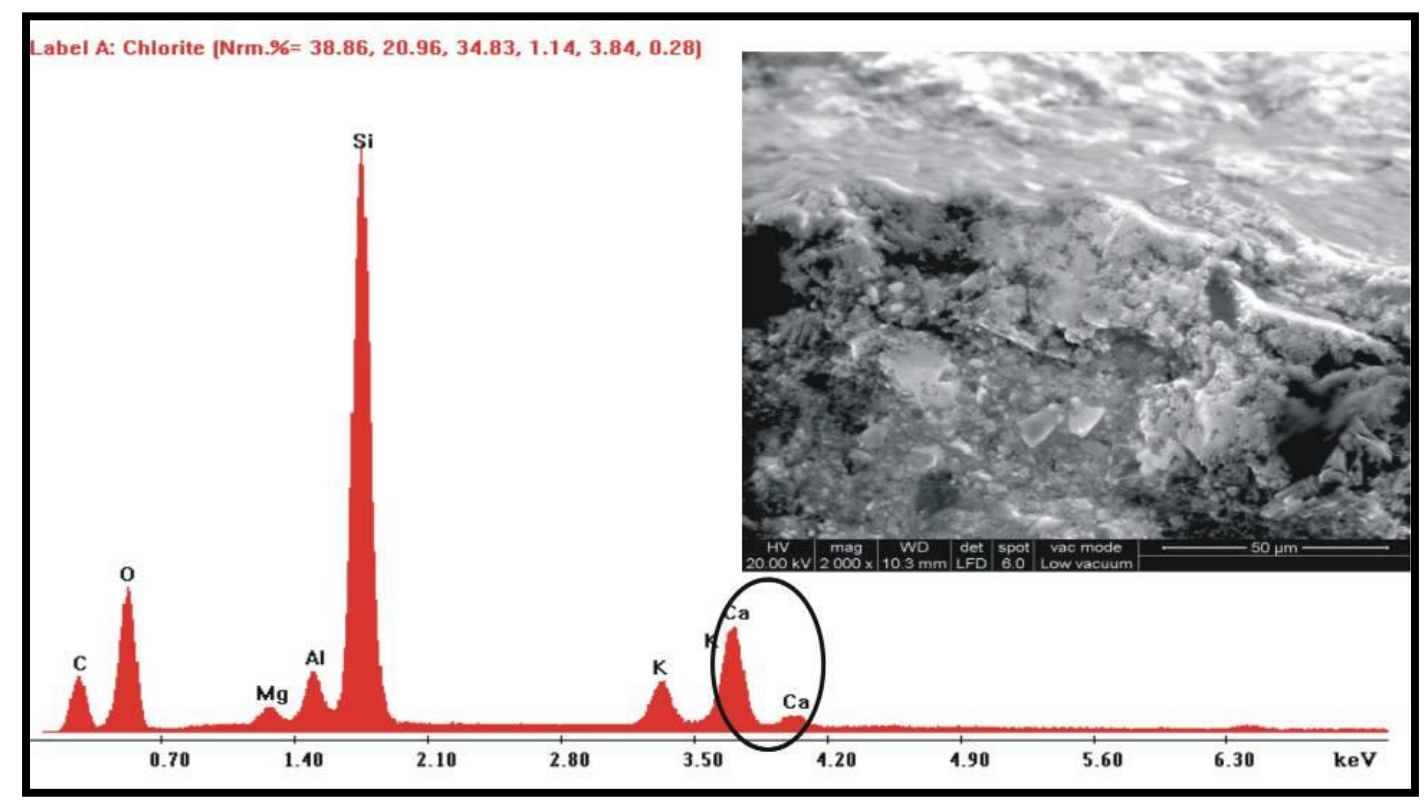

Figura 120: Micropulido de hueso observado bajo microscopio electrónico de barrido (modo ambiental 2000X) y curva de EDAX que evidencia picos de Ca, elemento constituyente.

\section{Trabajo sobre gramíneas}

Este material fue utilizado en el pasado para acondicionamiento de viviendas, usos medicinales, combustible o como materia prima para cesterías y otros utensilios. El coirón fueguino (Festuca gracillima) habría servido para la preparación de superficies de ocupación. Estos han sido observados en estratos de la cámara norte del sitio Cueva Maripe dispuestos en "camadas" y también en los pisos de ocupación "Patagoniense" de la Cueva 3 de los Toldos (Cardich y Miotti 1989). Fuera del Macizo central también fue registrado esta actividad en sectores cercanos al Río Pinturas (Gradín y Aguerre 1992) y mediante crónicas etnográficas también ha podido ser documentado (Claraz 1988).

Es así que el trabajo realizado experimentalmente sobre gramíneas, incluyó exclusivamente la actividad de corte, a partir de los cuatro bloques de tiempo formulados para los demás casos. Durante la experimentación se utilizaron 4 lascas y debido al alto contenido de sílice que posee el material trabajado, la formación de micropulido diagnóstico, se generó en un breve periodo de tiempo. A los 15' minutos de iniciada la actividad pudo observarse un fuerte redondeamiento del filo, con micropulido muy brillante, espeso, sobre superficies altas de la microtopografía. A medida que el trabajo continuaba, el micropulido se extendía sobre toda la microtopografía (superficies altas y bajas) y hacia el interior del filo. Ya a los 30 ' de 
iniciada la actividad el micropulido era diagnóstico del trabajo realizado, muy brillante, espeso, homogéneo, con estrías en forma de cometas como rasgo característico y un fuerte redondeamiento del filo.

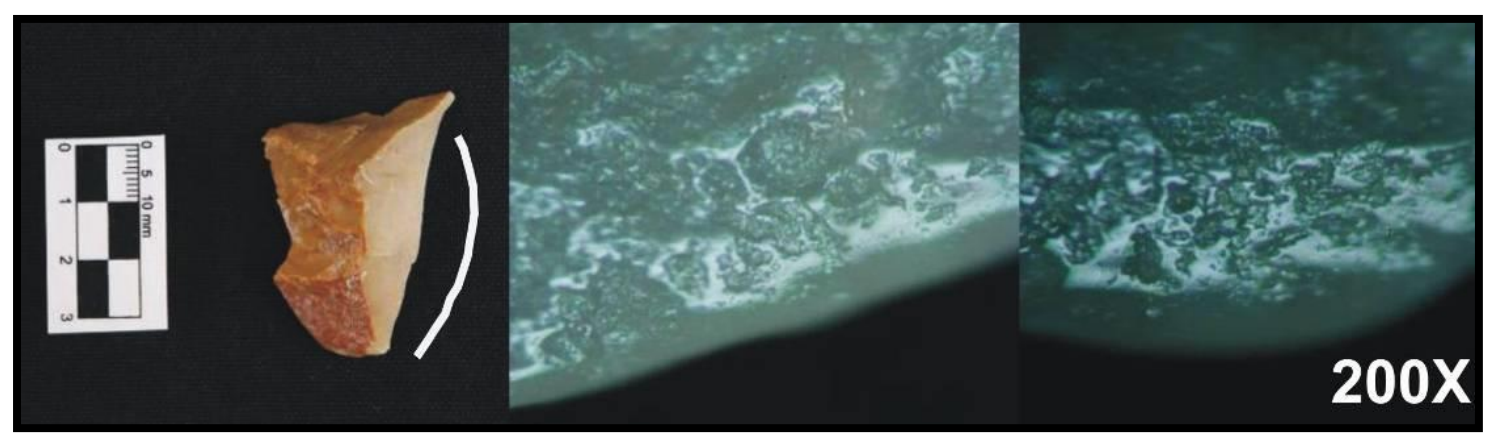

Figura 121: Lasca utilizada para corte de gramíneas (60’ de trabajo). Micropulido bien diferenciado con estrías en forma de cometa que permiten observar el movimiento efectuado.

La presencia de residuos hacia el interior del micropulido fue observado a mayor aumento (microscopio electrónico de barrido, 2000 a 5000X) evidenciando remanentes del tejido vegetal trabajado.

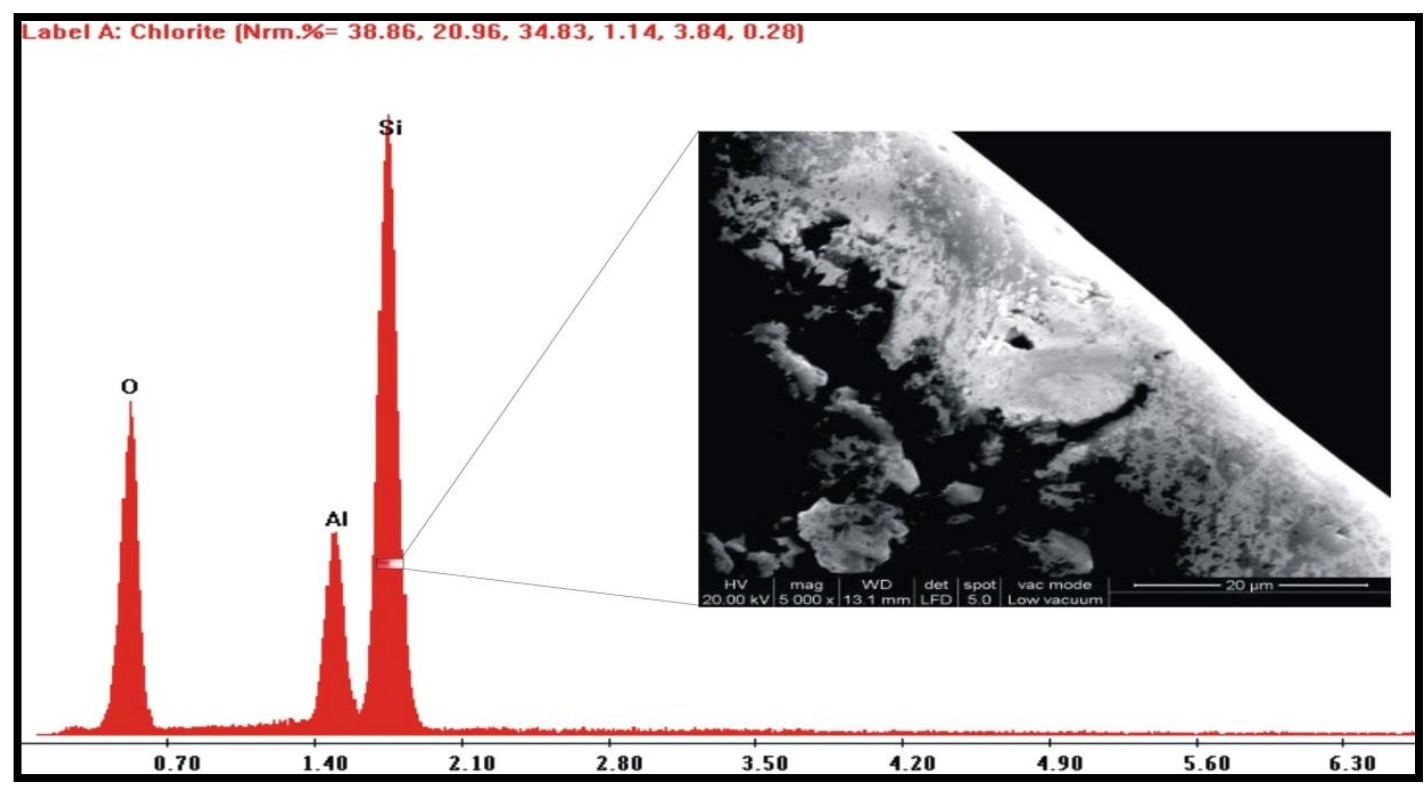

Figura 122: Vista del micropulido de gramíneas bajo microscopio electrónico de barrido (modo ambiental, 5000X) y curva de EDAX con alto contenido silíceo del material trabajado.

\section{$>\quad$ Trabajo sobre material mineral}

La realización del trabajo experimental consistió en la utilización de tres técnicas que fueron definidas inicialmente por Álvarez y Fiore (Álvarez y Fiore 1995; Álvarez et al. 1998): 
Incisión: implica el corte o hendidura del soporte mediante el movimiento unidireccional del artefacto, cuyo filo se desplaza en forma paralela a la dirección de la utilización.

Raspado: se trata de la abrasión del soporte mediante el movimiento bidireccional del artefacto, cuyo filo se desplaza en forma perpendicular a la dirección de utilización.

Horadación: implica la inserción gradual de un artefacto en el soporte mediante movimientos de rotación en sentido horario y antihorario.

Estas tres técnicas se definen por el tipo de mecánica ejercida, en función del movimiento y del artefacto necesario para realizarla, requiriendo presión.

Si bien Carden (2008a) infiere que las técnicas usadas con mayor frecuencia para la realización de motivos grabados en Piedra Museo son el picado y el machacado, en esta oportunidad tales técnicas no han sido contempladas. Esto último se debe a que la aplicación de las mismas produce fracturas en los bloques experimentales utilizados para la experimentación en laboratorio, consecuencia de su escasa dureza y grosor (Blanco et al.2010; Blanco y Lynch 2011). En cuanto a los rastros de uso identificados a partir de estas experiencias se pudo determinar desde los cinco minutos de comenzado el trabajo las etapas iniciales de modificación de las superficies de los filos.

En todas las piezas empleadas en las técnicas de incisión y raspado se produjo contacto con el material trabajado en ambas caras del filo, por lo que el desarrollo del micropulido implicó tanto la cara dorsal como la ventral. A los cinco minutos, todas las piezas tenían un buen desarrollo de micropulido sobre ambas caras, lo que en conjunto con la presencia de estrías permitió identificar con claridad la orientación del movimiento efectuado.

Las características generales que presentó el micropulido sobre soporte mineral fueron las siguientes: brillo muy brillante, regularidad intermedia, espesor intermedio a espeso, desarrollo del micropulido sobre las superficies altas y bajas de la microtopografía del filo y extensión intermedia. En el caso de esquirlamientos los primeros minutos de iniciada la actividad presentó mayor cantidad sobre el filo, una vez estabilizado el movimiento pasaron a ser medianos a escasos y discontinuos, probablemente como consecuencia de la escasa dureza del soporte trabajado. En su mayoría presentaron una morfología trapezoidal con terminaciones escalonadas. En todas las piezas utilizadas se determinó la presencia de abundantes estrías con morfología variable y una orientación dependiendo del movimiento efectuado (paralela al filo utilizado para los casos incisión, perpendicular en el raspado y en la horadación se dispusieron de dos maneras, una 
oblicua al filo utilizado y la otra de manera transversal en el sector distal de la pieza junto con movimiento rotatorios en el punto de apoyo).
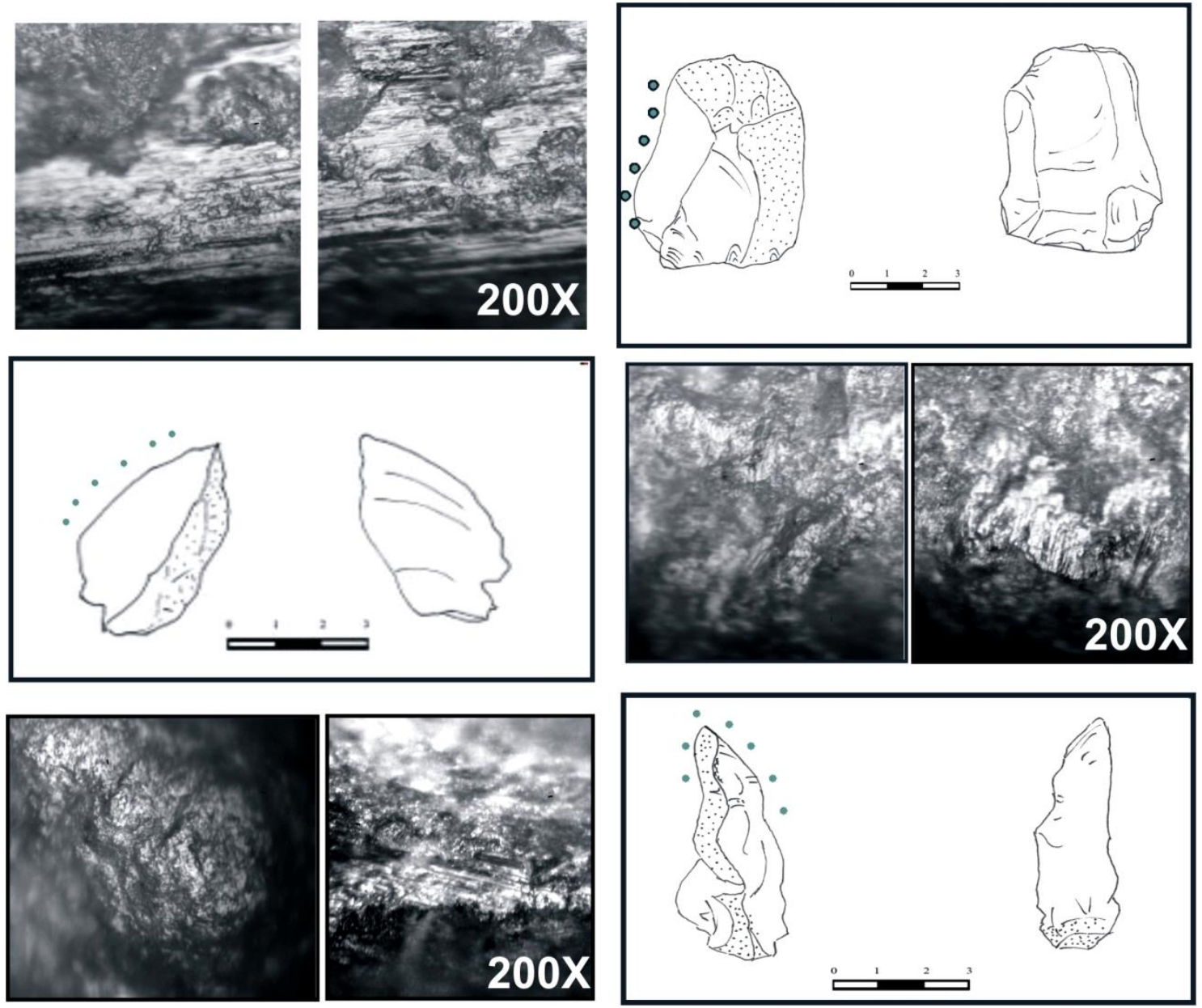

Figura 123: Dibujos realizados por la Lic. Blanco Rocío y microfotografías de las distintas técnicas empleadas sobre soporte mineral durante la etapa experimental (VL). A) Técnica de incisión. B) Técnica de raspado. C) Técnica de horadación, punto de apoyo y filos laterales.

\section{-Materia prima Heterogénea: Basalto}

Este tipo de materia prima de grano intermedio a grueso de coloración gris a negro, fue utilizada en la realización de una serie experimental con un número reducido de piezas. Esta serie incluyó un total de 11 artefactos no formatizados con filo natural y siglados desde EU150 a EU161. Al igual que en el caso anterior, la materia prima utilizada fue recolectada de fuentes identificadas a lo largo del cañadón La Primavera (coladas basálticas a unos 2 km. del sitio Cueva Maripe, Formación Bajo Pobre).

El basalto fue utilizado para el trabajo de distintos materiales (madera, hueso, cuero y gramíneas) pero en un único estado (ver tabla 2 Capítulo V). Este tipo de materia prima, 
como se ha mencionado con anterioridad difiere en cuanto a granulometría, en relación con las ignimbritas y riolitas silicificadas. Debido a esto la formación de rastros de uso presentaron ciertas diferencias en su desarrollo.

El trabajo sobre este tipo de materia prima incluyó un incremento en el tiempo empleado para la formación de micropulidos diagnósticos del material trabajado, en comparación con las rocas de grano fino. En casi todos los casos, el tiempo máximo empleado para generar rasgos diagnósticos, fue de 1 hora y 30 minutos. Mientras que en las rocas de grano fino, con 60' las huellas generadas permitieron determinar el material trabajado. Respecto al desarrollo de los micropulidos se pudieron observar ciertas diferencias. En todos los casos, al igual que en las rocas de grano fino, el desarrollo inicial de micropulido se generó en las superficies altas de la microtopografía pero en el trabajo sobre cuero el desarrollo hacia los niveles más bajos no se pudo observar, probablemente debido a las presencia de cristales de mayor tamaño y dureza.

En cuanto a las características generales de los micropulidos en relación al material trabajado, no se observaron grandes diferencias más allá del tiempo de formación y un fuerte redondeamiento del filo en la mayoría de los casos, independientemente del material utilizado.

El trabajo sobre cuero presentó un fuerte redondeamiento del filo, con estrías paralelas entre sí permitiendo inferir el movimiento efectuado (transversal al filo utilizado), sin embargo estas no fueron tan marcadas en comparación con el trabajo sobre sílice.

En cuanto al micropulido, se desarrolló principalmente en las superficies altas de la microtopografía de la pieza, de brillo mate y debido al ángulo de trabajo utilizado (agudo) de extensión media. En relación al trabajo sobre gramíneas, al igual que en el caso del sílex, tuvo un desarrollo temprano de micropulido diagnóstico (45' a 60') permitiendo observar en poco tiempo sus características principales (muy brillante, espeso, con estrías en forma de cometa y extendido homogéneamente sobre el filo). En los filos trabajados sobre gramíneas la presencia de residuos fue abundante aún después del procedimiento de limpieza.

En cuanto al trabajo sobre hueso, los filos utilizados presentaron abundantes esquirlamientos de morfología variada y el micropulido se extendió únicamente sobre las superficies altas de la microtopografía. Presentó las mismas características que en materias primas silíceas (muy brillante, espeso y desarrollo de craquelé como rasgos característico). Mientras que el trabajo de madera no estacionada presentó, al igual que en el caso de gramíneas, abundantes residuos sobre la superficie del filo, con 
esquirlamientos de morfología trapezoidal y micropulido brillante, espeso y con desarrollo principalmente sobre las superficies altas de la microtopografía de la pieza.

Como ha sido mencionado por varios autores las diferencias observadas se debe a la composición y relación matriz/cristales, de esta materia prima, como ocurre en el caso del cuarzo y/o cuarcita, donde la matriz está menos desarrollada en relación con los cristales, por lo que la formación de los rastros se generarán sobre estos y no en la matriz (para más información ver Keeley 1980; Lewenstein 1981; Knutsson 1986; Oayama 1995; Mansur 1999; Álvarez 2003; Yerkes et al. 2003; Leipus 2006; Pal 2009).

\begin{tabular}{|c|c|c|c|c|c|}
\hline $\begin{array}{l}\text { Material } \\
\text { trabajado }\end{array}$ & $\begin{array}{l}\text { Cantidad } \\
\text { de piezas }\end{array}$ & Tiempo & Estado & $\begin{array}{c}\text { Acción } \\
\text { empleada }\end{array}$ & $\begin{array}{c}\text { Ángulo de } \\
\text { trabajo }\end{array}$ \\
\hline $\begin{array}{l}\text { Madera } \\
\text { blanda }\end{array}$ & 4 & $1: 15$ & $\begin{array}{c}\text { No } \\
\text { estacionada }\end{array}$ & RP y AS & $45^{\circ}$ y $60^{\circ}$ \\
\hline Hueso & 3 & $1: 15$ & Fresco & RP y AS & $45^{\circ}$ y $90^{\circ}$ \\
\hline Cuero & 2 & $1: 30$ & Seco & $\mathrm{RP}$ & $45^{\circ}$ \\
\hline Gramíneas & 2 & $60^{\prime}$ & Fresco & $\mathrm{C}$ & $45^{\circ}$ \\
\hline
\end{tabular}

Tabla 12: Descripción del trabajo realizado a partir de lascas elaboradas sobre basalto. RP: raspado, AS: aserrado y C: corte. 


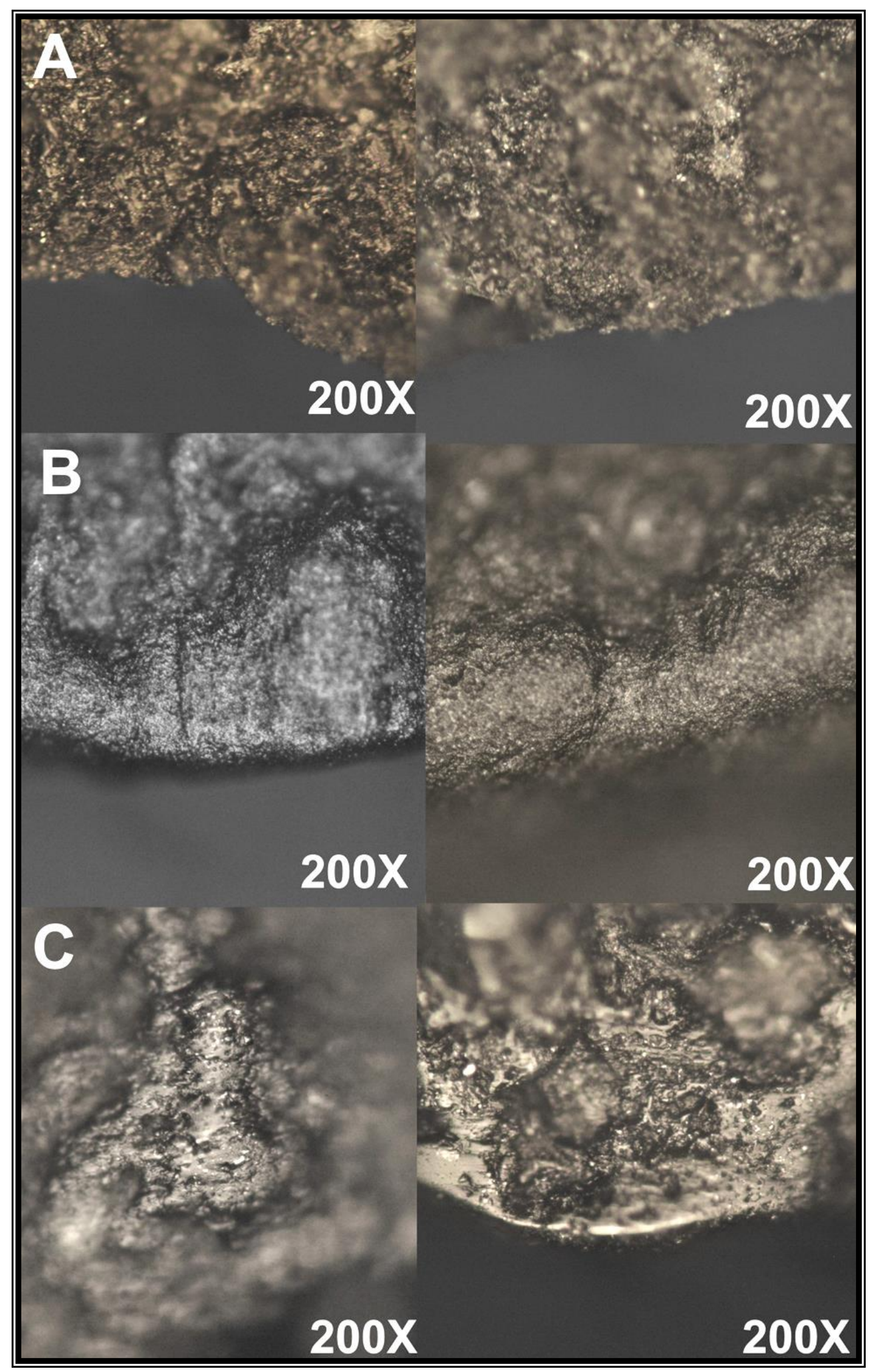

Figura 124: Piezas experimentales elaboradas sobre basalto y trabajadas en distintos materiales. A) Filo natural de piezas experimentales realizadas sobre basalto. B) Micropulido desarrollado por el trabajo sobre cuero seco de oveja (acción de raspado) y C) Micropulido del trabajo sobre gramíneas (corte). 


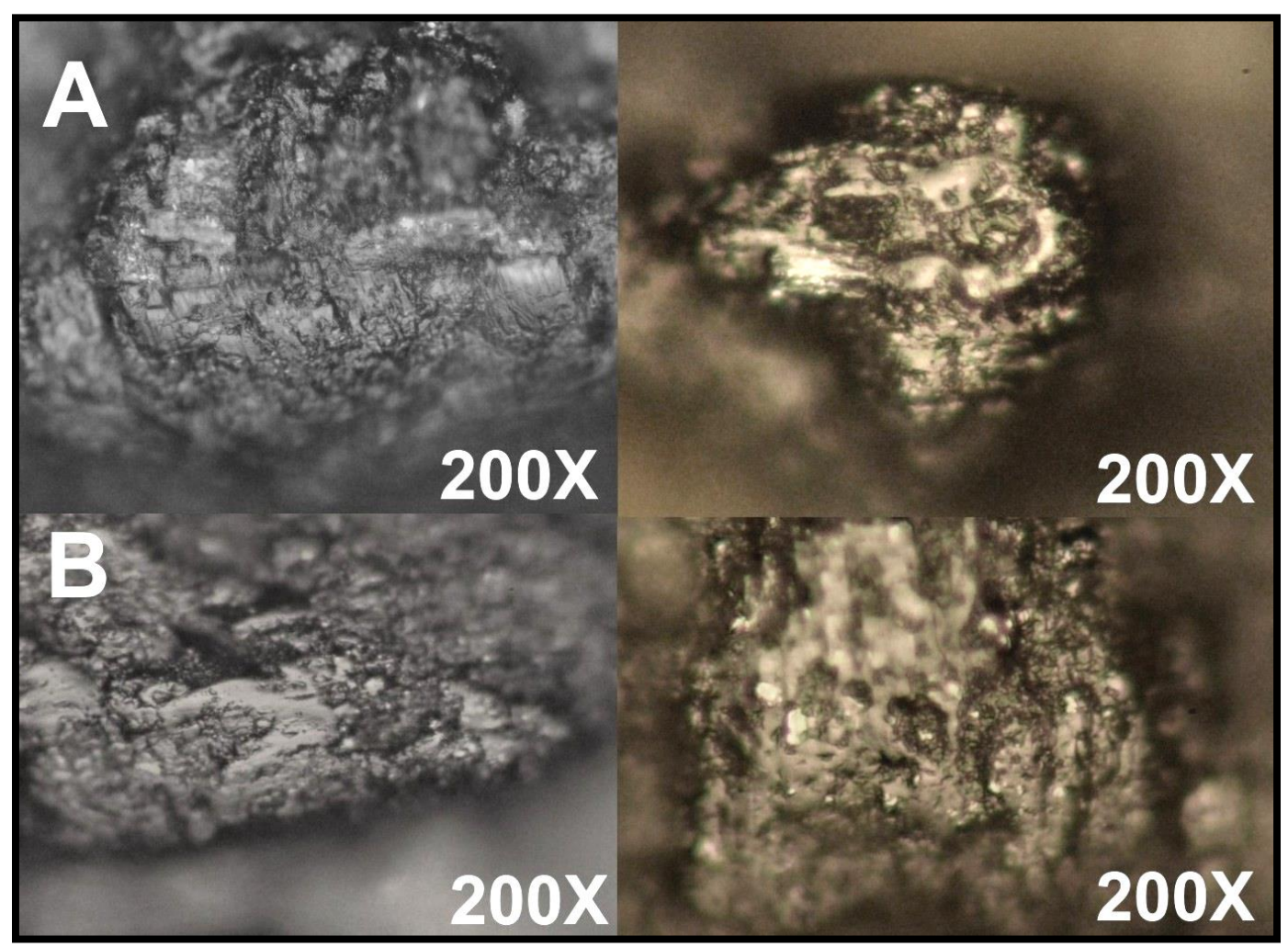

Figura 125: Trabajo sobre materiales duros a partir de lascas experimentales realizadas en basalto. A) Trabajo sobre hueso fresco (acción de raspado y de corte) y B) trabajo sobre madera blanda no estacionada (aserrado y raspado).

\subsection{Empleo de enmangues y posibilidad de identificación en el registro.}

Los dispositivos de enmangues en artefactos líticos tiene como ventaja el aumento de la efectividad de un útil, generando mayor comodidad en el agarre y permitiendo ejercer mayor presión sobre el material que se desea trabajar (González e Ibáñez 1999). Estos suelen estar ausentes en el registro arqueológico y por lo tanto es necesario buscar vías analíticas para poder "verlos", siendo el análisis funcional de base microscópica una metodología excelente para este fin. Las huellas de enmangue (producto del frotamiento entre el mango y el útil insertado durante el tiempo de utilización), son difíciles de detectar, sin embargo, ha sido posible inferirlas en reiteradas oportunidades a partir de la presencia de rastros como esquirlamientos, modificaciones de los filos, patinas diferenciales y adherencias (Anderson-Gerfaud y Herlmer 1987; Mansur y Lasa 2005; Moss y Newcomer 1982; Odell 1994b, Odell y Odell-Vereecken 1980; Rots 2002a, 2003, Rots et al. 2006, Stordeur 1987, Symens 1986).

Si bien se han realizados numerosos análisis considerando el uso de enmangues (Mansur-Franchomme 1983, Castro y Moreno 1994; Mansur y Lasa 2005), recientemente, se comenzaron a desarrollar estudios específicos asociados a los mismos 
(Castro y Moreno 1994 y Forlano y Dolce 2006-2007 y 2007). Sin embargo, siguen siendo escasos los escritos y numerosas las dificultades. De acuerdo a esto, la realización de una breve colección con instrumentos enmangados para identificar estos rastros específicos, ha sido uno de los objetivos planteados en este acápite.

\section{-Serie experimental}

Durante esta experiencia se realizaron 10 raspadores formatizados por percusión directa y retoques marginales, mediante percutores duros y blandos (Aschero 1975, 1983) y tres mangos para la inserción de los mismos. En la elaboración de las piezas líticas se consignaron las variables descriptas por Aschero $(1975,1983)$ para la designación del grupo tipológico de raspadores ${ }^{1}$. Las materias primas utilizadas fueron: ignimbrita y riolita silicificada; procedentes de LP-P1, una de las fuentes de aprovisionamiento que posee alta representatividad en los conjuntos artefactuales bajo estudio (Hermo 2008). Cada uno de los filos y sectores (cara dorsal y ventral) de los raspadores fue observado microscópicamente con anterioridad a su uso.

Se contempló un único tipo de enmangue, según el modelo denominado "cepillo de carpintero" empleado por los Tehuelches Septentrionales (Casamiquela 1978; MansurFranchomme 1983; 1987 c y d). Consiste en un trozo de madera de molle (Schinus sp) en cuyos sectores dístales se han efectuado escotaduras para la inserción de los raspadores. Se trata de un instrumento compuesto ya que lleva un raspador en cada cara del mango, insertado en una concavidad y fijado a la misma con una pasta de resina. Siguiendo la clasificación propuesta por Stordeur (1987), ha sido considerado un mango de tipo macho, en donde el artefacto lítico penetra en una escotadura realizada sobre un taco de madera. La posición del útil en el mango, es lateral y su dirección transversal, mientras que la orientación de la parte activa es perpendicular al mango utilizado, sin presencia de intermediario (Figura 126).

La inserción de los raspadores en el mango consistió en cubrir la porción proximal de las piezas con el "mastic" realizado e introducirlos en la concavidad correspondiente. Una vez allí se continuó rellenando los sectores vacíos de la hendidura hasta que la pieza quedó bien sujeta al soporte. La sujeción de los raspadores se realizó entre los 21 y $30 \mathrm{~mm}$. a partir de la porción proximal de cada uno.

${ }^{1}$ Es decir, artefacto formalizado por retoque, con bisel asimétrico, delineación convexa atenuada y extendida, sección longitudinal rectilínea y ángulo de filo superior a $45^{\circ}$. 


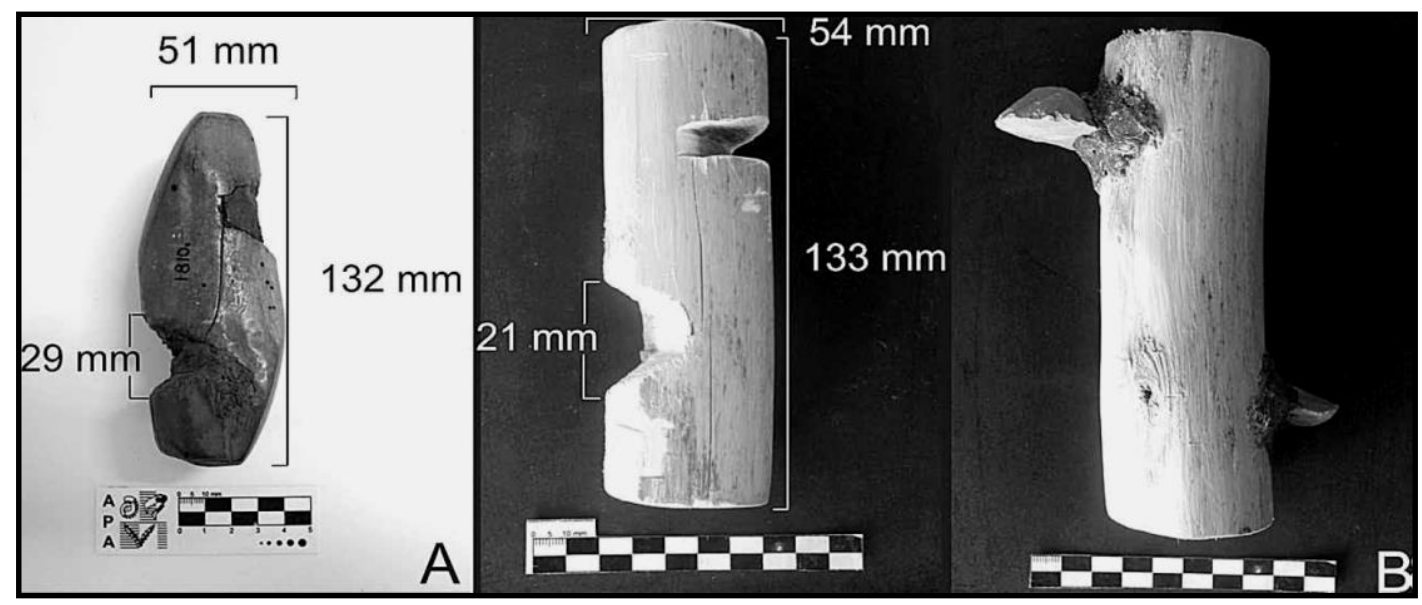

Figura 126: A) Mango etnográfico provenientes de la Prov. de Chubut. Colección Moreno, División Etnográfica del Museo de Ciencias Naturales de La Plata (Pieza No 1810). B) Mangos utilizados a lo largo de la experimentación.

En cuanto al material trabajado se empleó únicamente cuero seco de oveja (Ovis aries), extendido sobre un soporte duro y trabajado en la cara interna del mismo.

El proceso de extracción de la pieza se realizó luego del período de tiempo de uso seleccionado para cada instrumento y consistió en movimientos de palanca, que permitió fácilmente la separación del mango (ver tabla 13); ya que la aplicación de calor sobre los instrumentos podría generar alteraciones en los rastros microscópicos.

Una vez extraídas del soporte las piezas, inicialmente fueron observadas al microscopio sin haber sido lavadas, para determinar la presencia de residuos sobre las superficies e identificar así el límite de enmangue ${ }^{2}$. A continuación fueron lavadas con agua jabonosa y alcohol para poder ser vistas bajo el microscopio; mientras que la observación de los rastros de uso continuó el procedimiento habitual

\begin{tabular}{|c|c|c|c|c|c|c|c|c|c|c|c|}
\hline \multirow{2}{*}{\multicolumn{2}{|c|}{$N^{o} \operatorname{Exp}$}} & 1 & 2 & 3 & 4 & 5 & 6 & 7 & 8 & 9 & 10 \\
\hline & & 135 & 136 & 139 & 140 & 141 & 144 & 142 & 146 & 143 & 145 \\
\hline \multirow{7}{*}{ 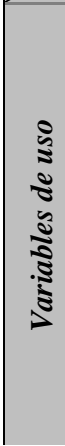 } & $\begin{array}{l}\text { Longitud } \\
(\mathrm{mm})\end{array}$ & 31 & 47 & 35 & 49 & 42 & 34 & 53 & 39 & 29 & 35 \\
\hline & $\begin{array}{l}\text { Ancho } \\
\text { (mm) }\end{array}$ & 47 & 61 & 53 & 30 & 39 & 31 & 40 & 28 & 36 & 33 \\
\hline & $\begin{array}{l}\text { Espesor } \\
(\mathrm{mm})\end{array}$ & 11 & 16 & 13 & 12 & 12 & 9 & 13 & 8 & 9 & 14 \\
\hline & Ang. fïlo & $70^{\circ}$ & $60^{\circ}$ & $75^{\circ}$ & $45^{\circ}$ & $70^{\circ}$ & $65^{\circ}$ & $70^{\circ}$ & $80^{\circ}$ & $50^{\circ}$ & $50^{\circ}$ \\
\hline & $\begin{array}{l}\text { Long. } \\
\text { filo }\end{array}$ & 36 & 49 & 34 & 44 & 37 & 32 & 39 & 30 & 34 & 33 \\
\hline & $\begin{array}{l}\text { Posición } \\
\text { de fijado }\end{array}$ & 24 & 30 & 24 & 22 & 24 & 21 & 29 & 25 & 21 & 21 \\
\hline & $\begin{array}{l}\text { Materia } \\
\text { prima }\end{array}$ & SV & IS & IS & IS & IS & IS & IS & IS & IS & IS \\
\hline
\end{tabular}

\footnotetext{
${ }^{2}$ Distancia desde el extremo proximal de la pieza hasta el límite de enmangue, representa la inserción de la pieza en el enmangue (Rots et al. 2006: 937)
} 


\begin{tabular}{|l|llllllllll|}
$\begin{array}{l}\text { Angulo } \\
\text { contac. }\end{array}$ & $90^{\circ}$ & $80^{\circ}$ & $+90^{\circ}$ & $90^{\circ}$ & +90 & +90 & +90 & +90 & +90 & $90^{\circ}$ \\
\hline $\begin{array}{l}\text { Cara de } \\
\text { contac. }\end{array}$ & $\mathrm{D}-\mathrm{V}$ & $\mathrm{V}$ & $\mathrm{D}-\mathrm{V}$ & $\mathrm{V}$ & $\mathrm{D}-\mathrm{V}$ & $\mathrm{D}-\mathrm{V}$ & $\mathrm{D}-\mathrm{V}$ & $\mathrm{D}-\mathrm{V}$ & $\mathrm{D}-\mathrm{V}$ & $\mathrm{V}$ \\
\hline \begin{tabular}{c} 
Actividad \\
\hline Tiempo
\end{tabular} & $\mathrm{RP}$ & $\mathrm{RP}$ & $\mathrm{RP}$ & $\mathrm{RP}$ & $\mathrm{RP}$ & $\mathrm{RP}$ & $\mathrm{RP}$ & $\mathrm{RP}$ & $\mathrm{RP}$ & $\mathrm{RP}$ \\
\hline
\end{tabular}

Tabla 13: Detalles de los experimentos realizados con raspadores enmangados. Materia prima: IS: ignimbrita silicificada SV: Roca silícea, micro a criptocristalina, de textura afanítica. Cara de contacto: D: dorsal/ V: ventral. RP: actividad de raspado [abrasión de una superficie con un artefacto, ángulo superior a $45^{\circ}$ (Mansur- Franchomme 1983)].

\section{-Resultados experimentales}

Los experimentos realizados permitieron detectar en la porción distal de cada una de las piezas el material sobre el cual se trabajó, a partir de micropulidos bien desarrollados (brillo mate, poco espeso, distribución homogénea y surcos profundos paralelos entre sí como rasgo característico que permitieron determinar el movimiento empleado con facilidad). La extensión de los micropulidos fue marginal, debido a un ángulo de trabajo superior a $90^{\circ}$, lo que implicó que tanto la cara ventral como la dorsal estuvieran en contacto con el material trabajado.

En los sectores medial y proximal (cara dorsal y ventral) de la mayoría de las piezas, pudieron observarse residuos de la resina utilizada para la fijación del mango con el instrumento. Solamente en la pieza EU135 no se detectó "mastic" luego del lavado.

La presencia de cristales modificados fue identificada en el $50 \%$ del conjunto experimental. Estas modificaciones han sido consideradas como los períodos iniciales del desarrollo de micropulido (Keeley 1977, 1980, Mansur-Franchomme 1981; 1983, 1987) observándose en algunos caso esquirlamientos sobre los bordes del cristal y en otros la presencia de redondeamiento y mayor volumen. Únicamente en dos casos (piezas EU136 y EU145), el micropulido ha sido diagnóstico para determinar el material que estuvo en contacto con la pieza (material duro de origen vegetal). En estos casos el micropulido presentaba un brillo brillante a muy brillante, de espesor medio a espeso, continuo y homogéneo (zonas altas y bajas). El desarrollo de micropulido diagnóstico sobre estas piezas probablemente haya sido consecuencia del desprendimiento del "mastic" utilizado para la fijación; entrando así en contacto directo con el mango los sectores más altos de la superficie de la pieza.

La presencia de esquirlamientos laterales inclinados fue registrada en el $50 \%$ del conjunto y podría deberse al proceso de extracción del mango; sobre todo en aquellos casos que no presentaban residuos en su interior. Mientras que los esquirlamientos que 
presentaban restos de resina fueron considerados consecuencia del proceso de talla (tecnológicos), y por lo tanto anteriores al proceso de enmangue. Únicamente en la pieza EU146 fue registrada una fractura en el borde lateral (porción medial) durante la extracción del mango.

La existencia en las porciones medial y proximal de micropulido de madera sobre la matriz de la roca (Mansur 1999) no fue registrada en ninguno de los experimentos realizados. El desarrollo de este micropulido en cristales sobre las piezas mencionadas anteriormente probablemente haya sido consecuencia del desprendimiento de "mastic" y como consecuencia de los procesos físico-químicos que actuaron diferencialmente sobre los cristales y la matriz. En este sentido, la falta de micropulido de madera sobre la matriz pudo deberse a dos cuestiones: 1) a que los sectores más altos de la microtopografía (en este caso cristales) fueron los primeros en entrar en contacto con el mango desarrollándose allí el micropulido y 2) a que el tiempo de trabajado no haya sido suficiente para su desarrollo sobre la matriz. Sin embargo, se considera que el micropulido de madera registrado sobre cristales constituye un fuerte indicador de la presencia de enmangues.

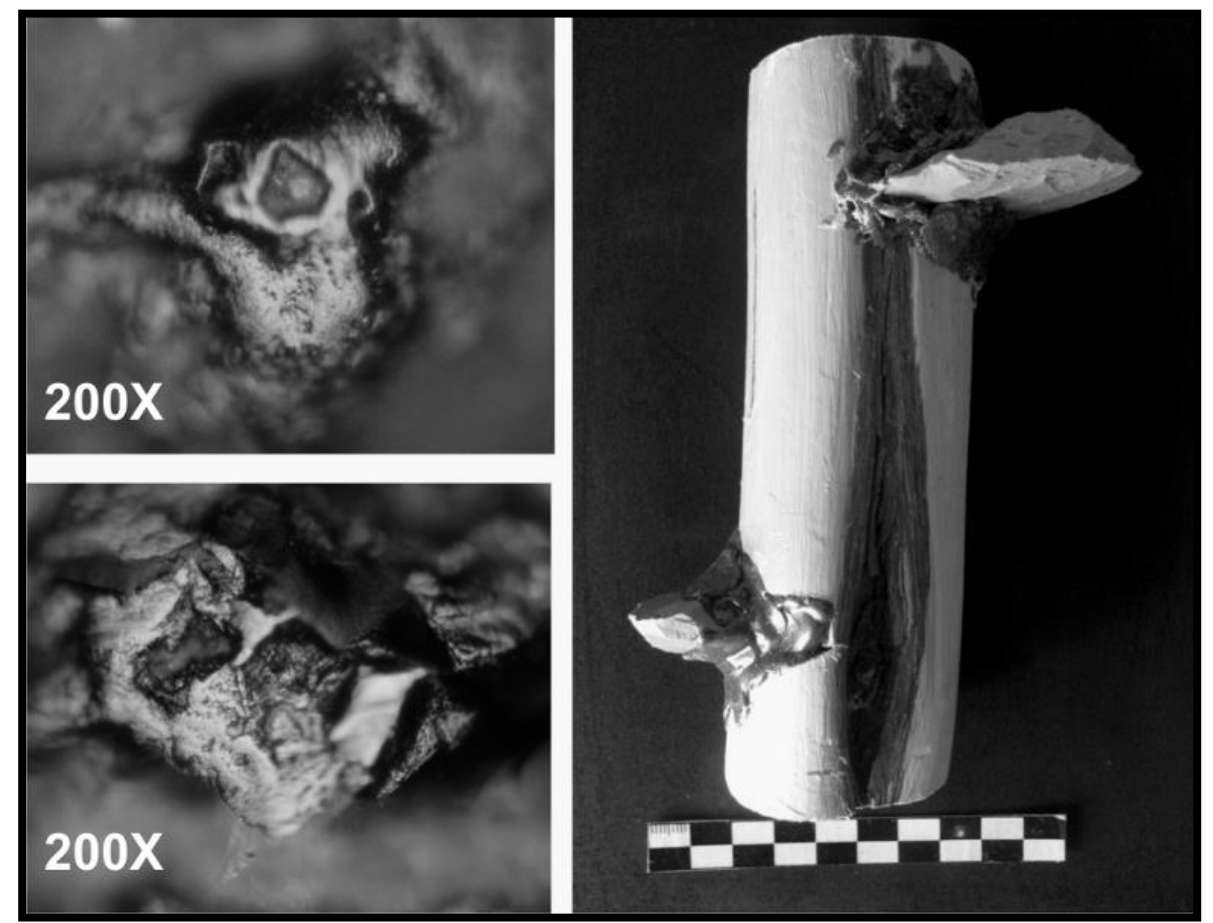

Figura 127: Desarrollo de micropulido de madera en la cara dorsal (porción medial) de uno de los raspadores empleados (EU145), consecuencia de un dispositivo de enmangue.

Teniendo en consideración los trabajos experimentales realizados y los resultados obtenidos se propuso dos tipos de indicadores que nos permitan hablar de la presencia de enmangues en el registro arqueológico: 
Indicadores primarios: resultado del contacto directo del mango sobre la superficie del instrumento; presencia de micropulido de madera en las porciones proximales y mediales de las piezas (tanto en matriz como en cristales).

Indicadores secundarios: rastros que indirectamente dan cuenta de la presencia de enmangues; a) detección de residuos sobre la superficie de las piezas, como consecuencia del uso de resinas para la fijación; b) Fracturas ocasionadas por el proceso de desmangue de las piezas (microesquirlamientos laterales inclinados) y c) Carencia de huellas de uso sobre los sectores mediales y laterales de los filos potencialmente utilizables.

El conjunto de estos rastros nos da la posibilidad de inferir la existencia de herramientas enmangadas en contextos arqueológicos en los que no se han preservado los mangos, sea por procesos culturales (descarte diferencial de mangos y de piezas líticas) o tafonómicos (por ejemplo, descomposición de materia orgánica). Esto resulta de suma importancia a los fines de estudios tecnológicos en los que se pretende lograr cierto conocimiento de las redes de actividades de las que formaron parte los artefactos líticos; es decir, no sólo determinando sus cadenas operativas, sino también de aquellos otros objetos y materias que fueron necesarios para su utilización. La presencia de enmangue forma parte de las decisiones tecnológicas de manufactura y uso de artefactos, cuya comparación entre contextos de diferentes coordenadas espaciales y/o temporales, puede nutrir hipótesis y modelos sobre las continuidades y discontinuidades culturales en una región.

De esta manera, contribuye a las discusiones sobre la tecnología de cazadoresrecolectores de ambientes en los que los materiales perecibles no se conservan, tales como los contextos del Macizo del Deseado que son objeto de esta investigación.

\subsection{Procesos postdepositacionales y su accionar en los rastros de uso.}

El estudio de la determinación de agentes que pudieron haber intervenido en la formación del depósito y sus efectos sobre la superficie de los artefactos, puede ser observado mediante distintos atributos (pátinas, lustres, abrasión). El accionar de estos procesos como objetivo particular dentro de la serie experimental de referencia permitió indagar, mediante análogos experimentales (inmersión en soluciones químicas), algunas de las posibles causas de las modificaciones identificadas en los contextos 
arqueológicos bajo estudio y analizar el grado de preservación de los rastros de uso en condiciones particulares de cuevas.

\section{-Serie experimental}

La presencia o ausencia de agua y cambios en la alcalinidad o acidez del sustrato pueden provocar modificaciones en la estructura primaria de las rocas afectando de manera diferencial las trazas de uso (Stapert 1976; Moss 1983; Mansur-Franchomme 1986; Plisson y Mauger 1988; Levi-Sala 1993; Burroni et al. 2002). Dado que se identificaron variaciones en la integridad artefactual de uno de los sitios bajo estudio (cámara norte y sur de Cueva Maripe), se ha considerado profundizar acerca de esta temática mediante análogos experimentales. Se realizaron 27 lascas sobre ignimbritas y riolitas silicificadas, procedentes de la región de estudio. Las piezas fueron trabajadas sobre distintos materiales (madera, hueso, gramíneas y cuero) y modos de uso (acciones longitudinales y transversales), hasta generar rasgos diagnósticos del trabajo realizado (en todos los casos se trabajó 60' cada pieza). Posteriormente, fueron introducidas en soluciones químicas con $\mathrm{pH}$ extremos: solución ácida $(\mathrm{pH}$ : 4,3-H2O desmineralizada y HCL), solución alcalina (pH: 8,9-1M NaHCO3 + exceso $\mathrm{CaCO} 3$ y $\mathrm{NaOH}$ ) y solución neutra ( $\mathrm{pH}$ : 7,4-H2O desmineralizada). Durante la experimentación se registró la constancia del pH, mediante un peachímetro Pometer PH-009 (I), y el estado de cada pieza anterior a su uso y luego del mismo (fotomicrografías). Una vez sumergidas en las soluciones se procedió a realizar seguimientos semanales durante tres meses para observar posibles cambios significativos sobre las piezas.

\begin{tabular}{|llll||}
\hline Solución/ & Alcalina & Ácida & $\begin{array}{l}\text { Neutra } \\
\text { Mat. Trab. }\end{array}$ \\
$\mathbf{( p H ~ 9 , 6 )}$ & $(\mathbf{p H ~ 4 , 3 )}$ & $(\mathbf{p H ~ 7 , 6 )}$ \\
MD-V & $E P 5(R P)$ & $E P 17(R P)$ & $E P 28(R P)$ \\
& $E P 6(A S)$ & $E P 36(A S)$ & $E P 29(A S)$ \\
$\mathbf{H}$ & $E P 9(R P)$ & $E P 20(R P)$ & $E P 32(R P)$ \\
& $E P 10(A S)$ & $E P 21(A S)$ & $E P 33(A S)$ \\
$\mathbf{C}$ & $E P 2(R P)$ & $E P 13(R P)$ & $E P 24(R P)$ \\
$\mathbf{G}$ & $E P 3(C)$ & $E P 15(C)$ & $E P 26(C)$
\end{tabular}




\begin{tabular}{|llll||} 
SU & $E P 46$ & $E P 43$ & $E P 49$ \\
$($ CONTROL $)$ & $E P 47$ & $E P 44$ & $E P 50$ \\
& $E P 48$ & $E P 45$ & $E P 51$ \\
Total & $\mathbf{N}: \mathbf{9}$ & $\mathbf{N}: \mathbf{9}$ & $\mathbf{N}: \mathbf{9}$ \\
\hline
\end{tabular}

Tabla 14: Detalle de las piezas experimentales trabajadas en distintos materiales y utilizadas en soluciones químicas: RP: acción de raspado, AS: aserrado, C: corte, MD-V: material duro de origen vegetal, H: hueso, C: cuero y G: gramíneas y SU: sin uso.

\section{-Resultados de la experimentación}

La experimentación desarrollada tuvo en consideración una serie de variables cuya observación ha podido ser diferenciada en relación a los medios utilizados (presencia de restos de carbonatos, desarrollo de lustre, redondeamiento de superficies o aristas, hoyuelos, pátinas blancas, puntos brillantes y/o modificaciones ocasionadas sobre rastros de uso (en distintos tipos de micropulidos o en el desarrollo de estrías).

\section{Solución alcalina}

A la primera semana de observación el $\mathrm{pH}$ se mantuvo constante $(8,9)$. Luego de su extracción las piezas fueron lavadas con $\mathrm{H}_{2} \mathrm{O}$ desmineralizada y el filo a observar repasado con alcohol para ser vistos bajo el microscopio. Macroscópicamente las piezas no habían sufrido ningún tipo de modificación, sin embargo, se observó restos de la solución de carbonatos en algunos sectores de la microtopografía de las piezas-cara dorsal, zonas de fracturas o de irregularidades de la superficie- . No se registró ningún tipo de modificación en los microrrastros generados por uso.

A los 15 días de iniciado la experimentación no pudo ser detectada ningún tipo de modificación en las superficies de las piezas a nivel macroscópico. Sin embargo, bajo microscopio metalográfico pudo observarse un incremento de sectores con adhesión de solución carbonática e igualmente en el número de piezas utilizadas en donde aparecieron estos sectores. No se observó presencia de lustres ni cambios en la superficie de los micropulidos ocasionado por el uso del instrumento.

Al mes de observación continuó sin poder registrarse modificaciones macroscópicamente. Sin embargo, a nivel microscópico se pudo observar la presencia de restos de solución carbonática en los sectores débiles de la microtopografía de las 
piezas (fracturas internas). En cuanto a los micropulidos desarrollados por uso no presentaron cambios en los rasgos diagnósticos.

A los dos meses de observación, se identificó a nivel macroscópico, que las piezas sumergidas en soluciones alcalinas presentaban una mayor opacidad en sus superficies. Microscópicamente se registró la presencia de concreciones calcáreas en sectores de fracturas y donde no había desarrollo de micropulidos.

En la etapa final de observación, las piezas presentaban una mayor opacidad en sus superficies con restos de la solución carbonática a simple vista. La presencia de hoyuelos y lustres sobre la superficie de las piezas no pudo ser registrada en ninguno de los casos, sin embargo, el desarrollo de concreciones carbonáticas, sobretodo en sectores débiles de la microtopografía, pudo ser identificadas en la totalidad de las piezas. Por otro lado, en sectores trabajados y donde había desarrollo de micropulidos, no se observaron depósitos de carbonatos. Este punto permitiría plantear la hipótesis que los micropulidos desarrollados por uso hayan actuado como "capa protectora" frente a un estado extremo de alcalinidad, esto pudo deberse a que en los sectores mencionados la superficie se presenta más lisa y homogénea.

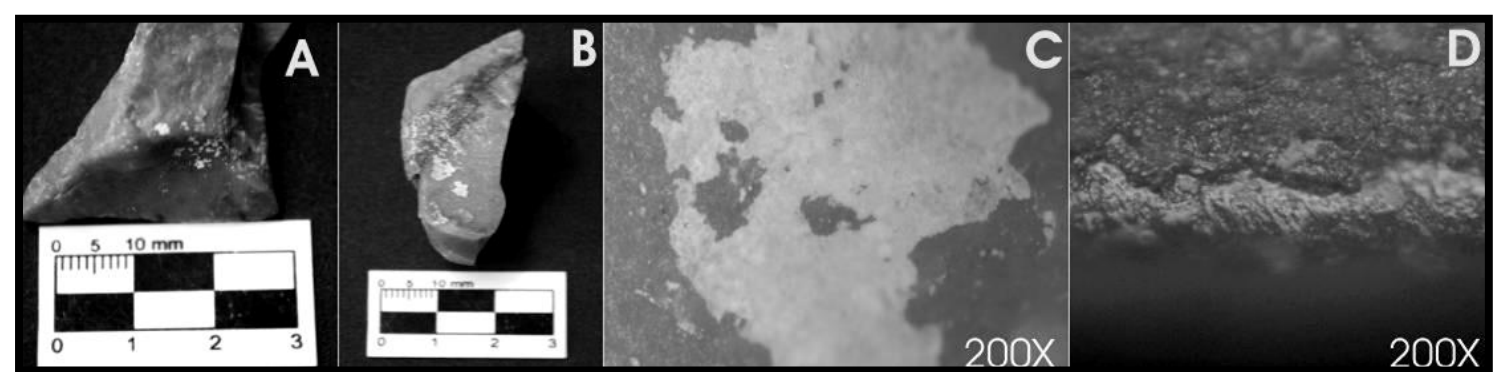

Figura 128: Experimento realizado en solución alcalina. A-B) Pieza realizada sobre sílice EP9, trabajada sobre material ósea (60). C) Concreción carbonática sobre cara dorsal de la pieza. D) Micropulido de hueso luego de inmersión en solución alcalina.

\section{Solución ácida}

La inmersión en este tipo de solución tuvo el mismo procedimiento de limpieza que en el caso anterior. A la semana de iniciada las observaciones el pH permaneció constante $(4,3)$. Tanto a nivel macroscópico como microscópicamente no se observaron modificación marcadas de la superficie.

A los 15 días de iniciado el tratamiento en soluciones no se reconocieron modificaciones de las piezas a nivel macroscópico. Sin embargo, en algunos casos (EP21, EP13, EP45 y EP43) se registró la presencia de hoyuelos que hasta el momento 
no habían sido identificados. Asimismo se observaron sectores con coloración blanquecina sobretodo en fracturas internas de la microtopografía.

Al mes de iniciada la experimentación, no se determinaron modificaciones sobre las superficies de las piezas a nivel macroscópico. Sin embargo, al incrementar el nivel de observación, se reconoció la presencia de hoyuelos en un mayor número de piezas. Por otro lado, también se identificó incremento de sectores con coloración blanquecina sobretodo en áreas de grietas y fracturas internas. En relación a la identificación de cambios en los micropulidos, una sola pieza (EP36) presentó menor volumen y brillo sobre su superficie.

A los dos meses pudo detectarse una mayor opacidad sobre la superficie de las piezas a nivel macroscópico. Mientras que microscópicamente se mantuvo constante la presencia de hoyuelos, sin desarrollo de lustre y niveles iniciales de pátina blanca en sectores donde no hubo desarrollo de micropulidos. En relación a los rastros de utilización se notaron cambios en los caracteres diagnósticos de los micropulidos. En el caso de aquellos originados por el trabajo en hueso, se observó un aplanamiento en el desarrollo del "craquéele".

Una vez finalizada la experimentación, se registró a simple vista un incremento en la opacidad de la superficie de las piezas que fueron sometidas a soluciones con acidez extrema. A nivel microscópico se registró el desarrollo de pátinas blancas en la totalidad de las piezas utilizadas. En aquellas que no fueron usadas, el desarrollo de esta pátina se originó a lo largo de todo el filo natural. Mientras que en las que fueron trabajadas, su desarrollo se dio en zonas ubicadas hacia el interior del filo, donde no presentaban desarrollo de micropulidos. Por otro lado, también se identificaron cambios sobre los rastros de uso. El micropulido de cuero, luego del tiempo estipulado, únicamente presentó surcos profundos paralelos entre sí impidiendo la identificación concreta del material trabajado. Ocurrió algo semejante con el micropulido de madera, perdiendo brillo y espesor, caracteres diagnósticos de su identificación. Por otra parte, en el caso del micropulido de hueso, si bien se observó cambios sobre su superficie las características principales pudieron ser identificadas. 


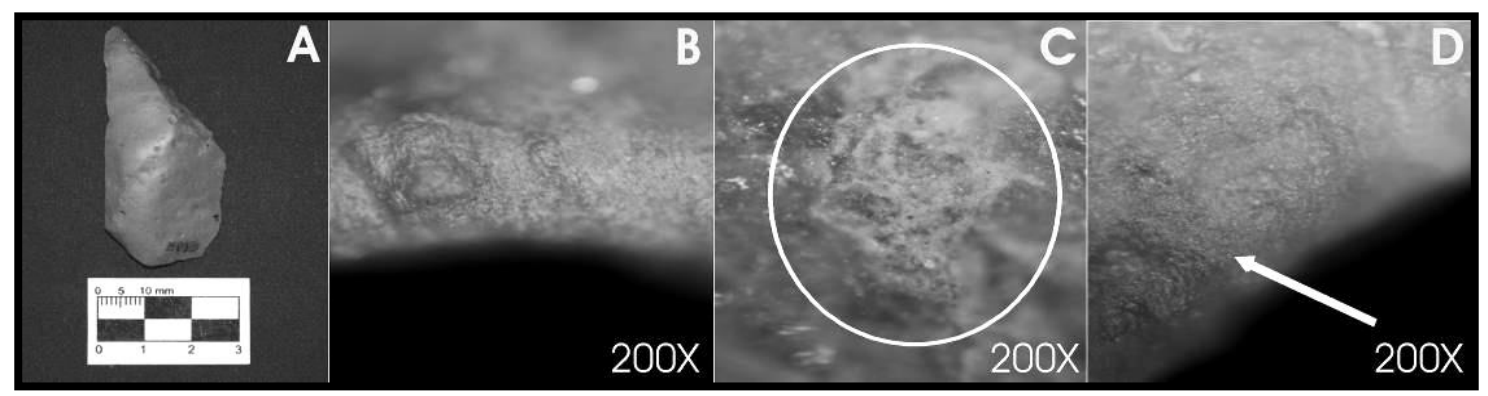

Figura 129: Experimento realizado en solución ácida. A-B) Pieza experimental EP13 confeccionada en ślice y micropulido generado en el filo por el trabajo sobre cuero seco. C) Desarrollo inicial de patina blanca sobre la pieza EP13. D) Surcos profundos dejados por el trabajo sobre cuero único rastro presente luego de la inmersión en solución ácida.

\section{Solución neutra}

Las piezas sumergidas en medios con $\mathrm{pH}$ neutro $(7,4)$ tuvieron el mismo tratamiento de limpieza que en los casos anteriores. A la semana de iniciada la observación a nivel macro y microscópico no pudieron observarse cambios significativos sobre la superficie de las piezas. El pH se mantuvo constante durante el período de observación, sin embargo no se registró el desarrollo de pátinas ni lustres sobre las superficies e igualmente sobre los microrrastros originados por el trabajo de las piezas sobre distintos materiales. Este punto permite plantear que el factor tiempo probablemente no haya sido suficiente para ocasionar cambios significativos en la estructura cristalina de la roca.

En resumen, el desarrollo de diversos grados de pátinas blancas en sectores "débiles" de la microtopografía (fracturas internas) se dio en condiciones extremas de acidez. En soluciones alcalinas se produjo la depositación en forma de "costra" de carbonatos. Mientras que las piezas sumergidas en medios con $\mathrm{pH}$ neutro $(\mathrm{pH}: 7,4)$ no sufrieron alteraciones que pudieran ocasionar cambios significativos de la roca a lo largo del período de observación. En cuanto a la preservación de micropulidos se pudo observar que, en medios ácidos el micropulido de cuero fue el primero en perder sus rasgos característicos. Luego del tiempo estipulado solo se registró surcos profundos donde anteriormente estaba el micropulido. Los rastros de uso consecuencia del trabajo de madera sufrieron modificaciones de rasgos que imposibilitaron su determinación, mientras que el de hueso, preservó sus características diagnósticas al igual que el de gramíneas. En la solución alcalina no hubo cambios significativos sobre los rastros de uso, sin embargo, la depositación de carbonatos sobre el filo dificultó la observación de los microrrastros. 
Este punto permitiría plantear la hipótesis de preservación diferencial de micropulidos. Los resultados obtenidos mediante la experimentación, ha permitido confirmar que los micropulidos generados por el trabajo sobre hueso y gramíneas tendrían una mejor preservación frente a cambios en el pH del sedimento.

Este punto fue señalado por otros investigadores, tal es el caso de los trabajos realizados por Levi Sala (1993) en el marco de su tesis doctoral, quien desarrolló una intensa serie de experimentos corroborando esta hipótesis.

Igualmente los trabajos presentados por Plisson y Mauger (1988) y las observaciones realizadas por Keeley (1981) sugiriendo además que los sectores no utilizados son mayormente susceptibles a ataques químicos que aquellos que presentaban desarrollo de micropulidos. La génesis de los procesos post-depositacionales que modifican las superficies de los materiales es muy compleja y comprende tanto factores mecánicos; como químicos (presencia o ausencia de agua en el medio, alcalinidad o acidez del sustrato y del agua, presencia de sedimento arenoso o gravoso, entre otros) (Schiffer 1987; Levi-Sala 1993; Favier Dubois 2001; Stein 1992, 2001; Borrazzo 2004, 2007; entre otros). La experimentación realizada ha permitido profundizar en el conocimiento de una parte del origen de estos procesos ocasionados por factores químicos y sus implicancias en el análisis de los rastros de uso de los sitios bajo estudio, donde fueron registradas diferencias en cuanto al grado de preservación de los micropulidos generados por el uso de un instrumento.

Las alteraciones naturales ocasionadas sobre artefactos líticos luego de su depositación pueden influenciar el grado de preservación de los rastros originados por el uso de un instrumento. Sin embargo, la intensidad en el que actúan estos procesos dependerá del tipo de sedimento y de los procesos microerosivos que sucedan en el sitio; pudiéndose expresar de diversas maneras (estrías, redondeamiento de aristas, lustre de suelos, etc.) El reconocimiento de cada uno de estos procesos, gestados durante el tiempo de permanencia de los artefactos y la manera en que estos influyen sobre las superficies líticas modificando los rastros de uso, permitirá a pesar de ellos realizar un análisis funcional consistente en los casos donde no hubo destrucción total y secundariamente interpretar los procesos que formaron parte del registro arqueológico.

Por lo tanto, mantener una perspectiva geoarqueológica como tafonómica en el análisis tanto de los artefactos líticos, como de otro tipo de material, es de suma importancia a la hora de interpretar el registro arqueológico como reflejo de la actividad humana del pasado. 
Nomenclatura y planilla para observación de rastros de uso

\section{Esquirlamientos:}

\section{Presencia:}

A: abundante (continuo o casi sobre todo el filo o por sectores).

M: mediano (grupos discontinuos)

E: escasos (negativos aislados o pocos grupos)

NP: no posee.

\section{Continuidad:}

C: continuos.

D: descontínuos

A: aislados.

\section{Morfologia:}

S: semicirculares.

$\mathrm{T}$ : trapezoidales o rectangulares.

M: melladuras ("half-moon fractures")

\section{Regularidad:}

$\mathrm{R}$ : regular.

I: irregular.

Terminaciones:

A: recto abrupto o escalonada.

$\mathrm{C}$ : en charnela.

$\mathrm{S}$ : simple afinada o difusa.

\section{Dimensiones:}

MI: micro (menores de $2 / 3$ del diámetro de campo o $0,33 \mathrm{~mm}$.)

MA: macro (mayores de 2/3 del diámetro de campo e/ 0,33 y $1 \mathrm{~mm}$.)

SA: súper macro (más de $1 \mathrm{~mm}$.).

MM: combinación de dos o más.

\section{Estrías:}

Estrias sobre matriz:

S: si.

$\mathrm{N}$ : no. 


\section{Estrias sobre cristales:}

S: si.

N: no.

\section{Orientación:}

PA: paralelas al filo.

PE: perpendiculares al filo.

\section{Longitud:}

C: cortas (menos de $1 / 3$ del diámetro de campo, $0,33 \mathrm{~mm}$.)

I: intermedias: (entre $1 / 3$ y 2/3 del diámetro de campo, 0,33 a 0,66 mm.)

L: largas (entre $2 / 3$ y $3 / 3$ del diámetro de campo, 0,66 a $1 \mathrm{~mm}$.)

\section{Tipo:}

A: de fondo rugoso, angosto profundo (oscuras, medianas a largas).

$\mathrm{M}$ : fondo rugoso, angosto profundo mini (oscuras, pequeñas por $\mathrm{Ej} .:$ en la carne).

$\mathrm{D}$ : de fondo rugoso, angosto profundo discontinuas ("estriaciones de depresiones intermitentes alineadas", etc.).

B: fondo rugoso liso, en banda o cinta (continuas, claras, anchas y brillantes).

F: franjas de estrías cortas perpendiculares y oblicuas al filo (1/2 de diámetro de campo).

H. fondo liso, en banda, en forma de helecho (claras, surco centro y líneas perpendiculares).

C: colmatadas.

E: de contorno irregular y fondo irregular escalonado.

\section{Micropulidos:}

\section{Presencia:}

S: si.

$\mathrm{N}$ : no.

\section{Brillo:}

M: mate.

LB: ligeramente brillante:

MB: muy brillante.

BG: brillante grasoso.

\section{Regularidad:}

L: liso.

I: intermedio.

\section{Espesor:}


P: plano.

I: intermedio.

E: espeso.

\section{Rasgos superficiales:}

$\mathrm{H}$ : depresiones em forma de cometas.

C: huecos tipo "corrosión".

S: huecos semiesféricos.

R: resquebrajaduras (craquelé típico de hueso.)

$\mathrm{Z}$ : zonas con surcos superficiales paralelos entre si, perpendiculares al filo ("shallow linear features" de Keeley, caract. De la piel).

SZ: combinación.

RZ: combinación.

\section{Extensión:}

M: marginal (menos de 1/3 del diámetro de campo, 0,33 mm.)

I: intermedio (entre $1 / 3$ y $2 / 3$ de diámetro de campo, 0,33 a 0,66 mm.)

P: profundo (entre $2 / 3$ y $3 / 3$ del diámetro de campo, 0,66 a $1 \mathrm{~mm}$. )

MP: muy profundo (más de $3 / 3$ de diámetro de campo, más de $1 \mathrm{~mm}$.)

\section{Distribución:}

C: en cúspides o salientes del filo.

$\mathrm{R}$ : reticulado.

H: homogéneo.

B: en banda o bandas paralelas al filo.

D: digitado (o bandas perpendiculares al filo)

Micropulido en concavidades de negativos:

S: si.

$\mathrm{N}$ : no.

Micropulidos en aristas en negativos:

S: si.

$\mathrm{N}$ : no.

Grado de desarrollo:

1: no diferenciado.

2: indeterminado.

3: desarrollado o diferenciado.

\section{Determinación Funcional:}

Uso: 
SU: sin uso.

ND. No determinable.

PR: utilización probable.

SG: utilización segura.

NDA: no determinable por alteración.

\section{Material trabajado}

$\begin{array}{ll}\text { C } & \text { Carne } \\ \text { CT } & \text { Faenamiento (carne, hueso, tendón, cartílago, etc.) } \\ \text { H } & \text { Piel } \\ \text { HF } & \text { Piel fresca } \\ \text { HS } & \text { Piel seca } \\ \text { L } & \text { Litico } \\ \text { LO } & \text { Ocre } \\ \text { MB-A } & \text { Material blando (animal) } \\ \text { MB-V } & \text { Material blando (vegetal) } \\ \text { MD-A } & \text { Material duro (animal) } \\ \text { MD-V } & \text { Material duro (vegetal) } \\ \text { O } & \text { Oseo (hueso) } \\ \text { OG } & \text { Oseo grasoso } \\ \text { P } & \text { Plantas no leñosas } \\ \text { PG } & \text { Gramineas } \\ \text { PJ } & \text { Juncos } \\ \text { V } & \text { Valva } \\ \text { W } & \text { Madera } \\ \text { ND } & \text { No determinable }\end{array}$

\section{Cara conductora:}

D: dorsal.

$\mathrm{V}$ : ventral.

\section{Cara de contacto.}

D: dorsal.

$\mathrm{V}$ : ventral.

\section{El movimiento:}

TR: transversal o perpendicular.

LO: Longitudinal o paralelo.

LT: Longitudinal y transversal.

RO: Rotación.

IM: Impacto o penetración.

ND: No determinable. 